
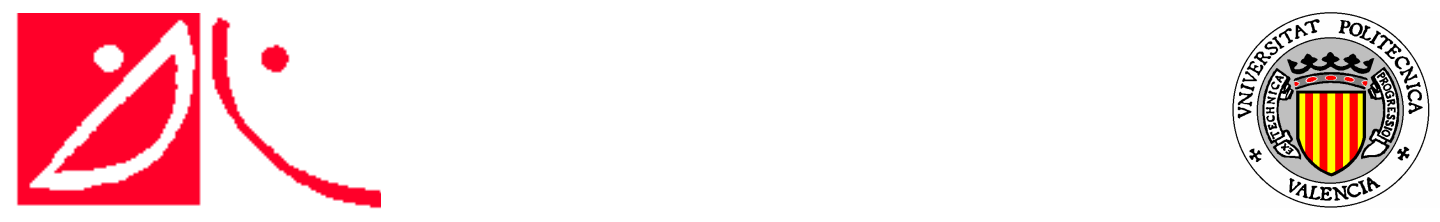

\title{
Caracterización del Canal Radio Móvil en el Interior de Edificios con Múltiples Plantas mediante Técnicas de Lanzado de Rayos
}

\author{
Santiago J. Flores Asenjo
}

Director: Dr. Narcís Cardona Marcet

Tesis Doctoral presentada en la Universidad Politécnica de Valencia para la obtención del título de Doctor Ingeniero de Telecomunicación

Gandia, Mayo 1998 

A mis amigos 



\section{Resumen}

Las técnicas de Lanzado de Rayos son métodos de modelado determinista, basados en la teoría de la Óptica Geométrica. Básicamente, consisten en la distribución espacial uniforme, a partir de un transmisor puntual, de un número finito pero suficiente de rayos, con los que se pretende modelar la propagación de los frentes de ondas, así como su interacción con el entorno.

Estas técnicas ya han sido ampliamente utilizadas para caracterizar el canal radio móvil en diversos tipos de entornos, relevándose especialmente útiles para modelar la propagación en el interior de edificios.

Pero, hasta ahora, en general, no se ha sabido aprovechar toda la potencia de este tipo de modelado, pues tradicionalmente se ha considerado que es excesivamente arduo, precisándose una gran cantidad de tiempo para ejecutar las simulaciones.

Sin embargo, la llegada de procesadores más potentes y veloces, así como la necesidad de realizar simulaciones que presenten una gran precisión en los resultados, han hecho de estas técnicas un objetivo principal de estudio dentro del campo del modelado de la propagación.

En esta Tesis se proponen algunas técnicas especiales basadas en el Lanzado de Rayos, analizando las ventajas y problemas que presentan. Se incidirá especialmente en la propagación tridimensional, ya que resulta absolutamente necesario considerar tal forma de propagación para analizar los sistemas de comunicaciones móviles implementados en el interior de edificios con múltiples plantas.

Se presenta, además, una variante particular del Lanzado de Rayos, consistente en lanzar estructuras tridimensionales, denominadas Tubos, formadas por varios rayos. La ventaja fundamental de esta variante, que puede ser denominada Lanzado de Tubos, es que resulta mucho más fácil determinar si se alcanza o no a un receptor concreto, no siendo necesario implementar complejos algoritmos de recepción, que resultan imprescindibles cuando las entidades que se lanzan son de naturaleza unidimensional. A pesar de todo, este último método particular tiene una serie de desventajas que también son analizadas con profundidad en esta Tesis, y que se manifiestan cuando el entorno de simulación es muy extenso o excesivamente complejo.

Todas esta técnicas son validadas mediante simulaciones que se han realizado en diversos entornos más o menos complejos. Concretamente, se comparan las medidas obtenidas en una campaña realizada en el interior de la ETSIT de Valencia, con las simulaciones obtenidas en un entorno similar. Los resultados son altamente satisfactorios. 
Por último, se puede demostrar que estas técnicas de modelado resultan ser perfectamente útiles para simular los rápidos desvanecimientos que sufre la señal recibida en situaciones de propagación multi-camino, ajustándose a los modelos teóricos de distribución estadística tanto como las propias medidas. 


\section{Índice General}

1 Introducción 1

1.1 Organización de la memoria . . . . . . . . . . . . . . 2

$2 \quad$ El Canal Radio Móvil Indoor 5

2.1 Introducción . . . . . . . . . . . . . . . . . . . . 5

2.1.1 Comunicaciones Móviles en banda ancha y en banda estrecha . . . . 6

2.2 Caracterización del Canal Radio Móvil en banda estrecha . . . . . . . . . . 6

2.2.1 Desvanecimientos a largo y a corto plazo . . . . . . . . . . . . 9

2.2 .2 Efecto Doppler . . . . . . . . . . . . . . . . . 10

2.3 Caracterización del Canal Radio Móvil en banda ancha . . . . . . . . . . . 11

2.3.1 El canal radio móvil como sistema lineal cronovariable. Funciones de Bello . . . . . . . . . . . . . . . . . . . . . . . 13

2.3.2 El canal móvil como sistema lineal cronovariable aleatorio . . . . . . 14

2.3.3 Caracterización del canal mediante la función de scattering . . . . . 18

2.3.4 Caracterización del canal radio móvil en los dominios frecuencial y

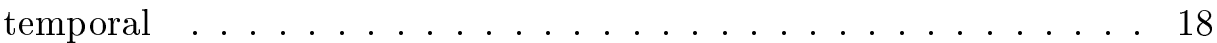

2.4 Peculiaridades del Canal Indoor . . . . . . . . . . . . . . . . . . . . 22

3 Métodos de Medida y Modelado del Canal Indoor 25

3.1 Introducción . . . . . . . . . . . . . . . . . . . . . . 25

3.2 Aspectos generales del modelado del Canal Indoor . . . . . . . . . . . . 26

3.3 Modelos y medidas en banda estrecha . . . . . . . . . . . . . . 28

3.3.1 Modelos empíricos de predicción de pérdidas . . . . . . . . . . 28

3.4 Modelos y medidas en banda ancha . . . . . . . . . . . . . . . . 33

3.4.1 Técnicas de medida en banda ancha . . . . . . . . . . . . . 35 
3.5 Modelos deterministas $\ldots \ldots \ldots \ldots$. . . . . . . . . . . . . 37

3.5.1 Método de las Imágenes Virtuales. Trazado de Rayos . . . . . . . . 38

3.5.2 Métodos de Lanzado de Rayos . . . . . . . . . . . . . . . . . . 38

3.5.3 Parámetros del entorno en los modelos deterministas . . . . . . . . . 40

3.5.4 Complejidad computacional de los métodos basados en GO* . . . . 40

3.6 Otras técnicas de modelado . . . . . . . . . . . . . . . . . . . 42

3.7 Consideraciones adicionales . . . . . . . . . . . . . . . . . . . 43

3.7 .1 Ruido . . . . . . . . . . . . . . . . . . 43

3.7 .2 Polarización . . . . . . . . . . . . . . . . . . . . . 44

3.8 Resumen . . . . . . . . . . . . . . . . . . . . . . 44

4 Medidas en el Edificio de la ETSIT de Valencia $\quad 47$

4.1 Introducción . . . . . . . . . . . . . . . . . . . . . . . 47

4.2 Medidas de pérdidas de propagación $\ldots \ldots \ldots \ldots$. . . . . . . . 48

4.2.1 Descripción del sistema de medida de pérdidas de propagación . . 49

4.2 .2 Ubicación de las medidas . . . . . . . . . . . . . . . . 51

4.2.3 Análisis de las medidas en banda estrecha . . . . . . . . . . . . . 54

4.3 Medidas en banda ancha . . . . . . . . . . . . . . . . . . . . . 59

4.3.1 Descripción del sistema de medida en banda ancha . . . . . . . . . . 59

4.3.2 Ubicación y disposición de las medidas en banda ancha . . . . . . . 65

4.3.3 Análisis de las medidas en banda ancha . . . . . . . . . . . 68

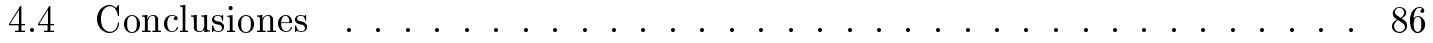

5 Técnicas de Lanzado de Rayos $\quad 87$

5.1 Introducción . . . . . . . . . . . . . . . . . 87

5.2 Separación angular de los rayos. Discretización de la esfera $\ldots$. . . . . . 89

5.3 Zona de influencia de los rayos. Radio de impacto . . . . . . . . . . . . 91

5.3.1 Determinación de la distancia entre el rayo y el receptor . . . . . . . 92

5.4 Problemas del Lanzado de Rayos . . . . . . . . . . . . . . . . . . . . . . . 94

5.4 .1 Zonas de sombra . . . . . . . . . . . . . . 95

5.4 .2 Impactos redundantes . . . . . . . . . . . . . . . . . 100

${ }^{*}$ Geometrical Optics, Óptica Geométrica 
5.5 Lanzado de Tubos . . . . . . . . . . . . . . . . . . . . 105

5.5.1 Teselación de la esfera . . . . . . . . . . . . . . . . 105

5.6 Estudio comparativo entre el Lanzado de Rayos y el Lanzado de Tubos . 110

5.6 .1 Calidad de la separación angular . . . . . . . . . . . . . . . 111

5.6 .2 Eficiencia en velocidad de procesado . . . . . . . . . . . . . 113

5.6 .3 Comportamiento frente a superficies . . . . . . . . . . . 115

5.6.4 Comportamiento frente a orificios, esquinas y entornos complejos . . 117

5.6.5 Conclusiones sobre la comparativa . . . . . . . . . . . 120

5.7 Métodos de optimización . . . . . . . . . . . . . . . . . . 120

5.7.1 Descarte de rayos y tubos por umbral local de potencia . . . . . . 121

5.7 .2 Lanzado previo . . . . . . . . . . . . . . . . . . 125

5.7 .3 Análisis de los métodos de optimización . . . . . . . . . . . . . 126

5.8 Implementación del programa de simulación . . . . . . . . . . . . . . . . . 129

5.8 .1 Datos físicos del entorno . . . . . . . . . . . . . . . 129

5.8 .2 Parámetros de configuración . . . . . . . . . . . 136

5.8 .3 Evolución de los rayos y tubos . . . . . . . . . . . . . 139

5.8 .4 Salida de información . . . . . . . . . . . . . . . . . 141

5.9 Resumen . . . . . . . . . . . . . . . . . . . . . . 141

6 Fenómenos de Propagación Electromagnética en los Modelos de Lanzado $\begin{array}{ll}\text { de Rayos } & 143\end{array}$

6.1 Introducción . . . . . . . . . . . . . . . . . . . . . . . 143

6.2 Radiación electromagnética . . . . . . . . . . . . . . . . . . . . . . 144

6.2.1 Efectos de la antena. Polarización y diagrama de radiación . . . . . 146

6.3 Incidencia sobre superficies dieléctricas . . . . . . . . . . . . . . . . . 148

6.3 .1 Reflexión . . . . . . . . . . . . . . . . 149

6.3 .2 Transmisión . . . . . . . . . . . . . . . . . 150

6.3.3 Modelo de pared multi-capa con múltiples reflexiones internas . . 158

6.3.4 Reflexión difusa. Pérdidas por scattering _ . . . . . . . . . . 162

6.4 Difracción en aristas . . . . . . . . . . . . . . . . . . . . 167

6.4.1 Teoría Geométrica de la Difracción . . . . . . . . . . . . . 168

6.4.2 Teoría Uniforme de la Difracción . . . . . . . . . . . . . . . 170 
6.4.3 Implementación de la difracción en el Lanzado de Tubos . . . . . . . 171

6.5 Resumen . . . . . . . . . . . . . . . . . . . . . . . 173

$\begin{array}{lll}7 & \text { Resultados de las Simulaciones } & \mathbf{1 7 5}\end{array}$

7.1 Introducción . . . . . . . . . . . . . . . . . . . . . . . 175

7.2 Primeras simulaciones . . . . . . . . . . . . . . . 175

7.2 .1 Entornos sencillos . . . . . . . . . . . . . 176

7.2 .2 Entornos más complejos . . . . . . . . . . . . . . . . . . . 182

7.3 Verificación de técnicas y fenómenos implementados . . . . . . . . . . . 189

7.3.1 Polarización y diagrama de radiación . . . . . . . . . . . . . 191

7.3.2 Eliminación de impactos redundantes . . . . . . . . . . . 195

7.3.3 Modelo de pared multi-capa . . . . . . . . . . . . . . . 198

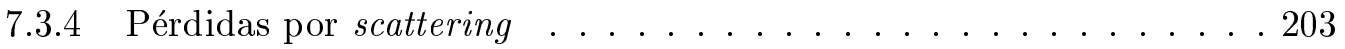

7.3.5 Difracción . . . . . . . . . . . . . . 207

7.4 Prestaciones del programa de simulación . . . . . . . . . . . . . . 216

7.4.1 Precisión de los resultados y tiempo de ejecución . . . . . . . . . 217

7.4.2 Sensibilidad a las tolerancias en la definición del entorno . . . . . . . 221

7.5 Comparación con medidas en el edificio de la ETSIT . . . . . . . . . . . 226

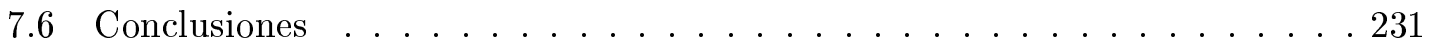

8 Caracterización Estadística del Canal Indoor 233

8.1 Introducción . . . . . . . . . . . . . . . . . . . . . . 233

8.1.1 Estimación de parámetros. Método de la Función de Máxima Verosimilitud . . . . . . . . . . . . . . . . . . . 234

8.2 Desvanecimientos a largo plazo . . . . . . . . . . . . . . . . . 235

8.3 Desvanecimientos a corto plazo . . . . . . . . . . . . . . . . 238

8.3.1 Desvanecimientos con estadística tipo Rice . . . . . . . . . . . 238

8.3.2 Desvanecimientos con estadística tipo Rayleigh . . . . . . . . . . . 241

8.3.3 Desvanecimientos con estadística tipo Nakagami . . . . . . . . . . 245

8.3.4 Desvanecimientos con estadística tipo Weibull . . . . . . . . . . . 248

8.4 Validación de los modelos de distribución estadística. Tests estadísticos . 250

8.4.1 El test $\chi^{2}$ de Pearson . . . . . . . . . . . . . . . . 251 
8.4.2 Validación de las distribuciones mediante las medidas realizadas en la ETSIT de Valencia . . . . . . . . . . . . . . . . . . 252

8.5 Estudio estadístico de las simulaciones . . . . . . . . . . . . . . 256

8.6 Resumen y conclusiones . . . . . . . . . . . . . . . . . . . . 260

9 Conclusiones y trabajos futuros $\quad 263$

9.1 Conclusiones . . . . . . . . . . . . . . . . . . . 263

9.2 Futuras líneas de investigación _. . . . . . . . . . . . . . . . 264 



\section{Índice de Figuras}

2.1 Envolvente de la señal recibida en un móvil para una velocidad de $50 \mathrm{~km} / \mathrm{h}$; $f_{c}=1 \mathrm{GHz} ;$ tiempo de observación: $1 \mathrm{~s} \ldots \ldots \ldots . \ldots \ldots$

2.2 Diagrama fasorial para dos componentes de multi-camino . . . . . . . 8

2.3 Espectro de la envolvente vista en la figura 2.1. $f_{d \mathrm{MAX}}=46.29 \mathrm{~Hz} \ldots \ldots . \quad 10$

2.4 Elipses de igual retardo. Los caminos $\overline{\mathrm{T}_{\mathrm{x}} \mathrm{BR}_{\mathrm{x}}}$ y $\overline{\mathrm{T}_{\mathrm{x}} \mathrm{CR}_{\mathrm{x}}}$ han de distinguirse por el ángulo de llegada, pues poseen el mismo valor de retardo . . . . . . . 12

2.5 Ángulo entre la dirección del receptor móvil y la de la señal recibida . . . . 12

2.6 Relación entre las distintas funciones de caracterización del canal, como sistema lineal variante en el tiempo . . . . . . . . . . . . . . . . . . . 14

2.7 Relaciones entre las distintas funciones de autocorrelación del canal, como sistema lineal cronovariable aleatorio . . . . . . . . . . . . . . . . 16

2.8 Relaciones entre las funciones de autocorrelación para canales WSSUS . . . 17

2.9 Distintos ejemplos de funciones de correlación en frecuencia . . . . . . . . 19

2.10 Ejemplos de Perfiles de potencia. (a) Situación con visibilidad directa entre antenas. (b), (c) y (d) Situaciones sin visibilidad directa . . . . . . . . 20

2.11 Ilustración del cálculo de la ventana de retardo $W_{q}$, y del intervalo de retardo

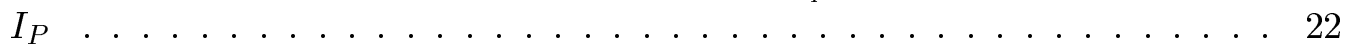

3.1 Guión para el desarrollo de un modelo de propagación indoor . . . . . . . . 27

3.2 Sondeo del canal mediante pulsos periódicos. $T_{1}$ y $T_{2}$ controlan, respectivamente, la resolución y la ambigüedad . . . . . . . . . . . . . 35

3.3 Complejidad computacional del Método de las Imágenes Virtuales. La curva a trazos se refiere al caso simplificado con $N=6$ (habitación rectangular cerrada) . . . . . . . . . . . . . . . . . . 42

4.1 Representación esquemática del sistema utilizado para realizar medidas de pérdidas de propagación . . . . . . . . . . . . . . . . . 49 49

4.2 Ubicación de antenas transmisoras y receptoras en el edificio de la ETSIT de Valencia. Se presenta la planta (arriba) y el alzado principal (abajo) . . 52 
4.3 Distancias entre plantas $\ldots \ldots \ldots \ldots \ldots \ldots$

4.4 Ejemplos de medidas donde se aprecian desvanecimientos profundos . . . . 54

4.5 Ejemplo de medidas con presencia de personas circulando por el entorno . . 55

4.6 Mismo ejemplo que figura 4.5, pero sin presencia de personas en el entorno $\quad 55$

4.7 Medidas en polarización horizontal . . . . . . . . . . . . . 56

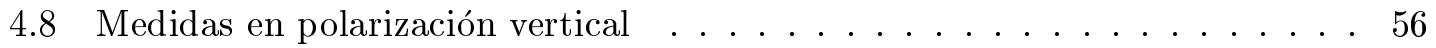

4.9 Esquema básico de propagación para transmisión en polarización horizontal 57

4.10 Esquema básico de propagación para transmisión en polarización vertical • 57

4.11 Periodicidad del fading respecto a la altura . . . . . . . . . . . 58

4.12 Esquema del sistema de medida empleado en banda ancha . . . . . . . . . . 60

4.13 Amplificadores SAT-90 en cascada. (a) Funcionamiento lineal. (b) Funcionamiento en saturación . . . . . . . . . . . . . . . . . . 62

4.14 Respuesta en frecuencia de los cables y amplificadores del puerto transmisor 63

4.15 Disposición de las trazas verticales, transversales y longitudinales en los pasillos del edificio . . . . . . . . . . . . . . . 66 66

4.16 Medidas en agrupaciones circulares para determinación de ángulos de llegada en el plano horizontal . . . . . . . . . . . . . . . 67

4.17 Medidas en banda estrecha (curva 1) comparadas con medidas en banda ancha utilizando el Teorema de Parseval. La curva 2 incluye todas las muestras, mientras que la 3 solamente aquellas con valor hasta $5 \mathrm{~dB}$ inferior al máximo . . . . . . . . . . . . . . . . . . . . . 69

4.18 Función de coherencia y Perfil de potencia-retardo. Situaciones en visión directa con presencia de reflexión importante . . . . . . . . . . 70

4.19 Función de coherencia y Perfil de potencia-retardo. Situación sin visibilidad directa, con presencia de fuerte reflexión lejana . . . . . . . . . . 71

4.20 Propagación entre plantas con polarización horizontal. Las primeras componentes que alcanzan al receptor tienen mayor amplitud. El rizado de la función de coherencia es menor . . . . . . . . . . . . . . . . . . . 73

4.21 Propagación entre plantas con polarización vertical. El ancho de banda de coherencia se reduce al disminuir la relación de amplitudes entre componentes multi-camino . . . . . . . . . . . . . . . . . 73

4.22 Perfiles de potencia promediados de distintos tipos de traza en un punto en particular . . . . . . . . . . . . . . . . . 75

4.23 Ejemplos de funciones de scattering calculadas a partir de trazas longitudinales. (a) Situación con visión directa entre antenas (LOS). (b) Propagación entre plantas . . . . . . . . . . . . . . . . . 78 
4.24 Función de scattering de trazas longitudinales, según la polarización. (a) Polarización Horizontal. (b) Polarización Vertical . . . . . . . . . . . . . . . 79

4.25 Comparación de funciones de scattering según el tipo de traza a partir de la cual es calculada. (a) Traza longitudinal. (b) Traza vertical . . . . . . . 80

4.26 Otro ejemplo de función de scattering de traza vertical. Se aprecia la presencia de componentes con desplazamiento Doppler nulo . . . . . . . . 81

4.27 Función de scattering calculada a partir de una traza transversal . . . . . . 81

4.28 Evolución de los ángulos de llegada en el plano horizontal en función del retardo....................... 83

4.29 Evolución de los ángulos de llegada en el plano vertical en función del retardo 85

5.1 Aproximación de los frentes de ondas electromagnéticas con rayos ópticos $\quad 88$

5.2 División de la esfera unidad en paralelos para el Lanzado de Rayos . . . . . 90

5.3 Situación espacial de dos rayos contiguos según sus coordenadas esféricas $\quad 90$

5.4 Determinación del impacto de un rayo en un receptor . . . . . . . . . . . . 91

5.5 Zona de influencia de un rayo en $2 \mathrm{D}$.................... 92

5.6 Cálculo de la distancia entre un rayo y un punto . . . . . . . . . . . . . 92

5.7 El parámetro $t$ permite determinar si efectivamente se produce intersección entre un rayo y un plano . . . . . . . . . . . . . . . . . . . . . . . . 94

5.8 Volumen de influencia de cada rayo en 3D . . . . . . . . . . . . . . . 95

5.9 Intersección de un rayo central $R_{n}$ y de varios rayos adyacentes al mismo, con un plano $P$ perpendicular a $R_{n} \ldots \ldots$. . . . . . . . . . . . 96

5.10 Aparición de zonas de sombra en el Lanzado de Rayos . . . . . . . . . . . . 96

5.11 Aparición de zonas de intersección en el Lanzado de Rayos . . . . . . . . . . 97

5.12 Separación angular entre dos rayos adyacentes pertenecientes a paralelos contiguos ....................... 98

5.13 Representación del cociente $\left(\Delta \theta^{\prime}\right) / \Delta \theta$, en función del número de paralelos de la esfera unidad . . . . . . . . . . . . . . . . . 99

5.14 Problema de impactos redundantes en el Lanzado de Rayos . . . . . . . . . 100

5.15 Función de ponderación empleada en el método de los frentes de onda distribuidos . . . . . . . . . . . . . . . . . . 102

5.16 Rayos adyacentes alcanzando a un receptor y provocando la aparición de un impacto redundante . . . . . . . . . . . . . . . 103

5.17 Dos rayos adyacentes mantienen su separación angular incluso tras sucesivas

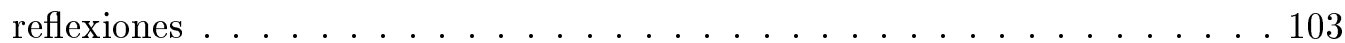


5.18 Dos rayos no adyacentes alcanzan al receptor con la misma orientación . . . 104

5.19 Creación de un tubo de sección triangular (tres rayos) . . . . . . . . . 106

5.20 Primeros pasos de la teselación de la esfera . . . . . . . . . . . . . 107

5.21 Proceso de teselación completado . . . . . . . . . . . . . . . . . . 108

5.22 Vista superior de la esfera teselada con $\Delta \theta=3^{\circ} \ldots \ldots \ldots$. . . . . 108

5.23 Alzado de $1 / 8$ de la esfera con la superficie teselada con $\Delta \theta=1.5^{\circ} \ldots 109$

5.24 Rayos que forman el tubo de sección triangular, y dibujo de la subdivisión (split) de un triángulo en otros cuatro más pequeños . . . . . . . . . . . 109

5.25 Desviación típica de la separación angular en el Lanzado de Tubos . . . . 111

5.26 Desviación típica de la separación angular en el Lanzado de Rayos . . . . . 112

5.27 Número de rayos y tubos emitidos por cada método de lanzado . . . . . . . 112

5.28 Comparación entre el tiempo de procesado medio de un rayo $\left(T_{1 r}\right)$ y de un tubo $\left(T_{1 t}\right)$, para un caso particular, en función del número $N$ de reflexiones consideradas . . . . . . . . . . . . . . . . . . . . . . . . 114

5.29 Comparación entre el tiempo total de simulación del Lanzado de Rayos $\left(T_{r}\right)$ y del Lanzado de Tubos $\left(T_{t}\right)$, para un caso particular, en función del número $N$ de reflexiones consideradas . . . . . . . . . . . . . . . 114

5.30 Comportamiento de un tubo frente a una superficie . . . . . . . . . . . 115

5.31 Comportamiento de un rayo frente a una superficie . . . . . . . . . . . 116

5.32 Comparación de resultados entre el Lanzado de Rayos y el Lanzado de Tubos ante superficies . . . . . . . . . . . . . . 116

5.33 La naturaleza tridimensional de un tubo dificulta su paso a través de orificios 117

5.34 A pesar de sus pequeñas dimensiones, el tubo no pasa por el orificio al incidir oblicuamente . . . . . . . . . . . . . . . . . 118

5.35 Comparación de los resultados obtenidos con Lanzado de Rayos y Lanzado de Tubos para las esquinas . . . . . . . . . . . . . . . . 119

5.36 Pérdidas de reflexiones y transmisiones en el Lanzado de Tubos, al impactar en varias superficies coplanares compuestas de distintos materiales . . . . 120

5.37 La potencia de los rayos $T_{2}$ y $T_{3}$ es despreciable frente a la potencia de $T_{1} .122$

5.38 Modificación del algoritmo de optimización empleando $P_{0}$ como potencia de referencia . . . . . . . . . . . . . . . . . . 122

5.39 Comparación de resultados para un Lanzado de Tubos, sin y con optimización 123

5.40 Efecto de asimetría provocado por la optimización de descarte de impactos 124

5.41 Resultados sin emplear optimización . . . . . . . . . . . . . . . 128 
5.42 Resultados con varios umbrales de optimización . . . . . . . . . . . . . . 128

5.43 Ejemplo de representación con 3DCARA . . . . . . . . . . . . . . 131

5.44 Dibujo de una planta de un edificio antes de ser transformada a formato tridimensional . . . . . . . . . . . . . . . . . . 132

5.45 Ejemplo de la transformación sufrida por una planta al añadir la tercera dimensión . . . . . . . . . . . . . . . . . . . 132

5.46 Esquema en el que se observa la organización de las caras y su significado . 136

5.47 Representación de la evolución de los rayos mediante un árbol binario . . . 139

6.1 Polarización horizontal . . . . . . . . . . . . . . . . . . . . . . . . 148

6.2 Polarización vertical . . . . . . . . . . . . . . . . . . . . . . . . . 149

6.3 Módulos del coeficiente de transmisión para $n^{2}=5-0,4 j$, calculados según $|\tau|=1-|\rho|$. Incidencia con polarización horizontal y vertical . . . . . 152

6.4 Módulos de los coeficientes de transmisión para $n^{2}=5-0,4 j$, según las expresiones correctas vistas en $(6.23)$ y $(6.24) \ldots \ldots$. . . . . . . . 152

6.5 Módulos del coeficiente de transmisión para $n^{2}=5-0,4 j$, calculados según $|\tau|=\sqrt{X}(1-|\rho|)$, con $X=0.5 \ldots \ldots \ldots \ldots \ldots$

6.6 Módulos del coeficiente de transmisión para $n^{2}=5-0,4 j$, calculados según

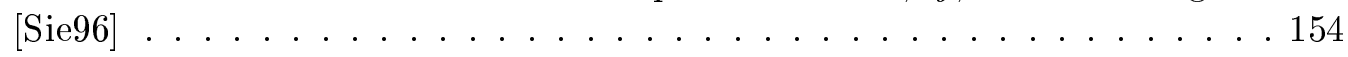

6.7 Modelado de una pared mediante dos superficies infinitas . . . . . . . . . 154

6.8 Ángulos de transmisión en el interior una pared dieléctrica sin pérdidas . . 156

6.9 Ángulos de transmisión en el interior una pared dieléctrica con pérdidas . . 157

6.10 Estructura multi-capa de una pared compleja . . . . . . . . . . . . . . . 158

6.11 Representación de las múltiples reflexiones y transmisiones en una pared multi-capa . . . . . . . . . . . . . . . . . 160

6.12 Detalle de la estructura y ondas resultantes en cada interfaz de la multi-capa161

6.13 Efecto sobre la reflexión de los distintos grados de rugosidad de las superficies 163

6.14 Modelo de rugosidad de superficie para el criterio de Rayleigh . . . . . . . 164

6.15 Coeficientes de reflexión sin y con scattering a $900 \mathrm{MHz}\left(\sigma_{h}=1 \mathrm{~mm}\right) \ldots 165$

6.16 Diferencia porcentual en el coeficiente de reflexión considerando el scattering

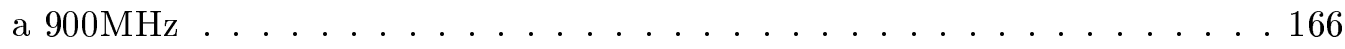

6.17 Diferencia porcentual en el coeficiente de reflexión considerando el scattering

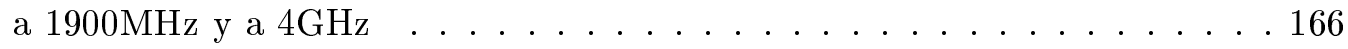

6.18 Geometría y ángulos implicados en la difracción GTD. Vista frontal . . . . 168

6.19 Geometría y ángulos implicados en la difracción GTD. Vista superior . . 168 
6.20 Difracción sobre una esquina en ángulo recto . . . . . . . . . . . . . 169

6.21 Posibles intersecciones de un tubo con las paredes . . . . . . . . . . . . . . 172

6.22 Distinción entre una esquina difractante y un rincón . . . . . . . . . . . 173

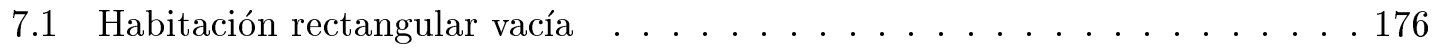

7.2 Potencia recibida en la habitación vacía sin reflexiones . . . . . . . . . . . 177

7.3 Potencia recibida en la habitación vacía, considerando una (a), dos (b) y tres reflexiones . . . . . . . . . . . . . . . 178

7.4 Potencia recibida en la habitación con pared lateral metálica . . . . . . . 179

7.5 Respuesta impulsional obtenida en un entorno con múltiples reflexiones . . 180

7.6 Funciones de scattering calculadas a partir de las trazas obtenidas mediante la simulación en la habitación vacía. (a) Traza paralela al frente de ondas directo. (b) Traza que se dirige directamente al transmisor . . . . . . . . . . . 181

7.7 Representación mediante curvas de nivel de la función de scattering obtenida a partir de la traza que se dirige directamente al transmisor . . . . . . 182

7.8 Habitación con pared metálica central y hueco . . . . . . . . . . . . . 183

7.9 Potencia recibida en la habitación con pared metálica central . . . . . . . 183

7.10 Planta de edificio sencillo . . . . . . . . . . . . . . . . . . . . 184

7.11 Representación tridimensional de la planta de la figura 7.10 . . . . . . . 185

7.12 Potencia recibida en la planta del edificio sencillo . . . . . . . . . . . . . . 185

7.13 Edificio vacío de tres plantas . . . . . . . . . . . . . . 186

7.14 Potencia recibida en las plantas inferiores del edificio vacío . . . . . . . . . 187

7.15 Planta y perspectiva $3 \mathrm{D}$ del edificio complejo . . . . . . . . . . . 188

7.16 Módulo de la respuesta impulsional obtenida en un punto del pasillo. En trazo discontinuo se muestra la versión filtrada. Retardo en ns . . . . . . 189

7.17 Funciones de scattering obtenidas de la trazas simuladas en el pasillo del edificio complejo. (a) Traza cercana al transmisor. (b) Traza alejada del

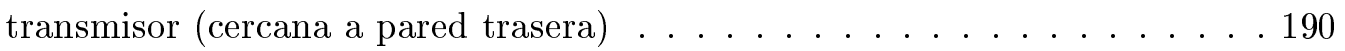

7.18 Diagrama de radiación de una antena isotrópica . . . . . . . . . . . . . 191

7.19 Diagrama de radiación de un dipolo elemental . . . . . . . . . . . . . . 192

7.20 Diagrama de radiación de un dipolo en $\lambda / 2 \ldots \ldots$. . . . . . . . 192

7.21 Diagrama de radiación de un dipolo de longitud $L=3 \lambda / 4 \ldots \ldots$. . . . . 192

7.22 Diagrama de radiación de un dipolo de longitud $L=\lambda \ldots \ldots$. . . . . 193

7.23 Diagrama de radiación de un dipolo de longitud $L=5 \lambda / 4 \ldots \ldots$. . . . . 193 
7.24 Diagrama de radiación de un dipolo de longitud $L=3 \lambda / 2 \ldots \ldots$. . . . . 193

7.25 Diagrama de radiación de un dipolo de longitud $L=2 \lambda \ldots \ldots$. . . . . . 194

7.26 Ejemplos de diagramas de radiación de antenas definidas mediante ficheros. (a) Antena isotrópica, (b) antena radiante en un semiespacio, (c) antena radiante en dos cuadrantes opuestos . . . . . . . . . . . . . . . . . 194

7.27 Primer entorno de prueba de los algorítmos de eliminación de impactos redundantes . . . . . . . . . . . . . . . . . . 195

7.28 Comparación de la potencia recibida en el primer entorno . . . . . . . . . 196

7.29 Comparación de los PDP promediados en el primer entorno . . . . . . . . . 197

7.30 Segundo y tercer entorno de prueba de los algorítmos de eliminación de impactos redundantes . . . . . . . . . . . . . . . 197

7.31 Comparación de la potencia recibida en el segundo y tercer entorno . . . . . 199

7.32 Reducción del error medio de cada algorítmo de eliminación de impactos redundantes . . . . . . . . . . . . . . . . . . . 199

7.33 Comparación de tiempos de ejecución de cada algorítmo de eliminación de impactos redundantes . . . . . . . . . . . . . . . . . 199

7.34 Habitación con pared multi-capa central . . . . . . . . . . . . . . . 200

7.35 Potencia recibida en la habitación con pared multi-capa central. Resultados sin considerar múltiples reflexiones (izquierda) y considerándolas mediante coeficientes equivalentes $($ derecha $) \ldots \ldots . \ldots . \ldots 201$

7.36 Habitación vacía con pared multi-capa en un fondo . . . . . . . . . . . . 201

7.37 Potencia recibida en la habitación con pared multi-capa lateral. Resultados con el método del seguimiento del rayo interno (izquierda) y mediante coeficientes equivalentes (derecha) _ . . . . . . . . . . . . 202

7.38 Resultados sin considerar el scattering y considerándolo con $\sigma_{h}=0 \mathrm{~mm}$. . . 204

7.39 Diferencia en la potencia recibida al considerar el scattering con distintos niveles de rugosidad . . . . . . . . . . . . . . . 205

7.40 Entorno de simulación simple para difracción _ . . . . . . . . . . . 208

7.41 Nivel de potencia sin difracción y con difracción (sin reflexiones) _ . . . . 208

7.42 Nivel de potencia sin difracción y con difracción (1 reflexión) . . . . . . 210

7.43 Diferencia en la potencia sin reflexiones (izquierda) o con una reflexión (derecha), al considerar la difracción . . . . . . . . . . . . . . . . 210

7.44 Entorno de simulación más complejo para difracción . . . . . . . . . . 211

7.45 Nivel de señal en entorno más complejo. Sin reflexiones (izquierda), y con

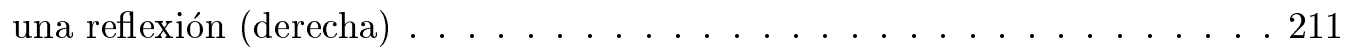


7.46 Nivel de señal en entorno más complejo al permitir hasta 10 reflexiones . 212

7.47 Nivel de señal en entorno más complejo con hasta 10 reflexiones. Paredes menos reflectantes . . . . . . . . . . . . . . . . . 213

7.48 Habitación vacía y posteriormente amueblada . . . . . . . . . . . . . 213

7.49 Nivel de potencia en la habitación vacía y con armario metálico central . 214

7.50 Influencia de la difracción en el armario metálico central . . . . . . . . . . 215

7.51 Nivel de potencia en la habitación totalmente amueblada . . . . . . . . 215

7.52 Reducción de error (desviación estándar, línea discontinua) y tiempo de ejecución (linea continua), en función del grado de resolución empleado . . . 218

7.53 Reducción de error (desviación estándar, línea continua) y tiempo de ejecución (linea discontinua), en función del número máximo de transmisiones y reflexiones permitido. Resultados en el edificio completo . . . . . . . . . . 219

7.54 Potencias recibidas a lo largo del pasillo, en función del número máximo permitido de transmisiones y reflexiones. En el gráfico de la izquierda, se han separado las trazas cada $10 \mathrm{~dB}$, para discernir mejor el grado de aproximación . . . . . . . . . . . . . . . . 2220

7.55 Reducción de error (desviación estándar, línea continua) y tiempo de ejecución (linea discontinua), en función del número máximo de transmisiones y reflexiones permitido. Resultados en pasillo con visibilidad directa . . . . 221

7.56 Potencia recibida a lo largo de las distintas trazas que recorren el pasillo . . 224

7.57 Error en la potencia recibida en cada traza del pasillo, respecto a la central 224

7.58 Número medio de impactos recibidos a lo largo del pasillo . . . . . . . . . . 225

7.59 (a) Errores absolutos y desviación típica (en trazo grueso) en la potencia recibida en cada punto a lo largo del pasillo, respecto a la posición central.

(b) Desviación típica del error en las cercanías de la traza central . . . . . . 225

7.60 Planos DXF bidimensionales de los pisos que forman parte del edificio de la ETSIT . . . . . . . . . . . . . . . . . . . 226

7.61 Alzado del edificio de la ETSIT, tal y como ha sido modelado para las simulaciones . . . . . . . . . . . . . . . . . 227

7.62 Representación gráfica del modelo de la ETSIT empleado en la simulación . 228

7.63 Simulación (línea a trazos) y medidas (lineas continuas) en el punto 3 del

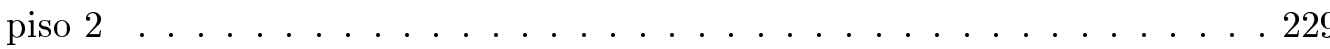

7.64 Simulación (línea a trazos) y medidas (líneas contínuas) en el punto 4 del

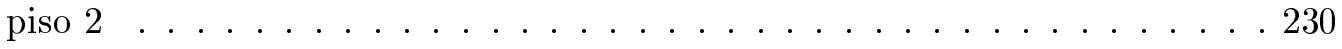

7.65 Simulación (línea a trazos) y medidas (líneas continuas) en el punto 2 del

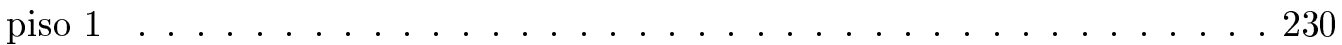


8.1 Función de densidad de probabilidad log-normal para distintos valores de

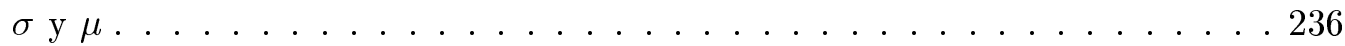

8.2 Función de densidad de probabilidad log-normal de la potencia en dBm, para distintos valores de $\sigma$ y $\ldots \ldots \ldots . \ldots \ldots 237$

8.3 Función de densidad de probabilidad Rice para distintos valores de $C$ y $\sigma \quad 239$

8.4 Función de densidad de probabilidad Rice de la potencia en dBm, para distintos valores de $C$ y $\sigma \ldots \ldots 24 \ldots \ldots \ldots$

8.5 Función de densidad de probabilidad Rayleigh para dos valores distintos de $\sigma 242$

8.6 Función de densidad de probabilidad Rayleigh de la potencia en dBm, para dos valores distintos de $6 \ldots \ldots$. . . . . . . . . . . . . 243

8.7 Función de densidad de probabilidad Nakagami para dos valores distintos

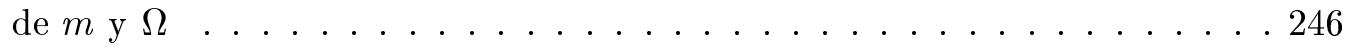

8.8 Función de densidad de probabilidad Nakagami de la potencia en $\mathrm{dBm}$, para dos valores distintos de $m$ y $\Omega \ldots$. . . . . . . . . . . 247

8.9 Funciones de densidad de probabilidad Nakagami para distintos valores de $m$, junto a la función de densidad de probabilidad Rayleigh . . . . . . . 247

8.10 Función de densidad de probabilidad Weibull para dos valores distintos de

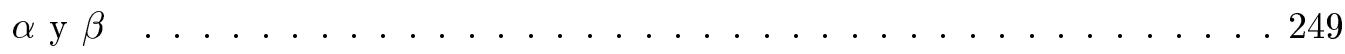

8.11 Función de densidad de probabilidad Weibull de la potencia en dBm, para dos valores distintos de $\alpha$ y $\beta \ldots . \ldots . \ldots . \ldots 250$

8.12 Histograma de medidas en el punto 2 del primer piso (polarización horizontal), comparado con las funciones de densidad de probabilidad teóricas . . . 254

8.13 Histograma de medidas en el punto $\mathrm{C}$ (pasillo de despachos) del primer piso (polarización vertical), comparado con las funciones de densidad de probabilidad teóricas . . . . . . . . . . . . . . . . . 254

8.14 Histograma de medidas en el punto 2 del segundo piso (polarización vertical), comparado con las funciones de densidad de probabilidad teóricas . . . 255

8.15 Ejemplos de histogramas de medidas que no se ajustan con confianza a ninguna función de densidad de probabilidad teórica . . . . . . . . . . 256

8.16 Histogramas de medidas realizados con visibilidad directa, comparados con las funciones de densidad de probabilidad teóricas. Polarización horizontal (izquierda) y vertical (derecha) . . . . . . . . . . . . . . . 257

8.17 Histograma de potencias obtenidas mediante simulación en el edificio sencillo, comparado con las funciones de densidad de probabilidad teóricas . . 259

8.18 Histograma de potencias obtenidas mediante simulación en el edificio complejo, comparado con las funciones de densidad de probabilidad teóricas . . 259 
8.19 Histogramas de potencias obtenidas mediante simulación en dos puntos del edificio de la ETSIT, comparados con las funciones de densidad de probabilidad teóricas . . . . . . . . . . . . . . . . 260 


\section{Índice de Tablas}

3.1 Clasificación de entornos indoor . . . . . . . . . . . . . . . 28

3.2 Parámetros optimizados de modelos empíricos . . . . . . . . . . . . . 33

3.3 Prestaciones de los modelos empíricos . . . . . . . . . . . . . . . 34

3.4 Prestaciones de los modelos basados en Óptica Geométrica . . . . . . . . 39

3.5 Parámetros eléctricos de algunos materiales . . . . . . . . . . . . . . . 41

4.1 Especificaciones del HP 83620A . . . . . . . . . . . . . . 50

4.2 Especificaciones del analizador de espectros HP 8920A . . . . . . . . . . 51

4.3 Parámetros de modelos de predicción de pérdidas . . . . . . . . . . . . 58

4.4 Características técnicas del amplificador de línea Televés SAT-90, utilizado en las medidas . . . . . . . . . . . . . . . . . . 6 61

4.5 Analizador de redes HP 8720B. Características principales . . . . . . . . 63

4.6 Parámetros de realización de las medidas en banda ancha . . . . . . . . . 65

4.7 Anchos de banda de coherencia a $-3 \mathrm{~dB}(r=0.5)$ y a $-6 \mathrm{~dB}(r=0.25)$. Tabla resumen . . . . . . . . . . . . . . . . 72

4.8 Anchos de banda de coherencia. Comparación entre distintas polarizaciones en dos casos particulares: trazas verticales en el pasillo principal $(\mathrm{p} 22 \mathrm{v}$ y v22v), y trazas longitudinales en visión directa (vd3h y vd3v) . . . . . . 72

4.9 Parámetros de exceso de retardo (en ns) promediados por trazas $\ldots \ldots$. . 76

4.10 Casos particulares de parámetros de exceso de retardo (en ns) . . . . . . . 76

5.1 Comparación de las características de los tubos lanzados para varias resoluciones . . . . . . . . . . . . . . . . . . . 110

5.2 Optimización de velocidad en función del número de receptores . . . . . . 126

5.3 Resultados de eficiencia en función del número máximo de reflexiones y transmisiones . . . . . . . . . . . . . . . . 127

5.4 Comparación entre los impactos descartados y la ganancia de velocidad . . 127 
5.5 Influencia del umbral de optimización en la velocidad . . . . . . . . . . . 128

5.6 Principales códigos de grupo y tipos de datos en DXF . . . . . . . . . . 133

5.7 Palabras clave que AutoCAD usa en sus ficheros DXF . . . . . . . . . 134

7.1 Parámetros de la simulación en la habitación vacía sin reflexiones . . . . . . 176

7.2 Parámetros de la simulación en la habitación vacía con reflexiones . . . . 177

7.3 Parámetros de la simulación en la habitación vacía con reflexiones . . . . 179

7.4 Parámetros de las simulaciones en banda ancha en la habitación vacía . . . 180

7.5 Parámetros de la simulación en la habitación con pared metálica central . . 183

7.6 Parámetros de la simulación en la planta de edificio sencillo . . . . . . . . . 184

7.7 Parámetros de la simulación en el edificio vacío de tres plantas . . . . . . 186

7.8 Parámetros de la simulación en banda ancha en edificio complejo . . . . . . 188

7.9 Parámetros de las simulaciones para evaluar la transmisión a través de paredes multi-capa . . . . . . . . . . . . . . . 200

7.10 Parámetros de las simulaciones para evaluar los métodos de múltiples reflexiones internas en estructuras multi-capa . . . . . . . . . . . . . 202

7.11 Tiempo de ejecución de los métodos que consideran las múltiples reflexiones internas en las estructuras multi-capa . . . . . . . . . . . . . 203

7.12 Parámetros de las simulaciones para evaluar las pérdidas por scattering . 203

7.13 Influencia del scattering en la potencia media recibida a $900 \mathrm{MHz}$. . . . . 206

7.14 Influencia del scattering en la potencia media recibida a $1.9 \mathrm{GHz}$. . . . . 206

7.15 Influencia del scattering en la potencia media recibida a $4 \mathrm{GHz} \ldots \ldots 206$

7.16 Influencia del scatering en los tiempos de ejecución . . . . . . . . . . . . 207

7.17 Parámetros de las simulaciones para comprobar los efectos de la difracción . 207

7.18 Parámetros de simulación en la habitación amueblada . . . . . . . . . . . . 213

7.19 Tiempos de simulación en la habitación amueblada . . . . . . . . . . . 216

7.20 Parámetros de la simulación para evaluar la velocidad y precisión del simulador en función del grado de resolución del lanzado . . . . . . . . . . . 217

7.21 Prestaciones del simulador en función del grado de resolución empleado . 217

7.22 Parámetros de la simulación para evaluar la velocidad y precisión del simulador en función del número máximo de transmisiones y reflexiones permitido para cada tubo . . . . . . . . . . . . . . . . . 218

7.23 Prestaciones del simulador en función del número máximo de transmisiones y refexiones permitido. Resultados en el edificio completo . . . . . . . . . 219 
7.24 Prestaciones del simulador en función del número máximo de transmisiones y refexiones permitido. Resultados en pasillo con visibilidad directa . . . . . 220

7.25 Parámetros de la simulación para evaluar la influencia de las variaciones en las constantes dieléctricas . . . . . . . . . . . . . . . . . . . . 222

7.26 Resultados obtenidos al variar las características eléctricas de los materieles del entorno . . . . . . . . . . . . . . . . . . . . . . . 2223

7.27 Parámetros de la simulación para evaluar la influencia de las variaciones en las posiciones de los receptores . . . . . . . . . . . . . . . . . . 223

7.28 Listado de los materiales que componen el edificio de la ETSIT, y valores de constantes dieléctricas asociadas . . . . . . . . . . . . . . 228

8.1 Test estadístico $\chi^{2}$ sobre las medidas realizadas en el pasillo principal del primer piso . . . . . . . . . . . . . . . . . . 253

8.2 Test estadístico $\chi^{2}$ sobre las medidas realizadas con visibilidad directa . . . 257

8.3 Test estadístico $\chi^{2}$ sobre las simulaciones realizadas en la planta del edificio sencillo . . . . . . . . . . . . . . . . . . 258 



\section{Capítulo 1}

\section{Introducción}

Existe un concepto, ampliamente conocido con el nombre de Negroponte Switch ${ }^{*}$, que viene a definir uno de los fenómenos tecnológicos más importante de los últimos años: las tecnologías que tradicionalmente utilizaban medios de transmisión en línea (como la telefonía), se están reconviertiendo a la transmisión vía radio, mientras que las que usaban este medio (como los sistemas de difusión masiva o broadcast), tienden a utilizar cada vez más el cable.

La razón que se aduce para tal cambio es que la información de bajo ancho de banda (la voz, por ejemplo) puede hacer un buen uso de aquellos canales de transmisión supuestamente de espectro limitado, es decir, canales de radiofrecuencia. Por otra parte, la transmisión de datos con grandes necesidades de ancho de banda, debe ser transmitida a través de canales de transmisión que, virtualmente, tengan ancho de banda ilimitado (si este se acaba, siempre se puede poner otro cable en paralelo).

Por su parte, George Gilder ${ }^{\dagger}$ apunta a que aún puede ser aprovechado más el espectro radioeléctrico, ya que el ancho de banda disponible en este medio puede llegar a ser virtualmente ilimitado gracias a la tecnología digital [Gil94].

Esto permitirá (o está ya permitiendo) que se desarrollen, cada vez más, sistemas de telecomunicación basados en la transmisión vía radio, que consigan aprovechar una de sus más importantes ventajas: la movilidad. Surge así un nuevo campo tecnológico denominado Comunicaciones Móviles que, partiendo de las técnicas propias de la Telefonía Móvil, las incorpora y amplía para aplicarlas a la transmisión de información de cualquier naturaleza y ancho de banda.

Sin embargo, según se hacen más complejos estos sistemas de Comunicaciones Móviles, que por necesidades de ubicuidad han de prestar un servicio lo más global posible, resulta imprescindible estructurarlos en forma de redes celulares, cuyas zonas de cobertura sean tanto más pequeñas como intensivo sea el acceso al sistema. Esta disminución del tamaño de las células es, además, indispensable cuando el usuario exige equipos de transmisión

${ }^{*}$ Se resume en la frase Everything wired would go wireless, and everything wireless would get wired, de Nicholas Negroponte, célebre divulgador tecnológico y director del Media Lab del Instituto Tecnológico de Massachussets (MIT).

†Otro famoso divulgador tecnológico y columnista, miembro del Discovery Institute. 
cada vez más pequeños por razones de portabilidad y ligereza de peso, y dotados a su vez de mayor autonomía. Ambas cosas son posibles si se utilizan terminales de baja potencia y, consecuentemente, corto alcance.

Tan pequeñas pueden llegar a ser las células, que puedan llegar a abarcar, no ya el interior de un edificio, sino incluso tan sólo una pequeña porción de él (una planta, un hall o, ¿por qué no?, una sola habitación). Así, aparecen conceptos como picocélula, e incluso femtocélula, utilizados en el ya reconocido subcampo de investigación de las Comunicaciones Móviles Indoor*.

Y conforme aumenta la cantidad de información a transmitir, más detallado ha de ser el estudio de cómo el ambiente influye en la calidad de la transmisión, es decir, cómo afecta el canal de propagación a las señales que se transmiten. De esta forma, los diseñadores de sistemas pueden, aprovechando el conocimiento de las características del canal, maximizar el uso del ancho de banda disponible mediante la evaluación de distintos métodos de codificación, modulación, recepción y otras muchas técnicas de telecomunicación.

Otra de las razones para investigar las características de propagación, en este caso en el interior de edificios, es la necesidad de planificar las ubicaciones de los distintos transmisores de la red cada vez con más detalle, debido a la reducción continua de las zonas de cobertura, incidiendo especialmente en los aspectos de reutilización de frecuencias. Esta planificación, en el caso del interior de edificios, deja de ser bidimensional para convertirse en volumétrica, apareciendo con ello la necesidad de hacer los estudios de propagación en tres dimensiones.

Con todo esto, aparece esta Tesis, cuyo modesto propósito no es más que contribuir al conocimiento de las características de propagación en el interior de edificios, vistos como entidades de naturaleza tridimensional por disponer a menudo de múltiples plantas, mediante la utilización de distintas técnicas y métodos de modelado, más o menos deterministas, basados en la Óptica Geométrica, y que se pueden ser llamados Métodos de Lanzado de Rayos.

\subsection{Organización de la memoria}

A continuación se detallará el contenido de esta memoria, explicando cuáles son los capítulos que la componen y qué se describe en cada uno de ellos.

El capítulo 1 es el presente y sirve de introducción al cuerpo general de la memoria de la Tesis.

Los capítulos 2 y 3 constituyen el estado del arte en la caracterización del canal radio móvil en el interior de edificios. En el primero se explica de modo general la forma de caracterizarlo matemáticamente, tanto en banda estrecha como en banda ancha. En el segundo, por su parte, se describen los distintos métodos habitualmente utilizados para

\footnotetext{
*En la redacción de esta memoria, se ha intentado por todos los medios utilizar términos y nomenclatura en castellano, salvo en los acrónimos y algún caso flagrante de imposibilidad de traducción. Sin embargo, se ha preservado el término indoor por su uso más que generalizado, sobre todo en referencia al canal, a pesar de que el autor es consciente de que es perfectamente traducible por interiores o interior de edificios, según sea el caso.
} 
obtener medidas en entornos indoor, así como las distintas técnicas de modelado (empíricas o deterministas) que se han venido utilizando hasta la actualidad.

En el capítulo 4 se presenta la campaña de medidas realizada en el interior del edificio de la Escuela Técnica Superior de Ingenieros de Telecomunicación de Valencia, que sirvió como punto de partida para la realización de esta Tesis. Se compararán los resultados obtenidos con los presentados en la literatura.

El capítulo 5 constituye la parte central de esta Tesis, pues en él se proponen y explican diversas técnicas para modelar el canal mediante Lanzado de Rayos. Concretamente se comparará el método genérico de lanzado con uno particular que se presenta en esta Tesis, y que puede ser denominado Lanzado de Tubos. Será tratada con detalle toda la problemática asociada a cada una de las variantes, especialmente en lo referente a la propagación tridimensional. Ciertos aspectos relacionados con la implementación y optimización de los modelos, serán también tenidos en cuenta.

Se ha extraído de dicho capítulo toda la física relacionada con la propia propagación electromagnética de los Rayos o Tubos, como entes que modelan una porción de frente de ondas. Esto se verá con detalle en el capítulo 6, donde, además, se propondrán técnicas válidas para modelar distintos fenómenos de propagación, como la incidencia en las paredes, suelos y techos, la reflexión difusa y la difracción en esquinas.

En el capítulo 7 se presentarán distintos resultados obtenidos mediante simulación. De esta forma, se validarán una a una todas las técnicas y fenómenos cuyos modelos han sido descritos en los dos capítulos anteriores. También se analizarán las prestaciones del simulador implementado, así como la sensibilidad que presenta a datos de entrada poco exactos. Finalmente, se compararán las medidas del capítulo 4 con las simulaciones obtenidas en un entorno similar.

El capítulo 8 es bastante autocontenido, pues se empieza explicando la forma de caracterizar estadísticamente el canal radio móvil en el interior de edificios, pasando luego a comparar las distintas distribuciones teóricas propuestas hasta ahora en la literatura, con las medidas presentadas en el capítulo 4. Sin embargo, el objetivo principal del capítulo es recordar los conocimientos necesarios para luego poder analizar estadísticamente los resultados obtenidos mediante simulación.

Por último, en el capítulo 9 se resumirán las principales conclusiones de esta Tesis y se propondrán diversas líneas de investigación a desarrollar a partir de ella. 



\section{Capítulo 2}

\section{El Canal Radio Móvil Indoor}

\section{$2.1 \quad$ Introducción}

El término Comunicaciones Móviles está referido a aquellos sistemas de comunicaciones en los que un enlace de comunicación vía radio une dos o más terminales, de los cuales, al menos uno, denominado usualmente estación móvil (o simplemente móvil), estará en movimiento o situado en una posición no especificada, mientras el otro actúa habitualmente como terminal fijo, y suele denominarse estación base (o sólo base).

El hecho de que ambos terminales o estaciones se encuentren en el interior de un edificio supone que el tratamiento necesario para la caracterización del canal presente ciertas peculiaridades. Sin embargo, es necesario empezar a estudiarlo de forma genérica, para luego mostrar dicha caracterización específica. Eso es lo que se va hacer en este capítulo. Primero se hará un repaso a los métodos habituales para caracterizar el canal radio móvil, para luego incidir algo más en aquellos aspectos propios de los entornos indoor.

En cualquier sistema de comunicaciones móviles genérico, entre la base y el móvil aparecerán numerosos elementos influyentes en la propagación de las ondas, tales como montañas, edificios o partes integrantes de los mismos (paredes, fachadas, techos, suelos), coches, personas, etc. Al situarse en el trayecto de propagación de la señal, actuarán como elementos difusores o scatterers y producirán que las señales transmitidas sufran fenómenos de reflexión, difracción y scattering.

En la antena receptora del móvil o la base, serán recibidas múltiples ondas que habrán sufrido procesos de reflexión y difracción diferentes. Debido a la diferencia en los caminos recorridos, estos ecos o réplicas de la señal transmitida llegarán con ángulos de incidencia, atenuación, desfases y retardos de propagación diferentes. Este efecto es conocido como efecto multi-camino o multi-path.

El movimiento del móvil y de los elementos difusores produce que las características del canal varíen aleatoriamente con el tiempo. De esta forma, la contribución de las ondas recibidas en determinados instantes puede ser constructiva en unos casos, y destructiva en otros, en función de las amplitudes y desfases que posean dichas ondas. Esto provoca que la potencia de la señal recibida no sea constante, sino que varíe con el tiempo, produ- 
ciéndose desvanecimientos o fading. En función de su duración, éstos pueden clasificarse en desvanecimientos a largo plazo o long-term fading, y desvanecimientos a corto plazo o short-term fading.

Este capítulo pretende ser una introducción a las características que presenta el canal radio en entornos móviles, y se estudiarán los fenómenos y efectos que se producen al establecer una comunicación a través de dicho canal móvil (efecto multi-camino, fading selectivo en tiempo y frecuencia, efecto Doppler, ensanchamiento o dispersión temporal, etc.). También se introducirán conceptos básicos relacionados con la caracterización del canal, que serán útiles en capítulos posteriores.

\subsubsection{Comunicaciones Móviles en banda ancha y en banda estrecha}

En general, los sistemas de comunicación pueden ser ampliamente clasificados en sistemas de banda estrecha (narrowband) y sistemas de banda ancha (wideband).

Según [Pro89], una señal puede definirse como de banda estrecha cuando el margen sobre el que se extienden sus componentes frecuenciales es pequeño en compararción con la frecuencia de su portadora $f_{c}$.

Para un sistema de comunicación, una definición más rigurosa sería la que relaciona la banda de frecuencias sobre la que se transmiten las señales, con los efectos del canal sobre esas frecuencias. Así, en Comunicaciones Móviles, cuando la señal transmitida posee un determinado ancho de banda, el multi-camino influye de forma desigual sobre las distintas frecuencias del ancho de banda. Se denomina ancho de banda de coherencia o ancho de banda de correlación, al ancho de banda dentro del cual las distintas componentes en frecuencia sufren de igual forma los efectos del multi-camino.

Por tanto, para un canal cuya respuesta impulsonal pueda considerarse esencialmente no nula sobre un margen de retardo dado por $T_{m}$, se puede definir su ancho de banda de coherencia como el recíproco de $T_{m}$ [Pro89], al cual se le conoce como ensanchamiento temporal (delay spread) del canal*. Se dice, con ello, que un sistema de comunicaciones es de banda estrecha cuando el ancho de banda de la señal a transmitir es menor que el ancho de banda de coherencia del canal. En caso contrario, se ha de considerar como de banda ancha.

En las dos siguientes secciones se estudiará la forma de caracterizar el canal radio móvil según se considere al sistema como de banda estrecha o como de banda ancha.

\subsection{Caracterización del Canal Radio Móvil en banda estre- cha}

La forma más sencilla de modelar una señal de banda estrecha a transmitir $x(t)$ es, simplemente, mediante una portadora sin modular de amplitud $A$ y frecuencia $f_{c}$ :

$$
x(t)=A e^{j 2 \pi f_{c} t}
$$

${ }^{*}$ Se verá una definición más exacta en la sección 2.3.4 
La señal recibida, debido a la presencia de difusores (scatterers) en el canal, estará formada por múltiples réplicas de la señal transmitida. Cada una de estas ondas llegará al receptor con un ángulo de incidencia y retardo de propagación diferente, producto de los fenómenos de reflexión y difracción sufridos a lo largo del trayecto.

En primera instancia, puede suponerse que el canal es estático. Con esta y las anteriores consideraciones, la señal recibida $w(t)$ tendrá la forma:

$$
w(t)=\sum_{i=1}^{N} A_{i} x\left(t-\tau_{i}\right)
$$

donde $N$ es el número total de ondas o contribuciones recibidas, $A_{i}$ es un número complejo cuyo módulo y fase representan el resultado de los procesos de reflexión y difracción de la onda $i$-ésima, y $\tau_{i}$ representa el retardo de propagación de dicha onda.

Si se sutituye la ecuación (2.1) en (2.2), se obtendrá la expresión de la señal recibida:

$$
w(t)=\left[\sum_{i=1}^{N} A_{i} e^{-2 \pi f_{c} \tau_{i}}\right] e^{j 2 \pi f_{c} t}
$$

Puede fácilmente comprobarse que la envolvente de la señal recibida no sufre ningún tipo de variación ni desvanecimiento, es decir, es invariante en el tiempo. Esto se debe a que se ha supuesto un canal estático, donde tanto el móvil como los difusores se encuentran fijos.

En consecuencia, aunque se produzca el efecto multi-camino, como todas las variables que influyen en él serán invariantes con el tiempo, la envolvente de la señal en recepción también lo será.

En un canal móvil, el propio terminal móvil y los elementos que constituyen el canal, causantes de los fenómenos de multi-camino, suelen estar en movimiento. En este caso, debe considerarse que el canal es variante en el tiempo, por lo que la expresión de la señal recibida al transmitir una portadora sin modular de frecuencia $f_{c}$ resultará ser:

$$
w(t)=\left[\sum_{i=1}^{N(t)} A_{i}(t) e^{-2 \pi f_{c} \tau_{i}(t)} e^{-j k v t \cos \theta_{i}}\right] e^{j 2 \pi f_{c} t}
$$

donde:

- el número de componentes $N$, la atenuación y desfase $A_{i}$, y el retardo de propagación $\tau_{i}$ de la onda $i$-ésima, dependerán ahora del tiempo, pues el canal es variante con el tiempo;

- $k$ es el número de onda, es decir, $2 \pi / \lambda$, siendo $\lambda$ la longitud de onda de la portadora;

- $v$ es la velocidad del móvil, $\mathrm{y}$

- $\theta_{i}$ es el ángulo que forman el vector velocidad del móvil y la dirección de llegada de la onda $i$-ésima. 
Por tanto, la envolvente de la señal recibida variará, en módulo y fase, con el tiempo, pues todas las variables que definen el canal $\left(N, A_{i}\right.$ y $\left.\tau_{i}\right)$ serán ahora dependientes del tiempo.

Efectivamente, en la figura 2.1 puede verse, como ejemplo, la evolución de la envolvente de la señal recibida en un móvil, en función del tiempo, para una frecuencia portadora de $1 \mathrm{GHz}$, un tiempo de observación de 1 segundo y una velocidad del móvil de $50 \mathrm{~km} / \mathrm{h}$. En trazo grueso se representa la media local de la envolvente.

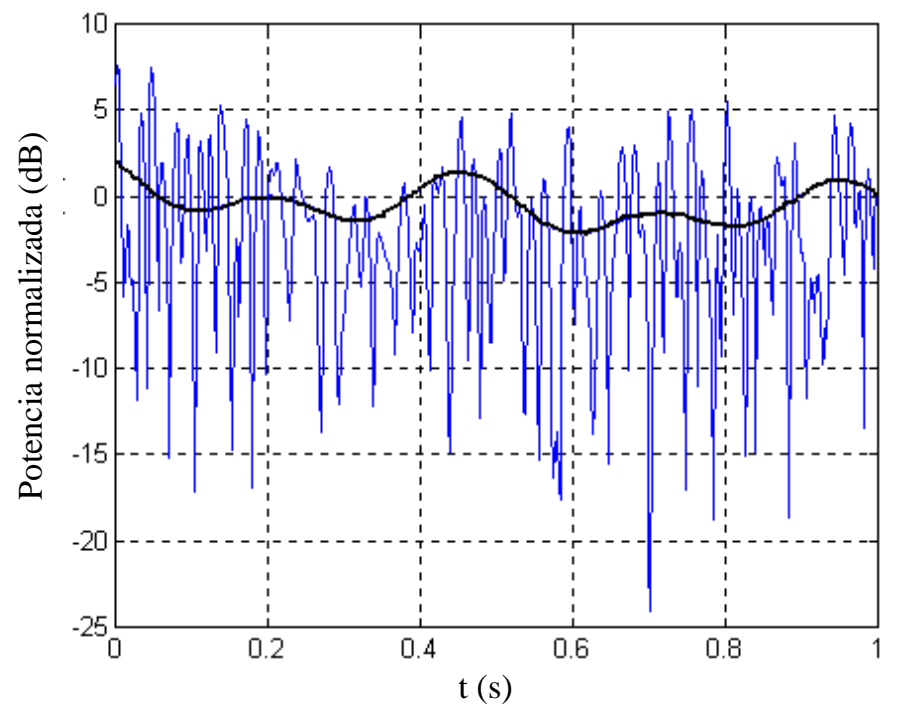

Figura 2.1: Envolvente de la señal recibida en un móvil para una velocidad de $50 \mathrm{~km} / \mathrm{h}$; $f_{c}=1 \mathrm{GHz} ;$ tiempo de observación: 1s

Para explicar estas variaciones hay que recordar que, debido al multi-camino, a la antena receptora llegarán múltiples ondas con una amplitud y fase determinada. Para ilustrar el problema y por simplicidad se va a suponer que sólo existen dos componentes, la componente directa y una componente reflejada (figura 2.2).

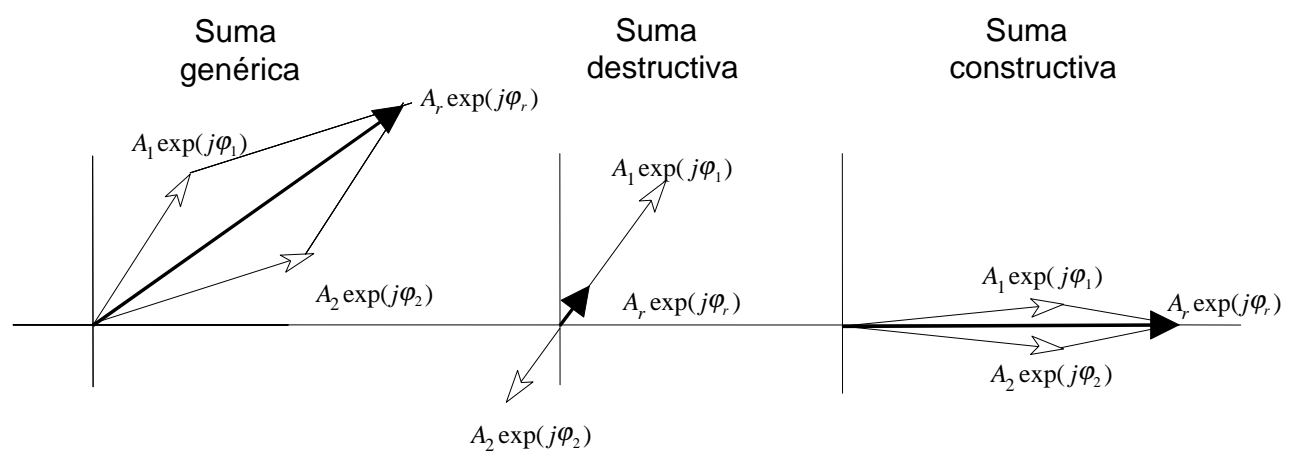

Figura 2.2: Diagrama fasorial para dos componentes de multi-camino

Cuando las fases de la onda reflejada $\varphi_{1}$ y la onda directa $\varphi_{2}$ sean iguales, ambas se sumarán de forma constructiva, aumentando la potencia recibida. Sin embargo, cuando estén en contrafase, sus amplitudes se restarán, produciéndose un desvanecimiento en la 
señal recibida.

\subsubsection{Desvanecimientos a largo y a corto plazo}

De la anterior figura 2.1 se desprende que existen dos tipos de variaciones: unos desvanecimientos lentos y de poca intensidad, que constituyen el comportamiento de la señal a largo plazo, y otro tipo de desvanecimientos más rápidos y profundos que caracterizan a la señal a corto plazo.

El fenómeno de presencia de desvanecimientos a largo plazo long-term fading, también llamado shadowing o media local (local mean), aparece cuando el móvil recorre trayectos de varios centenares de longitudes de onda. Es producido principalmente por la interposición entre el transmisor y el receptor de aquellos elementos más significativos del entorno, como la orografía del terreno (entorno plano o montañoso), el tipo de edificaciones (entorno urbano, rural, suburbano), entre otros. En el caso de entornos interiores, influyen en este tipo de desvanecimientos los objetos y obstáculos de naturaleza más o menos inmóvil, que se interpongan directamente entre el transmisor y el receptor.

Los desvanecimientos a corto plazo (short-term fading) son generalmente causados por las reflexiones y difracciones en objetos cuyas posiciones relativas al móvil varían rápidamente, es decir, casas, edificios, coches, personas u objetos que suelen encontrarse en su entorno más inmediato. Se observa en trayectos del móvil de decenas de longitudes de onda y provoca variaciones y desvanecimientos muy rápidos y profundos que, sin embargo, no modifican la potencia media recibida, ya que ésta depende exclusivamente del comportamiento a largo plazo.

Para estudiar el fenómeno de los desvanecimientos, se debe recurrir a una caracterización estadística de la señal, debido a la naturaleza aleatoria del canal móvil. Efectivamente, el número de difusores, sus características, su posición, su velocidad, etc. varían con el tiempo, haciendo que la amplitud y fase de las múltiples componentes que llegan al receptor tengan un carácter aleatorio. Las componentes recibidas se sumarán vectorialmente (de acuerdo con su amplitud y fase) para generar la envolvente de la señal que, en consecuencia, será una variable aleatoria que deberá ser caracterizada estadísticamente.

Con este objetivo, el primer paso a seguir es separar el comportamiento a largo plazo del de corto plazo, y comprobar a qué distribución se ajustan mejor los estadísticos de cada uno de ellos. Desde el punto de vista teórico, esta separación no es una tarea fácil. Puede haber recorridos de centenares de longitudes de onda sin variaciones sustanciales en el entorno de propagación, no sufriendo la señal recibida desvanecimientos de largo plazo.

Dar unas cifras de longitudes de recorridos para distinguir entre ambos es generalizar demasiado. Sin embargo, el análisis de varias campañas de medidas ha demostrado que, para recorridos de hasta $40 \lambda$ o $60 \lambda$ de longitud (o su equivalente temporal, dada la velocidad del móvil), sólo aparece el efecto del short-term fading [Lee85]. Este hecho resulta mucho más relevante en el caso de entornos indoor.

Más adelante, en el capítulo 8, se procederá a estudiar los distintos tipos de distribuciones estadísticas que se han propuesto para caracterizar ambos tipos de desvanecimientos, con especial atención a aquellas que sean válidas en el interior de edificios. 


\subsubsection{Efecto Doppler}

También se puede analizar cómo se manifiesta la variabilidad del canal radio móvil en el dominio de la frecuencia, a pesar de que el sistema sea considerado como de banda estrecha. Con este objetivo, se puede representar (figura 2.3) el espectro de la envolvente de la señal presentada en la figura 2.1 .

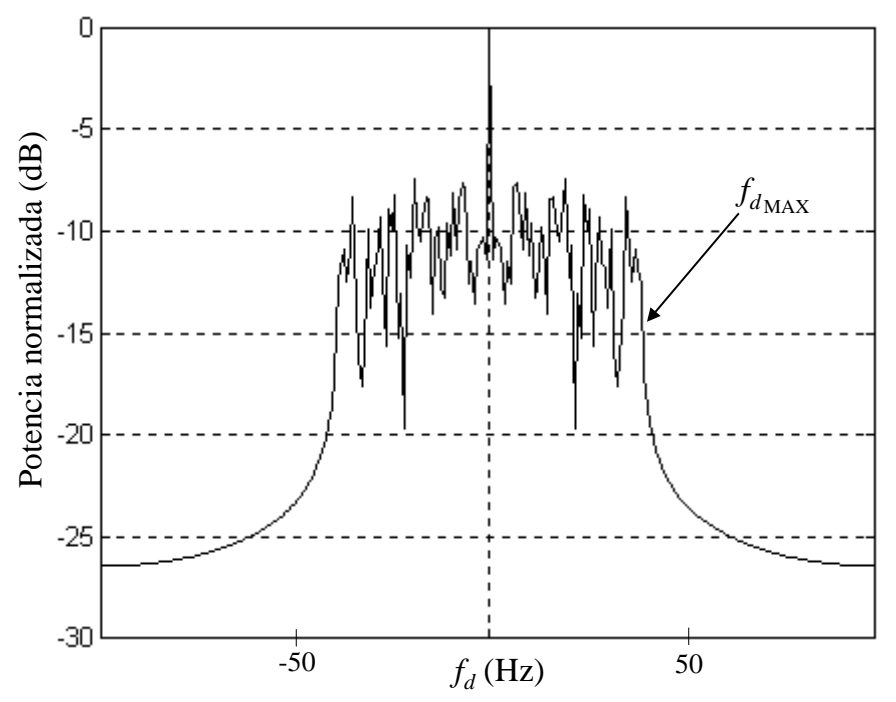

Figura 2.3: Espectro de la envolvente vista en la figura 2.1. $f_{d \mathrm{MAX}}=46.29 \mathrm{~Hz}$

Así, se puede apreciar que, aparte de la componente a frecuencia cero debida a la componente continua de la envolvente, aparecen otras componentes frecuenciales que se extienden hasta un valor máximo $f_{d \mathrm{MAX}}$ que, suponiendo detección lineal, se corresponde con lo que se denomina máxima frecuencia Doppler*, y que viene definida como:

$$
f_{d \mathrm{MAX}}=\frac{v}{\lambda}
$$

Obsérvese que la frecuencia Doppler depende de la velocidad absoluta del móvil $v, \mathrm{y}$ de la longitud de onda de la señal $\lambda$. Este efecto Doppler puede percibirse como un ruido de FM en los sistemas que usan tal tipo de modulación.

Así pues, los desvanecimientos temporales producen, en el dominio frecuencial, un ensanchamiento de banda de la señal, cuyo valor máximo dependerá de la velocidad del móvil, y que se denomina frecuencia Doppler. En este caso, se dice que el canal es dispersivo en frecuencia.

Otro concepto relacionado con la frecuencia Doppler y la variabilidad del canal es el tiempo de coherencia. El tiempo de coherencia define el intervalo de tiempo para el cual el canal puede considerarse invariante. Se puede ver también como el tiempo que se ha de esperar entre la recepción de dos portadoras para que sus envolventes puedan considerarse incorreladas. El tiempo de coherencia dependerá inversamente tanto de la velocidad del móvil como de la frecuencia Doppler.

*La mayoría de las veces se obvia el que sea máxima 


\subsection{Caracterización del Canal Radio Móvil en banda ancha}

Una caracterización en banda ancha permite estudiar una serie de parámetros del canal de gran interés a la hora de diseñar sistemas de comunicaciones indoor, tales como la magnitud del ensanchamiento de retardo que provoca el multi-camino, los anchos de banda máximos para los cuales el deterioro de la señal es aproximadamente el mismo, o las posiciones de los principales difusores (scatterers) del canal. Además, aporta una mejor comprensión de los mecanismos físicos del multi-camino.

Si el ancho de banda de la señal a transmitir es lo suficientemente estrecho, la máxima diferencia de frecuencia entre sus componentes espectrales es tal que los caminos eléctricos recorridos por cada una de ellas son muy parecidos, lo cual supone que las distintas componentes frecuenciales sufrirán variaciones de amplitud y fase semejantes. Se dice entonces que sufre una serie de desvanecimientos planos en frecuencia.

Sin embargo, cuando el ancho de banda de la señal transmitida es grande, conforme aumenta la separación entre las distintas componentes en frecuencia, los caminos eléctricos recorridos por cada una difieren más, con lo que sufrirán distintas variaciones de amplitud $\mathrm{y}$, sobre todo, de fase, ya que la fase puede cambiar varios radianes incluso para diferencias pequeñas en los caminos. Aparecen entonces desvanecimientos selectivos en frecuencia del nivel de señal recibida. Si, además, el sistema es variante como consecuencia del movimiento del transmisor o del receptor, aparecen una serie de desvanecimientos espaciales (que pueden ser vistos también como desvanecimientos en el tiempo), además de un fenómeno de desplazamiento de frecuencia de la señal recibida debido al efecto Doppler, tal y como se ha visto en la sección anterior.

En transmisiones de pulsos de banda ancha, el efecto fundamental del multi-camino es producir una serie de réplicas atenuadas y retardadas del pulso original transmitido, cada una de las cuales se corresponde con los distintos difusores del canal. En un sistema de comunicaciones móviles indoor, la longitud de los diferentes caminos de propagación varía con el tiempo en función del movimiento del transmisor o del receptor. La existencia de distintos tiempos de llegada permite la identificación de los distintos caminos de propagación, o lo que es lo mismo, de los difusores que los originan.

Pero para hacer esta distinción no basta con considerar la diferencia entre los instantes de llegada sino que además es necesario conocer la dirección de llegada de la componente del multi-camino. Si se consideran todos los caminos que han sufrido una única reflexión, aquellos que tengan igual retardo, es decir, que hayan recorrido una misma longitud, pueden localizarse en una elipse en cuyos focos estarían transmisor y receptor. Para cada valor de retardo (o longitud recorrida), puede trazarse una elipse cofocal a la anterior (figura 2.4).

Dentro de una misma elipse los caminos se distinguen por su ángulo de llegada. El ángulo de llegada puede estimarse a partir de la frecuencia Doppler ya que, siempre que transmisor o receptor estén en movimiento, la señal transmitida experimenta un desplazamiento en frecuencia $f_{d}$ que está relacionado con la velocidad del móvil $v$, y el ángulo $\alpha$ que forman la dirección de desplazamiento del receptor, y la dirección de llegada de la 


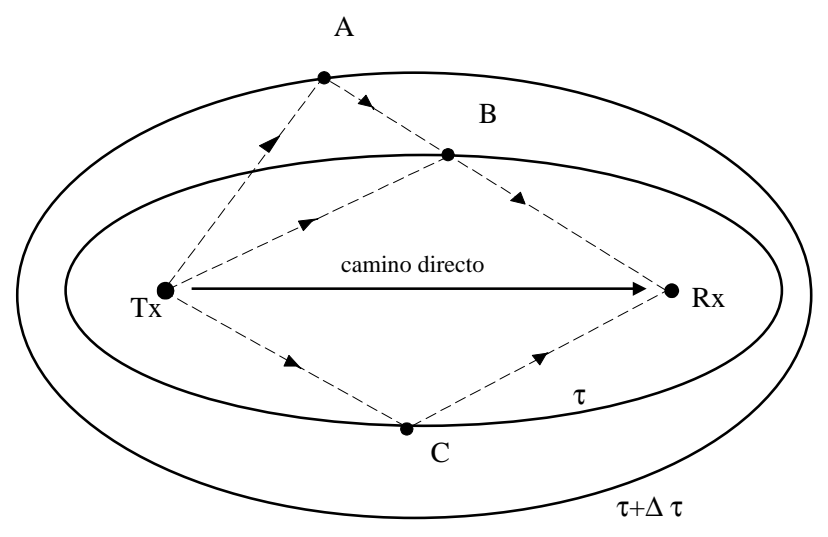

Figura 2.4: Elipses de igual retardo. Los caminos $\overline{\mathrm{T}_{\mathrm{x}} \mathrm{BR}_{\mathrm{x}}}$ y $\overline{\mathrm{T}_{\mathrm{x}} \mathrm{CR}_{\mathrm{x}}}$ han de distinguirse por el ángulo de llegada, pues poseen el mismo valor de retardo

señal (figura 2.5). Dicho desplazamiento en frecuencia viene dado por:

$$
f_{d}=\frac{v}{\lambda} \cos \alpha
$$

siendo $\lambda$ la longitud de onda de la señal. Su valor máximo es el que ya se presentó en la ecuación (2.5).

Si se transmite un pulso de radiofrecuencia y se mide su tiempo de llegada y su desplazamiento de frecuencia Doppler en el receptor, se podría llegar a identificar la longitud del camino recorrido y el ángulo de llegada, quedando la incertidumbre de si la señal llega por la derecha o por la izquierda del receptor, es decir, el signo del ángulo, que puede determinarse si se usan antenas directivas.

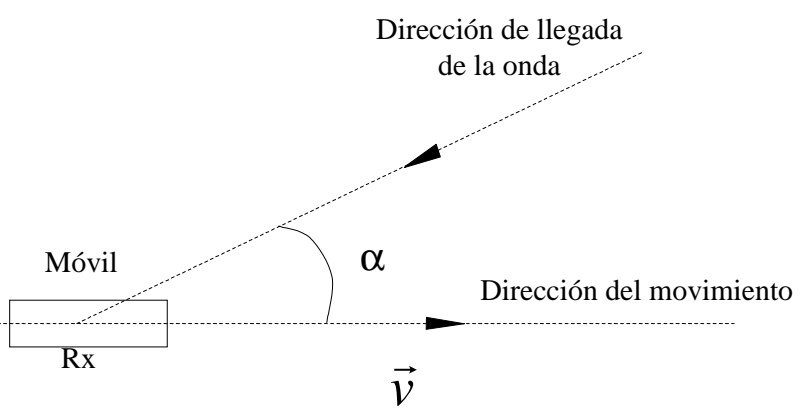

Figura 2.5: Ángulo entre la dirección del receptor móvil y la de la señal recibida 


\subsubsection{El canal radio móvil como sistema lineal cronovariable. Funciones de Bello}

Con el objeto de describir el canal, se suelen utilizar una serie de funciones en los dominios temporal y frecuencial conocidas como Funciones de Bello, en honor a P. A. Bello, ya que fue este el precursor de su empleo en la caracterización de canales lineales variantes en el tiempo (cronovariables) [Bel63]. La justificación de estas funciones puede encontrarse de forma más extensa, además de en la citada referencia, en [Par82] y en [Par92].

Conviene, para usar tales funciones, sustituir la señal paso banda real $x(t)$, por su envolvente compleja $z(t)$, relacionada con la anterior mediante:

$$
x(t)=\operatorname{Re}\left[z(t) e^{j 2 \pi f_{c} t}\right]
$$

donde $f_{c}$ es la frecuencia portadora. Puede entonces calcularse la envolvente compleja de la señal de salida del canal como:

$$
w(t)=\int_{-\infty}^{\infty} z(t-\tau) h(t, \tau) d \tau
$$

en la que $h(t, \tau)$ es la envolvente compleja de la respuesta impulsional del canal variable en el tiempo, siendo $\tau$ una variable de retardo. A $h(t, \tau)$, se le denomina Función de ensanchamiento de retardo a la entrada*. Físicamente, $h(t, \tau)$ puede interpretarse como la respuesta del canal en el instante $t$ a un impulso de entrada generado $\tau$ segundos antes. Puesto que el canal real es causal, en la ecuación anterior el límite de integración inferior debe ser cero y el superior puede ser un tiempo finito de observación.

El canal móvil también puede ser caracterizado en el dominio de la frecuencia mediante el uso de la función dual de $h(t, \tau)$ en tal dominio, la Función de ensanchamiento Doppler a la salida ${ }^{\dagger} H(f, \nu)$. La envolvente compleja del espectro de la señal de salida del canal, $W(f)$, puede entonces calcularse como:

$$
W(f)=\int_{-\infty}^{\infty} Z(f-\nu) H(f-\nu, \nu) d \nu
$$

Esta función $W(f)$ puede interpretarse como una superposición de réplicas del espectro de la señal de entrada $Z(f)$, filtradas y desplazadas en frecuencia debido al efecto Doppler. La variable $\nu$ es el desplazamiento Doppler experimentado en el canal. Tiene, por tanto, dimensiones de frecuencia, y está relacionado con el desplazamiento en frecuencia Doppler $f_{d}$ que sufre la señal recibida en un receptor que se mueva a una velocidad $v$ mediante la siguiente expresión:

$$
f_{d}=v \cdot \nu
$$

Otra función empleada para definir el canal es la Función de transferencia cronovariable $^{\ddagger} T(f, t)$, que es la transformada de Fourier de la respuesta impulsional variable en

\footnotetext{
${ }^{*}$ Input delay-spread function

${ }^{\dagger}$ Output Doppler-spread function

†ime-variant transfer function
} 
el tiempo. Puede interpretarse, por tanto, como la función de transferencia del canal variando en el tiempo, y puede estimarse mediante medidas sucesivas en el tiempo de la respuesta en frecuencia del canal. La envolvente compleja de la señal de salida del canal puede hallarse a partir de $T(f, t)$ como sigue:

$$
w(t)=\int_{-\infty}^{\infty} Z(f) T(f, t) e^{2 \pi f t} d f
$$

A diferencia de $h(t, \tau)$, que permite distinguir entre caminos de diferentes longitudes, y de $H(f, \nu)$, que permite observar diferentes desplazamientos Doppler, relacionados con los ángulos de llegada, la función $T(f, t)$ no da una visión física clara y directa del fenómeno multi-camino.

La función que mejor describe el canal multi-camino en ambos dominios, retardo $\tau \mathrm{y}$ desplazamiento Doppler $\nu$, es la Función de ensanchamiento Doppler/retardo* $S(\tau, \nu)$. La señal de salida del canal puede expresarse en función de ella como:

$$
w(t)=\int_{-\infty}^{\infty} \int_{-\infty}^{\infty} z(t-\tau) S(\tau, \nu) e^{2 \pi \nu t} d \nu d \tau
$$

donde puede verse que la señal de salida del canal se obtiene como una suma de réplicas de la señal de entrada con distinto retardo y distinto desplazamiento Doppler en frecuencia.

Todas estas funciones que se han visto están relacionadas mediante transformadas simples de Fourier, tal y como puede observarse esquemáticamente en la figura 2.6.

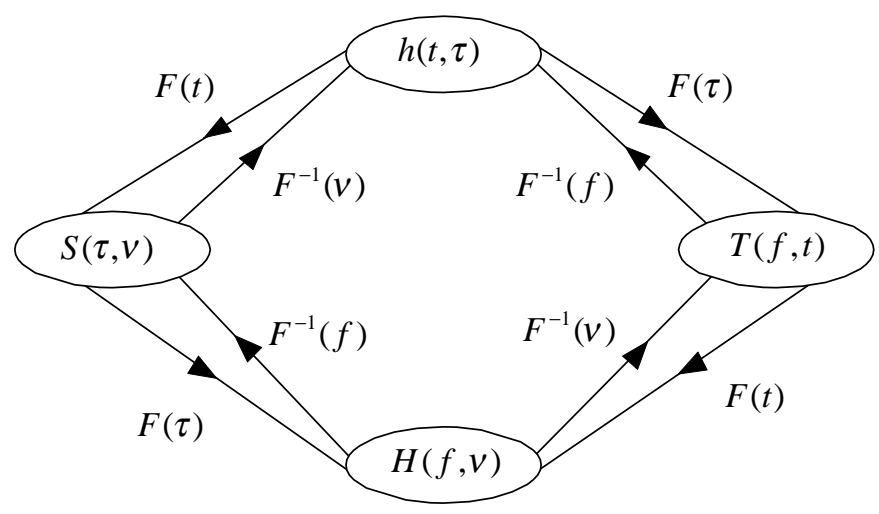

Figura 2.6: Relación entre las distintas funciones de caracterización del canal, como sistema lineal variante en el tiempo

\subsubsection{El canal móvil como sistema lineal cronovariable aleatorio}

Las funciones anteriores permiten el estudio de canales que tienen un comportamiento determinista. Sin embargo, los canales reales, en la práctica, no pueden ser estudiados de

\footnotetext{
${ }^{*}$ Doppler/delay-spread function
} 
forma determinista, por lo que hay que recurrir a una caracterización estadística del canal. Las funciones del sistema han de tratarse entonces como procesos estocásticos. Ahora bien, una descripción exacta del canal de forma estadística requiere el conocimiento de las funciones de densidad de probabilidad conjuntas multidimensionales de todas las variables aleatorias del sistema, lo que rara vez es posible, por lo que se recurre al estudio de los momentos estadísticos de los procesos estocásticos que describen el sistema. Habitualmente, el conocimiento de la media y la correlación suele ser suficiente.

Supóngase, para simplificar las expresiones, que los procesos aleatorios son de media nula. En ese caso, los procesos reales $x(t)$ pueden ser descritos en la práctica mediante la función de autocorrelación de su envolvente compleja $z(t)$, definida como:

$$
R_{z}(t, s)=\mathrm{E}\left[z(t) z^{*}(t)\right]
$$

Las funciones de autocorrelación de las funciones de caracterización del canal pueden obtenerse entonces mediante:

$$
\begin{aligned}
R_{h}(t, s ; \tau, \eta) & =\mathrm{E}\left[h(t, \tau) h^{*}(s, \eta)\right] \\
R_{T}(f, g ; t, s) & =\mathrm{E}\left[T(f, t) T^{*}(g, s)\right] \\
R_{H}(f, g ; \nu, \mu) & =\mathrm{E}\left[H(f, \nu) H^{*}(g, \mu)\right] \\
R_{S}(\tau, \eta ; \nu, \mu) & =\mathrm{E}\left[S(\tau, \nu) S^{*}(\eta, \mu)\right]
\end{aligned}
$$

ecuaciones en las que $t$ y $s$ son variables de tiempo, $f$ y $g$ son variables de frecuencia, $\nu$ y $\mu$ son variables de desplazamiento Doppler y $\operatorname{con} \tau$ y $\eta$ variables de retardo.

La función de autocorrelación de la salida del canal para entradas complejas $z(t)$ deterministas, puede hallarse entonces como:

$$
R_{w}(t, s)=\int_{-\infty}^{\infty} \int_{-\infty}^{\infty} z(t-\tau) z^{*}(s-\nu) R_{h}(t, s ; \tau, \eta) d \tau d \eta
$$

donde $R_{h}$ es la función de autocorrelación de la respuesta impulsional variable en el tiempo. $R_{w}$ también puede calcularse a partir de cualquiera de las funciones de autocorrelación mostradas. En la figura 2.7 se representan esquemáticamente las relaciones entre las distintas funciones de autocorrelación descritas, relaciones que se traducen en transformadas dobles de Fourier.

\section{Canales estacionarios en sentido amplio y de scattering incorrelado (WSSUS)}

Muchos de los radiocanales reales pueden considerarse como WSSUS*. Este tipo de canales combina, por un lado, las características de los canales estacionarios en sentido amplio (WSS) y, por otro, las de los canales de scattering incorrelado en la variable de retardo (US).

Por el hecho de ser un canal estacionario en sentido amplio, WSS, sus estadísticos pueden considerarse estacionarios para intervalos de tiempo suficientemente pequeños (distancias si el canal es móvil), lo que supone que las funciones de autocorrelación del canal

\footnotetext{
${ }^{*}$ Wide Sense Stacionary and Uncorrelated Scattering
} 


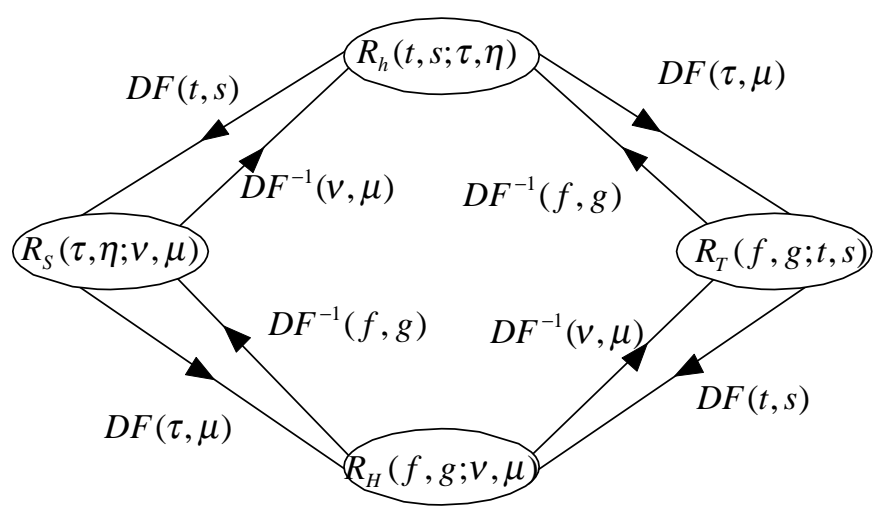

Figura 2.7: Relaciones entre las distintas funciones de autocorrelación del canal, como sistema lineal cronovariable aleatorio

no cambian al sufrir una traslación en el tiempo o en el espacio. O, dicho de otra forma, las funciones de autocorrelación del canal sólo dependen del intervalo de desplazamiento y no de los instantes o posiciones particulares considerados. Por tanto, para un canal WSS, las ecuaciones (2.14) y (2.15) pueden ponerse como:

$$
\begin{aligned}
& R_{h}(t, t+\xi ; \tau, \eta)=R_{h}(\xi ; \tau, \eta) \\
& R_{T}(f, g ; t, t+\xi)=R_{T}(f, g ; \xi)
\end{aligned}
$$

donde $\xi$ es el intervalo de tiempo considerado, $\xi=s-t$.

Además, puede demostrarse que la estacionariedad en sentido amplio da lugar a scattering con desplazamientos Doppler incorrelados [Bel63], lo que permite poner las expresiones (2.16) y (2.17) como:

$$
\begin{aligned}
R_{H}(f, g ; \nu, \mu) & =\delta(\nu-\mu) P_{H}(f, g ; \nu) \\
R_{S}(\tau, \eta ; \nu, \mu) & =\delta(\nu-\mu) P_{S}(\tau, \eta ; \nu)
\end{aligned}
$$

en las que $P_{S}$ y $P_{H}$ son, respectivamente, las densidades espectrales de potencia de $R_{h} \mathrm{y}$ $R_{T}$, es decir, sus transformadas de Fourier respecto de la variable temporal $\xi$. El especial comportamiento de la función $\delta(\nu-\mu)$ para $\nu=\mu$, indica que el contenido del espectro para diferentes desplazamientos Doppler está incorrelado, lo que supone que el scattering se produce en difusores distintos y angularmente incorrelados.

Por otra parte, considerar el canal como de scattering incorrelado en la variable retardo, US, significa que las contribuciones de los distintos difusores del canal a la señal recibida están incorreladas. Este tipo de canales han servido para modelar satisfactoriamente ciertos tipos de canales físicos (propagación troposférica, reflexión en la Luna, etc.)

Los canales estacionarios en sentido amplio y los de scattering incorrelado son duales en tiempo-frecuencia [Bel63], por lo que los últimos pueden considerarse, además, como 
WSS en la variable frecuencial, puesto que las funciones de aurocorrelación dependen sólo de la diferencia entre frecuencias $\Omega=g-f$.

La presencia de scattering incorrelado en la variable retardo permite expresar las ecuaciones (2.19) y (2.22), para un canal WSSUS, de la siguiente forma:

$$
\begin{aligned}
R_{h}(t, t+\xi ; \tau, \eta) & =\delta(\tau-\eta) P_{h}(\xi, \tau) \\
R_{S}(\tau, \eta ; \nu, \mu) & =\delta(\tau-\eta) \delta(\nu-\mu) P_{S}(\tau, \nu)
\end{aligned}
$$

donde $P_{h}$ es la transformada de Fourier de $R_{T}$ en la variable $\Omega$, y $P_{S}$ la densidad espectral de potencia Doppler/retardo. $P_{S}$ puede ponerse entonces como la transformada doble de Fourier de $R_{T}$ respecto de $\Omega$ y de $\xi$ :

$$
P_{S}(\tau, \nu)=\int_{-\infty}^{\infty} \int_{-\infty}^{\infty} R_{T}(\Omega, \xi) e^{-j 2 \pi \tau \Omega} e^{-j 2 \pi \nu \xi} d \Omega d \xi
$$

Así mismo, la consideración de los canales US como estacionarios en sentido amplio en la variable frecuencial, $\Omega=g-f$, permite expresar las ecuaciones (2.20) y (2.21), para un canal WSSUS, de la siguiente forma:

$$
\begin{aligned}
R_{T}(f, f+\Omega ; t, t+\xi) & =R_{T}(\Omega, \xi) \\
R_{H}(f, f+\Omega ; \nu, \mu) & =\delta(\nu-\mu) P_{H}(\Omega, \xi)
\end{aligned}
$$

En definitiva, las relaciones entre las distintas funciones de correlación para canales WSSUS quedan tal y como están representadas en la figura 2.8. Como puede apreciarse, en este tipo de canales el número de variables a considerar disminuye notablemente.

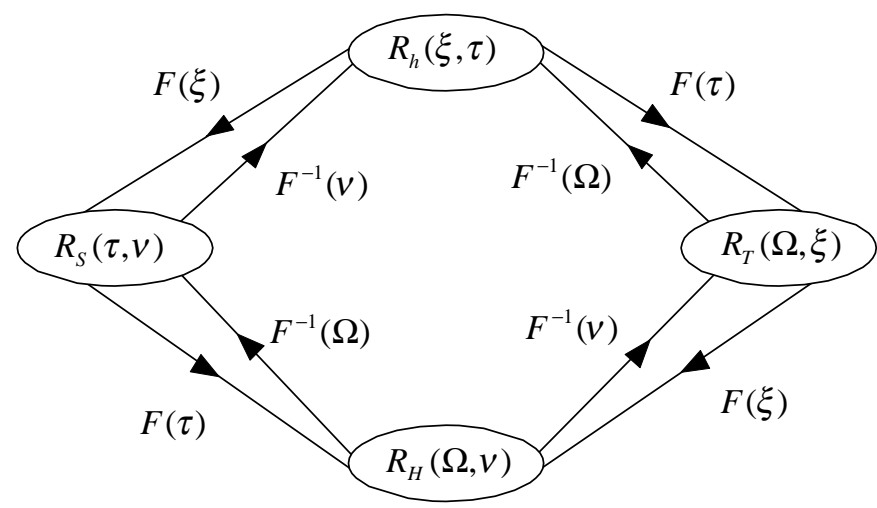

Figura 2.8: Relaciones entre las funciones de autocorrelación para canales WSSUS

A partir de las anteriores expresiones, se puede dar la siguiente interpretación física para los canales WSSUS. El canal puede ser visto como un conjunto de difusores o scatterers, cuyas posiciones están incorreladas entre sí, y de ahí la incorrelación en retardo (distancia) y desplazamiento Doppler (posición angular). Además, las estadísticas del canal, tanto en 
tiempo como en frecuencia, son estacionarias en sentido amplio, es decir, no varían para intervalos temporales suficientemente cortos (o distancias suficientemente pequeñas, si se trata de un radiocanal móvil), ni para intervalos de frecuencia pequeños.

\subsubsection{Caracterización del canal mediante la función de scattering}

En los canales WSSUS, la densidad espectral de potencia Doppler/retardo, $P_{S}(\tau, \nu)$ definida en (2.25), coincide con lo que en Radiolocalización se denomina función de scattering de un blanco radar $\sigma(\tau, \nu)$, por lo que a $P_{S}$ se la suele llamar función de scattering del canal.

La función de scattering da una descripción completa de los procesos físicos que tienen lugar en el canal, ya que muestra la distribución de la potencia recibida en el móvil en función de los retardos $\tau$ con los que llegan las distintas componentes de scattering, y en función de los desplazamientos Doppler $\nu$, que a su vez están relacionados con los ángulos de incidencia en el receptor $\alpha$ de las ondas dispersadas mediante la siguiente expresión, que se deduce inmediatamente a partir de (2.6) y (2.10):

$$
\nu=\frac{1}{\lambda} \cos \alpha
$$

Teniendo en cuenta esta expresión, puede resultar útil escalar el desplazamiento Doppler, no en unidades habituales de frecuencia $(\mathrm{Hz})$, sino en unidades $1 / \lambda$, siendo $\lambda$ la longitud de onda de la portadora, siendo interpretado de esta forma como frecuencia espacial, en lugar de temporal. Así, los desplazamientos Doppler observables estarán confinados entre $-1 / \lambda$ y $1 / \lambda$ y representarán directamente el valor del coseno del ángulo de llegada de cada contribución. Aquellas ondas que alcancen a la antena propagándose en su mismo sentido de desplazamiento, mostrarán desplazamientos Doppler negativos, mientras que aquellos que alcancen la antena propagándose en sentido contrario al movimiento de ésta, exhibirán desplazamientos positivos.

\subsubsection{Caracterización del canal radio móvil en los dominios frecuencial y temporal}

Si bien la función de scattering da una visión del fenómeno físico, ciertas funciones de correlación y de densidad de potencia, tanto en el dominio temporal como en el dominio de la frecuencia, permiten obtener una serie de parámetros de gran interés a la hora de describir el comportamiento del canal de radiocomunicaciones móviles.

Así, en el dominio de la frecuencia, el parámetro fundamental empleado para describir las características del canal radio móvil, es el ancho de banda de coherencia. Este parámetro permite acotar la selectividad en frecuencia inherente al multi-camino.

El estudio de esta selectividad frecuencial se realiza a través de la función de autocorrelación en frecuencia, la cual puede hallarse, en la práctica, tanto a partir de medidas temporales, como frecuenciales. Como ya se ha visto, en canales WSSUS, la función de autocorrelación de la función de transferencia cronovariable es estacionaria en sentido amplio, tanto en frecuencia como en tiempo: $R_{T}(\Omega, \xi)$. Esta función de correlación 
tiempo-frecuencia puede hallarse fácilmente mediante la correlación de medidas directas de la función de transferencia en instantes o posiciones espaciales distintas.

Si las muestras se toman con separación temporal nula, la función de autocorrelación tiempo-frecuencia se reduce a una función de correlación en frecuencia, $R_{T}(\Omega)$. Se define entonces el ancho de banda de coherencia $B_{c}$ como el valor mínimo para el cual la función de correlación en frecuencia es igual a un cierto valor del coeficiente de correlación. Suelen tomarse como valores de estudio 0.9, $0.5(-3 \mathrm{~dB})$ y $0.25(-6 \mathrm{~dB})$. En la figura 2.9 se representan, como ejemplo, algunas de las funciones de correlación (también conocidas como funciones de coherencia) halladas a partir de medidas realizadas en el edificio de la ETSITV (ver capítulo 4).
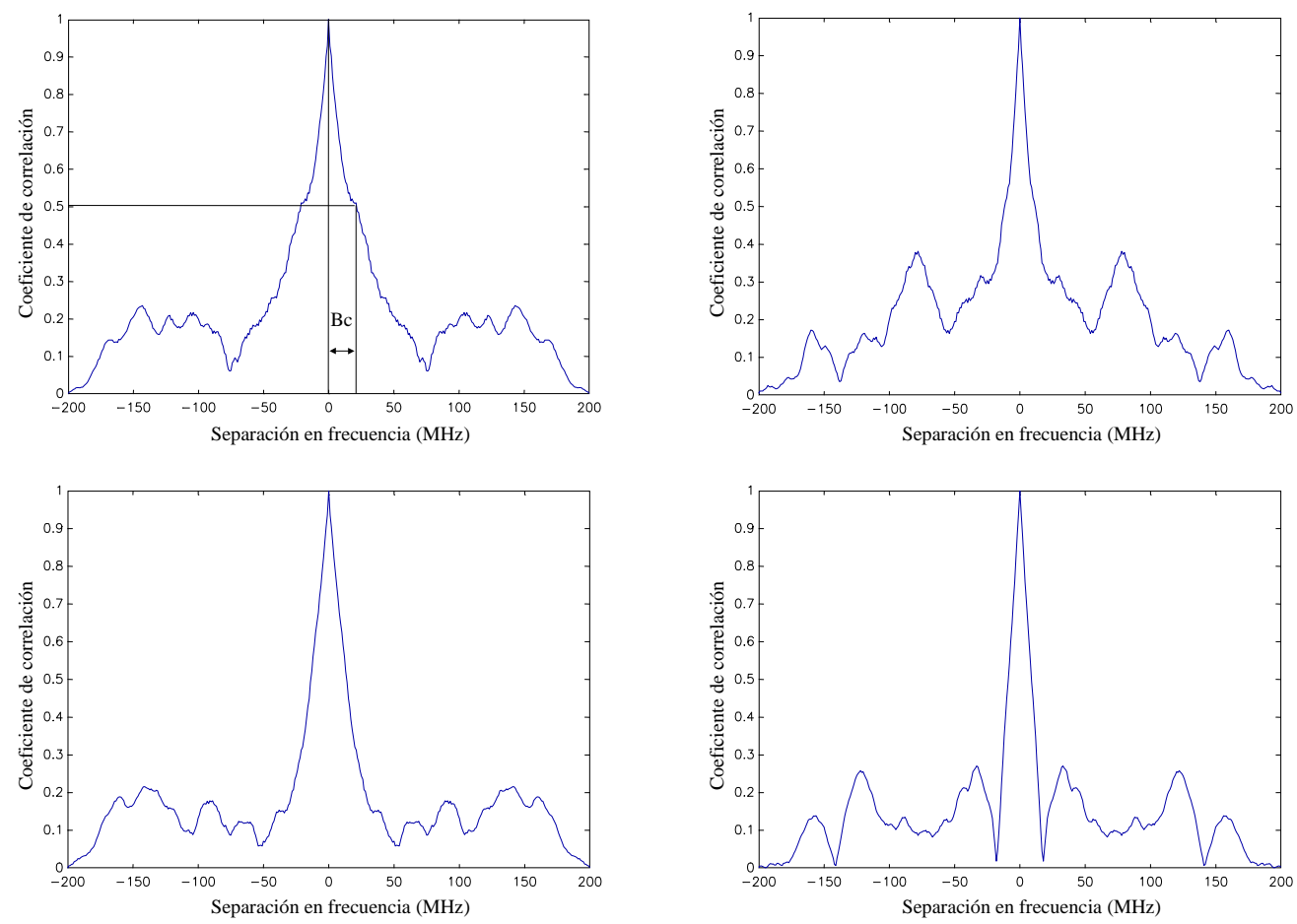

Figura 2.9: Distintos ejemplos de funciones de correlación en frecuencia

Por otro lado, en el dominio del tiempo, se emplean varios parámetros para caracterizar el canal, tales como retardos medios, ensanchamientos de retardo, y ventanas e intervalos de retardo. Estos parámetros se obtienen a partir de los Perfiles de potencia-retardo o PDP*. A continuación se procederá a definir estos Perfiles de potencia (que es como también se les suele llamar de forma abreviada).

Para canales WSSUS, la función de autocorrelación de la salida del canal $R_{w}(t, s)$ puede expresarse, haciendo uso de las ecuaciones (2.18) y (2.23), como:

$$
R_{w}(t, t+\xi)=\int_{-\infty}^{\infty} \int_{-\infty}^{\infty} z(t-\tau) z^{*}(s-\nu) \delta(\eta-\tau) P_{h}(\xi, \tau) d \tau d \eta
$$

\footnotetext{
*Power Delay Profile
} 
Si la separación entre instantes de observación es nula (es decir, $\xi=0$ ), entonces $P_{h}(\xi, \tau)$ se reduce a una densidad de potencia en la variable retardo, $P_{h}(\tau)$. Por otro lado, si la duración de $z(t)$ es mucho menor que el ensanchamiento de retardo debido al multicamino que produce el canal, entonces $|z(t)|^{2}$ puede considerarse impulsional respecto a $P_{h}(\tau)$. Bajo estas condiciones la ecuación (2.29) puede ponerse como:

$$
R_{w}(t, t)=\int_{-\infty}^{\infty}|z(t)|^{2} P_{h}(\tau) d \tau=P_{h}(t)
$$

Esta función $P_{h}(t)$ es a la que se le da el nombre de Perfil de potencia-retardo. En la figura 2.10 se muestran ejemplos de Perfiles de potencia hallados a partir de medidas realizadas en el edificio de la ETSITV (capítulo 4).

(a)
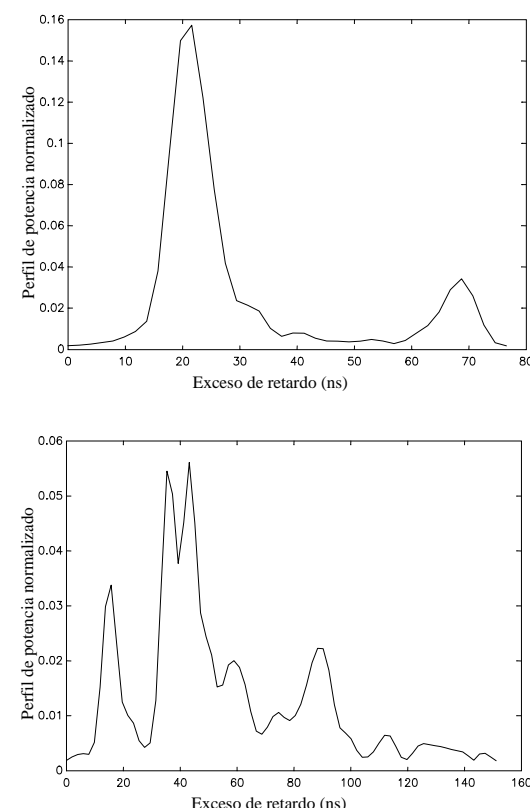

(c)

(b)

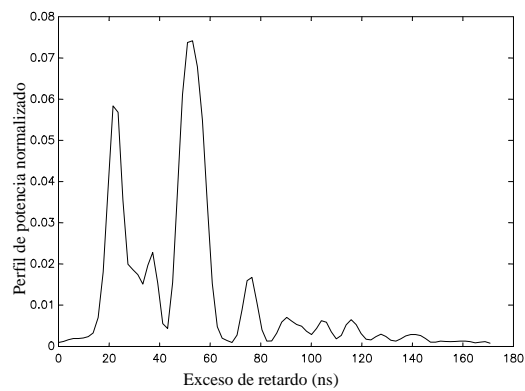

(d)

Figura 2.10: Ejemplos de Perfiles de potencia. (a) Situación con visibilidad directa entre antenas. (b), (c) y (d) Situaciones sin visibilidad directa

Si se hace coincidir el origen de tiempos de la función $P_{h}$, con el retardo del primer eco recibido (es decir, $P_{h}(\tau)=P_{h}\left(t-t_{0}\right)$ ), dicha función queda descrita en términos de la variable exceso de retardo, $\tau$.

$P_{h}(\tau)$ puede ser considerada como una distribución estadística de la potencia que llega en cada instante de retardo $\tau$ debido a los ecos recibidos. De esta forma, se pueden definir los siguientes parámetros, que suelen ser utilizados para describir, a grosso modo, las características temporales del canal:

Retardo medio (average delay), D. Es el momento central de primer orden del Perfil de potencia-retardo respecto del instante de llegada del primer eco recibido; es decir, 
la media de los retardos, ponderados por su potencia asociada $P_{h}(\tau)$ :

$$
D=\frac{\int_{0}^{\infty} \tau P_{h}(\tau) d \tau}{\int_{0}^{\infty} P_{h}(\tau) d \tau}
$$

Ensanchamiento de retardo (delay spread), $S$. También conocido como $R M S$ delay spread $\left(\sigma_{\tau}\right)$, es la raíz cuadrada del momento central de segundo orden del Perfil potencia-retardo respecto del instante de llegada del primer eco; es decir, la desviación típica de los retardos ponderados por $P_{h}(\tau)$ :

$$
S=\sqrt{\frac{\int_{0}^{\infty}\left(\tau^{2}-D^{2}\right) P_{h}(\tau) d \tau}{\int_{0}^{\infty} P_{h}(\tau) d \tau}}
$$

El parámetro $S$ es una buena medida de la dispersión temporal provocada por el multi-camino y permite valorar el posible efecto de interferencia entre símbolos que puede provocar el canal. Suele utlizarse este parámetro más que el retardo cuadrático medio $\tau_{\text {rms }}$, con el que no debe confundirse.

Los valores referenciados en la bibliografía para estos parámetros dependen fuertemente del tamaño y tipo de edificio, [Has93, Has94, Agu91], por lo que será preciso estimarlo o medirlo en cada tipo de entorno.

Ventana de retardo (delay window), $W_{q}$. Es la duración del tramo central del PDP que contiene el $q \%$ de la potencia total, de modo que, a ambos lados de la ventana de retardo, la potencia restante sea la misma.

Intervalo de retardo (delay interval), $I_{P}$. Es la diferencia entre los excesos de retardo correspondientes al primer punto del Perfil potencia-retardo que sobrepasa un umbral que está $P \mathrm{~dB}$ por debajo del máximo del perfil y el último punto en el que el perfil cae por debajo de tal valor.

Usando como ejemplo el Perfil de potencia-retardo de la figura 2.11, la ventana de retardo se obtendría como: $W_{q}=\left(\tau_{4}-\tau_{1}\right)$, donde los límites $\tau_{4}$ y $\tau_{1}$ se definen de forma que a ambos lados de la ventana la potencia restante sea la misma:

$$
\int_{\tau_{1}}^{\tau_{4}} P_{h}(\tau) d \tau=q \int_{\tau_{0}}^{\tau_{5}} P_{h}(\tau) d \tau=q P_{\text {tot }}
$$

mientras que el intervalo de retardo correspondería a: $I_{P}=\left(\tau_{3}-\tau_{2}\right)$.

Todos estos parámetros se pueden calcular, tanto para un solo PDP como para el resultado de promediar los obtenidos a partir de muestras espaciales tomadas a lo largo de un cierto número de longitudes de onda. De esta última forma, dichos parámetros caracterizarían el entorno de medida. 


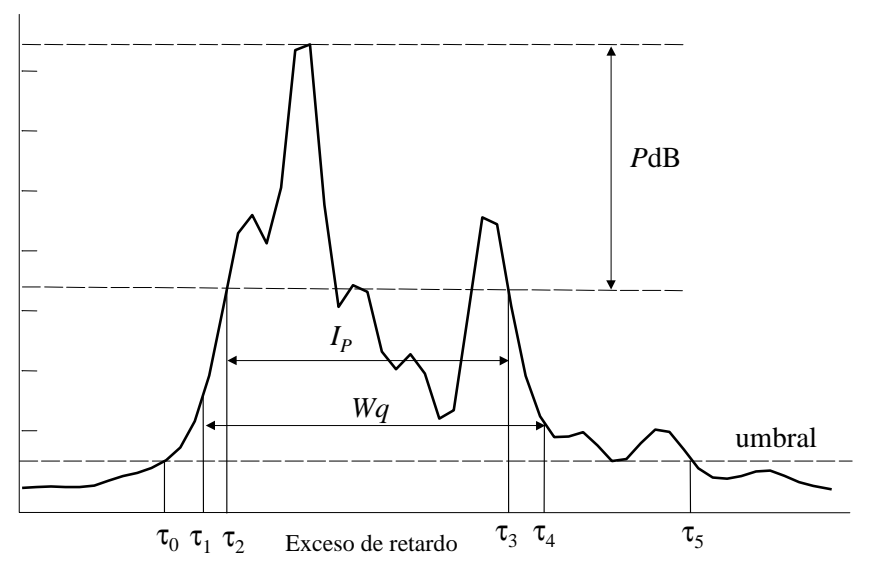

Figura 2.11: Ilustración del cálculo de la ventana de retardo $W_{q}$, y del intervalo de retardo $I_{P}$

\subsection{Peculiaridades del Canal Indoor}

El canal móvil en entornos interiores (Canal indoor) es similar al de entornos exteriores solamente en sus aspectos más básicos. Así, ambos experimentan el fenómeno de la dispersión multi-camino debido a la influencia de gran número de reflectores y difusores de la señal. Los mismos modelos matemáticos pueden ser utilizados para caracterizarlo, tanto en banda estrecha como en banda ancha. Sin embargo, existen grandes diferencias, que serán descritas en esta sección.

En ambientes interiores, el entorno es mucho más influyente que la distancia entre las antenas. Las paredes internas y externas, junto con los suelos y techos, provocan grandes atenuaciones y, por tanto, grandes cambios en la potencia media recibida. El mobiliario y las estructuras metálicas incrustadas en paredes y techos hacen que los procesos de scattering y difracción puedan ser, en principio, más importantes que en entornos abiertos.

Las distancias entre transmisor y receptores suelen ser mucho más cortas, tanto por la elevada atenuación que existe, como por la baja potencia de los equipos utilizados, además de por la propia dimensión reducida del entorno. Por tanto, generalmente se tendrá un menor retardo entre los distintos ecos que llegan al receptor y, consecuentemente, un menor ensanchamiento temporal (delay spread). Así, los márgenes habituales para el delay spread en entornos indoor están desde algunas decenas hasta unos 100ns, mientras que en exteriores son del orden de varios microsegundos.

Las variaciones temporales del canal indoor son lentas, en comparación con el canal outdoor, debido a la baja movilidad de los usuarios. Por tanto, el efecto Doppler resulta despreciable. Pero, por otro lado, estas variaciones espacio-temporales resultan poco estacionarias y de estadística más bien compleja. Además, generalmente, las variaciones temporales son debidas simplemente a la presencia de personas y objetos circulando en las cercanías de las antenas. 
Abundando algo más en este asunto de la estacionariedad del canal indoor, cabe recordar que la función de scattering puede ser definida de forma estricta, tal como se ha visto, solamente cuando el canal es WSSUS. En ambientes exteriores la función de scattering se ha empleado en la investigación de las características de los canales de radio móviles [Baj82]. En tales entornos, la hipótesis WSSUS se considera válida, ya que, junto al comportamiento aleatorio propio de los entornos outdoor, para distancias de algunas longitudes de onda, en torno a $40 \lambda$, se puede considerar que el proceso físico de scattering no cambia apreciablemente. Sin embargo, en el interior de edificios la situación es muy distinta, puesto que:

1. Los fenómenos electromagnéticos que ocurren en entornos indoor pueden modelarse, hasta cierto punto, de forma determinista, debido a que los edificios poseen estructuras geométricas regulares que permiten la identificación de caminos directos, caminos de reflexión o de difracción. Sin embargo, la existencia de mobiliario, puertas, ventanas, cableado, etc, introduce un cierto grado de variabilidad, que permite utilizar los métodos estadísticos.

2. El entorno físico cambia mucho más rápidamente con el movimiento de las antenas, ya que las distancias relativas entre los dispersores y las antenas son pequeñas. Se hace entonces difícil diferenciar claramente entre variaciones a corto y a largo plazo.

3. La longitud de onda, a las frecuencias de trabajo en entornos indoor, puede llegar a ser comparable con el tamaño de los dispersores.

Estas razones hacen que la hipótesis de que el canal es estacionario en sentido amplio y de scattering incorrelado sea, cuando menos, cuestionable en entornos indoor. A pesar de ello, se ha demostrado que la función de scattering puede ser empleada de forma válida en ambientes interiores [Pér93, Der93], y que arroja información muy valiosa sobre los fenómenos físicos que tienen lugar. Precisamente esto se verá más detenidamente en el capítulo 4.

Hay un par de detalles más a tener en cuenta en este tipo de entornos. En primer lugar, la severidad de las posibles interferencias electromagnéticas ocasionadas entre el terminal móvil y los equipos electrónicos del edificio (normalmente abundantes en hospitales, oficinas, laboratorios o industrias). Y, también, hay que tener en cuenta el tipo de equipos utilizados para comunicaciones indoor: terminales pequeños y ligeros, consecuentemente de baja potencia, operando en las proximidades del cuerpo humano.

En cualquier caso, ha quedado bastante claro en este capítulo que el estudio del canal radio móvil en el interior de edificios resulta de una complejidad tal que se hace necesario abordar el problema a través de otro tipo de caracterización más simplificada: el modelado.

También, que resulta inevitable acudir a las oportunas campañas de medidas que sirvan tanto para estudiar los fenómenos de propagación más destacados, como para validar los modelos que se propongan.

En el próximo capítulo, se mostrarán las contribuciones más destacadas de los distintos investigadores en estos dos campos, así como las líneas de investigación que actualmente se encuentran abiertas. 



\section{Capítulo 3}

\section{Métodos de Medida y Modelado del Canal Indoor}

\section{$3.1 \quad$ Introducción}

Se ha visto en el capítulo anterior que el canal radio móvil en entornos interiores (Canal Indoor) difiere considerablemente del de entornos exteriores (Canal Outdoor), por otra parte mucho más estudiado. En cualquier caso, se ha realizado un gran esfuerzo investigador en el estudio de las condiciones de propagación en el interior de edificios, la mayor parte del cual ha sido en la forma de medidas experimentales. Existe una amplísima biliografía al respecto, pero puede encontrarse resumida en [Mol91] y en [Has93].

En este capítulo, se describirá gran parte de la literatura existente relacionada con las medidas del canal indoor que se han venido realizando hasta la fecha*, así como de los modelos de dicho canal basados en esos resultados.

Se hará especial hincapié en aquellos resultados presentados recientemente a lo largo de las distintas reuniones del COST 231, y que pueden verse resumidas en [Dam96]. El COST (también conocido como EURO-COST ${ }^{\dagger}$ ) es un programa de cooperación paneuropeo, cuya Acción número $231^{\ddagger}$ se ha ocupado de estudiar distintos aspectos de las redes de comunicaciones móviles terrestres, incluyendo las personales, presentando sus resultados en múltiples reuniones de trabajo celebradas desde abril de 1989, hasta abril de 1996, después de tres años de prórroga. En esta acción han trabajado distintas empresas, operadores, universidades y otros centros de investigación de toda Europa.

La Universidad Politécnica de Valencia, y más concretamente el Grupo de Comunicaciones Móviles del Departamento de Comunicaciones, ha participado, en la medida de sus posibilidades, en varios campos de estudio de este COST 231, así como en su continuación,

\footnotetext{
*En el capítulo 4 también se mostrarán algunos resultados particulares de los trabajos más sobresalientes, aunque, en este caso, comparados con los obtenidos en la campaña de medidas que en dicho capítulo se presenta.

${ }^{\dagger}$ European Cooperation in the field of Scientific and Technical research

${ }^{\ddagger}$ Evolution of Land Mobile (including personal) Communications
} 
el COST 259*, cuyo kick off (reunión definititoria inicial, en el argot) tuvo lugar en Abril de 1997.

\subsection{Aspectos generales del modelado del Canal Indoor}

La predicción de las características de propagación entre dos antenas situadas en el interior de un edificio, es especialmente importante para el diseño de sistemas de telefonía sin hilos (cordless telephone), así como para las redes locales sin hilos (WLAN ${ }^{\dagger}$ ). También el diseño de sistemas celulares en los que se tenga prevista la instalación de estaciones sase en el interior de edificios especiales (grandes almacenes, oficinas, etc.), necesitan de un conocimiento amplio de dichas características de propagación.

Para obtener con exactitud los detalles de la propagación, habría que resolver las ecuaciones de Maxwell con las condiciones de contorno que expresaran las propiedades físicas de los materiales que forman el edificio y que dispersan las ondas. Desafortunadamente, la solución numérica de dicho problema no es todavía una opción rentable para entornos complejos a altas frecuencias. Por ello, durante los últimos años se han venido desarrollando multitud de modelos de propagación, con el fin de que sean usados en las fases de desarrollo y/o evaluación de las redes de comunicaciones móviles (en el cálculo de las áreas de cobertura o en la selección de las localizaciones óptimas para las estaciones transmisoras, por ejemplo).

El modelo se construye normalmente incorporando la información del canal, para que forme parte de la herramienta analítica, numérica o de simulación, y así ayude a un mejor conocimiento de su comportamiento. Con respecto al modelado de las características más representativas del canal, se debe tener un fiel conocimiento de los mecanismos físicos de propagación, ya que es la base elemental de su comportamiento. Este conocimiento se debe obtener a través de la combinación de suposiciones teóricas y de medidas físicas (ya que en los complejos escenarios reales, el proceso de la propagación de ondas es demasiado complicado para permitir un enfoque puramente teórico).

En secciones sucesivas se mostrarán ejemplos de cada una de las categorías en que pueden ser divididos los distintos modelos de propagación indoor. A saber:

- modelos empíricos de banda estrecha, que solamente predicen pérdidas de propagación y que están basados en campañas de medidas;

- modelos empíricos de banda ancha, que predicen la forma aproximada de los Perfiles de potencia-retardo ( $\left.\mathrm{PDP}^{\ddagger}\right)$ a partir del delay spread promediado de distintas medidas en entornos similares;

- modelos que predicen la variación temporal del canal, y

- modelos deterministas que intentan simular físicamente la propagación de las ondas de radio, y que pueden permitir caracterizar el canal tanto en banda estrecha como

\footnotetext{
${ }^{*}$ Wireless Flexible Personalised Communications

${ }^{\dagger}$ Wireless Local Area Network

${ }_{\ddagger}^{\ddagger}$ Power Delay Profile
} 
en banda ancha.

En función de las necesidades del diseño al que se vaya a aplicar el modelo, se deberá escoger entre un modelo empírico o uno determinista. Los primeros se usan normalmente para aplicaciones estándar de desarrollo de redes, mientras que los modelos deterministas se adaptan mejor en las aplicaciones que requieren gran precisión. La ventaja de los modelos empíricos, comparados con los deterministas, es que son normalmente menos complejos y que requieren menor cantidad de parámetros de entrada. Sin embargo, no predicen las características instantáneas de la señal o los desvanecimientos en una localización específica del entorno modelado. Para este tipo de predicciones se debe recurrir a un modelo más determinista.

Como se refleja en la figura 3.1, ambos métodos deben complementarse con un conjunto suficientemente amplio de medidas físicas realizadas en el entorno que se va a modelar. Los modelos empíricos aplican esas medidas en la optimización sus parámetros. Los modelos deterministas puros, aunque no incluyen coeficientes empíricos, usan valores físicos como parámetros de entrada, como, por ejemplo, la constante dieléctrica compleja de los materiales del edificio. Además, puesto que la descripción del entorno es siempre aproximada (más o menos idealizada) y no incluye todos los detalles que afectan a la propagación, debe verificarse el buen funcionamiento del modelo determinista comparando sus resultados con las medidas realizadas.

De todas formas, cuando un modelo sea capaz de ofrecer una predicción correcta de las características del canal, evitará la necesidad de realizar amplias campañas de medidas en el edificio en cuestión, con el consiguiente ahorro de tiempo y dinero.

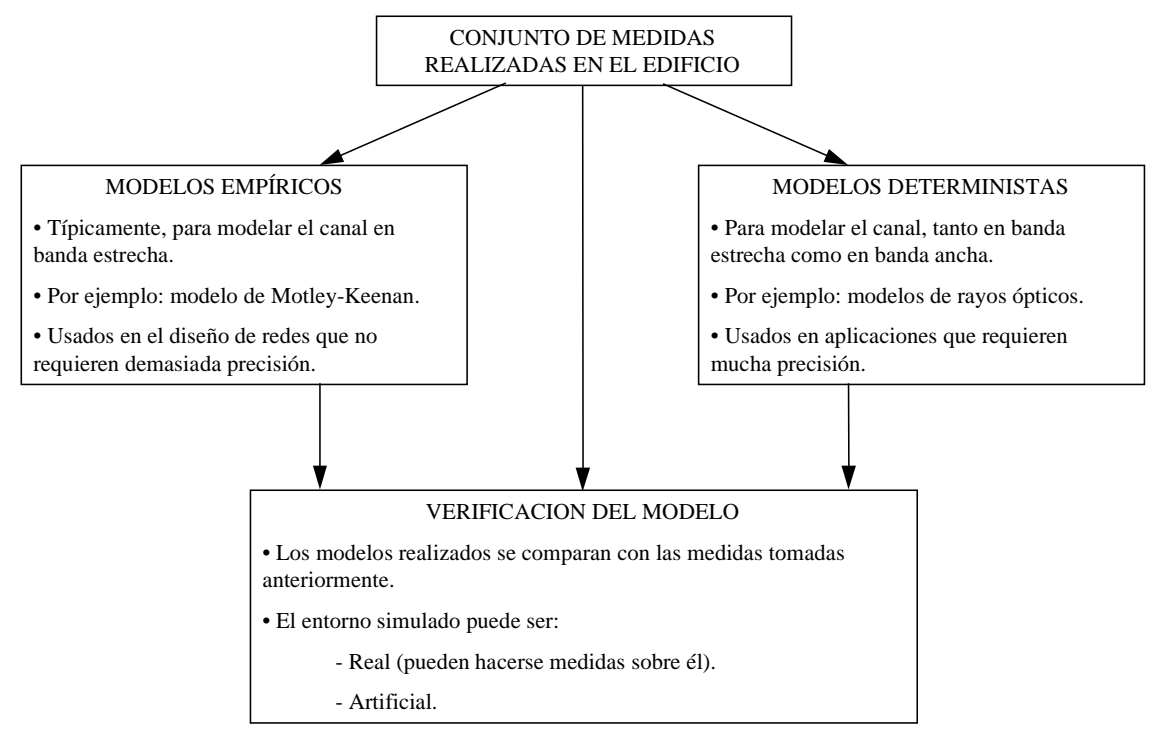

Figura 3.1: Guión para el desarrollo de un modelo de propagación indoor 


\subsection{Modelos y medidas en banda estrecha}

Tal y como se vio en la sección 2.1.1, se dice que un sistema de comunicaciones es de banda estrecha cuando el ancho de banda de la señal a transmitir es menor que el ancho de banda de coherencia del canal.

De esta forma, en estos sistemas, todas las frecuencias de la señal transmitida están sujetas a las mismas atenuaciones y distorsiones, siendo el canal, por tanto, no selectivo en frecuencia. Tales canales pueden ser descritos adecuadamente mediante modelos sin memoria, y caracterizados por su atenuación media, más las estadísticas de las variaciones alrededor de dicho valor medio.

La mayor parte de la labor investigadora para la caracterización del Canal Indoor, se ha hecho para canales en banda estrecha debido, sobre todo, a la relativa simplicidad de los equipos de medida requeridos.

El COST 231 no ha estado ajeno a estos estudios [Dam96], presentándose multitud de medidas, realizadas fundamentalmente en la banda de frecuencias entre los $900 \mathrm{y}$ los 1800MHz. Se ha puesto especial énfasis en el estudio de edificios de oficinas, los cuales constituyen la principal área de aplicación de los sistemas de comunicaciones móviles indoor. Se ha propuesto, asimismo, diferenciar los distintos entornos indoor existentes entre cuatro tipos de categorías distintas, tal y como se muestra en la tabla 3.1.

\begin{tabular}{|l|l|}
\hline Entorno & Descripción \\
\hline \hline Denso & $\begin{array}{l}\text { Entornos con habitaciones pequeñas } \\
\text { Oficinas en las que cada empleado tiene su propia habitación } \\
\text { Mayoritariamente NLOS }\end{array}$ \\
\hline Abierto & $\begin{array}{l}\text { Entornos con grandes habitaciones } \\
\text { Oficinas con habitaciones compartidas por varios empleados } \\
\text { Mayoritariamente LOS }\end{array}$ \\
\hline Espacioso OLOS
\end{tabular}

Tabla 3.1: Clasificación de entornos indoor

\footnotetext{
${ }^{a}$ Non Line Of Sight, sin visibilidad directa entre transmisor y receptor

${ }^{b}$ Line Of Sight, con visibilidad directa

${ }^{c}$ Obstructed Line Of Sight, con visibilidad directa obstruida
}

\subsubsection{Modelos empíricos de predicción de pérdidas}

Como ya se ha comentado anteriormente, con objeto de predecir las pérdidas de propagación y evitar, en la medida de lo posible, la necesidad de realizar medidas in situ, se han desarrollado, entre otros, unos modelos empíricos de predicción de pérdidas basados en campañas de medidas. Estos modelos se suelen utilizar para el cálculo de las áreas de 
cobertura y en la selección de localizaciones óptimas para las estaciones transmisoras.

Suelen venir expresados en forma de una simple ecuación matemática que da como resultado las pérdidas medias de propagación entre el transmisor y el receptor. En estas ecuaciones, que suelen ser función de la distancia, se optimizan mediante regresión, una serie de coeficientes a partir de los datos de campañas de medidas realizadas. Evidentemente, este ajuste minimiza el error del modelo en el edificio en el que se han realizado las medidas; pero si el modelo es lo suficientemente bueno, puede servir para predecir de forma aproximada los resultados en edificios con características similares.

Existen dos tipos de modelos empíricos comúnmente utilizados. Por un lado aquellos que tienen como parámetro fundamental la distancia, y por otro lado aquellos que emplean, además, coeficientes empíricos de pérdidas para los distintos suelos y paredes.

\section{Modelos dependientes exclusivamente de la distancia}

Modelos exponenciales En este tipo de modelo, las pérdidas de propagación crecen exponencialmente con la distancia, es decir:

$$
\bar{L}(d) \propto\left(\frac{d}{d_{0}}\right)^{n}
$$

donde $\bar{L}$ representa las pérdidas medias de propagación, $n$ es el exponente de pérdidas, que es el que controla la velocidad de crecimiento de las pérdidas de propagación con la distancia entre transmisor y receptor $d$, y $d_{0}$ es una distancia de referencia a la que suele darse por valor un metro. Esta relación entre potencia y distancia se convierte en una relación lineal al representar en escala logarítmica los ejes de ordenadas y abcisas.

Precisamente, el parámetro a ajustar es $n$, la pendiente de pérdidas con el logaritmo de la distancia. Debido al carácter indoor del modelo, dicha pendiente será, en general, muy superior a la observada en espacio libre $(n=2)$, aunque bajo ciertas condiciones del entorno (pasillos y corredores), puede aparecer un efecto guía de ondas que provoque valores de $n$ inferiores a 2 . En definitiva, este parámetro suele tomar valores entre 1 y más de 5, dependiendo fuertemente del entorno. Así, en [Cox83] está en torno a 3 en propagación indoor, mientras que en [Ale83] se dan márgenes desde 1.2 hasta 6.5, dependiendo del tipo de entorno.

El valor de las pérdidas medias de propagación en unidades logarítmicas (dB) puede hallarse, entonces, mediante la siguiente expresión:

$$
\bar{L}=L_{0}+10 n \log _{10}\left(\frac{d}{d_{0}}\right)
$$

en la que $L_{0}$ es una constante, en $\mathrm{dB}$, cuyo valor puede asumirse que es igual a las pérdidas de propagación en espacio libre, para una separación entre transmisor y receptor igual a la distancia de referencia $d_{0}$. O, por el contrario, con el fin de conseguir un mejor ajuste o minimización del error medio, puede optimizarse mediante regresión a partir de las medidas. En este caso, el modelo sería biparamétrico.

Tal y como está formulado en (3.2), a este modelo se le ha asignado en el COST 231 el nombre de One-Slope Model (1SM). 
Modelos lineales Estos modelos son los más sencillos, ya que sólo presentan un único parámetro de ajuste (modelos uniparamétricos), asumiendo que la dependencia del exceso de pérdidas de propagación con la distancia (descontando las del espacio libre) es de tipo lineal. Unos de los primeros trabajos proponiendo tal tipo de modelos es [Dev90]. En el COST 231 se la ha llamado Linear Attenuation Model (LAM), y la expresión que cuantifica las pérdidas medias, en $\mathrm{dB}$, viene dada por:

$$
\bar{L}=L_{\mathrm{fs}}(d)+\alpha d
$$

donde $\alpha$ es el parámetro o coeficiente a ajustar de forma empírica a partir del conjunto de medidas y representa el coeficiente de atenuación del entorno, en $\mathrm{dB} / \mathrm{m} ; L_{\mathrm{fs}}$ representa a las pérdidas de propagación en espacio libre y $d$ es la distancia entre la antena transmisora y la receptora.

En [Dev90] se sugieren valores de atenuación lineal $\alpha$ entre 0.23 y $0.62 \mathrm{~dB} / \mathrm{m}$.

A este modelo se le puede añadir también los efectos de las paredes y suelos con el fin de mejorar sus prestaciones [Kar95], ya que de este modo se aumentan los grados de libertad.

\section{Modelos empíricos dependientes del entorno}

Cuando la única información que se tiene en cuenta es la distancia entre el transmisor y el receptor, el error cometido resulta elevado. En los anteriores modelos, los parámetros estimados mediante regresión $\left(n, L_{0}, \alpha\right)$ dependen mucho de factores como la estructura del edificio, el número de plantas de separación, el número de paredes interpuestas, la disposición de las plantas del edificio, etc. Y no sólo del edificio y los materiales que lo constituyen, sino también del tipo de entorno en que se efectúan las medidas: pasillos, hall, despachos, etc. Sin embargo, pueden usarse como una primera aproximación. De todos modos, para reducir el error sería necesario introducir esta información del entorno, lo cual conduce a los modelos empíricos dependientes del entorno.

Modelo de Motley y Keenan Este conocido modelo, propuesto en [Kee90], calcula las pérdidas medias como las producidas en espacio libre más unas pérdidas adicionales por cada pared o suelo que se interpone en el camino directo entre transmisor y receptor. Los parámetros del modelo son precisamente los coeficientes de atenuación de suelos y paredes. La expresión del modelo que calcula dichas pérdidas en $\mathrm{dB}$ a una frecuencia dada, es la siguiente:

$$
\bar{L}=L_{\mathrm{fs}}(d)+L_{\mathrm{ap}}+L_{0}+\sum_{i=1}^{N} k_{\mathrm{w} i} L_{\mathrm{w} i}+\sum_{j=1}^{M} k_{\mathrm{f} j} L_{\mathrm{f} j}
$$

en la cual, $L_{\mathrm{fs}}, L_{\mathrm{ap}}, L_{0}, L_{\mathrm{w} i}$ y $L_{\mathrm{f} j}$ están en $\mathrm{dB}$ y representan lo siguiente:

$L_{\mathrm{fs}}(d)$ son las pérdidas en espacio libre a la distancia $d$ entre transmisor y receptor,

$L_{\mathrm{ap}}$ es un coeficiente introducido para compensar el diagrama de radiación de la antena, 
$L_{0}$ es un término constante producido por la regresión lineal, y que indica el exceso de pérdidas que no depende del número de paredes o suelos, por lo que engloba el exceso de pérdidas debidas a scattering, perdidas por difracción, etc.,

$L_{\text {wi }}$ es el coeficiente de pérdidas de paredes del tipo $i$, de los $N$ considerados dentro del edificio,

$L_{\mathrm{f} j}$ es el coeficiente de pérdidas de suelos del tipo $j$, de los $M$ a considerar, y

$k_{\mathrm{w} i}$ y $k_{\mathrm{f} j}$ son, respectivamente, el número de paredes del tipo $i$ y el número de suelos del tipo $j$ atravesados por la línea directa que une a transmisor y receptor.

Multi-Wall Model (MWM) Este modelo puede considerarse una evolución del anterior, y ha sido consensuado en el COST 231. Básicamente es idéntico, pero solamente se tiene en cuenta un único tipo de suelo $(M=1)$. Por contra, se introduce un factor empírico adicional $b$, ya que se ha observado que las pérdidas totales debidas a los suelos, son una función no lineal del número de suelos penetrados [Tör93]. Cuando el tamaño de los edificios es pequeño este factor puede eliminarse de la ecuación de pérdidas.

La expresión que cuantifica las pérdidas medias viene dada por:

$$
\bar{L}=L_{\mathrm{fs}}(d)+L_{C}+\sum_{i=1}^{N} k_{\mathrm{w} i} L_{\mathrm{w} i}+k_{\mathrm{f}}\left(\frac{k_{\mathrm{f}}+2}{k_{\mathrm{f}}+1}-b\right) L_{\mathrm{f}}
$$

donde $L_{C}$ es un coeficiente de ajuste a las medidas optativo, y suele tomar valores cercanos a cero. $L_{\mathrm{fs}}$ representa las pérdidas en espacio libre, incluyendo también los efectos de la antena. Puede unirse al anterior con el fin de simplificar el modelo. Al igual que el modelo de Motley y Keenan, $L_{\mathrm{f}}$ y $L_{\mathrm{w}}$ representan, respectivamente, los coeficientes de atenuación de los suelos y de las paredes, mientras que $k_{\mathrm{f}}$ y $k_{\mathrm{w}}$ son, respectivamente, el número de suelos y el número de paredes que se atraviesan.

Hay que tener en cuenta que los coeficientes de atenuación de los suelos y paredes no representan solamente las pérdidas físicas, sino que se incluyen tanto el efecto del mobiliario, encofrados, etc., como el efecto de guía de ondas que se puedan formar en los pasillos o entre suelo y techo de un mismo piso.

En general, suele simplificarse la anterior expresión considerando sólo dos tipos de paredes: paredes que no poseen vanos, y paredes que integran puertas o superficies acristaladas. En entornos de oficinas puede ser interesante introducir también en el modelo un coeficiente de pérdidas de tabiques separadores o soft partitions, $L_{s p}$, puesto que se ha demostrado que estos elementos introducen pérdidas lo suficientemente apreciables. Así, se han medido valores entre 0.92 y $1.57 \mathrm{~dB}$ [Sei92].

En [Owe89] se considera que es posible obtener un mejor ajuste al modelo, especialmente a cortas distancias, si sólo se considera la distancia horizontal entre transmisor y receptor, en lugar de la real. las dos posibles razones que se apuntan para ello son el hecho de que las pérdidas debidas a los suelos ya están incorporadas en los coeficientes (con lo que no hay que volver a contar el efecto de la distancia vertical), y el fenómeno de guiado de ondas producido en las escaleras y huecos de ascensores. 


\section{Dependencia de los parámetros empíricos}

Los coeficientes de atenuación de los suelos dependen de la antigüedad y el tamaño del edificio. Se ha comprobado, [Läh94], que en edificios nuevos los coeficientes de pérdidas de los suelos son mayores que en edificios de más antigüedad. Varias son las explicaciones para este hecho. Por un lado, la técnica de construcción típica de los suelos en los edificios de reciente construcción es el empleo de encofrado, lo que lleva a suelos de mayor espesor que los realizados sólo de hormigón, típicos de construcciones más antiguas, además de la posibilidad de que los huecos de las bovedillas del encofrado provoquen fenómenos de scattering y reflexión múltiple en función de su diámetro y de la frecuencia empleada.

Por otro lado, en los edificios de reciente construcción la cantidad de cableado y elementos metálicos tales como bandejas de soporte del cableado, estructuras de soporte de los bajotechos, tuberías, etc., es mucho mayor que en los edificios de antigua construcción.

En cuanto al tamaño del edificio, las construcciones de mayores dimensiones y número de plantas suelen tener estructuras más sólidas que los edificios de menor tamaño, lo que explicaría tal dependencia.

Aparte de la no linealidad de las pérdidas totales debidas a los suelos, comentada anteriormente, también se ha constatado que los coeficientes de perdidas de los suelos son una función decreciente del número de plantas entre transmisor y receptor [Sei92], [Läh94].

Para dar una explicación a este decrecimiento de $L_{\mathrm{f}}$ suele argumentarse que, conforme aumenta el número de pisos interpuestos, una porción cada vez mayor de la energía de la señal alcanza el transmisor por caminos que no atraviesan directamente los suelos, que bien pueden ser exteriores (como difracción en ventanas o reflexión en edificios próximos), o bien interiores (como propagación a través de huecos de ascensores, escaleras o conductos de ventilación). Se ha observado también que esta dependencia es más acentuada cuanto mayor es la frecuencia, lo cual puede deberse a que, cuanto menor es la longitud de onda, más fácil es la propagación a través de todos aquellos vanos que conecten las distintas plantas de los edificios. Por ello se suelen introducir factores de corrección de $L_{\mathrm{f}}$ en función del número de pisos de separación para así reducir los errores entre el modelo y las medidas reales.

Según [Läh93], las pérdidas de las paredes, $L_{\mathrm{w}}$, dependen muy levemente de la frecuencia entre las bandas de $900 \mathrm{MHz}$ y $1800 \mathrm{MHz}$, por lo que pueden usarse los mismos valores en ambas zonas del espectro. Sin embargo, en [Joe94] se apunta la posibilidad de que, en función de la frecuencia de trabajo y del espesor de las paredes, pueden aparecer fenómenos de resonancia que hagan que las pérdidas introducidas por algunas paredes sean casi nulas.

Todos estos modelos se muestran mucho más precisos cuando se evalúan sobre un entorno concreto, como pueda ser la propagación en una misma planta, propagación entre dos plantas consecutivas, o en un tipo particular de edificios. Sin embargo, no son tan buenos cuando se pretenden generalizar, lo cual era ya de esperar. Por otro lado, la imposibilidad de reducir los errores cometidos, aún al confinar el estudio a un entorno concreto, hace que las pérdidas de propagación medidas muestren un comportamiento vagamente lineal con la distancia entre transmisor y receptor, como puede verse, por ejemplo, en [Sei92] y en [Läh94]. Bien es cierto que la diferencia de técnicas de construcción, plantas, 
estructuras, materiales, junto con otros factores como posición de transmisores y receptores, proximidad de edificios, diagramas de radiación de las antenas, etc., puede explicar tales errores. Sin embargo, en la literatura consultada, las medidas que se presentaban se habían realizado para una o a lo sumo dos alturas de la antena receptora, de modo que no se han encontrado estudios en los que se realizasen medidas a múltiples alturas.

En el capítulo 4 se mostrarán las medidas realizadas en la Escuela Técnica Superior de Ingenieros de Telecomunicación de Valencia, cuyo propósito inicial fue cubrir esta deficiencia de datos.

Parámetros empíricos óptimos Las medidas presentadas a lo largo del COST 231, y que ya han sido comentadas anteriormente, han servido para optimizar los parámetros de los distintos modelos empíricos. Estos valores optimizados se muestran en la tabla 3.2, clasificados según el tipo de entorno de medida.

\begin{tabular}{|l|c|c|c|c|c|c|c|}
\hline & \multicolumn{2}{|c|}{ One-Slope } & \multicolumn{4}{c|}{$\begin{array}{c}\text { Multi-Wall Model } \\
\text { ENTORNO }\end{array}$} & \multicolumn{4}{c|}{$\begin{array}{c}\text { Linear Atten. } \\
\text { Model (1SM) }\end{array}$} & \multicolumn{5}{|c|}{ (MAM) } \\
& $L_{0}(\mathrm{~dB})$ & $n$ & $L_{\mathrm{w} 1}(\mathrm{~dB})$ & $L_{\mathrm{w} 2}(\mathrm{~dB})$ & $L_{\mathrm{f}}(\mathrm{dB})$ & $b$ & $\alpha$ \\
\hline Denso & & & & & & & \\
mismo piso & 33.3 & 4.0 & & & & & 0.62 \\
dos pisos & 21.9 & 5.2 & & & & & \\
más pisos & 44.9 & 5.4 & 3.4 & 6.9 & 18.3 & 0.46 & 2.8 \\
\hline Abierto & 42.7 & 1.9 & & & & & 0.22 \\
\hline Espacioso & 37.5 & 2.0 & & & & & \\
\hline Pasillo & 39.2 & 1.4 & & & & & \\
\hline
\end{tabular}

Tabla 3.2: Parámetros optimizados de modelos empíricos

Estos parámetros han sido optimizados para una frecuencia de $1800 \mathrm{MHz}$. De todos modos, también es aplicable para $900 \mathrm{MHz}$ si se reduce el coeficiente $L_{0}$ en $6 \mathrm{~dB}$, apreciándose también una diferencia de $1.5 \mathrm{~dB}$ menos en las atenuaciones de las paredes, y de $3.5 \mathrm{~dB}$ en la de los suelos.

En la tabla 3.3, se presenta el error medio y su desviación típica para los resultados obtenidos en dichas campañas de medidas. A la vista de los resultados se desprende que el modelo 1SM resulta mejor con un número reducido de pisos, mientras que el MWM se comporta mejor a medida que aumenta el número de pisos. Todos los modelos resultan optimistas en la predicción de la potencia media recibida.

\subsection{Modelos y medidas en banda ancha}

De acuerdo con la definición dada en la sección 2.1.1, se puede decir que un sistema de comunicación ha de considerarse como de banda ancha cuando la señal a transmitir tenga un ancho de banda mayor que el ancho de banda de coherencia del canal. Por tanto, cada una de las componentes frecuenciales de la señal transmitida puede estar sujeta a distinta atenuación debida al entorno de propagación. 


\begin{tabular}{|c|c|c|c|c|c|c|}
\hline \multirow{2}{*}{$\begin{array}{l}\text { Conjunto } \\
\text { de datos }\end{array}$} & \multicolumn{2}{|c|}{$\begin{array}{c}\text { One-Slope } \\
\text { Model (1SM) }\end{array}$} & \multicolumn{2}{|c|}{$\begin{array}{l}\text { Multi-Wall Model } \\
\text { (MWM) }\end{array}$} & \multicolumn{2}{|c|}{$\begin{array}{l}\text { Linear Attenuation } \\
\text { Model (LAM) }\end{array}$} \\
\hline & $\begin{array}{l}\text { STD } \\
\text { (dB) }\end{array}$ & $\begin{array}{c}\text { Error } \\
\text { medio }(\mathrm{dB})\end{array}$ & $\begin{array}{l}\text { STD } \\
(\mathrm{dB})\end{array}$ & $\begin{array}{c}\text { Error } \\
\text { medio }(\mathrm{dB})\end{array}$ & $\begin{array}{l}\text { STD } \\
(\mathrm{dB})\end{array}$ & $\begin{array}{c}\text { Error } \\
\text { medio }(\mathrm{dB})\end{array}$ \\
\hline $\begin{array}{l}\text { Dos pisos } \\
856 \mathrm{MHz} \\
\end{array}$ & 10.3 & -2.7 & 8.3 & -8.2 & 10.2 & -16.1 \\
\hline $\begin{array}{l}\text { Dos pisos } \\
1800 \mathrm{MHz}\end{array}$ & 12.2 & -7.3 & 7.1 & -11.1 & 11.6 & -20.3 \\
\hline $\begin{array}{l}\text { Más de } 2 \text { pisos } \\
856 \mathrm{MHz}\end{array}$ & 10.7 & -7.1 & 7.9 & -7.2 & 9.7 & -19.6 \\
\hline $\begin{array}{l}\text { Más de } 2 \text { pisos } \\
1800 \mathrm{MHz}\end{array}$ & 11.9 & -11.8 & 7.5 & -9.7 & 10.9 & -23.8 \\
\hline
\end{tabular}

Tabla 3.3: Prestaciones de los modelos empíricos

Esta selectividad en frecuencia viene dada por la propagación multicamino, por lo que la mayor parte de los modelos de propagación en banda ancha intentan simular este fenómeno.

Así, uno de los más antiguos y conocidos modelos multicamino para radiocomunicaciones es el desarrollado por Rummler [Rum81], utilizado para simular radioenlaces de microondas con visibilidad directa. La versión simplificada es de dos contribuciones, con un retardo de separación $\tau$ fijo de 6.3 ns. Se puede demostrar que este retardo fijo no resta flexibilidad al modelo. La ecuación que define el modelo es:

$$
H(j \omega)=a\left[1-b e^{\left(-j\left(\omega-\omega_{0}\right) \tau\right)}\right]
$$

donde $a$ y $b$ controlan la atenuación de las dos contribuciones, y $\omega_{0}$ controla la frecuencia de la posición del mínimo (notch) de un desvanecimiento que puede estar dentro o fuera del ancho de banda del canal.

Por otra parte, existe una serie de modelos empíricos en banda ancha, basados en el presentado en [Sal87], con los que se intenta predecir el comportamiento de los Perfiles de potencia-retardo en un determinado entorno, a partir de las medidas realizadas en entornos similares.

Así, en estos modelos se suele dar como parámetros la suma coherente de todas las contribuciones (calculada según alguno de los modelos de prediccción de pérdidas expuestos anteriormente), el exceso de retardo RMS ( $R M S$ delay spread) y el tipo de decaimiento que presenta el Perfil de potencia (habitualmente exponencial o geométrico). Valores típicos de exceso de retardo RMS que se han presentado en el COST 231 son de 20 a 60ns, dependiendo en gran medida del tipo de entorno considerado [Dam96].

Otros modelos alternativos son los que describen los tiempos de llegada de cada una de las componentes de la propagación multicamino, o los intervalos entre dos consecutivas. Suelen modelarse tales procesos estocásticos como de Poisson o como alguna de sus variantes [Suz77]. En el COST 231 se han presentado variantes de tales modelos válidas para entornos indoor, ya que no necesariamente asumen que el móvil tenga una velocidad constante, sino que, por el contrario, su trayectoria y su velocidad pueden ser erráticas, 
propias de un ser humano deambulando con su terminal por el interior de un edificio.

\subsubsection{Técnicas de medida en banda ancha}

La mayoría de los datos experimentales obtenidos de campañas de medidas en banda ancha son obtenidos en forma de resultados temporales, es decir, son medidas o estimaciones de la respuesta impulsional del canal en función del tiempo.

Para determinar la respuesta impulsional en un determinado entorno, se pueden utilizar técnicas para sondear el canal. Tales experimentos pueden realizarse transmitiendo pulsos aislados o señales de ancho de banda extendido (ruido o secuencias pseudoaleatorias).

También pueden utilizarse técnicas de medida en el dominio frecuencial, utilizando para ello analizadores de redes.

A continuación se describirán varios de los métodos basados en todas las anteriores técnicas, válidos para la realización de medidas en la banda de 1 a $2.5 \mathrm{GHz}$, pero que también son susceptibles de utilización con ondas milimétricas, tal y como se muestra en [Tha88] y [All91].

\section{Sondeo del canal mediante impulsos periódicos aislados}

Este método consiste en la transmisión de pulsos de radiofrecuencia muy estrechos ( $\mathrm{im}$ pulsos o deltas), repetidos periódicamente. La señal recibida es la convolución del impulso con el canal, es decir, la respuesta impulsional del canal. Cuanto menor sea la duración del pulso ( $T_{1}$ en la figura 3.2), mayor será la capacidad del sistema para discernir entre ecos distintos, es decir, mayor será la resolución en retardo. El periodo de la señal transmitida $\left(T_{2}\right)$ debe ser mayor que el retardo del eco mas lejano esperado, para asegurar que no se produzca ambigüedad en los pulsos recibidos.

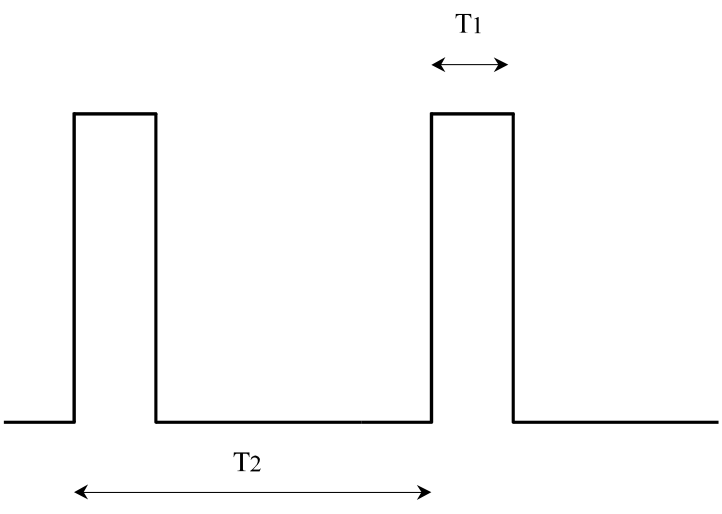

Figura 3.2: Sondeo del canal mediante pulsos periódicos. $T_{1}$ y $T_{2}$ controlan, respectivamente, la resolución y la ambigüedad

Por contra, $T_{2}$ debe ser suficientemente pequeño como para permitir la observación de 
las variaciones temporales (espaciales, si el sistema de medida está en movimiento), del canal. La principal limitación que presenta este método es la dificultad de obtener pulsos de elevada potencia y a la vez pequeña duración, lo que exige un compromiso entre la cobertura a explorar y la resolución conseguida. Ejemplos de uso de estos sistemas se pueden encontrar en [Sal87] y [Rap89]. En ambos casos, se utilizó detección de envolvente, con lo que la información de la fase se pierde, imposibilitando el cálculo de los desplazamientos Doppler. Para hallar el Doppler, es necesario demodular las componentes en cuadratura.

\section{Métodos de compresión de pulsos}

Se basan en la propiedad de los sistemas lineales por la cual, si se correla la respuesta de un sistema a un ruido blanco, con una versión retardada del ruido de entrada, el resultado es proporcional a la respuesta impulsional del canal. Si $n(t)$ es el ruido blanco, su función de autocorrelación, $R_{n}(\tau)$, es:

$$
R_{n}(\tau)=E\left[n(t) n^{*}(t-\tau)\right]=N_{0} \delta(\tau)
$$

donde $N_{0}$ es la densidad espectral de potencia del ruido.

La señal de salida del sistema cuando la entrada es ruido, será:

$$
w(t)=\int_{-\infty}^{\infty} h(s) n(t-s) d s
$$

donde $h(t)$ es la respuesta impulsional del sistema lineal. La correlación entre la salida y una versión de la entrada retardada en $\tau$, es entonces:

$$
E\left[w(t) n^{*}(t-\tau)\right]=\int_{-\infty}^{\infty} h(s) E\left[n(t-s) n^{*}(t-\tau)\right] d s=\int_{-\infty}^{\infty} h(s) R_{n}(\tau-s) d s=N_{0} h(\tau)
$$

En la práctica, no es posible utilizar un ruido blanco para sondear el canal, por lo que en su lugar se emplean secuencias binarias pseudoaleatorias de longitud máxima, generadas mediante registros de desplazamiento que modulan a una frecuencia portadora. El margen dinámico en estos métodos, aumenta con la longitud de la secuencia empleada, pero esta no se puede ampliar indefinidamente puesto que, para conseguir buena resolución en Doppler con una secuencia pseudoaleatoria de gran longitud, son necesarias velocidades de desplazamiento del móvil muy bajas [Par92].

Las técnicas de compresión de pulsos (o de espectro expandido) difieren según el procedimiento empleado para realizar la correlación. Así, se tiene, en primer lugar, la técnica de convolución con filtro adaptado en recepción, en la que la señal recibida se hace pasar por un dispositivo $\mathrm{SAW}^{*}$, diseñado para comportarse como un filtro adaptado a la secuencia pseudoaleatoria generada. Esta técnica tiene las ventajas de trabajar en tiempo real y no tener que regenerar la secuencia transmitida en recepción, con lo que no hay problemas de sincronismo. Sin embargo, la información recibida requiere complejos sistemas de muestreo para permitir su almacenamiento. Además, la realización práctica de los SAW

${ }^{*}$ Surface Acoustic Wave 
presenta limitaciones que reducen la capacidad de detección de ecos débiles y que se hacen más importantes cuando la longitud de la secuencia pseudoaleatoria crece. Ejemplos de uso de esta técnica pueden encontrarse en [Par82] y [Baj82].

Otra técnica basada en la compresión de pulsos es la STDCC*, propuesta en [Cox72]. Esta técnica consiste en la correlación de la señal recibida con una secuencia pseudoaleatoria idéntica a la transmitida, pero regenerada con una velocidad levemente menor, es decir, empleando un reloj de sincronismo más lento que en transmisión. La diferencia entre las frecuencias de reloj determina el ancho de banda de correlación y el factor de escalado, que es el número de respuestas impulsionales a la salida del correlador. Cada cierto tiempo, la secuencia regenerada en el receptor se reinicializa para conseguir una nueva serie de respuestas impulsionales. Este tiempo de reinicialización es el correspondiente al factor de escalado por el máximo retardo considerado para una respuesta impulsional. Para obtener los desplazamientos Doppler es necesario demodular en fase y cuadratura. La STDCC requiere gran sincronismo entre los relojes de emisión y transmisión, por lo que todas las frecuencias empleadas en el transmisor y en el receptor suelen derivarse de osciladores gemelos. Cuando se necesita resolución entre ecos muy próximos, como ocurre en el caso indoor, son necesarias elevadas frecuencias de reloj. Con este método resulta necesario el almacenamiento de los datos para su posterior procesado. Esta técnica se ha empleado, por ejemplo, en [Lo92], [Flo93] y [Der93].

\section{Medidas del canal mediante el uso de analizadores de redes}

Es un método muy sencillo, válido para el estudio del canal en el interior de edificios, y que ha sido elegido para realizar las medidas que se muestran en el capítulo 4, donde se analizará con más detenimiento.

Simplemente, se puede avanzar que está basado en la medida, mediante analizadores de redes, de la función de transferencia del canal en módulo y fase, a partir de la cual, al igual que con la respuesta impulsional, se puede tener perfectamente caracterizado el canal.

Sistemas basados en analizadores de redes han sido utilizados, por ejemplo, en [Pah89], [Agu91], [Rui91], [Mel92], [Pér93], [Der93], [Has94] y [Pér95].

\subsection{Modelos deterministas}

Con este tipo de modelos se puede considerar de forma más aproximada los efectos del entorno que en los modelos empíricos, permitiendo realizar un estudio más completo de las características del canal, ya que permiten predecir, además de las pérdidas medias de propagación, la estadística de la señal, y otros parámetros propios de banda ancha, tales como la respuesta impulsional, los ángulos de llegada de las distintas contribuciones, etc.

Existen diversas técnicas de modelado determinista. Concretamente, en aplicaciones indoor se han estudiado, sobre todo, dos tipos: las basadas en el cálculo FDTD (Finite

${ }^{*}$ Swept Time-Delay Cross-Correlation 
Difference Time Domain), y las basadas en la Óptica Geométrica (GO*). Se ha demostrado que estas últimas resultan computacionalmente más eficientes que la FDTD [Bar95b].

La aproximación de Óptica Geométrica sólo es aplicable en aquellos casos en los que las dimensiones de los obstáculos que encuentre la señal sean mucho mayores que la longitud de onda. Las frecuencias utilizadas en entornos indoor permiten suponer tal aproximación.

Entre los métodos o procedimientos para obtener las distintas trayectorias de las contribuciones que alcanzan al receptor móvil puede citarse el Método de las Imágenes Virtuales y los métodos basados en técnicas de Lanzado de Rayos, que se describirán a continuación.

\subsubsection{Método de las Imágenes Virtuales. Trazado de Rayos}

Esta técnica de modelado consiste en calcular las imágenes del receptor con las paredes y suelos más importantes, normalmente los más cercanos, y posteriormente considerar las trayectorias desde el transmisor hasta cada una de las imágenes. El método dual (cálculo de las imágenes del transmisor, y las trayectorias hasta los receptores) también es válido. Uno de los primeros trabajos en los que se usa esta técnica es [McK91].

Al tener calculados la posición del transmisor y la de las imágenes de los receptores (o viceversa), las trayectorias de los rayos ópticos que definen el frente de ondas quedan perfectamente definidas, y pueden ser trazadas con exactitud. Por ello, muchas veces a esta técnica se le conoce como Trazado de Rayos (Ray Tracing ${ }^{\dagger}$ ). En el COST 231, a esta técnica se le ha puesto el nombre de IAM ${ }^{\ddagger}$.

La potencia total recibida se puede obtener como la suma coherente de todas las contribuciones, teniendo en cuenta el retardo si se desea, además, caracterizar la respuesta impulsional del canal.

Este método resulta desaconsejable cuando el entorno se complica, y muy especialmente cuando se trata de considerar reflexiones en número superior a dos, ya que el tiempo de cálculo crece exponencialmente con el orden de las reflexiones.

El efecto del mobiliario puede tenerse en cuenta añadiendo ciertas pérdidas adicionales, en torno a $3 \mathrm{~dB}$. También conviene limitar las pérdidas de penetración de paredes cuando el ángulo de incidencia es muy pequeño. Un valor límite adecuado sería, por ejemplo, el doble en $\mathrm{dB}$ del que tome con incidencia normal.

\subsubsection{Métodos de Lanzado de Rayos}

Los métodos basados en el Lanzado de Rayos consisten básicamente en lanzar desde el transmisor un número finito pero suficiente de rayos, uniformemente en la distintas direcciones del espacio, cubriendo así el ángulo sólido completo. Para cada rayo lanzado

\footnotetext{
${ }^{*}$ Geometrical Optics

${ }^{\dagger}$ No confundir con la técnica de modelado tridimensional de imágenes (renderización) que tiene el mismo nombre. De hecho, el Ray Tracing para renderización es más similar al Lanzado de Rayos, que se verá después.

${ }^{\ddagger}$ Image Approach Method
} 
se consideran las múltiples reflexiones y transmisiones que pueda sufrir hasta alcanzar al receptor.

El número de reflexiones o transmisiones a considerar dependerá del nivel de señal a partir del cual una contribución pueda ser considerada como poco significativa, o bien tras un número limitado de interacciones con los obstáculos.

Este método es muy útil en entornos complicados ya que permite un fácil seguimiento de las reflexiones. Pero, sin embargo, resulta complejala localización de los receptores debido a la dificultad de saber si un rayo alcanza o no un objeto puntual, ya que el número de rayos lanzados, mayor o menor, siempre es finito y de naturaleza unidimensional.

Para solucionar el problema de los objetos puntuales (receptores, elementos difractantes, scatterers, etc.) se suele recurrir a una esfera de incertidumbre alrededor de ellos. El radio de tal esfera (o círculo, en $2 \mathrm{D}$ ) ha de ser dependiente de la distancia recorrida por el rayo, así como de la resolución angular con la que se lanzan los distintos rayos.

En la tabla 3.4 se comparan los dos métodos basados en GO, a partir de las campañas de medidas presentadas a lo largo del COST 231. El método de Lanzado de Rayos presentado (RLM* ${ }^{*}$, según la nomenclatura del COST 231), tenía en cuenta hasta 5 reflexiones y 12 penetraciones por rayo; por otra parte, el método de las imágenes (IAM) con el que se comparó, incluía reflexiones de hasta segundo orden, además de los elementos difractores principales. De los valores del error medio y de su desviación típica se comprueba que estos modelos deterministas proporcionan mejores resultados que los métodos empíricos, y que el Lanzado de Rayos mejora, en general, las prestaciones del método de las imágenes, especialmente a mayores frecuencias.

\begin{tabular}{|l|c|c|c|c|}
\hline $\begin{array}{l}\text { Conjunto } \\
\text { de datos }\end{array}$ & \multicolumn{2}{|c|}{ Método de las Imágenes } & \multicolumn{2}{c|}{ Lanzado de Rayos } \\
\hline $\begin{array}{l}\text { DTD pisos } \\
856 \mathrm{MHz}\end{array}$ & 9.0 & Error medio (dB) & STD (dB) & Error medio (dB) \\
\hline $\begin{array}{l}\text { Dos pisos } \\
1800 \mathrm{MHz}\end{array}$ & 11.3 & -2.7 & 6.2 & 0.3 \\
\hline $\begin{array}{l}\text { Más de 2 pisos } \\
856 \mathrm{MHz}\end{array}$ & 7.8 & 10.3 & 8.7 & 0.1 \\
\hline $\begin{array}{l}\text { Más de 2 pisos } \\
1800 \mathrm{MHz}\end{array}$ & 10.9 & -2.6 & 9.1 & -4.6 \\
\hline
\end{tabular}

Tabla 3.4: Prestaciones de los modelos basados en Óptica Geométrica

\section{Lanzado de tubos}

En esta Tesis, además de analizar con más detalle un método genérico de Lanzado de Rayos, se presentará una variante del mismo en el que, en lugar de lanzar rayos individuales, se lanzan tubos de sección triangular, formados por tres rayos que lo delimitan más un rayo central que determina sus características electromagnéticas.

\footnotetext{
${ }^{*}$ Ray Launching Model
} 
Con este método ya no es necesario el uso de una esfera de incertidumbre para cada obstáculo o receptor puntual, ya que pueden considerarse alcanzados todos los puntos contenidos en el interior del tubo.

Para conseguir un lanzado uniforme de tubos triangulares, se ha de proceder a la discretización de una esfera alrededor del transmisor. Este proceso tiene que garantizar una cierta uniformidad en el tamaño y forma de los distintos triángulos que lo componen, por lo que su complejidad depende del grado de resolución deseado.

El principal problema de este modelo es la complejidad computacional del algoritmo de lanzado, debido a la existencia de cuatro rayos por tubo, junto con la imposibilidad geométrica de dividir el espacio en tubos triangulares del mismo tamaño. Esto sólo puede conseguirse considerando un icosaedro alrededor del emisor, lo cual proporciona una baja resolución (12 tubos en total) si no se recurre al splitting.

Se ha comprobado, [May97], que este método no es demasiado útil, respecto al Lanzado de Rayos, cuando el entorno se complica mucho con puertas, ventanas y otros huecos. Sin embargo, se comporta mucho mejor en situaciones inroom [Bar95a], es decir, en entornos cerrados en los que, tanto transmisor como receptor, se encuentran en la misma habitación. Teniendo en cuenta que las frecuencias de trabajo en comunicaciones móviles en el interior de edificios van a ir progresivamente aumentando, no es descabellado pensar que sería necesario ubicar transmisores en cada habitación, debido a las altas atenuaciones producidas por las paredes, y especialmente en el caso de redes inalámbricas de transmisión de datos (WLAN).

Será en el capítulo 5 donde se verá con más detalle las distintas técnicas de Lanzado de Rayos y de Tubos que se han implementado para llevar a cabo esta Tesis.

\subsubsection{Parámetros del entorno en los modelos deterministas}

Uno de los principales problemas de los modelos deterministas es conocer la influencia en la propagación de los distintos materiales que conforman el entorno. La mayoría de las veces estos datos no se conocen, por lo que se recurre a aproximaciones o a valores tabulados y que han sido validados en entornos similares.

En la tabla 3.5 se recogen los valores de la constante dieléctrica compleja relativa, $\varepsilon_{r}{ }^{\prime}+j \varepsilon_{r}{ }^{\prime \prime}$, para los materiales más habituales, según los modelos de la Universidad de Karlsruhe (Alemania) y los de la compañía telefónica finlandesa VTT [Dam96], válidos para las frecuencias habituales de trabajo en condiciones indoor.

\subsubsection{Complejidad computacional de los métodos basados en Óptica Geométrica}

Para medir la complejidad computacional de estos métodos, puede evaluarse el número de diferentes trayectorias que hay que examinar para completar el trazado de rayos, $M$, considerando reflexiones hasta un determinado orden $k$.

Así, en el caso del método de las imágenes, para cada receptor, se ha de considerar 


\begin{tabular}{|l|c|c|c|c|c|}
\hline Material & \multicolumn{2}{|c|}{ U. Karlsruhe } & \multicolumn{2}{|c|}{ VTT } & Anchura típica (cm) \\
& $\varepsilon_{r}{ }^{\prime}$ & $\varepsilon_{r}{ }^{\prime \prime}$ & $\varepsilon_{r}{ }^{\prime}$ & $\varepsilon_{r}{ }^{\prime \prime}$ & \\
\hline \hline Hormigón & 9 & 0.9 & 6 & 0.7 & 25 \\
\hline Hormigón ligero & & & 2 & 0.5 & 10 \\
\hline Ladrillo & & & 4 & 0.1 & 13 \\
\hline Tabique de separación & 6 & 0.6 & 2.5 & 0.1 & $2 \times 1.3$ \\
\hline Tabique aglomerado & & & 3 & 0.2 & $2 \times 1.3$ \\
\hline Madera & 2.5 & 0.03 & & & 5 \\
\hline Vidrio & 6 & 0.05 & 6 & 0.05 & $2 \times 0.3$ \\
\hline Estantería & 2.5 & 0.3 & & & 30 \\
\hline
\end{tabular}

Tabla 3.5: Parámetros eléctricos de algunos materiales

una trayectoria por cada imagen calculada. En general, dicho número de imágenes puede expresarse en la forma siguiente [Hus94]:

$$
M=1+\sum_{i=1}^{k} N(N-1)^{i-1}
$$

donde $N$ es el número de paredes del entorno. En el caso particular de una habitación rectangular, con seis paredes, y donde todos los ángulos son de $90^{\circ}$, la expresión anterior se simplifica, y $M$ se reduce a [Dri93]:

$$
M=1+\sum_{i=1}^{k}\left(4 i^{2}+2\right)
$$

Este método es muy eficiente para órdenes pequeños de reflexión $(k=1$ ó 2$)$ y para pocas paredes. Si el entorno consta de un gran número de paredes, y además se requiere $k \geq 3$, entonces el número de imágenes, y consecuentemente el de trayectorias a considerar, resulta excesivamente alto, tal y como se aprecia en la figura 3.3.

Además, en este caso, el algoritmo se detiene mucho tiempo comprobando todas las imágenes para encontrar las que realmente contribuyen a la señal recibida. Como ejemplo, citar que, en el caso de una habitación de 6 paredes ortogonales entre sí, y con un orden de reflexión igual a 2, aparecen 37 imágenes por cada receptor. Sin embargo, sólo 25 de ellas representan un camino físicamente realizable por el rayo.

En el caso de Lanzado de Rayos (o su variante de Tubos), se consideran tantas trayectorias como rayos se lanzan. Su precisión se ve mejorada incrementando este número y, por tanto, su tiempo de computación.

Así, para este método, el número de trayectorias a considerar será [Hus94]:

$$
M=4 \pi(k+1)^{2}\left(\frac{d_{\max }}{\Delta}\right)^{2}
$$

donde $d_{\max }$ es la máxima distancia que pueda recorrer el rayo hasta alcanzar al receptor, y $\Delta$ es la resolución espacial del lanzado que se puede predefinir mediante:

$$
\lambda<\Delta<d_{R}
$$




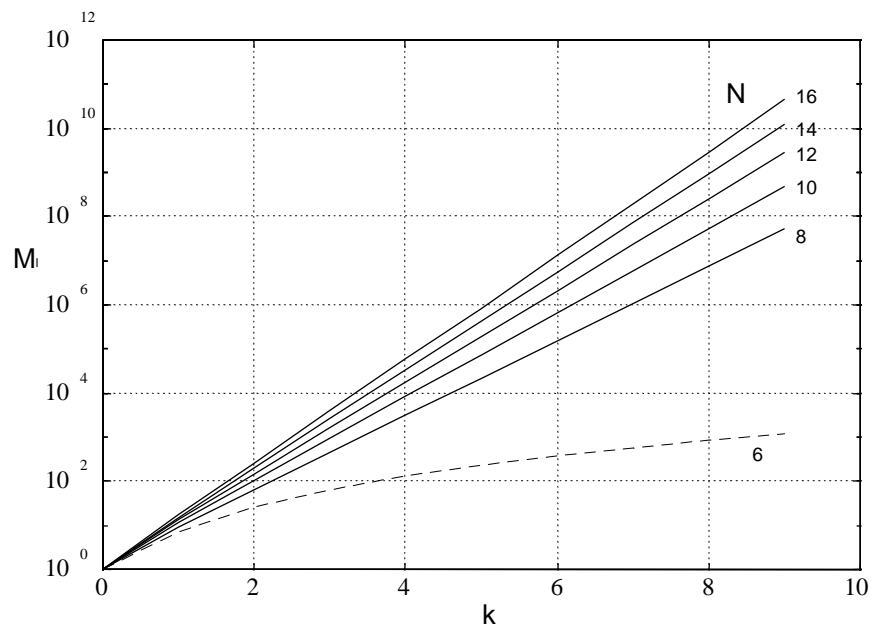

Figura 3.3: Complejidad computacional del Método de las Imágenes Virtuales. La curva a trazos se refiere al caso simplificado con $N=6$ (habitación rectangular cerrada)

siendo $d_{R}$ el tamaño del reflector más pequeño, y $\lambda$ la longitud de onda de trabajo.

Como se puede ver, además de que el grado de complejidad es controlable a priori, resulta que crece de forma geométrica con $k$, en lugar de hacerlo exponencialmente como en el caso del método de las imágenes.

Además, los algoritmos de Lanzado de Rayos resultan más eficientes con entornos realistas, ya que cada trayectoria puede calcularse una sola vez, independientemente del número de receptores estudiados.

\subsection{Otras técnicas de modelado}

Entre otras técnicas de modelado conocidas, se pueden destacar los sistemas simuladores, ya sean hardware o software. Este tipo de simuladores generalmente no pretenden predecir un nivel de señal bajo unas determinadas condiciones de propagación, sino generar una señal que pueda asumirse que tenga características similares a la recibida en un sistema móvil.

Entre los primeros trabajos de este tipo, está el simulador hardware descrito en [Arr73], capaz de generar una señal con estadísitcas de desvanecimientos tipo Rayleigh. Una versión software de este simulador puede ser encontrada en [Smi75]. Otros simuladores en banda estrecha están descritos en [Bod82] y [Cas90].

Un método bastante sencillo para simular un canal de comunicaciones móviles en banda ancha (como cualquier otro sistema lineal y variante con el tiempo), es mediante el uso de filtros transversales, con retardos entre cada rama constantes o variables, y con los pesos multiplicadores variables y siguiendo una distribución generalmente Rayleigh. 
Descripciones detalladas de tales simuladores pueden ser vistos en [Fai89].

Comparativamente, el esfuerzo investigador para la elaboración de modelos en el dominio de la frecuencia, es mucho menor que en el caso del dominio del tiempo. Quizá sea debido a la naturaleza mucho más intuitiva de este último. En [How92] se presenta un modelo autorregresivo (AR) en el dominio de la frecuencia, además de su correspondiente dual en el dominio temporal. Son modelos realmente poco intuitivos, pero que con pocos parámetros consiguen ajustarse bien a las medidas.

\subsection{Consideraciones adicionales}

El modelado del canal radio móvil requiere investigar y tener en cuenta un gran número de factores y consideraciones adicionales, de forma que los modelos resulten lo más completos posible.

A continuación se va a comentar algunos de esos factores adicionales que quizá no estén incluidos en los modelos descritos en este capítulo. Concretamente se hablará del ruido y de la polarización.

\subsubsection{Ruido}

En el canal radio móvil indoor existe un gran número de posibles fuentes de ruido. Estas pueden ser el ruido térmico natural del sistema de comunicación, o emisiones electromagnéticas a la misma frecuencia o a frecuencias cercanas, además del ruido impulsivo de gran variedad de fuentes artificiales.

Las emisiones a frecuencias cercanas son tratadas normalmente como interferencias, y un poco aparte del resto del ruido.

En la mayoría de los casos, el ruido es tratado de forma simple como un proceso estocástico, con estadística gausiana y densidad espectral de potencia constante en toda la banda, que se superpone aditivamente a la señal útil. En otras palabras, ruido blanco gausiano aditivo $\left(\mathrm{AWGN}^{*}\right)$.

Sin embargo, ciertas medidas han demostrado que la realidad no es tan simple. Así, en [Bla91] se describe una serie de medidas llevadas a cabo en entornos indoor para determinar las fuentes de ruido. Se encontró que las fotocopiadoras, impresoras, ascensores y hornos microondas resultan ser fuentes significativas de ruido impulsivo con amplitudes de hasta $50 \mathrm{~dB}$ por encima del ruido térmico ambiente, y con duraciones de los pulsos de hasta $10 \mu \mathrm{s}$. Algunas de estas fuentes sólo afectan a ciertas frecuencias. Así, el ruido generado por los hornos microondas era detectado únicamente cuando se operaba a $2.44 \mathrm{GHz}$, pero no a $918 \mathrm{MHz}$ o $4.0 \mathrm{GHz}$.

Otra posible fuente de ruido a tener en cuenta en entornos indoor, son los tubos fluorescentes empleados en la iluminación interior del edificio. En [Mel92], se ha comprobado que los tubos fluorescentes pueden producir un desvanecimiento temporal continuo de la

*Additive White Gaussian Noise 
señal recibida, con una frecuencia doble de la frecuencia de la red eléctrica (por tanto, en el caso europeo, $100 \mathrm{~Hz}$ ). Este desvanecimiento produce variaciones en torno a $2 \mathrm{~dB}$ en el módulo y de alrededor de $12^{\circ}$ en la fase de la señal, a la frecuencia de $900 \mathrm{MHz}$.

\subsubsection{Polarización}

En la práctica totalidad de los modelos del canal radio móvil, se asume que las señales transmitida y recibida mantienen la misma polarización, ya que se supone que existe muy poca cros-polarización en el canal, es decir, que sólo una muy pequeña parte de la potencia de la señal transmitida se convierte en señal electromagnética con polarización ortogonal a la anterior.

Esto, que en escenarios externos resulta razonablemente veraz, no lo es tanto en el caso de entornos indoor, tal y como se muestra en [Cox86]. Las razones para tal crospolarización de canal, también tratada como despolarización de la señal transmitida, se encuentran en la reflexión no especular sobre las superficies rugosas que forman el entorno. Así, en [Cel85] se describe la excitación por resonancia que se produce en una superficie rugosa, lo cual provoca un fenómeno de reflexión con difusión (scattering) con cierta despolarización.

Por tanto, un receptor con polarización lineal orientada de la misma forma que el transmisor, puede llegar a recibir solamente la mitad de la potencia que potencialmente pueda captar, debido a que la señal transmitida se haya despolarizado en su recorrido.

Por otra parte, este fenómeno puede ser aprovechado mediante el uso de diversidad de polarización en el receptor, que se ha demostrado mucho más eficiente frente al fading que la diversidad espacial, tal y como se comenta en [Koz84] y [Rui90]. Por ejemplo, medidas realizadas bajo diferentes condiciones (LOS y NLOS) y presentadas en [Rui93], demuestran que se pueden conseguir coeficientes de correlación muy bajos (siempre inferiores a 0.6) entre dos señales recibidas con distinta polarización.

\subsection{Resumen}

En este capítulo se ha descrito parte de la literatura existente acerca de las distintas campañas de medida de las características del canal radio móvil indoor, así como de los modelos propuestos, generalmente basados en los resultados obtenidos en las anteriores.

Dependiendo de las necesidades particulares que se tengan a la hora de planificar los sistemas de comunicaciones móviles indoor, se necesitará un tipo de modelo u otro. Así, si bastara simplemente con tener una idea aproximada de la potencia media recibida en una zona determinada, se podría acudir a sencillos modelos de pérdidas de propagación suficientemente contrastados, que, además, pueden tener en cuenta, en cierta medida, los efectos del entorno.

Sin embargo, en aquellos casos en que el sistema deba ser considerado como de banda ancha, se necesitará un modelo que tenga en cuenta tal circunstancia, ya sea de forma empírica a partir de medidas realizadas bajo condiciones similares a las de estudio, o de 
forma más determinista, intentando en lo posible simular el comportamiendo de las ondas propagándose por el entorno.

Precisamente, se ha demostrado que los modelos deterministas basados en la Óptica Geométrica presentan unos resultados bastante satisfactorios, sobre todo cuando el entorno es relativamente complejo y caracterizado tridimensionalmente. La complejidad computacional que requieren es elevada, pero la existencia de ordenadores y algoritmos cada vez más potentes hace previsible que estos modelos acaben imponiéndose, sobre todo como herramienta de planificación de sistemas en los que se requiera de gran precisión en las prediciones de la potencia recibida, la estadística de desvanecimientos y las características de banda ancha del canal.

En esta Tesis serán estudiados con más detalle los métodos de Lanzado de Rayos y de Lanzado de Tubos (una variante del anterior). Aunque, previamente, se presentará una campaña de medidas realizada en el edificio de la ETSIT de Valencia, con la que se pretendía cubrir cierto déficit de medidas realizadas entre las distintas plantas de un edificio, teniendo en cuenta, además, la influencia de la posición de las antenas respecto al suelo y al techo. 



\section{Capítulo 4}

\section{Medidas en el Edificio de la ETSIT de Valencia}

\subsection{Introducción}

Al abordar el estudio de las características que presenta el Canal Radio Móvil en un determinado entorno, siempre hay que acudir, en una primera fase, a un análisis detallado de las medidas que se dispongan. Estos conjuntos de medidas deberían abarcar multitud de condiciones distintas, pues de este modo se garantiza que no existirá sesgo alguno en el análisis posterior.

Como ya se ha visto en el capítulo 3, existe ya a disposición del investigador una gran cantidad de campañas de medidas realizadas en el interior de edificios. De todos modos, no todas ellas han sido realizadas teniendo en cuenta el carácter intrínsecamente tridimensional de este tipo de entornos, máxime si lo que se pretende caracterizar son las condiciones de propagación entre puntos situados en distintas plantas del edificio.

Así, si se tiene en cuenta que prácticamente todas las medidas entre plantas han sido realizadas manteniendo fija las alturas de las antenas (o como mucho con dos alturas distintas de antena receptora [Sei92]), se deduce que no se ha tenido suficientemente en cuenta la posición relativa de las antenas respecto a suelo y techo, cuando todo parece indicar que estos obstáculos van a tener un papel predominante en la propagación en el interior de un edificio.

Al utilizar estas campañas incompletas para comparar las medidas con los modelos de propagación que se han ido proponiendo, se pueden apreciar algunos hechos significativos.

Así, suele ocurrir que, al ajustar las pérdidas de propagación medidas entre diferentes plantas, a las predicciones de modelos empíricos similares al MWM* propuesto en el COST 231, el error cuadrático medio que se comete es mucho mayor que en el caso de medidas en una sola planta (véase, por ejemplo, [Läh94]).

Así mismo, en estos modelos, se suele recurrir a una serie de parámetros empíricos, con

${ }^{*}$ Multi-Wall Model (3.5) 
una interpretación física unas veces clara y otras no tanto, que se muestran dependientes del número de suelos atravesados. Por ejemplo, en [Läh94] aparece un factor $L_{C}$ que representa una constante de pérdidas, y que resulta ser función del número de suelos atravesados, aunque no se puede llegar a establecer ninguna dependencia formal. De hecho, no se puede ni siquiera deducir claramente si dicho factor es creciente o decreciente con el número de suelos atravesados.

Además, en [Hon93] se afirma que el valor medio de lo que allí se denomina Factor de Atenuación de cada Suelo $\left(\mathrm{FAF}^{*}\right)$, calculado a partir de las medidas que se presentaban en ese mismo trabajo, resulta no ser una función lineal del número de suelos entre antenas transmisora y receptora. Viene a decirse, por tanto, que cada suelo provoca una atenuación de propagación distinta, dependiendo de cuántos suelos hayan sido ya atravesados, lo cual resulta un tanto contradictorio con el sentido físico que se pretende dar a dicho factor.

Por último, en el mismo modelo MWM que se ha propuesto finalmente en el COST 231, se reconoce que las pérdidas de propagación no son función lineal del número de suelos atravesados, apareciendo, como ya se vio en (3.5), un nuevo factor empírico $b$ sin ningún significado físico.

En opinión del autor de esta Tesis, estas interpretaciones pueden resultar erróneas si se ha partido de medidas que no contemplen un amplio abanico de casos posibles. Así, al igual que se han realizado medidas en multitud de entornos distintos (pasillos, halls, etc.), evaluando la influencia de la distancia entre antenas y el número y tipos de paredes o suelos atravesados, debería haberse hecho medidas tendentes a evaluar la influencia de la altura de las antenas, con lo cual, implícitamente se evaluaría la naturaleza tridimensional del entorno indoor.

Ante la carencia de tales tipos de medidas, y como primer paso de esta Tesis que aquí se presenta, se realizó una campaña de medidas en el Edificio de la Escuela Técnica Superior de Ingenieros de Telecomunicación (ETIST) de Valencia, con la intención principal de evaluar si la altura de la antena en recepción influye de manera determinante en las condiciones de propagación indoor entre las distintas plantas de un edificio.

En este capítulo se describirá dicha campaña, así como se comentarán las conclusiones fundamentales que se obtuvieron a partir de su análisis. Estos resultados fueron presentados en el COST 231 [Flo95a] y en el X Symposium Nacional de la URSI [Flo95b].

\subsection{Medidas de pérdidas de propagación}

En primer lugar, se realizó una campaña de medidas en banda estrecha, con la intención de medir las pérdidas de propagación entre las distintas plantas del edificio de la ETSIT, en función de la altura de la antena receptora, manteniendo fija la transmisora en otro punto de una planta distinta.

Se describirá a continuación el sistema empleado en dichas medidas de banda estrecha, las características principales de la instrumentación y el método seguido para llevarlas a cabo.

${ }^{*}$ Floor Atenuation Factor 


\subsubsection{Descripción del sistema de medida de pérdidas de propagación}

Aprovechando la instrumentación que dispone el Departamento de Comunicaciones en la ETSIT de Valencia, se decidió implementar un sistema de medida de pérdidas de propagación consistente en la generación y transmisión de un tono de frecuencia puro, y la medida de la envolvente de la señal recibida. Aunque los sistemas de comunicaciones indoor de desarrollo actual y futuro, están ubicados en la banda de los $1800 \mathrm{MHz}$ (como el DECT) o incluso a frecuencias superiores, la no disponibilidad de antenas adecuadas que trabajasen en esa zona del espectro, y la limitación a $1 \mathrm{GHz}$ de la frecuencia máxima del analizador de espectros empleado, obligó a realizar las medidas en la banda de $900 \mathrm{MHz}(\lambda \simeq 33.3 \mathrm{~cm})$ que, por otra parte, es la utilizada por ciertos estándares de telefonía sin hilos, como el CT2 británico y el DCT sueco, además de, como ya es sabido, para el GSM.

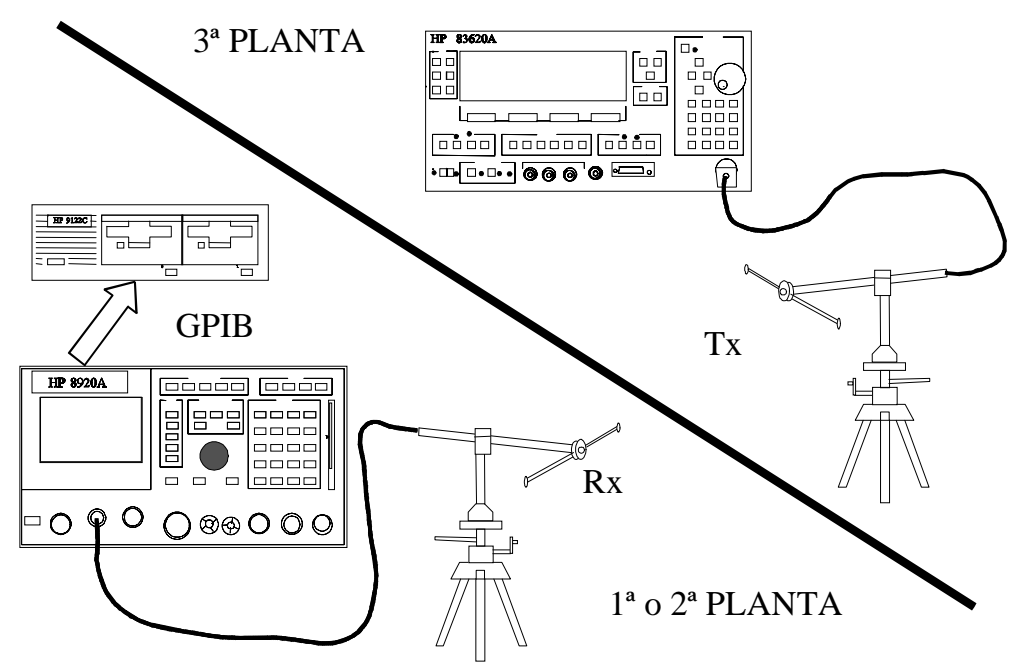

Figura 4.1: Representación esquemática del sistema utilizado para realizar medidas de pérdidas de propagación

Los equipos utilizados en la confección del sistema fueron (figura 4.1):

Antenas. Se emplearon dos dipolos en $\lambda / 2$ gemelos, ajustables en frecuencia, que permiten trabajar en el margen de $400 \mathrm{MHz}$ a $1 \mathrm{GHz}$, variando su longitud.

Los dipolos presentan una ganancia a $900 \mathrm{MHz}$ de $1.42(1.5 \mathrm{~dB})$, pérdidas del balun incluidas, y una $\mathrm{ROE}^{*}$ menor de 1.6.

Disponen de conectores de entrada tipo $\mathrm{N}$ hembra. La máxima potencia de entrada que admiten es $50 \mathrm{~W}(46,9 \mathrm{dBm})$. La impedancia de entrada para la que están adaptados es de $50 \Omega$.

Cables. Se emplearon dos tramos de cable RG 214/U. El tramo empleado en transmisión, tenía una longitud de $3.05 \mathrm{~m}$ y presentaba unas pérdidas a $900 \mathrm{MHz}$ de $0.93 \mathrm{~dB}$. El

\footnotetext{
${ }^{*}$ Relación de Onda Estacionaria
} 
empleado en recepción poseía una longitud de $9.97 \mathrm{~m}$ y unas pérdidas de $2.67 \mathrm{~dB}$. La impedancia característica de los cables era de $50 \Omega$.

Sintetizador de frecuencias HP 83620A. Fue el equipo utilizado como transmisor. Puede trabajar tanto en modo de barrido en frecuencia, en el margen de $10 \mathrm{MHz}$ a $20 \mathrm{GHz}$, como en onda continua (CW), modo en el que se empleó para generar el tono puro de $900 \mathrm{MHz}$ a transmitir.

El sintetizador dispone de un puerto de salida con conector tipo SMA, al que se acopla un aislador con el objeto de prevenir que posibles reflexiones de la señal de salida puedan causar daños al equipo. El equipo se empleó a su potencia máxima de salida, $25 \mathrm{dBm}$. En el pico del espectro, la potencia de salida que se obtenía era de $15.3 \mathrm{dBm}$. Se requiere un tiempo de precalentamiento, o caldeo, de al menos 30 minutos, que es conveniente respetar si no se quiere ver cómo el pico del espectro transmitido se desplaza en frecuencia durante la realización de las medidas.

\begin{tabular}{|l|c|}
\hline Potencia de salida máxima & $25 \mathrm{dBm}$ \\
Resolución en amplitud & $0.02 \mathrm{~dB}$ \\
Estabilidad térmica en amplitud & $0.01 \mathrm{~dB} /{ }^{\circ} \mathrm{C}$ \\
Margen de frecuencias & $10 \mathrm{MHz}$ a $20 \mathrm{GHz}$ \\
Resolución en frecuencia & $1 \mathrm{~Hz}$ \\
\hline
\end{tabular}

Tabla 4.1: Especificaciones del HP 83620A

Analizador de Radiocomunicaciones HP 8920A. Se trata de un equipo modular que dispone de osciloscopio, generador de señales, codificador-descodificador de tonos multifrecuencia, y analizador de espectros, opción esta última, empleada en la realización de las medidas que aquí se presentan.

El equipo es bastante portátil. Posee una unidad de tarjetas extraíbles de memoria permanente de 32 Kbytes y puede alimentarse mediante corriente alterna o a través de una batería de corriente continua. Dispone de un procesador interno así como de unidades de memoria no volátil, que permiten almacenar programas y ejecutarlos desde el propio analizador, aún después de una desconexión de la red eléctrica, sin la necesidad de un controlador externo, lo que proporciona una gran autonomía. Tales programas se elaboran en el lenguaje HP-IBASIC* y pueden ser editados incluso desde el propio analizador, aunque es una tarea muy engorrosa. Es mucho más practico editar los programas en un PC y posteriormente enviarlos al equipo mediante el bus GPIB.

El puerto de antena se utilizó como entrada para las señales recibidas. Este acceso está recomendado para señales de potencia inferior a los $200 \mathrm{~mW}(23 \mathrm{dBm})$, y posee un conector BNC hembra. El HP 8920A dispone también de otro puerto de entrada RF-IN/OUT, capaz de soportar señales de hasta $60 \mathrm{~W}(47.78 \mathrm{dBm})$, dotado de un conector $\mathrm{N}$ hembra. La sensibilidad del analizador de espectros es de $-130 \mathrm{dBm}$. El margen de barrido de frecuencias empleado durante todas las medidas fue de $200 \mathrm{KHz}$, lo cual imponía un ancho de banda de resolución de $3 \mathrm{KHz}$. Se recomienda un tiempo de precalentamiento del equipo de unos 15 minutos.

${ }^{*}$ Hewlett Packard Instrument Basic 


\begin{tabular}{|l|c|}
\hline Margen de frecuencias & $400 \mathrm{KHz}$ a $1 \mathrm{GHz}$ \\
Resolución en amplitud & $\pm 2.5 \mathrm{~dB}$ \\
Display & logarítmico, $10 \mathrm{~dB} / \mathrm{div}$ \\
Margen de amplitudes representado & $80 \mathrm{~dB}$ \\
Margen del nivel de referencia & $+50 \mathrm{dBm}$ a $-50 \mathrm{dBm}$ \\
Respuesta a espúreas no armónicas & $>60 \mathrm{~dB}$ \\
& (para señales de entrada $\leq 30 \mathrm{dBm}$ ) \\
Rechazo a imágenes & $>50 \mathrm{~dB}$ \\
\hline
\end{tabular}

Tabla 4.2: Especificaciones del analizador de espectros HP 8920A

Con la instrumentación referida, el márgen dinámico del sistema se situaba en torno a los $144 \mathrm{dBm}$.

En los primeros momentos de la preparación del sistema se optó por el uso de la tarjeta externa, en base a criterios de movilidad y sencillez del sistema, pero se desechó tal propósito a causa de la limitación de memoria de la tarjeta y al continuo proceso de transvase de datos, de la tarjeta a discos flexibles, a que ello obligaba. Se usó por tanto una unidad de disco flexible externa HP 9122C, conectada al analizador mediante el bus GPIB. En cuanto a la alimentación, desde un principio se desechó la opción de alimentación mediante corriente continua (el HP 8920A puede alimentarse mediante el uso de una batería externa), por la limitación de autonomía que impone. Además, la existencia de un gran número de tomas de la red eléctrica en los pasillos del edificio donde se iban a realizar las medidas, eliminaba la posible limitación de movilidad derivada de la conexión a la red.

\subsubsection{Ubicación de las medidas}

Como se ha señalado anteriormente, uno de los objetivos de esta campaña de medias era el estudio del comportamiento de la propagación entre las distintas plantas de un edificio, así como la posible influencia de la posición relativa de las antenas respecto al suelo y al techo.

Se decidió, por tanto, ubicar las antenas receptoras a lo largo de los pasillos principal y de despachos del edificio de la ETSIT de Valencia (figura 4.2), concretamente en las plantas primera y segunda (el edificio posee 3 plantas además de la planta baja). En el pasillo principal se eligieron 4 puntos $(1,2,3,4)$ y otros tres en los pasillos de despachos $(\mathrm{A}, \mathrm{B}, \mathrm{C})$.

Para cada uno de los pasillos se eligió una posición de antena transmisora (TX1 y TX2 en la figura 4.2), aunque siempre colocadas en el tercer (último) piso. Con estas configuraciones se conseguía estudiar la propagación entre plantas en dos entornos distintos: uno abierto y con presencia de grandes huecos entre plantas (pasillo principal) y otro más cerrado y tipo corredor estrecho (pasillo de despachos).

En primera instancia, se realizaron pruebas en las que las muestras en vertical que componían las trazas se tomaron cada $\lambda / 10$ (unos $3.3 \mathrm{~cm}$ ), lo que no arrojó los resultados esperados. Por ello, en las medidas definitivas, las muestras que formaban las trazas ver- 


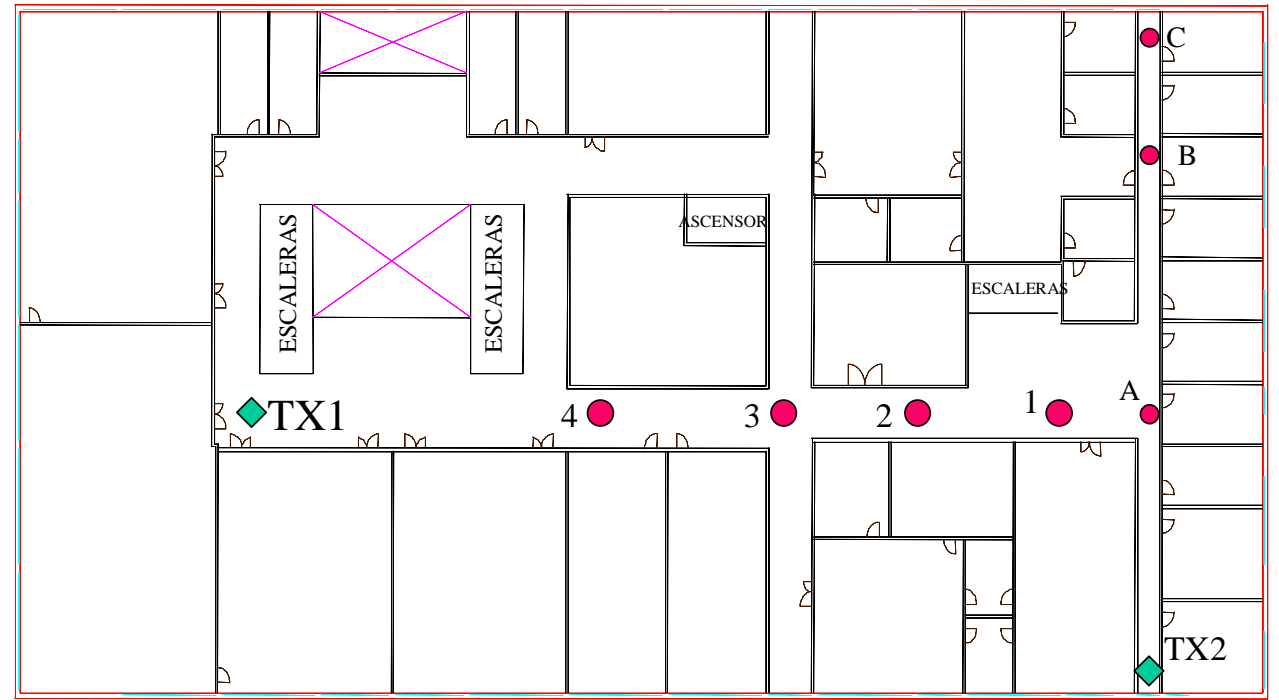

Piso 3

$\diamond \mathrm{TX} 1$

Piso 2

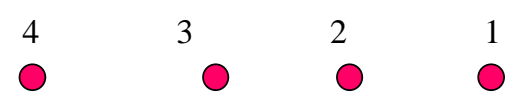

Piso 1

$\begin{array}{llll}4 & 3 & 2 & 1 \\ 0 & 0 & 0 & 0\end{array}$

\section{Planta Baja}

Figura 4.2: Ubicación de antenas transmisoras y receptoras en el edificio de la ETSIT de Valencia. Se presenta la planta (arriba) y el alzado principal (abajo) 
ticales se tomaron con un espaciado en altura de un centímetro. Las antenas se montaron sobre trípodes o pies de foto. La mínima altura a la que podía colocarse la antena usando tales elementos era de $53 \mathrm{~cm}$ y la máxima de $200 \mathrm{~cm}$ (figura 4.3 ). Las trazas verticales cubrían así una distancia de $147 \mathrm{~cm}$. La distancia entre el suelo y el bajotecho es de unos $292 \mathrm{~cm}$. La distancia entre el bajotecho y el forjado es de unos $95 \mathrm{~cm}$, y el espesor del forjado de unos $42 \mathrm{~cm}$. Con objeto de tomar todas las muestras de una traza sobre la misma vertical se empleó un péndulo o plomada para posicionar la antena, ya que el empleo de los pies de foto obligaba a cambiar la configuración de los mismos cada cierto número de medidas. En cada punto se realizaron tres trazas verticales con objeto de asegurar la fiabilidad del mecanismo de posicionado de las antenas y observar la posible variación temporal de las medidas.

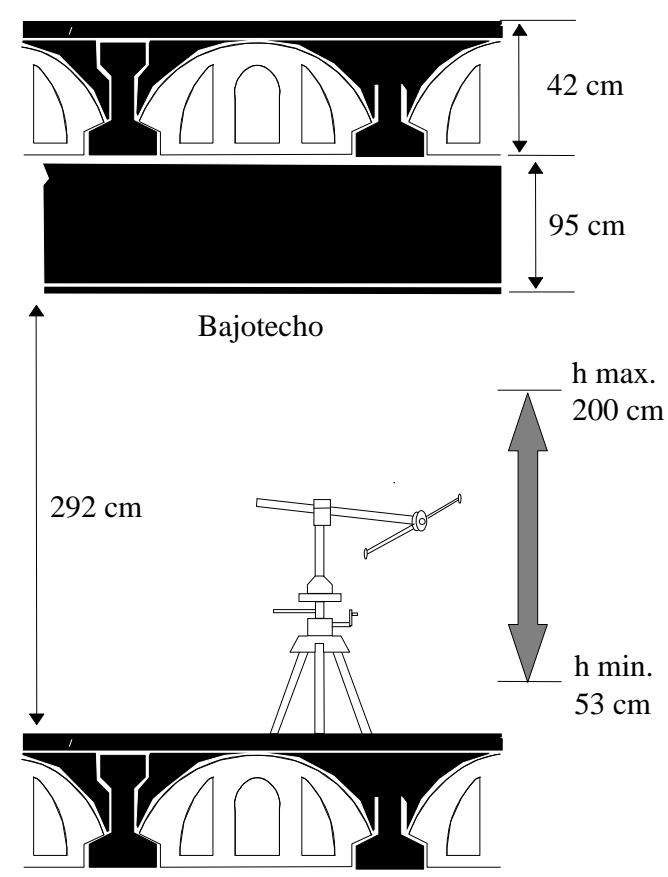

Figura 4.3: Distancias entre plantas

El procedimiento de medida consistía en detectar el máximo medido en la pantalla del analizador de espectros, promediarlo temporalmente 32 veces (proceso que requería 6 segundos, aproximadamente) y almacenar este promedio. La señal así almacenada, era pues, la potencia recibida a la frecuencia a la que esta era máxima, y que coincidía con la frecuencia para la cual la potencia de salida del sintetizador de frecuencias era también máxima. El resto de las muestras de una misma traza se realizaban a dicha frecuencia. La máxima desviación de frecuencia permitida, respecto de $900 \mathrm{MHz}$, fue de $10 \mathrm{KHz}$. Los resultados de las medidas en cada traza vertical se almacenaban en ficheros con formato ASCII. 


\subsubsection{Análisis de las medidas en banda estrecha}

La conclusión más importante e inmediata que se obtiene de las medidas realizadas es la clara influencia en las condiciones de propagación de la posición de la antena receptora respecto al suelo. Como se puede ver en la figura 4.4, la potencia recibida sufre desvanecimientos muy acusados conforme se desplaza la antena en altura a lo largo de una traza vertical.

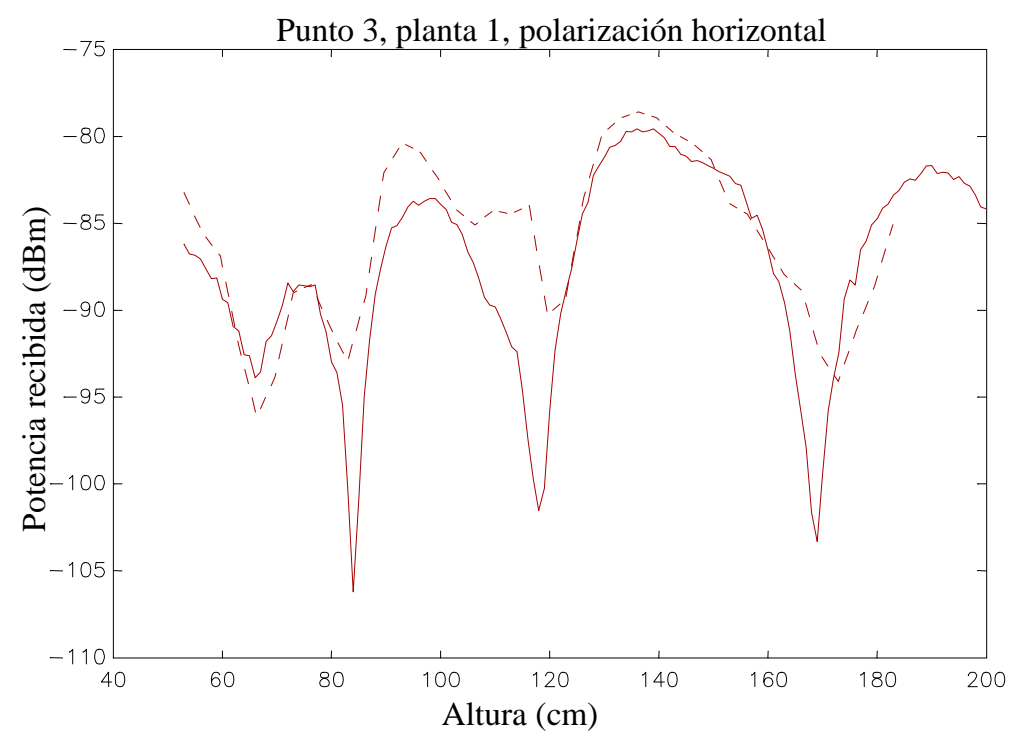

Figura 4.4: Ejemplos de medidas donde se aprecian desvanecimientos profundos

Este primer resultado implica que los tradicionales modelos empíricos de predicción de pérdidas de propagación, como los vistos en la sección 3.3.1, que no tienen en cuenta dicha posición relativa, resultan incompletos para aplicaciones en las que se exija un conocimiento más exacto de las condiciones de propagación en el interior de edificios.

Por otra parte, esta dependencia de la potencia recibida con la altura de la antena receptora, puede ser el factor fundamental a la hora de explicar la gran variabilidad que presentan de unas campañas de medidas a otras los distintos parámetros de tales modelos.

Este fading en altura, resultado del multi-camino, es relativamente rápido. Así, en las primeras medidas, en las que se tomaron muestras en altura cada $\lambda / 10(\simeq 3.33 \mathrm{~cm})$ no pudo ser observado de forma clara. Fue necesario muestrear cada centímetro para observarlo con mayor nitidez. Así, en la anterior figura 4.4, se representa con trazo discontinuo una medida realizada con muestras cada $\lambda / 10$, mientras que con trazo continuo se representa una medida en el mismo punto con muestras cada centímetro. Se observa en esta última representación que, en distancias inferiores a $10 \mathrm{~cm}(\lambda / 2=16.6 \mathrm{~cm})$, se producen desvanecimientos próximos a $15 \mathrm{~dB}$.

Parte de las medidas se realizó en un ambiente que podríamos calificar como cuasiestacionario, ya que se desarrolló en periodo vacacional, mientras que otra parte de las mismas se recogió bajo un normal devenir de personas en el edificio. Este trasiego de gente por los pasillos del edificio obstaculiza de forma más o menos intermitente los posibles caminos 
de propagación, dando lugar a un fading rápido superpuesto a la señal recibida. Puede observarse el efecto de la presencia de personas moviéndose en el entorno por comparación entre dos medidas realizadas en el mismo punto: en un ambiente cuasiestacionario (figura 4.6), y con movimiento de personas en el entorno (figura 4.5).

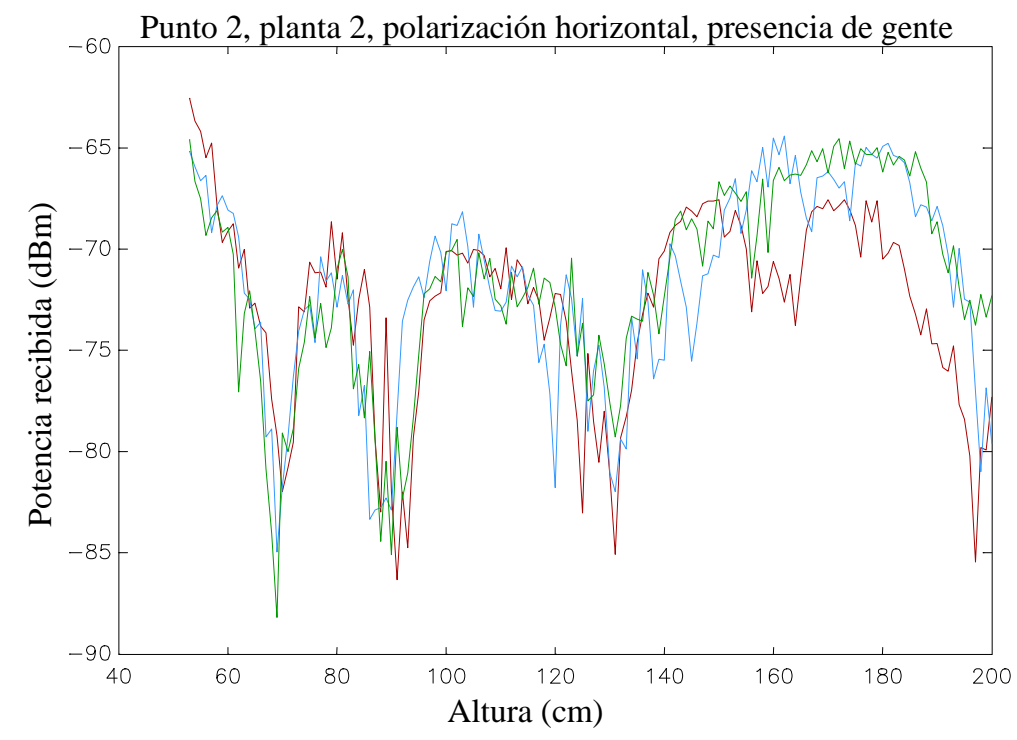

Figura 4.5: Ejemplo de medidas con presencia de personas circulando por el entorno

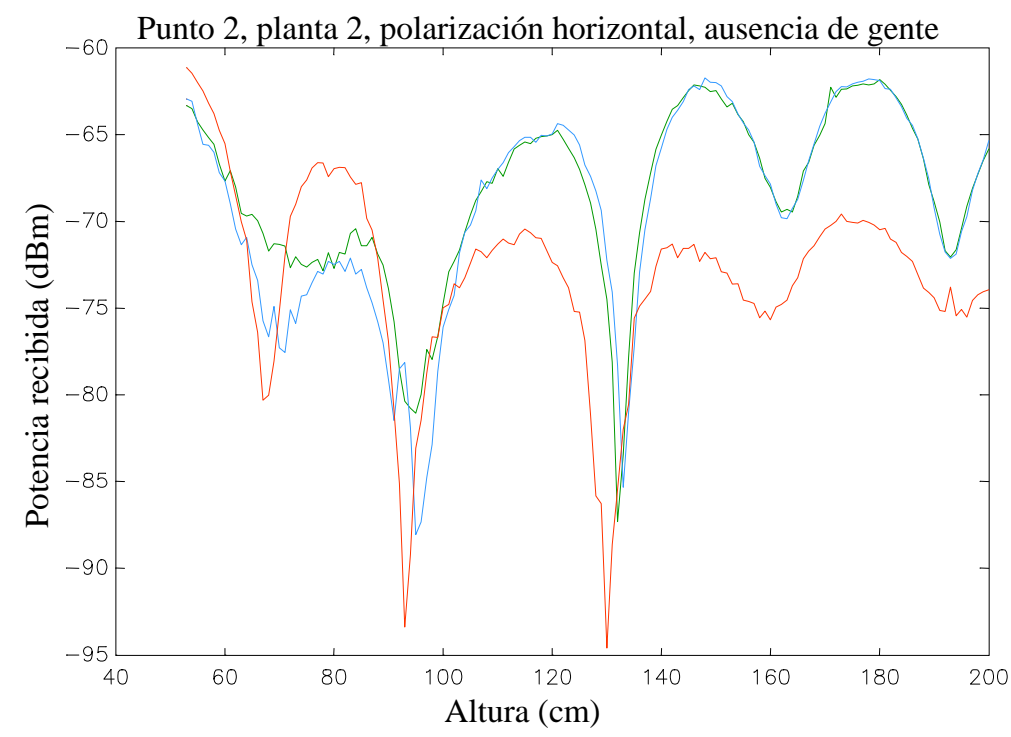

Figura 4.6: Mismo ejemplo que figura 4.5, pero sin presencia de personas en el entorno

Se puede observar que este fading rápido debido al movimiento de personas en el entorno, enmascara en parte las variaciones de la señal recibida que son debidas al multicamino.

Otro hecho muy importante que se observa en las medidas realizadas, es que este fading multi-camino es mucho más acusado con polarización horizontal que con vertical. 
Así, la figura 4.7 corresponde a ejemplos de medidas en polarización horizontal, mientras la figura 4.8 se corresponde con medidas en los mismos puntos, pero con polarización vertical.
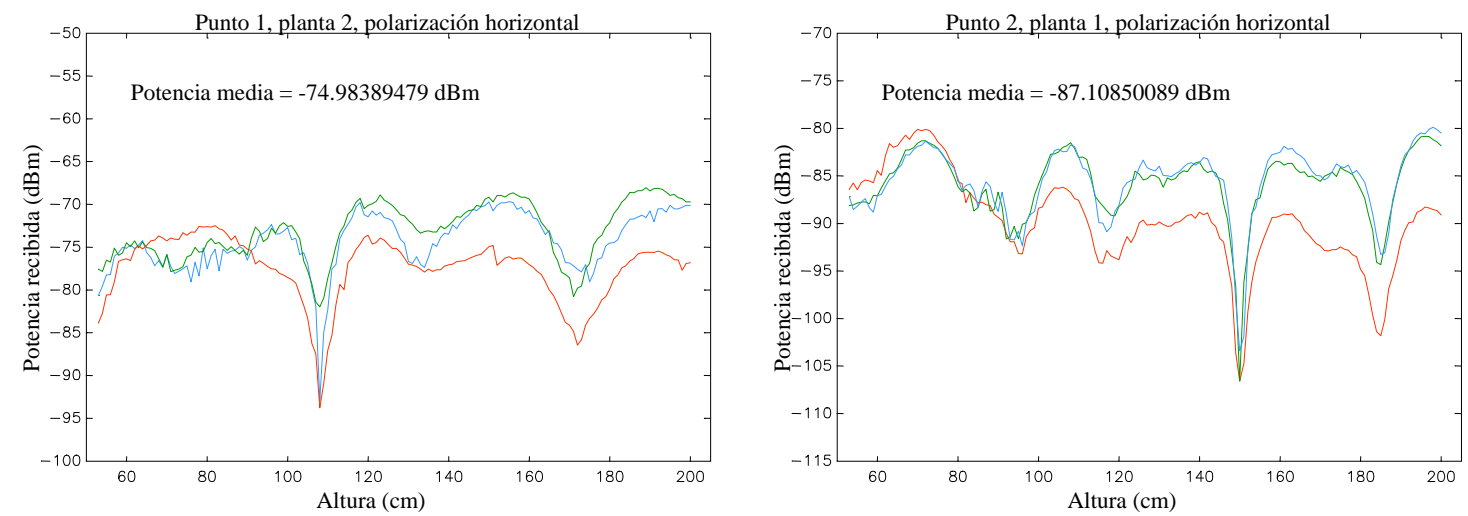

Figura 4.7: Medidas en polarización horizontal
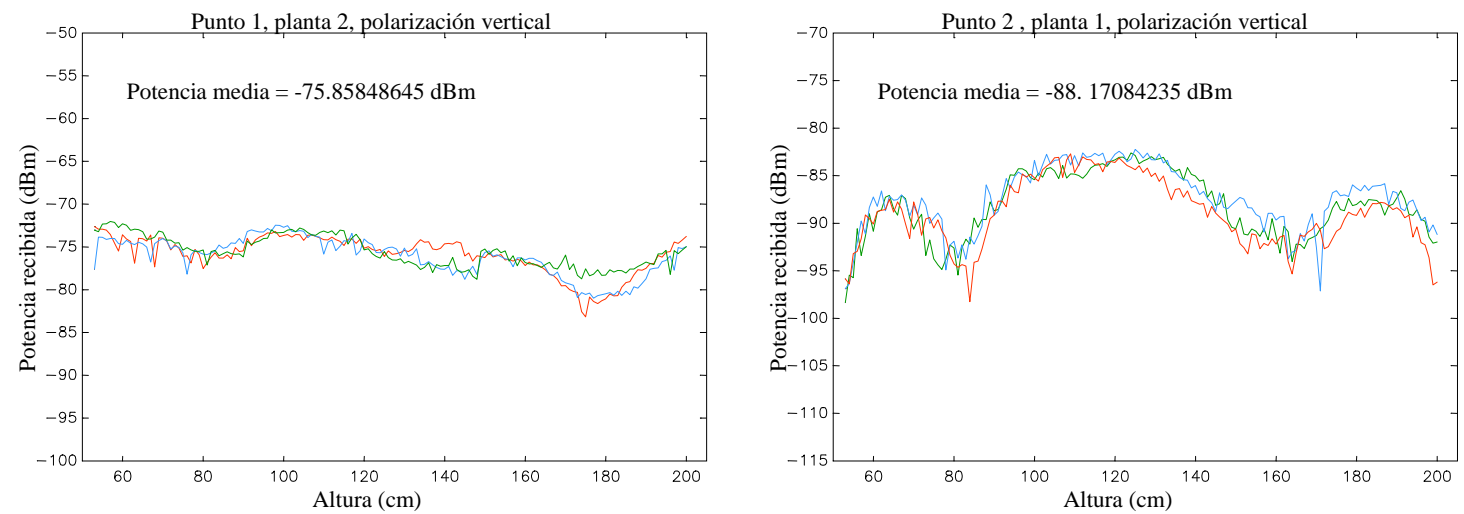

Figura 4.8: Medidas en polarización vertical

Este fenómeno hace pensar que dichos desvanecimientos profundos deben estar provocados por el efecto multi-camino debido a múltiples reflexiones en suelos y techos, y no tanto en las paredes laterales, ya sean interiores o exteriores. Esto, en cierta medida, puede explicarse teniendo en cuenta los diagramas de radiación de las antenas utilizadas, dipolos en $\lambda / 2$.

Así, en polarización horizontal, gran parte de la potencia radiada se propagará hacia plantas inferiores y superiores, tras atravesar suelos y techos respectivamente, mientras que sólo una pequeña parte de la potencia total radiada, dará lugar a procesos de reflexión en las paredes laterales. Además, el dipolo receptor posee una mayor capacidad para captar los rayos reflejados en suelos y techos, que los procedentes de las paredes laterales.

Por el contrario, en polarización vertical, la mayor parte de la potencia quedará confinada en la misma planta en la que se encuentre la antena transmisora, produciéndose las reflexiones en las paredes. Sólo una pequeña porción de la potencia total radiada se propagará hacia otras plantas del edificio a través del suelo y el techo. La casi ausencia de desvanecimientos profundos con esta polarización, indica que la contribución de los 

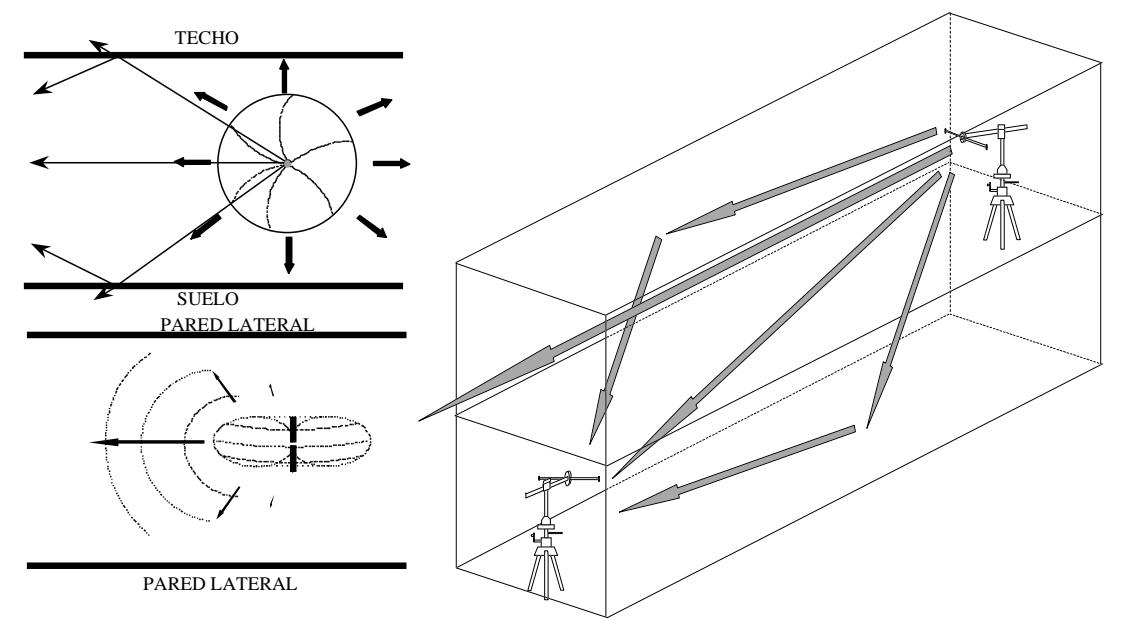

Figura 4.9: Esquema básico de propagación para transmisión en polarización horizontal

rayos reflejados en las paredes laterales debe ser escasa en la propagación entre plantas, en comparación con la potencia total recibida.

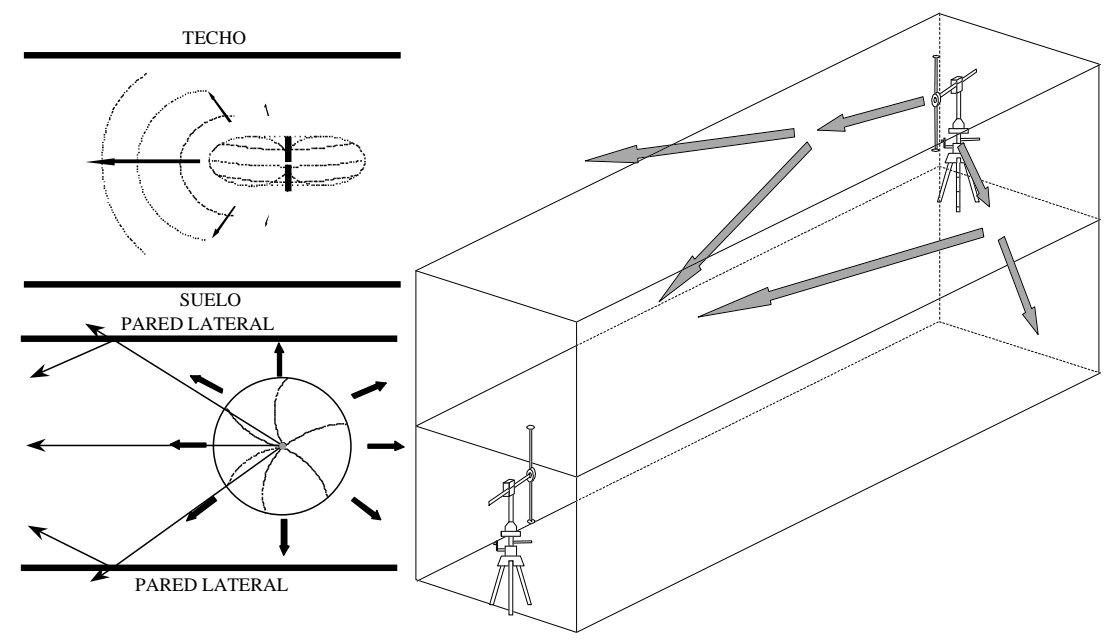

Figura 4.10: Esquema básico de propagación para transmisión en polarización vertical

Por otro lado, en polarización horizontal, el fading presenta, en la mayoría de los puntos, cierta periodicidad, que no es posible asociar con un valor constante relativo a la longitud de onda de trabajo. Como puede observarse claramente en la figura 4.11, nulos espaciados en distancias próximas a $\lambda$, se intercalan con otros a distancias menores. 

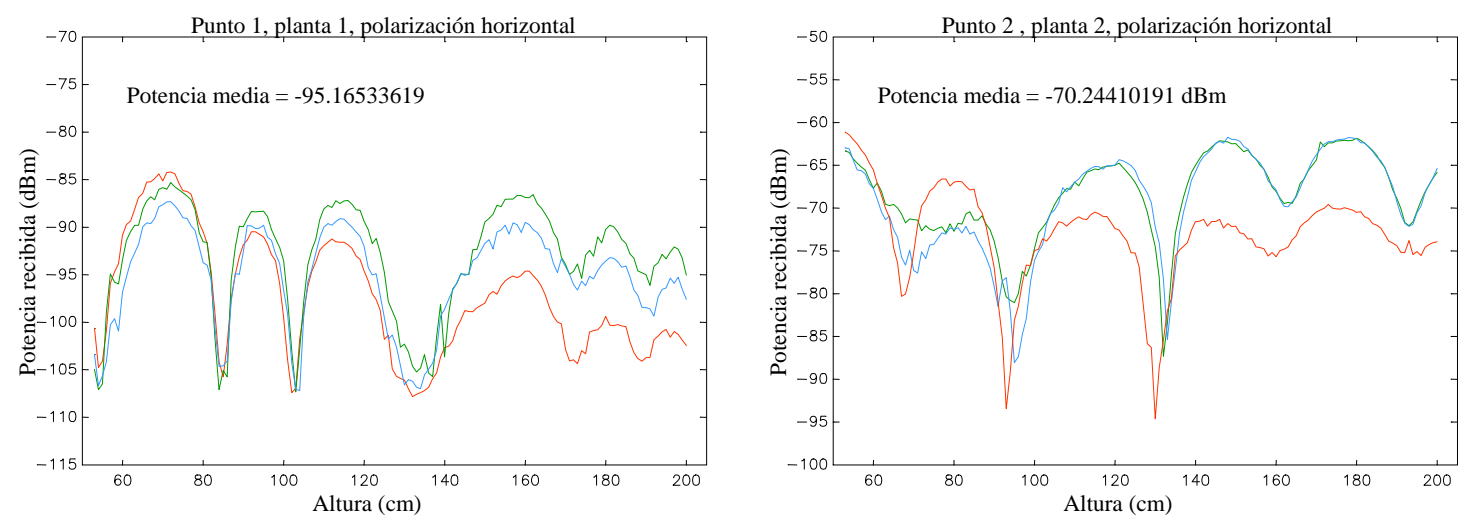

Figura 4.11: Periodicidad del fading respecto a la altura

\section{Obtención de parámetros de modelos empíricos a partir de las medidas}

Dejando aparte este comportamiento peculiar de la propagación entre múltiples plantas, se presenta a continuación el análisis, mediante algunos modelos clásicos de predicción de pérdidas, de las medidas recogidas, cuyos resultados se presentan resumidos en la tabla 4.3.

\begin{tabular}{|c|c|c|c|c|}
\hline \multicolumn{2}{|c|}{} & $\begin{array}{c}\text { Modelo } \\
\text { Exponencial }\end{array}$ & \multicolumn{2}{c|}{$\begin{array}{c}\text { Modelo de } \\
\text { Motley \& Keenan }\end{array}$} \\
\hline Polarización & Entorno & $n$ & $L_{0}$ & $L_{\mathrm{f}}$ \\
\hline Horizontal & Pasillo principal & 4.0581 & 3.4194 & 19.2346 \\
& Pasillo despachos & 4.2655 & 11.8641 & 12.6206 \\
& Ambos pasillos & 4.1329 & 7.0385 & 16.4001 \\
\hline Vertical & Pasillo principal & 4.2058 & 11.3703 & 15.0829 \\
& Pasillo despachos & 4.0868 & 1.6887 & 16.9092 \\
& Ambos pasillos & 4.1629 & 7.2210 & 15.8656 \\
\hline Ambas & Ambos pasillos & 4.1479 & 7.1298 & 16.1328 \\
\hline
\end{tabular}

Tabla 4.3: Parámetros de modelos de predicción de pérdidas

Los valores mostrados en la tabla 4.3, se han obtenido mediante regresión lineal, a partir de la potencia de la señal recibida. A pesar de que el número de medidas consideradas no es muy elevado, (42 trazas en total, en 14 puntos diferentes, para cada polarización), y que se realizaron siempre en dos entornos de pasillos (eso sí, uno mucho más amplio que el otro), es posible hallar en la literatura valores acordes con los aquí encontrados.

Recordando el modelo exponencial 1SM propuesto por el COST 231, visto en (3.2), y considerando la distancia de referencia $d_{0}$ igual a un metro, la expresión de sus pérdidas medias en $\mathrm{dB}$, en función de la distancia, queda de la siguiente forma:

$$
\bar{L}=L_{0}+10 n \log _{10} d
$$

en la que $L_{0}$ representa las pérdidas de propagación en espacio libre a la distancia de un metro, y $n$ es el exponente de pérdidas.

Los valores obtenidos de $n$ están ligeramente por encima de 4 . Un exponente mayor 
de 2, como en este caso, implica pérdidas mayores a las que se producen en espacio libre. Valores de $n$ de 4.33 se han referenciado en [Sei92], dentro de edificios de oficinas.

El modelo de Motley y Keenan, cuya expresión se vio en (3.4), se simplifica notablemente cuando no se atraviesan paredes y existe un solo tipo de suelo, condiciones bajo las que se realizaron las medidas, quedando entonces como:

$$
\bar{L}=L_{\mathrm{fs}}(d)+L_{\mathrm{ap}}+L_{0}+k_{\mathrm{f}} L_{\mathrm{f}}
$$

donde $L_{0}$ es un coeficiente que corresponde al exceso de pérdidas que no se deben a atenuación en espacio libre ni a las que producen suelos o paredes. A este exceso de pérdidas contribuyen, por ejemplo, las pérdidas ocasionadas por scattering en elementos de suelos y techos, o las pérdidas por difracción. $L_{\mathrm{f}}$ es el coeficiente de pérdidas por suelos. Como puede verse en la tabla 4.3, los valores obtenidos a través de todo el conjunto de medidas en ambas polarizaciones están en torno a $16 \mathrm{~dB}$ para $L_{\mathrm{f}}$, y en torno a $7 \mathrm{~dB}$ para $L_{0}$. Para suelos del mismo tipo a los existentes en el edificio de la ETSIT (encofrado de bovedillas y viguetas), se han encontrado valores de $L_{\mathrm{f}}$ entre $13 \mathrm{~dB}$ y $25 \mathrm{~dB}$ y de $L_{0}$ entre 5 y 18dB [Läh94]. También se han referido valores para $L_{\mathrm{f}}$ de $13 \mathrm{~dB}$ en [Hon92].

Finalmente, es interesante observar los valores de $L_{\mathrm{f}}$ obtenidos. En polarización horizontal, existe una diferencia próxima a $7 \mathrm{~dB}$ entre los valores de $L_{\mathrm{f}}$ hallados para el pasillo principal (19.23dB) y para el pasillo de despachos (12.62dB). Sin embargo, en polarización vertical esta diferencia es menor de $2 \mathrm{~dB}$. Este hecho puede explicarse teniendo en cuenta la mayor importancia que ha demostrado poseer el fading multi-camino con polarización horizontal en la propagación entre plantas.

\subsection{Medidas en banda ancha}

A la vista de los resultados obtenidos y las conclusiones a las que se llegaron con las medidas en banda estrecha, se decidió la realización de una nueva campaña de medidas, pero esta vez en banda ancha, en las mismas ubicaciones anteriores.

El propósito fundamental era el de proceder a realizar un análisis más exhaustivo del fenómeno de propagación multi-camino en el interior del edificio a considerar. Es bien sabido que un conocimiento de las funciones de Bello [Bel63] permite realizar este análisis con cierta comodidad. Estas funciones pueden ser estimadas, como ya se comentó en la sección 2.3.1, a partir del muestreo (temporal o espacial) de la función de transferencia cronovariable, o de la función de ensanchamiento Doppler a la salida, asumiendo, eso sí, que el canal tiene un comportamiento WSUSS.

En esta sección se procederá a describir el sistema de medida, así como a analizar los resultados más importantes que se obtuvieron.

\subsubsection{Descripción del sistema de medida en banda ancha}

En esta sección se describirá el sistema de medida empleado en la realización de las medidas de banda ancha que, de forma esquemática, se puede contemplar en la figura 4.12. 


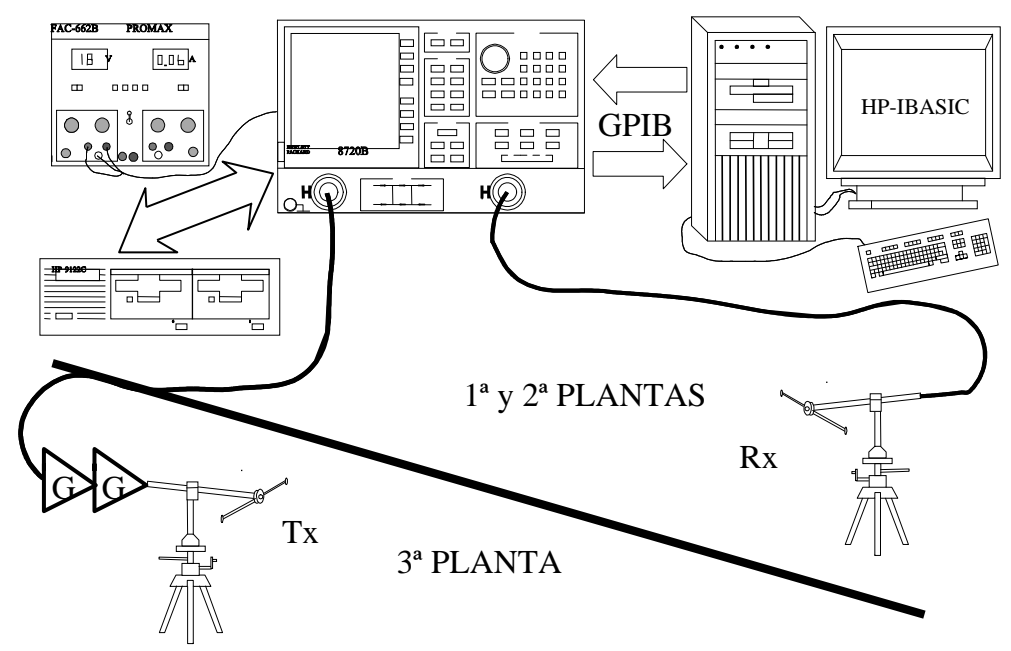

Figura 4.12: Esquema del sistema de medida empleado en banda ancha

Se trata de un sistema basado en la medida de la respuesta en frecuencia del canal, mediante el uso de un analizador de redes. Este equipo nos permite medir el parámetro de scattering $S_{21}$ del canal, es decir, su ganancia de tensión o función de transferencia en frecuencia, para posteriormente, mediante las transformaciones de Fourier vistas con anterioridad en esta Tesis, calcular funciones de respuesta impulsional, Perfiles de potencia-retardo (PDP), o funciones de scattering. Las principales limitaciones de este método son:

- Los cables de los puertos transmisor y receptor limitan la movilidad del sistema, por lo que no es posible realizar medidas en movimiento. Esto restringe los desplazamientos Doppler observables, y obliga a tomar un gran número de muestras espaciales, con pequeños desplazamientos respecto a $\lambda$, para conseguir una buena resolución en frecuencia Doppler. Además, los cables añaden pérdidas que es necesario compensar mediante amplificadores cuando, como en este caso, la potencia de señal entregada por el analizador de redes, es insuficiente para conseguir un margen dinámico adecuado.

- Es un método válido para la caracterización de canales indoor, pero imposible de aplicar en ambientes exteriores, tales como entornos urbanos o suburbanos.

Ahora bien, se trata de equipos que suelen estar entre la instrumentación de laboratorio, por lo que se elimina la necesidad de implementar un sistema específico para la realización de las medidas, con las consiguientes ventajas en tiempo y dinero. La disponibilidad de tal instrumentación determinó, de manera fundamental, la elección del sistema de medida.

A continuación se describen los distintos componentes del sistema utilizado (figura 4.12):

Antenas. La falta de disponibilidad de antenas de banda ancha, tales como dipolos 
bicónicos o dipolos gordos, obligó a que fueran empleados el mismo conjunto de antenas usado en el desarrollo de las medidas de banda estrecha, adaptando su longitud para que trabajasen en resonancia a la frecuencia de $900 \mathrm{MHz}$, es decir, la frecuencia central del ancho de banda cubierto: de $800 \mathrm{MHz}$ a $1 \mathrm{GHz}$.

Aun no siendo las antenas más adecuadas, pueden usarse válidamente en el ancho de banda de $200 \mathrm{MHz}$ elegido. Así lo indica, por un lado, la variación menor de $1 \mathrm{~dB}$ de su ganancia máxima en dicho ancho de banda, y, por otro, la relación de aspecto de los dipolos:

$$
\frac{H}{2 a}=16.6
$$

donde $H$ es la longitud de uno de los brazos del dipolo $(\lambda / 4$ para la frecuencia a la que el dipolo es resonante), y $a$ es el radio del dipolo, que para las antenas empleadas toma el valor de $0.25 \mathrm{~cm}$. Así, a $900 \mathrm{MHz}$, la relación de aspecto de los dipolos es menor que 20, por lo que se puede considerar que la antena posee un ancho de banda suficientemente grande [Bal82].

Otro aspecto de las antenas utilizadas a tener en cuenta, es la longitud del balun, $48.5 \mathrm{~cm}$. Las medidas recogidas se corrigieron para compensar el retardo producido por la propagación a lo largo de los baluns de las antenas transmisora y receptora. No corregir este efecto provocaría errores en el retardo absoluto medido, y en el cálculo de los ángulos de llegada (variación de fase).

Amplificadores. La limitada potencia de salida del analizador de redes empleado (unos $-10 \mathrm{dBm}$ ), la atenuación provocada por el cable del puerto transmisor, y la fuerte atenuación debida a la propia propagación entre plantas (objeto de estudio), hacían necesario amplificar la señal de salida del analizador de redes, antes de transmitirla. Se disponía para ello, en principio, de un amplificador de línea cuyas características se muestran en la tabla 4.4 .

\begin{tabular}{|l|c|}
\hline Margen de frecuencia de utilización & 950 a $1750 \mathrm{MHz}$ \\
Ganancia & $21 \pm 2 \mathrm{~dB}$ \\
Pérdidas de retorno a la entrada & $\geq 10 \mathrm{~dB}$ \\
Pérdidas de retorno a la salida & $\geq 8 \mathrm{~dB}$ \\
Figura de ruido & $<4 \mathrm{~dB}$ \\
Alimentación & $18 \pm 2 \mathrm{Vcc}$ \\
Consumo & $30 \mathrm{~mA}$ \\
Impedancia característica & $50 \Omega$ \\
Conectores & BNC hembra \\
\hline
\end{tabular}

Tabla 4.4: Características técnicas del amplificador de línea Televés SAT-90, utilizado en las medidas

Sin embargo, los $21 \mathrm{~dB}$ de ganancia del amplificador, no eran suficientes para contrarrestar las pérdidas totales del sistema, por lo que se utilizaron dos amplificadores colocados en cascada al final del cable del puerto transmisor, y justo a la entrada de la antena transmisora, localización elegida para garantizar su funcionamiento lineal, evitando la saturación. Se comprobó que la saturación de los amplificadores aparecía al inyectarle señales cuya potencia sobrepasaba los $-20 \mathrm{dBm}$, por lo que se ajustó 
la potencia de salida del analizador de redes para que, contando con la atenuación de los cables del puerto transmisor, no se superase dicho valor a la entrada de ninguno de los amplificadores. La figura 4.13 muestra el comportamiento de los dos amplificadores dispuestos en cascada.
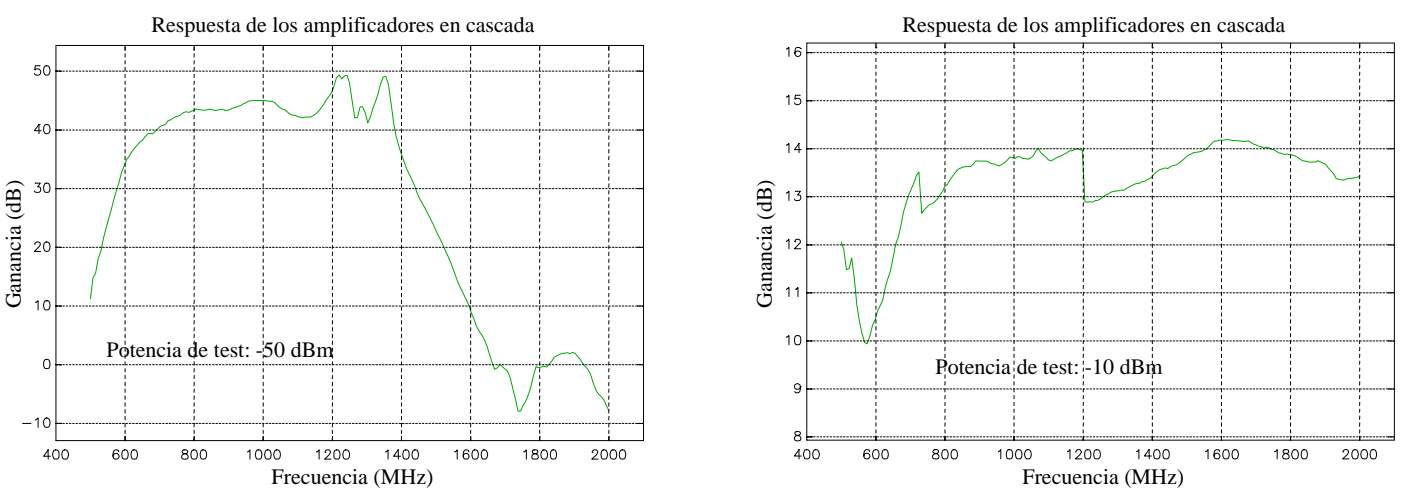

Figura 4.13: Amplificadores SAT-90 en cascada. (a) Funcionamiento lineal. (b) Funcionamiento en saturación

Cables. En los sistemas de sondeo basados en amplificadores de redes, la longitud de los cables empleados determina la cobertura máxima del canal que podrá ser caracterizada. Justo a la salida de los dos puertos del analizador de redes, se dispuso un tramo de cable coaxial HP 85131-60012 con conectores APC de 3.5mm, cuya atenuación es prácticamente despreciable (del orden de décimas de $\mathrm{dB}$ ). Al final de estos tramos de coaxial existen sendas transiciones de APC 3.5mm a SMA. A continuación se conectaron, en ambos accesos, tramos de cable coaxial RG 223/U (0.35m en transmisión y $3.22 \mathrm{~m}$ en recepción), cuya finalidad primordial era evitar la torsión o estiramiento de los coaxiales HP 85131-60012.

En el puerto transmisor se conectó un cable RG 213/U de 41.70m de longitud, al que se añadió un tramo de cable RG $214 / \mathrm{U}$ de $9.97 \mathrm{~m}$ mediante una transición $\mathrm{N}$ hembra-hembra. Así pues, la longitud total de los cables empleados en transmisión era de 51m. En recepción, tras el tramo de cable RG 223/U, se dispuso un tramo de $3.05 \mathrm{~m}$ de cable RG 214/U. La longitud total de los cables empleado en recepción fue de $6.27 \mathrm{~m}$. Con tales cables, fue posible alcanzar los puntos $2,3,4, \mathrm{~A}, \mathrm{~B}$ y C de la segunda planta y los puntos 3 y 4 de la primera (figura 4.2 ).

La impedancia característica de todos los cables empleados era de $50 \Omega$, con lo que se aseguraba la adaptación con los amplificadores y las antenas, así como entre los distintos tramos de cable. En la figura 4.14 se muestra la función de transferencia total de cables y amplificadores.

Analizador de redes HP 8720B. Se trata de un equipo destinado al estudio de redes de dos accesos. Permite la medida de parámetros de admitancia, e impedancia, así como de los parámetros de scattering. Para las medidas que aquí se presentan, el interés se centraba en la variación con la frecuencia del parámetro $S_{21}$, es decir, la función de transferencia en frecuencia.

La potencia máxima de salida que otorga el analizador de redes es de $-10 \mathrm{dBm}$, por lo que, en principio, no es un equipo ideal para su utilización en medidas de sistemas 


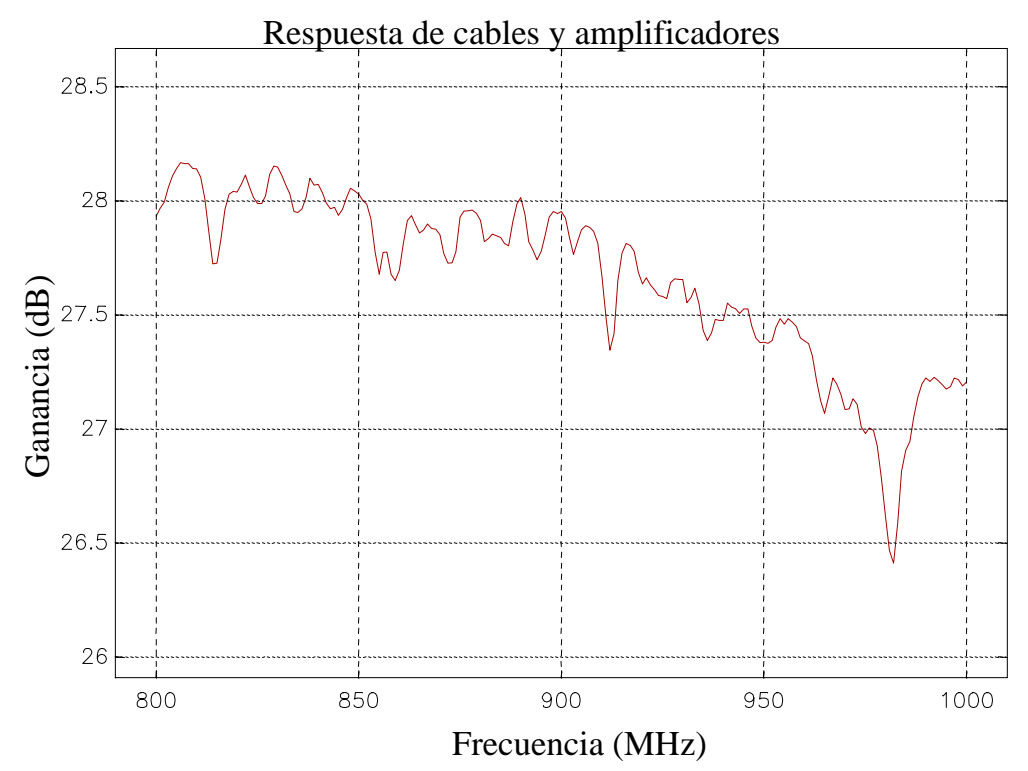

Figura 4.14: Respuesta en frecuencia de los cables y amplificadores del puerto transmisor

con grandes pérdidas, como es el canal radio. Como se acaba de comentar, este problema de escasa potencia, se salvó con el uso de los amplificadores.

\begin{tabular}{|l|c|}
\hline Margen de frecuencias & $130 \mathrm{MHz}$ a $20 \mathrm{GHz}$ \\
Resolución en frecuencia & $1 \mathrm{~Hz}$ \\
Potencia de salida & $-10 \mathrm{a}-65 \mathrm{dBm}$ en pasos de $5 \mathrm{~dB}$ \\
& (en ambos canales) \\
Potencia máxima a la entrada & $22 \mathrm{dBm}$ (en ambos canales) \\
Conectores de los puertos & APC $3.5 \mathrm{~mm}$ \\
Impedancia de los puertos & $50 \Omega$ \\
\hline
\end{tabular}

Tabla 4.5: Analizador de redes HP 8720B. Características principales

El equipo puede controlarse a través de un PC mediante el bus GPIB. Los programas de control se realizan en el lenguaje HP-IBASIC. A diferencia del analizador de radiocomunicaciones, el analizador de redes no puede ejecutar los programas, sino que estos han de ejecutarse en un PC mediante el editor de IBASIC. El HP 8720B puede, sin embargo, funcionar como máster del bus, para controlar impresoras, plotters o disqueteras. El equipo permite la alimentación de dispositivos activos conectados en sus accesos, gracias a la existencia de un conector BNC hembra, por cada puerto de test, situado en el panel posterior del equipo. Estos puertos de alimentación admiten tensiones DC de entrada de hasta 40V y corrientes de hasta $500 \mathrm{~mA}$. En este acceso se conectó la fuente de alimentación, empleada para alimentar los amplificadores de línea.

El analizador de redes dispone de tres formas de reducir el ruido, aunque sólo dos de ellas afectan realmente a las medidas; la tercera es, simplemente, un filtrado de vídeo que 
sólo afecta a la presentación en pantalla. La primera forma de reducir el ruido es mediante la especificación del ancho de banda de frecuencia intermedia, con lo que se elimina el ruido que queda fuera de la banda especificada. Durante la realización de las medidas, el ancho de banda de frecuencia intermedia se fijó en $3 \mathrm{KHz}$. La segunda técnica para reducir el ruido, es la realización de promediados de los parámetros medidos. Cada vez que se dobla el factor de promediado se reduce el ruido en 3dB. Para maximizar el margen dinámico, en medidas de transmisión, se recomienda utilizar factores de promediado superiores a 16 . El factor de promediado elegido fue 32 . No se emplearon factores de promediado mayores, ya que elevaban notablemente el tiempo necesario para la toma de las muestras y, por contra, no mostraban una reducción de ruido apreciable. En resumen, el margen dinámico máximo que es capaz de medir el analizador, depende de:

- el tipo de medida realizada (medidas de transmisión o de reflexión),

- la frecuencia de medida,

- el tipo de conectores empleados en la calibración,

- el factor de promediado,

- el ancho de banda de frecuencia intermedia escogido, y

- la relación entre potencia transmitida y nivel de ruido del sistema.

El margen dinámico nominal del analizador de redes, para medidas en transmisión y en la banda de 0.5 a $2 \mathrm{GHz}$, es de $80 \mathrm{~dB}$. Sin embargo, varios de los anteriores parámetros, con los que se halló este valor nominal, no corresponden a los que se utilizaron en la realización de las medidas, por lo que es de esperar, que el margen dinámico real fuera ligeramente inferior. Teniendo en cuenta la atenuación de los cables, la ganancia de los amplificadores y la directividad de las antenas, el margen dinámico total del sistema se situaba en 108dB. Sin embargo, se detectó que el analizador de redes, e incluso también el PC utilizado para controlarlo, provocaba interferencias en la banda de interés, ya que la limitada longitud de los cables del puerto receptor, hacía que en algunos instantes la separación entre la antena receptora y los equipos del sistema, fuese inferior a $1 \mathrm{~m}$. Se comprobó que la amplitud de dicha interferencia era poco sensible a la polarización de la antena receptora.

El HP 8720B puede mostrar también la variación en el tiempo de los parámetros medidos, mediante la realización de transformaciones de Fourier, pudiendo seleccionarse ciertos tipos de enventanado predefinidos. Cabe así la posibilidad de medir, no la función de transferencia en frecuencia del canal indoor, sino directamente la respuesta impulsional. El proceso que sigue para ello el analizador es medición en frecuencia y posterior transformación, con lo que el tiempo de barrido se incrementa notablemente al realizar las medidas de la respuesta impulsional. El factor tiempo, que en otras ocasiones podría no ser relevante, determinó algunas de las decisiones tomadas a la hora de planear la campaña de medidas, puesto que, por un lado, interesaba realizar las medidas en cada punto en una misma sesión, pero por otro lado, los periodos en los que el canal permanecía estático eran limitados, por lo cual interesaba poder realizar el mayor número de medidas posibles, en tales espacios de tiempo. Por tanto, se decidió medir la respuesta en frecuencia del canal. 
La frecuencia central de las medidas se mantuvo en $900 \mathrm{MHz}$. El ancho de banda de RF se fijó en $200 \mathrm{MHz}$, fundamentalmente por el tipo de antenas utilizadas. Este ancho de banda permite resolver caminos cuya diferencia de retardo sea mayor de 5ns, es decir, cuyas distancias recorridas difieran en más de unos $1.5 \mathrm{~m}$. El número de puntos utilizado en cada barrido de frecuencia fue de 201, con lo que el máximo retardo observable era de $1.005 \mu \mathrm{s}$, es decir, el recorrido del camino observable más largo era de $301 \mathrm{~m}$, aproximadamente. Dadas las dimensiones del edificio, este retardo máximo se estimó suficiente. El tiempo que requería el barrido de los 201 puntos de la respuesta en frecuencia, era de $100 \mathrm{~ms}$. Existe, para cada número de muestras en frecuencia, un tiempo de barrido mínimo que no es posible rebajar, pero sí fijar a valores superiores. Las 32 medidas de la respuesta en frecuencia y su promediado requerían en torno a 6 segundos. Así, se puede asegurar que el efecto de los fluorescentes (fuente de ruido más importante a considerar, según lo apuntado en la sección 3.7.1) queda promediado, aparte del posible ruido impulsivo. El tiempo total necesario para medir y almacenar en el disco duro del PC cada muestra espacial, se situaba alrededor de los 18 segundos.

\begin{tabular}{|l|c|}
\hline Potencia entregada por el analizador & $-25 \mathrm{dBm}$ \\
Potencia transmitida & $1.5 \mathrm{dBm}$ \\
Ancho de banda de RF & $200 \mathrm{MHz}$ \\
Frecuencia central & $900 \mathrm{MHz}$ \\
Ancho de banda de FI & $3 \mathrm{KHz}$ \\
Tiempo de barrido & $100 \mathrm{~ms}$ \\
Factor de promediado & 32 \\
Muestras en frecuencia & 201 \\
\hline
\end{tabular}

Tabla 4.6: Parámetros de realización de las medidas en banda ancha

\subsubsection{Ubicación y disposición de las medidas en banda ancha}

Las medidas en banda ancha se localizaron también en los pasillos de la ETSIT, en posiciones similares a las de las medidas en banda estrecha. La antena transmisora se situó en los mismos puntos que en las medidas de banda estrecha. Por su parte, la antena receptora se desplazó describiendo tres tipos de trazas (verticales, longitudinales y transversales) en torno a las mismas posiciones que se muestrearon en las mediciones en banda estrecha. La limitación impuesta por la longitud de los cables del sistema, sólo permitió medir, como ya se ha comentado, en los puntos $2,3,4, \mathrm{~A}, \mathrm{~B}, \mathrm{y} \mathrm{C}$, de la segunda planta, y en los puntos 3 y 4 de la primera planta del edificio.

Las medidas eran estáticas, es decir, el receptor realmente no estaba en movimiento. Lo que se hizo fue simular el movimiento tomando un gran número de muestras espaciales dispuestas a lo largo de las trazas. Recuérdese que esto no supone una limitación a la hora de evaluar el efecto Doppler, ya que con lo que se trabaja es con el desplazamiento Doppler $\nu$, que es independiente de la velocidad del móvil. Puede obtenerse el desplazamiento de frecuencia Doppler $f_{d}$ multiplicando dicha unidad por la velocidad del móvil, tal y como se vio en $(2.10)$.

Las medidas se realizaron en periodos en los que el trasiego de personas en el edificio era mínimo, con objeto de que el canal permaneciese lo más estático posible. Las mues- 
tras espaciales, en todas las trazas, se tomaron cada $4 \mathrm{~cm}$ (aproximadamente $\lambda / 8$ para la frecuencia central, según se aconseja en [Der93]). Cada muestra espacial se almacenaba en un archivo distinto en formato ASCII.

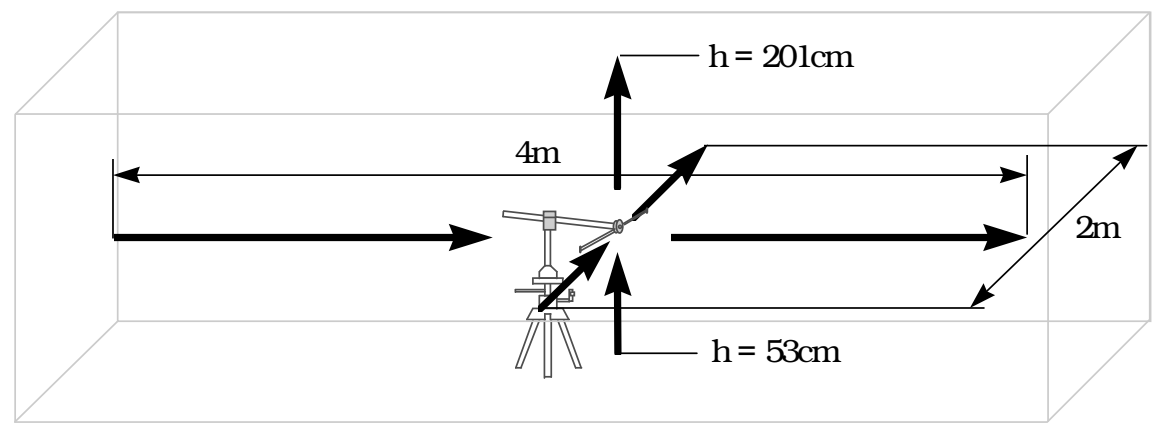

Figura 4.15: Disposición de las trazas verticales, transversales y longitudinales en los pasillos del edificio

Las trazas verticales seguían la dirección suelo a techo. Su longitud era de $148 \mathrm{~cm}$, desde los $53 \mathrm{~cm}$ sobre el suelo, hasta la altura de $201 \mathrm{~cm}$ (38 muestras espaciales). La resolución en desplazamiento Doppler que se consigue con trazas de tal longitud es de 0.225 unidades $1 / \lambda$. La trazas longitudinales seguían la dirección de los pasillos y su sentido era el de acercamiento a la antena transmisora. La dimensión de las trazas longitudinales fue de $4 \mathrm{~m}$ (101 muestras), con lo que la resolución en desplazamiento Doppler en estas trazas es de $0.083(1 / \lambda)$. Las trazas transversales seguían direcciones perpendiculares a la dirección de los pasillos y tenían una longitud de $2 \mathrm{~m}$ (51 muestras espaciales), y, por tanto, una resolución en desplazamiento Doppler de $0.166(1 / \lambda)$, salvo en el punto 3 de la segunda planta, en el que tenían $4 \mathrm{~m}$ de recorrido. En los pasillos principales, se realizaron dos (y en algunos puntos tres) trazas transversales y longitudinales, coincidiendo con máximos y mínimos de las medidas en banda estrecha, así como una traza vertical, por cada punto cubierto. En el pasillo de despachos se realizó una sola traza longitudinal y otra vertical por cada posición. La estrechez de estos pasillos no permitía la realización de trazas transversales.

La mayor parte de las medidas se tomaron en polarización horizontal, pero también se realizaron algunas en polarización vertical con objeto de contrastar resultados. Se hicieron, además, algunas medidas en situación de visión directa entre las antenas.

\section{Medidas de ángulos de llegada}

Además de los resultados típicos, tales como Perfiles de potencia-retardo o funciones de scattering, que se obtienen a partir de las funciones de transferencia, es posible mediante este tipo de medidas obtener información sobre los ángulos con los que las componentes multi-camino alcanzan la antena receptora, obteniéndolos, además, en función del retardo. Tales ángulos pueden calcularse mediante sencillas técnicas de síntesis de agrupaciones de antenas [Lo92].

Así, aprovechando las trazas verticales, ya realizadas, se sintetizaron agrupaciones 
lineales para determinar los ángulos de llegada en el plano vertical. Por otro lado, se realizaron nuevas medidas para determinar los ángulos de llegada en el plano horizontal, mediante la síntesis de agrupaciones circulares. Para ello se tomaron 9 muestras espaciales (figura 4.16), una en el centro, y las 8 restantes equiespaciadas en la circunferencia de un círculo de radio $\lambda / 3$ (unos $11 \mathrm{~cm}$ a $900 \mathrm{MHz})$.

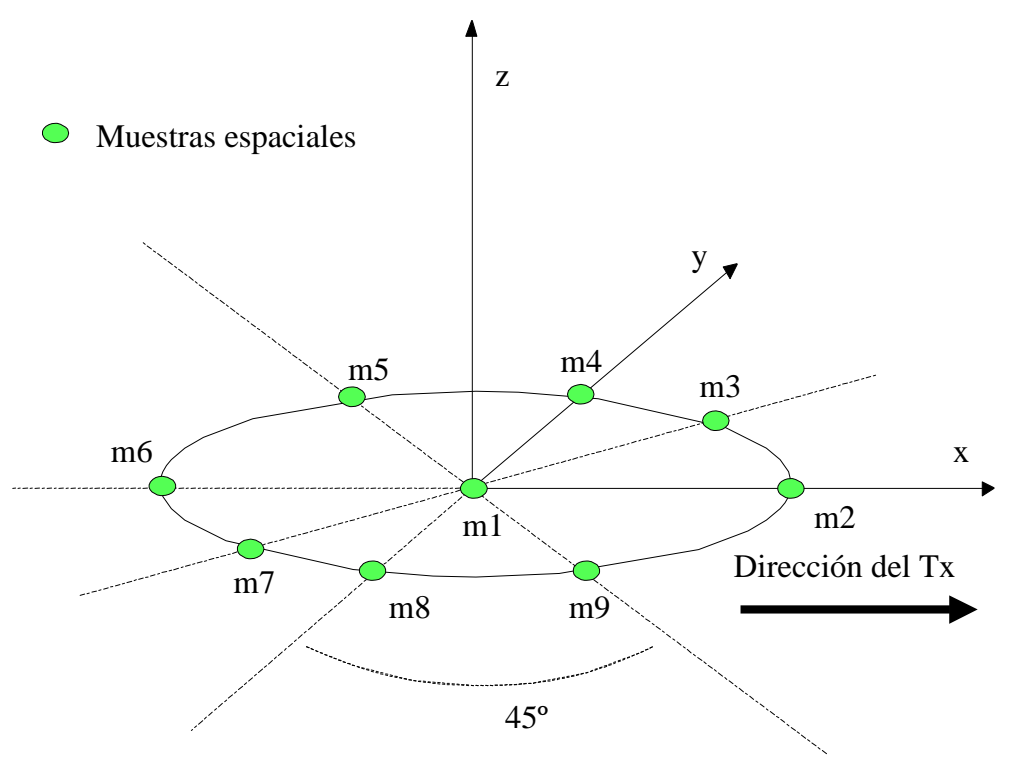

Figura 4.16: Medidas en agrupaciones circulares para determinación de ángulos de llegada en el plano horizontal

El centro del círculo se situó en los centros de las trazas transversales y longitudinales (puntos 2, 3, 4, A, B, C y puntos con visión directa), y a las mismas alturas a las que se realizaron tales trazas. Al igual que en el resto de las medidas de banda ancha, en cada posición espacial se midió y promedió la respuesta en frecuencia del canal 32 veces, almacenándola en un archivo independiente. Una vez hallada la respuesta impulsional, mediante la transformada de Fourier de las respuestas en frecuencia, es posible construir el diagrama de radiación de la agrupación circular, o lineal, utilizando los valores de tensión de las distintas posiciones espaciales como tensiones de alimentación de los radiadores, y esto por cada valor de retardo de la respuesta impulsional.

Así, considerando la agrupación circular de la figura 4.16, se puede calcular la distribución de ángulos de llegada en función del retardo $\tau$ mediante la siguiente expresión:

$$
A(\theta, \phi, \tau)=h_{1}(\tau)+\sum_{n=2}^{9} h_{n}(\tau) e^{j k r \cos (\theta) \cos \left(\phi-(n-2) \frac{\pi}{4}\right)}
$$

donde $h_{j}(\tau)$ es la respuesta impulsional en la muestra espacial m $j$ de la agrupación circular; $k$ el número de onda $(2 \pi / \lambda) ; r$ es el radio del círculo; $\theta$ es el ángulo de elevación respecto al plano que contiene a los elementos de la agrupación, y $\phi$ es el ángulo de acimut respecto a la dirección en que se encuentra el transmisor.

Por otra parte, para calcular la distribución de ángulos de llegada a partir de las agrupaciones lineales formadas por las trazas verticales, se puede utilizar la siguiente 
expresión:

$$
A(\theta, \phi, \tau)=\sum_{n=0}^{N-1} h_{n}(\tau) e^{j k n d \cos \theta}
$$

siendo $N$ el número de puntos de la agrupación lineal (38 en el caso de las trazas verticales); $h_{n}(\tau)$ la respuesta impulsional en cada punto de la traza; $k$ el número de onda; $d$ la distancia entre cada punto de la traza, y $\theta$ el ángulo de elevación respecto a la dirección de la traza.

Ejemplos significativos de los resultados obtenidos se presentarán al final de la siguiente sección.

\subsubsection{Análisis de las medidas en banda ancha}

Como se ha comentado, las medidas en banda ancha se realizaron empleando como posiciones centrales de las trazas, las mismas localizaciones en las que se midió en banda estrecha. En concreto, las trazas verticales coincidían exactamente (dejando aparte el espaciado de las muestras) con las realizadas en banda estrecha. Aprovechando esta circunstancia, se puede comprobar si a partir de medidas en banda ancha es posible calcular la variación de la potencia recibida, y consiguientemente, de las pérdidas de propagación.

Según el Teorema de Parseval, la potencia $P$ recibida en un punto puede estimarse mediante alguno de los siguientes dos modos:

$$
P=\sum_{t_{i}}\left|h\left(t_{i}\right)\right|^{2}=\sum_{f_{i}}\left|T\left(f_{i}\right)\right|^{2}
$$

donde $T\left(f_{i}\right)$ son las muestras en frecuencia de la transformada de Fourier de la respuesta impulsional, cuyas muestras temporales son $h\left(t_{i}\right)$. Por tanto, si para cada posición espacial $x$, se suman los cuadrados de los módulos de las muestras temporales de las respuestas impulsionales $h\left(x, t_{i}\right)$ (función de ensanchamiento Doppler a la salida), o bien los de las muestras frecuenciales de las respuestas en frecuencia del canal $T\left(f_{i}, x\right)$ (función de transferencia cronovariable), se obtiene la potencia recibida en dicha posición.

En la figura 4.17, la curva etiquetada como 1 corresponde a una medida en banda estrecha utilizando el sistema descrito en la sección 4.2.1. Las curvas 2 y 3 se hallaron mediante el teorema de Parseval a partir de medidas en banda ancha, sumando los cuadrados de los módulos de las respuestas impulsionales para cada posición en altura de la antena receptora. En el cálculo de la curva 2 se sumaron todas las componentes de la respuesta impulsional, mientras que para la obtención de la curva 3, sólo se sumaron aquellas componentes de la respuesta impulsional cuyo nivel era hasta $5 \mathrm{~dB}$ inferior al máximo.

Se puede observar que las curvas 2 y 3 siguen, aunque de forma más suave, la misma variación con la altura que las curvas correspondientes a medidas en banda estrecha. La curva 3, sigue de forma más clara esta variación, lo que es de esperar debido a que, en su cálculo, únicamente se tienen en cuenta las componentes de señal, mientras que en la obtención de la curva 2 se suman también muchas componentes de ruido. La diferencia de potencia media recibida que se observa entre las medidas de banda ancha y banda 


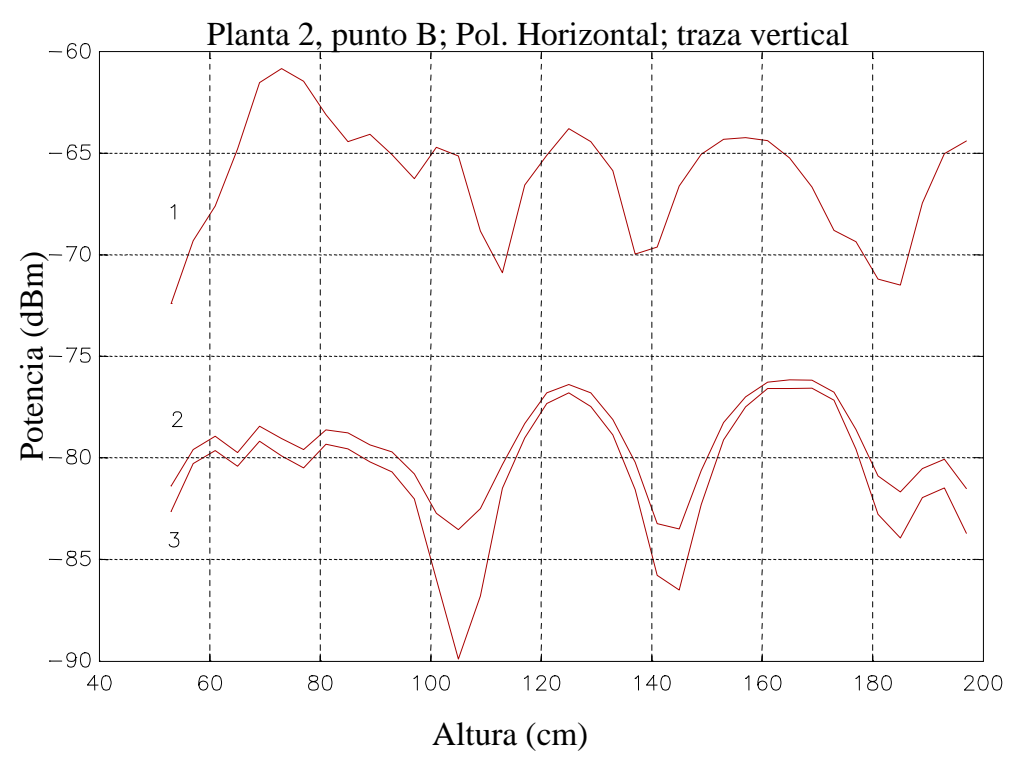

Figura 4.17: Medidas en banda estrecha (curva 1) comparadas con medidas en banda ancha utilizando el Teorema de Parseval. La curva 2 incluye todas las muestras, mientras que la 3 solamente aquellas con valor hasta $5 \mathrm{~dB}$ inferior al máximo

estrecha, es consecuencia lógica de las diferencias entre los equipos y métodos de medida empleados.

\section{Funciones de coherencia y Perfiles de potencia-retardo}

Como ya se ha apuntado, los resultados directos de las medidas eran funciones de transferencia cronovariables, $T(f, x)$. A partir de estas, se obtuvieron funciones de ensanchamiento Doppler a la salida, funciones de correlación en frecuencia (que aquí serán denominadas funciones de coherencia), Perfiles de potencia-retardo (PDP), y funciones de scattering.

Los anchos de banda de coherencia dan una idea de la selectividad en frecuencia ocasionada por el multi-camino. Las funciones de coherencia permiten, pues, estimar los anchos de banda de transmisión máximos, para los que las señales transmitidas sufrirán un desvanecimiento plano en frecuencia. El comportamiento de las funciones de coherencia está íntimamente ligado al número, amplitud y retardo de las componentes multi-camino que alcanzan el receptor. Por lo tanto, pueden establecerse relaciones entre la forma de las funciones de coherencia y la forma los Perfiles de potencia-retardo, correspondientes a una misma posición espacial.

Así, las distintas componentes del multi-camino provocan una modulación o rizado de la función de coherencia. La figura 4.18 corresponde a tres muestras espaciales de una misma traza longitudinal, realizada en una situación de visión directa o LOS (Line Of Sight). En dicha figura puede verse que la existencia de una componente, o agrupación de ellas (la resolución del sistema no permite concretarlo), que llega con un retardo próximo a los $200 \mathrm{~ns}$, provoca el rizado de la función de coherencia.

Se observa que, al aumentar la amplitud relativa al máximo del pico situado en torno a 

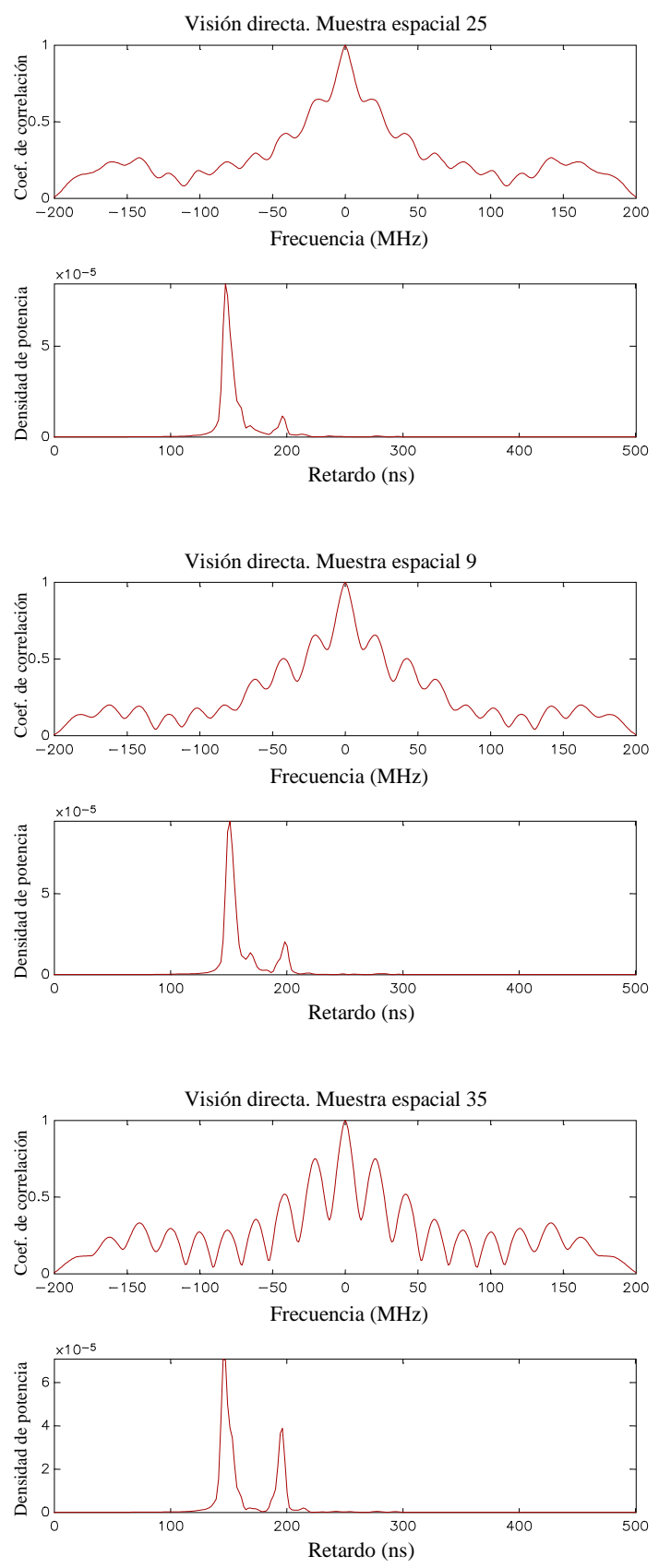

Figura 4.18: Función de coherencia y Perfil de potencia-retardo. Situaciones en visión directa con presencia de reflexión importante 
200ns, aumenta también la amplitud de la oscilación que muestra la función de coherencia. Por otro lado, la frecuencia de esta ondulación es mayor cuanto más retardada llega una componente. Así, en la figura 4.19, se observa cómo la señal que llega con un retardo alrededor de $375 \mathrm{~ns}$, provoca un rizado de gran frecuencia en la función de coherencia. Este gran pico de señal se identificó como una reflexión en un edificio próximo (edificio de la EUITI*).
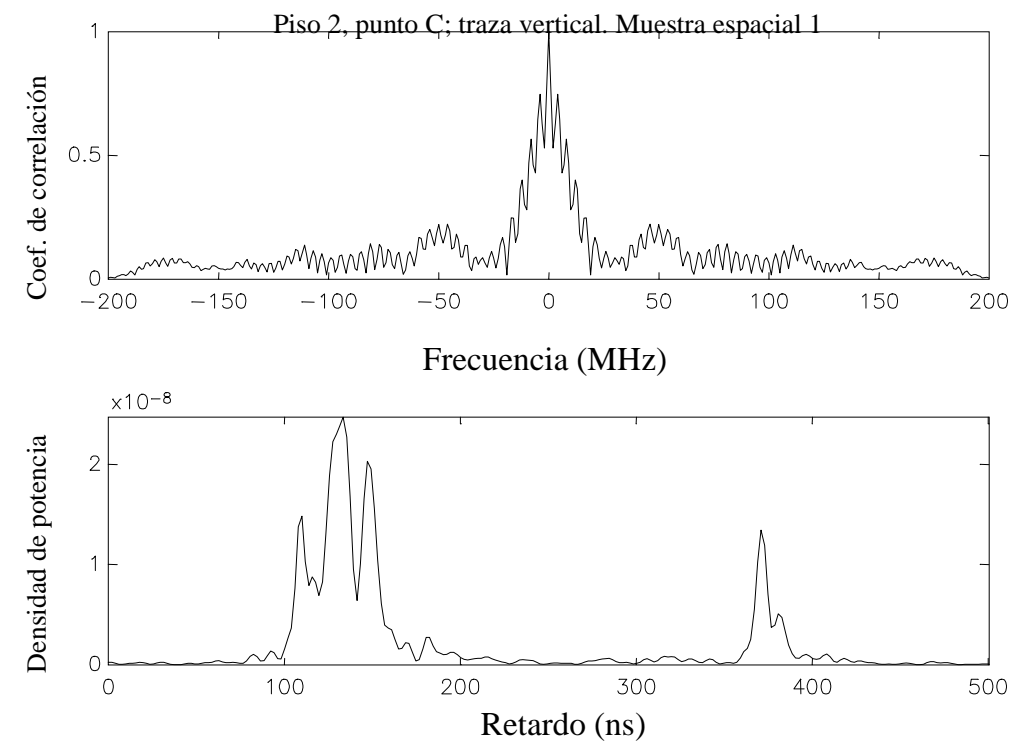

Figura 4.19: Función de coherencia y Perfil de potencia-retardo. Situación sin visibilidad directa, con presencia de fuerte reflexión lejana

Es interesante comprobar que en la función de coherencia de la figura 4.19, el ancho de banda de coherencia a $-3 \mathrm{~dB}$ (coeficiente de correlación 0.5 ) es mayor que el ancho de banda hasta el primer mínimo. Este mínimo tan cercano indica una fuerte descorrelación que, sin embargo, no alcanza el valor de 0.5. En estos casos, considerar el ancho de banda de coherencia como el calculado a $-3 \mathrm{~dB}$ es una suposición demasiado optimista [Baj82], y debería considerarse en su lugar el ancho de banda hasta el primer mínimo.

En resumen, cuanto mayor es el número de componentes multi-camino, y mayor su amplitud y su exceso de retardo respecto a la primera componente recibida, menor será el ancho de banda de coherencia.

A partir de las funciones de coherencia halladas, se calcularon los anchos de banda de coherencia. La tabla 4.7 muestra los valores medios, junto con los máximos y mínimos, para cada tipo de traza. Al elaborar la dicha tabla, sólo se han considerado las trazas verticales y longitudinales realizadas en la segunda planta del edificio, así como las medidas con visión directa. La relación señal a ruido en las trazas transversales y en las medidas de la primera planta apenas alcanzaba, en el mejor de los casos, los $15 \mathrm{~dB}$, y en alguno de ellos, estaba por debajo incluso de los $10 \mathrm{~dB}$, por lo que no se han tenido en cuenta al

${ }^{*}$ Escuela Universitaria de Ingenieros Técnicos Industriales de Valencia, situada en las proximidades de la ETSIT 
hallar estos promedios.

\begin{tabular}{|l|c|c|c|c|c|c|}
\hline Trazas & \multicolumn{2}{|c|}{ Máximo } & \multicolumn{2}{c|}{ Mínimo } & \multicolumn{2}{c|}{ Media } \\
& $r=0.5$ & $r=0.25$ & $r=0.5$ & $r=0.25$ & $r=0.5$ & $r=0.25$ \\
\hline \hline Verticales & 16.65 & 51.28 & 7.28 & 21.94 & 11.18 & 33.16 \\
\hline Longitudinales & 16.57 & 40.26 & 6.37 & 16.37 & 10.08 & 24.87 \\
\hline Visión directa & 69.49 & 142.75 & 16.41 & 47.87 & 32.58 & 79.24 \\
\hline
\end{tabular}

Tabla 4.7: Anchos de banda de coherencia a $-3 \mathrm{~dB}(r=0.5)$ y a $-6 \mathrm{~dB}(r=0.25)$. Tabla resumen

Puede observarse en la tabla 4.7 que las trazas verticales y longitudinales tienen anchos de banda de coherencia pequeños (y muy similares), mientras que las trazas con visión directa muestran anchos de banda de coherencia mucho mayores (como era de esperar).

También se pudo observar (tabla 4.8) que, en la transmisión entre plantas, los anchos de banda de coherencia a $-3 \mathrm{~dB}$, son menores en polarización vertical que en horizontal, mientras que en las situaciones en las que las antenas estaban en visión directa se produce el fenómeno contrario. Para dar una explicación a tal hecho, es necesario tener presente el entorno en que se realizaron las medidas (entre plantas para las trazas p22v y v22v, y con visión directa para las trazas vd3h y vd3v), y el diagrama de radiación de la antena en cada polarización.

\begin{tabular}{|c|c|c|c|c|c|}
\hline Nombre de la traza & Polarización & \multicolumn{2}{|c|}{$r=0.5(-3 \mathrm{~dB})$} & \multicolumn{2}{c|}{$r=0.25(-6 \mathrm{~dB})$} \\
& & media & desv típica & media & desv. típica \\
\hline \hline $\mathrm{p} 22 \mathrm{v}$ & Horizontal & 10.23 & 1.78 & 24.65 & 13.65 \\
\hline $\mathrm{v} 22 \mathrm{v}$ & Vertical & 7.28 & 2.87 & 25.89 & 25.00 \\
\hline \hline $\mathrm{vd} 3 \mathrm{~h}$ & Horizontal & 16.41 & 9.07 & 47.87 & 10.06 \\
\hline $\mathrm{vd} 3 \mathrm{v}$ & Vertical & 69.49 & 4.81 & 142.75 & 6.76 \\
\hline
\end{tabular}

Tabla 4.8: Anchos de banda de coherencia. Comparación entre distintas polarizaciones en dos casos particulares: trazas verticales en el pasillo principal (p22v y v22v), y trazas longitudinales en visión directa $(\mathrm{vd} 3 \mathrm{~h}$ y vd3v)

Cuando se trata de propagación entre plantas, y en polarización horizontal, a la antena receptora llegan componentes multi-camino de elevada amplitud que corresponden en general a caminos que atraviesan directamente los suelos, junto a otras componentes de menor amplitud que, o bien han sufrido alguna reflexión tras atravesar los suelos, o bien han alcanzado la antena receptora por otros mecanismos como difracción, difusión o scattering, o múltiples reflexiones. Así, la diferencia relativa de amplitud entre las componentes que primero alcanzan el receptor (camino cuasidirecto) y el resto de componentes multi-camino, es alta, y consecuentemente los anchos de banda de coherencia son elevados. En polarización vertical, dado el diagrama de radiación de las antenas (dipolos en $\lambda / 2$ ), las componentes que alcanzan el receptor atravesando los suelos, son de amplitud mucho menor que en el caso de polarización horizontal. La diferencia relativa entre las amplitudes de las distintas componentes es menor, lo que provoca que el rizado de la función de coherencia sea más intenso. Los anchos de banda de coherencia resultantes son menores 
que en polarización horizontal (figuras 4.20 y 4.21).
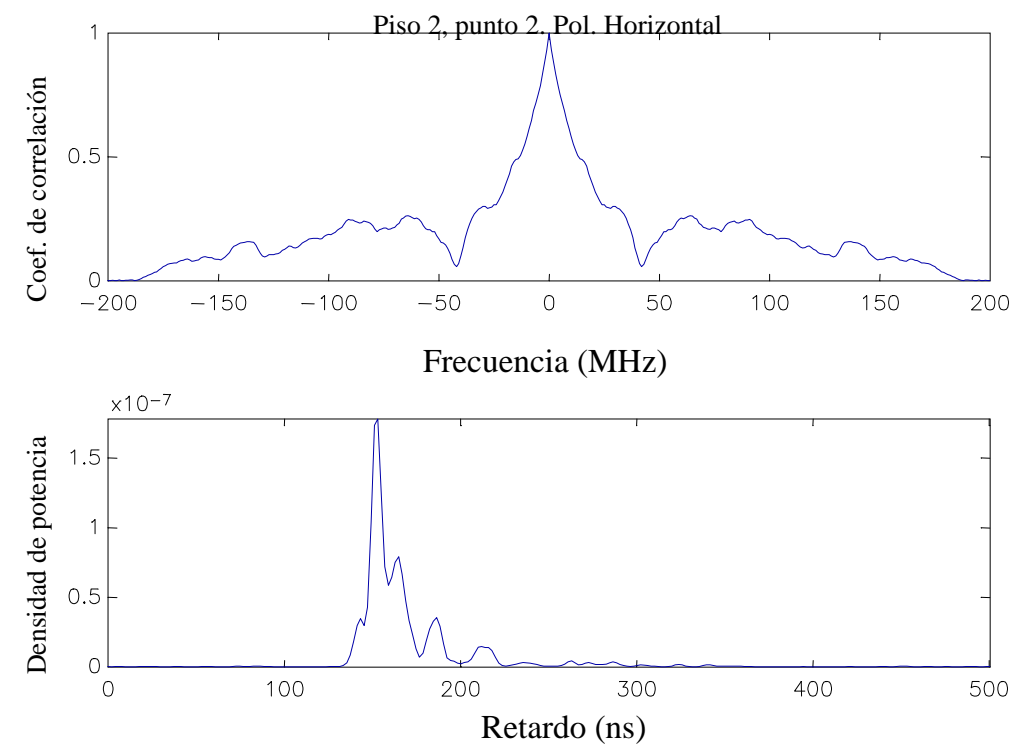

Figura 4.20: Propagación entre plantas con polarización horizontal. Las primeras componentes que alcanzan al receptor tienen mayor amplitud. El rizado de la función de coherencia es menor
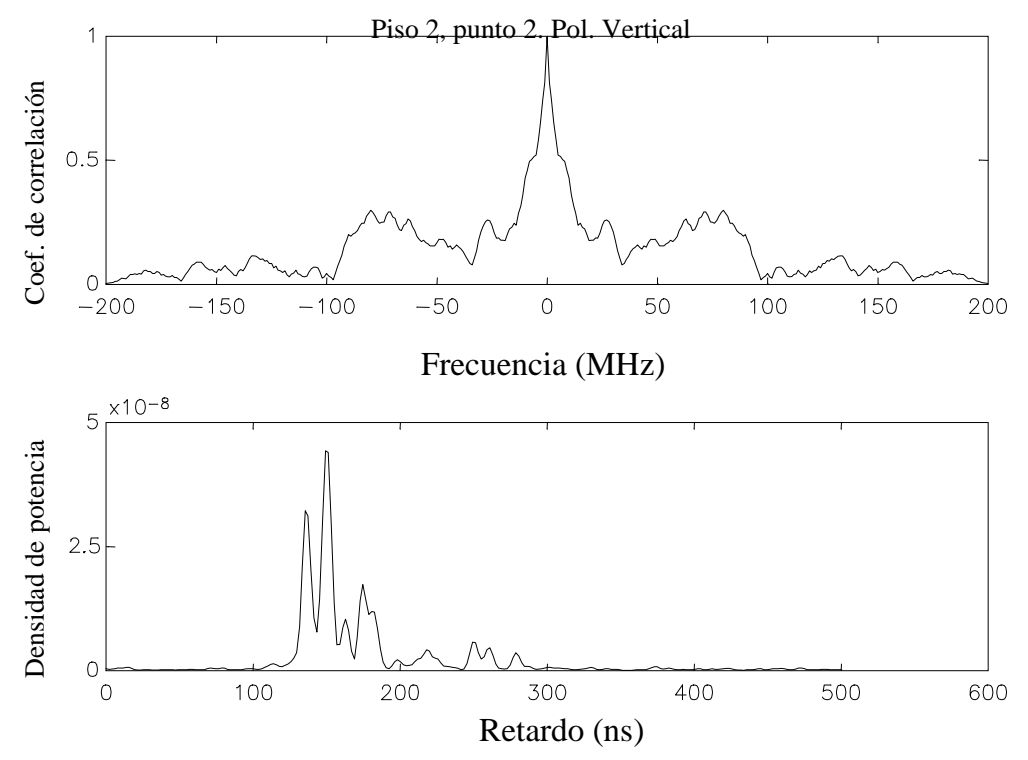

Figura 4.21: Propagación entre plantas con polarización vertical. El ancho de banda de coherencia se reduce al disminuir la relación de amplitudes entre componentes multicamino

En propagación con visión directa, y con las antenas alineadas, ambas polarizaciones muestran un máximo del diagrama de radiación en la dirección de la recta que une las dos antenas. Ahora bien, en polarización horizontal se producen importantes reflexiones 
en el techo y, sobre todo, en el suelo, siendo este un medio totalmente continuo entre ambas antenas. Así, junto a la componente directa existirá también una componente de reflexión en el suelo de amplitud elevada. En el caso de las trazas vd3h (pasillo principal $2^{a}$ planta), dadas la distancia entre antenas $(43 \mathrm{~m})$ y la altura de las mismas $(1.50 \mathrm{~m})$, la esperada reflexión en el suelo se restará a la componente directa. Por el contrario, en polarización vertical (traza vd3v), el diagrama de radiación del dipolo hace que las principales reflexiones se produzcan en las paredes, siendo más rugosas y, sobre todo, mucho más discontinuas, debido a la presencia de distintas puertas, la cámara anecoica, intersecciones con otros pasillos ... Además, la reflexión en el suelo será de menor amplitud que en polarización horizontal dado el diagrama de radiación del dipolo, por lo que la amplitud correspondiente al camino directo sufrirá una menor atenuación. Por tanto, la diferencia relativa entre la amplitud de la primera componente que llega al receptor y el resto, será mayor en polarización vertical y, en consecuencia, los anchos de banda de coherencia serán también mayores que en polarización horizontal.

A la hora de comparar los resultados obtenidos con los anchos de banda de coherencia o con parámetros de retardo de otros trabajos consultados, surgen varios inconvenientes:

- En primer lugar, en los estudios sobre el canal indoor basados en medidas de banda ancha que se han analizado, no se suelen calcular los anchos de banda de coherencia, sino, básicamente, los parámetros de retardo temporal tales como el retardo medio ( $D$ en $(2.31)$ ) y el delay spread $\left(S\right.$ o $\sigma_{\tau}$ en $(2.32)$ ), o más bien sus valores en exceso si se considera como origen de tiempos el valor de retardo de la primera componente de señal recibida.

Bien es verdad que este último parámetro y el ancho de banda de coherencia $B_{c}$, están relacionados por la expresión:

$$
B_{c}=C \cdot \sigma_{\tau}^{-\beta}
$$

válida para $B_{c}$ en $\mathrm{MHz}$, y $\sigma_{\tau}$ en ns, y en la que $C$ es una constante de proporcionalidad y $\beta$ es un parámetro empírico de valor próximo a la unidad [How92].

- En la bibliografía consultada, las medidas se realizaron habitualmente con ambas antenas emplazadas en una misma planta.

- La polarización de las antenas utilizada y los umbrales de detección de las componentes multi-camino rara vez se indican.

Aun con estas dificultades, se pueden encontrar en la literatura anchos de banda de coherencia a $-3 \mathrm{~dB}(r=0.5)$ de unos $15 \mathrm{MHz}$ [Agu91], o de 7.74 y $7.71 \mathrm{MHz}$ [How92], para medidas en edificios de oficinas, con las antenas transmisora y receptora situadas en una misma planta, y para la banda de $900 \mathrm{MHz}$.

También puede observarse que la desviación típica es alta en comparación con el valor medio de los anchos de banda de coherencia. Este hecho se explica por la gran variabilidad que tiene el canal de transmisión en entornos indoor. En el interior de los edificios, el tamaño de los difusores y las distancias entre estos y las antenas, pueden estar próximos en términos de la longitud de onda de trabajo. De este modo, pequeños desplazamientos 
de la posición de las antenas pueden provocar importantes cambios en el comportamiento del canal, alterando, por ejemplo, las condiciones de ocultación o iluminación de rayos, o debido a los cambios en la fase de las distintas componentes del multi-camino que alcanzan el receptor. Así, el número y amplitud de las componentes detectadas en recepción cambian rápidamente al desplazar las antenas. Esta variación es mucho más importante cuando no existe visión directa entre las antenas, ya que, en estos casos, el número de componentes multi-camino que llegan al receptor es mayor y, además, la diferencia de amplitud entre las distintas componentes del multi-camino es menor.

En la figura 4.22 se aprecia que los Perfiles de potencia de las trazas verticales y longitudinales muestran mayores niveles de potencia recibida y, a la vez, en estas trazas, la diferencia relativa entre las amplitudes de las componentes es mayor. Por el contrario, en las trazas transversales aparece una mayor dispersión en retardo de las componentes recibidas, así como una menor diferencia de niveles entre componentes (recuérdese que, en las trazas transversales, la dirección correspondiente a la recta que unía las antenas correspondía aproximadamente con un nulo del diagrama de radiación de la antena, existiendo un máximo en la dirección de la pared). Este hecho confirma la hipótesis de que la transmisión a través de los suelos y techos, y la reflexión en estos, predomina sobre la reflexión en las paredes laterales exteriores o interiores.

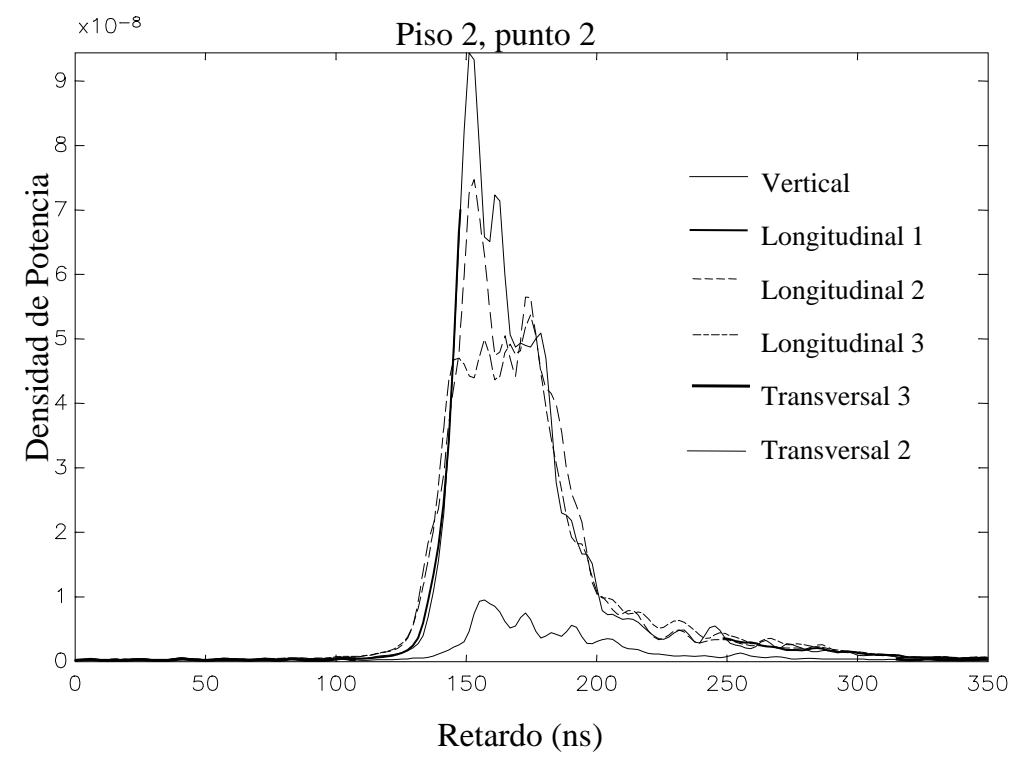

Figura 4.22: Perfiles de potencia promediados de distintos tipos de traza en un punto en particular

A partir de los Perfiles de potencia-retardo calculados se obtuvieron parámetros tales como retardos medios, delay spread, intervalos y ventanas de retardo, considerando siempre sus valores en exceso, no sus valores absolutos. En la tabla 4.9 se recogen los valores promediados para los distintos tipos de trazas, teniendo en cuenta solamente aquellas en las que la relación señal a ruido fuera suficientemente elevada.

Aunque en algunas trazas la relación señal a ruido superaba los $30 \mathrm{~dB}$, se eligió el valor de $-20 \mathrm{~dB}$ como umbral de detección, ya que permitía tratar un número elevado de datos y, al mismo tiempo, obtener parámetros suficientemente representativos, aunque en 
ocasiones resultase un valor muy conservador. Para hallar estos parámetros, el área de todos los Perfiles de potencia-retardo, detectados sobre el valor umbral, se normalizó a la unidad, y se tomó como origen de tiempos el instante correspondiente al primer valor que superaba dicho umbral.

\begin{tabular}{|l|c|c|c|c|c|c|}
\hline Tipo de traza & \multicolumn{2}{|c|}{ Retardos } & \multicolumn{2}{c|}{ Intervalos de retardo } & \multicolumn{2}{c|}{ Ventanas de retardo } \\
& medio & delay spread & $-5 \mathrm{~dB}$ & $-10 \mathrm{~dB}$ & $50 \%$ & $90 \%$ \\
\hline \hline Longitudinales & 61.54 & 31.41 & 39.60 & 74.40 & 31.95 & 100.10 \\
\hline Verticales & 44.40 & 26.88 & 31.73 & 62.48 & 28.13 & 87.01 \\
\hline Visión directa & 31.99 & 18.95 & 20.60 & 48.08 & 18.15 & 63.30 \\
\hline
\end{tabular}

Tabla 4.9: Parámetros de exceso de retardo (en ns) promediados por trazas

\begin{tabular}{|l|c|c|c|c|c|c|}
\hline Nombre & \multicolumn{2}{|c|}{ Retardos } & \multicolumn{2}{c|}{ Intervalos de retardo } & \multicolumn{2}{c|}{ Ventanas de retardo } \\
de la traza & medio & delay spread & $-5 \mathrm{~dB}$ & $-10 \mathrm{~dB}$ & $50 \%$ & $90 \%$ \\
\hline $\mathrm{p} 22 \mathrm{v}$ & 50.11 & 28.99 & 39.25 & 62.81 & 29.44 & 96.18 \\
\hline $\mathrm{v} 22 \mathrm{v}$ & 53.55 & 37.42 & 43.18 & 66.73 & 39.25 & 125.62 \\
\hline \hline $\mathrm{vd} 3 \mathrm{~h}$ & 39.80 & 20.72 & 17.66 & 66.73 & 21.59 & 62.81 \\
\hline $\mathrm{vd} 3 \mathrm{v}$ & 22.97 & 14.21 & 13.74 & 21.59 & 9.81 & 56.92 \\
\hline
\end{tabular}

Tabla 4.10: Casos particulares de parámetros de exceso de retardo (en ns)

De las tablas 4.9 y 4.10 , se observa que los parámetros retardo medio y delay spread tienen comportamientos complementarios o duales a los mostrados por los anchos de banda de coherencia. Así, tales parámetros son, en general, menores en polarización horizontal que en vertical para el caso de transmisión entre plantas (trazas p22v y v22v), debido a que la menor diferencia relativa entre las amplitudes de las componentes existentes en polarización vertical, provoca que los retardos medidos, para un nivel de detección dado, sean mayores. Por contra, para el caso particular de visión directa analizado (vd3h y vd3v), el retardo medio y el delay spread eran mayores en polarización horizontal. Como ya se comentó, la existencia en tal polarización de una fuerte reflexión en el suelo, que hacía disminuir la amplitud de la componente directa debido a la diferencia de caminos, provocaba que la diferencia relativa de amplitudes entre las distintas componentes detectadas fuese menor que en polarización vertical, y, consecuentemente, para un nivel de detección fijo, que los parámetros retardo medio delay spread fueran mayores. Hay que tener en cuenta que, cuanto mayor es el exceso de retardo particular y la amplitud de una componente no directa, mayor es el aumento del retardo medio total y el delay spread total que dicha componente provoca.

En la literatura se referencian, para edificios de oficinas y en medidas a $900 \mathrm{MHz}$, retardos medios de $19.11 \mathrm{~ns}$ y $21.03 \mathrm{~ns}$, y delay spread de $7.56 \mathrm{~ns}$ y $8.06 \mathrm{~ns}$ [How92], para medidas en una misma planta y distancias máximas entre antenas por debajo de $50 \mathrm{~m}$ (se ha comprobado la dependencia con la distancia entre antenas de $D$ y $\sigma_{\tau}$ [Has93] y [Has94]). Se dan valores de delay spread entre $13 \mathrm{~ns}$ y $25 \mathrm{~ns}$ (frecuencia central $1100 \mathrm{MHz}$ ) [Has94], y entre $5 \mathrm{~ns}$ y $50 \mathrm{~ns}$ (frecuencia central 900MHz) [Agu91], en medidas dentro de una misma planta, radicadas en edificios de oficinas. También se encuentran valores de delay spread entre 20ns y $200 \mathrm{~ns}$ en el interior de fábricas dentro de una misma planta (distancias entre 
antenas en el intervalo de $10 \mathrm{~m}$ a $25 \mathrm{~m})$ [Rap89].

Además de haberse comprobado empíricamente la dependencia del dealy spread con la distancia entre las antenas transmisora y receptora, también se ha comprobado su dependencia con el tamaño del edificio, con la existencia o ausencia de caminos con visión directa [Has93], con las pérdidas de propagación [Has94] y con la frecuencia de trabajo [Agu91]. En el caso que aquí se presenta, y para medidas entre plantas, la distancia entre antenas estuvo comprendida entre los $41 \mathrm{~m}$ para el punto 2 de la segunda planta y los $15 \mathrm{~m}$ del punto 4 de la misma planta. Las medidas con visión directa se realizaron con distancias entre la antena transmisora y los puntos centrales de las trazas entre 43 y $45 \mathrm{~m}$.

En [Agu91], se refieren también intervalos de retardo a -10dB entre 25ns y 55ns, ventanas de duración temporal del $50 \%$ con valores semejantes a los correspondientes delay spread, y ventanas al $90 \%$ con tiempos semejantes al intervalo de retardo a $-10 \mathrm{~dB}$, pero sin especificar valores. Las medidas aquí presentadas muestran también gran similitud entre los valores del delay spread y las correspondientes ventanas al $50 \%$, tanto para las trazas verticales y longitudinales entre plantas, como para las realizadas con visión directa. No aparece, sin embargo, la referida semejanza entre los valores de ventanas al $90 \%$ y los de intervalo de retardo a $-10 \mathrm{~dB}$. Se observa en la tabla 4.9 que los valores de intervalos y ventanas de retardo son mayores cuando no existe visión directa entre las antenas, tal y como era de esperar, ya que, en estos casos, el número de componentes multi-camino es mayor.

\section{Funciones de scattering}

Además de funciones de coherencia y Perfiles de potencia-retardo, se calcularon funciones de scattering. Estas, constituyen una poderosa herramienta para analizar el fenómeno del multi-camino, ya que muestran los retardos de las distintas componentes (lo que permite determinar la distancia recorrida por cada una), frente a los desplazamientos Doppler (lo que posibilita identificar la dirección de la que proviene cada componente). Se recogerán en este apartado las representaciones, tanto en formato tridimensional, como mediante curvas de nivel, de algunas de las funciones de scattering más representativas.

Para analizar las funciones de scattering halladas, es necesario tener presente cuál era la posición y el movimiento aparente de las antenas (ver figura 4.15). Aquellas componentes multi-camino que se aproximen a la antena receptora en sentido contrario al movimiento (ficticio) de esta, mostrarán desplazamientos positivos. Por contra, las que se aproximen en su mismo sentido de movimiento, exhibirán desplazamientos Doppler negativos. En apartados anteriores se explicó que los desplazamientos Doppler aparecen escalados según $1 / \lambda$.

Las funciones de scattering pueden constituir un importante instrumento a la hora de determinar las posiciones de los scatterers principales existentes en el canal. Cuando la geometría del entorno es relativamente simple, el análisis de las funciones de scattering permite identificar con gran exactitud el origen de las distintas componentes mostradas.

Sin embargo, cuando la geometría es compleja, como en el caso de transmisión a través de plantas, sólo es posible un análisis aproximado. Un claro ejemplo podemos verlo en la figura 4.23, en la que se muestra las funciones de scattering correspondientes a situaciones 
de visión directa y propagación a través de suelos.
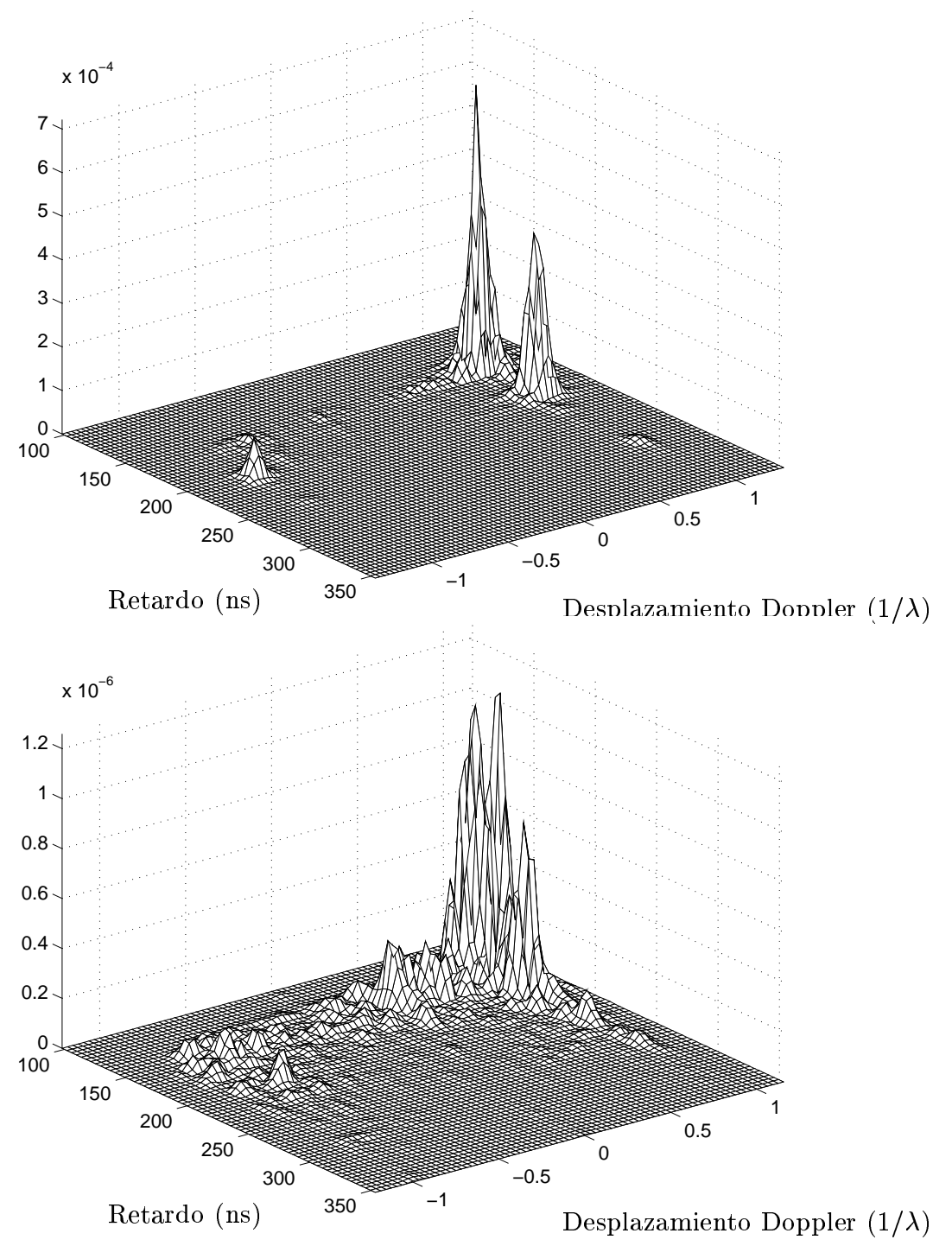

Figura 4.23: Ejemplos de funciones de scattering calculadas a partir de trazas longitudinales. (a) Situación con visión directa entre antenas (LOS). (b) Propagación entre plantas

En la situación LOS de la figura 4.23(a), el pico principal que aparece con desplazamiento Doppler próximo a la unidad, y retardo en torno a 140ns corresponde al camino directo, más la posible reflexión en el suelo. La señal con Doppler próximo a uno y retardo $180 \mathrm{~ns}$, puede identificarse con una reflexión en la pared posterior a la antena transmisora. La componente que aparece en 190ns con desplazamiento Doppler cercano a -1, se puede atribuir a una reflexión en la pared situada tras la antena receptora. Por otra parte, si se observa la figura 4.23(b), se aprecia que las componentes están mucho más dispersas, tanto en Doppler, como en retardo. Al tratarse de propagación entre dos plantas, la geometría se complica, por lo que no es sencillo determinar con precisión el posible origen de cada componente. Aun así, el análisis de las funciones de scattering permite ponderar la impor- 
tancia de las componentes, su número, y su dispersión en retardo (distancias recorridas) y en Doppler (direcciones de llegada).

La figura 4.24 corresponde a funciones de scattering en polarización horizontal y vertical obtenidas en el punto 2 de la segunda planta. Como puede apreciarse, la dispersión, tanto en retardo como en Doppler, es mayor en polarización horizontal. Este hecho viene a confirmar la mayor influencia de la transmisión entre plantas en polarización horizontal.
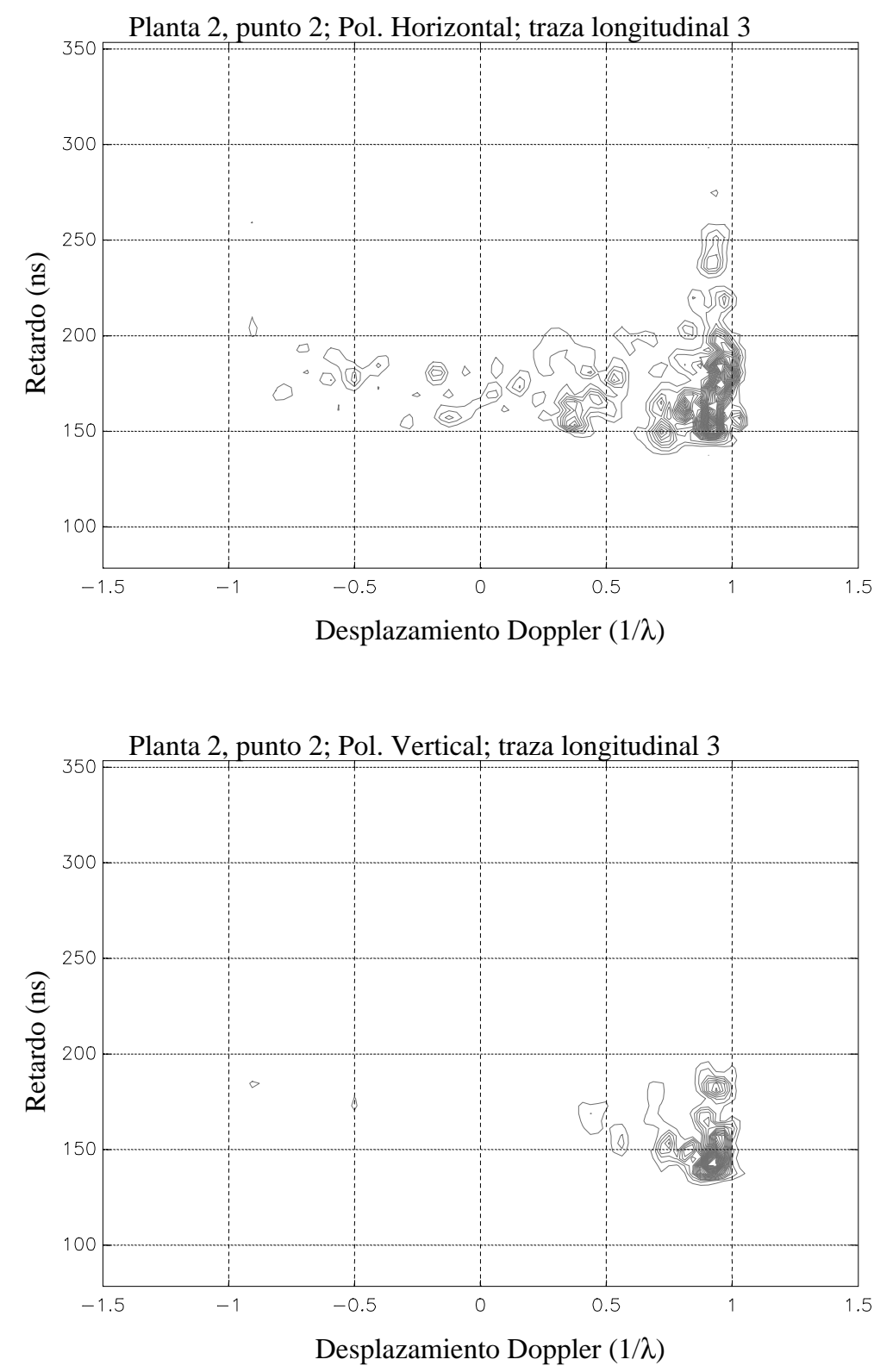

Figura 4.24: Función de scattering de trazas longitudinales, según la polarización. (a) Polarización Horizontal. (b) Polarización Vertical

También es interesante comprobar que, en las trazas verticales, la dispersión de las componentes en Doppler es mucho mayor que en las trazas longitudinales, como puede apreciarse en la figura 4.25. Se pone así de manifiesto la importante variación de la señal 
recibida con respecto a la altura del receptor sobre el suelo y se comprueba, por tanto, que la naturaleza tridimensional del entorno influye enormemente en las características de la señal recibida.
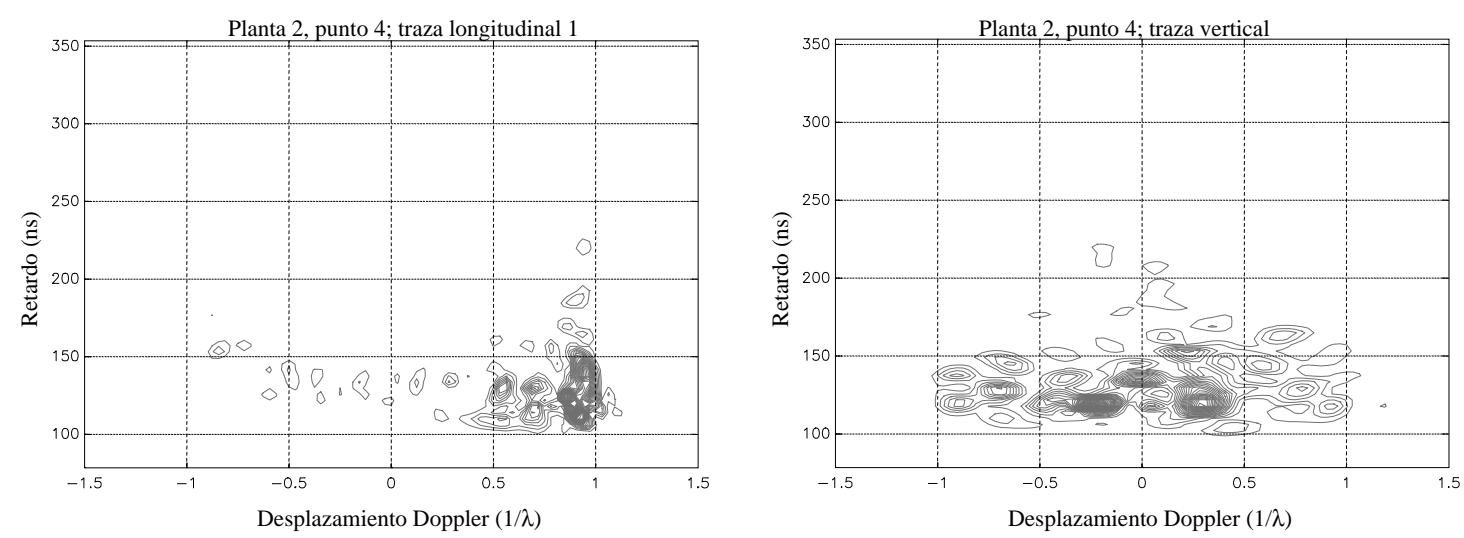

Figura 4.25: Comparación de funciones de scattering según el tipo de traza a partir de la cual es calculada. (a) Traza longitudinal. (b) Traza vertical

Se observa también que las principales contribuciones que aparecen en las trazas verticales, exhiben desplazamientos Doppler menores, lo que es consecuencia del recorrido de la traza y la dirección con la que estas componentes alcanzan la antena receptora. En la figura 4.25(b) se aprecian claramente la componente correspondiente al camino directo (Doppler positivo) y la reflexión de la señal en el suelo (Doppler negativo), con retardos prácticamente semejantes debido a la resolución del sistema. La existencia de un gran número de componentes con desplazamientos Doppler positivos distintos, concentradas en un pequeño intervalo de retardo, puede estar motivada por el efecto de difusión que producen tanto los elementos del forjado como los objetos metálicos existentes en el bajotecho.

Resulta curiosa la presencia, en las trazas verticales, de componentes con desplazamientos Doppler prácticamente nulos, como las que pueden apreciarse en las figuras 4.255(b) y 4.26. Un desplazamiento Doppler nulo, en una traza vertical, evidencia la existencia de componentes que alcanzan la antena receptora en dirección normal a la de elevación de esta. Estas componentes podrían deberse a fenómenos de difracción en el hueco de las escaleras principales y/o a fenómenos de guiado de ondas en el piso en el que está situado el receptor.

Se calcularon también funciones de scattering a partir de las medidas correspondientes a trazas transversales (figura 4.27). Así como en las trazas longitudinales y verticales, las funciones de scattering muestran la existencia de componentes de mucho mayor nivel que el resto, correspondiéndose en general con los caminos de menor distancia entre antenas (cuasidirectos), las funciones de scattering calculadas a partir de las trazas transversales, muestran en conjunto una elevada dispersión, tanto en retardo como en desplazamiento Doppler, así como un gran número de componentes entre las que rara vez existe alguna que destaque claramente sobre las demás. Este resultado confirma, ya definitivamente, el hecho de que, en la propagación entre plantas, las componentes principales de la señal provienen de la transmisión y reflexión en los suelos, y que las reflexiones en paredes laterales tienen una importancia mucho menor. 


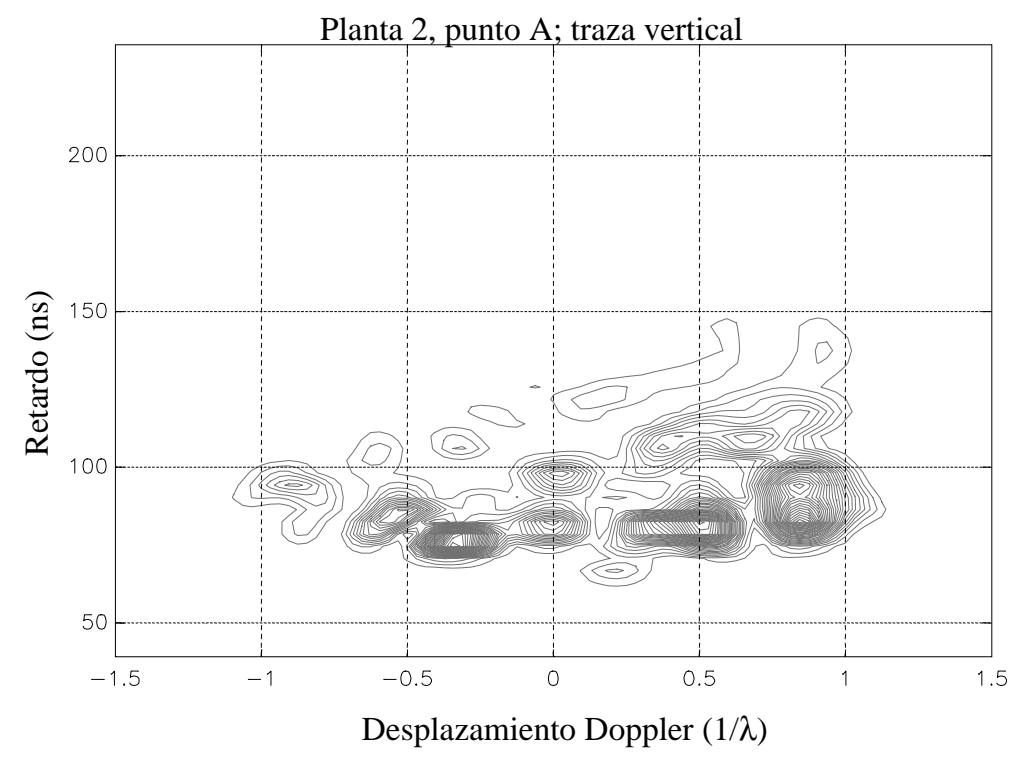

Figura 4.26: Otro ejemplo de función de scattering de traza vertical. Se aprecia la presencia de componentes con desplazamiento Doppler nulo

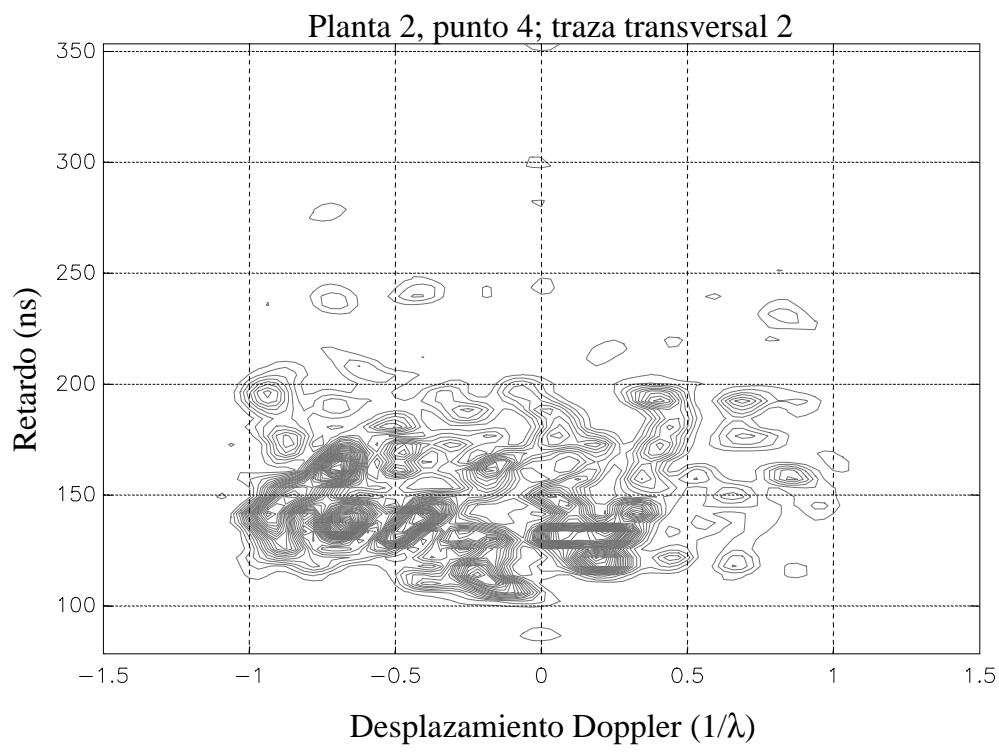

Figura 4.27: Función de scattering calculada a partir de una traza transversal 


\section{Ángulos de llegada}

Hasta ahora se ha visto cómo es posible analizar el fenómeno multi-camino mediante funciones de coherencia, Perfiles de potencia-retardo y funciones de scattering. Se ha comprobado la equivalencia entre funciones de retardo y funciones de coherencia y cómo las funciones de scattering permiten distinguir las componentes del multi-camino mediante sus distintos desplazamientos Doppler, a diferencia de los Perfiles de potencia en los que se muestra la suma de la potencia de las distintas componentes que alcanzan el receptor para cada valor de retardo. La función de scattering permite, además, la determinación de la posición de scatterers gracias a la relación entre retardo y frecuencia Doppler.

Otra forma de determinar la posición de los principales elementos de difusión y/o reflexión es mediante la determinación de los ángulos con los que llegan las componentes a la antena receptora. El conocimiento de tales ángulos y de la distancia recorrida por cada componente (retardo), permite también la determinación de la procedencia de las componentes del multi-camino.

Como se refirió anteriormente, se realizaron medidas específicas para la determinación de los ángulos de llegada en el plano horizontal, mediante la síntesis de agrupaciones circulares. Además, estos ángulos de llegada pueden ser representados en función del retardo si se parte de las respuestas impulsionales en cada punto de la agrupación. Por otro lado, las medidas correspondientes a las trazas verticales realizadas, se utilizaron para sintetizar agrupaciones lineales, con el objeto de determinar los ángulos de llegada en el plano vertical.

Antes de pasar a mostrar los resultados obtenidos, es necesario tener en cuenta las limitaciones que este tipo de análisis presenta. Estas son básicamente, por un lado, la limitada precisión en el posicionamiento de la antena receptora en los puntos de muestreo, lo que provocará errores, fundamentalmente en la fase, a la hora de realizar la síntesis de las agrupaciones. Sin embargo, la principal limitación consiste en la no estacionariedad del canal. En una agrupación real, las muestras de señal se recogen todas en el mismo instante, lo que permite obtener la relación de fases entre las señales captadas por los distintos elementos de la agrupación. Si el canal es estacionario en el tiempo, las distintas muestras espaciales pueden tomarse sin limitación de tiempo. Sin embargo, el canal real no es estacionario. Como es sabido, en estos casos, la técnica para hacer abordable el estudio del canal consiste en suponer que, durante espacios suficientemente cortos de tiempo, las características del canal no varían de manera fundamental, es decir, se considera que el canal es cuasiestacionario. Las nueve muestras espaciales tomadas para la síntesis de las agrupaciones circulares, se tomaban en un periodo inferior a cinco minutos. Sin embargo, en la toma de las muestras correspondientes a cada traza vertical, se empleaban aproximadamente entre 45 y 60 minutos. Este intervalo de tiempo pudo resultar demasiado elevado en algunas ocasiones, de modo que las muestras en altura se pudieron realizar bajo distintos estados del canal. Como consecuencia, los resultados obtenidos en la determinación de los ángulos de llegada en vertical no siempre responden al comportamiento esperado. Sin embargo, en varios casos los resultados encontrados son satisfactorios y permiten, utilizando tanto los valores de retardo como los ángulos así determinados, calcular el origen de las principales componentes multi-camino.

En la figura 4.28, se muestra la evolución de los ángulos de llegada en el plano horizontal 

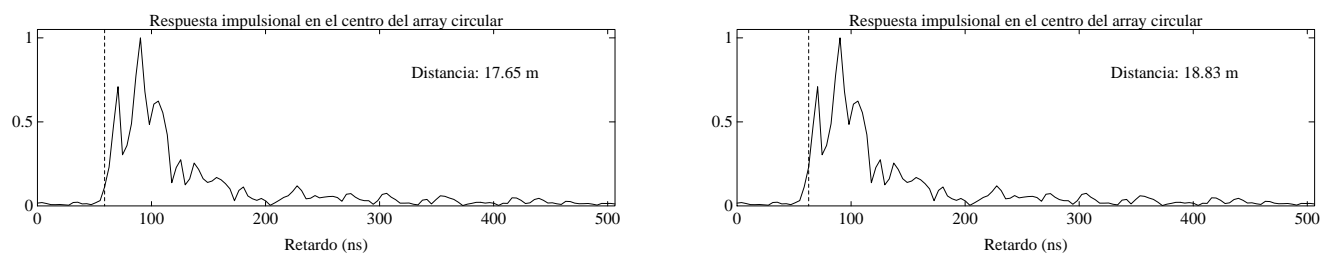

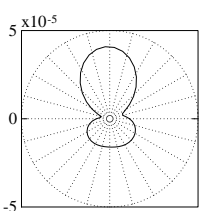

(a)
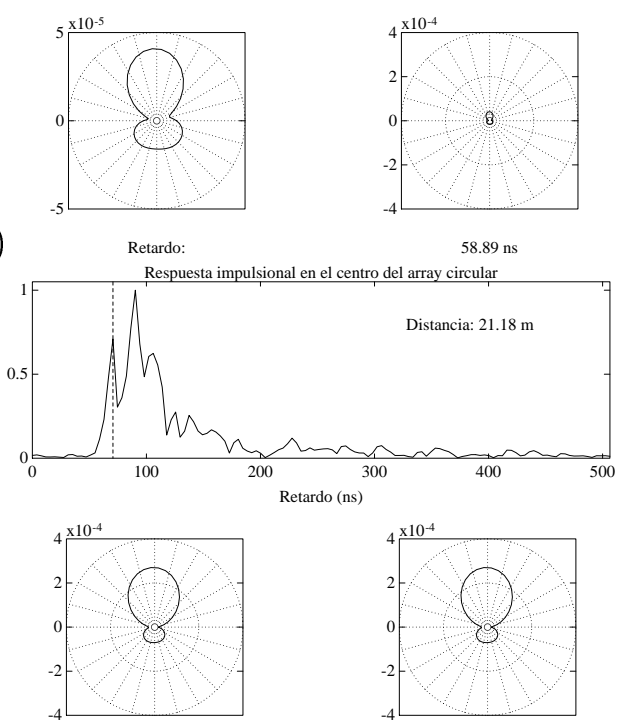

(c)
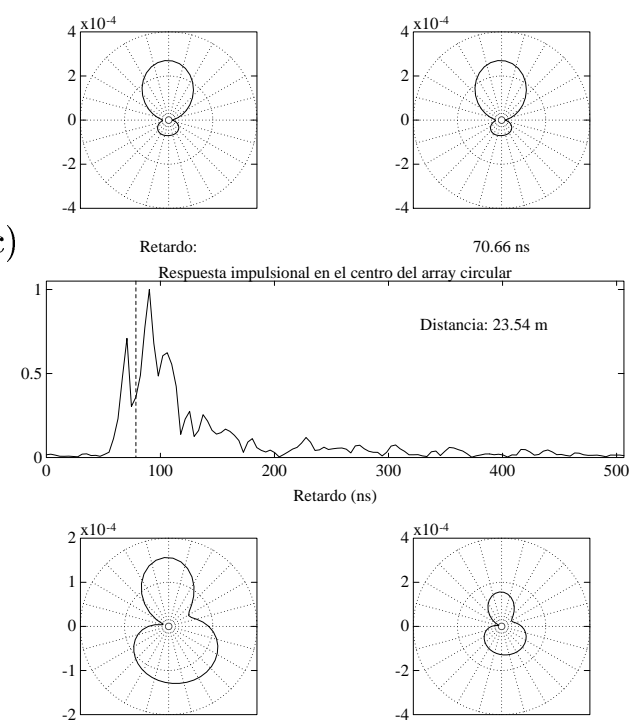

(e)
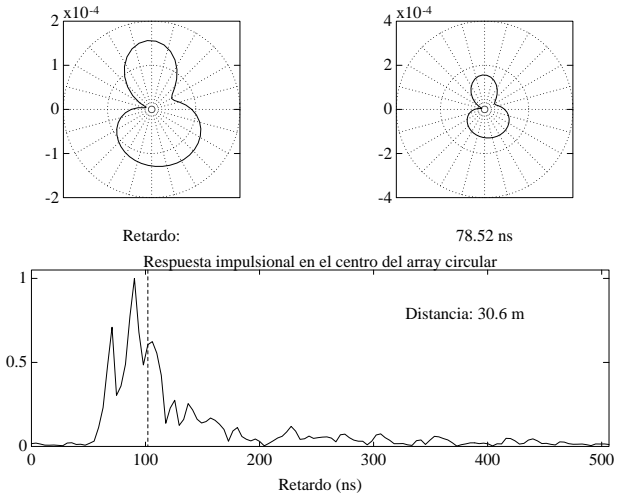

$(\mathrm{g})$

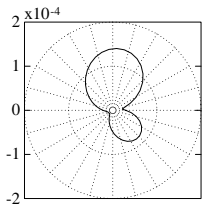

Retardo:

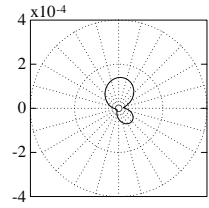

$102.1 \mathrm{~ns}$ (b)

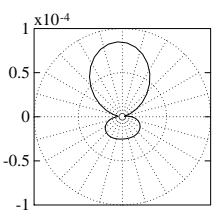

Retardo:
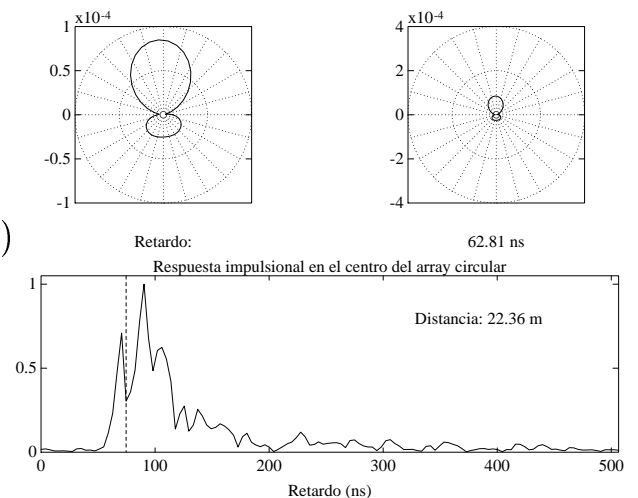

(d)
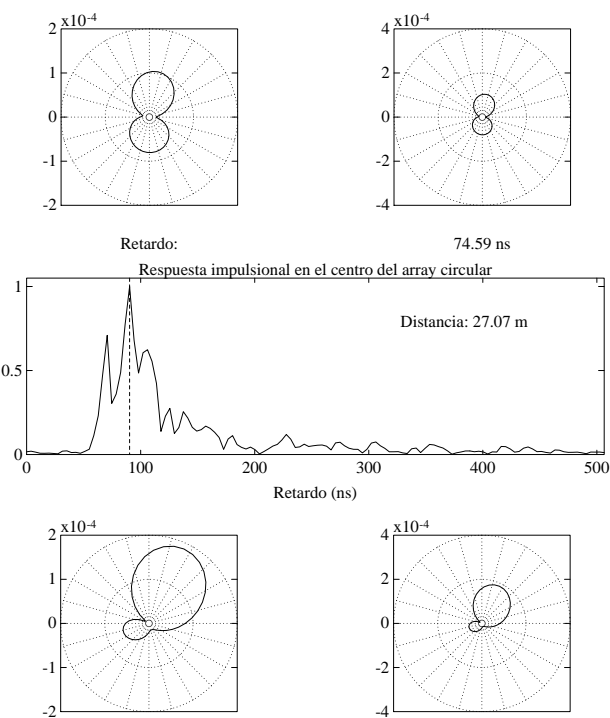

(f)
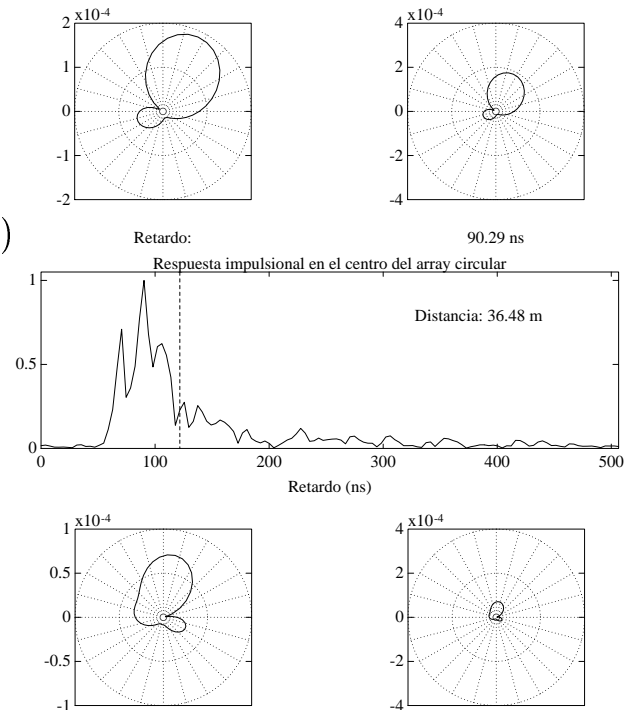

(h)

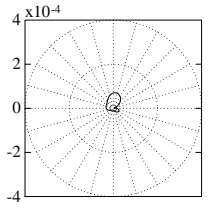

$121.7 \mathrm{~ns}$

Figura 4.28: Evolución de los ángulos de llegada en el plano horizontal en función del retardo 
(ángulo $\phi$ ), calculados en el punto 4 de la $2^{a}$ planta. En cada subfigura se representa la respuesta impulsional, normalizada en amplitud, correspondiente al punto central de la agrupación circular. Bajo ella, se muestra el diagrama de radiación de la agrupación calculado a partir de los valores de tensión de las respuestas impulsionales de todos los elementos de la agrupación, para cada instante de tiempo. El diagrama se muestra tanto autoescalado, como bajo una escala referida al máximo a lo largo de todos los instantes de tiempo, lo que permite determinar con mayor exactitud qué diagramas corresponden a componentes de señal y cuáles son debidos simplemente a ruido.

En dicha secuencia de figuras, se puede ver cómo el diagrama de radiación de la agrupación, que indica las direcciones prioritarias por las que la señal alcanza la antena receptora, modifica tanto su forma como su amplitud. Se observa que, al inicio, las componentes fundamentales provienen desde delante de la antena (figura 4.28 (a), (b) y (c)). A continuación, el lóbulo posterior aumenta su amplitud ((d) y (e)). Desde (f) hasta (h), se observan cambios en las direcciones de llegada de las componentes. Como puede observarse, los diagramas no muestran una gran resolución angular en el plano horizontal. Recuérdese que las agrupaciones se construyeron a partir de nueve muestras espaciales, tomadas en el centro y en la periferia de un círculo de radio aproximadamente igual a $\lambda / 3$.

Por otro lado, la figura 4.29 muestra la evolución de los diagramas que proporcionan los ángulos de llegada en el plano vertical, para medidas realizadas en el punto $\mathrm{C}$ del pasillo de despachos. Dichas gráficas se corresponden con la síntesis de agrupaciones lineales de 16 elementos espaciados cada $8 \mathrm{~cm}$ (aproximadamente $\lambda / 4$ ). Al igual que en el caso de ángulos en horizontal, las tensiones de alimentación se toman a partir de las muestras temporales de las respuestas impulsionales.

En esta secuencia de la figura 4.29, se observa cómo aparecen al unísono una componente con ángulo de llegada en torno a $15^{\circ}$, correspondiente al camino directo, y otra con un ángulo aproximado de $-12^{\circ}$, que se puede identificar con una reflexión en el suelo. Dada la distancia existente entre las antenas cuando la receptora se situa en el punto $\mathrm{C}$ (unos $30 \mathrm{~m}$ ), y teniendo en cuenta las alturas de las antenas y el grosor de los suelos, la componente directa debería llegar con un ángulo próximo a $8.5^{\circ}$, y la posible reflexión en el suelo debería mostrar un ángulo cercano a $-10^{\circ}$. Estas diferencias pueden ser achacadas a ciertas deficiencias en la calibración inicial de los equipos, hecho que pudo introducir errores en la fase.

En (e) y (f), se aprecian componentes en torno a $60^{\circ}$ que, dado el retardo que presentan, se pueden asociar a reflexiones en el techo del tercer piso. Por último, en $(\mathrm{g})$ y $(\mathrm{h})$ se muestra el pico de señal correspondiente a la reflexión en el edificio de la EUITI, que aparece con un ángulo de elevación prácticamente nulo.

Como puede verse, el conocimiento de los retardos y los ángulos de llegada de las distintas componentes, además de datos sobre la geometría del edificio, permite la determinación, más o menos aproximada según las condiciones de estacionariedad del canal y el grado de precisión del sistema, del origen y circunstancias de las principales componentes multi-camino. 

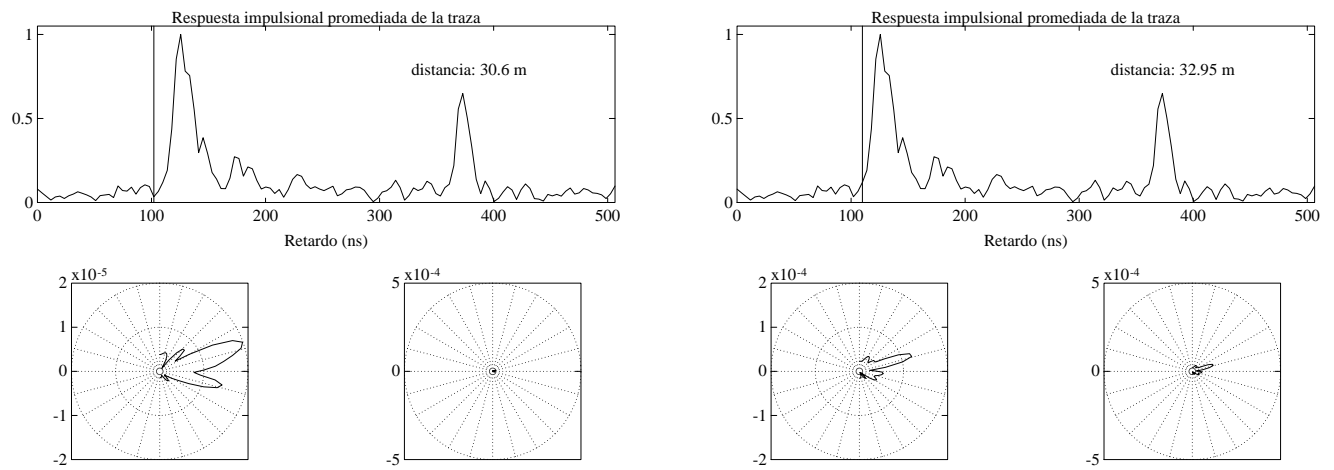

(a)

$102.1 \mathrm{~ns}$

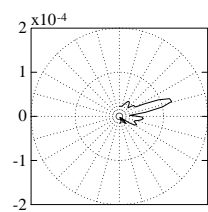

(b)
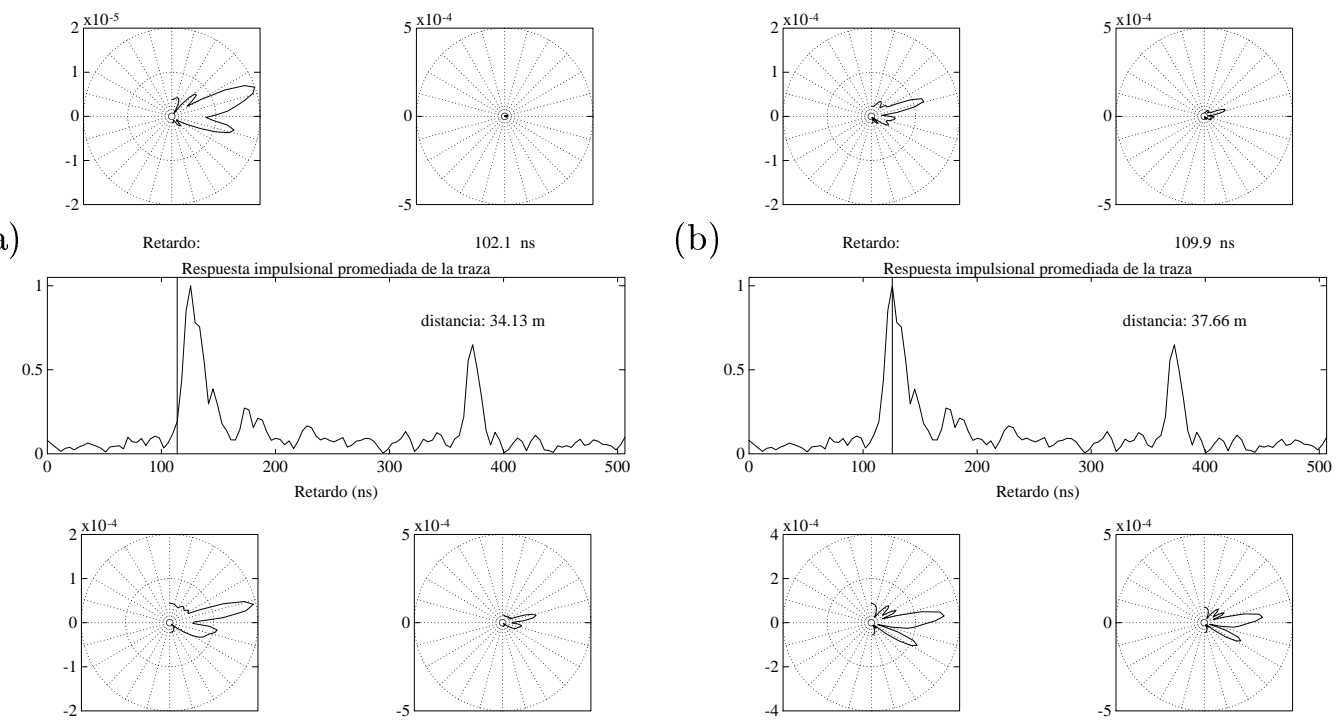

(c)

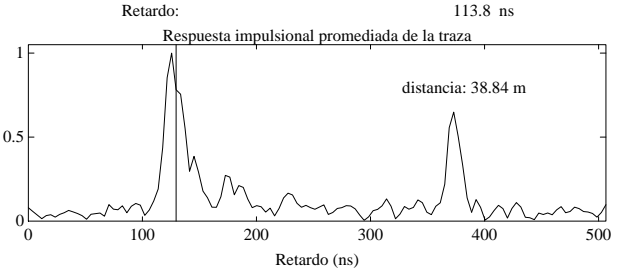

(d)
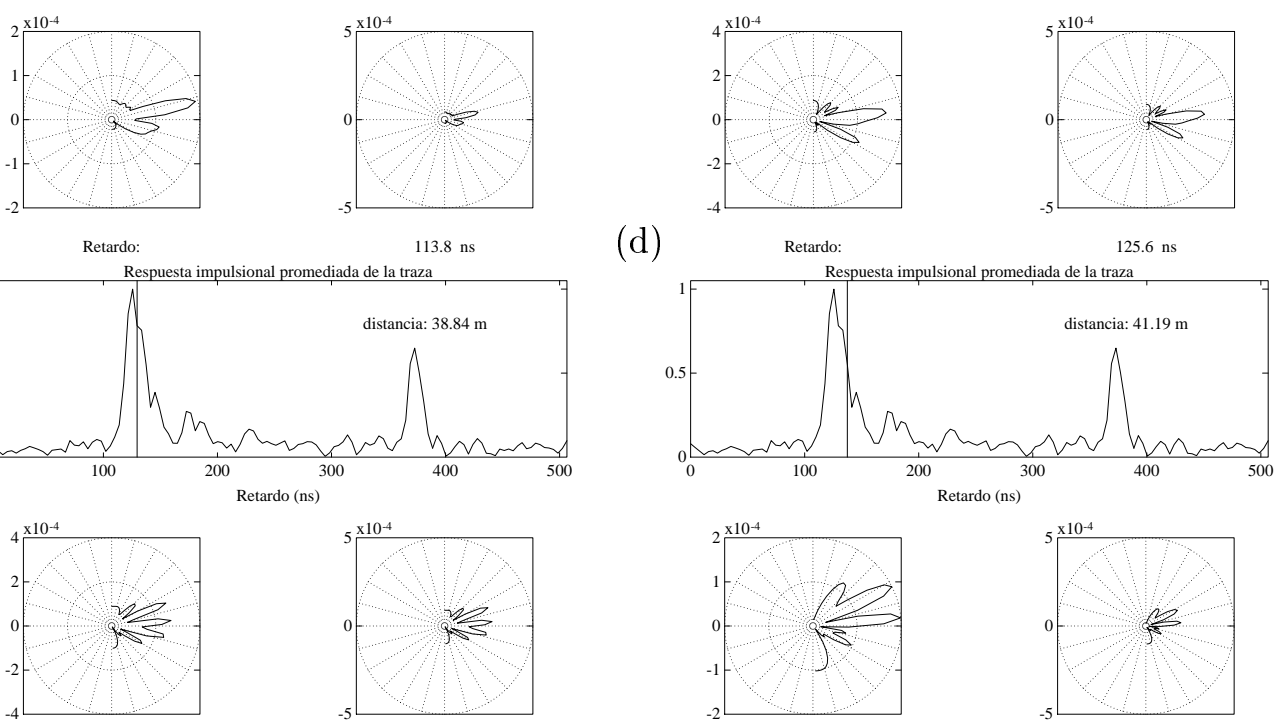

(e)

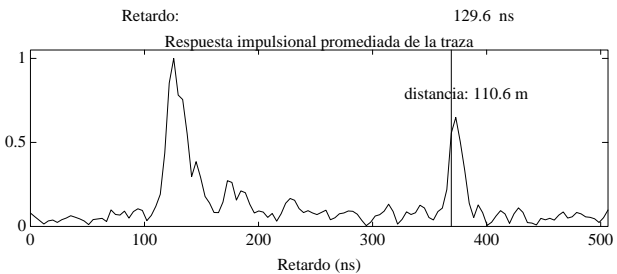

(f)
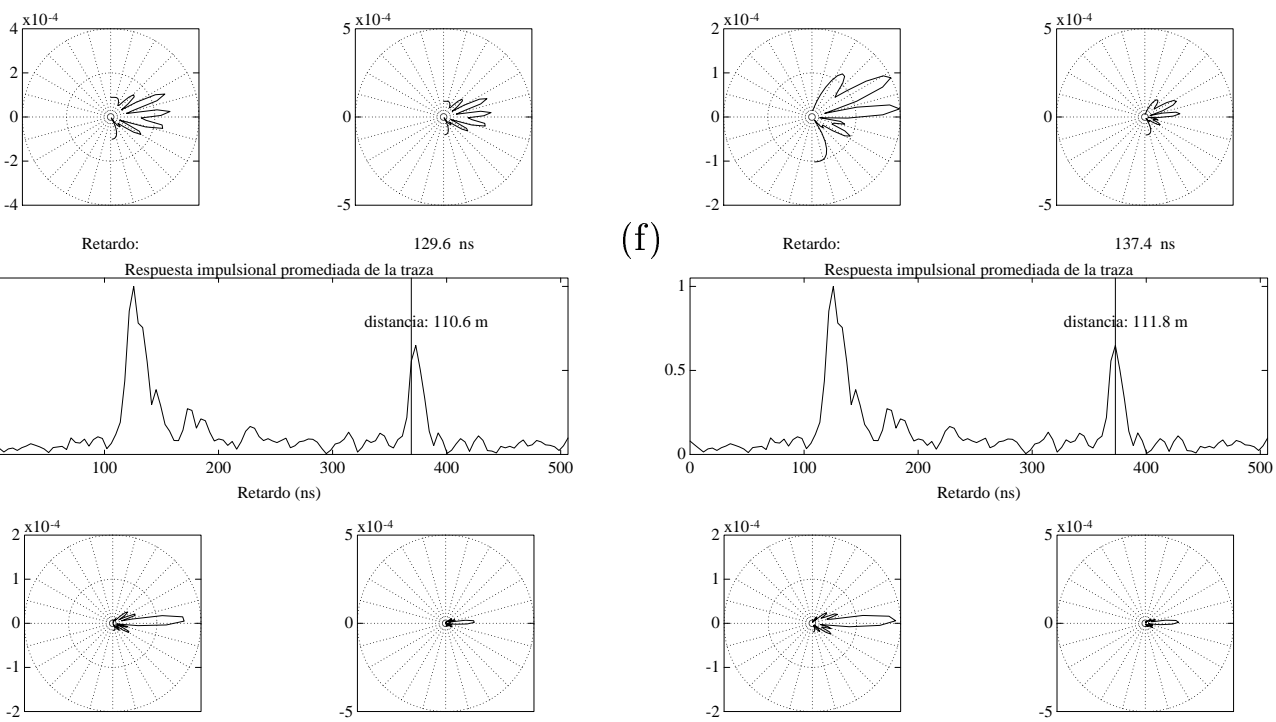

(g)

$369 \mathrm{~ns}$

(h)
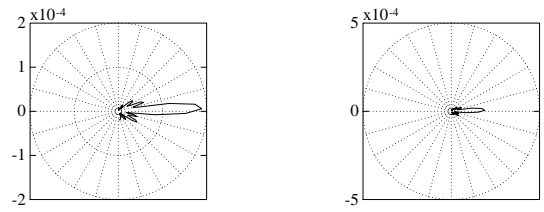

372.9 ns

Figura 4.29: Evolución de los ángulos de llegada en el plano vertical en función del retardo 


\subsection{Conclusiones}

Se ha presentado en este capítulo la campaña de medidas realizada en el interior del edificio de la ETSIT de Valencia, con la que se pretendía confirmar la fuerte dependencia de las condiciones de propagación con la posición de las antenas respecto al suelo y el techo.

Del análisis de dichas medidas se deduce que dicha dependencia parece ser debida, fundamentalmente, a las múltiples reflexiones en el suelo y en el techo de la planta en la que se encuentra la antena receptora, lo cual refuerza el carácter intrínsecamente tridimensional del canal indoor.

Aparece, por tanto, la necesidad de cuantificar este carácter tridimensional, para así incluirlo en los modelos que pretendan simular el comportamiento del canal, especialmente cuando tengan en cuenta la transmisión entre plantas.

Así, los modelos empíricos que tienen en cuenta solamente el número de suelos atravesados y no su posición relativa a la de las antenas, pueden resultar insuficientes para diseñar ciertos tipos de sistemas de comunicaciones indoor que requieran una precisión mayor a la habitual.

Se ha de acudir, en estos casos, a modelos más deterministas que tengan en cuenta la propagación multi-camino, como, por ejemplo, los basados en técnicas de Lanzado de Rayos, que son los que en esta Tesis se pretenden evaluar. 


\section{Capítulo 5}

\section{Técnicas de Lanzado de Rayos}

\section{$5.1 \quad$ Introducción}

En el capítulo 3 se vio que el comportamiento del canal radio móvil puede ser estudiado usando ciertas técnicas, más o menos deterministas, basadas en la Óptica Geométrica. Entre estas técnicas, destacan las basadas en el Lanzado de Rayos, ya que son métodos de aproximación flexibles y eficientes, perfectamente aplicables a la simulación de sistemas de comunicaciones móviles indoor.

La metodología es bastante similar a la del Trazado de Rayos (Ray Tracing) empleado en la síntesis de imágenes creadas por ordenador (renderización). El objetivo de estas técnicas gráficas es la creación de escenarios virtuales tan realistas, que parezcan la imagen recogida por una cámara fotográfica. Para ello, se definen los objetos visibles en el escenario (sus formas, tamaños, posiciones, colores, texturas, etc.), el punto de observación, la dirección de observación y la iluminación. Los rayos parten de una fuente de luz y, tras interaccionar con los objetos del entorno, inciden sobre un plano de observación que simula el campo visual del observador. De esta forma, los rayos iluminan la escena, creando reflexiones, refracciones, sombras, etc.

Aplicado a la Radiopropagación, el Lanzado de Rayos es solamente una aproximación, un método para simular el avance de los frentes de ondas transmitidos (figura 5.1). Así, de acuerdo con las leyes de la Óptica Geométrica, cada rayo representa la dirección de propagación de la onda electromagnética y, según el principio de Fermat, su trayectoria a seguir será aquella que haga que la longitud óptica del camino recorrido sea mínima. Esto significa que, en un medio homogéneo e isótropo, el rayo mantendrá una trayectoria rectilínea, hasta que se encuentre con alguna discontinuidad que le haga reflejarse, refractarse o difractarse.

Al ser sólo una aproximación, hay que tener en cuenta sus posibles limitaciones. La exactitud va a depender, principalmente, de la relación de la longitud de onda a transmitir, respecto a las dimensiones de los dispersores (es decir, cualquier obstáculo que influya en el recorrido de los rayos) y al volumen del entorno a simular. El método será más exacto cuando el punto en el que se estudie el rayo se encuentre a varias longitudes de onda de los elementos dispersores más cercanos (paredes, techos, etc.), y cuando todos estos 


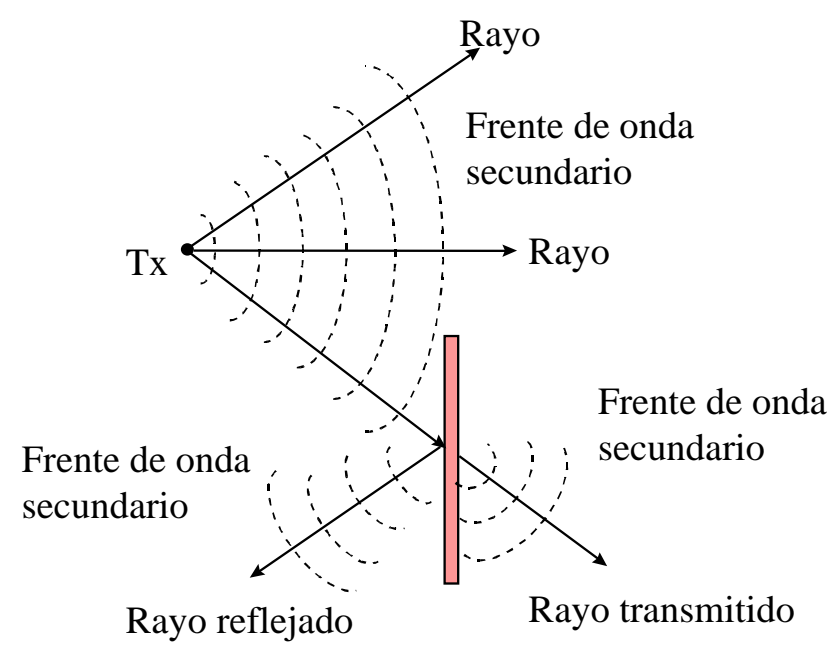

Figura 5.1: Aproximación de los frentes de ondas electromagnéticas con rayos ópticos

dispersores sean grandes y lisos en comparación con dicha longitud de onda. Por lo tanto, la aproximación del Lanzado de Rayos viene limitada por la condición de campo lejano (5.1) y por el criterio de Rayleigh para superficies rugosas (5.2):

$$
\begin{gathered}
r \cdot k \gg 1 \\
h<\frac{\lambda}{8 \cos \theta_{\mathrm{i}}}
\end{gathered}
$$

donde $r$ es la distancia al transmisor; $k$ es el número de onda $(2 \pi / \lambda) ; h$ es la máxima diferencia en altura entre las irregularidades de las superficies del entorno, y $\theta_{\mathrm{i}}$ el ángulo de incidencia a dichas superficies, respecto a la normal. En el capítulo 6 se harán más consideraciones sobre esta última condición.

Estos requisitos se cumplen con bastante holgura en los entornos típicos indoor, ya que la frecuencia de trabajo es elevada (mínimo unos $900 \mathrm{MHz}$, por ejemplo), con lo que la longitud de onda es pequeña (menos de $33 \mathrm{~cm}$ ). Por ello, solamente será necesario incluir en la descripción del entorno físico los elementos de gran tamaño, como son las paredes, los techos y suelos, las puertas, las ventanas, etc. Además, bajo estas condiciones, puede considerarse que la onda mantiene sus propiedades en las reflexiones y transmisiones.

Los métodos de Lanzado de Rayos se han venido utilizando desde que se propusieron en [Hon92]. A menudo se le ha denominado Ray Tracing (como en [Sch92], [Sei94] y otros muchos), pero se ha preferido utilizar la nomenclatura de Lanzado de Rayos para distinguirlo del método de las imágenes, en el que los rayos son trazados desde su origen hasta su destino mediante rutas calculadas de antemano. Esta nomenclatura, o su equivalente en inglés (Ray Launching), es utilizada en [Law92], [Law94], [Cic94b] y [Dur97a], entre otros. Otras nomenclaturas utilizadas son Forward Ray Tracing en [Sie96], o Shoot-andBouncing Ray (SBR) en [Che97].

La evolución de los rayos se puede seguir de dos formas: cada rayo individualmente, o agrupando varios rayos para que formen un tubo piramidal con origen en el emisor. 
Esta última técnica se puede denominar Lanzado de Tubos y ha sido uno de los métodos particulares que se han estudiado en esta Tesis. Dadas sus peculiaridades, se estudiará en una sección posterior. A continuación, se explicará la técnica genérica de Lanzado de Rayos.

\subsection{Separación angular de los rayos. Discretización de la esfera}

En las técnicas de Lanzado de Rayos, el transmisor es tratado como un punto infinitamente pequeño del que emanan rayos en todas las direcciones. Aunque los programas de Trazado de Rayos para aplicaciones gráficas envían rayos solamente en unas direcciones específicas, un modelo válido para electromagnetismo debe tener en cuenta todas las posibles direcciones relativas tanto al transmisor como a los receptores. Si el lanzado se realiza en tres dimensiones, los rayos deben distribuirse uniformemente en los $4 \pi$ estereoradianes.

Así, el transmisor y el receptor se van a modelar como fuentes puntuales, situadas dentro del edificio. Para determinar todos los posibles rayos que puedan partir del emisor y alcanzar al receptor, será necesario considerar todos los posibles ángulos de partida y llegada entre ambos. Es decir, habrá que lanzar los rayos y estudiar su propagación en el espacio tridimensional. Adicionalmente, los frentes de onda formados pueden ser subdivididos para poder mantener la resolución espacial constante a pesar de la dispersión que sufren los rayos al avanzar. A esta técnica se le suele denominar splitting [Kre93, Cic95].

Para conseguir un Lanzado de Rayos uniforme en todas direcciones, se ha de emplear un procedimiento que consiga que dichos rayos mantengan entre sí una separación angular con la menor dispersión posible. Téngase en cuenta que este problema es imposible de resolver matemáticamente de forma exacta, y que sólo se puede recurrir a aproximaciones más o menos precisas. Entre ellas está el método del icosaedro, consistente en lanzar rayos por cada uno de los vértices de un icosaedro cuyo centro geométrico sea el transmisor. Aunque este método proporciona una resolución muy baja, puede procederse a una teselación de cada una de sus caras en triángulos tan diminutos como se desee [Sei94, Che97, Dur97a].

En esta Tesis se ha evaluado otro método que proporciona mejores resultados en cuanto a velocidad y uniformidad del lanzado [Dam96]. El primer paso de este método consiste en tomar una esfera unidad imaginaria con centro en el emisor, y dividirla en $n$ paralelos separados entre sí en elevación un ángulo $\Delta \theta=2 \pi / n$. Después, por cada uno de estos paralelos se hace pasar un conjunto de rayos que, a su vez, han de estar separados en acimut un ángulo $\Delta \theta$. De esta forma, dos rayos contiguos cualesquiera quedarán separados entre sí un ángulo $\alpha \simeq \Delta \theta^{*}$ (figura 5.2).

Para una resolución angular deseada de $\alpha=\Delta \theta$, la elevación de cada rayo que parte del emisor y pasa por el paralelo $n$ viene determinada por el ángulo $\theta_{n}$, dado por:

$$
\theta_{n}=\Delta \theta / 2+(n-1) \Delta \theta
$$

\footnotetext{
*Posteriormente se verá que, para el caso de dos rayos contiguos ubicados en paralelos consecutivos, no siempre se conseguirá que sea exactamente igual
} 


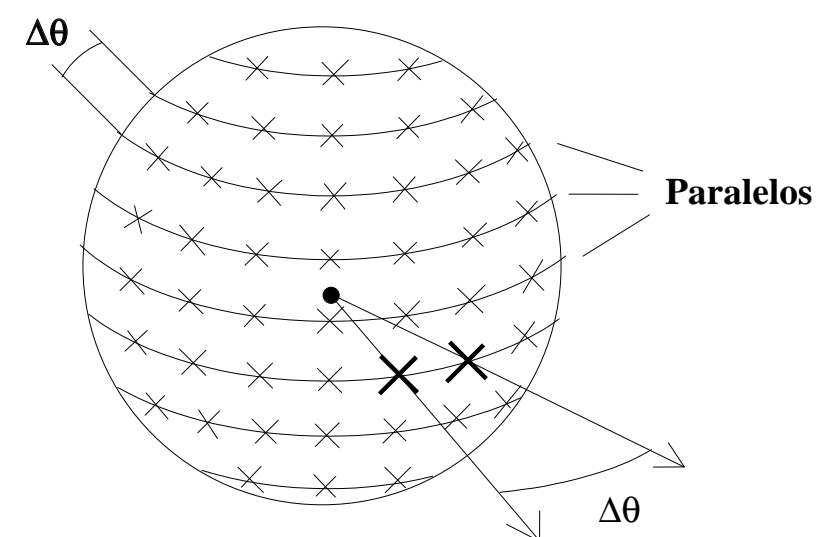

Figura 5.2: División de la esfera unidad en paralelos para el Lanzado de Rayos

Cada uno de los paralelos contendrá un número determinado de rayos, separados en acimut un ángulo $\Delta \phi_{n}$, dado por:

$$
\Delta \phi_{n}=\Delta \theta / \sin \theta_{n}
$$

No confundir esta separación con la propia separación angular de los rayos pertenecientes a un mismo paralelo, que será $\Delta \theta$ (figura 5.3).

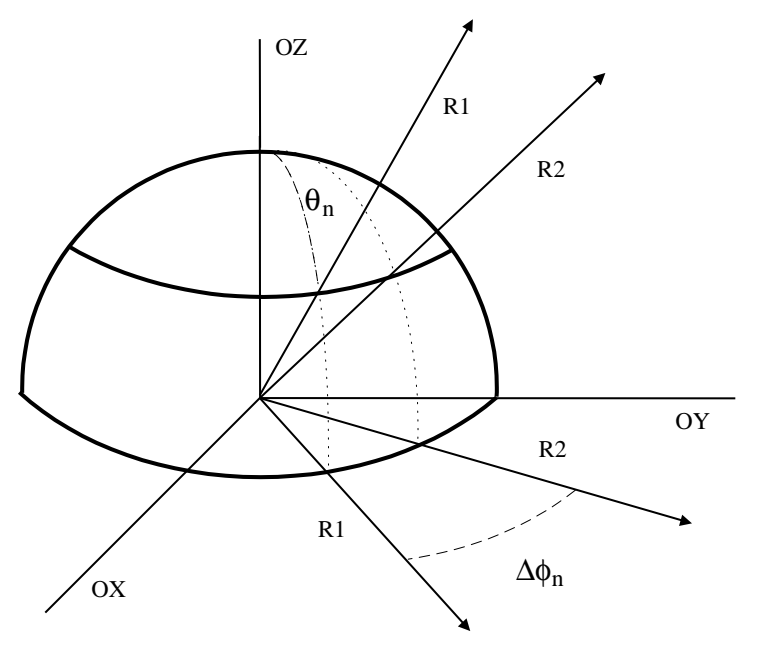

Figura 5.3: Situación espacial de dos rayos contiguos según sus coordenadas esféricas

A pesar de que la calidad de la discretización puede aumentarse mediante la elección de una separación angular suficientemente pequeña, debe insistirse en que siempre se tratará de una aproximación, y que los rayos que se generan no estarán separados exactamente por la misma distancia angular. Esto provocará una serie de problemas que serán comentados en apartados posteriores. 


\subsection{Zona de influencia de los rayos. Radio de impacto}

A la hora de implementar el algoritmo de Lanzado de Rayos, aparece el problema de tener que saber si los receptores son alcanzados o no por cada rayo que es lanzado. Se ha de tener presente que los receptores son considerados como entidades puntuales, y que los rayos son estructuras unidimensionales, sin volumen. Por lo tanto, va a resultar muy difícil que un rayo pase exactamente por un determinado punto.

El método más ampliamente empleado para determinar si se produce o no impacto, consiste en determinar un radio de impacto alrededor de cada receptor, de forma que defina una zona de tolerancia. Si la distancia entre un rayo determinado y el receptor bajo estudio es menor que dicho radio de impacto, se considerará que ha sido alcanzado.

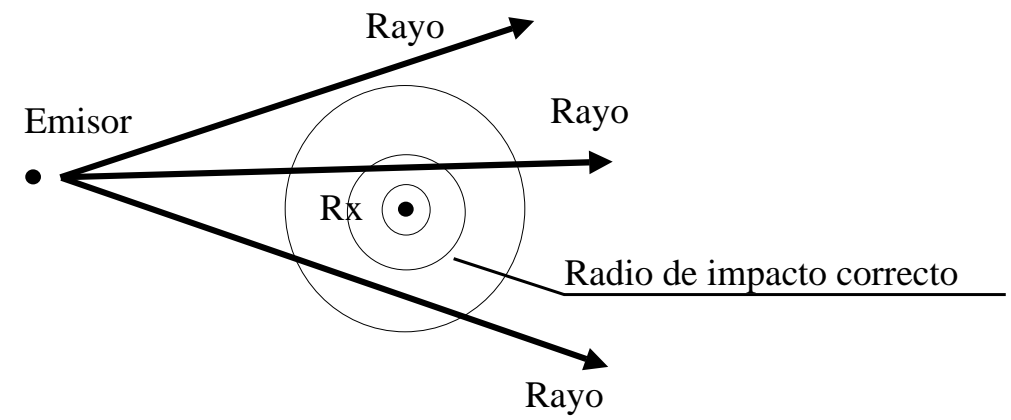

Figura 5.4: Determinación del impacto de un rayo en un receptor

En cuanto a la determinación del valor de dicho radio de impacto, se debe adoptar el siguiente criterio: para cualquier posible ubicación de un receptor en el espacio, sólo pueda impactar en él un rayo, y sólo uno, que surja directamente del emisor, o que haya sufrido únicamente propagación a través de los obstáculos, y no reflexiones. De esta forma se garantizará que cada rayo represente de forma unívoca al frente de ondas que alcanza al receptor en una determinada dirección. Así, si el radio de impacto fuera demasiado grande, habría receptores que recibirían dos o más rayos adyacentes, lo que equivaldría a contar varias veces la misma contribución de campo, lo cual no es correcto. Y si el radio es excesivamente pequeño, algunos receptores pueden no ser alcanzados por ningún rayo, cosa que tampoco es válida (figura 5.4).

En dos dimensiones, el problema es fácil de resolver. Dos rayos adyacentes, separados un ángulo $\alpha$, tras haber recorrido una distancia $d$, se encontrarán separados una distancia $D=\alpha d$. Por tanto, para un receptor dado, se podrá tomar un radio de impacto $r=\alpha d / 2$, donde $d$ será la distancia recorrida por el rayo cuyo impacto sobre el receptor se quiere determinar. De esta forma, se garantiza que se recibirá un impacto, y sólo uno, por cada frente de ondas [Sch92].

Bajo esta condiciones, un rayo con una determinada dirección dada por el ángulo $\phi$ cubre una fracción del plano bidimensional delimitada por el intervalo $[\phi-\alpha / 2, \phi+\alpha / 2]$. Se llamará a esta zona del espacio, zona de influencia del rayo (figura 5.5). Tal y como se ha definido el radio de impacto, ninguna de estas zonas se superpone con las de otros rayos y, en conjunto, cubren todo el plano. 


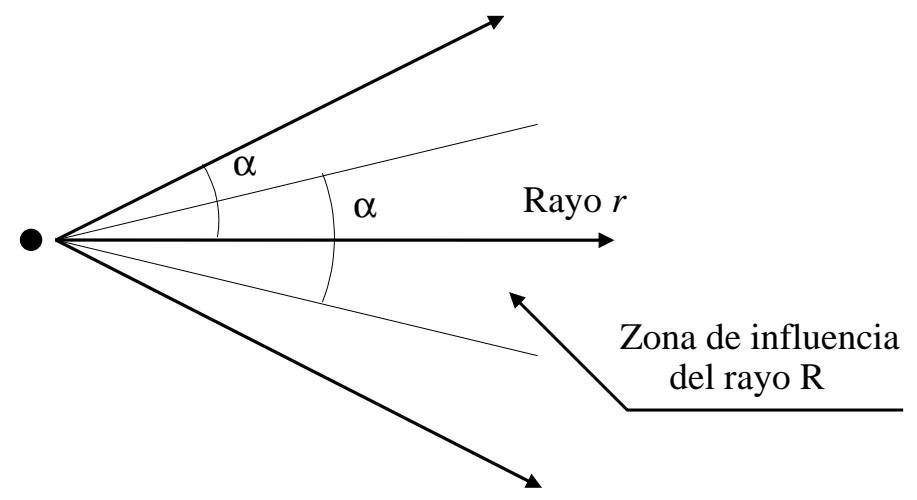

Figura 5.5: Zona de influencia de un rayo en 2D

En principio, cabría pensar que dicho valor de radio de impacto también sería aplicable para el caso tridimensional. Aunque intuitivamente este razonamiento parece correcto, no lo es, ya que este criterio origina una serie de problemas en 3D. Estos problemas y la forma de solucionarlos serán comentados con detalle más adelante, en secciones posteriores.

\subsubsection{Determinación de la distancia entre el rayo y el receptor}

Tal y como se ha visto en el apartado anterior, determinar la distancia existente entre un rayo y un receptor es esencial para determinar si el primero impacta sobre el segundo. A continuación se resolverá el problema geométricamente.

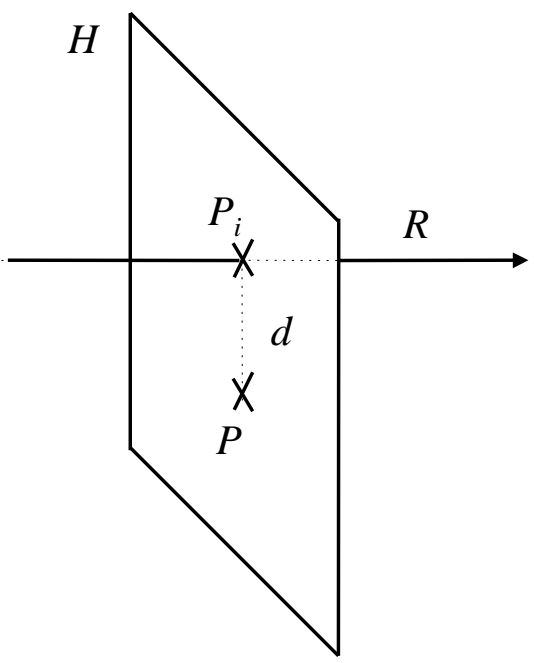

Figura 5.6: Cálculo de la distancia entre un rayo y un punto

Se planteará el problema considerando que la distancia entre un rayo $R$ y un punto $P$ es igual a la distancia entre dicho punto $P$ y la intersección $P_{i}$ del rayo $R$ con el plano $H$, ortogonal a $R$ y que pasa por $\mathrm{P}$ (figura 5.6). Se puede definir geométricamente el rayo con 
la siguiente expresión:

$$
R(t)=R_{0}+\vec{R}_{V} t
$$

donde $t>0$ es la distancia recorrida por el rayo; $R_{0}$ es el punto de origen del rayo, con coordenadas $\left(R_{0_{X}}, R_{0_{Y}}, R_{0_{Z}}\right)$, y $\vec{R}_{V}$ es el vector normalizado que define la dirección en la que se propaga el rayo, con coordenadas $\left(R_{V_{X}}, R_{V_{Y}}, R_{V_{Z}}\right)$.

Se puede definir geométricamente el plano $H$ mediante la expresión:

$$
A x+B y+C z+D=0
$$

donde $A^{2}+B^{2}+C^{2}=1$.

Como el plano es perpendicular a la dirección de propagación del rayo, el vector director del plano, $\vec{H}_{n}$, será igual a:

$$
\vec{H}_{n}=(A, B, C)=\left(R_{V_{X}}, R_{V_{Y}}, R_{V_{Z}}\right)=\vec{R}_{V}
$$

Con esto, sólo queda por determinar el valor de $D$ en la ecuación del plano. Como el punto $P$ ha de estar contenido en el plano $H$, se puede determinar $D$ sustituyendo el valor de las coordenadas de $P$ en la ecuación del plano. Así, si las coordenadas de $P$ son $\left(P_{X}, P_{Y}, P_{Z}\right)$, se obtiene:

$$
D=-A x-B y-C z=-\left(R_{V_{X}} P_{X}+R_{V_{Y}} P_{X}+R_{V_{Z}} P_{X}\right)=-\vec{R}_{V} \cdot P
$$

Una vez caracterizados el plano $H$ y el rayo $R$, puede calcularse la distancia desde el origen del rayo hasta su intersección con el plano $H$, sustituyendo la ecuación del rayo en la del plano:

$$
A\left(R_{0_{X}}+R_{V_{X}} t\right)+B\left(R_{0_{Y}}+R_{V_{Y}} t\right)+C\left(R_{0_{Z}}+R_{V_{Z}} t\right)+D=0
$$

Despejando $t$, se obtiene:

$$
t=-\frac{A R_{0_{X}}+B R_{0_{Y}}+C R_{0_{Z}}+D}{A R_{V_{X}}+B R_{V_{Y}}+C R_{V_{Z}}}
$$

o, lo que es lo mismo:

$$
t=-\frac{R_{0} \cdot \vec{H}_{n}+D}{\vec{R}_{V} \cdot \vec{H}_{n}}
$$

Como $\vec{H}_{n}=\vec{R}_{V}$, y ambos vectores están normalizados, resulta que $\vec{R}_{V} \cdot \vec{H}_{n}=1$, con lo que $t$ queda como:

$$
t=-\left(R_{0} \cdot \vec{H}_{n}+D\right)=-R_{0} \cdot \vec{H}_{n}+\vec{R}_{V} \cdot P
$$

Llegado a este punto, debe señalarse que, hasta ahora, se ha definido el rayo $R$ mediante la ecuación de la recta, lo cual no es exacto. Un rayo corresponde más bien a un segmento 
de dicha recta, ya que tiene un punto de origen $R_{0}$ (que puede ser el emisor, si es un rayo directo, o bien el obstáculo a partir del cual se ha originado la reflexión o transmisión), y un punto final (al ser el rayo interceptado por otro obstáculo del entorno). Esto implica que, aunque la recta definida por la ecuación $R(t)$ corte al plano $H$ (lo cual ocurrirá siempre que no sean paralelos), el segmento que corresponde al rayo no tiene por qué hacerlo.

Se puede determinar cuándo hay efectivamente intersección entre el rayo $R$ y el plano $H$ a partir de la distancia recorrida $t$. Así, sea un rayo contenido en la recta $R$, limitado por el punto de origen $R_{0}$ y el punto final $R_{f}$, situado a una distancia $t_{f}$ del origen. Si la recta corta al plano $H$ a una distancia $t$, el rayo sólo atravesará el plano si $0<t<t_{f}$. De no ser así, no hay intersección (figura 5.7).

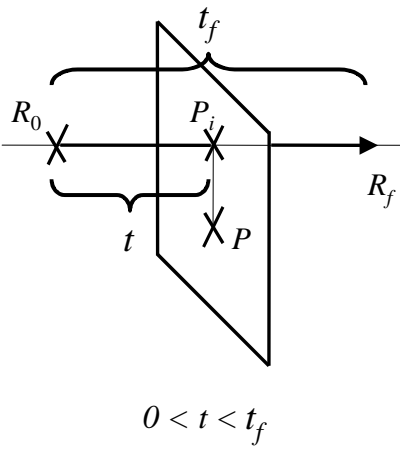

Hay intersección rayo/plano

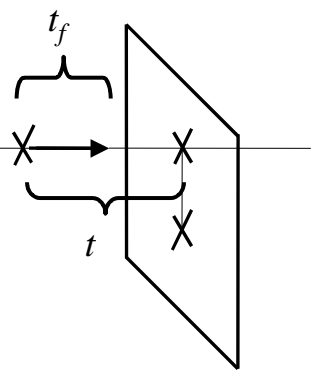

$t>t_{f}$

No hay intersección rayo/plano

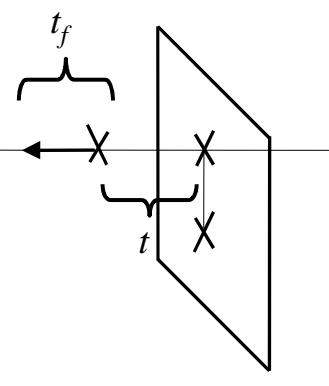

$t<0$

No hay intersección rayo/plano

Figura 5.7: El parámetro $t$ permite determinar si efectivamente se produce intersección entre un rayo y un plano

Si no hay intersección entre el rayo $R$ y el plano $H$, puede considerarse que el rayo no se acerca lo suficiente al punto $P$ bajo estudio, descartándose directamente el posible impacto, sin hacer ninguna comprobación más.

De no ser así, se determina la posición del punto $P_{i}$ en que el rayo $R$ corta al plano $H$, sustituyendo el valor de $t$ que se ha obtenido para la intersección, en la ecuación de la recta. Una vez obtenido $P_{i}$, la determinación de la distancia entre $R$ y $P$ es inmediata, pues coincide con la distancia entre $P$ y $P_{i}$.

\subsection{Problemas del Lanzado de Rayos}

La problemática del Lanzado de Rayos en entornos tridimensionales viene relacionada, como ya se apuntó en secciones anteriores, con la técnica para determinar si un receptor es alcanzado o no por cada rayo generado.

A continuación se comentarán los problemas que aparecen, así como los métodos utilizados para su solución. 


\subsubsection{Zonas de sombra}

Como ya se ha comentado, la determinación del radio de impacto de los receptores es fundamental de cara a determinar si éstos son alcanzados por los rayos emitidos desde el transmisor. Se propueso que, para tres dimensiones, pudiera hacerse extensivo el radio de impacto calculado para dos dimensiones, es decir, $r=\alpha d / 2$, siendo $d$ la distancia recorrida por el rayo, y $\alpha$ la separación angular con que se emiten. Sin embargo, el empleo de este radio $2 \mathrm{D}$ provoca errores en simulaciones realizadas en entornos $3 \mathrm{D}$.

Lo primero que se ha de considerar es que el concepto de zona de influencia del rayo cambia al pasar de dos a tres dimensiones. Al trabajar en 2D, como ya se ha dicho, la zona de influencia del rayo corresponderá a un área plana triangular delimitada en torno a dicho rayo. Sin embargo, trabajando en 3D, se tratará de un volumen tridimensional delimitado por una superficie cónica con su vértice en el origen de rayos, siendo su eje central el propio rayo (figura 5.8).

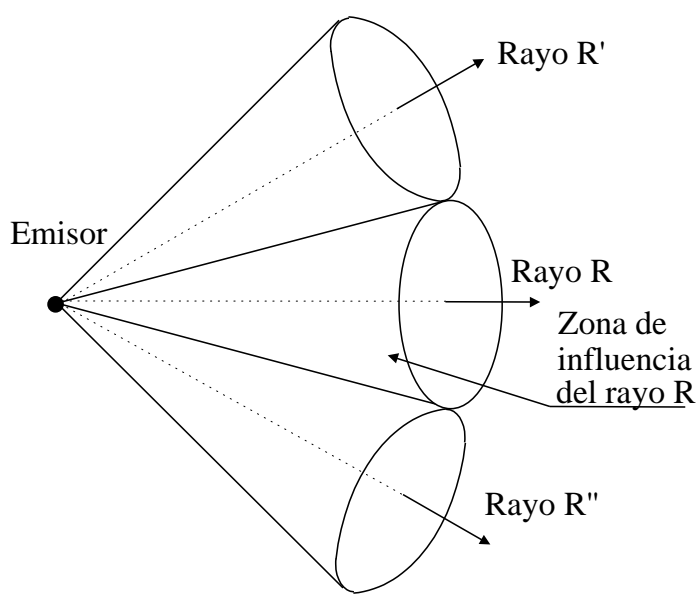

Figura 5.8: Volumen de influencia de cada rayo en 3D

Sea un corte sobre una de estas zonas de influencia, formado por un plano $P$ perpendicular a un rayo $R_{n}$ a una distancia arbitraria $d$ del origen de rayos (figura 5.9). Como aproximación, se puede suponer que los puntos donde los distintos rayos emitidos cortan a dicho plano, están separados entre sí una distancia $D=\alpha d$. De esta forma, los puntos de corte quedan distribuidos formando una cuadrícula de anchura $D$.

Esta aproximación sólo será válida para los rayos próximos al rayo $R_{n}{ }^{*}$, pero resulta razonable considerando una densidad de rayos lanzados suficientemente alta. También es válido suponer que, para esos rayos próximos al rayo $R_{n}$, las intersecciones entre las zonas de influencia de esos rayos y el plano $P$ tendrán forma de circunferencias de radio $r=\alpha d$, centradas en los puntos de la cuadrícula (figura 5.10), siempre y cuando se haya tomado como radio de impacto el establecido en entornos $2 \mathrm{D}$.

Como puede verse en la figura 5.10, entre las zonas de influencia de $R_{n}$ y sus rayos adyacentes quedan unas zonas de sombra que no pertenecen a ninguna de las zonas de

${ }^{*}$ En general, todos estos rayos adyacentes estarán definiendo el mismo frente de ondas 


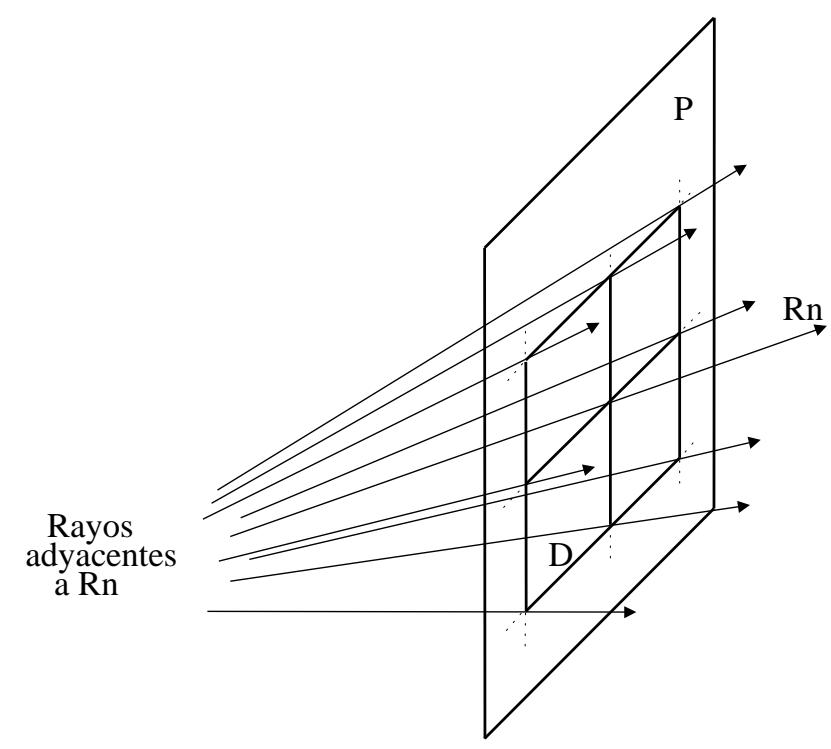

Figura 5.9: Intersección de un rayo central $R_{n}$ y de varios rayos adyacentes al mismo, con un plano $P$ perpendicular a $R_{n}$

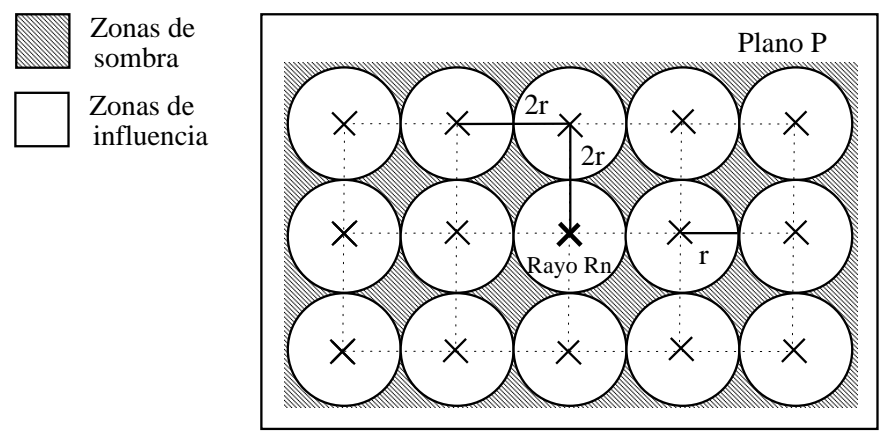

Figura 5.10: Aparición de zonas de sombra en el Lanzado de Rayos 
influencia de cada rayo. Los posibles receptores contenidos en esas zonas no recibirán ningún rayo, generandose así un error, pues sería equivalente a que el frente de ondas que definen estos rayos no alcanza a estos receptores.

En principio, este problema puede ser resuelto aumentando el radio de impacto hasta cubrir estas zonas de sombra. Así, si se asigna al radio de impacto un valor igual a la mitad de la diagonal de los cuadrados que forman la cuadricula (figura 5.11), las zonas de sombra desaparecen. Por tanto, el radio de impacto en 3D podría quedar definido como $r^{\prime}=D \sqrt{2}=\alpha d / \sqrt{2}$. Sin embargo, esto conlleva un nuevo inconveniente ya que, si se utiliza un radio de impacto mayor que $d / 2$, las zonas de influencia de los rayos adyacentes intersectarán entre sí, provocando que los posibles receptores situados en dichas zonas de intersección sean alcanzados por más de un rayo procedente de un mismo frente de ondas, lo cual equivaldría a contabilizar dos veces el mismo aporte de campo eléctrico recibido. Este problema de los impactos redundantes, y su solución, será tratado posteriormente con más detenimiento en la sección 5.4.2.

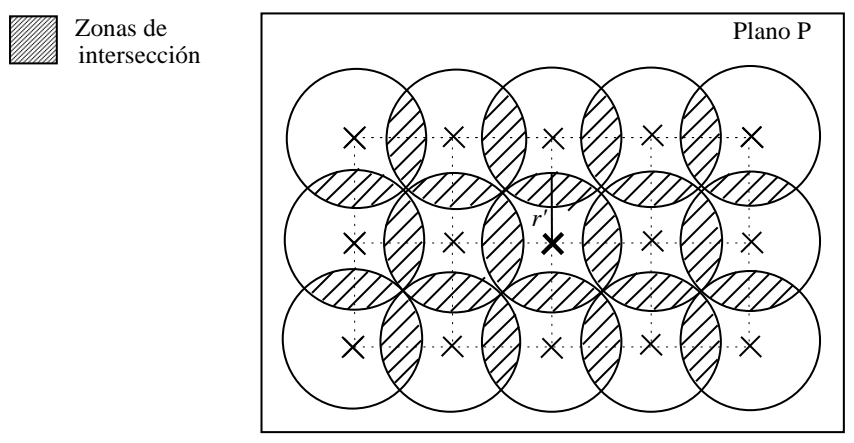

Figura 5.11: Aparición de zonas de intersección en el Lanzado de Rayos

Efectivamente, al aumentar el radio de impacto hasta $\alpha d / \sqrt{2}$, se consigue reducir la cantidad de receptores que quedan sin cobertura para un determinado frente de ondas. Sin embargo, tras realizar varias simulaciones previas, se pudo comprobar que todavía aparecían algunos huecos en los resultados obtenidos.

Las causas son debidas a que, hasta ahora, se ha estado suponiendo que el Lanzado de Rayos se hacía uniformemente con una separación angular $\alpha$ constante. Sin embargo, como se verá a continuación, hay un pequeño margen de variación en dicha separación angular, de tal forma que, en algunos casos, el valor real de la separación angular es algo mayor que el valor nominal. Esto provocará nuevas zonas de sombra en torno a algunos rayos.

Recuérdese el planteamiento del método utilizado para lanzar rayos desde un emisor. Para conseguir una distancia angular constante $\alpha=\Delta \theta$, se procede a dividir una esfera unidad centrada en el emisor en $n$ paralelos, cada uno de ellos separados entre sí en 
elevación por una separación angular $\Delta \theta=2 \pi / n$. A través de cada uno de estos paralelos, se hace pasar un conjunto de rayos separados entre sí, igualmente, una distancia angular $\Delta \theta$.

De acuerdo con este procedimiento, es evidente que aquellos rayos adyacentes que pasen por un mismo paralelo de la esfera unidad mantendrán una separación angular exacta de $\Delta \theta$. Pero no sucede lo mismo con aquellos rayos adyacentes que correspondan a paralelos contiguos.

Sea un caso general, como el mostrado en la figura 5.12. En ella se muestra un rayo $R$ emitido desde el transmisor $T_{X}$, con una orientación definida por las coordenadas esféricas $\left(\phi_{R}, \theta_{R}\right)$, y que pasa por el paralelo $n$. Se muestra también un rayo $R^{\prime}$, también emitido desde el transmisor $T_{X}$, adyacente a $R$, con una orientación definida por $\left(\phi_{R^{\prime}}, \theta_{R^{\prime}}\right), \mathrm{y}$ perteneciente al paralelo $n+1$ (separado de $n$ por una elevación $\Delta \theta$ ).

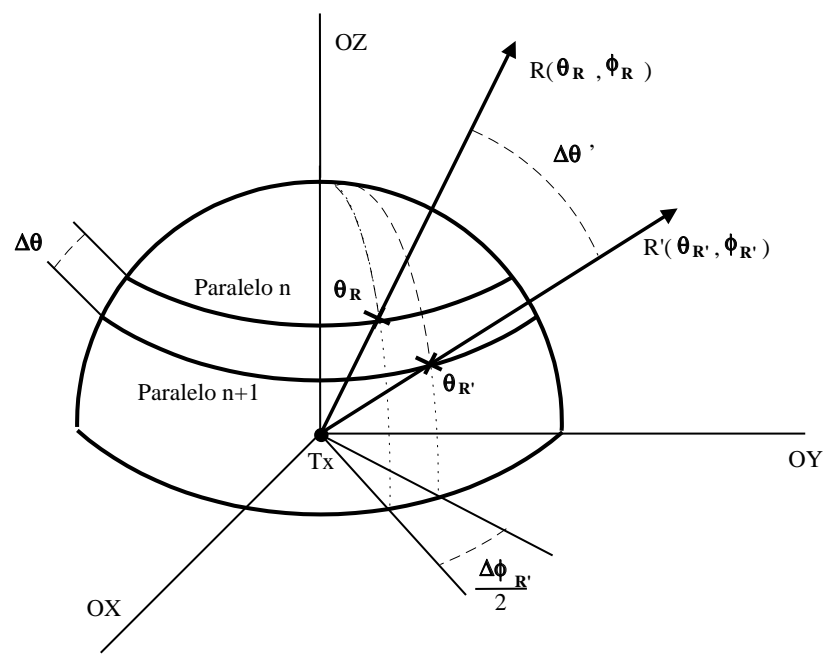

Figura 5.12: Separación angular entre dos rayos adyacentes pertenecientes a paralelos contiguos

En el caso óptimo, cuando $\phi_{R^{\prime}}=\phi_{R}$, ocurrirá que los rayos $R$ y $R^{\prime}$, efectivamente, mantendrán una separación angular de $\Delta \theta$. Sin embargo, esto no tiene por qué cumplirse siempre. El valor de $\phi_{R}$ puede estar desviado respecto de $\phi_{R^{\prime}}$. El grado de desviación dependerá del valor de $\Delta \phi_{n+1}$ dado por la ecuación (5.4), de manera que la máxima desviación posible será:

$$
\phi_{R^{\prime}}=\phi_{R}+\Delta \phi_{n+1} / 2
$$

Naturalmente, hay muchos más rayos en el paralelo $n$ con una desviación respecto a $R$ mucho mayor, pero se tratarán de rayos no contiguos.

Por lo tanto, se ha de calcular la máxima separación angular $\Delta \theta^{\prime}$ entre $R$ y $R^{\prime}$. Para ello, se empezará hallando el valor de los vectores directores de cada rayo, $\vec{V}_{R}$ y $\vec{V}_{R^{\prime}}$, normalizados y en coordenadas cartesianas:

$$
\vec{V}_{R}=\left(\sin \theta_{R} \cos \phi_{R}, \sin \theta_{R} \sin \phi_{R}, \cos \theta_{R}\right)
$$




$$
\vec{V}_{R^{\prime}}=\left(\sin \theta_{R^{\prime}} \cos \phi_{R^{\prime}}, \sin \theta_{R^{\prime}} \sin \phi_{R^{\prime}}, \cos \theta_{R^{\prime}}\right)
$$

Hay que tener en cuenta que el rayo $R$ pertenece al paralelo $n$, mientras que el $R^{\prime}$ pertence al paralelo $(n+1)$. Por tanto, teniendo en cuenta las ecuaciones (5.3) y (5.4), y que $\theta_{R}=\theta_{n}$ y $\theta_{R^{\prime}}=\theta_{n}+\Delta \theta$, se podrá calcular el producto escalar entre los vectores $\vec{V}_{R}$ y $\vec{V}_{R^{\prime}}$, obteniendo el valor del coseno del ángulo que forman, es decir, $\cos \Delta \theta^{\prime}$. Así, despejando $\Delta \theta^{\prime}$, resulta:

$$
\Delta \theta^{\prime}=\arccos (\sin \theta \sin (\theta+\Delta \theta) \cos (\Delta \theta / 2 \sin (\theta+\Delta \theta)))+\cos \theta \cos (\theta+\Delta \theta)
$$

Como puede verse, los valores que pueda tomar $\Delta \theta^{\prime}$ dependen de dos factores: la resolución empleada en el lanzado $\Delta \theta$, y la elevación de cada rayo $\theta$. En la figura 5.13 se representa el cociente entre el máximo valor que pueda tomar $\Delta \theta^{\prime}$ y la resolución con que se hace el lanzado $\Delta \theta$, en función de el número de paralelos $N$ en que se divida la esfera.

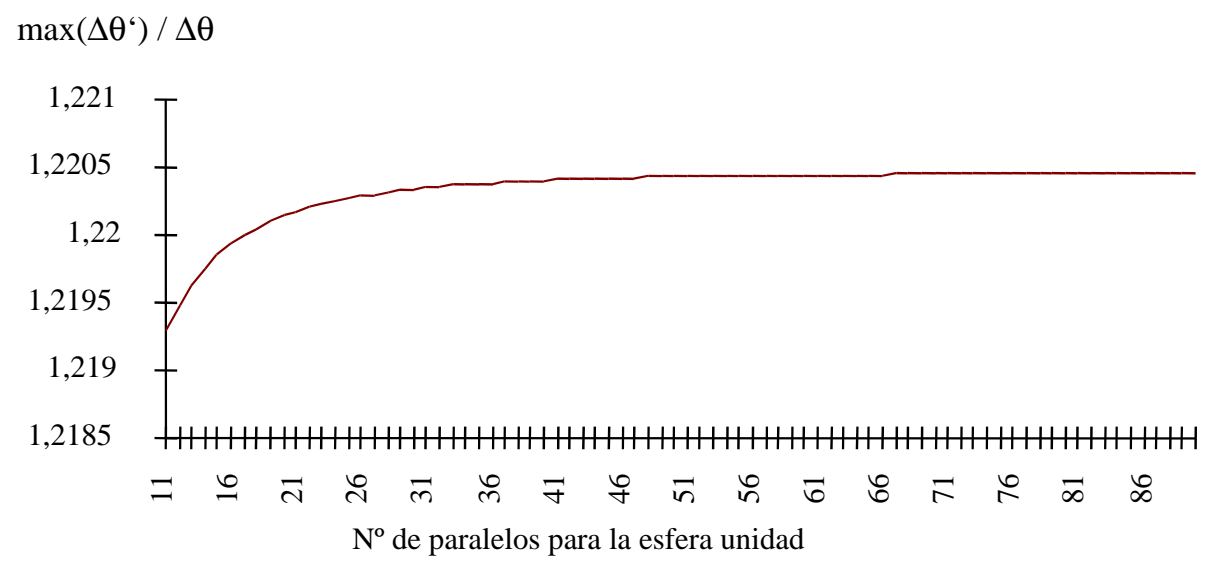

Figura 5.13: Representación del cociente $\max \left(\Delta \theta^{\prime}\right) / \Delta \theta$, en función del número de paralelos de la esfera unidad

En dicha figura se aprecia que el valor del cociente converge a medida que aumenta la resolución angular del lanzado, de manera que se puede afirmar que, para cualquier resolución utilizada, se cumple que:

$$
\Delta \theta^{\prime}<1,2205 \cdot \Delta \theta
$$

De acuerdo con esto, si se emplea un radio de impacto tal que el valor de $\alpha$ considerado no sea el nominal $(\Delta \theta)$, sino el máximo posible $\left(\alpha_{\max }=\max \left(\Delta \theta^{\prime}\right)\right)$, se garantiza que no quedará ni un solo punto del espacio que no sea susceptible de ser alcanzado por un rayo de un determinado frente de ondas. Por tanto, este radio de impacto deberá ser:

$$
r=\alpha_{\max } d / \sqrt{2}=1,2205 \cdot \frac{\alpha d}{\sqrt{2}}
$$

siendo $d$ la distancia recorrida por el frente de ondas, y $\alpha$ la resolución nominal pretendida. 


\subsubsection{Impactos redundantes}

Como se ha visto en la sección anterior, debe asignarse al radio de impacto un valor por exceso para eliminar el problema de las zonas de sombra. Sin embargo, esto crea nuevas complicaciones, ya que provoca que las zonas de influencia de cada rayo intersecten entre sí. Los receptores que estén situados dentro de estas zonas de intersección recibirán más de un rayo procedente de un mismo frente de ondas, lo que físicamente es tan erróneo como no recibir ninguno, ya que equivale a contabilizar varias veces la misma contribución de campo eléctrico recibido. Un ejemplo de los efectos que provoca, se representa en la figura 5.14, donde se muestran los resultados obtenidos para una simulación particular, usando tanto el método de Lanzado de Tubos (que no presenta este problema de redundancia y que más adelante se explicará), como el de Lanzado de Rayos sin haber solucionado este problema de los impactos redundantes. La simulación se ha hecho para un entorno vacío y sin considerar posibles reflexiones. Como puede verse, con el Lanzado de Rayos aparecen zonas puntuales con niveles de potencia superiores a lo esperable. Estos puntos se corresponden con receptores que están recibiendo más de un rayo directo.

Lanzado de Tubos

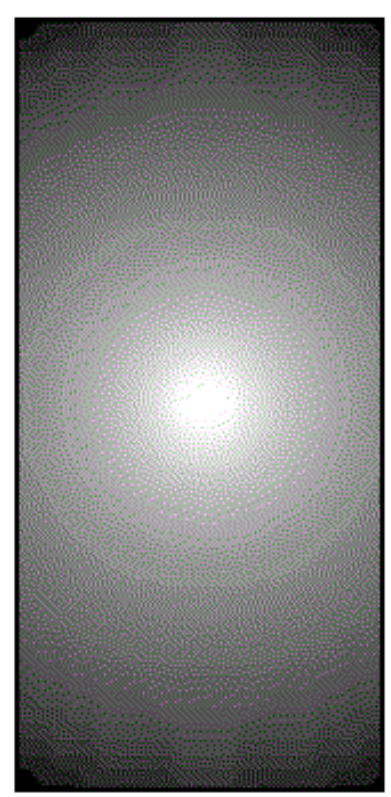

\section{Lanzado de Rayos}

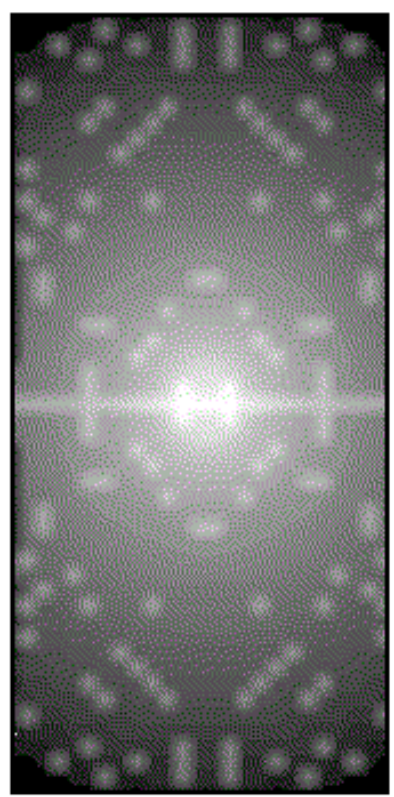

Figura 5.14: Problema de impactos redundantes en el Lanzado de Rayos

Efectivamente, la probabilidad de que dos rayos contiguos impacten sobre una misma esfera de recepción es bastante alta. Geométricamente, y considerando un frente de ondas ideal en el que las esferas de recepción se distribuyan con geometría hexagonal, siendo el radio de impacto igual al lado de un hexágono, dicha probabilidad vale:

$$
\frac{2 \pi}{3 \sqrt{3}}-1 \approx 21 \%
$$


valor que puede ser considerado como cota mínima.

Cada impacto redundante provocará un aumento de la potencia recibida de hasta $6 \mathrm{~dB}$, suponiendo suma coherente (situación habitual teniendo en cuenta que los rayos pertenecen al mismo frente de ondas). Suponiendo una distribución uniforme de receptores, la potencia media recibida se verá incrementada en, al menos, $1.26 \mathrm{~dB}$, introduciendo una desviación estándar del error de $2.4 \mathrm{~dB}$ adicionales. De hecho, en simulaciones realizadas se han observado comportamientos aun peores.

Este problema de los impactos redundantes fue detectado de forma simultánea por dos grupos de trabajo: el liderado por el autor de esta Tesis, y publicado en [May97], y el MPRG* de la Universidad Politécnica de Virginia [Dur97a, Dur97b]. A continuación se presentará la solución adoptada en este último trabajo, comparándose posteriormente con la que se propone en esta Tesis.

\section{Eliminación de impactos redundantes mediante frentes de onda distribuidos}

En [Dur97a] se propone un método de procesado de los impactos redundantes, que puede ser denominado método de los frentes de onda distribuidos, consistente en una ponderación de los rayos que impactan en cada esfera de recepción, en función de la distancia que mantienen con el receptor. Así, si el radio impacta directamente en el receptor, no se considerará ninguna corrección, pero si impacta en las cercanías del borde de la esfera de recepción, muy probablemente habrá que considerarlo como un impacto redundante, por lo que habrá que atenuar su importancia.

En definitiva, se considerará que el campo recibido en un punto $R$ será igual a:

$$
\vec{E}_{R}=\sum_{i} \vec{E}_{i} f\left(x_{i}\right)
$$

siendo $\vec{E}_{i}$ cada una de las contribuciones de campo asociada a los rayos impactantes, cuya distancia mínima con el receptor es $x_{i}$, y $f(x)$ la función de ponderación considerada.

Esta función de ponderación está tabulada y ha sido obtenida mediante el método de Monte-Carlo. Los valores de la tabla se detallan en [Dur97a], y se representa en la figura 5.15

Se ha comprobado que este método resulta óptimo para simulaciones en banda estrecha en entornos amplios (exteriores) [Dur97b]. Sin embargo, como más adelante se comprobará (capítulo 7), no es útil en situaciones indoor en las que las contribuciones, debidas sobre todo a las múltiples reflexiones en el entorno, pueden llegar de infinidad de direcciones. Esta desconsideración afecta necesariamente, además, a las simulaciones en banda ancha.

\section{Eliminación de impactos redundantes mediante verificación exhaustiva}

Para solucionar el problema de los impactos redundantes, se puede optar por un algoritmo alternativo. Se trata de verificar de forma exhaustiva (es decir, para cada rayo) si el

\footnotetext{
${ }^{*}$ Mobile and Portable Radio Research Group
} 


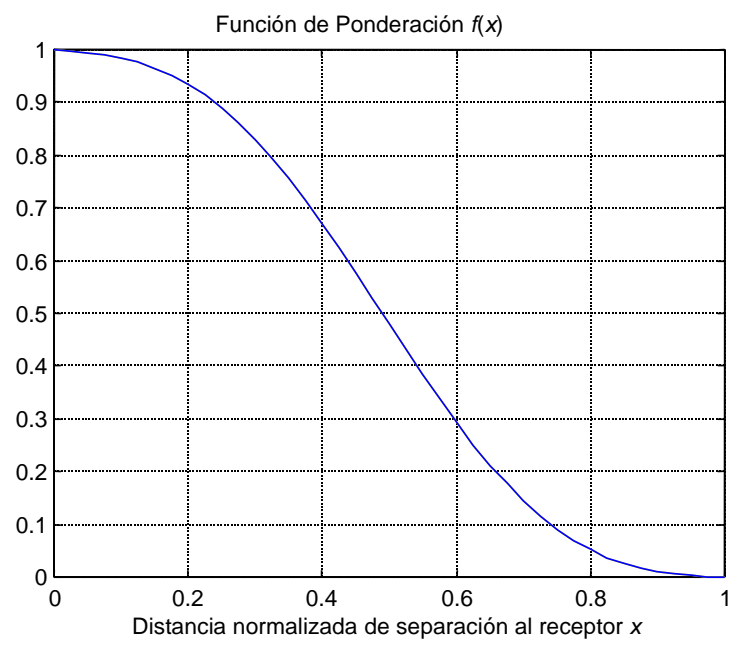

Figura 5.15: Función de ponderación empleada en el método de los frentes de onda distribuidos

aporte de campo sobre un receptor se ha tenido ya en cuenta mediante otro rayo que haya impactado previamente durante el transcurso de la simulación, en cuyo caso, esta nueva aportación será descartada.

Si no se consideraran reflexiones en la simulación, no habría problema en determinar cuándo sucede esto, puesto que ninguno de los receptores considerados en la simulación puede ser alcanzado por más de un rayo. Por tanto, si un receptor recibiera un segundo impacto, automáticamente se sabría que es redundante, y por tanto podría ser descartado. Sin embargo, normalmente se considerarán reflexiones hasta la $n$-ésima generación. En ese caso, un receptor puede recibir una cantidad indeterminada de impactos, de los cuales algunos corresponderán a distintas aportaciones de campo provocadas por las reflexiones, y otros serán redundantes. Para poder distinguir unos de otros y resolver este problema, se ha diseñado el algoritmo de verificación de redundancia que se describe a continuación.

Dados dos rayos que alcancen a un mismo receptor (siguiendo el criterio establecido por el radio de impacto), se supondrá que ambos aportan la misma contribución de campo (es decir, uno de ellos es redundante) si tienen una orientación muy próxima y además han sufrido el mismo número de reflexiones o transmisiones (figura 5.16).

La condición de orientación próxima está basada en el hecho de que dos rayos redundantes que atraviesen el espacio definido por el radio de impacto de un receptor, por fuerza tienen que ser rayos adyacentes, lo cual implica tener una dirección de propagación muy parecida. Este razonamiento puede mantenerse tanto para rayos que hayan recorrido mucha distancia como para aquellos que hayan sufrido varias reflexiones o transmisiones. Aunque la separación lineal entre los dos rayos se incrementa con la distancia, su separación angular se mantiene constante e igual a la que hubiera entre ellos en el origen de rayos (figura 5.17).

En cuanto a la condición del orden de reflexión o transmisión idéntico se basa en que es posible que un receptor reciba dos rayos con la misma orientación y que, sin embargo, se 


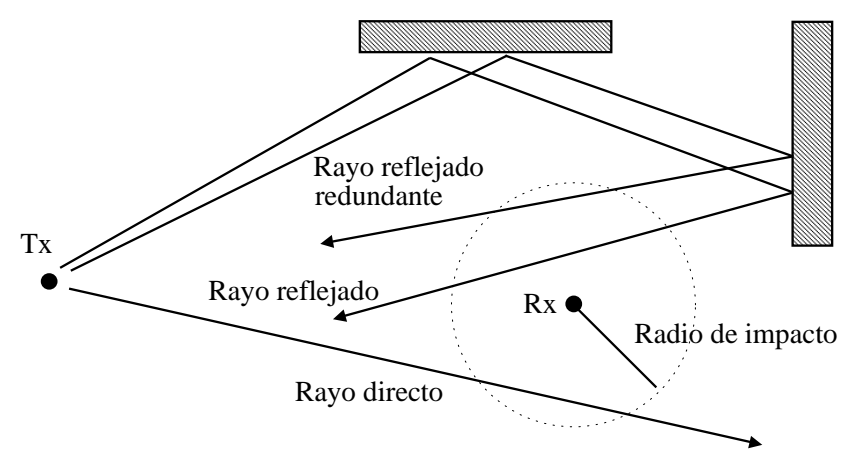

Figura 5.16: Rayos adyacentes alcanzando a un receptor y provocando la aparición de un impacto redundante

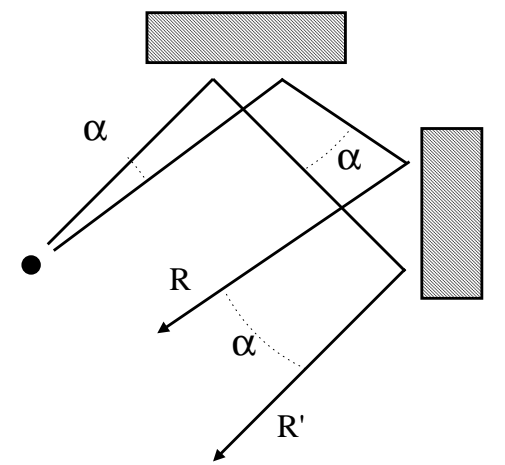

Figura 5.17: Dos rayos adyacentes mantienen su separación angular incluso tras sucesivas reflexiones 
correspondan con distintos frentes de onda, con lo cual descartar uno de los dos impactos no sería válido. En la figura 5.18 aparece un claro ejemplo de dicha situación. El rayo directo $R_{1}$ y el rayo reflejado $R_{2^{\prime}}$ alcanzan al receptor exactamente con la misma dirección de propagación, aunque uno corresponde al campo directo, y otro al que se refleja en la pared $P$.

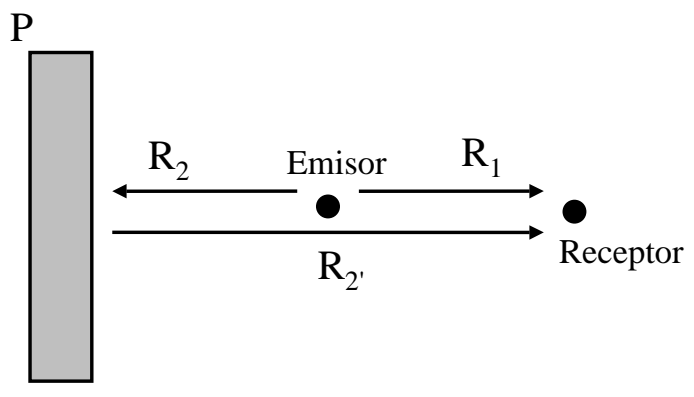

Figura 5.18: Dos rayos no adyacentes alcanzan al receptor con la misma orientación

Lo único que queda por determinar es cuál será el criterio según el cual se ha de considerar que dos rayos tienen una orientación similar. En principio, se puede pensar en calcular la distancia angular entre los rayos usando el producto escalar. Por trigonometría, la separación angular entre dos rayos $\alpha_{R_{1}, R_{2}}$ será:

$$
\alpha_{R_{1}, R_{2}}=\arccos \left(\vec{V}_{R_{1}} \cdot \vec{V}_{R_{2}}\right)
$$

donde $\vec{V}_{R_{1}}$ y $\vec{V}_{R_{2}}$ son los vectores normalizados en la dirección de los rayos $R_{1}$ y $R_{2}$. Como antes se ha determinado que el valor máximo de separación angular que puede darse en el Lanzado de Rayos es de $\alpha_{\max }=1,2205 \cdot \alpha_{\max }$, se podrá considerar que los rayos $R_{1}, R_{2}$, son adyacentes si:

$$
\alpha_{R_{1}, R_{2}}<\alpha_{\max }
$$

Pero existe un problema de implementación. Aunque este criterio es perfectamente válido, usarlo implica que el algoritmo implementado tendría que realizar repetidamente una operación trigonométrica (el cálculo del arcocoseno del producto escalar de los vectores directores), provocando una importantísima pérdida de velocidad. Así que, en lugar de eso, se ha optado por otro baremo para interpretar que dos rayos están lo bastante próximos, angularmente hablando, como para ser considerados adyacentes.

Así, se considerará que un rayo $r$, cuya dirección venga determinada por las coordenadas esféricas $(\phi, \theta)$, es redundante respecto a otro rayo de referencia $r_{\text {ref }}$ previamente contabilizado y con su dirección definida por $\left(\phi_{\text {ref }}, \theta_{\text {ref }}\right)$, si se cumple que*:

$$
\left(\phi_{\text {ref }}-K_{\phi} \Delta \phi_{\text {local }}<\phi<\phi_{\text {ref }}-K_{\phi} \Delta \phi_{\text {local }}\right) \wedge\left(\theta_{\text {ref }}-K_{\theta} \Delta \theta_{\text {local }}<\theta<\theta_{\text {ref }}-K_{\theta} \Delta \theta_{\text {local }}\right)
$$

o, dicho de otra forma, si cada uno de los valores de coordenadas esféricas que definen la dirección de $r$ son próximos a los de $r_{\text {ref }}$.

${ }^{*}$ El signo $\wedge$ representa la función lógica $A N D$ 
El criterio de proximidad viene determinado por los valores de $\Delta \phi_{\text {local }}$ y $\Delta \theta_{\text {local }}$, es decir, los valores de $\Delta \phi$ y $\Delta \theta$ correspondientes al paralelo de la esfera unidad asociado al lanzado del rayo $r$, y que determinan su separación angular respecto de sus rayos adyacentes. Las variables $K_{\phi}$ y $K_{\theta}$ son factores de corrección empíricos. Cuanto mayores sean, más probable es que los rayos $r$ y $r_{\text {ref }}$ sean adyacentes. Se han obtenido buenos resultados con valores de $K_{\phi}=1,5$ y $K_{\theta}=1,5$.

En el capítulo 7 se evaluará la bondad de este método, comparando los resultados con los obtenidos mediante el método anteriormente descrito. Se comprobará que en todos los casos es igual o más eficiente, superándolo ampliamente en entornos indoor con gran cantidad de receptores en situación NLOS o que sean alcanzados por un gran número de frentes de onda, no necesitando mucho más tiempo de computación a pesar de su exhaustividad.

\subsection{Lanzado de Tubos}

Ya se ha comentado anteriormente que este método es un caso particular del Lanzado de Rayos, en el que no se considera cada rayo por separado, sino que se agrupan de tres en tres, formando Tubos que se propagan como si fueran una única entidad. Puesto que el transporte de la potencia radiada se relaciona con el ángulo sólido que define cada tubo, parece más apropiado usar esa última opción. Así pues, será deseable que cada tubo formado por tres rayos ocupe el mismo ángulo sólido, y que cada frente de ondas tenga una misma forma y tamaño a cualquier distancia del transmisor.

La principal ventaja de este método es que no es necesaria una algorítmica compleja para determinar si un receptor es alcanzado o no. Cada tubo representa de forma unívoca una porción del frente de ondas desplazándose en su propia dirección y puede contabilizarse el campo eléctrico asociado a cada tubo cuando los receptores queden en su interior. No aparecen, por tanto, problemas de zonas de sombra ni de impactos redundantes.

A pesar de las ventajas, este método no se comporta exactamente igual que el de Lanzado de Rayos bajo ciertas situaciones, tanto en lo que se refiere a velocidad de proceso, como a los resultados obtenidos. Más adelante se comentarán tales diferencias. A continuación se procederá a describir cómo se genera este nuevo tipo de lanzado.

\subsubsection{Teselación de la esfera}

Para generar un Lanzado de Tubos uniforme, se ha de dividir (teselar) la superficie de la esfera que rodea al transmisor, en triángulos con superficies semejantes.

El transporte de la potencia se realiza en el interior de los tubos que parten del emisor. Por tanto, para asegurar una distribución uniforme, lo ideal es que cada tubo de rayos ocupe el mismo ángulo sólido $\Delta \Omega$, y que cada porción del frente de ondas tenga la misma forma y tamaño a una cierta distancia del transmisor. También es deseable que la forma del frente de ondas sea divisible para poder aplicar la técnica de división de tubos (splitting). Así se mantendría constante la resolución espacial del haz independientemente de la distancia recorrida, y se compensaría la dispersión que sufren los rayos al propagarse. 
Por tanto, se podría optar por crear tubos de sección triangular, creados al trazar tres rayos que pasen por el centro de la esfera y por los vértices de cada uno de los triángulos. La técnica para crear estos tubos triangulares es, aparentemente, sencilla. Se procede a dibujar una esfera de radio unidad centrada en el transmisor y se tesela su superficie. Los rayos se trazan partiendo del centro (posición del emisor) y atraviesan los vértices de las figuras en que se ha fragmentado el área total. La figura 5.19 ilustra este procedimiento.

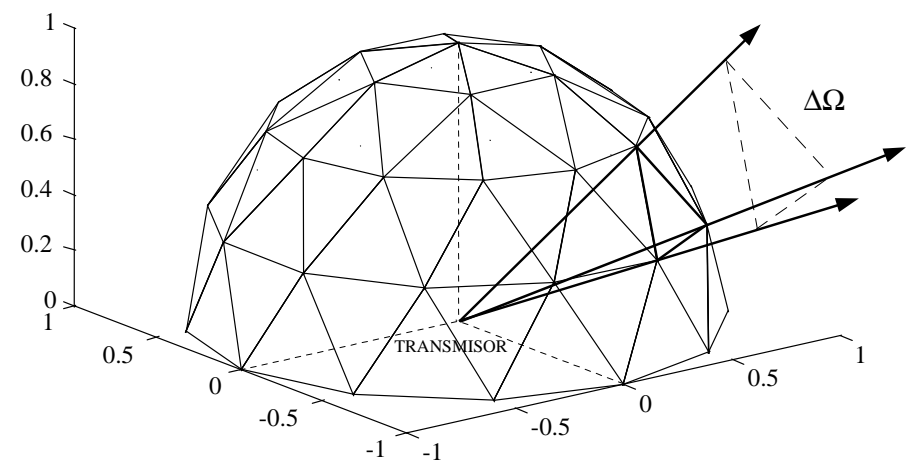

Figura 5.19: Creación de un tubo de sección triangular (tres rayos)

El problema aparece cuando se ha de dividir la superficie de la esfera en triángulos de igual forma y tamaño, sin dejar ningún hueco. Para un plana la solución es sencilla, puesto que triángulos equiláteros, cuadrados y hexágonos regulares pueden cubrir completa y perfectamente un área plana. En cambio, para una superficie tridimensional, aunque la separación angular constante puede ser fácil de visualizar e imaginar, los mecanismos para conseguirla son bastante complejos.

En principio, se podría utilizar el método del icosaedro con subteselación posterior, pero tiene el problema de la aparición de aberraciones geodésicas en la zona próxima a los vértices, además del bajo control que se tiene con este método sobre la resolución final conseguida [Dur97a].

Se ha optado por desarrollar un nuevo método que permite dividir la superficie de la esfera de radio unidad en triángulos casi iguales. Matemáticamente, es totalmente imposible que sean todos perfectamente iguales ya que solamente se puede conseguir generando un icosaedro, el cual proporciona solamente 20 triángulos equiláteros. En cualquier caso, como el propósito es dividir el espacio de la forma más uniforme posible, se puede aceptar una pequeña variación de las áreas de los triángulos sin que ello afecte al resultado final.

En primer lugar, se procede a dividir una semiesfera en $N$ paralelos, en función del grado de resolución que se desee. De esta forma, la separación angular entre ellos será constante y valdrá:

$$
\Delta \theta=\frac{\pi / 2}{N}
$$

Por lo tanto, la resolución espacial va a depender del número de paralelos en que se divida la esfera. A mayor cantidad de estos, menor será la separación angular y más triángulos se crearán para dividir totalmente la superficie de la semiesfera. 
El primer paso para teselar la superficie de la semiesfera consiste en inscribir un hexágono regular en la circunferencia formada por el primer paralelo, centrada en $\theta=0^{\circ}$. Después, desde su centro se trazan segmentos que lo dividen en 6 triángulos. El resultado de esta fase se puede observar en la figura 5.20(a), que presenta una vista en planta de la semiesfera de radio unidad y el hexágono hasta ahora construido. En este ejemplo se han dispuesto sólo 5 paralelos, para facilitar la visualización de todo el proceso.

(a)

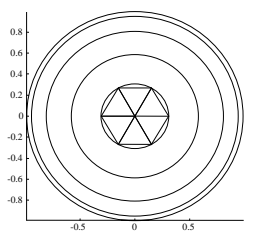

(b)

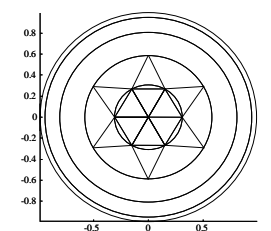

(c)

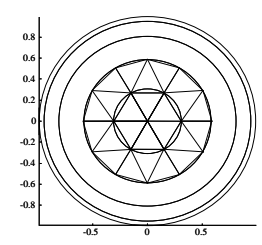

Figura 5.20: Primeros pasos de la teselación de la esfera

En el siguiente paso (que podría ser denominado paso 2.1), se crean parte de los triángulos que serán situados entre los paralelos primero y segundo (en el ejemplo, $\theta=\pi / 10$ y $\theta=\pi / 5$, respectivamente). Para ello, se calculan las imágenes invertidas de los triángulos de la fase anterior. Estos nuevos triángulos son idénticos a los primeros. Tal situación se puede observar en la figura 5.20(b).

Para completar la construcción de los triángulos situados entre los paralelos 1 y 2 , se dibujarán nuevos triángulos en los huecos dejados por los anteriores. Pero para ello hay que estudiar antes la variación de la longitud de los perímetros de dichos paralelos. $\mathrm{Al}$ ir aumentando el valor de $\theta$, la longitud de los paralelos sobre los que se apoyan los triángulos también va creciendo (el perímetro de un paralelo vale $2 \pi \sin \theta$ ). Si no se tiene en cuenta este efecto, los huecos dejados por los triángulos creados en el paso 2.1 podrían ser demasiado grandes y provocar el crecimiento desmesurado de los triángulos insertados en ellos. Obsérvese que, si se unen los triángulos de la figura 5.20(b) para crear 6 nuevos triángulos, la diferencia entre unos y otros sería notable. Para evitarlo, cuando la longitud de un paralelo supera en una cierta cantidad a la longitud del paralelo inmediatamente anterior (de longitud menor, necesariamente), se ha de repartir el hueco entre dos nuevos triángulos. El incremento de longitud fijado para el ejemplo mostrado es de 1.5 veces.

En la figura 5.20(c) se ve que, efectivamente, se han tenido que dividir los triángulos que se han añadido en el tercer paso para compensar el crecimiento del que se ha hablado. Sin embargo, en la construcción de los triángulos del siguiente paralelo (figura 5.21), se aprecia que no ha sido necesario realizar dicha división.

Todo el proceso hasta aquí descrito se repite para cada paralelo, hasta llegar al ecuador de la esfera. En la figura 5.21 se presenta la imagen de la semiesfera ya completamente teselada.

En las figuras 5.22 y 5.23 se presentan en planta y alzado, respectivamente, las imágenes de las superficies de dos esferas teseladas con un número elevado de paralelos. En la primera, el $\Delta \theta$ es de $3^{\circ}$ (30 paralelos), y en la segunda, de $1.5^{\circ}$ (60 paralelos).

Los cálculos se realizan solamente para el hemisferio superior (una semiesfera), ya que la otra mitad de los tubos se obtiene cambiando el signo de la componente $z$ (la altura) 


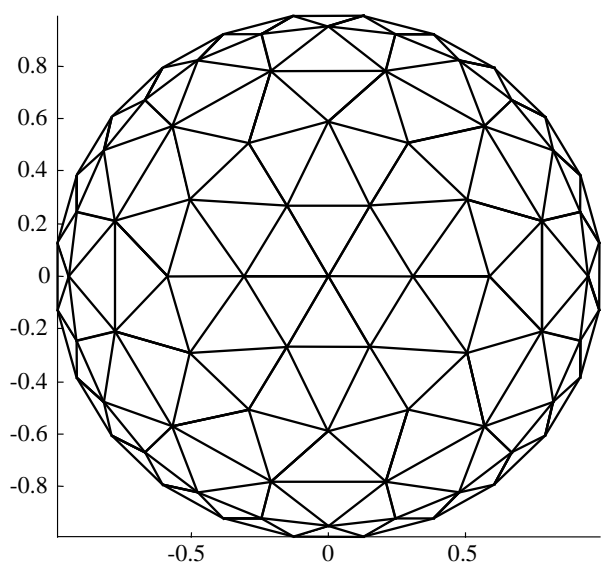

Figura 5.21: Proceso de teselación completado

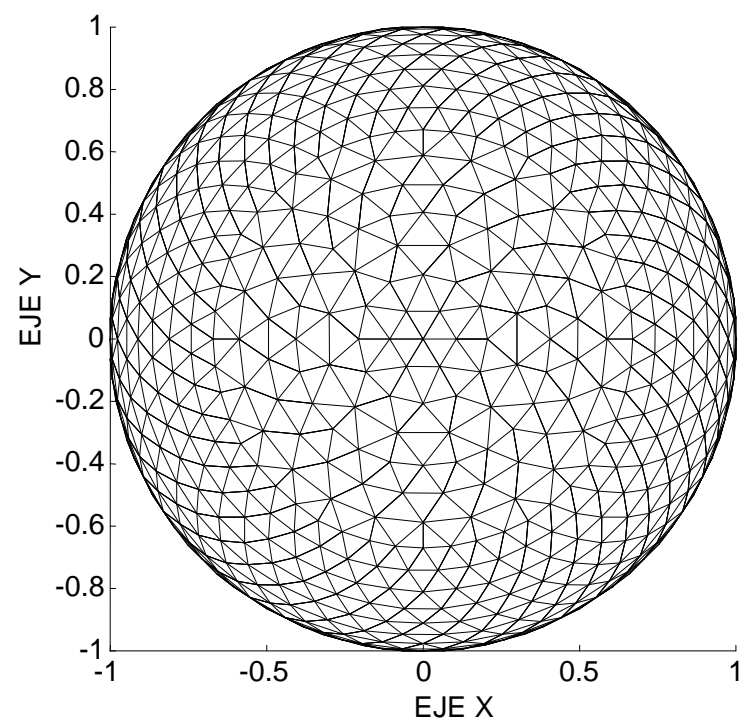

Figura 5.22: Vista superior de la esfera teselada con $\Delta \theta=3^{\circ}$ 


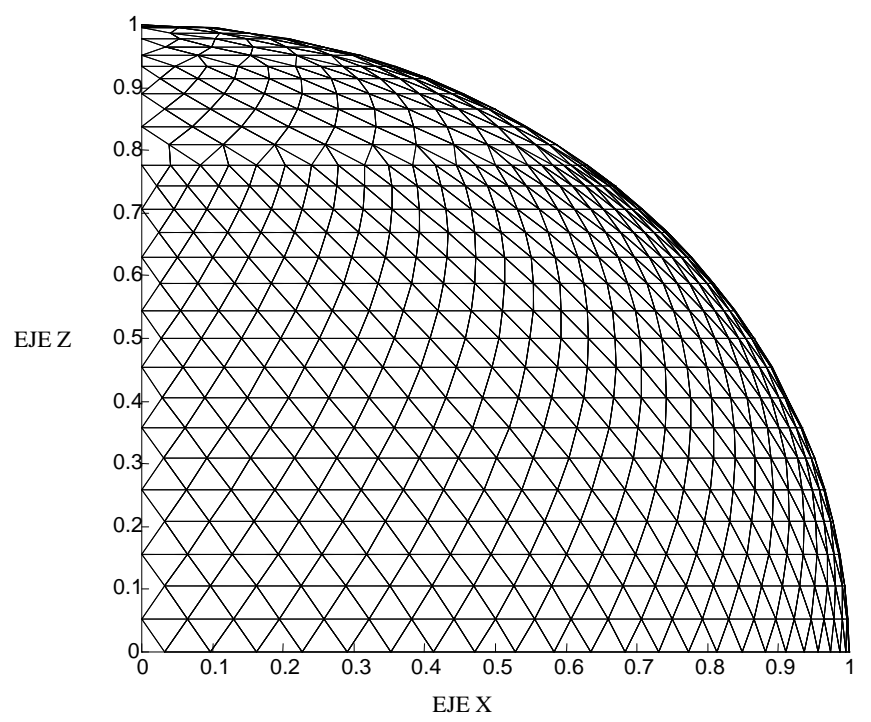

Figura 5.23: Alzado de 1/8 de la esfera con la superficie teselada con $\Delta \theta=1.5^{\circ}$

a todos los triángulos obtenidos antes. De esta forma se ahorra tiempo y espacio de información, ya que se ha de crear un archivo con la información de los triángulos, que puede alcanzar un tamaño considerable.

Más tarde, este fichero será utilizado para ir creando uno a uno los tubos, tal y como se ilustra en la figura 5.24. Los rayos 1,2 y 3 definen el volumen del tubo de sección triangular, y el rayo medio es el que se usa para transportar la información de la onda electromagnética.

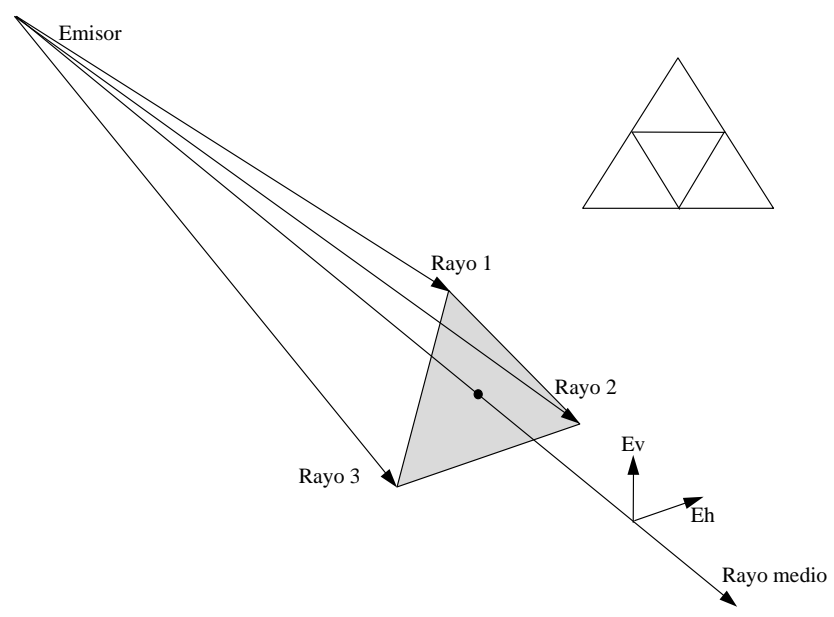

Figura 5.24: Rayos que forman el tubo de sección triangular, y dibujo de la subdivisión (split) de un triángulo en otros cuatro más pequeños 
Si se evalúa la uniformidad de las figuras halladas con el anterior proceso de teselación, se obtiene la tabla 5.1, donde se presentan las estadísticas más importantes de los triángulos para tres resoluciones distintas.

\begin{tabular}{|l|r|r|r|}
\hline & \multicolumn{3}{|c|}{ RESOLUCIÓN } \\
& 9 paralelos $\left(10^{\circ}\right)$ & 30 paralelos $\left(3^{\circ}\right)$ & 90 paralelos $\left(1^{\circ}\right)$ \\
\hline \hline Número de tubos & 648 & 8280 & 82200 \\
\hline Superficie media ideal & 0.01939254 & 0.00151767 & 0.000152875 \\
\hline Superficie media obtenida & 0.01920637 & 0.00151653 & 0.000152863 \\
\hline $\begin{array}{l}\text { Desviación típica de las } \\
\text { superficies }\end{array}$ & 0.00305938 & 0.00023059 & 0.00003198 \\
\hline Longitud media de los & $(15 \%)$ & $(15 \%)$ & $(20 \%)$ \\
lados de los triangulos & 0.21194761 & 0.05936632 & 0.01891337 \\
\hline $\begin{array}{l}\text { Desviación típica de los } \\
\text { lados de los triángulos }\end{array}$ & 0.02342933 & 0.00558833 & 0.00246266 \\
& $(11 \%)$ & $(9 \%)$ & $(13 \%)$ \\
\hline
\end{tabular}

Tabla 5.1: Comparación de las características de los tubos lanzados para varias resoluciones

En principio, no importan demasiado las grandes variaciones que hay en superficies triangulares obtenidas, ya que el objetivo no es obtener triángulos exactamente iguales, sino una distribución espacial homogénea de los tubos. Para el Lanzado de Tubos, estas variaciones no representan un inconveniente grave para el mecanismo de detección de impactos. Cada tubo tiene claramente delimitada la parte del espacio que abarca (aquella que cae dentro de sus límites), independientemente de la separación angular con los tubos adyacentes a su alrededor.

Se pensó en aprovechar este procedimiento para llevar a cabo también el Lanzado de Rayos. Sin embargo, como se ha visto, en este método sí afecta el problema de que la separación angular entre los rayos no se mantenga absolutamente constante. En el Lanzado de Rayos, la detección del impacto de un rayo en un receptor se realiza en función del radio de impacto, y que ese radio de impacto depende de la separación angular entre rayos, que se supone perfectamente constante. Si el valor real de distancia angular se desvía respecto del valor nominal con el que estamos trabajando, se obtendrán resultados erróneos. Una desviación típica del valor nominal respecto de la media del orden del $20 \%$ (figura 5.25) resulta excesiva para poder utilizar esta técnica de teselación de la esfera. Por ello se mantuvo, para el Lanzado de Rayos genérico, el método de discretización comentado en secciones anteriores.

\subsection{Estudio comparativo entre el Lanzado de Rayos y el Lanzado de Tubos}

El procedimiento de separación angular constante utilizado en la versión genérica del Lanzado de Rayos, tiene varias ventajas sobre el de la discretización de la esfera unidad utilizado en el Lanzado de Tubos. Para empezar, es mucho menos complejo, por lo que consume menos tiempo de computación. Además, los datos de la orientación de los rayos 


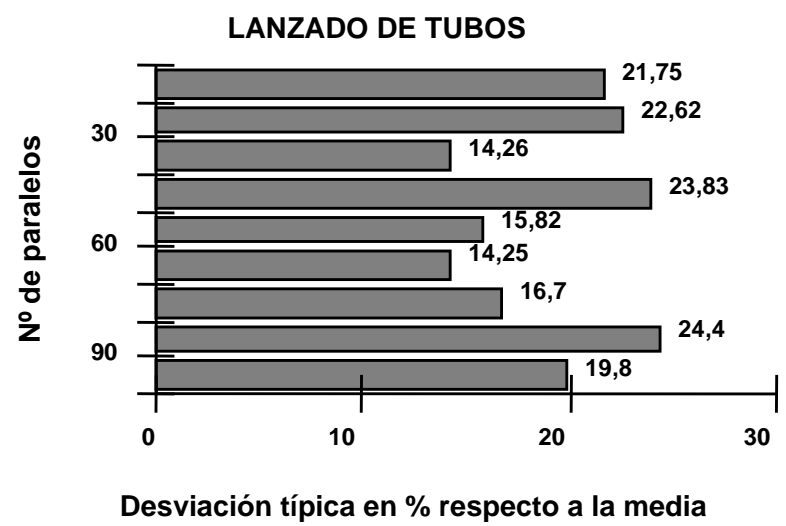

Figura 5.25: Desviación típica de la separación angular en el Lanzado de Tubos

no tienen que obtenerse al principio de la simulación y almacenarse en un fichero para poder acceder luego a ellos, sino que pueden calcularse en cualquier momento, durante el transcurso de la simulación, mediante el empleo de las ecuaciones (5.3) y (5.4).

Por otra parte, la principal problemática del Lanzado de Rayos es el algorítmo utilizado para determinar si un receptor es alcanzado, algo realmente simple cuando se trata de Tubos, como ya se ha comentado.

Por otra parte, estas no son las únicas consideraciones a realizar para elegir un método de lanzado u otro. En las siguientes secciones, se procederá a comparar con detalle cada uno de los métodos. De esta forma, se podrá llegar al final a algunas conclusiones y directrices respecto a qué método se ha de elegir para realizar simulaciones bajo cada circunstancia determinada.

\subsubsection{Calidad de la separación angular}

En cuanto al nivel de calidad de la separación angular, el método utilizado para el Lanzado de Rayos es muy superior al que se utiliza para los Tubos, ya que la desviación típica que experimenta la separación angular respecto de la media es menor del 1\%, disminuyendo rápidamente a medida que aumenta el número de paralelos en que se divide la esfera unidad que rodea al transmisor, tal y como se ve en la figura 5.26. Como ya se afirmó, el Lanzado de Tubos presenta una desviación típica mucho mayor (ver figura 5.25).

Además de esto, el método de Lanzado de Rayos tiene una ventaja adicional: para un mismo valor de resolución angular exigido, la cantidad de rayos directos a emitir desde el transmisor es mucho menor que la de tubos directos que se envían con el método que usa el Lanzado de Tubos. De hecho, este método emite un número de tubos del orden del doble del número de rayos que se requiere con el otro (figura 5.27).

Una desigualdad tan desproporcionada en ambos métodos para un mismo valor de 


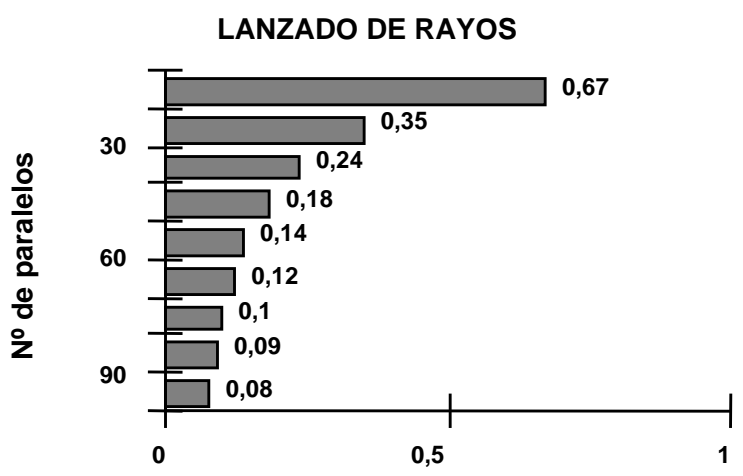

Desviación típica en \% respecto a la media

Figura 5.26: Desviación típica de la separación angular en el Lanzado de Rayos

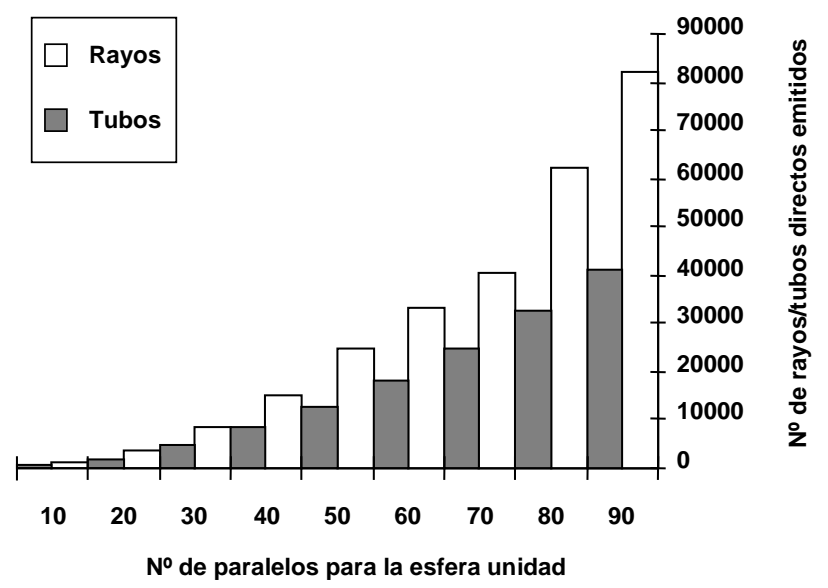

Figura 5.27: Número de rayos y tubos emitidos por cada método de lanzado 
$\Delta \theta$ resulta algo chocante. La explicación se encuentra en el hecho de que el método de discretización para el Lanzado de Tubos no es demasiado preciso de cara a obtener la separación angular constante, y tiene tendencia a llevar a cabo la discretización por exceso. Es decir, obtiene una resolución mayor de la que se exige en principio, para ciertas zonas de la esfera. Esto explica la desproporcionada cantidad de tubos que se generan respecto al método de Lanzado de Rayos, mucho más preciso en este sentido. Como consecuencia, cuando se emplee este último sistema para una simulación, se podrá ahorrar una importante cantidad de tiempo, al menos en lo que se refiere a esta circunstancia.

En cualquier caso, se han de considerar las secciones anteriores para mostrar que el método utilizado para Lanzado de Rayos presenta una serie de problemas (impactos redundates, zonas de sombra, ... ) que no tiene el Lanzado de Tubos.

\subsubsection{Eficiencia en velocidad de procesado}

La principal ventaja de los tubos está en que, al contrario de lo que sucede con los rayos, las zonas de influencia de los tubos adyacentes no intersectan entre sí, por lo que no es necesario procesar los impactos recibidos para comprobar si provienen de tubos adyacentes. Esto sí es necesario en el Lanzado de Rayos y consume un importante tiempo de computación a través del algoritmo de verificación de redundancia, ya que debe hacerse, por cada rayo, para todos los impactos acumulados hasta ese momento y para todos los receptores que estén en su zona de influencia.

La mayor velocidad del Lanzado de Tubos frente al de rayos se deja notar especialmente para casos en los que el número de impactos acumulados en los receptores es muy importante. Por ejemplo, si se trabaja con un elevado número de reflexiones o transmisiones se recibirá una gran cantidad de impactos en los receptores. En el caso de los rayos, cuantos más impactos haya recibido un receptor durante la simulación, más elementos tendrá la lista de impactos que habrá de compararse con cada rayo nuevo que se reciba, por lo que la pérdida de tiempo causada por la comprobación de impactos redundantes será mayor.

Como ejemplo, en la figura 5.28, se muestran los resultados de comparar las velocidades de ambos métodos, para un caso particular. Concretamente se trata de un plano de receptores paralelo al plano OXY, perteneciente a una habitación rectangular vacía. Se presenta la media del tiempo invertido por el simulador para procesar un rayo directo, y todos los rayos generados a partir de éste en sucesivas reflexiones (en el ejemplo no hay transmisiones), comparada con la misma magnitud, pero para el caso de un tubo.

Debe tenerse en cuenta que lo que se compara en dicha gráfica es la eficiencia entre el tiempo medio de procesado de cada tubo y el de cada rayo, en el curso de una simulación. Si la comparación se realiza en función del tiempo necesario para llevar a cabo una simulación completa mediante Lanzado de Tubos o Lanzado de Rayos, la situación cambia totalmente. Así, en la figura 5.29, referente a la misma simulación, se observa que el cociente entre el tiempo total de simulación mediante Lanzado de Rayos $T_{r}$, y el tiempo total usando Lanzado de Tubos $T_{t}$, para el caso de considerar pocas reflexiones o transmisiones, está por debajo de la unidad; o, lo que es lo mismo, que la simulación por rayos requiere menos tiempo que la de tubos. Sin embargo, se mantiene la tendencia según la cual, a medida que 


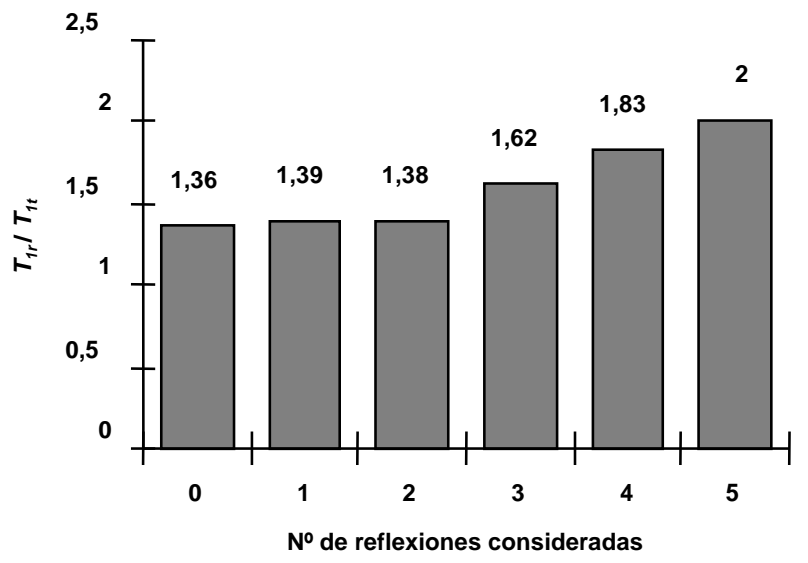

Figura 5.28: Comparación entre el tiempo de procesado medio de un rayo $\left(T_{1 r}\right)$ y de un tubo $\left(T_{1 t}\right)$, para un caso particular, en función del número $N$ de reflexiones consideradas

se consideran más reflexiones o transmisiones, el cociente $T_{r} / T_{t}$ aumenta, hasta hacerse mayor que la unidad.

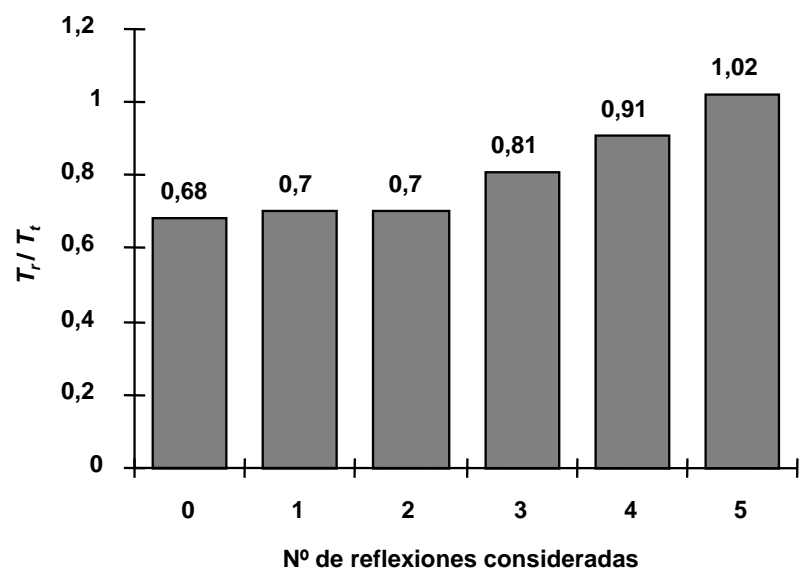

Figura 5.29: Comparación entre el tiempo total de simulación del Lanzado de Rayos $\left(T_{r}\right)$ y del Lanzado de Tubos $\left(T_{t}\right)$, para un caso particular, en función del número $N$ de reflexiones consideradas

El aparente contrasentido tiene su explicación. La menor duración de la simulación por rayos con valores de $N$ pequeños, no se debe al propio funcionamiento interno de los rayos, sino a la forma en la que se consigue una separación angular constante entre los mismos, tal y como se apuntó en la sección anterior. Recuérdese que el algoritmo de ambos métodos de lanzado se lleva a cabo discretizando una esfera unidad imaginaria centrada en el transmisor, en función de la resolución angular deseada. En cada caso, el proceso 
se realiza de una forma distinta, de manera que, para una misma resolución angular, el número total de rayos necesarios es de aproximadamente la mitad del número total de tubos, tal y como se ilustraba en la gráfica de la figura 5.27.

Esto hace que, en principio, una simulación con rayos pueda requerir de menos tiempo que una con tubos. Sin embargo, si el número de impactos por receptor es muy importante (por ejemplo, al considerar un elevado número de reflexiones o transmisiones), el tiempo requerido por el algoritmo de Lanzado de Rayos para eliminar los impactos redundantes será lo bastante elevado como para necesitar más tiempo que el algoritmo de tubos, a pesar de que se lancen muchos más tubos que rayos.

\subsubsection{Comportamiento frente a superficies}

La distinta naturaleza que tienen los rayos y los tubos, aparte de la algorítmica utilizada en cada caso para hacer su seguimiento, hace que presenten un comportamiento diferente en situaciones y entornos similares. Así ocurre cuando, por ejemplo, una de estas entidades lanzadas se encuentra con una superficie reflectante. En principio, en ambos casos se deberá producir una reflexión, además de la posible transmisión de energía al otro lado de la superficie. Sin embargo, se ha de considerar qué ocurre cuando se pretende evaluar la potencia recibida justo al otro lado de la pared.

Para ello, considérese el siguiente caso. Sea una superficie metálica interpuesta entre el emisor y el receptor, muy próxima a este último, de manera que el frente de ondas no lo alcance directamente. Cada uno de los métodos de simulación que está comparando, se comportará de una manera distinta.

Para el Lanzado de Tubos, no existe ningún problema (figura 5.30). Desde el emisor se envían los rayos que forman el tubo, hasta que cortan con la superficie. De esta forma, la zona de influencia del tubo queda delimitada por sus propias paredes y la misma superficie. Como era de esperar, el algoritmo de simulación no considerará que el tubo emitido alcanza al receptor situado al otro lado de la pared metálica.

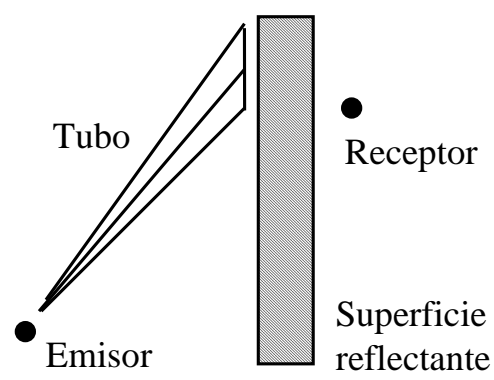

Figura 5.30: Comportamiento de un tubo frente a una superficie

En el caso del Lanzado de Rayos, se emite cada rayo hasta que intersecta con la superficie. Pero, en este caso, para determinar la recepción, lo que se hace es comparar la distancia entre rayo y receptor con el radio de impacto. Si esta distancia es lo bastante pequeña, el algoritmo considerará que el rayo impacta al receptor, sin tener en cuenta 
que hay obstáculos entre ellos (figura 5.31). Este efecto es particularmente grave cuando el radio de impacto es elevado, es decir, en lanzados con baja resolución, o en el caso de rayos que hayan recorrido una gran distancia.

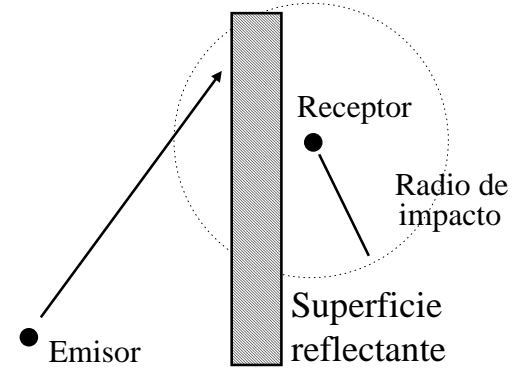

Figura 5.31: Comportamiento de un rayo frente a una superficie

En la figura 5.32 se muestra un ejemplo que ilustra lo expuesto. Se trata de los resultados de una simulación realizada para una habitación vacía, exceptuando una superficie totalmente reflectante a lo largo de la misma, que tiene una abertura en su centro. La simulación se ha efectuado tanto mediante Lanzado de Rayos, como mediante Lanzado de Tubos. Obsérvese la distorsión en torno a la superficie reflectante que se produce utilizando el método de Lanzado de Rayos, y compárese con la casi perfecta definición obtenida al usar el método de Lanzado de Tubos.

\section{Lanzado de Rayos Lanzado de Tubos}

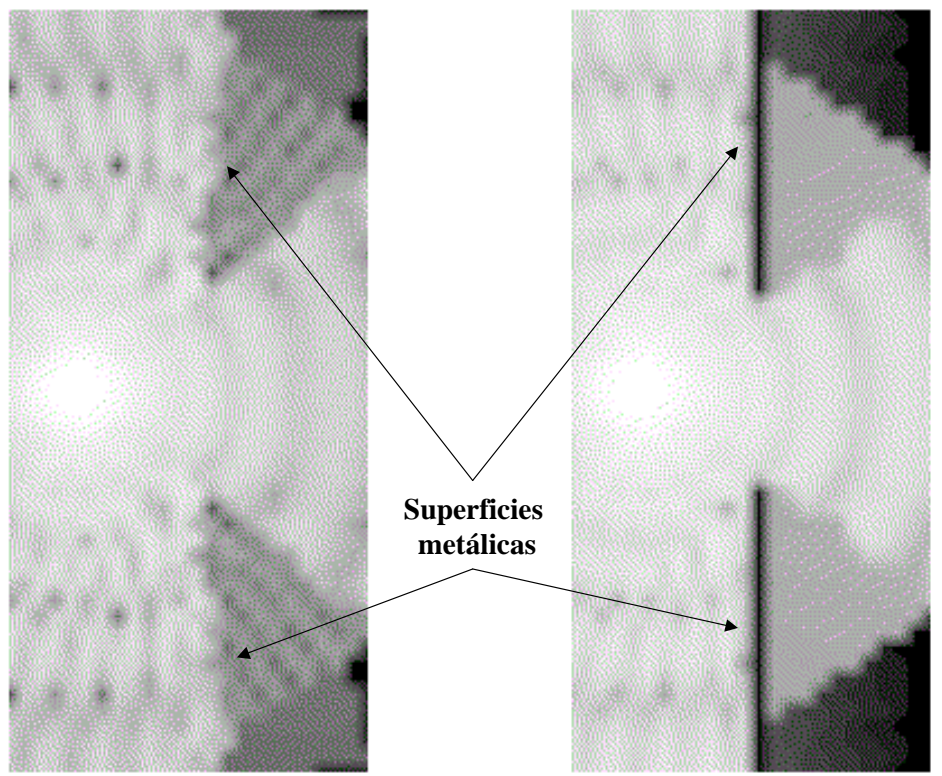

Figura 5.32: Comparación de resultados entre el Lanzado de Rayos y el Lanzado de Tubos ante superficies

En cualquier caso, todo parece indicar que es un problema menor y que sólamente afectará a puntos situados inmediatamente después de una pared con la que se encuentre 
el frente de ondas. No parece necesario complicar el algoritmo de Lanzado de Rayos para descartar estos errores. Sin embargo, téngase en cuenta que el Lanzado de Tubos tiene un comportamiento mejor en estos casos.

\subsubsection{Comportamiento frente a orificios, esquinas y entornos complejos}

Al contrario que en el anterior caso, existen situaciones en las que la naturaleza tridimensional de los tubos provoca una serie de problemas que no se presentan en el caso de los rayos unidimensionales.

Así, sea el caso de una superficie metálica situada entre el transmisor y los posibles receptores, sobre la que se practica un agujero de pequeñas dimensiones. En principio, los receptores sólo serán alcanzados por la parte del frente de ondas que pueda atravesar dicho orificio. Pero, en una simulación, la influencia de ese orificio en el resultado dependerá de la resolución angular con la que se trabaje. Cuanto menor sea la resolución, menos probable será que uno de los rayos o tubos transmitidos pase por esa apertura.

Sin embargo, un rayo tiene muchas más posibilidades de atravesarla que un tubo. Un rayo es unidimensional, así que, si el orificio se encuentra en su camino, seguro que pasará a través de él. Por el contrario, un tubo está compuesto de varios rayos divergentes, por lo que, aunque esté orientado hacia el orificio, puede que alguno de estos rayos intersecte con la superficie que lo contiene (algo bastante probable para orificios pequeños, o en el caso de utilizar una resolución baja), con lo cual el algoritmo, por simplicidad, deberá considerar que el tubo en su conjunto no pasa (figura 5.33).

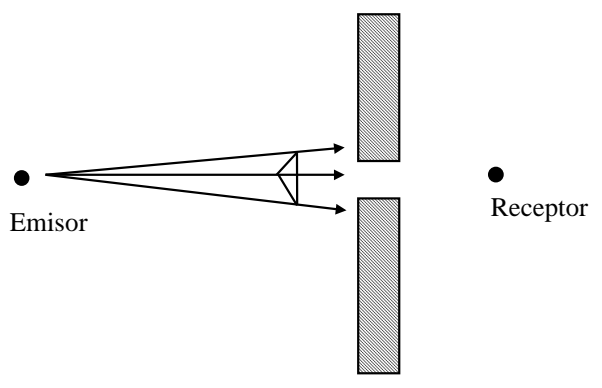

Figura 5.33: La naturaleza tridimensional de un tubo dificulta su paso a través de orificios

Incluso en el caso de utilizar resoluciones elevadas, un tubo puede tener problemas para atravesar ciertos orificios. Será el caso en el que el tubo incida sobre el orificio en una dirección muy oblicua, ya que los rayos que lo forman cortarán a la superficie que contenga el orificio en puntos muy alejados espacialmente. Alguno de estos rayos no podrá pasar por el orificio, con lo que el simulador tendrá que considerar que el tubo se detiene ahí (figura 5.34).

Una variante de este problema se produce en las zonas próximas a las esquinas. En principio, lo correcto sería que el algoritmo tuviera en cuenta el efecto de la porción de frente de ondas que se refleja en cada pared que forma una esquina. Ahora bien, 


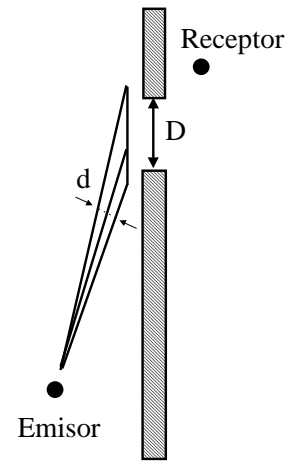

Figura 5.34: A pesar de sus pequeñas dimensiones, el tubo no pasa por el orificio al incidir oblicuamente

trabajando con tubos, aquellos que alcancen una esquina en su camino se encontrarán con que alguna de las aristas del tubo intersectan con una de las superficies que forman la esquina, mientras que otras lo hacen en la otra superficie.

En principio, este es un claro ejemplo en el que sería necesario acudir a un splitting, es decir, una subdivisión del tubo en otros más pequeños, cada uno reflejado por una de las superficies. Si no se quiere recurrir a la implementación del splitting, evitando con ello la consiguiente pérdida de tiempo, el algoritmo puede implementarse de forma que prescinda de la reflexión del tubo en estas situaciones. Pero, en tal caso, se obtendrán zonas de sombra en torno a las esquinas, al no aparecer en su interior el efecto de la reflexión. La figura 5.35 ilustra esta situación. Se trata de los resultados obtenidos para un entorno correspondiente a una habitación que contiene varios tabiques divisorios, formando esquinas entre sí. La simulación se ha efectuado usando tanto Lanzado de Rayos, como Lanzado de Tubos, considerando receptores situados en un plano horizontal en una zona próxima a una esquina. Obsérvese la zona de sombra que aparece en torno a la esquina, en el caso de Lanzado de Tubos.

Otro problema que aparece con los tubos es el que se produce en entornos complejos de grandes dimensiones, como puedan ser edificios grandes de varios pisos. En este tipo de entornos es habitual que, al emplear el Lanzado de Tubos, se pierdan un gran número de contribuciones de campo reflejado o transmitido. Las causas de que esto suceda están muy relacionadas con las características propias de los tubos, el tipo de entorno y la resolución empleada para el Lanzado de Rayos en la simulación.

En primer lugar, se ha de tener en cuenta que realizar simulaciones con una separación angular entre rayos excesivamente pequeña, implica tener que procesar tantos rayos o tubos que el tiempo total requerido sería excesivo. Por otra parte, se sabe que, para cada uno de los tubos que intervienen en la simulación, los rayos que lo delimitan divergen entre sí según un ángulo definido por la resolución empleada, de manera que la distancia entre ellos se incrementa a medida que los rayos se alejan del transmisor. Para entornos en los que las distancias a recorrer no sean demasiado elevadas (como pueda ser una habitación o una vivienda pequeña), esto no es un problema, pues la distancia entre rayos adyacentes (y, por tanto, las dimensiones del tubo) se mantienen por debajo de las dimensiones de los obstáculos que el tubo pueda encontrar en su camino. 
Lanzado de Rayos

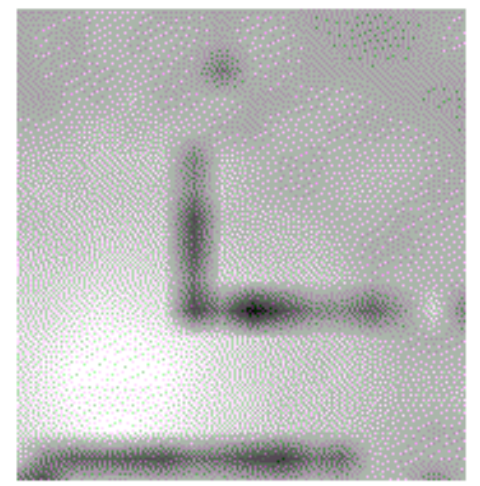

Lanzado de Tubos

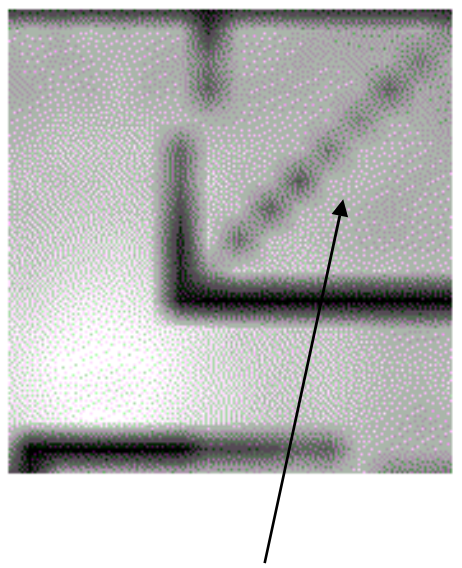

Defecto en esquinas

Figura 5.35: Comparación de los resultados obtenidos con Lanzado de Rayos y Lanzado de Tubos para las esquinas

Sin embargo, en entornos de grandes dimensiones, la situación cambia, ya que la distancia entre rayos puede aumentar demasiado. Así, en un edificio amplio, considerando una separación angular entre los rayos que integran los tubos del orden de un grado, es perfectamente normal que un tubo deba recorrer decenas metros antes de salir del recinto, por lo que la separación de los rayos que lo componen puede alcanzar perfectamente valores del orden de un metro o más.

Esto ya ocasiona de por sí algunos inconvenientes como, por ejemplo, el problema de los orificios que ya se ha comentado. Pero, además, se ha de tener en cuenta la naturaleza del entorno en el que se trabaja. En un edificio de oficinas, si bien las superficies que limitan suelos y techos suelen ser continuas, no sucede así en el caso de las paredes, que pueden estar compuestas por distintas superficies: las de la propia pared, y las que delimitan puertas y ventanas, cuyas dimensiones pueden ser comparables a las que alcanza la apertura de un tubo tras un largo recorrido.

Esto implica que, fácilmente, un tubo pueda impactar sobre una pared, de manera que parte de sus rayos corten una de las caras que la integran, y el resto corten la otra. Como cada una de las capas que delimitan las caras tiene un valor distinto de permitividad asociado, no es posible determinar con qué coeficiente de reflexión o de transmisión se propagarán los correspondientes tubos reflejado y transmitido, respectivamente. El criterio más sencillo para adoptar en estos casos puede ser descartar esas posibles reflexiones y transmisiones, con el consiguiente falseamiento de los resultados. En el Lanzado de Rayos, cada rayo impactará siempre en una única cara de la pared, con lo que este problema nunca se plantea (figura 5.36).

Siempre podrá implementarse algún tipo de parche que resuelva este tipo de problemas. La necesidad de tales modificaciones vendrá determinada por el compromiso entre la exactitud requerida en los resultados y la velocidad de proceso resultante. 

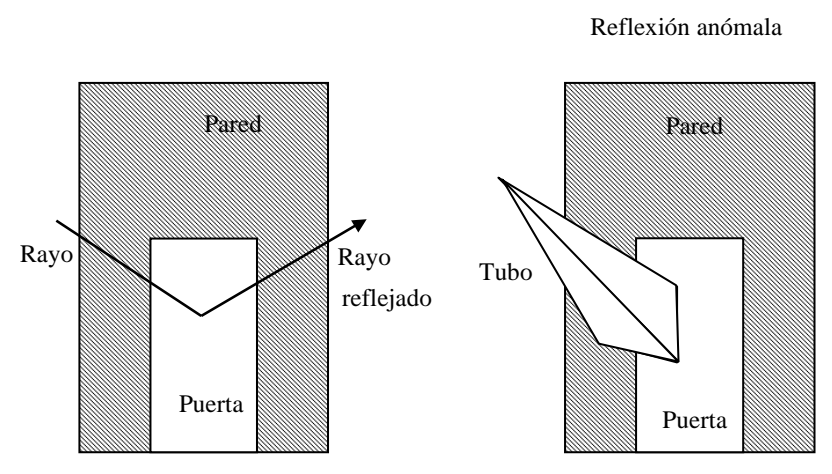

Figura 5.36: Pérdidas de reflexiones y transmisiones en el Lanzado de Tubos, al impactar en varias superficies coplanares compuestas de distintos materiales

\subsubsection{Conclusiones sobre la comparativa}

Dadas las limitaciones de cada método de lanzado descrito, no es factible decantarse de forma genérica por ninguno. Según el tipo de entorno y de simulación que se pretenda realizar, puede resultar más conveniente uno u otro.

Como primer criterio, puede admitirse que el Lanzado de Tubos es más útil en entornos inroom, es decir, zonas limitadas a una sola habitación no necesariamente pequeña, además de entornos indoor de dimensiones pequeñas y no demasiado complicados. Los problemas suelen a aparecer en zonas próximas a las esquinas y al considerar pequeños orificios en las superficies (ventanas o puertas).

Por otro lado, el Lanzado de Rayos resulta mejor en entornos indoor de grandes dimensiones, siendo proclive a errores en receptores muy próximos a las paredes traspasadas, y ralentizándose mucho el proceso a medida que se considere mayor número de reflexiones y transmisiones.

\subsection{Métodos de optimización}

Uno de los mayores problemas que presentan los distintos métodos de Lanzado de Rayos es la elevada cantidad de tiempo que puede requerir la ejecución de una simulación concreta.

Dependiendo de la resolución exigida para la simulación (tanto para la separación angular en el lanzado como en la separación y número de puntos donde evaluar la recepción), y de la complejidad del entorno de trabajo, así como de las características del equipamiento hardware utilizado, el tiempo requerido para que un simulador genere resultados puede ser fácilmente de varias horas, o incluso días, lo cual supone una limitación considerable de cara a su rendimiento. Es por ello que se ha trabajado en una serie de métodos de op- 
timización que, modificando la algorítmica original, reduzca en cierta medida la cantidad de tiempo necesaria durante una simulación.

\subsubsection{Descarte de rayos y tubos por umbral local de potencia}

Para conseguir la mejora en velocidad del algoritmo de simulación, se ha partido del hecho de que una gran parte del tiempo que se invierte en las simulaciones se emplea en el estudio de la recepción. Para cada rayo o tubo, reflejado o transmitido, que se genere en la simulación, debe comprobarse, para cada uno de los receptores bajo estudio, si cae dentro de los limites que definen el tubo o de la esfera de impacto, según sea el caso, para determinar así si se produce o no la recepción.

Este proceso debe realizarse un número muy elevado de veces. Así, para una simulación con una resolución angular de $2^{\circ}$, y un número máximo de reflexiones o transmisiones de $n=4$, pueden generarse del orden de 300.000 tubos o rayos, entre directos, reflejados y transmitidos. Si dicha simulación se realiza, por ejemplo, para una matriz de receptores de $10 \times 10$ metros, con una resolución de $10 \mathrm{~cm}$ (lo cual supone 10.000 receptores), se deduce que la rutina que determina la recepción tendrá que repetirse unos 300 millones de veces.

Sin embargo, se podría prescindir de una fracción importante de estas operaciones, ya que muchos de los rayos que impactan en un receptor transportan un nivel de potencia despreciable respecto de la potencia total que al final se acumulará en dicho receptor. En los distintos métodos de lanzado de rayos, tradicionalmente se utiliza un umbral absoluto de potencia, por debajo de la cual el rayo o tubo deja de ser significativo, con lo que puede dejar de ser seguido su recorrido. Sin embargo, este umbral absoluto puede no ser suficiente para descartar muchos de los rayos que, al final, no van a influir apenas en la potencia total recibida en un receptor determinado.

Así, por ejemplo, en la figura 5.37, se muestra un receptor que recibe los impactos de varios rayos. El rayo $T_{1}$, que corresponde a un impacto directo, transporta un determinado nivel de potencia al alcanzar al receptor, mientras los rayos $T_{2}$ y $T_{3}$, que han sufrido varias reflexiones, impactan con un nivel de potencia mucho más bajo que el del rayo directo; tanto, que podrían descartarse estos impactos sin necesidad de comprobar si realmente llegan a alcanzar o no al receptor. Siguiendo este criterio, es decir, no considerando el estudio de recepción de los rayos sobre aquellos receptores que lleven acumulado, hasta ese momento, un nivel de potencia mucho mayor que la que transportan esos rayos, se podría ahorrar mucho tiempo de computación.

Para llevar a cabo la optimización del algoritmo, se ha definido un parámetro, denominado umbral local de optimización. Este umbral indica a partir de qué nivel se considera que la potencia que transporta un rayo o tubo es despreciable respecto al nivel de potencia acumulado en un receptor, permitiendo, por tanto, descartarlo para dicho receptor.

Por tanto, el criterio según el cual la potencia de un rayo es despreciable frente a la del receptor queda regulado mediante dicha variable umbral local. Así, por ejemplo, para un umbral local de $-10 \mathrm{~dB}$, si la potencia de un rayo entrante está más de $10 \mathrm{~dB}$ por debajo de la potencia acumulada en un receptor, no será tenido en cuenta para ese receptor en particular. 


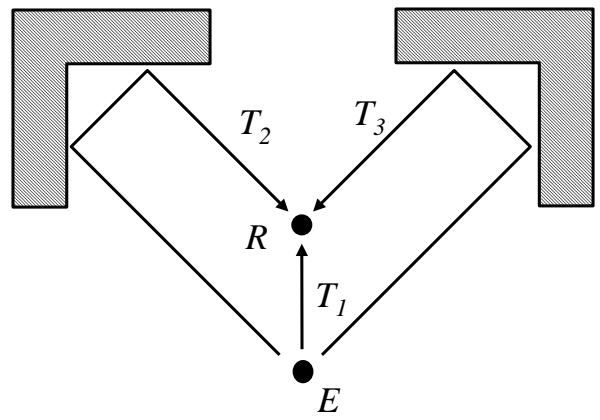

Figura 5.37: La potencia de los rayos $T_{2}$ y $T_{3}$ es despreciable frente a la potencia de $T_{1}$

Con el fin de evitar que el cálculo de la potencia transportada por un rayo en la posición de un receptor determinado, ralentizara aún más el algoritmo en lugar de acelerarlo, se optó por la siguiente variante: para determinar si hay que descartar un rayo para un receptor determinado, no se compara la potencia que transportaría ese rayo en el momento de alcanzar al receptor, sino su potencia tras reflejarse o transmitirse a través del último obstáculo encontrado en su camino.

Sea el ejemplo de la figura 5.38, donde se muestra un receptor $R$, con una potencia acumulada $P_{R}$, sobre el que impacta un nuevo rayo $t_{n}$, originado a partir de la reflexión del rayo $t_{n-1}$ con la pared $c_{1}$. En el momento inmediatamente posterior al impacto, $t_{n}$ transporta una potencia $P_{0}$. Más tarde, cuando $t_{n}$ alcanza a $R$, lo hace con una potencia $P_{1}$, tal que $P_{1}<P_{0}$, debido a la atenuación provocada por la distancia recorrida. Por tanto, es lógico suponer que si $P_{0}$ es despreciable respecto de la potencia de referencia $P_{R}$, con toda seguridad $P_{1}$ también lo será, luego se podrá descartar el impacto del rayo $t_{n}$ sobre el receptor.

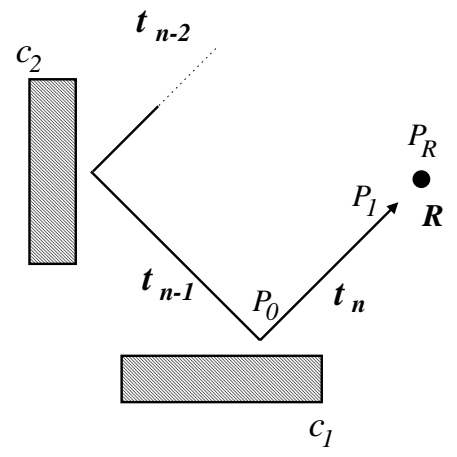

Figura 5.38: Modificación del algoritmo de optimización empleando $P_{0}$ como potencia de referencia

El único problema de este método es que habrá casos para los que, aunque la potencia de un rayo al impactar sobre una cara no sea despreciable respecto de la de un receptor, su potencia al alcanzar dicho receptor sí lo será. Esto implica que cierto porcentaje de rayos de entre los descartables a priori, serán tenidos en cuenta. Sin embargo, a pesar de ello, 
este método de optimización es mucho mejor que el original. Esto se debe a que antes, por cada rayo, debían efectuarse cálculos de potencia para cada uno de los receptores que intervienen en la simulación. Por el contrario, ahora sólo hay que hacer un cálculo de potencia por rayo, puesto que $P_{0}$ es independiente de la posición de cada uno de los receptores.

Sin embargo, con esta modificación aparece un nuevo problema. Para ilustrarlo, se van a comparar los resultados que se obtienen al efectuar una simulación para un caso particular, tanto con la versión sin optimizar del algoritmo, como con la nueva versión optimizada.

La simulación se ha efectuado para el entorno de una habitación completamente vacía de $5 \times 10 \times 3$ metros, con un transmisor en su mismo centro. Se ha calculado la potencia recibida en una matriz de receptores paralela al suelo, que se extiende por toda la habitación, y que está situada a la misma altura que el transmisor.

Como es lógico, dada la simetría de la habitación, la representación gráfica de los resultados generados por el simulador en nivel de potencia también debe ser simétrica. Sin embargo, si bien esto es cierto en el resultado obtenido mediante el algoritmo original, no sucede así con el algoritmo optimizado, donde los resultados presentan cierta asimetría (figura 5.39).
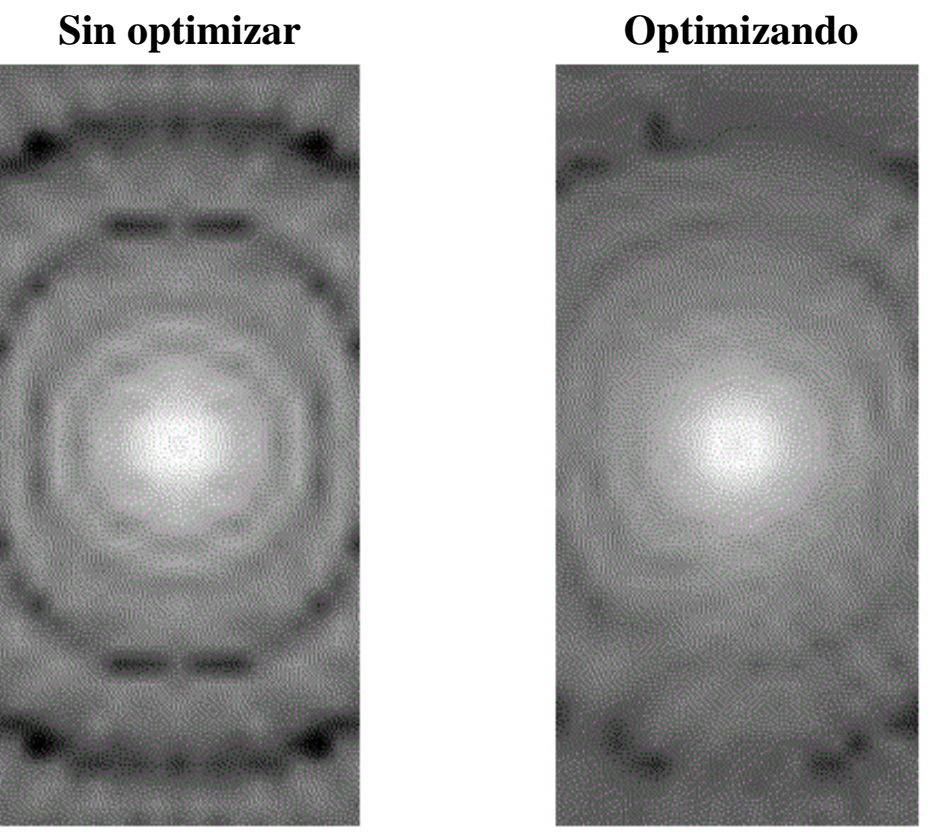

Figura 5.39: Comparación de resultados para un Lanzado de Tubos, sin y con optimización

El origen de esta asimetría está en el mismo algoritmo de optimización. Recuérdese que el criterio de descarte de rayos para un receptor dado se realiza utilizando una potencia de referencia específica para dicho receptor. Dicha potencia de referencia es la que el receptor ha ido acumulando en el curso de la simulación.

Se ha de tener en cuenta que en la simulación se van procesando, uno por uno, todos 
los rayos que se generan durante la ejecución, sumando las aportaciones de cada uno al campo total recibido en cada receptor, cada vez que se produce un impacto.

El problema está en el orden en el que se realiza el proceso de Lanzado de Rayos. Para efectuar este lanzado, lo más lógico es tomar uno de los rayos emitidos directamente por el transmisor, y estudiar la recepción de todos los rayos transmitidos o reflejados generados a partir de él, hasta la $n$-ésima generación, siendo $n$ el máximo número de reflexiones o transmisiones que se consideren durante la simulación. A continuación se toma otro rayo, y se repite el proceso, y así sucesivamente. Esto implica que un receptor pueda recibir primero los impactos directos antes que los originados por transmisión o reflexión del frente de ondas, mientras que otro receptor, en una posición espacial distinta, pero en un entorno similar, puede recibir esos impactos en distinto orden. Esto no tiene importancia al usar el algoritmo original, pero sí en la versión optimizada, ya que en ésta se descartan, para un receptor, aquellos impactos con una potencia demasiado pequeña respecto de aquellos impactos que ya se hayan considerado durante el transcurso de la simulación.

Por tanto, al lanzar los rayos de forma progresiva y siguiendo un determinado orden, unos receptores se verán alcanzados por más contribuciones, porque primero llegan las menos significativas, mientras que otros se verán alcanzados por menos, al ser descartadas estas contribuciones respecto a otras que han llegado antes y son más importantes. En la figura 5.40 se ilustra este hecho: en el receptor $R_{1}$ se podrá descartar el rayo $T_{2^{\prime}}$ al ser analizado después que el rayo $T_{1}$, mucho más potente; sin embargo, en el receptor $R_{2}$, simétrico al anterior y con la misma potencia esperable, sí se contabilizará la contribución del rayo $T_{3^{\prime}}$ a pesar de ser mucho menos importante que el $T_{4}$, simplemente por el hecho de que ha llegado antes.

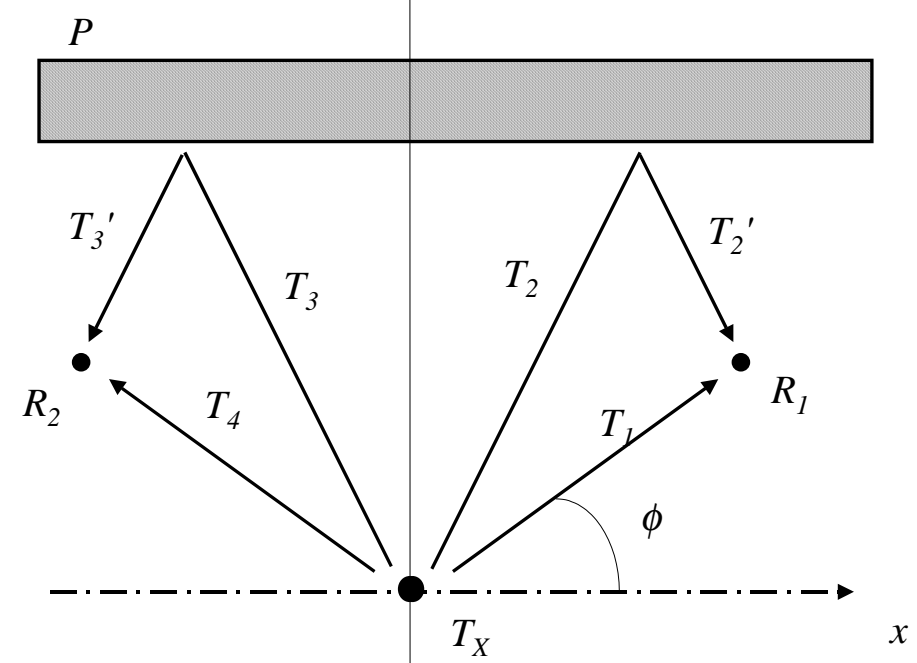

Figura 5.40: Efecto de asimetría provocado por la optimización de descarte de impactos

Evidentemente, este efecto de asimetría podrá ser minimizado eligiendo de forma adecuada el umbral local de optimización, para así descartar lo que efectivamente no sea significativo, y si por alguna circunstancia no se descarta, que no altere los resultados. En el ejemplo donde se ponía de manifiesto la asimetría del proceso, se utilizó un umbral 
demasiado pequeño.

Este no es el único inconveniente que presenta este método de optimización. Obsérvese que, tal y como se está efectuando el lanzado, hay una importante proporción de receptores que recibirán primero los tubos reflejados y, más tarde, los impactos directos, con lo que hay menos descarte de rayos. Por tanto, se gana en la optimización menos tiempo que si los impactos directos se recibieran antes.

Estos problemas podrían resolverse modificando la secuencia de lanzado, de tal manera que se enviaran primero los tubos que generan impactos directos, es decir los de nivel de reflexión (pero no de transmisión) nulo, y luego los demás. Sin embargo, eso complicaría enormemente dicha secuencia de lanzado. En lugar de eso, se ha preferido modificar este algoritmo de optimización, extendiéndolo con un nuevo procedimiento: el lanzado previo de rayos, que se pasará a explicar a continuación.

\subsubsection{Lanzado previo}

El principal problema del anterior algoritmo de optimización es que la potencia de referencia de los receptores, que determina si se descarta o no un rayo, no obedece a un criterio constante, sino que cambia durante el transcurso de la simulación para cada receptor. Esto puede provoca ciertos problemas de asimetría y de perdida de eficiencia de optimización.

La solución está en predeterminar un valor de la potencia de referencia de cada receptor antes de empezar la simulación, y mantener constantes esos valores a medida que evolucione ésta.

Parece lógico pensar, por lo que se ha dicho hasta ahora, que dicha potencia de referencia debe ser la que aporta a un receptor el impacto directo de un rayo emitido desde un transmisor, pues, en general, será la que tenga un orden de magnitud más importante. Una posible forma de determinar estas potencias de referencia, consiste en lanzar un rayo desde el transmisor directamente a cada receptor que se considere en la simulación. El valor de potencia con el que el rayo directo alcance a su correspondiente receptor, será utilizado como potencia de referencia para dicho receptor a lo largo de toda la simulación.

Lo que se pretende es definir una potencia de referencia que se inicialice según la potencia aportada por los rayos directos o, en su defecto, por los cuasi directos, es decir, aquellos que corresponden a rayos propagados en línea recta, que han sido atenuados no sólo por la distancia, sino también por los obstáculos del entorno. Es razonable hacer esto puesto que, en muchos casos, las paredes y obstáculos atravesados con un rayo cuasi directo también tendrán que ser atravesados por los reflejados y transmitidos, por lo que es lógico suponer que dicha potencia de referencia seguirá siendo mucho mayor que la asociada a gran parte de los impactos reflejados que recibirá el receptor.

Podría pensarse que este lanzado previo consume cierto tiempo de computación, lo cual se opone al objetivo inicial de optimizar la velocidad de procesado. Sin embargo, esta pérdida de tiempo es mínima, pues el lanzado previo se limita a una cantidad de rayos muy pequeña (solamente uno por cada receptor bajo estudio). Por lo tanto, en general, el tiempo que se gane mediante la optimización será mucho mayor que la fracción de tiempo que se invierte en este lanzado previo. 
El algoritmo de optimización de descarte de impactos resulta ser muy superior cuando se incorpora el lanzado previo. Por un lado, los resultados resultan ser mucho más regulares, sin efectos de asimetría, ajustándose mucho más a los resultados que se hubiéran obtenido sin emplear optimización.

Además, las mejoras en velocidad del simulador optimizado son muy importantes, ya que, para cada receptor, la potencia de referencia es la que nos da el máximo valor de potencia que puede aportar un impacto, y se mantiene constante desde el principio de la simulación. Por esta razón, se descarta el máximo número posible de impactos para todos los receptores, independientemente del orden en que se procesen los rayos, con el consiguiente ahorro de tiempo.

\subsubsection{Análisis de los métodos de optimización}

Una vez definido el método final de optimización, se efectuaron una serie de pruebas destinadas a determinar cómo influyen las condiciones en las que se realiza la simulación, en las mejoras de velocidad obtenidas. Estas pruebas también proporcionan información relativa al grado de desviación que sufren los resultados respecto a los que se obtienen sin optimizar la velocidad.

En primer lugar, debe hacerse notar que el grado de mejora no es constante, sino que variará en función de algunos de los parámetros de la simulación, como puedan ser la cantidad de receptores considerados durante la misma o el número de niveles de reflexión o transmisión que se admitan en la simulación (que a su vez está relacionado con el número de rayos procesados).

Para ilustrar este comportamiento, se han realizado varios grupos de simulaciones para el entorno definido por una habitación vacía con un receptor en su centro. Para cada grupo de simulaciones, se ha ido variando uno de estos parámetros, y se han mantenido constantes los demás.

Como puede verse en las tablas 5.2 y 5.3, a medida que el número de reflexiones o transmisiones y el número de receptores a considerar aumentan, se incrementa el porcentaje de mejora de la velocidad. Esto se debe a que el número total de rayos o tubos lanzados durante la simulación está relacionado con ambos parámetros.

\begin{tabular}{|c|c|c|c|}
\hline $\begin{array}{c}\text { Número de } \\
\text { receptores }\end{array}$ & $\begin{array}{c}\text { Tiempo sin optimizar } \\
T_{s}\end{array}$ & $\begin{array}{c}\text { Tiempo optimizando } \\
T_{o}\end{array}$ & $\begin{array}{c}\text { Cociente } \\
T_{s} / T_{o}\end{array}$ \\
\hline 176 & $0 \mathrm{~h} 9 \mathrm{~m} 3 \mathrm{~s}$ & $0 \mathrm{~h} 7 \mathrm{~m} 26 \mathrm{~s}$ & 1.21 \\
\hline 276 & $0 \mathrm{~h} 12 \mathrm{~m} 6 \mathrm{~s}$ & $0 \mathrm{~h} 8 \mathrm{~m} 59 \mathrm{~s}$ & 1.34 \\
\hline 490 & $0 \mathrm{~h} 19 \mathrm{~m} 45 \mathrm{~s}$ & $0 \mathrm{~h} 13 \mathrm{~m} 31 \mathrm{~s}$ & 1.34 \\
\hline 1104 & $0 \mathrm{~h} 40 \mathrm{~m} 58 \mathrm{~s}$ & $0 \mathrm{~h} 25 \mathrm{~m} 47 \mathrm{~s}$ & 1.58 \\
\hline 4416 & $3 \mathrm{~h} 5 \mathrm{~m} 6 \mathrm{~s}$ & $1 \mathrm{~h} 34 \mathrm{~m} 16 \mathrm{~s}$ & 1.96 \\
\hline
\end{tabular}

Tabla 5.2: Optimización de velocidad en función del número de receptores

Un aspecto importante a tener en cuenta es que, con bajo número de reflexiones o transmisiones, la mejora de velocidad es limitada en comparación con la cantidad de impactos descartados. Los resultados que aparecen en la tabla 5.4 (que se corresponden 


\begin{tabular}{|c|c|c|c|}
\hline $\begin{array}{c}\text { Número de } \\
\text { reflexiones }\end{array}$ & $\begin{array}{c}\text { Tiempo sin optimizar } \\
T_{s}\end{array}$ & $\begin{array}{c}\text { Tiempo optimizando } \\
T_{o}\end{array}$ & $\begin{array}{c}\text { Cociente } \\
T_{s} / T_{o}\end{array}$ \\
\hline 0 & $0 \mathrm{~h} 2 \mathrm{~m} 56 \mathrm{~s}$ & $0 \mathrm{~h} 3 \mathrm{~m} 24 \mathrm{~s}$ & 0.86 \\
\hline 1 & $0 \mathrm{~h} 5 \mathrm{~m} 7 \mathrm{~s}$ & $0 \mathrm{~h} 4 \mathrm{~m} 10 \mathrm{~s}$ & 1.22 \\
\hline 2 & $0 \mathrm{~h} 7 \mathrm{~m} 9 \mathrm{~s}$ & $0 \mathrm{~h} 4 \mathrm{~m} 35 \mathrm{~s}$ & 1.56 \\
\hline 3 & $0 \mathrm{~h} 8 \mathrm{~m} 29 \mathrm{~s}$ & $0 \mathrm{~h} 4 \mathrm{~m} 41 \mathrm{~s}$ & 1.81 \\
\hline 4 & $0 \mathrm{~h} 9 \mathrm{~m} 41 \mathrm{~s}$ & $0 \mathrm{~h} 4 \mathrm{~m} 51 \mathrm{~s}$ & 2.89 \\
\hline
\end{tabular}

Tabla 5.3: Resultados de eficiencia en función del número máximo de reflexiones y transmisiones

con el grupo de simulaciones descritas anteriormente), se muestra claramente este hecho. Efectivamente, las operaciones para el estudio de recepción de los rayos en los receptores sólo consumen una parte del tiempo total de ejecución, por lo que la optimización no dará buenos resultados cuando el factor principal de consumo de tiempo no sea el número de pares rayo-receptor. Así, para simulaciones con un número de receptores relativamente pequeño y considerando un número bajo de reflexiones, el algoritmo optimizado puede llegar a tardar más tiempo en presentar resultados que el original.

\begin{tabular}{|c|c|c|c|c|}
\hline $\begin{array}{c}\text { Número de } \\
\text { reflexiones }\end{array}$ & $\begin{array}{c}\text { Núm. de impactos } \\
\text { sin optimización }\end{array}$ & $\begin{array}{c}\text { Núm. de impactos } \\
\text { con optimización }\end{array}$ & $\begin{array}{c}\text { \% de impactos } \\
\text { descartados }\end{array}$ & $\begin{array}{c}\text { \% de mejora } \\
\text { de velocidad }\end{array}$ \\
\hline 0 & 1200 & 1200 & $0 \%$ & $-14 \%$ \\
\hline 1 & 8392 & 3975 & $53 \%$ & $22 \%$ \\
\hline 2 & 26370 & 3978 & $85 \%$ & $56 \%$ \\
\hline 3 & 55713 & 3980 & $93 \%$ & $81 \%$ \\
\hline 4 & 75993 & 3980 & $95 \%$ & $189 \%$ \\
\hline
\end{tabular}

Tabla 5.4: Comparación entre los impactos descartados y la ganancia de velocidad

También debe considerarse cuál será el valor de umbral local de optimización más apropiado a la hora de configurar los parámetros de simulación. Se trata de conseguir un compromiso entre la velocidad y la calidad de los resultados. Así, un umbral negativo muy grande (en valor absoluto) hará que se descarte un número reducido de impactos, lo cual dará una gran precisión en los valores de campo obtenidos para los receptores, respecto de los resultados sin optimizar, pero limitará el tiempo que se pueda ganar respecto de la simulación original. Por otra parte, un umbral próximo a 0dB, supondrá el descarte de un importante número de impactos, es decir, un importante ahorro de tiempo frente a una menor aproximación de los resultados obtenidos. En general, se recomienda mantener los valores de umbral entre $-10 \mathrm{y}-20 \mathrm{~dB}$. Como ejemplo, se ha llevado a cabo un nuevo grupo de simulaciones, para el mismo entorno que en los casos anteriores, variando en esta ocasión el parámetro del umbral local. Se presentan tanto los porcentajes de mejora de velocidad (tabla 5.5) como la representación gráfica de los valores de potencia recibida en la matriz de receptores (figuras 5.41 y 5.42), para cada valor de umbral local.

Como puede verse en la tabla 5.5 y en las figuras 5.41 y 5.42 , a medida que se baja el valor del umbral local, el resultado es más próximo al obtenido sin recurrir a la optimización, pero a costa de perder mejora de velocidad. 


\begin{tabular}{|c|c|c|c|}
\hline $\begin{array}{c}\text { Simulación } \\
\text { optimizada }\end{array}$ & $\begin{array}{c}\text { Umbral local de } \\
\text { optimización }\end{array}$ & Tiempo invertido & $T_{s} / T_{o}$ \\
\hline NO & - & $0: 8: 29$ & - \\
\hline SI & -5 & $0: 4: 17$ & 1.98 \\
\hline SI & -10 & $0: 4: 41$ & 1.81 \\
\hline SI & -15 & $0: 5: 33$ & 1.53 \\
\hline SI & -20 & $0: 6: 51$ & 1.24 \\
\hline
\end{tabular}

Tabla 5.5: Influencia del umbral de optimización en la velocidad

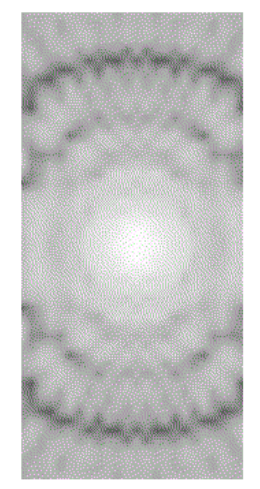

Figura 5.41: Resultados sin emplear optimización

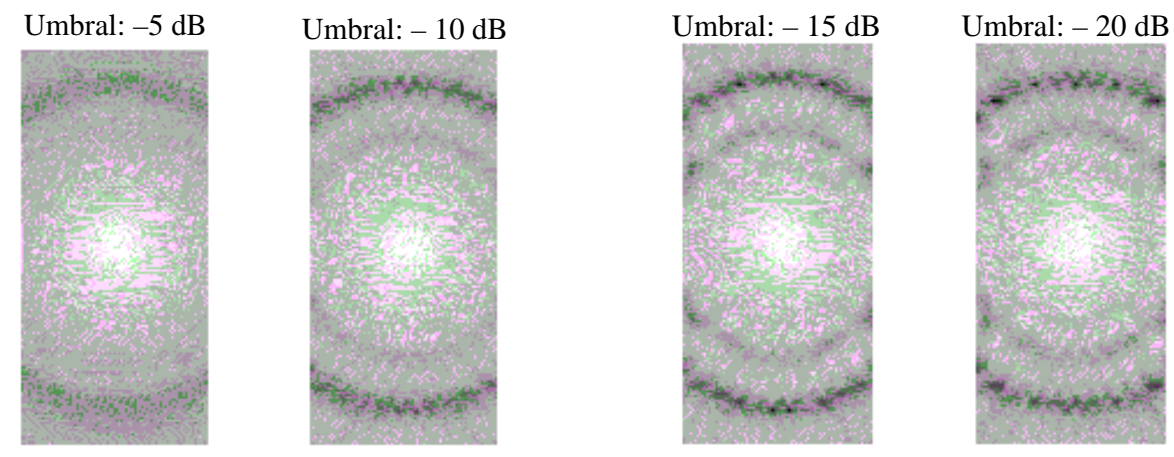

Figura 5.42: Resultados con varios umbrales de optimización 


\subsection{Implementación del programa de simulación}

Hasta ahora, se han expuesto las distintas técnicas basadas en el Lanzado de Rayos. En esta sección, se va a abordar el estudio del tratamiento de la información del entorno, así como ciertos aspectos de la implementación de los algoritmos de simulación.

Todo ello se puede realizar mediante un programa de simulación implementado en cualquier lenguaje de alto nivel. Es aconsejable utilizar un lenguaje orientado a objetos, con capacidad para manipular estructuras de datos de forma modular y susceptible de ser compilado tanto en un PC como en una estación de trabajo. Concretamente, las simulaciones que se presentan en esta Tesis han sido realizadas mediante un programa implementado en $\mathrm{C}++$ que, en su última versión, funciona sobre una estación de trabajo en entorno UNIX.

De forma general, en un programa para la predicción del comportamiento del canal móvil de radiopropagación, se han de distinguir dos partes principales:

Parte común a todos los modelos: sirve para interpretar el formato de la información de entrada y transformarla al formato propio que va a manejar el programa. En el programa de simulación que se ha desarrollado, se han implementado varias clases* en las que se introducen tanto datos procedentes de diversos ficheros de entrada, como datos que se calculan tras un pre-procesado de estas clases, así como otro tipo de información que se puede solicitar al usuario y/o se puede adquirir mediante un fichero de configuración. Esto se hace al principio del programa para mejorar la organización de los datos y ahorrar tiempo de computación a los algoritmos posteriores.

Parte específica de cada modelo: en la que se desarrolla el algoritmo propio del modelo de simulación elegido y que trabaja con los datos antes preparados. En el caso que aquí se presenta, el algoritmo implementado es de tipo determinista, y usa la técnica de Lanzado de Rayos o la de Lanzado de Tubos (a elección del usuario) para aproximar el comportamiento de las ondas electromagnéticas en el entorno escogido. Es aconsejable que esta fase sea interactiva, de forma que puedan ser introducidos o modificados los parámetros propios de la simulación (frecuencia, permitividades complejas de los materiales de construcción, directividades y polarización de las antenas, potencia, posición del emisor y de los receptores, etc.) o que pueda ser indicado el nombre y ruta del fichero que contiene dichos parámetros.

\subsubsection{Datos físicos del entorno}

Puesto que, si se pretenden estudiar los mecanismos de la propagación indoor con un método determinista, es necesario conocer con bastante exactitud la posición y las características físicas del entorno (paredes, techos, puertas, ventanas, etc.), será imprescindible incorporar dicha información a la herramienta de predicción. Para ello se ha optado por utilizar el programa de diseño gráfico AutoCAD. Se eligió este programa por lo generalizado y extendido que es su uso, tanto en la industria como en los centros de investigación,

${ }^{*}$ Estructuras de datos propias de $\mathrm{C}++$ 
y porque gran parte de los edificios que se suelen estudiar ya poseen una representación en planta con este programa.

Además, AutoCAD proporciona la posibilidad de importar o exportar ficheros con formato DXF*. Este formato está estandarizado, es reconocido por muchas otras aplicaciones, es sencillo y ya lo están empleando algunos investigadores en sus modelos. Por ello, ha sido elegido como enlace entre la herramienta de dibujo y el programa de simulación que se ha desarrollado.

\section{Forma de representar la información}

Ya se vio al comienzo de este capítulo que las técnicas de modelado basadas en la Óptica Geométrica requieren que la longitud de onda usada en la simulación sea pequeña en comparación con las dimensiones del entorno con el que interactuaba. Por tanto, solamente resulta necesario incluir en la descripción del entorno los objetos de gran tamaño, esto es, las paredes, los techos, los suelos, las puertas y las ventanas, principalmente.

También, es de sobra sabido que la caracterización del canal radio dentro de un edificio ha de realizarse en tres dimensiones. Por este motivo, la información del entorno proporcionada a la herramienta de predicción, deberá también estar descrita en formato tridimensional. Por tanto, hay que presentar al programa de simulación un fichero con formato DXF que contenga las entidades rectangulares que componen el edificio descrito de forma tridimensional.

Dibujar un edificio directamente en tres dimensiones puede ser una tarea compleja y muy laboriosa. Además, dado que muchos de ellos ya han sido representados en planta con AutoCAD, parece más razonable permitir una descripción en dos dimensiones (en planta) y más tarde transformarla mediante alguna aplicación, añadiendo las alturas de los elementos. De esta forma, AutoCAD se usaría únicamente para dibujar la planta de cada uno de los pisos que componen el entorno a simular y, en último término, para modificar algún resultado tras la transformación.

Para representar la información tridimensional del entorno, se ha optado por la entidad de AutoCAD llamada 3DCARA (o 3DFACE, en su versión en inglés). La orden 3DCARA permite crear una entidad de superficie plana limitada por tres o cuatro lados rectos. Las esquinas de una 3DCARA pueden tener distinta coordenada $z$, lo cual permite representar superficies planas con cualquier alineación.

Para trabajar con el programa de simulación que se ha elaborado, es necesario que la representación tridimensional del edificio a la que finalmente se debe llegar, tenga las siguientes características:

- La estructura del edificio se deberá modelar utilizando únicamente la entidad 3DCARA, de forma que cada uno de los rectángulos que representa, constituya el límite entre dos materiales (aire y ladrillo, o ladrillo y escayola, por ejemplo).

- El nombre de la capa que se asigna a cada entidad en AutoCAD será el que identifique al tipo de pared, (identificará, por tanto, el límite entre dos materiales concretos).

* Drawing eXchange Format 
Más tarde, dicho nombre servirá para poder definir los parámetros eléctricos de los materiales de construcción que hay a cada lado. Para evitar errores, no se permite usar la capa 0 (asignada por defecto) con ninguna de las entidades 3DCARA usadas para definir el entorno.

- Las 3DCARA que formen una misma estructura (una pared, un techo, etc.) se dibujarán paralelas. Esto permite la definición de estructuras con cierto grosor, y formadas por diferentes materiales (estructuras multi-capa).

Siguiendo ese sencillo modelo, es posible construir estructuras con la complejidad que se desee. En la figura 5.43 se puede observar un ejemplo de representación 3D, en la que no se han dibujado los suelos y techos para facilitar la visión.

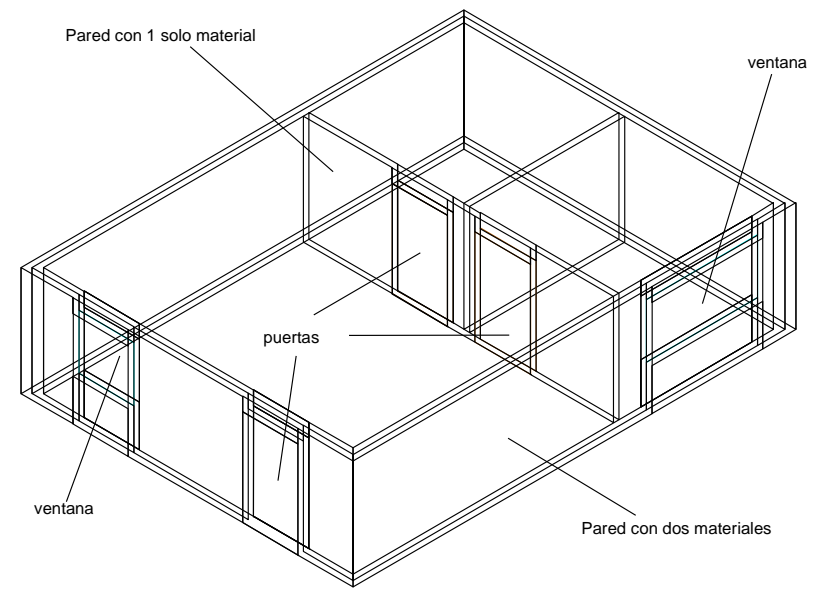

Figura 5.43: Ejemplo de representación con 3DCARA

Como puede verse, se ha elegido una forma muy simple de describir los elementos, para facilitar su dibujo. Además, si ya existe una representación con una herramienta CAD, será bastante sencillo y rápido transformarla simplificando y eliminando todos aquellos elementos que no sean necesarios en la definición del entorno. En las figuras 5.44 y 5.45 se puede observar, como ejemplo, la transformación que sufre una de las plantas del edificio de la Escuela Técnica Superior de Ingenieros de Telecomunicación de Valencia al convertirla a formato tridimensional.

El fichero DXF con la representación tridimensional del entorno, actuará de enlace entre AutoCAD y el simulador desarrollado. A continuación, se estudiará la estructura de los ficheros con formato estándar DXF.

\section{El formato DXF}

El DXF es un formato público de fichero que genera una descripción ASCII de un dibujo de AutoCAD. Puede utilizarse para intercambiar datos de dibujo de AutoCAD con otras aplicaciones gráficas o para importar a AutoCAD dibujos creados por otros programas. 


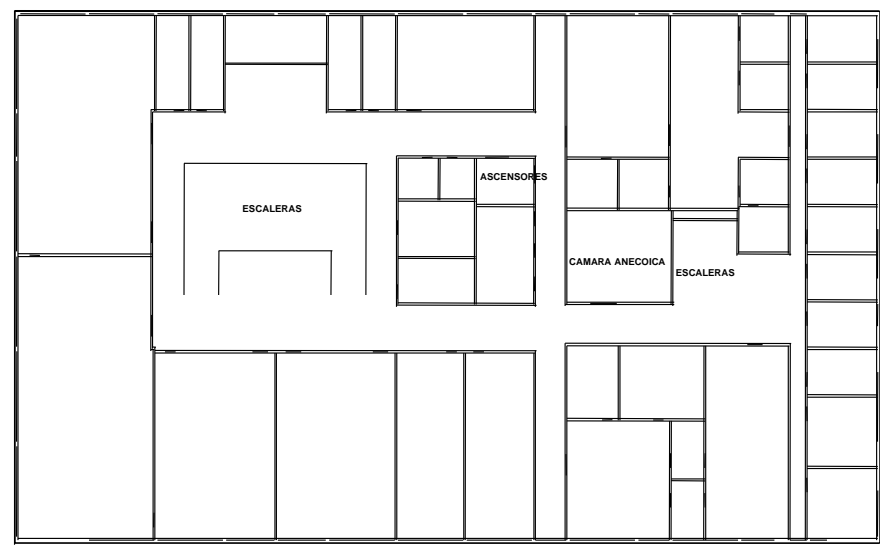

Figura 5.44: Dibujo de una planta de un edificio antes de ser transformada a formato tridimensional

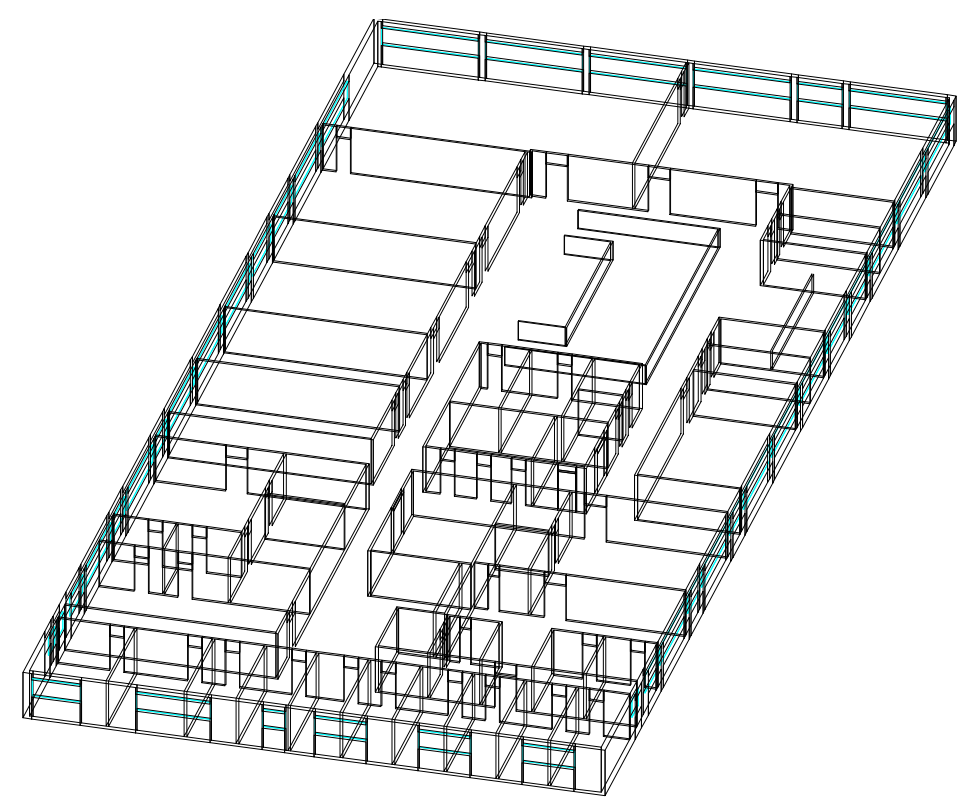

Figura 5.45: Ejemplo de la transformación sufrida por una planta al añadir la tercera dimensión 
Aunque originalmente fue diseñado para transferir datos gráficos entre AutoCAD y otras herramientas, el formato estándar DXF también puede usarse para otras tareas avanzadas. Mediante la modificación de un fichero DXF se pueden actualizar datos del dibujo que son difícilmente accesibles, o realizar grandes cambios en el dibujo a través del acceso a la base de datos gráficos. Puesto que el archivo DXF describe completamente el dibujo, acceder a él y modificarlo proporciona una manera rápida y potente de controlarlo. Así pues, si los cambios que se desean realizar son importantes, un programa que procese los datos del fichero DXF será más rápido que si las actualizaciones se hacen con el editor gráfico. La única limitación del procesado de un DXF, es que el fichero resultante no debe contener ningún dato no permitido por las especificaciones del formato.

AutoCAD guarda los dibujos en ficheros binarios con formato DWG. Esto le permite guardar los datos de forma más compacta y acceder a ellos más rápidamente. Sin embargo, el formato DWG no viene documentado en ningún libro y puede ser modificado en cada nueva versión del programa sin previo aviso. Por ello, las ventajas del DXF son evidentes. El formato DXF se ha convertido en un estándar de la industria del CAD. Además, no hay que ser un experto programador para poder entender, usar y modificar los ficheros con formato DXF. Trabajar con este formato no es difícil, sino simplemente tedioso.

Los ficheros DXF están formados por una serie de grupos de códigos y datos, dispuestos en forma de columna y en formato ASCII. La presentación es siempre la misma: cada uno de estos grupos ocupa dos líneas; la primera es el código que identifica a la segunda línea, y esta es la que almacena los datos. Los principales tipos de grupos y sus códigos DXF se muestran en la tabla 5.6.

\begin{tabular}{|c|l|l|}
\hline VALOR CODIGO & TIPO DE DATO & PRINCIPALES USOS \\
\hline \hline $0-9$ & Cadenas de caracteres & $\begin{array}{l}\text { Tipos de entidades, nombres de objetos, } \\
\text { texto e identificadores }\end{array}$ \\
\hline $10-37$ & Números Reales & Coordenadas \\
\hline 38,39 & Números Reales & Elevación, grosor \\
\hline $40-59$ & Números Reales & Factores de escala, ángulos \\
\hline $60-79$ & Números Enteros & Colores, banderas, cuentas, modos \\
\hline $80-209$ & No usados & \\
\hline $210,220,230$ & Números Reales & Dirección de extrusión X Y Z \\
\hline 999 & Cadenas de caracteres & Comentarios \\
\hline $1000-1009$ & Cadenas de caracteres & Otros datos \\
\hline $1010-1059$ & Números Reales & Otros datos \\
\hline $1060-1079$ & Números Enteros & Otros datos \\
\hline
\end{tabular}

Tabla 5.6: Principales códigos de grupo y tipos de datos en DXF

A grandes rasgos, un fichero con formato DXF se organiza en cuatro secciones, con cuatro tipos de información bien diferenciados:

Sección de Cabecera. Contiene la información general del dibujo, incluyendo todas las variables del sistema vinculadas al dibujo con sus valores. Sus datos están relacionados con la configuración de inicio del programa: nombre del menú usado, ángulo de rotación, punto de vista del dibujo, etc. Comienza con el identificador "Header", 
y cada variable está precedida por el código de grupo 9.

Sección de Tablas. AutoCAD usa tablas para almacenar listados de las capas, tipos de líneas, vistas, estilos, identificadores, sistemas de coordenadas personales, estilos de cotas, configuración de las ventanas, etc. La sección empieza con la clave "Tables". Incluye además los símbolos LAYER, LTYPE, VIEW, STYLE, VPORT, DIMSTYLE, APPID y UCS para separar cada tabla.

Sección de Bloques. Lista todos los bloques definidos en el dibujo. La definición incluye el nombre del bloque, el punto de inserción, la capa de creación, propiedades, y las entidades que forman el bloque. Su identificador es la palabra "Blocks".

Sección de Entidades. Contiene las características de todas las entidades del dibujo. Normalmente es la sección más larga del fichero. AutoCAD soporta 15 tipos de entidades, dos de las cuales son subentidades de las entidades complejas. Cada tipo de entidad requiere distintos datos para su definición, aunque hay cinco propiedades que son comunes a todas las entidades: capa, tipo de línea, color, elevación y grosor. Todas las propiedades, con excepción de la capa, son opcionales puesto que algunas de ellas son irrelevantes en la definición de alguna de las entidades. Por ejemplo, la elevación y el grosor no son necesarios ni con 3DFACE ni con LINE. El listado empieza tras la aparición de "Entities". En los ficheros que maneja el simulador implementado, las únicas entidades que deben encontrarse son 3DFACE.

Además de los nombres de las secciones, AutoCAD usa otras palabras clave para facilitar el entendimiento del formato. Estas palabras indican típicamente el inicio y final de las secciones, tablas, definiciones de bloques, entidades complejas y el final del fichero. Cada palabra clave va precedida del código 0. En la tabla 5.7 se muestran los detalles.

\begin{tabular}{|l|l|}
\hline PALABRA CLAVE & SIGNIFICADO \\
\hline \hline SECTION & Marca el principio de una sección \\
\hline ENDSEC & Marca el final de una sección \\
\hline TABLE & Marca la entrada de una nueva tabla \\
\hline ENDTAB & Marca el final de la tabla \\
\hline BLOCK & Marca el principio de la definición de un bloque \\
\hline ENDBLK & Marca el final de la definición del bloque \\
\hline SEQEND & Marca el final de las entidades complejas \\
\hline EOF & Marca el final del fichero DXF \\
\hline
\end{tabular}

Tabla 5.7: Palabras clave que AutoCAD usa en sus ficheros DXF

La única parte del fichero DXF que interesa para la descripción del entorno, es la que contiene la definición de todas las entidades (3DFACE). Si se desea que el fichero ocupe menos espacio, se puede utilizar la opción de salvar solamente las entidades, pero puede haber problemas si se desea usar el fichero en un entorno distinto a AutoCAD, ya que algunos intérpretes de DXF no reconocen ficheros sin cabecera. 


\section{Importación de los datos del entorno}

El programa de simulación que se ha implementado necesita información concreta y detallada del entorno físico. Por ello, en la fase previa a la simulación, se ha debido llegar a una representación del edificio en la que, tal y como se ha dicho, solamente se utilice la entidad 3DCARA. Una vez completada dicha fase, se habrá salvado la información en un fichero con formato DXF que va a ser el punto de partida para las diversas rutinas que realizan la simulación.

La primera de ellas debe ser capaz de abrir el fichero de intercambio de datos e interpretar el formato DXF, para poder extraer los parámetros de las entidades 3DCARA que definen todo el edificio. Cuando dicha rutina abra el fichero, deberá recorrerlo hasta encontrar dentro de una nueva sección la palabra "Entities". A partir de ese identificador, se deben hallar las 3DCARA's.

Para el manejo de los datos del entorno en el programa de simulación, se ha definido una clase denominada cara. Así, para cada uno de los rectángulos leídos en el fichero DXF, se crea un objeto perteneciente a dicha clase. En esta estructura de datos se almacenan los valores de cada superficie rectangular que forme parte de una estructura del edificio (de una pared, un suelo, una puerta, etc.). Para almacenar de forma estructurada todos los datos importados se utiliza una lista enlazada de elementos que contendrán un elemento de la clase cara y el puntero al elemento siguiente. La lista enlazada es una técnica avanzada de manejo de estructuras, que permite la asignación dinámica de memoria para las mismas. Puesto que el número de 3DCARAs que se leen del fichero de intercambio es desconocido a priori, se van añadiendo elementos a la lista de forma dinámica, hasta completar la cantidad de entidades que definían el edificio.

Cada cara (al igual que las 3DCARA's del fichero DXF) representará el límite entre dos materiales que forman parte de una de las estructuras del edificio, es decir, un suelo, un techo, una pared o parte de alguno de ellos. En la figura 5.46, por ejemplo, la cara 1 es la que separa el aire del material tipo 1 , y la cara 2 es la que separa los materiales 1 y 2.

Puede observarse también en la figura 5.46 que cada superficie tiene asignado un vector unitario normal a ella. Su dirección se obtiene inmediatamente de la ecuación del plano definido por tres de sus cuatro vértices. Su sentido lo impone el tipo de cara dentro de la estructura. Si es interior, el vector está siempre dirigido en el sentido positivo del eje. Si es exterior (hace de límite entre el aire y un material), el sentido es siempre hacia afuera. Al considerar el sentido del vector unitario normal al plano, se está definiendo un plano con dos lados bien diferenciados. Esto es útil por varios motivos: permite distinguir entre el material de un lado y del otro, permite apuntar a las caras adyacentes por ambos lados, y también sirve para ahorrar tiempo de computación en las rutinas de búsqueda de intersecciones rayo-plano.

Todos los datos de cada cara estudiados hasta el momento (los 4 puntos límite de la superficie, la ecuación del plano y el vector normal) se obtienen fácilmente a partir de los 4 vértices de la 3DCARA con la que se corresponde.

Así pues, lo que se necesita saber es, atendiendo al ejemplo de la figura 5.46, que las caras 1, 2 y 3 forman una pared; que las caras 4,5 y 6 forman otra pared distinta; que la cara adyacente a la 1 en el sentido opuesto a su vector normal es la 2, etc. Las ventajas de 


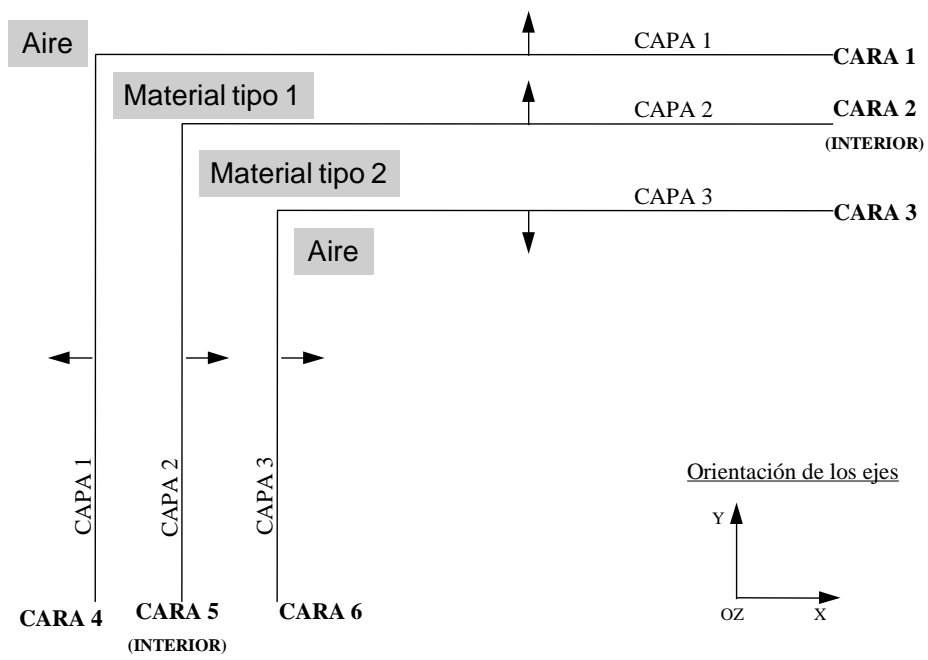

Figura 5.46: Esquema en el que se observa la organización de las caras y su significado

conocer cuál o cuáles son las caras adyacentes a una dada se entenderán cuando se estudien los cálculos que se realizan durante la interacción de los rayos o tubos con estructuras de tipo multi-capa (capítulo 6).

\subsubsection{Parámetros de configuración}

Tras la interpretación del fichero DXF, aún no se ha completado la asignación de todas las variables que definen cada suelo, techo, pared o cualquier otro objeto del entorno. Todavía hay que definir los valores de las constantes dieléctricas complejas de los materiales que cada cara tiene a ambos lados. Puesto que esta información no puede ser extraída directamente de los datos gráficos, será el usuario el que la introduzca a petición del programa, o bien se asignará un fichero de configuración donde estén indicados dichos valores. Para ello, se usará el identificador de la capa a la que pertenece la 3DCARA y, por lo tanto, también la cara.

Los datos de las constantes dieléctricas complejas se han de dar, para cada material que componga cada estructura, en parte real (permitividad relativa $\varepsilon_{r}=\varepsilon / \varepsilon_{0}$, siendo $\varepsilon_{0}$ la permitividad del vacío) y parte imaginaria con su signo $\left(-j \frac{\sigma}{\omega \varepsilon_{0}}\right.$, siendo $\sigma$ la conductividad del medio, y $\omega$ la frecuencia angular de trabajo).

Con el conocimiento de estas constantes dieléctricas se completa la información requerida sobre el entorno, pero aún es necesario conocer otros parámetros de configuración para realizar la simulación. A continuación se listarán los demás parámetros que son necesarios en el programa de simulación que se ha implementado. 
Frecuencia de trabajo. Es la frecuencia a la que transmite el equipo emisor y que se asocia a cada rayo o tubo. En el simulador que se ha implementado, se expresa en MHz. Ha de cuidarse que se adecúe a las condiciones del entorno, de forma que cumpla las condiciones para que sea válido el estudio mediante Óptica Geométrica.

Tipo de antena transmisora. Tal y como se explicará en el capítulo 6, se han implementado distintos diagramas de radiación, todas ellas con polarización lineal: antena isotrópica, dipolo corto, dipolo en $\lambda / 2$, dipolo de longitud arbitraria, o una antena definida por un diagrama de radiación contenido en un fichero. Al simulador hay que indicarle con cuál se quiere trabajar.

Polarización de la antena. Las antenas implementadas proporcionan una polarización lineal a la onda transmitida. Por lo tanto, la polarización de la señal estará condicionada por la orientación del vector campo eléctrico en el momento de ser transmitido. Se posibilitan las siguientes polarizaciones:

- polarización vertical, es decir, perpendicular a suelos y techos,

- polarización horizontal paralela al eje de coordenadas OX, o bien

- polarización horizontal paralela al eje de coordenadas OY.

Potencia transmitida. Es la potencia efectiva entregada a la antena transmisora. Se debe expresar en vatios (W).

Número máximo de reflexiones/transmisiones. Este número va a limitar el seguimiento que se hace de cada rayo o tubo emitido. Como ya se estudiará más adelante, cuando un rayo encuentra un obstáculo en su trayectoria, se divide en uno reflejado y en otro transmitido. Este parámetro es el límite que impide que tal comportamiento se repita indefinidamente.

Umbral absoluto de potencia. En el párrafo anterior se ha comentado que se interrumpe el seguimiento de un rayo o tubo al sobrepasar el número máximo permitido de reflexiones o transmisiones. En este caso, la limitación vendrá impuesta por la potencia que transporta. Si debido a las sucesivas pérdidas que ha sufrido al propagarse e interactuar con el entorno, la potencia no supera el umbral definido en la configuración, se interrumpe el estudio de dicho tubo. El umbral se expresa en $\mathrm{dB}$, respecto a la potencia transmitida.

Posición del transmisor. Sirve para definir la posición que ocupa la antena del transmisor dentro del edificio, es decir, sus coordenadas $x, y$ y $z$, expresadas en metros. 
Zona de estudio de la recepción. Puesto que el propósito de la simulación es el de conocer la señal que llega a un receptor situado en cualquier punto del edificio, será necesario definir también su posición. Para que el programa sea más flexible y se adapte a otros estudios, se permite la definición de un solo punto de recepción, de un vector lineal de puntos o de una matriz bidimensional de receptores. La zona de estudio se especifica mediante la asignación de valores a las variables siguientes:

- Esquina inferior izquierda de la matriz de receptores,

- Esquina superior derecha de la matriz de receptores, y

- Incremento de distancia entre receptores en las tres direcciones $(\Delta x, \Delta y$ y $\Delta z)$.

El funcionamiento es mejor verlo con ejemplos (todas las coordenadas se deben expresar en metros):

- Estudio en un punto: receptor situado en $(2,3,1.5)$. Para indicar al programa que estudie la recepción en esa posición hay que configurar la entrada de la siguiente forma:

- Esquina inferior izquierda $=$ Esquina superior derecha $=(2,3,1.5)$

- Incremento en la distancia entre receptores $=(0,0,0)$

- Estudio en una recta: vector de receptores situado a lo largo de una línea vertical que se encuentra en $(5,5)$ y que se extiende en altura desde 0.5 hasta 2 metros. La separación en altura entre ellos es de 1cm. La configuración de la entrada será la siguiente:

- Esquina inferior izquierda $=(5,5,0.5)$

- Esquina superior derecha $=(5,5,2)$

- Incremento en la distancia entre receptores $=(0,0,0.01)$

- Estudio en un plano: receptores situados en un plano horizontal que se encuentra a 1 metro de altura respecto al suelo. El área debe cubrir una habitación de $5 \times 10$ metros con la esquina sobre el origen. La separación de los receptores será de $10 \times 10 \mathrm{~cm}$. Habría que configurar la entrada como sigue:

- Esquina inferior izquierda $=(0,0,1)$

- Esquina superior derecha $=(5,10,1)$

- Incremento en la distancia entre receptores $=(0.1,0.1,0)$

Además de todos estos parámetros, hay que indicar al programa si se desean incluir ciertos fenómenos de propagación particulares, como las pérdidas de scattering o la difracción, así como la resolución del lanzado, expresado en número de paralelos en que se quiere dividir las esfera alrededor del transmisor. 


\subsubsection{Evolución de los rayos y tubos}

Anteriormente se ha estudiado cómo lanzar rayos o tubos al espacio uniformemente desde el emisor. Además, habrá que hacer un seguimiento de estos y ver de qué forma interactúan con el entorno. Se explicará a continuación la algorítmica de seguimiento, dejando para el capítulo 6 la física asociada a la propagación e interacción de los rayos o tubos con el entorno.

Básicamente, el mecanismo consiste en tomar un rayo o un tubo que parta del emisor, y buscar su intersección con la estructura más cercana. Seguidamente, se han de analizar los posibles impactos en los receptores a considerar. Así, en el caso de los tubos, se buscan los receptores existentes en el interior del cono de sección triangular que se forma al propagarse el tubo. En el caso de los rayos, se utiliza un algoritmo más complejo descrito en la sección 5.3.

Si, efectivamente, el rayo o el tubo impacta en algún receptor, se calcula la cantidad de señal que aporta. A continuación se divide en uno reflejado y en uno transmitido, y el proceso descrito se repite hasta que se sale de la zona de estudio, no transporta suficiente potencia o se supera el número máximo de reflexiones o transmisiones permitido.

En definitiva, cada rayo o tubo lanzado desde el transmisor puede ser representado como un árbol binario (figura 5.47). Cada intersección con una estructura del edificio se simboliza con un nodo en ese árbol. Como se puede ver en la figura 5.47, cada vez que ocurre esto, el rayo o el tubo incidente se descompone en dos nuevos: uno reflejado y otro transmitido.

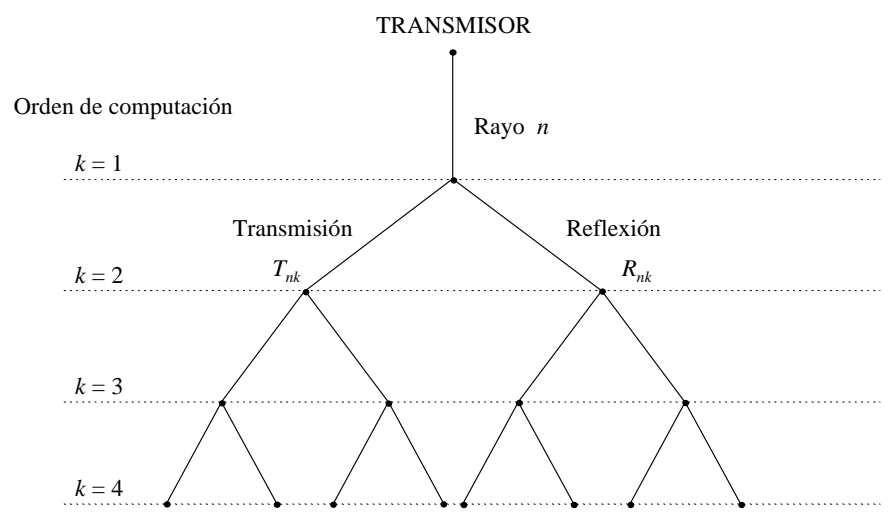

Figura 5.47: Representación de la evolución de los rayos mediante un árbol binario

Puesto que cada rayo incidente en una superficie da lugar a dos nuevos, el número de trayectorias que hay que calcular crece enormemente si el número de obstáculos (paredes, suelos, techos, puertas, ventanas, etc.) también crece. Es decir, si un edificio es grande y tiene numerosas habitaciones, habrá que permitir un gran número de reflexiones y transmisiones, con lo que el número de rayos a evaluar será mayor y la simulación durará mucho 
más. Teóricamente, el número de rayos que se originan por cada uno lanzado desde el emisor, es igual a $2 k-1$, donde $k$ es el número máximo de reflexiones y transmisiones que se permita en la simulación. Pero algunos se descartarán durante su seguimiento por varios motivos. Esto significa que no se puede conocer a priori con exactitud la complejidad de la simulación.

Cuando los rayos o tubos se propagan por el interior de una estructura sobre la que ha incidido (una pared, por ejemplo), y hasta que vuelve a salir al exterior de ella, no es necesario estudiar los posibles impactos, ya que en el interior de una estructura no hay receptores.

Los rayos de primera generación tienen su primer origen en la posición del emisor, pero en las sucesivas intersecciones con las caras, el origen de cada rayo se va actualizando a los puntos de intersección calculados sobre cada una de ellas. Las ecuaciones que se usan para el cálculo de los puntos de intersección de los rayos con los rectángulos, se han estudiado previamente en la sección 5.3.1. En cuanto a las direcciones de esos rayos, solamente deben cambiar cuando se crea un rayo reflejado, puesto que como se verá en el capítulo 6, se considera que el rayo transmitido se propaga con la misma dirección que el incidente. La expresión que se usa para el cálculo del vector director del rayo reflejado $\vec{R}$ es:

$$
\vec{R}=\vec{I}-2(\vec{N} \cdot \vec{I}) \vec{N}
$$

donde, $\vec{I}$ es la dirección del rayo incidente, y $\vec{N}$ es el vector normal a la superficie.

En el caso de los tubos, para obtener los vectores con direcciones normales a los planos que forman cada tubo de sección triangular, se usan los vectores de dirección de los rayos que lo delimitan. Al hacer el producto vectorial de dos vectores situados sobre un mismo plano, se obtiene un nuevo vector, que es además perpendicular a dicho plano. El sentido del vector resultante vendrá determinado por el orden con el que los vectores que se multiplican. Estos productos únicamente se realizan para cada tubo que parte directamente del emisor. Cuando se genera un tubo reflejado a partir de ellos, sólo hay que calcular las reflexiones de cada uno de los rayos que lo forman con la fórmula antes vista. Así se ahorra tiempo de computación, ya que un producto escalar es más rápido que uno vectorial.

Posteriormente a una incidencia, se ha de realizar una serie de verificaciones para saber si el rayo o el tubo aún cumple las condiciones para generar un nuevo nivel de computación. Lo primero que se hace es comparar el número de reflexiones y transmisiones que ha sufrido, con el máximo que se definió en la configuración. Si pasa este test, se actualizan las distintas variables, y se calculan el coeficiente de reflexión y la potencia que todavía transportan los rayos o tubos reflejado y transmitido. Para cada uno de ellos, si no alcanzan el umbral de potencia que se definió también en la configuración, se actualizan el resto de las variables y se hace la llamada recursiva a la rutina correspondiente. En el caso de los rayos internos a las estructuras, no es necesario verificar el nivel de reflexiones, ya que este contador solamente se incrementa en el rayo padre, habiéndose realizado ya dicha comprobación en el reflejado. Si este pasa la comprobación, el transmitido también. 


\subsubsection{Salida de información}

Una vez finalizada la ejecución de la simulación, el programa guarda en varios ficheros información referente a la señal recibida en cada uno de los receptores que se ha estudiado.

Así, en un fichero ASCII guarda las potencias recibidas en dBm en cada punto de la matriz definida mediante los parámetros de entrada. En otro fichero adicional, se guarda el número total de impactos recibidos en cada punto.

Para proporcionar información en banda ancha, también se guarda en un solo fichero binario diversos datos acerca de cada uno de los receptores considerado: sus posiciones en coordenadas cartesianas, el tiempo de llegada (retardo absoluto de propagación) de cada rayo o tubo, así como el campo eléctrico asociado a cada uno (parte real e imaginaria) y sus ángulos de llegada respecto al receptor.

De esta forma, es factible obtener fácilmente la respuesta impulsional compleja del canal en un punto o en varios, permitiendo además calcular todas las funciones de Bello (función de transferencia, función de scattering ... ).

Como se puede ver, la información proporcionada por el simulador es lo suficientemente amplia como para utilizarla en muy diversos campos relacionados con la caracterización del canal radio móvil indoor: análisis de coberturas de pico-células indoor; prestaciones de sistemas de modulación, de métodos de ecualización o de técnicas de diversidad; caracterización estadística de la señal recibida, etc.

\subsection{Resumen}

En este capítulo se han descrito con detalle distintas técnicas empleadas en los métodos de Lanzado de Rayos, presentándolas como aproximaciones propias del campo de la Óptica Geométrica aplicadas a la Radiopropagación.

Entre las técnicas empleadas, se han destacado las utilizadas para solventar la problemática referente a la recepción en objetos puntuales. Estos problemas son más relevantes al considerar propagación tridimensional, complicando la algorítmica asociada al estudio de la recepción.

Se ha presentado como alternativa otro método de lanzado más particular: el Lanzado de Tubos. Esta técnica consite en dotar de estructura tridimensional a las entidades lanzadas, con lo que se resuelve de manera muy sencilla el problema de la recepción. Sin embargo, también se han tenido en consideración los problemas que se plantean con este método al utilizarlo en entornos complejos o muy grandes, debido al ensanchamiento de los tubos con la distancia recorrida. Este problema puede ser resuelto mediante la subdivisión o splitting, aunque complica la técnica.

Finalmente, se han propuesto una par de métodos sencillos para acelerar las simulaciones, consistentes básicamente en el descarte previo de aquellos rayos o tubos que al final no vayan a ser muy significativos en el resultado final.

Todas estas técnicas han sido implementadas en un programa de simulación que tam- 
bién ha sido descrito con detalle en este capítulo.

Para el siguiente capítulo se ha dejado toda la física asociada a la propagación de los rayos o tubos y su interacción con los objetos del entorno, en forma de reflexión, transmisión o difracción. 


\section{Capítulo 6}

\section{Fenómenos de Propagación Electromagnética en los Modelos de Lanzado de Rayos}

\subsection{Introducción}

Tal y como se vió en el capítulo 3, para crear un modelo de un sistema de comunicaciones móviles, es preciso desarrollar descripciones matemáticas, más o menos sencillas, del transmisor, del receptor y de los efectos que el entorno provoca en la señal transmitida. Combinando tales descripciones, el modelo queda listo para poder evaluar las prestaciones de un sistema teórico, sin necesidad de tener que implementarlo previamente.

El modelo final puede, así, quedar representado en forma de un conjunto de ecuaciones que, normalmente, se han de incorporar a un programa de simulación por ordenador, debido a la complejidad que suelen llevar asociada.

Se ha visto en el capítulo anterior la algorítmica relacionada con las distintas técnicas basadas en los métodos de Lanzado de Rayos, dejándose para este capítulo toda la física asociada a los fenómenos de propagación electromagnética que se pretenden simular mediante tales técnicas.

Por tanto, en este capítulo se procederá a describir los modelos que se han utilizado para simular la propia propagación de los rayos, así como la influencia de los distintos objetos que forman el entorno al incidir sobre ellos los frentes de ondas que son representados mediante dichos rayos.

Tal influencia puede ser descrita en términos de reflexión en superficies (ya sea especular o difusa), transmisión a través de ellas, y difracción en aristas. También se harán consideraciones respecto al diagrama de radiación de las antenas que se han simulado, y la polarización de los campos asociados a los rayos.

En este capítulo, se comentarán también con detalle todas aquellas simplificaciones que, irremediablemente, se hayan tenido que realizar para poder hacer abordable los modelos 
finalmente implementados.

\subsection{Radiación electromagnética}

Para definir de forma adecuada un modelo para el transmisor y el receptor que fuera útil en condiciones de propagación indoor, se podría recurrir, en una primera aproximación, al modelo teóricamente más ideal y más fácil de simular: una fuente puntual que radiase por igual en todas las direcciones, cuya potencia transmitida decreciera con la distancia, pero que, a una distancia fija, dicha potencia fuera constante con independencia de la orientación del transmisor.

Bajo estas condiciones tan ideales, se sabe que la potencia radiada viene inmediatamente determinada por el vector de Poynting [Col85]. Así, para esta fuente ideal, puntual y ominidireccional, se puede calcular la potencia recibida, en dBW, a una cierta distancia $r$ mediante:

$$
P(r)=P_{1}-20 \log _{10}\left(\frac{r}{r_{1}}\right)
$$

donde $P_{1}$ es la potencia recibida, en dBW, a una distancia radial $r_{1}$ del transmisor. En [Pro89] se propone la siguiente expresión para esta potencia $P_{1}$ :

$$
P_{1}=P_{T}+20 \log _{10}\left(\frac{\lambda}{4 \pi r_{1}}\right)
$$

siendo $P_{T}$ la potencia transmitida en $\mathrm{dBW}$, y $\lambda$ la longitud de onda de la señal.

La ecuación (6.1) es válida para condiciones de campo lejano $(r \gg \lambda)$. Cuando la distancia al transmisor $r$ decrece, la potencia recibida aumenta, pudiendo llegar a superar a la potencia transmitida, alcanzando una singularidad en $r=0$.

La idealidad de la fuente puntual ominidireccional presenta, además, una deficiencia en su propia definición: se sabe que tales fuente puntuales son electromagnéticamente imposibles [Col85]. Los campos electromagnéticos radiados solamente pueden ser generados mediante variaciones en una carga, es decir, mediante corrientes. Para que existan tales corrientes, ha de existir un medio físico sobre el que discurran, y tal medio no puede ser un objeto puntual.

Sin embargo, cabe la posibilidad de definir un dipolo infinitamente pequeño, pero que tenga asociada una determinada alineación, por el cual fluya una corriente que genere los campos. Así, tomando dicho dipolo como origen de un sistema de coordenadas, alineándolo según el eje $z$, y suponiendo que a través de su longitud infinitesimal $(\Delta z)$ fluye una corriente en régimen permanente sinusoidal de valor efectivo $I_{0}$, se calcula la expresión del vector complejo campo magnético $\vec{H}$ a una distancia $r$ en coordenadas esféricas mediante [Col85]:

$$
\vec{H}=\frac{I_{0} \Delta z}{4 \pi}\left(\frac{\gamma}{r}+\frac{1}{r^{2}}\right) e^{-\gamma r} \sin \theta \hat{\phi}
$$


donde $\gamma$ es la constante de propagación del medio y viene determinada por $\gamma^{2}=-\omega^{2} \mu \varepsilon$ (considerándo al medio como un dieléctrico sin pérdidas), siendo $\omega$ la frecuencia angular de oscilación de la corriente, y $\varepsilon$ y $\mu$ la permitividad y la permeabilidad del medio, respectivamente.

Así mismo, el vector campo eléctrico vendrá dado por:

$$
\begin{aligned}
\vec{E}=\frac{I_{0} \Delta z}{2 \pi} e^{-\gamma r}\left\{\left(\sqrt{\frac{\mu}{\varepsilon}} \frac{1}{r^{2}}+\frac{1}{j \omega \varepsilon r^{3}}\right) \cos \theta\right. & \hat{r} \\
& \left.+\frac{1}{2}\left(\frac{j \omega \mu}{r}+\sqrt{\frac{\mu}{\varepsilon}} \frac{1}{r^{2}}+\frac{1}{j \omega \varepsilon r^{3}}\right) \sin \theta \hat{\theta}\right\}
\end{aligned}
$$

Los versores $\hat{r}, \hat{\theta}$ y $\hat{\phi}$ son los que forman la base ortonormal en coordenadas esféricas. Así, $\vec{H}$ resulta ser un vector que gira alrededor del eje $z$. Además, el vector de Poynting, que, tal y como se ha dicho antes, denota la potencia que está siendo radiada, puede calcularse mediante el siguiente producto vectorial:

$$
\begin{aligned}
\vec{E} \times \vec{H}^{*}=\left(\frac{I_{0} \Delta z \beta^{2}}{4 \pi}\right)^{2} \sqrt{\frac{\mu}{\varepsilon}}\left\{\operatorname { s i n } ^ { 2 } \theta \left(\frac{1}{(\beta r)^{2}}+\right.\right. & \left.\frac{1}{(j \beta r)^{5}}\right) \hat{r} \\
& \left.\quad+j \sin (2 \theta)\left(\frac{1}{(\beta r)^{3}}+\frac{1}{(\beta r)^{5}}\right) \hat{\theta}\right\}
\end{aligned}
$$

donde $\beta=\omega \sqrt{\mu \varepsilon}=-j \gamma$ es la constante de fase del medio* ${ }^{*}$ y $\vec{H}^{*}$ es el vector complejo conjugado de $\vec{H}$.

En puntos suficientemente alejados del dipolo, los términos $(1 / r)^{2}$ y aquellos con potencias superiores, pueden ser despreciados, resultando entonces una onda plana, donde el vector campo magnético tiene la siguiente expresión:

$$
\vec{H}=\frac{I_{0} \Delta z}{4 \pi} \frac{\gamma}{r} e^{-\gamma r} \sin \theta \hat{\phi}=\frac{I_{0} \Delta z}{4 \pi} \frac{j \beta}{r} e^{-j \beta r} \sin \theta \hat{\phi}
$$

y el vector campo eléctrico:

$$
\vec{E}=\frac{I_{0} \Delta z}{4 \pi} \frac{j \omega \mu}{r} e^{-\gamma r} \sin \theta \hat{\theta}=\frac{I_{0} \Delta z}{4 \pi} \sqrt{\frac{\mu}{\varepsilon}} \frac{j \beta}{r} e^{-j \beta r} \sin \theta \hat{\theta}
$$

En este caso, puede calcularse la densidad de potencia recibida (medida en $\mathrm{W} / \mathrm{m}^{2}$ ) en puntos suficientemente alejados del dipolo elemental mediante la expresión:

$$
P=\|\vec{E}\|\|\vec{H}\|=\frac{\vec{E} \cdot \overrightarrow{E^{*}}}{\eta}
$$

\footnotetext{
${ }^{*}$ Cuando el medio es el vacío, también se le llama número de onda y se suele representar mediante la letra $k$. En este caso, $k=\omega \sqrt{\mu_{0} \varepsilon_{0}}=\omega / c=2 \pi / \lambda$, siendo $c=1 / \sqrt{\mu_{0} \varepsilon_{0}}$ la velocidad de propagación de la onda, y $\lambda$ su longitud de onda.
} 
donde $\eta$ es la impedancia intrínseca del medio, que representa la relación entre las normas de los vectores campo eléctrico y campo magnético, y que puede ser calculada mediante:

$$
\eta=\sqrt{\frac{\mu}{\varepsilon-j \frac{\sigma}{\omega}}}
$$

siendo $\sigma$ la conductividad del medio, que si es nula simplifica la expresión de la impedancia intrínseca en $\eta=\sqrt{\mu / \varepsilon}$, haciéndola real. Con todo ello, la densidad de potencia $P$ queda de la siguiente forma*:

$$
P=\left(\frac{I_{0} \Delta z \beta}{4 \pi}\right)^{2} \sqrt{\frac{\mu}{\varepsilon}} \frac{1}{r^{2}} \sin ^{2} \theta
$$

Se ha demostrado, por tanto, que hasta la fuente más elemental de radiación provoca una dependencia de la potencia recibida con el ángulo $\theta$, por lo que resulta imposible la radiación perfectamente omnidireccional.

Sin embargo, una conclusión bastante importante se extrae de todo este estudio, y es que, si se considera que todos los objetos influyentes en la propagación de las ondas (reflectores, difractores, difusores, ... ) se encuentran lo suficientemente alejados de la fuente de radiación, esta radiación podrá ser tratada como una onda plana, quedando perfectamente definida solamente con uno de los campos, generalmente el campo $\vec{E}$. Ello proporciona una significante reducción de la complejidad computacional, al no ser necesario tratar con las complejas ecuaciones que, en otros casos, relacionan los campos electromagnéticos.

\subsubsection{Efectos de la antena. Polarización y diagrama de radiación}

En los modelos de Lanzado de Rayos que se han implementado, y cuyas técnicas se vieron en el capítulo 5, se asocia a cada rayo lanzado (o a cada tubo), un valor complejo que representa, en módulo y fase, el campo eléctrico de la porción de onda plana que define dicho rayo. Dicho valor vendrá determinado, tal y como se ha visto, por la potencia transmitida, la distancia recorrida por dicho rayo, la frecuencia de la señal, así como por otros coeficientes que representarán las interacciones que haya tenido el rayo con los objetos del entorno en su recorrido (reflexiones, transmisiones, difracción, ... ).

Para describir adecuadamente el transmisor en un modelo que tenga en cuenta las condiciones de propagación en las tres dimensiones del entorno, resulta necesario, además, simular el comportamiento del diagrama de radiación de la antena transmisora.

Ello resulta relativamente sencillo si el campo eléctrico asociado a cada rayo se multiplica por una función que represente a ese diagrama de radiación. Por tanto, dicho campo asociado podrá expresarse de la siguiente forma, teniendo en cuenta todas las consideraciones hechas hasta ahora:

$$
\vec{E}=\vec{E}_{0} f_{T}(\theta, \phi) \frac{e^{-j k d}}{d} \prod_{n} \rho_{n} \prod_{m} \tau_{m}
$$

${ }^{*}$ Para calcular la potencia recibida (en $\mathrm{W}$ ), habría que calcular el flujo de esta densidad de potencia $P$ a través de la porción de frente de ondas captado por el receptor, es decir, multiplicarla por el área efectiva de la antena receptora. 
donde $\vec{E}_{0}$ es el vector de referencia del transmisor, que representa tanto la potencia transmitida como la polarización y la orientación de la antena transmisora*; $f_{T}(\theta, \phi)$ es el diagrama de radiación en campo normalizado de la antena transmisora, siendo $\theta$ y $\phi$ los ángulos con los que es lanzado el rayo asociado desde el transmisor; $d$ es la distancia recorrida por el rayo, $k$ es el número de onda (o constante de fase en el vacío), y $\rho_{n}$ y $\theta_{m}$ son los distintos coeficientes de reflexión y transmisión, respectivamente, que se asocien al rayo, teniendo en cuenta las interacciones que haya sufrido con los objetos del entorno. Las expresiones de tales coeficientes, además de los efectos de la difracción, serán descritos en secciones sucesivas.

En el modelo que se ha desarrollado, se han implementado distintos diagramas de radiación. En todos los casos, se trata de antenas tipo dipolo con polarización lineal, y orientadas según algún eje coordenado. Hay que tener en cuenta que esto no es una limitación, pues se sabe que cualquier polarización puede ser descompuesta como superposición de dos polarizaciones lineales ortogonales entre sí. Las expresiones de los diagramas de radiación que se han implementado, para el caso de dipolos orientados según el eje $z$, son las siguientes:

- Antena isotrópica:

$$
f_{T}(\theta, \phi)=1
$$

- Dipolo corto (longitud menor a $\lambda / 50)$ :

$$
f_{T}(\theta, \phi)=\sin \theta
$$

- Dipolo $\lambda / 2$ :

$$
f_{T}(\theta, \phi)=\frac{\cos \left(\frac{\pi}{2} \cos \theta\right)}{\sin \theta}
$$

- Dipolo de longitud $L$ :

$$
f_{T}(\theta, \phi)=\frac{\cos \left(\frac{k L}{2} \cos \theta\right)-\cos \frac{k L}{2}}{\sin \theta}
$$

Además, se ha implementado la posibilidad de definir un diagrama de radiación arbitrario mediante un fichero de datos que contenga una tabla con los valores discretos del diagrama de radiación para cada ángulo $\theta$ entre 0 y $90^{\circ}$, y cada ángulo $\phi$ entre 0 y $359^{\circ}$ (total: 91 filas por 360 columnas). La única limitación es que se trate de diagramas de campo normalizados de antenas con polarización lineal, orientadas según algún eje coordenado que se ha de especificar.

Para no cargar la complejidad computacional del modelo, se ha supuesto que las antenas receptoras son isotrópicas, por lo que no se han tenido en cuenta sus diagramas de radiación a la hora de evaluar el campo recibido en cada punto. De todas formas, cabe recordar que, con este modelo, es factible conocer con qué dirección llegan los distintos rayos a cada receptor, por lo que un procesado posterior de los resultados permitiría ponderar cada rayo por el diagrama de radiación en recepción.

\footnotetext{
${ }^{*}$ Estrictamente, $E_{0}$ no tiene unidades de campo eléctrico, sino que $E_{0}=E_{1} r_{1}$, siendo $E_{1}$ el módulo de campo eléctrico recibido a una distancia arbitraria $r_{1}$. Por tanto, teniendo en cuenta la ecuación (6.2), se tiene que $E_{0}=\sqrt{\eta P_{T} / 4 \pi}$, siendo $P_{T}$ la potencia radiada efectiva en W.
} 


\subsection{Incidencia sobre superficies dieléctricas}

Solamente las superficies conductoras perfectas pueden reflejar completamente las ondas electromagnéticas. Por ello, resulta especialmente necesario caracterizar el entorno mediante dieléctricos con pérdidas, caracterizados mediante los siguientes parámetros electromagnéticos: permitividad $\varepsilon$, permeabilidad $\mu$, y conductividad $\sigma$.

De esta forma, podrán calcularse las pérdidas que se produzcan en la potencia de una onda electromagnética al incidir en una superficie, mediante los correspondientes coeficiente de reflexión $\rho$ y de transmisión $\tau$ definidos mediante la relación entre los campos eléctricos reflejado y transmitido, respectivamente, y el campo eléctrico incidente. Téngase en cuenta que dichos campos tienen asociado un módulo y una fase, por lo que tales coeficientes resultarán ser, en general, complejos.

Se sabe que estos coeficientes son dependientes del ángulo de incidencia de la onda, de su polarización, y de su frecuencia, así como de las características de los materiales que definen la superficie sobre la que inciden.

Ya que, como se ha dicho, cualquier polarización puede ser descompuesta como superposición de dos polarizaciones lineales ortogonales entre sí, solamente se estudiará la incidencia en superficies para dos tipos de polarización, en ambos casos lineales: la polarización horizontal y la polarización vertical.

Se dice que una onda linealmente polarizada incide en una superficie con polarización horizontal cuando el vector campo eléctrico incidente es paralelo a la superficie sobre la que incide (figura 6.1). En este caso, dicho vector permanecerá perpendicular a lo que se denomina plano de incidencia, que es el que contiene la trayectoria de la onda. Por otro lado, el vector campo magnético estará contenido en dicho plano.

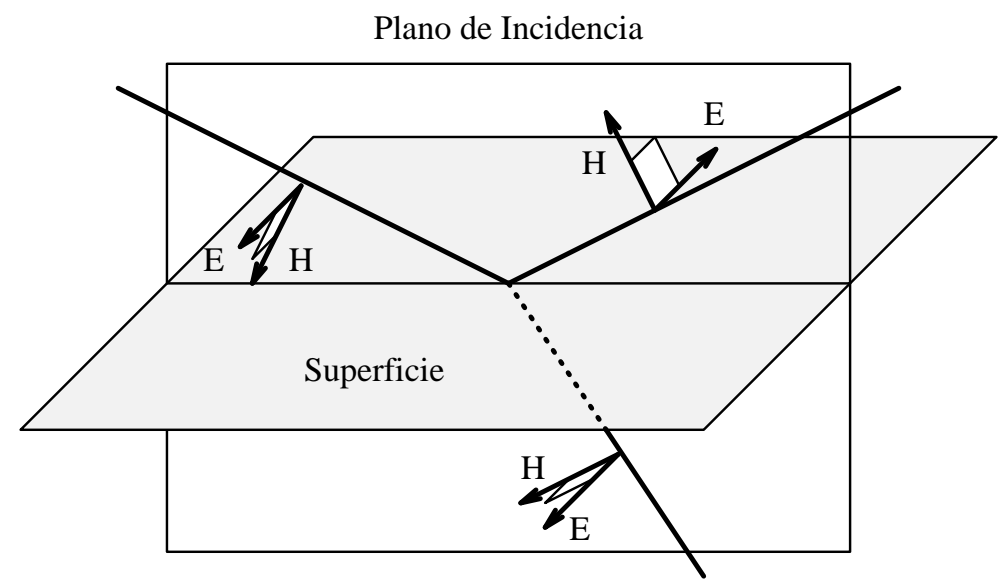

Figura 6.1: Polarización horizontal

Por el contrario, se dice que una onda incide con polarización vertical en una superficie cuando el vector campo eléctrico incidente está incluido en el plano de incidencia (figura 6.2). En este caso, el vector campo magnético incide horizontalmente sobre la superficie. Se le denomina polarización vertical porque, en el caso de que el ángulo de incidencia (el que forma la trayectoria de la onda incidente con la superficie sobre la que incide) sea muy 
pequeño (incidencia rasante), el vector de campo eléctrico incidente resulta casi vertical a la superficie. Esto, que no es ni mucho menos verdadero cuando el ángulo de incidencia es notable, sí es bastante habitual en el caso de propagación en exteriores, cuando la distancia entre transmisor y el punto en el que se produce la reflexión (habitualmente situado en el suelo) es grande. Aunque este hecho no tiene por qué ocurrir en entornos indoor, se mantiene la nomenclatura por convenio.

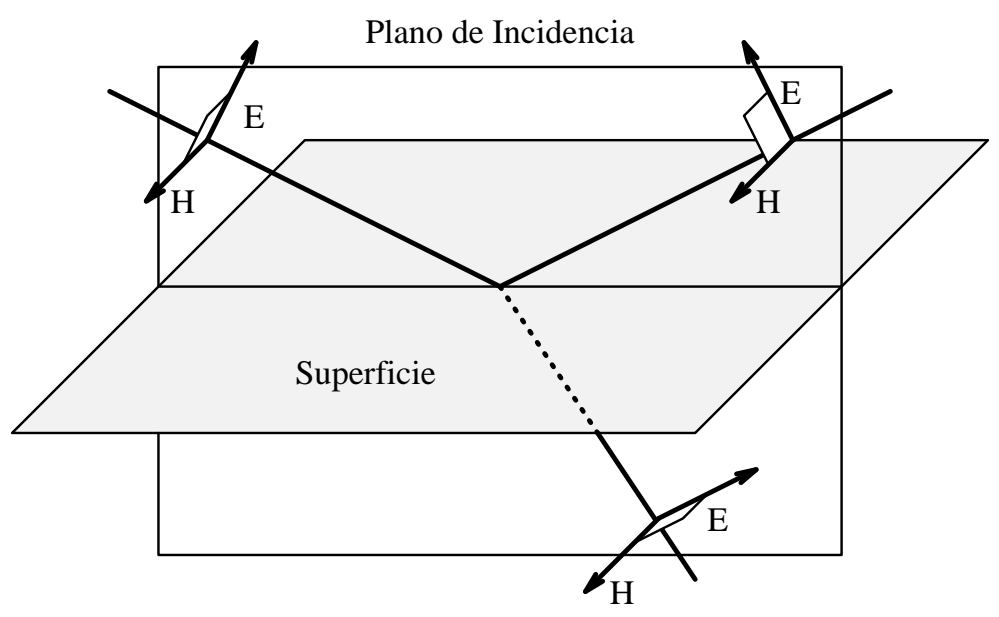

Figura 6.2: Polarización vertical

Por otra parte, hay que tener en cuenta que, en entornos complejos tridimensionales, como son los del interior de un edificio, una misma onda con una determinada polarización lineal puede incidir con distinta polarización según sea el obstáculo una estructura horizontal (techo o suelo) o vertical (paredes). Este hecho ha de ser tenido en cuenta en la implementación del modelo.

\subsubsection{Reflexión}

Un modelo bastante realista válido para las superficies reflectoras, sería el de un plano infinito que separase dos medios dieléctricos con distintas características electromagnéticas. Inicialmente se puede suponer que ambos medios son semi-infinitos, es decir, la única discontinuidad existente es dicha superficie de separación. Otras suposiciones adicionales serían considerar los medios como homogéneos y la superficie como perfectamente lisa.

De esta forma, definiendo la impedancia intrínseca de cada medio mediante la ecuación (6.9), y asumiendo que ninguno de los medios es ferromagnético (con lo que, para ambos medios, $\mu=\mu_{0}=4 \pi \cdot 10^{-7} \mathrm{H} / \mathrm{m}$ ), se define el índice de refracción $n$ entre ambos medios 1 y 2 , mediante la siguiente ecuación:

$$
n^{2}=\left(\frac{\eta_{1}}{\eta_{2}}\right)^{2}=\frac{\varepsilon_{2}-j \frac{\sigma_{2}}{\omega}}{\varepsilon_{1}-j \frac{\sigma_{1}}{\omega}}
$$

A la expresión $\varepsilon-j \frac{\sigma}{\omega}$ se le llama constante dieléctrica compleja del medio*, y lo caracteriza electromagnéticamente para una determinada frecuencia de trabajo. Se suele

\footnotetext{
${ }^{*}$ Muy habitualmente, esta constante es dada con el formato $\underline{\varepsilon}=\varepsilon^{\prime}+j \varepsilon^{\prime \prime}$
} 
trabajar con su valor relativo, es decir, normalizado respecto al que tiene el vacío $\left(\varepsilon_{0} \approx\right.$ $\left.8,854 \cdot 10^{-12} \mathrm{~F} / \mathrm{m}\right)$.

Para estudiar la relación entre las normas de los vectores campo eléctrico incidente $\left(E_{i}\right)$, reflejado $\left(E_{r}\right)$ y transmitido $\left(E_{t}\right)$, y bajo las condiciones apuntadas anteriormente, se ha de acudir a la siguiente relación, que es válida para cualquier polarización [Ree53]:

$$
\frac{E_{r}^{2}}{E_{i}^{2}}=1-\frac{\eta_{1}}{\eta_{2}} \frac{E_{t}^{2} \cos \theta_{t}}{E_{i}^{2} \cos \theta_{i}}
$$

siendo $\theta_{i}$ y $\theta_{t}$ los ángulos que forman las trayectorias de las ondas incidente y transmitida, respectivamente, respecto a la normal a la superficie de incidencia. Teniendo en cuenta las leyes de la óptica geométrica y la ley de Snell, se sabe que el ángulo de la onda incidente $\theta_{i}$ es igual al ángulo de la onda reflejada $\theta_{r}$, y que:

$$
\cos \psi=\sin \theta_{i}=n \sin \theta_{t}
$$

siendo $\psi$ el ángulo de incidencia, es decir, el ángulo que forma la trayectoria de la onda incidente (y también la reflejada) respecto a la superficie de incidencia.

Conocida también la siguiente relación, válida solamente con polarización horizontal [Ree53]:

$$
\left(\frac{E_{t}}{E_{i}}\right)_{H}=1+\left(\frac{E_{r}}{E_{i}}\right)_{H}
$$

se puede llegar a calcular la expresión del coeficiente de reflexión en el caso de polarización horizontal:

$$
\rho_{H}=\frac{E_{r}}{E_{i}}=\frac{\sin \psi-\sqrt{n^{2}-\cos ^{2} \psi}}{\sin \psi+\sqrt{n^{2}-\cos ^{2} \psi}}
$$

Para calcular este mismo coeficiente en el caso de polarización horizontal, hay que ayudarse de esta otra relación, válida en dichas condiciones [Ree53]:

$$
\left(\frac{E_{t}}{E_{i}}\right)_{V}=\left(1-\left(\frac{E_{r}}{E_{i}}\right)_{V}\right) \frac{\cos \theta_{i}}{\cos \theta_{t}}
$$

que, junto con la ecuación (6.17), resulta:

$$
\rho_{V}=\frac{E_{r}}{E_{i}}=\frac{n^{2} \sin \psi-\sqrt{n^{2}-\cos ^{2} \psi}}{n^{2} \sin \psi+\sqrt{n^{2}-\cos ^{2} \psi}}
$$

\subsubsection{Transmisión}

Tomando las mismas consideraciones que se han visto en el caso de reflexión, se pueden calcular los coeficientes de transmisión para el caso de polarización horizontal [Bal89]:

$$
\tau_{H}=\frac{E_{t}}{E_{i}}=\frac{2 \sin \psi}{\sin \psi+\sqrt{n^{2}-\cos ^{2} \psi}}
$$


y para el de polarización vertical:

$$
\tau_{V}=\frac{E_{t}}{E_{i}}=\frac{2 n \sin \psi}{n^{2} \sin \psi+\sqrt{n^{2}-\cos ^{2} \psi}}
$$

Muchos autores, entre ellos [Bur83], afirman que los módulos de los coeficientes de reflexión y de transmisión se relacionan mediante la expresión $|\tau|=1-|\rho|$. Puede comprobarse fácilmente que esto solamente es cierto para el caso de polarización horizontal. Es importante remarcarlo, pues, en caso contrario, es posible incurrir en incongruencias graves.

El error surge por confusión con la ecuación que relaciona los coeficientes de transmisión y reflexión en el caso de incidencia sobre dieléctricos no conductores. Cuando $\sigma=0$, dichos coeficientes son reales e independientes de la frecuencia. Representan un cociente entre módulos de campos eléctricos y, por lo tanto, también relacionan las raíces de las potencias transmitida y reflejada con la de la potencia incidente. Así, en este caso, puede aplicarse el principio de conservación de la energía y afirmarse sin género de duda que $\tau=1-\rho$.

Pero en el caso genérico en el que $\sigma \neq 0$, dichos coeficientes pasan a ser complejos y dejan de representar relaciones entre potencias. Aparecen efectos de tipo pelicular y de resonancia que, en principio, no son de interés para la propagación de las ondas, aunque sí los desfases entre rayos que se producen en el interfaz de separación entre medios. Esta es otra de las razones por la que se debe rechazar el trabajar con los módulos, en lugar de con las expresiones complejas.

Así, si se representa el módulo del coeficiente de transmisión calculado según la fórmula errónea $|\tau|=1-|\rho|$, para el caso particular en el que $n^{2}=5-0,4 j$ (figura 6.3), se observa que existe un ángulo de incidencia para el cual el módulo del coeficiente de transmisión toma un valor cercano a la unidad en el caso de polarización vertical. A este ángulo se le conoce como ángulo de Brewster y permite a la onda atravesar el interfaz entre los dos medios sin apenas atenuación.

Pero, si se comparan dichos resultados con los proporcionados por las fórmulas correctas dadas por [Bal89], se aprecia que, en realidad, el ángulo de Brewster no existe en este caso particular (figura 6.4).

Por tanto, tal y como se ha visto, en la implementación de los modelos basados en técnicas de Lanzado de Rayos, el escoger erróneamente el coeficiente de transmisión puede provocar que algunos de los rayos, tras atravesar varias superficies formando ciertos ángulos, tengan asociada una potencia mucho mayor que la que debiera, falseando así los resultados.

Se han detectado en la literatura otras formulaciones para el coeficiente de transmisión igualmente erróneas. Así, en [Hon92] se da la siguiente expresión del módulo del coeficiente de transmisión que, además, pretende modelar la dispersión (reflexión no especular):

$$
|\tau|=\sqrt{X}(1-|\rho|)
$$

donde $0<X<1$. Tras probar con distintos valores de $X$, se llega a la conclusión de que el valor más acorde con las medidas es $X=0.5$. Pero, si se representa el módulo del coeficiente de transmisión según esta expresión para el caso anterior (figura 6.5), se 


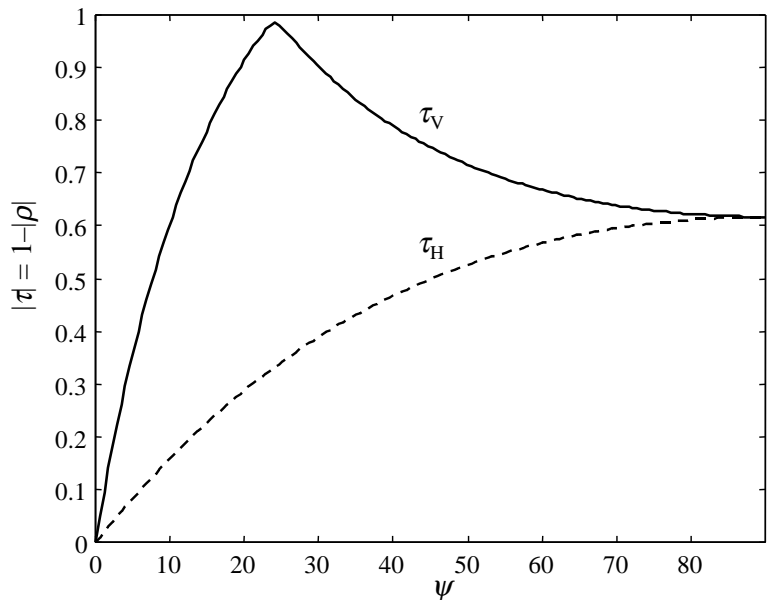

Figura 6.3: Módulos del coeficiente de transmisión para $n^{2}=5-0,4 j$, calculados según $|\tau|=1-|\rho|$. Incidencia con polarización horizontal y vertical

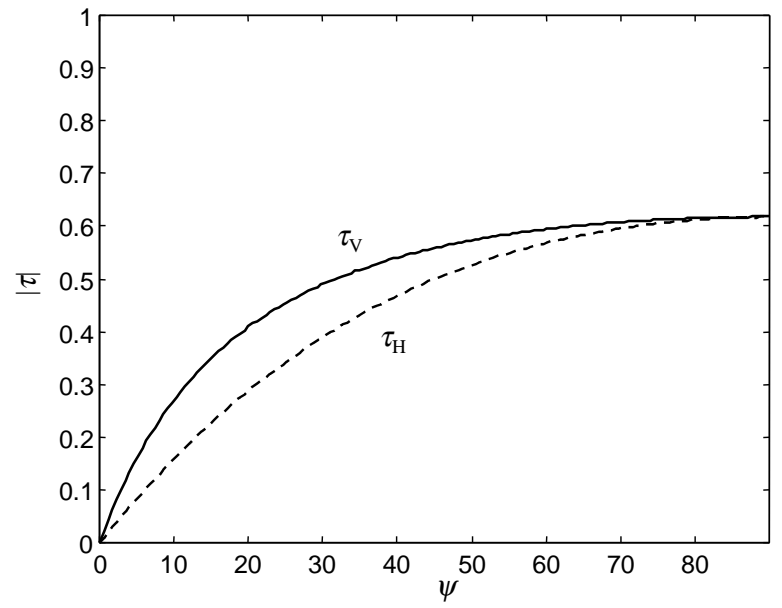

Figura 6.4: Módulos de los coeficientes de transmisión para $n^{2}=5-0,4 j$, según las expresiones correctas vistas en (6.23) y (6.24) 
aprecia que sigue apareciendo el ángulo de Brewster, aunque ahora el valor máximo ya no es tan cercano a la unidad. Además, con esta expresión (al igual que con la anterior), solamente se puede trabajar con el módulo, y no con el valor complejo del coeficiente, por lo que no es posible relacionar las fases de los rayos incidente y transmitido.

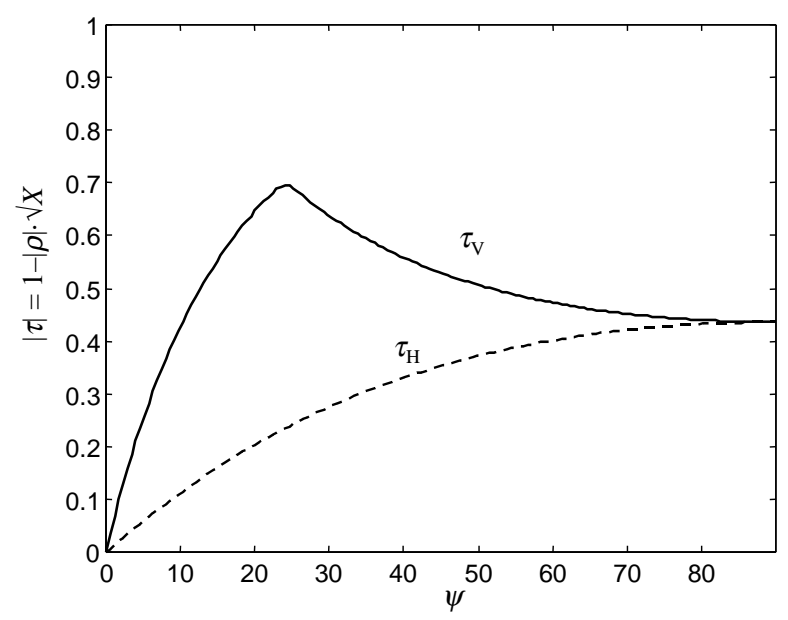

Figura 6.5: Módulos del coeficiente de transmisión para $n^{2}=5-0,4 j$, calculados según $|\tau|=\sqrt{X}(1-|\rho|), \operatorname{con} X=0.5$

Otras fórmulas que se han demostrado igualmente erróneas aparecen en [Sie96]. Según este trabajo, los coeficientes de transmisión para polarización vertical y horizontal son, respectivamente:

$$
\tau_{V}=\frac{\frac{4}{n^{2}} \sin \psi \sqrt{n^{2}-\cos ^{2} \psi}}{\left(\sin \psi+\frac{\sqrt{n^{2}-\cos ^{2} \psi}}{n^{2}}\right)^{2}}
$$

y:

$$
\tau_{H}=\frac{4 \sin \psi \sqrt{n^{2}-\cos ^{2} \psi}}{\left(\sin \psi+\sqrt{n^{2}-\cos ^{2} \psi}\right)^{2}}
$$

Puede verse que, al representarlos en módulo para el caso particular que aquí se trata, aparece de nuevo el ángulo de Brewster que, en este caso particular, se ha visto que no existe (figura 6.6).

Algunas otras expresiones detectadas en la literatura sobre este tema (que, lógicamente, no vale la pena citar), permiten incluso que los rayos se amplifiquen al atravesar las paredes, lo cual, obviamente no es posible.

\section{Incidencia en paredes simples}

Si se considera que el medio sobre el que inciden las ondas está limitado por una segunda superficie paralela a la primera, y suponiendo el tercer medio con unas características 


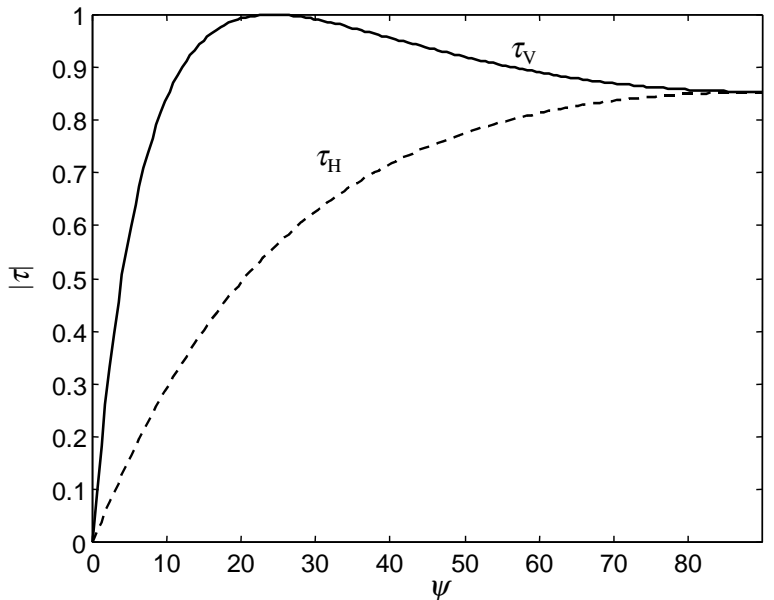

Figura 6.6: Módulos del coeficiente de transmisión para $n^{2}=5-0,4 j$, calculados según [Sie96]

electromagnéticas similares a la del primero, puede modelarse de manera sencilla los efectos de una pared (figura 6.7).

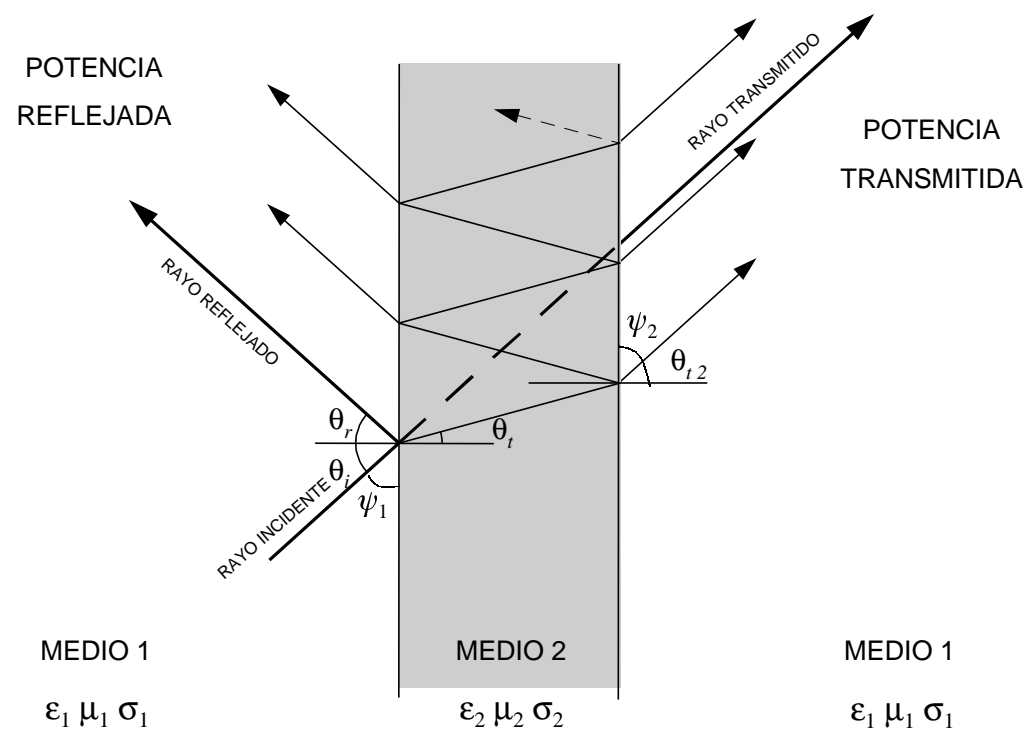

Figura 6.7: Modelado de una pared mediante dos superficies infinitas

En principio, se podría suponer que la pared es lo suficientemente delgada como para despreciar tanto las posibles reflexiones internas causadas por la segunda superficie, como 
los retardos de propagación por su interior. De esta forma, y teniendo en cuenta que el campo inicialmente transmitido $E_{t}$ vuelve a incidir sobre otra superficie, se puede calcular el coeficiente de transmisión total como la relación entre el campo finalmente transmitido $E_{t_{2}}$ y el incidente al principio $E_{i}$. Para el caso de polarización horizontal, esta relación quedaría como [Lau94]:

$$
\tau_{H}=\frac{E_{t_{2}}}{E_{i}}=\frac{4 \sin \psi \sqrt{n^{2}-\cos ^{2} \psi}}{\left(\sin \psi+\sqrt{n^{2}-\cos ^{2} \psi}\right)^{2}}
$$

mientras que en el caso de polarización vertical, sería:

$$
\tau_{V}=\frac{E_{t_{2}}}{E_{i}}=\frac{4 n^{2} \sin \psi \sqrt{n^{2}-\cos ^{2} \psi}}{\left(n^{2} \sin \psi+\sqrt{n^{2}-\cos ^{2} \psi}\right)^{2}}
$$

Para estas expresiones se ha supuesto que el medio de propagación intermedio no tiene pérdidas, y que no existe atenuación por distancia en su interior. Por tanto, es lógico pensar que resulta más exacto volver a calcular los coeficientes de transmisión en el segundo interfaz, tras la propagación dada por la anchura de la pared, no aumentando con ello la complejidad del modelo. Esto evita, además, tener que implementar el código adicional para el cálculo de estos coeficientes equivalentes de transmisión.

Por otra parte, no basta con caracterizar el rayo o tubo transmitido a partir del coeficiente de transmisión $\tau$. Hay que dotarlo con una dirección y un punto de partida.

Es fácil demostrar que el ángulo de salida del rayo transmitido $\psi_{2}$ es igual al de entrada $\psi$, sea cual sea el material que forme la pared (figura 6.7). Así, aplicando dos veces la Ley de Snell, dada por la ecuación (6.18), se tiene que:

$$
\cos \psi_{2}=\sin \theta_{t 2}=\frac{\eta_{1}}{\eta_{2}} \sin \theta_{t}=\sin \theta_{i}=\cos \psi
$$

donde $\eta_{1}$ y $\eta_{2}$ son las impedancias intrínsecas de ambos medios (considerándose al medio 1 , habitualmente, como el vacío).

Sin embargo, debe estudiarse con cierto detenimiento qué ocurre en el interior de la pared, para así determinar, en cierta medida, el error cometido al no considerar esta refracción interna.

Sea el caso de incidencia sobre una pared (medio 2 en la figura 6.7) compuesta por un material dieléctrico sin pérdidas, es decir, aquel cuya constante de propagación $\gamma_{2}$ tenga parte real nula, lo cual implica que también lo será su conductividad $\sigma_{2}$, resultando una impedancia intrínseca $\eta_{2}$ real e igual a su permitividad $\varepsilon_{2}$. En ese caso se puede calcular de forma inmediata el ángulo de transmisión interno de la estructura, $\theta_{t}$ :

$$
\theta_{t}=\arcsin \left(\frac{\eta_{2}}{\eta_{1}} \sin \theta_{i}\right)=\arcsin \left(\sqrt{\frac{\varepsilon_{1}}{\varepsilon_{2}}} \sin \theta_{i}\right)
$$

siendo $\theta_{i}$ el ángulo del rayo incidente respecto a la normal a la superficie, es decir, el complementario a $\psi$. 


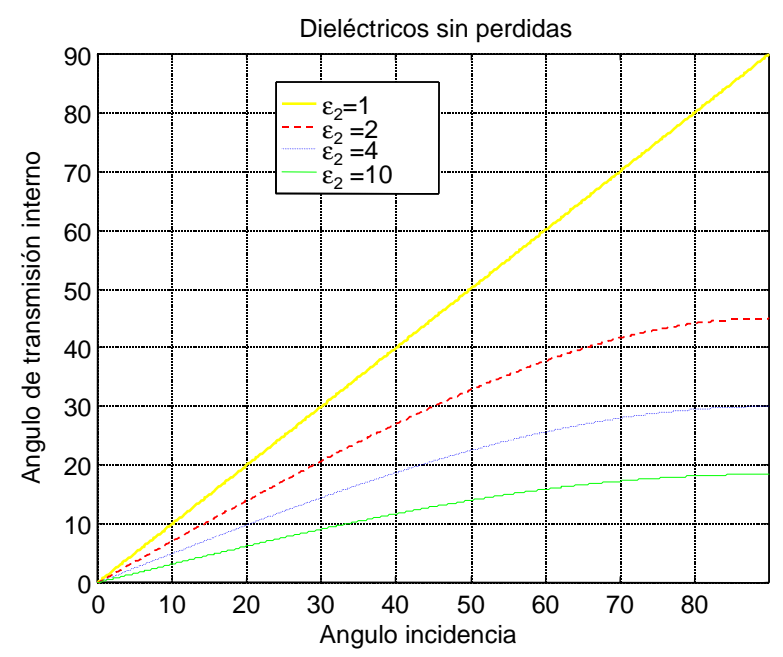

Figura 6.8: Ángulos de transmisión en el interior una pared dieléctrica sin pérdidas

En la figura 6.8 se representa ese ángulo de transmisión interno, en función del ángulo de incidencia, para distintos valores de permitividad de la pared $\left(\varepsilon_{2}\right)$, y considerando que el medio que la rodea es el vacío $\left(\varepsilon_{1}=1\right)$.

Puede observarse que, a medida que aumenta la permitividad de la pared, mayor es el error cometido al considerar que el rayo no sufre refracción interna en el medio, puesto que mayor será la diferencia entre el ángulo de salida (igual al de incidencia, tal y como se ha propuesto) y el ángulo de transmisión interno.

Cuando la pared está formada por un dieléctrico con pérdidas, no puede recurrirse a la ecuación (6.31), puesto que solamente es válida para ángulos reales. La presencia de ángulos con componente imaginaria puede ser interpretada mediante la aparición de ondas superficiales en la pared. En tal caso, se ha de recurrir a esta otra expresión para calcular el ángulo de transmisión interno [Bal89]:

$$
\cos \theta_{t}=\sqrt{1-\sin ^{2} \theta_{t}}=\sqrt{1-\left(\frac{\eta_{2}}{\eta_{1}}\right)^{2} \sin ^{2} \theta_{i}}
$$

Considerando que el medio 1 que rodea a la pared no tiene pérdidas (es el vacío, por ejemplo), se tendrá que:

$$
\cos \theta_{t}=\sqrt{1-\frac{\varepsilon_{1}}{\varepsilon_{2}-j \frac{\sigma_{2}}{\omega}} \sin ^{2} \theta_{i}}
$$

El resultado de $\cos \theta_{t}$ será un número complejo que se podrá poner en forma de módulo y fase como $s e^{j \xi}$. Por otra parte, es más conveniente expresar el cociente del interior de 
la raíz de esta otra forma*:

$$
s e^{j \xi}=\sqrt{1-\left(\frac{j \beta_{1}}{\alpha_{2}+j \beta_{2}}\right)^{2} \sin ^{2} \theta_{i}}
$$

Así, definiendo previamente los siguientes valores:

$$
\begin{gathered}
u=\beta_{1} \sin \theta_{i} \\
q=s\left(\alpha_{2} \sin \xi+\beta_{2} \cos \xi\right)
\end{gathered}
$$

se podrá, finalmente, calcular el ángulo interno $\theta_{t}$ mediante:

$$
\theta_{t}=\arctan \frac{u}{q}
$$

De esta forma se pueden obtener las gráficas de la figura 6.9. Al igual que en el caso de materiales dielectricos sin pérdidas, a medida que aumenta la parte real de la constante dieléctrica compleja de la pared $\underline{\varepsilon}_{2}$, mayor es la diferencia entre el ángulo de incidencia y el ángulo de transmisión interno. Así mismo, dicha diferencia crece también con las pérdidas en el medio, es decir, al aumentar la parte imaginaria (las curvas se arquean más).
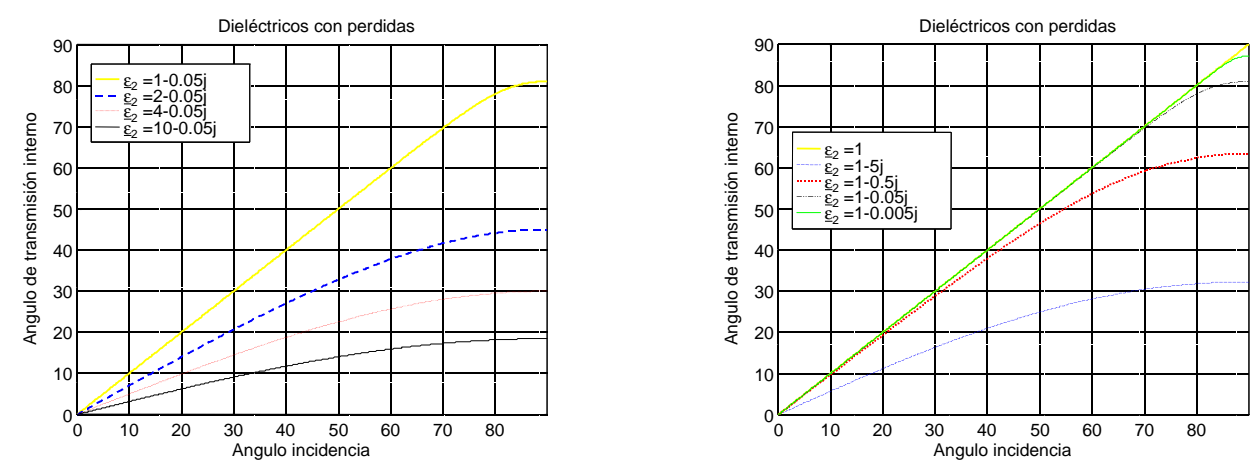

Figura 6.9: Ángulos de transmisión en el interior una pared dieléctrica con pérdidas

En conclusión, se tiene que, efectivamente, en todos los casos existe una refracción interna en la pared que provoca que el punto de salida del rayo transmitido no esté en la misma dirección que la del rayo incidente. A pesar de ello, la diferencia entre ambos puntos es mínima, y más suponiendo que el grosor de las parede es, en general, pequeño en comparación con el recorrido total de los rayos.

En cualquier caso, si además se consideran las múltiples reflexiones internas, el campo total transmitido vendrá dado por las contribuciones de los múltiples rayos transmitidos, no sólo el principal, por lo que considerar un único punto como origen del rayo transmitido resulta un tanto ambiguo. Lo mismo puede decirse en cuanto al campo total reflejado.

${ }^{*}$ Obsérvese que los valores $\alpha_{2}$ y $\beta_{2}$ de esta ecuación se corresponden, respectivamente, con las constantes de atenuación y de fase del dieléctrico con pérdidas que compone la pared, formando conjuntamente la constante de propagación $\gamma_{2}=\alpha_{2}+j \beta_{2}$. Por su parte, el valor $j \beta_{1}$ se corresponde con la constante de propagación $\gamma_{1}$ del dieléctrico sin pérdidas que rodea a la pared (el vacío, por ejemplo) [Bal89]. 
En definitiva, en aras de una mayor facilidad de implementación de la incidencia en una pared en los modelos de Lanzado de Rayos, podrá suponerse que el rayo o tubo transmitido es el mismo que el incidente en cuanto a dirección y sentido, aunque atenuado y desfasado según el coeficiente de transmisión adecuado. Así, el punto de salida del rayo transmitido no habrá de calcularse, sino que vendrá determinado por el grosor de la pared y la inclinación del rayo incidente respecto a ella, despreciándose cualquier refracción interna en la pared.

\subsubsection{Modelo de pared multi-capa con múltiples reflexiones internas}

Una vez vista la física relacionada con la incidencia en superficies dieléctricas, se presentará a continuación el modelo que se propone en esta Tesis para ser implementado junto con las distintas técnicas de Lanzado de Rayos, para modelar la incidencia en estructuras complejas de tipo multi-capa. Parece lógico pensar que son necesarias algunas simplificaciones que, en la medida de lo posible, no afecten demasiado a la voluntad determinista del modelo.

En primer lugar, se considerará que cualquier pared, suelo o techo va a estar formado por un conjunto de $n$ capas de distinto espesor, paralelas entre sí, y formadas por un determinado material dieléctrico con pérdidas, tal y como se representa en la figura 6.10.

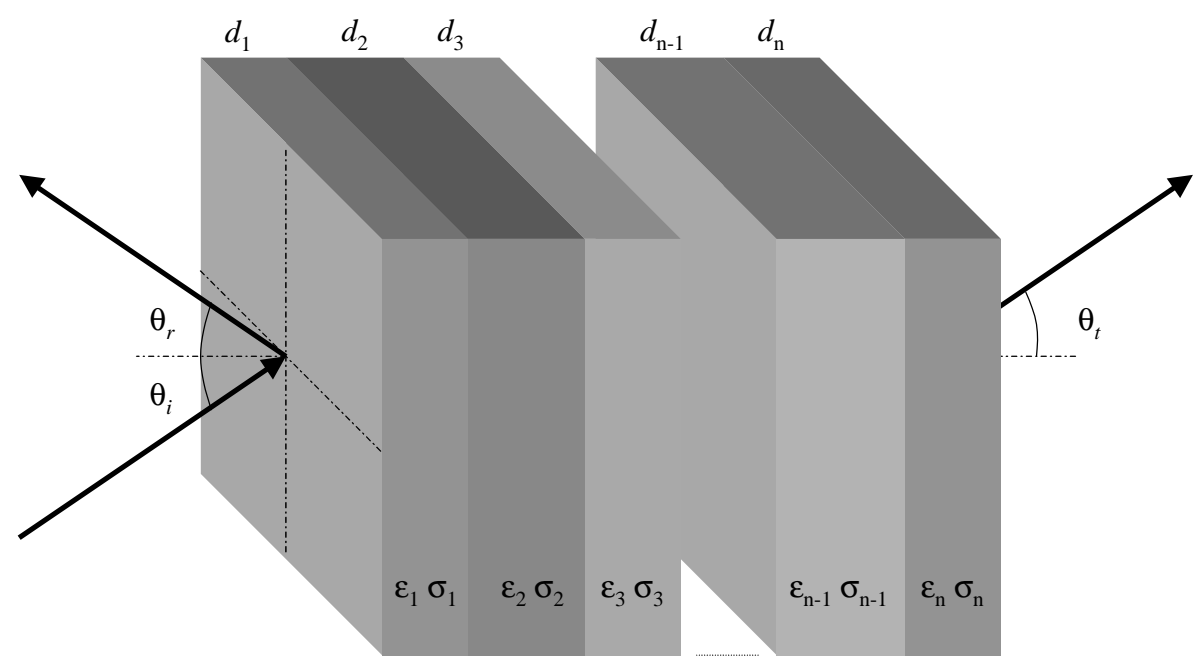

Figura 6.10: Estructura multi-capa de una pared compleja

Cada capa $i$ tendrá asociada constante dieléctrica compleja $\underline{\varepsilon}_{i}$ que vendrá determinada por la permitividad $\varepsilon_{i}$ y la conductividad $\sigma_{i}$ del dieléctrico que pretende modelar, y por la frecuencia $\omega$ de la onda incidente, mediante:

$$
\underline{\varepsilon}_{i}=\varepsilon_{i}+j \frac{\sigma_{i}}{\omega}
$$

Así pues, no se considerarán materiales ferromagnéticos en la composición multi-capa de las paredes, suelos y techos de los edificios. 
Se estimará que la dirección del rayo finalmente transmitido es la misma que la del rayo incidente. Es decir, se trata del mismo rayo o tubo, pero modificado por el efecto de la pared, que más adelante se evaluará. Así mismo, el rayo finalmente reflejado será único y su dirección vendrá determinada por las leyes de la reflexión especular.

Sin embargo, sí se tendrán en cuenta las múltiples reflexiones internas a la estructura multi-capa. Esto afectará al cálculo del campo total reflejado y transmitido.

Se proponen dos métodos para evaluar los campos transmitido y reflejado: el método del seguimiento del rayo interno, que es el método que utiliza la fuerza bruta de cálculo del simulador, y el método de los coeficientes equivalentes que simplifica al anterior con resultados satisfactorios. A continuación se describirá cada uno de los métodos.

\section{Método del seguimiento del rayo interno}

Este método consiste, básicamente, en aplicar el algoritmo de seguimiento de cada rayo, incluso en el interior de las estructuras multi-capa.

Así, se establece un árbol binario por cada rayo incidente similar al descrito en la figura 5.47 del capítulo 5. En cada transición, antes de calcular los subrayos reflejado y transmitido mediante las leyes de Snell y las expresiones descritas para transiciones simples, se comprueba si se ha sobrepasado el número máximo establecido de reflexiones o transmisiones. En caso contrario, se actualiza la distancia recorrida por el rayo incidente, para así calcular la potencia que transporta. Sólo si esta potencia es superior al umbral mínimo establecido, se crean los subrayos reflejado y transmitido.

Evidentemente, este método resulta muy exacto, pero es demasiado exhaustivo y ralentiza sumamente las simulaciones. Las primeras simulaciones realizadas utilizando este método mostraban incrementos en el tiempo de ejecución superiores a un $250 \%$ al considerar las paredes como multi-capa, respecto a lo que se tardaba al considerarlas sencillas, por lo que fue inmediatamente descartado.

\section{Método de los coeficientes equivalentes}

Este método está basado en el cálculo de unos coeficientes de reflexión y transmisión equivalentes para cada estructura multi-capa, para así poderlas considerar como sencillas.

Estos coeficientes equivalentes se calculan mediante una matriz característica de la multi-capa, que inicialmente fue utilizada en el campo de las células de cristal líquido en la Universidad de Karlsruhe [Wöh90, Bar95a, Bar95b, Lay97].

Para definir dicha matriz, considérese la pared multi-capa mostrada en la figura 6.10. Sean una onda electromagnética incidente $\vec{W}_{0}^{R}$ propagándose hacia la derecha, con un vector de propagación $\vec{k}_{i}$. Al incidir sobre el dieléctrico 1 , dará como resultado un rayo reflejado, que contribuirá a una onda reflejada $\vec{W}_{0}^{L}$ propagándose hacia la izquierda (vector de propagación $\vec{k}_{r}$ ), y un rayo transmitido que contribuirá a una onda transmitida $\vec{W}_{1}^{R}$ propagándose hacia la derecha a través del medio 1 (vector de propagación $\vec{k}_{i}^{\prime}$ ). Esta onda transmitida, a su vez, sufrirá el mismo proceso al incidir sobre el dieléctrico 2 , dando lugar 
a una onda reflejada $\vec{W}_{1}^{L}$ y una transmitida $\vec{W}_{2}^{R}$. Este proceso se irá repitiendo en un sentido y en el contrario hasta llegar a los confines de la pared (figura 6.11).

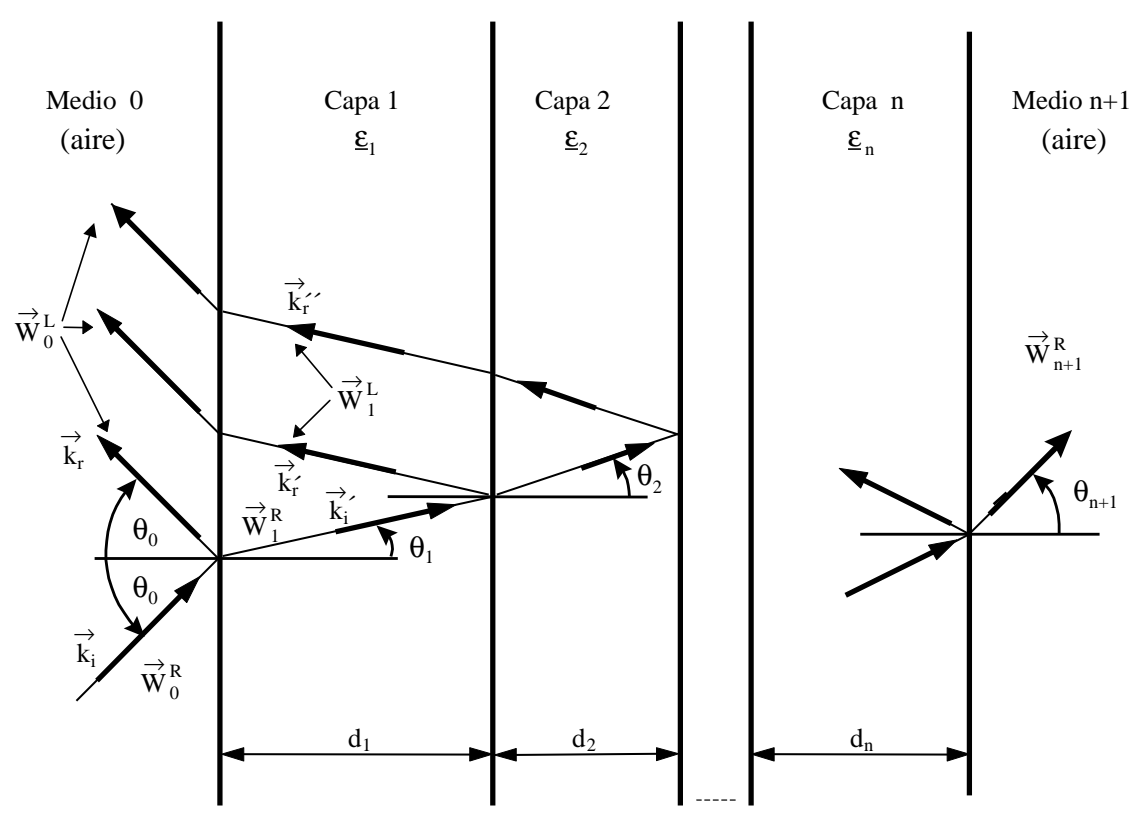

Figura 6.11: Representación de las múltiples reflexiones y transmisiones en una pared multi-capa

De esta forma, la onda reflejada final estará compuesta por la superposición de todos los rayos provenientes de las reflexiones y transmisiones que se propaguen hacia la izquierda, mientras que la onda transmitida final provendrá de las reflexiones y transmisiones que se propaguen hacia la derecha.

Si se estudia más detalladamente las ondas contenidas en el dieléctrico $i$-ésimo (figura 6.12 ), se aprecia que los vectores de propagación $\vec{k}_{i}^{\prime}$ y $\vec{k}_{i}^{\prime \prime}$ son el mismo, por lo que, efectivamente, formarán parte de la misma onda $\vec{W}_{i}^{L}$ propagándose hacia la izquierda. Se puede, por tanto, simplificar la situación en cada interfaz si se considera una única onda resultante propagándose hacia la izquierda y otra hacia la derecha.

Se define, así, el vector columna de ondas a la izquierda del interfaz entre el dieléctrico $i$ y el $i+1$ como:

$$
[\vec{W}]_{i}=\left[\begin{array}{l}
\vec{W}_{i}^{R} \\
\vec{W}_{i}^{L}
\end{array}\right]
$$

De esta forma, puede representarse la propagación en el interior del medio $i$ mediante la relación entre los vectores de ondas $[\vec{W}]_{i}$ y $\left[\vec{W}^{\prime}\right]_{i}$ (este último define las ondas a la derecha del interfaz entre el dieléctrico $i-1$ y el $i$ ), mediante la matriz de propagación 


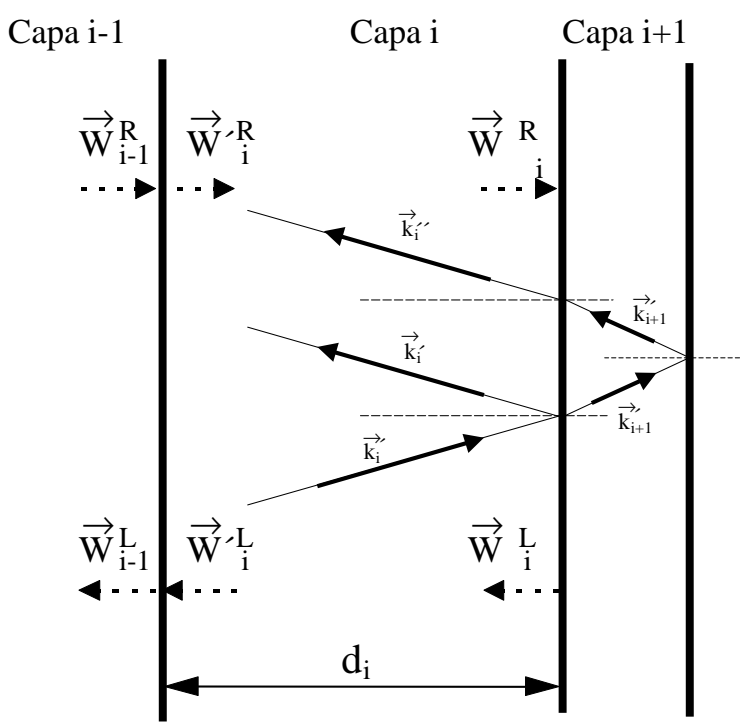

Figura 6.12: Detalle de la estructura y ondas resultantes en cada interfaz de la multi-capa $[P]_{i}:$

$$
\left[\begin{array}{c}
\vec{W}_{i}^{\prime} \\
\vec{W}_{i}^{\prime} \\
i
\end{array}\right]=[P]_{i}\left[\begin{array}{l}
\vec{W}_{i}^{R} \\
\vec{W}_{i}^{L}
\end{array}\right]
$$

que, teniendo en cuenta el espesor $d_{i}$ del dieléctrico, la constante de propagación en el interior $\gamma_{i}=j \omega \sqrt{\mu \underline{\varepsilon}_{i}}$, y el ángulo de incidencia $\theta_{i}$, vendrá dada por:

$$
[P]_{i}=\left[\begin{array}{cc}
e^{\Psi_{i}} & 0 \\
0 & e^{-\Psi_{i}}
\end{array}\right]
$$

donde $\Psi_{i}=\gamma_{i} d_{i} / \cos \theta_{i}$, para $i=1, \ldots, n, \mathrm{y} \Psi_{0}=0$. Obsérvese que, al no ser nula la parte real de la constante de propagación, además de tener en cuenta el desfase por distancia, introducirá un término adicional de pérdidas en el medio.

Del mismo modo, se puede representar la transmisión a través del interfaz entre el medio $i-1$ y el $i$ mediante la matriz de transmisión $[D]_{i}$ :

$$
\left[\begin{array}{l}
\vec{W}_{i-1}^{R} \\
\vec{W}_{i-1}^{L}
\end{array}\right]=[D]_{i}\left[\begin{array}{c}
\vec{W}_{i}^{R} \\
\vec{W}_{i}^{\prime}
\end{array}\right]
$$

que, dados los coefiecientes de reflexión $\rho_{i-1, i}$ y transmisión $\tau_{i-1, i}$ en dicho interfaz, vendrá determinada por:

$$
[D]_{i}=\frac{1}{\tau_{i-1, i}}\left[\begin{array}{cc}
1 & \rho_{i-1,1} \\
\rho_{i-1,1} & 1
\end{array}\right]
$$


Con todo esto, es fácil obtener la relación entre los vectores de onda situados a la izquierda de dos interfaces consecutivos:

$$
\left[\begin{array}{l}
\vec{W}_{i-1}^{R} \\
\vec{W}_{i-1}^{L}
\end{array}\right]=[D]_{i}[P]_{i}\left[\begin{array}{l}
\vec{W}_{i}^{R} \\
\vec{W}_{i}^{L}
\end{array}\right]
$$

Finalmente, de forma iterativa podrá obtenerse la relación entre los vectores de onda inicial (incidente en la pared) y final (transmitido a través de ella):

$$
\left[\begin{array}{l}
\vec{W}_{0}^{R} \\
\vec{W}_{0}^{L}
\end{array}\right]=[G]\left[\begin{array}{l}
\vec{W}_{n+1}^{R} \\
\vec{W}_{n+1}^{L}
\end{array}\right]
$$

donde $[G]$ es la matriz característica de la estructura multi-capa, y que viene dada por:

$$
[G]=\left[\begin{array}{ll}
G_{11} & G_{12} \\
G_{21} & G_{22}
\end{array}\right]=\left(\prod_{i=1}^{n}[D]_{i}[P]_{i}\right)[D]_{i+1}
$$

A partir de aquí, se pueden definir los coeficientes de reflexión y transmisión de toda la estructura como:

$$
\rho_{\mathrm{eq}}=\frac{G_{21}}{G_{11}}
$$

y:

$$
\tau_{\text {eq }}=\frac{1}{G_{11}}
$$

respetivamente, puesto que representarán las relaciones entre la onda incidente $\vec{W}_{0}^{R}$ y la finalmente reflejada $\vec{W}_{0}^{L}$, o la finalmente transmitida $\vec{W}_{n+1}^{R}$, respectivamente.

La formulación, tal y como se ha dado, no tiene en cuenta la propagación de la onda plana a través del medio y su dependencia inversa con la distancia recorrida. En cualquier caso, esta dependencia puede quedar ya contabilizada si se considera la distancia total recorrida por cada rayo o tubo, sin descontar los tramos en los que viaja por el interior de las estructuras.

En esta Tesis, se ha escogido este método para caracterizar la incidencia en paredes multi-capa, ya que se ha demostrado que apenas añade tiempo adicional de cómputo, tal y como se explicará en el capítulo de simulaciones.

\subsubsection{Reflexión difusa. Pérdidas por scattering}

Se ha visto en la sección 6.3.1 que, cuando la señal incide sobre una superficie perfectamente lisa, el campo se refleja en una sola dirección, con un ángulo idéntico al formado por la dirección de propagación del campo incidente con dicha superficie. Bajo estas suposición, la amplitud del campo reflejado puede relacionarse con la amplitud del campo incidente mediante el coeficiente de reflexión de la superficie dado por las expresiones de Fresnel vistas en (6.20) y (6.22). 
Sin embargo, cuando la superficie presenta irregularidades, el campo no es reflejado en una sola dirección, sino que la energía se distribuye entre distintas direcciones, dependiendo de la rugosidad de la superficie, además de la naturaleza del material que la compone. En la figura 6.13 se representa el efecto de los distintos niveles de rugosidad en comparación con la longitud de onda $\lambda$. Cuando la superficie es completamente lisa $\left(\sigma_{h}=0\right)$ sólo se refleja energía en la dirección especular, es decir, aquella en que el ángulo reflejado es igual al ángulo de incidencia. A medida que la superficie se va haciendo rugosa en comparación con la longitud de onda, va desapareciendo la componente especular, reflejándose la energía de manera más difusa.
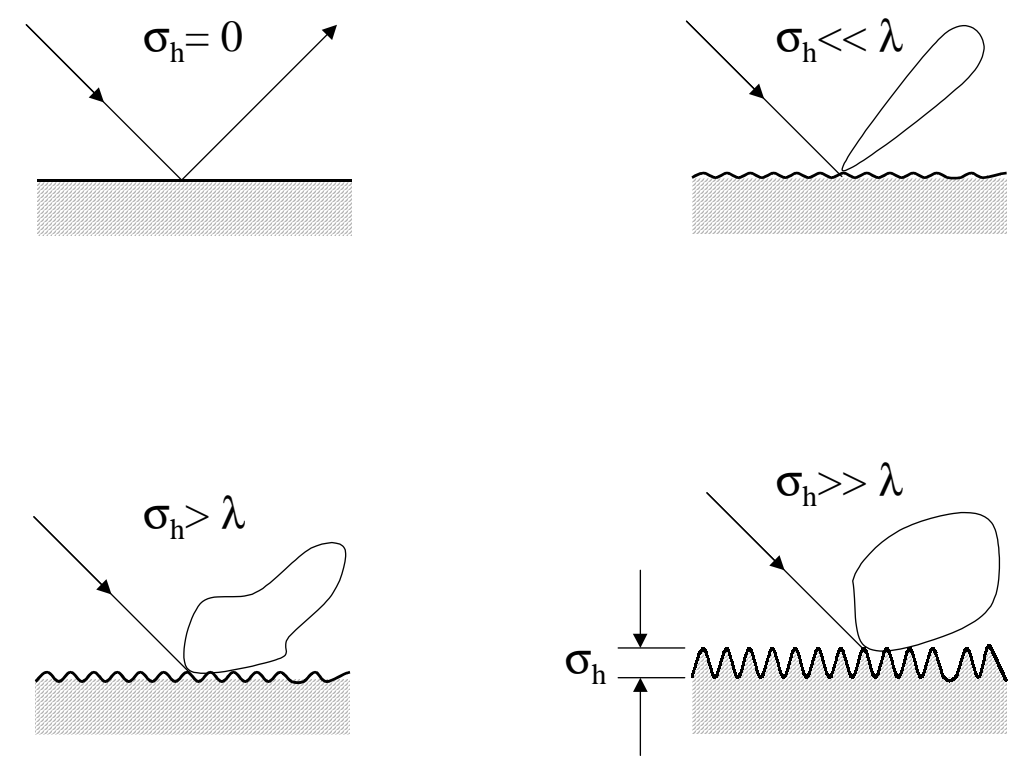

Figura 6.13: Efecto sobre la reflexión de los distintos grados de rugosidad de las superficies

Un análisis riguroso del proceso de reflexión sería extremadamente complejo en aquellas situaciones no suficientemente simples y, por lo tanto, se tendrán que aproximar los efectos que se producen sobre la onda en el proceso de reflexión.

Cualquier superficie que forma parte de un entorno, ya sea pared, puerta, etc., es una superficie rugosa, es decir, presenta unas pequeñas irregularidades. Esta rugosidad afectará en mayor o menor grado a la reflexión de las ondas electromagnéticas que inciden sobre la superficie.

Considérese el criterio de Rayleigh [Lee92], que se obtiene analizando el desfase existente entre dos rayos que se reflejan sobre la superficie rugosa, cuyo modelo aproximado puede observarse en la figura 6.14 .

Este criterio establece la máxima rugosidad $h_{\max }$ de la superficie para la cual puede suponerse reflexión especular. Si la diferencia de fase es lo suficientemente pequeña, los dos rayos estarán aproximadamente en fase, con lo que podrá considerarse que la energía sólo se refleja en una dirección. Si se admite un desfase máximo de $\pi / 2$, por el criterio de 


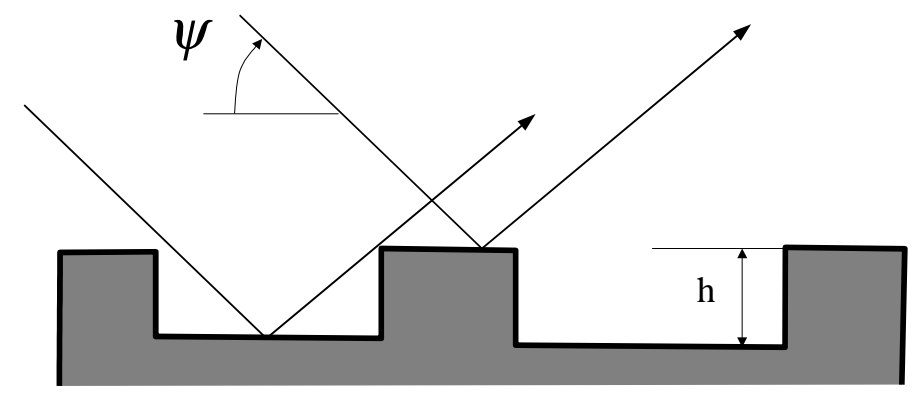

Figura 6.14: Modelo de rugosidad de superficie para el criterio de Rayleigh

Rayleigh, se obtiene:

$$
h_{\max }=\frac{\lambda}{8 \sin \psi}
$$

siendo $\lambda$ la longitud de onda de la señal y $\psi$ el ángulo de incidencia sobre la superficie.

Si la altura de las irregularidades es menor que esta $h_{\max }$, entonces se puede utilizar aproximaciones de Óptica Geométrica, pues a efectos prácticos se comporta como una superficie lisa y, por lo tanto, los efectos del scattering de la superficie pueden ser ignorados [Ree53].

Sin embargo, cuando las irregularidades no pueden ser despreciadas, aparecen dos efectos a considerar. En primer lugar, el ya comentado de radiación en más de una dirección y, además, se produce un efecto de despolarización, es decir, una interacción entre las distintas polarizaciones en que pueda descomponerse la onda.

Si las irregularidades son grandes, las distintas reflexiones serán aleatorias con una determinada distribución y se sumarán para dar lugar al campo reflejado. Si el número de estas contribuciones es lo suficientemente elevado, la distribución final resulta ser gausiana compleja, traduciéndose en una distribución Rayleigh para la amplitud, más una uniforme para la fase [Nav94].

Para modelar el efecto del scattering sobre el frente de ondas, se puede utilizar las modificacionas de las expresiones de Fresnel del coeficiente de reflexión presentadas en [Ame53]. En este trabajo se propone un factor adicional de pérdidas por scattering $\rho_{s}$, el cual tiene en cuenta la pérdida de energía causada por las rugosidades de la superficie. Este factor puede aproximarse mediante la siguiente expresión:

$$
\rho_{s}=\exp \left[-8\left(\frac{\pi \sigma_{h} \sin \psi}{\lambda}\right)^{2}\right]
$$

donde $\sigma_{h}$ es la desviación estándar de las alturas de las irregularidades sobre la media, $\lambda$ es la longitud de onda y $\psi$ es el ángulo de incidencia.

Este coeficiente modifica a las expresiones de Fresnel, tanto para el caso de polarización horizontal como el de polarización vertical, de la siguiente forma:

$$
\rho_{\text {rugoso }}=\rho_{s} \cdot \rho
$$


Con esta aproximación se asume que la distribución de las alturas de las irregularidades de la superficie posee una estadísitica de tipo gausiano, despreciando los efectos de sombra y los bordes afilados. Puede mejorarse esta expresión de la siguiente forma [Boi87]:

$$
\rho_{s}=\exp \left[-8\left(\frac{\pi \sigma_{h} \sin \psi}{\lambda}\right)^{2}\right] I_{0}\left[8\left(\frac{\pi \sigma_{h} \sin \psi}{\lambda}\right)^{2}\right]
$$

donde $I_{0}$ representa la función de Bessel modificada de orden cero. Ambas expresiones son aproximadamente iguales cuando el argumento de la función de Bessel es pequeño.

Como puede comprobarse, estos coeficientes de pérdidas adicionales no tienen en cuenta la despolarización sufrida por la onda. Esta despolarización es causada por la excitación resonante en las irregularidades de la superficie, y pueden modelarse mediante ecuaciones de segundo orden como las presentadas en [Val67].

Si se representa el coeficiente de reflexión respecto al ángulo de incidencia, considerando y sin considerar el scattering, puede observarse el efecto de la rugosidad en el coeficiente de reflexión, con una $\sigma_{h}=1 \mathrm{~mm}$, a una frecuencia de $900 \mathrm{MHz}$ (figura 6.15).
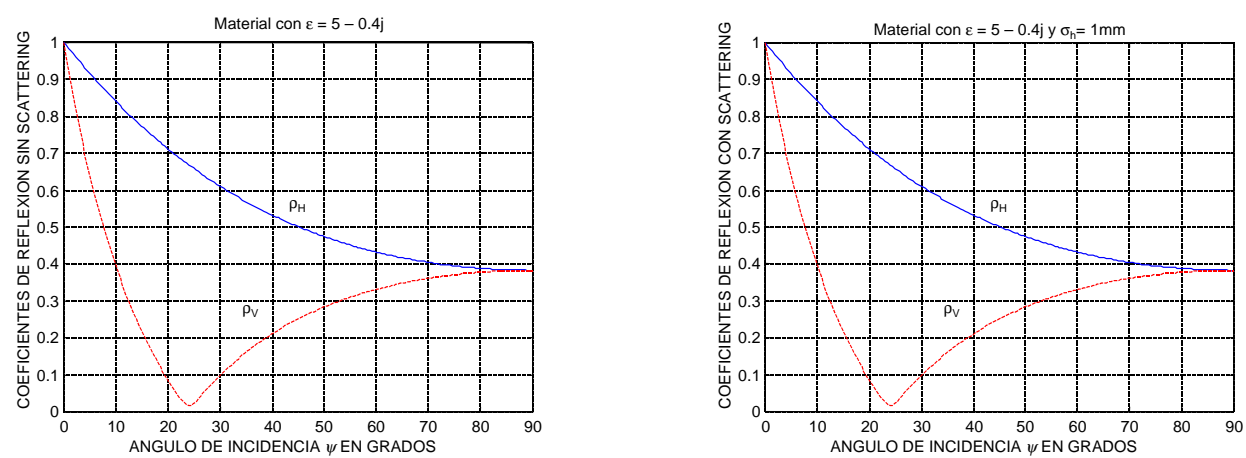

Figura 6.15: Coeficientes de reflexión sin y con scattering a $900 \mathrm{MHz}\left(\sigma_{h}=1 \mathrm{~mm}\right)$

Aunque a primera vista parezcan idénticos, existe una pequeña diferencia (debida precisamente al factor $\rho_{s}$ ) que se aprecia mejor si se representa en porcentaje (figura 6.16). Se observa que, aunque es muy pequeña, existe una ligera diferencia. Como es lógico, cuando el ángulo de incidencia se aproxima a la normal $\left(\psi=90^{\circ}\right)$ la diferencia tiende a cero, siendo máxima cuando $\psi=0^{\circ}$.

No obstante, a medida que aumenta la frecuencia, la rugosidad de las superficies dieléctricas empieza a ser mayor que la longitud de onda, aumentando el efecto del scattering. Así, en la figura 6.17 se representa la diferencia entre el coeficiente de reflexión con y sin scattering para las frecuencias de $1900 \mathrm{MHz}$ y $4 \mathrm{GHz}$, y para el mismo material del ejemplo anterior. Se aprecia que el efecto es más importante.

Parece claro que, en cualquier caso, la influencia del scattering en entornos indoor es prácticamente despreciable. La definición del entorno parece suficiente para tener en cuenta las irregularidades de las superficies que lo componen, al contrario de lo que ocurre en el exterior, donde una fachada de un edificio presenta múltiples salientes y recodos 


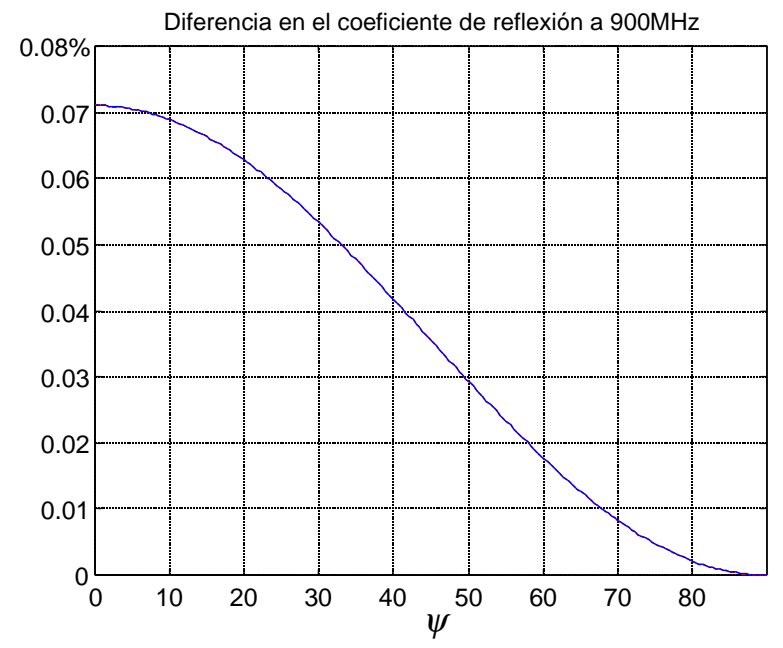

Figura 6.16: Diferencia porcentual en el coeficiente de reflexión considerando el scattering a $900 \mathrm{MHz}$
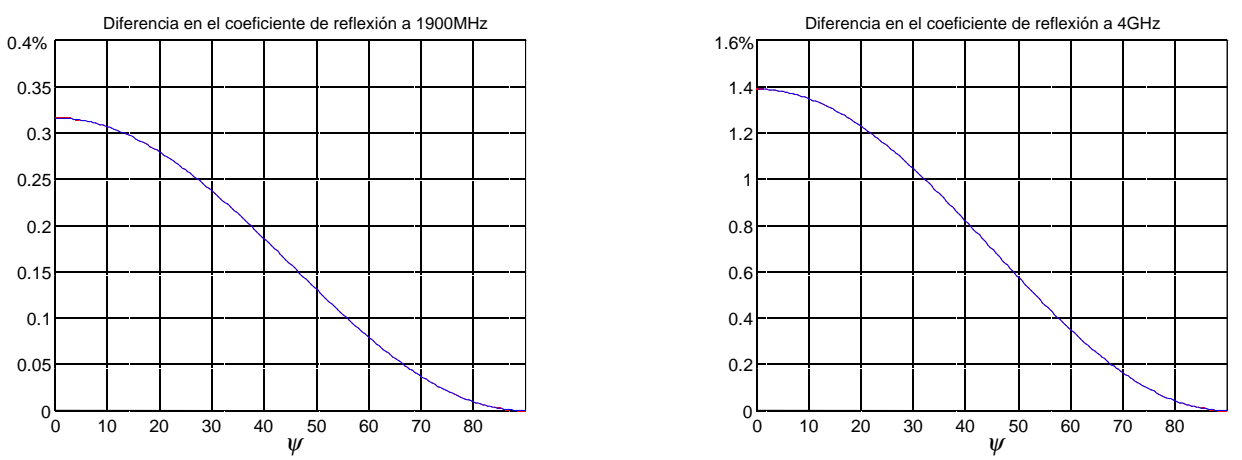

Figura 6.17: Diferencia porcentual en el coeficiente de reflexión considerando el scattering a $1900 \mathrm{MHz}$ y a $4 \mathrm{GHz}$ 
habitualmente no reflejados en los datos que se dispone (modelos digitales del terreno, ... ) .

Sin embargo, el coeficiente que se ha presentado resulta útil para ajustar los valores obtenidos de los coeficientes de reflexión de los materiales a partir de una campaña de medidas. Más concretamente, en [Lan93] se asegura que se obtienen mejores resultados en las simulaciones utilizando un coeficiente de reflexión medio $\rho_{\text {medio }}$, calculado mediante la siguiente combinación de los coeficientes de reflexión anteriores, con y sin scattering:

$$
\rho_{\text {medio }}=\left(\frac{1+\rho_{\text {rugoso }}}{2}\right) \rho
$$

En el próximo capítulo se harán más consideraciones adicionales acerca de la influencia del fenómeno de scattering, tal y como se ha implementado, en las simulaciones realizadas.

\subsection{Difracción en aristas}

La aplicación directa de la teoría de la Óptica Geométrica proporciona un método simple y efectivo para predecir el comportamiento del canal radio móvil. Sin embargo, este método es una aproximación y posee ciertas limitaciones. Por ejemplo, en situaciones donde no hay visibilidad directa (situaciones NLOS), no se tiene en cuenta la posible recepción en zonas de sombra debida al fenómeno de difracción.

La difracción es un fenómeno causado cuando una onda electromagnética incide sobre una discontinuidad del entorno que tenga un tamaño del orden de su longitud de onda, tales como bordes, esquinas, etc. Esta discontinuidad, por el principio de Huygens, actúa como un reemisor secundario de parte de la energía electromagnética incidente. De esta manera, puede aparecer una onda propagándose al otro lado de una esquina.

Quizás el modelo más conocido para resover el problema de la difracción en aristas sea el método del filo de cuchillo de Fresnel. Fue propuesto por primera vez hace más de 60 años en [Sch33] y todavía continúa usándose ampliamente en ciertas situaciones. Sin embargo, esta técnica ignora algunos parámetros importantes referentes al fenómeno de la difracción, como la polarización de la onda incidente, la conductividad y permitividad de las paredes que forman el borde, y todos aquellos datos que se disponen del entorno cuando se hace uso de la Óptica Geométrica.

Durante los últimos años, se han desarrollado múltiples modelos adicionales para resolver con más exactitud el problema de la difracción. Así, cronológicamente, se tiene la Teoría Geométrica de la Difracción $\left(\mathrm{GTD}^{*}\right)$, la Teoría Uniforme de la Difracción $\left(\mathrm{UTD}^{\dagger}\right)$ y la Teoría Asimptótica Uniforme de la Difracción (UAT ${ }^{\ddagger}$.

La GTD, fue propuesta en [Kel62] en los años 60. Desde entonces ha sido ampliada y mejorada eliminando ciertas limitaciones relativas a las regiones de reflexión y de sombra, surgiendo así la UTD [Kou74]. Posteriormente, se incorporó al modelo el efecto de sustituir los bordes conductores por dieléctricos con pérdidas [Lue84].

\footnotetext{
${ }^{*}$ Geometrical Theory of Diffracction

${ }^{\dagger}$ Uniform Theory of Diffraction

${ }^{\ddagger}$ Uniform Asymptotic Theory of diffraction
} 


\subsubsection{Teoría Geométrica de la Difracción}

La Teoría Geométrica de la Difracción (GTD) extiende las posibilidades del Lanzado de Rayos para modelar el comportamiento ante bordes o esquinas. Con las restricciones propias de cada caso, los coeficientes de difracción calculados mediante la GTD son muy simples de evaluar, ya que no dependen de la distancia entre la fuente, el punto de difracción y el receptor, y no hacen uso de las integrales de Fresnel.

En [Kel62] se considera la difracción causada por el borde de un plano conductor perfecto infinito. Una onda incidente en el borde produce un cono de componentes de campo como el que se muestra en las figuras 6.18 y 6.19 .

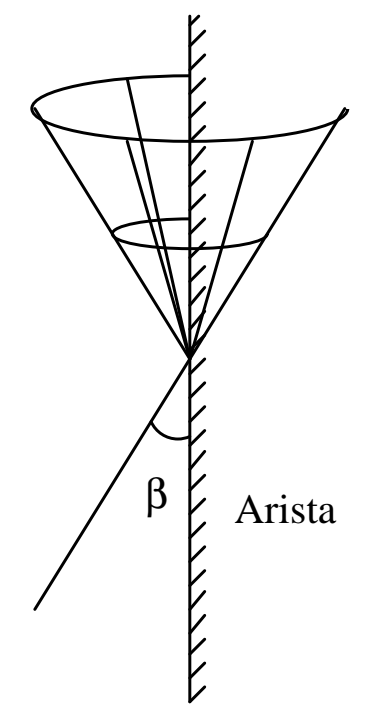

Figura 6.18: Geometría y ángulos implicados en la difracción GTD. Vista frontal

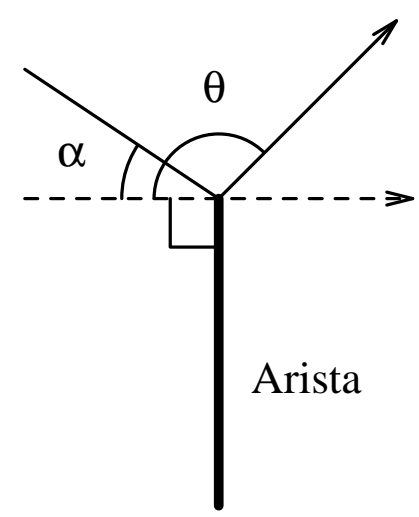

Figura 6.19: Geometría y ángulos implicados en la difracción GTD. Vista superior

Para los ángulos $\alpha, \beta$, y $\theta$ definidos en dichas figuras, se define el coeficiente de difracción $D$ como:

$$
D=-\frac{e^{j \pi / 4}}{2 \sqrt{2 \pi k} \sin \beta}\left[\sec \left(\frac{1}{2}(\theta-\alpha)\right) \pm \csc \left(\frac{1}{2}(\theta+\alpha)\right)\right]
$$


siendo $k$ el número de onda.

El signo positivo se elige en el caso de tener polarización horizontal, y el signo negativo en el caso de polarización vertical. El campo difractado vendrá dado por:

$$
E_{d}=E_{i} D \sqrt{r} e^{j k r}
$$

donde $E_{i}$ es el campo incidente en la arista y $r$ es la distancia desde el punto de observación al punto de difracción en el borde.

Este coeficiente $D$ puede modificarse para el caso de una cuña difractante formada por dos paredes. La expresión quedaría como:

$$
D=-\frac{e^{j \pi / 4} \sin (\pi / m)}{m \sqrt{2 \pi k} \sin \beta}\left[\left(\cos \frac{\pi}{m}-\cos \frac{\theta-\alpha}{m}\right)^{-1} \mp\left(\cos \frac{\pi}{m}-\cos \frac{\theta+\alpha+\pi}{m}\right)^{-1}\right]
$$

donde $(2-m) \pi$ es el ángulo interior del borde.

En el interior de edificios, las esquinas suelen estar formadas por dos paredes formando ángulo recto (figura 6.20 ), por lo que $m=3 / 2$, quedando el coeficiente de difracción de la siguiente forma:

$$
D=-\frac{e^{j \pi / 4}}{\sqrt{6 \pi k} \sin \beta}\left[\left(\frac{1}{2}-\cos \frac{2(\theta-\alpha)}{3}\right)^{-1} \mp\left(\frac{1}{2}-\cos \frac{2(\theta+\alpha+\pi)}{3}\right)^{-1}\right]
$$

siendo $\alpha, \beta$, y $\theta$ los ángulos definidos anteriormente. El campo difractado resultante de un rayo incidente es un cono formado por rayos que parten del punto de incidencia. Si $\alpha$ o $\theta$ están entre $-\pi / 2$ y $-\pi$, entonces el coeficiente de difracción se define como nulo.

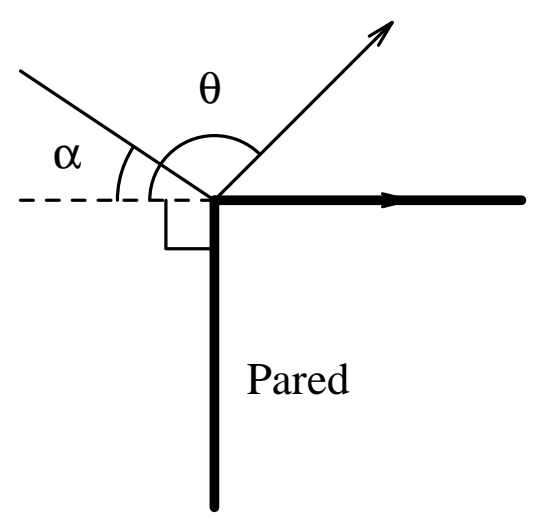

Figura 6.20: Difracción sobre una esquina en ángulo recto

Como puede observarse, efectivamente, estos coeficientes son muy simples de calcular. Sin embargo, su mayor limitación viene impuesta por las singularidades que presenta en las regiones de reflexión y de sombra. La Teoría Uniforme de la Difracción (UTD) permite sobrepasar estos límites obteniendo un campo suave y continuo en estas regiones. La Teoría Uniforme Asintótica de la Difracción (UAT) también predice campos finitos en estas situaciones pero da una visión menos física de lo que ocurre y puede dar lugar a problemas de cálculo [Sie96], por lo que no será estudiada. 


\subsubsection{Teoría Uniforme de la Difracción}

En [Kou74] se extiende la teoría geométrica de la difracción (GTD) para eliminar las discontinuidades del campo en las fronteras de reflexión y sombra. Esta extensión se denomina Teoría Unificada de la Difracción (UTD) y viene descrita por las siguientes expresiones:

$$
\begin{array}{r}
D=-\frac{e^{-j \pi / 4}}{2 m \sqrt{2 \pi k} \sin \beta}\left\{\left[\cot \frac{\pi+(\theta-\alpha)}{2 m} F\left(k L a^{+}(\theta-\alpha)\right)\right.\right. \\
\left.+\cot \frac{\pi-(\theta-\alpha)}{2 m} F\left(k L a^{-}(\theta-\alpha)\right)\right] \mp\left[\cot \frac{\pi+(\theta+\alpha)}{2 m} F\left(k L a^{+}(\theta+\alpha)\right)\right. \\
\left.\left.+\cot \frac{\pi-(\theta+\alpha)}{2 m} F\left(k L a^{-}(\theta+\alpha)\right)\right]\right\} \\
L=\frac{s s^{\prime} \sin ^{2} \beta}{s+s^{\prime}} \\
a^{ \pm}(\gamma)=2 \cos ^{2}\left(\frac{2 m \pi N^{ \pm}-\gamma}{2}\right)
\end{array}
$$

donde $s$ es la distancia entre el transmisor y el punto de incidencia; $s^{\prime}$ es la distancia entre el punto de incidencia y el receptor; $\gamma=\theta \pm \alpha$, y $N^{ \pm}$es el entero que mejor satisface la relación:

$$
2 \pi n N^{ \pm}-\gamma= \pm \pi
$$

siendo $n=\frac{2 \pi-\alpha}{\pi}$.

La función $F$ recibe el nombre de Función de Transición de Fresnel, e implica el cálculo de una integral de Fresnel:

$$
F(X)=2 j \sqrt{X} e^{j X} \int_{\sqrt{X}}^{\infty} e^{-j \tau^{2}} d \tau
$$

Esta función puede ser expresada mediante series infinitas, llegando a simplificarse hasta la siguiente expresión:

$$
F(X) \simeq\left[\sqrt{\pi X}-2 X e^{j \pi / 4}-\frac{2}{3} X^{2} e^{-j \pi / 4}\right] e^{j\left(\frac{\pi}{4}+X\right)}
$$

cuando $X$ es pequeño $(X<0,3)$, o como:

$$
F(X) \simeq 1+j \frac{1}{2 X}-\frac{3}{4} \frac{1}{X^{2}}-j \frac{15}{8} \frac{1}{X^{3}}+\frac{75}{16} \frac{1}{X^{4}}
$$

cuando $X$ es grande $(X>5,5)$. 
Con el coeficiente $D$ visto anteriormente, el campo difractado puede calcularse mediante:

$$
E_{d}=E_{i} D A\left(s, s^{\prime}\right) e^{-j k s}
$$

donde $A\left(s, s^{\prime}\right)$ es el llamado Spread Factor, que permite que se cumpla el principio de conservación de la energía:

$$
A\left(s, s^{\prime}\right)=\sqrt{\frac{s^{\prime}}{s\left(s+s^{\prime}\right)}}
$$

Este coeficiente es independiente del tipo de polarización del campo incidente. Sin embargo, es posible modificar esta expresión para incorporar este dato, junto con los efectos que aporta la sustitución de las paredes conductoras perfectas por paredes de dieléctricos, tal y como se presenta en [Lue84]. El coeficiente de difracción queda entonces como:

$$
\begin{aligned}
D=- & \frac{e^{-j \pi / 4}}{2 m \sqrt{2 \pi k} \sin \beta}\left[\cot \frac{\pi+(\theta-\alpha)}{2 m} F\left(k L a^{+}(\theta-\alpha)\right)\right. \\
+\cot \frac{\pi-(\theta-\alpha)}{2 m} F\left(k L a^{-}(\theta-\alpha)\right) & +\rho_{1} \cot \frac{\pi+(\theta+\alpha)}{2 m} F\left(k L a^{+}(\theta+\alpha)\right) \\
& \left.+\rho_{2} \cot \frac{\pi-(\theta+\alpha)}{2 m} F\left(k L a^{-}(\theta+\alpha)\right)\right]
\end{aligned}
$$

donde $\rho_{1}$ y $\rho_{2}$ son los coeficientes de reflexión de Fresnel vistos en (6.20) y (6.22), para las dos superficies que forman la cuña, y que serán dependientes del ángulo de incidencia y de la polarización de la onda.

Tal y como queda finalmente formulado, este coeficiente proporciona continuidad de campo eléctrico en las regiones de reflexión y sombra para paredes dieléctricas con pérdidas.

A pesar de parecer complicado, puede programarse fácilmente para ser calculado a partir de los ángulos de incidencia. Sin embargo, el cálculo del campo difractado eleva la complejidad computacional del simulador, por lo que se deberá limitar el cálculo de estos coeficientes de manera que solamente se evalúen difracciones de primer orden. La contribución de difracciones de segundo orden puede considerarse despreciable, tal y como indican la mayoría de autores [Law92, Che97].

\subsubsection{Implementación de la difracción en el Lanzado de Tubos}

En el modelo de Lanzado de Rayos genérico podría implementarse fácilmente el efecto de la difracción, pero resulta imprescindible identificar previamente los posibles puntos de difracción de forma manual. Sobre estos difractores pre-identificados, se pueden aplicar los algoritmos de recepción vistos en el capítulo 5 para saber si son alcanzados por los distintos rayos lanzados. La necesaria pre-identificación manual hizo que se descartara la implementación de la difracción en este tipo de modelo. 
Se ha optado por implementar el estudio de la difracción sólo para el modelo de Lanzado de Tubos, ya que permite una detección automatizada de las esquinas difractantes. Así, recordando lo explicado en la sección 5.6.4, cuando un tubo intersecta una pared, podían ocurrir las siguientes dos situaciones:

- que todos los rayos que forman la estructura del tubo impacten sobre la misma pared o en una pared coplanar a la que impacta el rayo medio (reflexión regular), o bien

- que alguno de los rayos de la estructura impacte en una pared no paralela (consecuentemente, en general, va a ser perpendicular) a la que impacta el rayo medio (reflexión irregular).

En el primer caso, se calculaban los coeficientes de reflexión y de transmisión, y se continuaba con el lanzado normalmente. Pero, en el segundo caso, el algoritmo tomaba la iniciativa de no proseguir con el estudio de dicho tubo, pasando al siguiente.

Aprovechando esta circunstancia, se puede averiguar si la zona sobre la que impacta el tubo cuando existe una reflexión irregular, se trata de un rincón o, por el contrario, se trata de una esquina, sobre la cual existirá difracción (figura6.21).

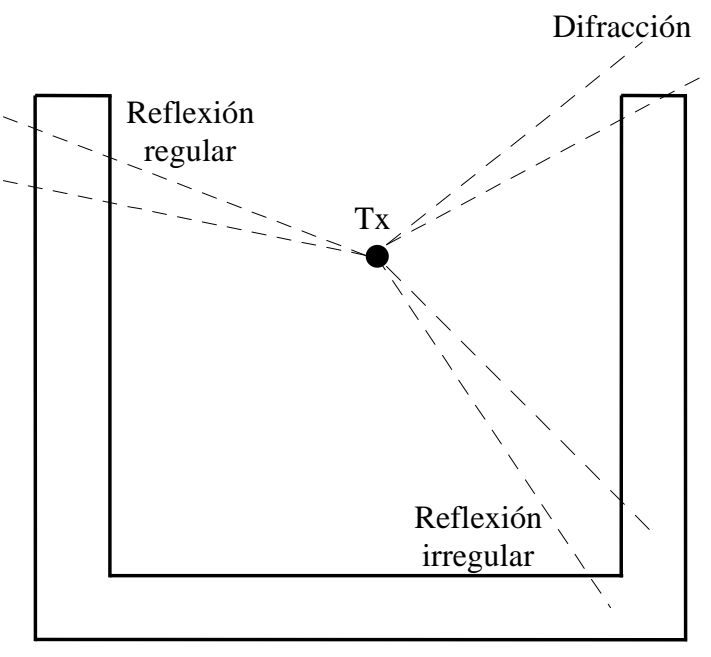

Figura 6.21: Posibles intersecciones de un tubo con las paredes

Para hacer esta distinción, se comparan el vector director de la pared donde incide el rayo medio del tubo, con el vector que une el punto de impacto de dicho rayo medio y el punto de impacto de uno de los rayos que no incida sobre la misma pared que el anterior. Si el ángulo que forman es mayor que $\pi / 2$, se tratará de una esquina difractante, mientras que si es menor, se tratará de un rincón (figura 6.22).

Una vez determinado que, efectivamente, el tubo impacta en una esquina difractante, se procederá a calcular los ángulos $\alpha, \beta$ y $\theta$ descritos en apartados anteriores, para así obtener el campo difractado.

Téngase en cuenta que existe una discretización tanto en el propio lanzado de los tubos como en la definición de la posición de los receptores (que son considerados puntuales), por 


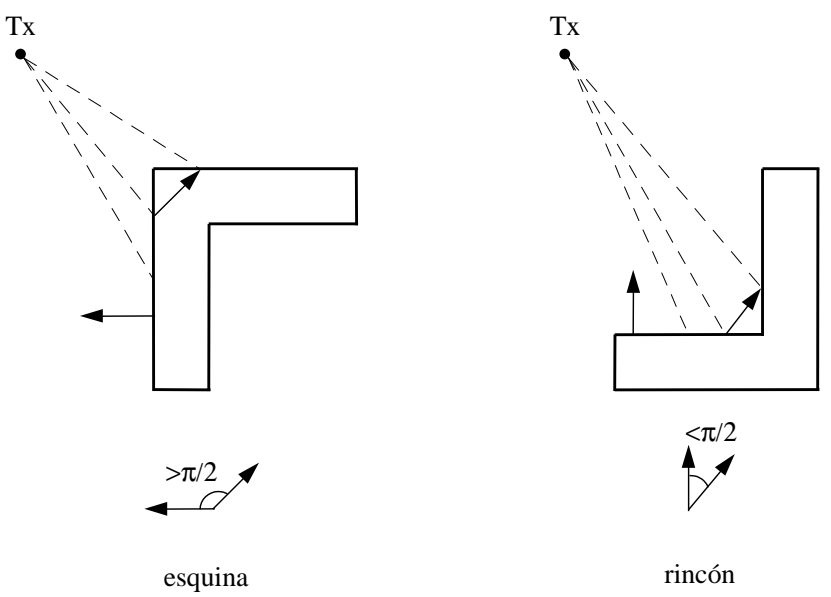

Figura 6.22: Distinción entre una esquina difractante y un rincón

lo que se han de suponer alcanzados todos aquellos receptores que se encuentren contenidos entre los conos de difracción definidos por los ángulos $\beta-\Delta \theta / 2$ y $\beta+\Delta \theta / 2$, donde $\Delta \theta$ es el ángulo que define la resolución angular del lanzado. De esta forma, se tiene la suficiente tolerancia para no tener que recurrir a otros métodos de recepción más complejos.

Ya que sólo se tendrán en cuenta las difracciones finales de primer orden, no se estudiarán aquellos receptores que no se encuentren en visión directa con la esquina difractante. Es decir, cualquier efecto posterior del tubo difractado (reflexión, transmisión o difracción adicional) no será considerado.

\subsection{Resumen}

En este capítulo se ha mostrado con detalle la física relacionada con la propia propagación de los rayos o tubos, así como las distintas interacciones de éstos con los objetos del entorno.

Se han establecido unos métodos de cálculo de los coeficientes de reflexión y transmisión a través de suelos, techos y paredes, proponiéndose un método rápido para modelar estas estructuras cuando están formadas por varias capas de distinto material.

La reflexión difusa es un fenómeno que puede ser modelado de forma sencilla, siempre y cuando no se incurra en consideraciones acerca de la despolarización que conlleva. En cualquier caso, se ha demostrado que resulta poco apreciable a las frecuencias usuales de trabajo en comunicaciones móviles, por lo que puede ser despreciada.

Se han explicado las distintas teorías existentes hasta ahora para modelar el efecto de la difracción en esquinas, optándose por la más completa de ellas: la Teoría Uniforme de la Difracción (UTD). Se ha escogido el método de Lanzado de Tubos (más específico que el de Lanzado de Rayos genérico) para implementar el modelo, ya que resulta muy fácil identificar de forma automática las distintas esquinas difractoras. Sólamente se ha imple- 
mentado la difracción final de primer orden, ya que está suficientemente demostrado que difracciones de orden superior, al igual que cualquier efecto posterior del rayo difractado, resulta poco significativo.

En el próximo capítulo, entre otras muchas simulaciones, no sólo se estudiará la influencia efectiva de la difracción tal y como se ha implementado, sino cualquier otro fenómeno, con sus aproximaciones, que se haya considerado en este capítulo. Además, se evaluarán los incrementos de tiempo de ejecución producidos al implementar cada uno de los modelos presentados. 


\section{Capítulo 7}

\section{Resultados de las Simulaciones}

\subsection{Introducción}

En este capítulo se van a presentar los resultados que se han venido obteniendo al poner en práctica las distintas técnicas y modelos que se han propuesto.

Se comenzará con la verificación en diversos entornos sencillos que, posteriormente, se irán complicando, haciéndose al mismo tiempo cada vez más realistas. Ya que el simulador incluye el modelado de distintos fenómenos de propagación (efectos de las antenas, incidencia en paredes complejas, reflexión difusa, difracción, etc.), también se verificará su influencia y grado de aproximación con la realidad.

Además, se verificará, en concreto, el método de eliminación de impactos redundantes, necesario para eliminar errores en los algoritmos de recepción del Lanzado de Rayos genérico. Se comparará con el otro método encontrado en la literatura, menos estricto que el propuesto en esta Tesis y sólo aparentemente más rápido.

También se analizará la eficiencia del simulador, sobre todo en cuanto a velocidad de procesado respecto al grado de aproximación que se desee. Se sabe que resulta extremadamente difícil modelar con exactitud el entorno y las condiciones de propagación que existen en la realidad, por lo que se analizará la influencia que puedan tener los errores en su definición a la hora de obtener resultados. Para ello, se estudiará la tolerancia del simulador a las variaciones tanto de los valores de las características electromagnéticas del entorno, como a los errores en las posiciones de los receptores.

Por último, se mostrarán los resultados obtenidos en un entorno tan complejo como la propia ETSIT de Valencia, comparando los resultados con la campaña de medidas vista en el capítulo 4.

\subsection{Primeras simulaciones}

A continuación, se mostrará una serie de simulaciones primarias, con las que se pretende, fundamentalmente, mostrar la validez de las técnicas de modelado mediante Lanzado de 
Rayos o Tubos.

Se empezará con entornos de extrema sencillez, pasando a continuación a estudiar la propagación en situaciones más complejas y, a la vez, más realistas.

\subsubsection{Entornos sencillos}

Primeramente, se describirán algunos resultados obtenidos en entornos que, a pesar de su sencillez, muestran el comportamiento de los métodos de simulación que se han implementado.

\section{Habitación vacía}

La primera simulación que se presentará es la más sencilla que se pueda realizar. Se trata de una habitación rectangular completamente vacía de dimensiones $5 \times 10 \times 3$ metros (figura 7.1).

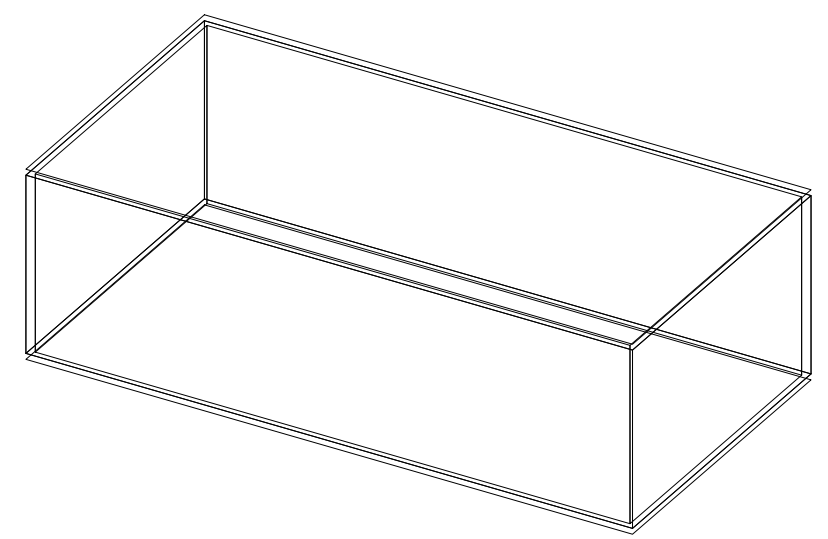

Figura 7.1: Habitación rectangular vacía

En primera instancia, no se considerará ninguna reflexión, por lo que es indiferente qué parámetros electromagnéticos tengan las paredes, suelos y techos. Se pretende evaluar tan sólo la eficiencia de los métodos de lanzado de rayos, de naturaleza discreta, para modelar los frentes de onda continuos.

Los parámetros de la simulación se muestran en la tabla 7.1. Se escogió una frecuencia baja (mucho más baja que la habitualmente utilizada en comunicaciones indoor) para forzar al máximo la condición de utilización de la Óptica Geométrica en el modelado de la propagación de ondas.

\begin{tabular}{|l|c|}
\hline Frecuencia de trabajo $(\mathrm{MHz})$ & 100 \\
\hline Antena transmisora & Dipolo elemental vertical \\
\hline Resolución en el lanzado & $2^{\circ}$ \\
\hline Número de reflexiones & 0 \\
\hline
\end{tabular}

Tabla 7.1: Parámetros de la simulación en la habitación vacía sin reflexiones 
Se utilizó como antena transmisora un dipolo elemental con polarización vertical respecto al suelo. De todas formas, se ha evaluado la potencia recibida en una matriz de receptores paralela al plano $\mathrm{H}$, equiespaciados cada $10 \mathrm{~cm}$, de forma que se cubriera la habitación, por lo que no se apreciará el efecto de la antena por ser omnidireccional en ese plano.

En la figura 7.2 se representa mediante curvas de nivel y mapa de grises la potencia recibida en $\mathrm{dB}$ respecto al máximo. Se aprecia que el método de lanzado de rayos modela con precisión el decaimiento de la potencia de los frentes de onda con la distancia.
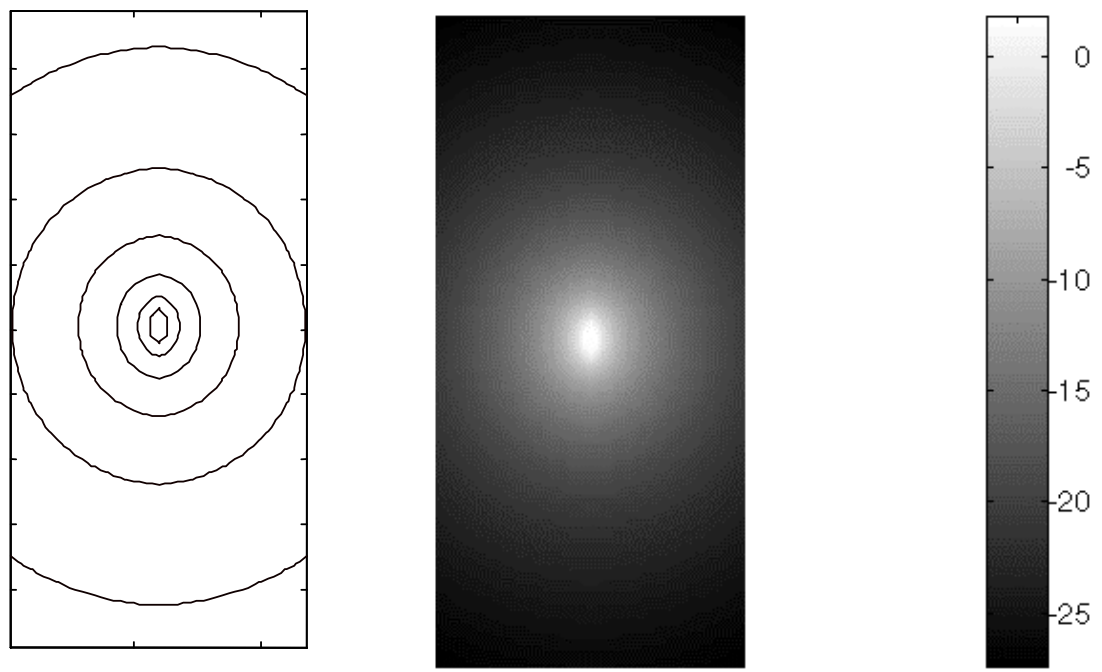

Figura 7.2: Potencia recibida en la habitación vacía sin reflexiones

\section{Habitación vacía con reflexiones}

En el mismo entorno que en la sección anterior (figura 7.1), se procedió a realizar una serie de simulaciones para evaluar la influencia de las reflexiones en la potencia recibida. Se hicieron pruebas con una, dos y tres reflexiones, considerando todos los elementos del entorno (suelo, techo y paredes) con una constante dieléctrica compleja, relativa a la del vacío, $\underline{\varepsilon}_{r}=5-0.4 j$. El grosor de dichos obstáculos no es relevante, pues no se consideró la transmisión fuera de la habitación. En la tabla 7.2 se muestran los parámetros de las simulaciones.

\begin{tabular}{|l|c|}
\hline Frecuencia de trabajo $(\mathrm{MHz})$ & 100 \\
\hline Antena transmisora & Dipolo elemental vertical \\
\hline Resolución en el lanzado & $3^{o}$ \\
\hline Número de reflexiones & $1-3$ \\
\hline Paredes exteriores, suelo y techo & $\underline{\varepsilon}_{r}=5-0.4 j$ \\
\hline
\end{tabular}

Tabla 7.2: Parámetros de la simulación en la habitación vacía con reflexiones

Los resultados de las simulaciones se presentan en la figura 7.3. Se aprecia la aparición de zonas con desvanecimientos considerables, a pesar de la baja frecuencia. El número de 
estas zonas crece con la cantidad de reflexiones consideradas, sin que aumente demasiado su profundidad, como era de esperar, pues son las reflexiones de primer orden las que producen desvanecimientos más profundos.

(a)
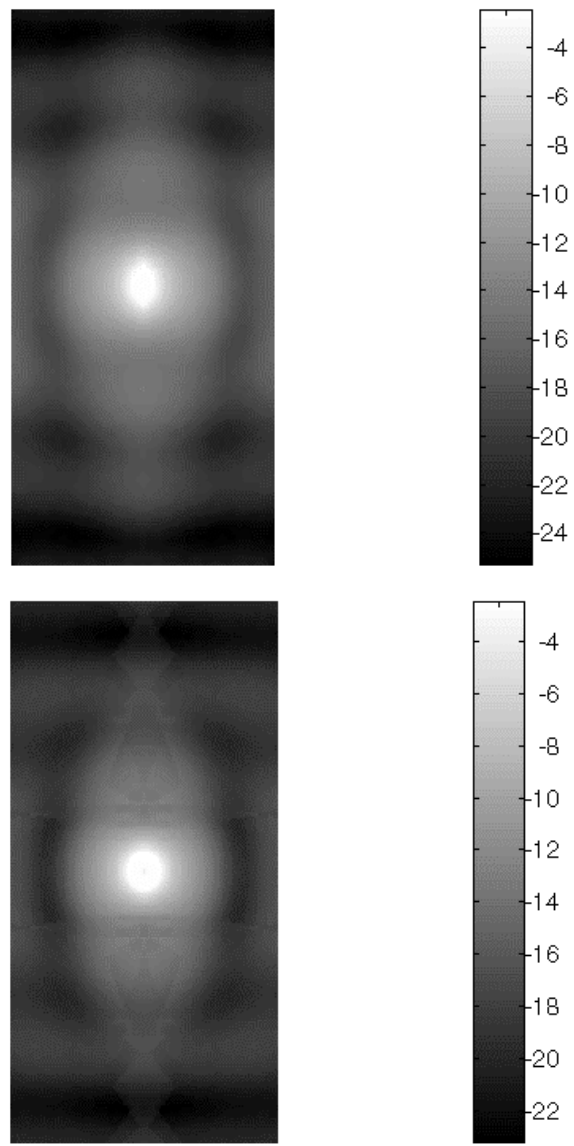

(b)
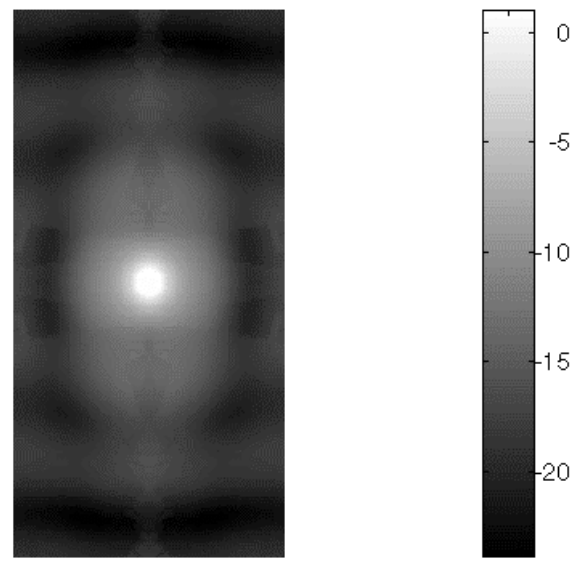

(c)

Figura 7.3: Potencia recibida en la habitación vacía, considerando una (a), dos (b) y tres reflexiones 


\section{Habitación vacía con pared metálica lateral}

Se procederá a estudiar los efectos de una superficie metálica de gran tamaño. El entorno será el mismo de la habitación vacía, pero sustituyendo una de las paredes laterales por una superficie con muy alta conductividad (pared metálica).

Los parámetros de la simulación se presentan en la tabla 7.3. Sólo se considerarán las reflexiones en la pared metálica. Para ello se supondrá que el resto de elementos de la habitación posee una constante dieléctrica igual a la del vacío $\left(\underline{\varepsilon}_{r}=1\right)$.

\begin{tabular}{|l|c|}
\hline Frecuencia de trabajo $(\mathrm{MHz})$ & 100 \\
\hline Antena transmisora & Dipolo elemental vertical \\
\hline Resolución en el lanzado & $2^{o}$ \\
\hline Número de reflexiones & 1 \\
\hline Tres paredes exteriores, suelo y techo & $\underline{\varepsilon}_{r}=1$ \\
Pared metálica & $\underline{\varepsilon}_{r}=1-100000 \mathrm{j}$ \\
\hline
\end{tabular}

Tabla 7.3: Parámetros de la simulación en la habitación vacía con reflexiones

El resultado esperado, según la teoría de imágenes, ha de ser equivalente al de una agrupación de dos dipolos verticales. Efectivamente, en la figura 7.4 se aprecian los múltiples lóbulos producidos por esta agrupación.
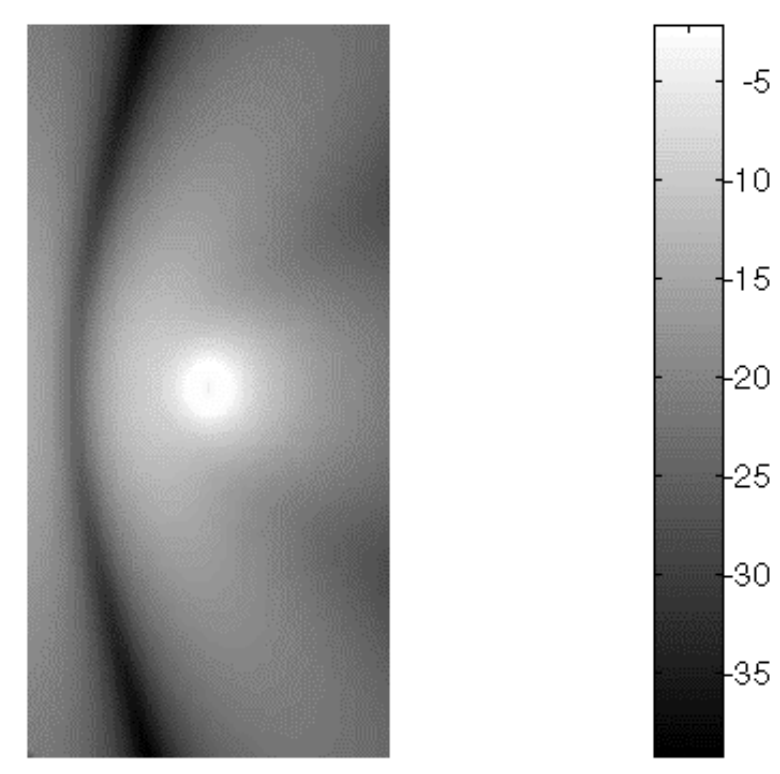

Figura 7.4: Potencia recibida en la habitación con pared lateral metálica

Tanto en este caso, como en los anteriores ya descritos, las simulaciones mediante Lanzado de Rayos o Tubos dan resultados idénticos, por lo que no se han diferenciado. 


\section{Simulaciones en banda ancha en entornos sencillos}

Para demostrar las posibilidades del simulador implementado para generar información en banda ancha, se realizó una nueva simulación en la habitación vacía descrita en la sección 7.2.1, pero considerando un gran número de reflexiones.

Concretamente, se evaluó la respuesta impulsional en dos trazas. La primera discurría paralelamente a una de las paredes cortas, recibiendo la señal de un transmisor situado al otro lado de la habitación. De esta forma, las componentes directas se reciben casi perpendicularmente a la traza.

La otra traza fue dispuesta de forma que se dirigiera directamente al transmisor, discurriendo por el centro de la habitación paralelamente a las paredes largas. Los parámetros de simulación se resumen en la tabla 7.4.

\begin{tabular}{|l|c|}
\hline Frecuencia de trabajo $(\mathrm{MHz})$ & 900 \\
\hline Antena transmisora & Dipolo en $\lambda / 2$ vertical \\
\hline Resolución en el lanzado & $1^{o}$ \\
\hline Número de reflexiones & 10 \\
\hline Suelo y techo & $\underline{\varepsilon}_{r}=9-0.9 j$ \\
Paredes exteriores, & $\underline{\varepsilon}_{r}=4-0.1 j$ \\
\hline
\end{tabular}

Tabla 7.4: Parámetros de las simulaciones en banda ancha en la habitación vacía

Para dar una idea de la influencia de las contribuciones multi-camino en la señal recibida, se representa en la figura 7.5 el módulo de la respuesta impulsional de un punto perteneciente a la primera traza.

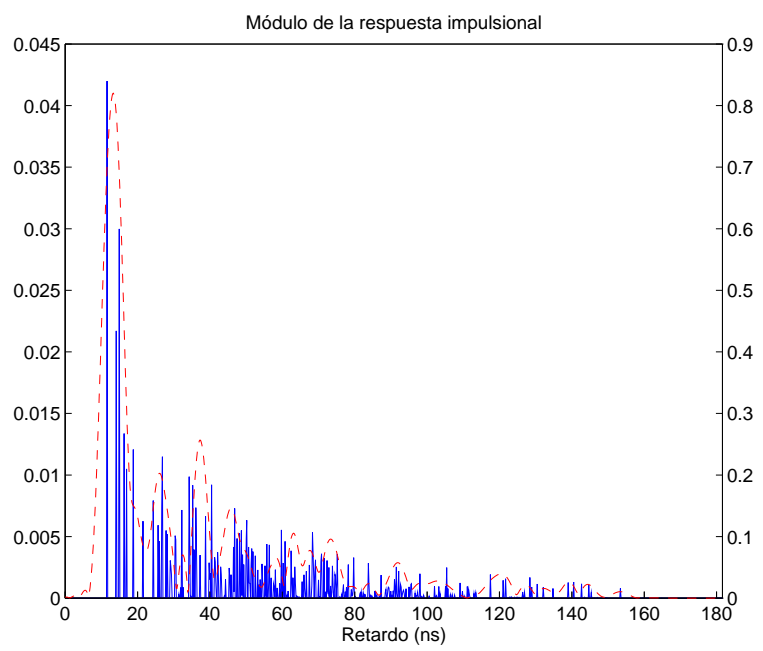

Figura 7.5: Respuesta impulsional obtenida en un entorno con múltiples reflexiones

Se aprecia la enorme cantidad de contribuciones recibidas en un espacio de tiempo bastante reducido (unos $150 \mathrm{~ns}$ ). En trazo discontinuo se representa una versión filtrada de dicha respuesta impulsional. Hay que tener en cuenta que, en el simulador, los retardos pueden tomar cualquier valor, no existiendo prácticamente ninguna limitación en cuanto 
a resolución temporal. Sin embargo, cualquier método de medida tendrá una cierta resolución dada por el ancho de banda de los equipos de instrumentación. Se ha optado por trabajar con versiones filtradas de la respuesta impulsional, limitando el ancho de banda de la respuesta en frecuencia en $200 \mathrm{MHz}$.

Dada la alta resolución espacial de las trazas simuladas $(4 \mathrm{~cm}, \lambda / 8)$, fueron aprovechadas para estimar la función de scattering en sus puntos centrales (figura 7.6).

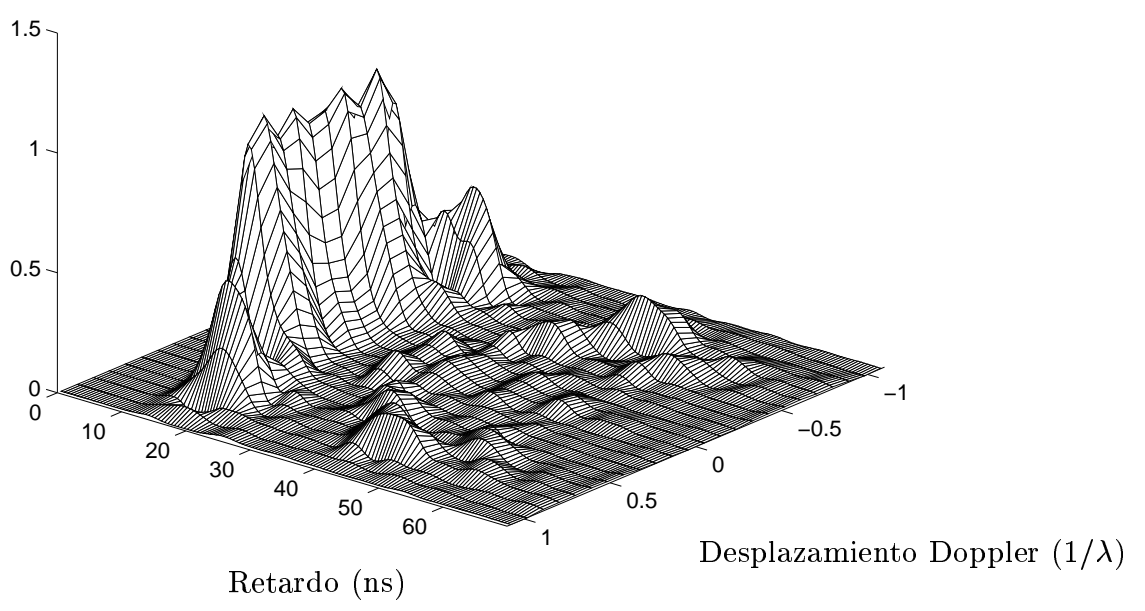

(a)

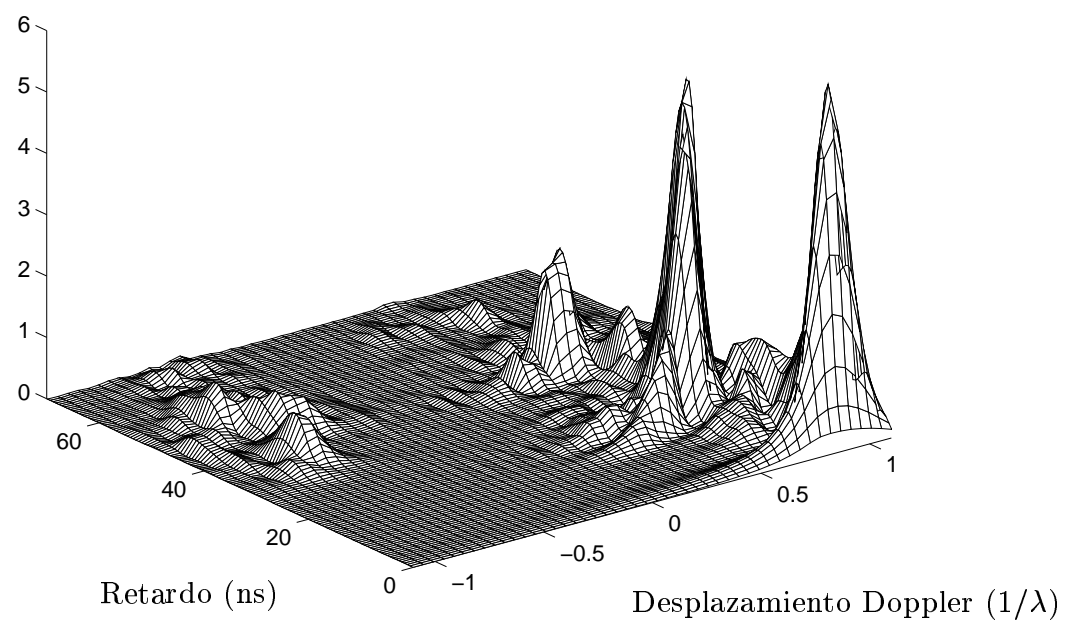

Figura 7.6: Funciones de scattering calculadas a partir de las trazas obtenidas mediante la simulación en la habitación vacía. (a) Traza paralela al frente de ondas directo. (b) Traza que se dirige directamente al transmisor

Como la traza que discurre paralela a una de las paredes cortas es más corta $(4.6 \mathrm{~m}$ frente a los 6.8 de la que se dirige directamente al transmisor), se obtiene una resolución en desplazamiento Doppler menor (en torno a 0.072 unidades $(1 / \lambda)$ ). Por ello, no es posible discernir las múltiples contribuciones que llegan con menor retardo. 
Por el contrario, la resolución que se obtiene de la traza que se dirige al transmisor por el centro de la habitación (unas 0.049 unidades $(1 / \lambda)$ ), permite distinguir, al menos, las componentes directas (desplazamiento Doppler igual a 1), de las reflejadas en las paredes del fondo (Doppler igual a -1). Esto se aprecia mejor en una representación mediante curvas de nivel (figura 7.7). En cualquier caso, las componentes muy atenuadas no se perciben con claridad.

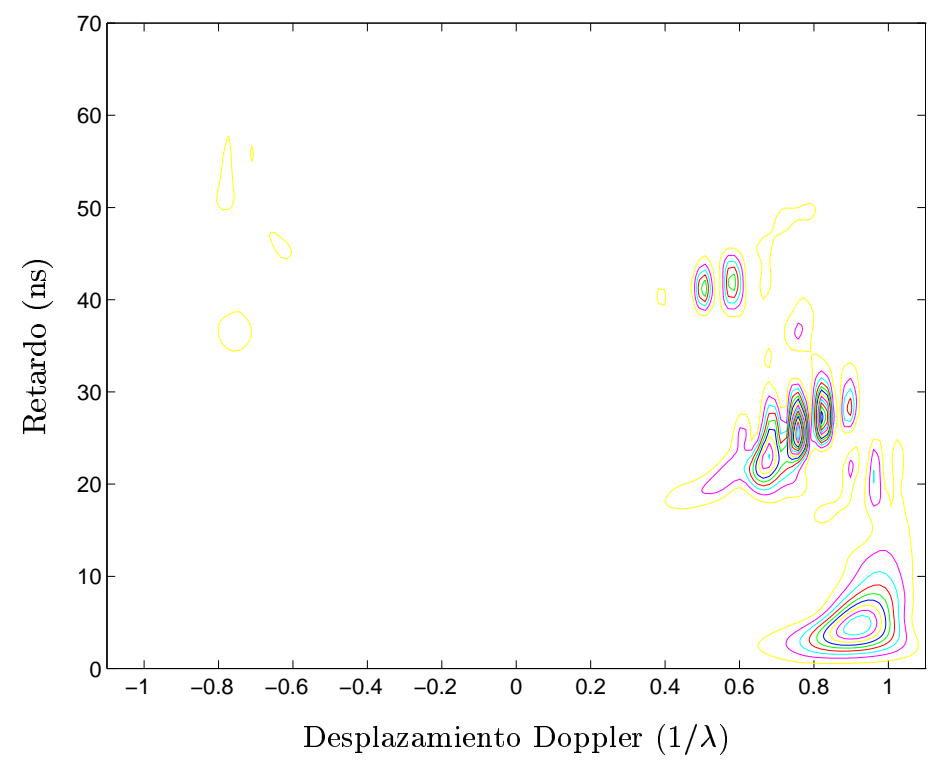

Figura 7.7: Representación mediante curvas de nivel de la función de scattering obtenida a partir de la traza que se dirige directamente al transmisor

\subsubsection{Entornos más complejos}

A continuación se procederá a mostrar algunas simulaciones en entornos más complejos que los anteriores. De esta forma se evaluará el simulador en situaciones más realistas.

\section{Habitación vacía con pared metálica central}

Con el ánimo de complicar algo más el entorno, se procedió a hacer una simulación en una habitación de tamaño similar a la que se ha utilizado hasta ahora, pero con un tabique de separación central sobre el que se ha dejado un hueco intermedio a modo de puerta (figura 7.8). De esta forma se intentaba evaluar el efecto de bloqueo de dicha pared sobre los rayos y tubos.

Para magnificar este efecto de bloqueo, se ha considerado que la pared estaba compuesta de material metálico, mientras que el resto de los materiales se ha seguido considerando dieléctrico. Los parámetros se presentan en la tabla 7.5.

Los resultados obtenidos para el Lanzado de Tubos se presentan en la figura 7.9. Existen ciertas diferencias con respecto al Lanzado de Rayos, que ya han sido mostradas al comparar el comportamiento de ambos métodos ante superficies, esquinas y huecos (ver 


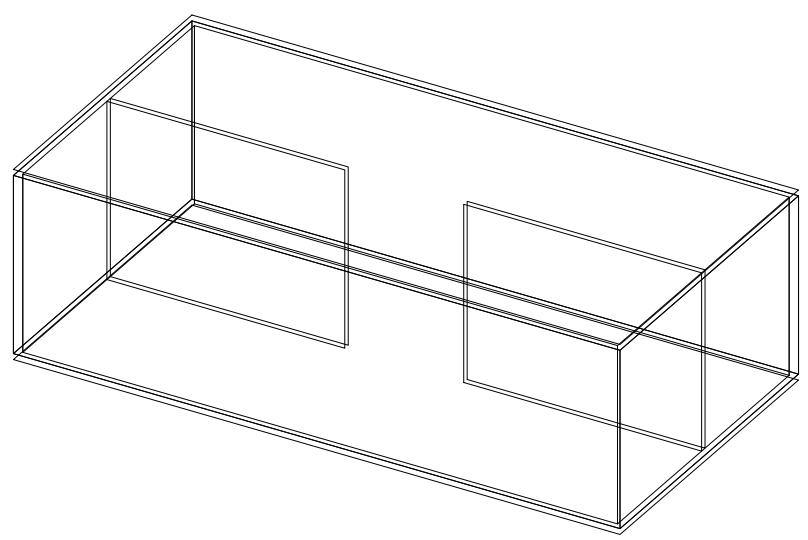

Figura 7.8: Habitación con pared metálica central y hueco

\begin{tabular}{|l|c|}
\hline Frecuencia de trabajo $(\mathrm{MHz})$ & 900 \\
\hline Antena transmisora & Dipolo elemental vertical \\
\hline Resolución en el lanzado & $1.5^{\circ}$ \\
\hline Número de reflexiones/transmisiones & 4 \\
\hline Paredes exteriores, suelo y techo & $\underline{\varepsilon}_{r}=5-0.4 j$ \\
Pared metálica central & $\underline{\varepsilon}_{r}=1-100000 j$ \\
\hline
\end{tabular}

Tabla 7.5: Parámetros de la simulación en la habitación con pared metálica central secciones 5.6.3 y 5.6.4).
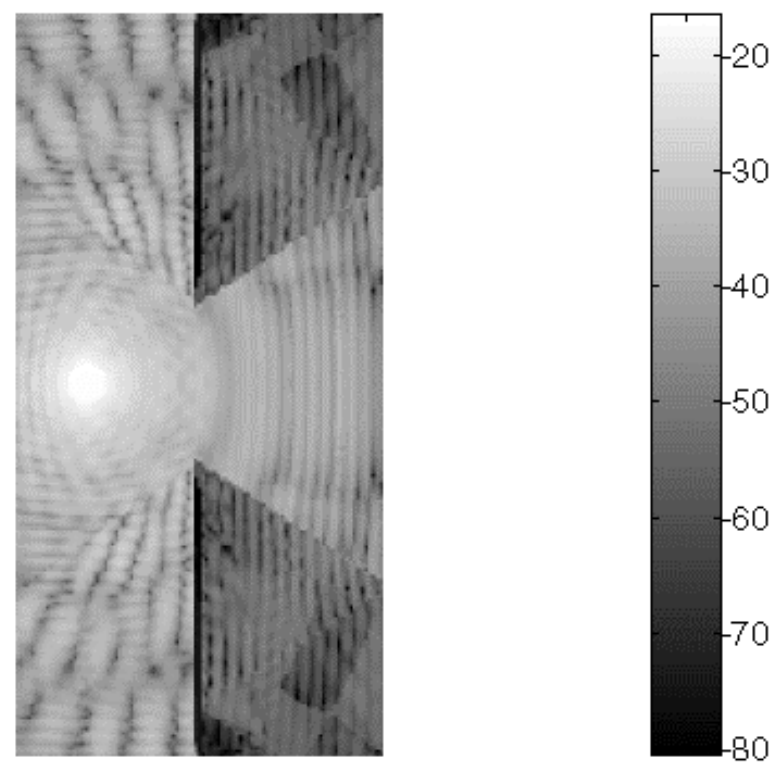

Figura 7.9: Potencia recibida en la habitación con pared metálica central

Se ha aumentado la frecuencia a niveles próximos a los comúnmente utilizados en comunicaciones indoor, permitiéndose además hasta cuatro reflexiones o transmisiones. Por ello se aprecian en los resultados unas variaciones de la señal mucho más rápidas y 
profundas.

\section{Planta de edificio sencillo}

Una vez comprobados ciertos aspectos básicos del modelado mediante los distintos métodos de lanzado, ya se está en disposición de realizar una simulación más acorde con lo disponible en la realidad.

Para ello se considerará una sencilla planta de un pequeño edificio (puede considerarse como una parte de otro más grande) de dimensiones $6 \times 6 \times 3.5$ metros.

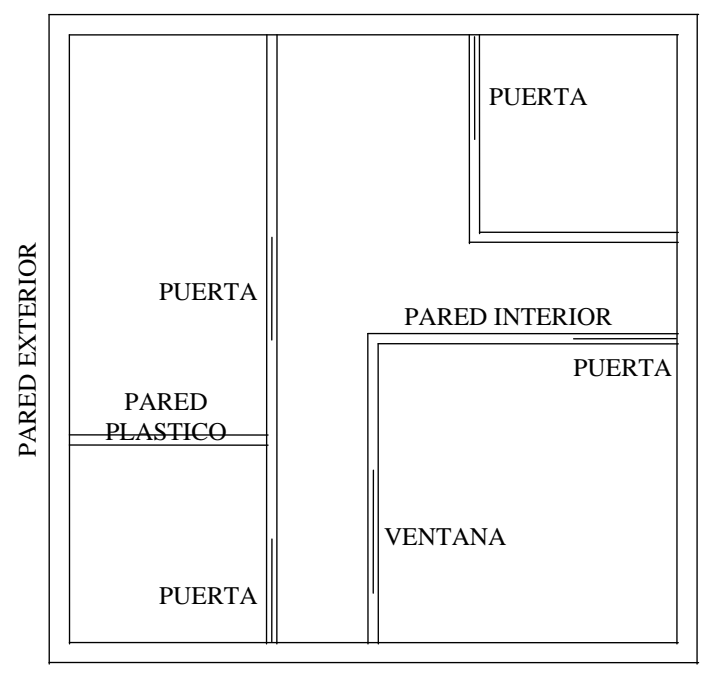

Figura 7.10: Planta de edificio sencillo

En su interior se han dispuesto algunas paredes de distintos materiales, sobre las que se han practicado diversas puertas y ventanas. En la figura 7.10 se representa la planta del edificio, mientras que en la 7.11 se representa en tres dimensiones. Aunque existía, se ha eliminado de la representación el techo para clarificar la imagen, manteniéndose el suelo.

Los parámetros de la simulación se presentan en la tabla 7.6, y los resultados de las simulaciones realizadas mediante Lanzado de Tubos se presentan en la figura 7.12.

\begin{tabular}{|l|c|}
\hline Frecuencia de trabajo $(\mathrm{MHz})$ & 900 \\
\hline Antena transmisora & Dipolo elemental vertical \\
\hline Resolución en el lanzado & $1.125^{\circ}$ \\
\hline Número de reflexiones/transmisiones & 6 \\
\hline Paredes exteriores, suelo y techo & $\underline{\varepsilon}_{r}=2-0.5 j$ \\
Paredes interiores de ladrillo & $\underline{\varepsilon}_{r}=4-0.1 j$ \\
Paredes interiores de material plástico & $\underline{\varepsilon}_{r}=4-0.4 j$ \\
Vidrios de las ventanas & $\underline{\varepsilon}_{r}=6-0.05 j$ \\
\hline
\end{tabular}

Tabla 7.6: Parámetros de la simulación en la planta de edificio sencillo 


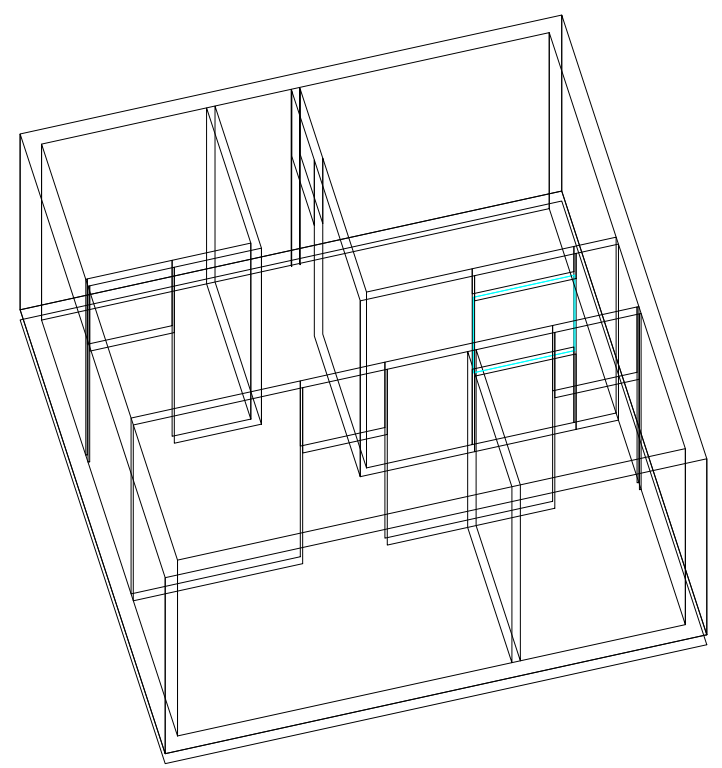

Figura 7.11: Representación tridimensional de la planta de la figura 7.10

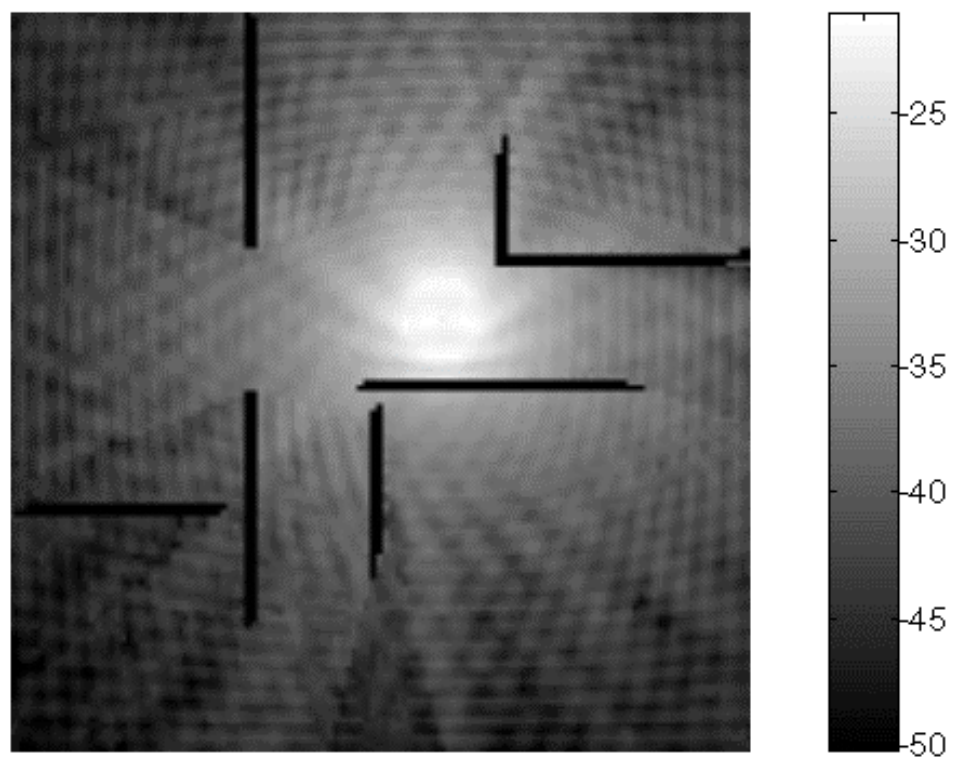

Figura 7.12: Potencia recibida en la planta del edificio sencillo 
Se pueden observar ciertos detalles interesantes, como los efectos de las aberturas. En general, se aprecia un decaimiento muy importante de la potencia recibida, a pesar de las reducidas dimensiones del entorno.

\section{Edificio vacío de tres plantas}

Por último, se mostrarán los resultados obtenidos en un entorno claramente tridimensional. Se trata de un sencillo edificio vacío de tres plantas (figura 7.13). Las dimensiones son suficientemente realistas: cada planta se ha supuesto de $33.6 \times 75.6 \times 2.92$ metros, estando separadas entre sí 1.37 metros (aquí se contabiliza la parte del forjado y el hueco del bajotecho).

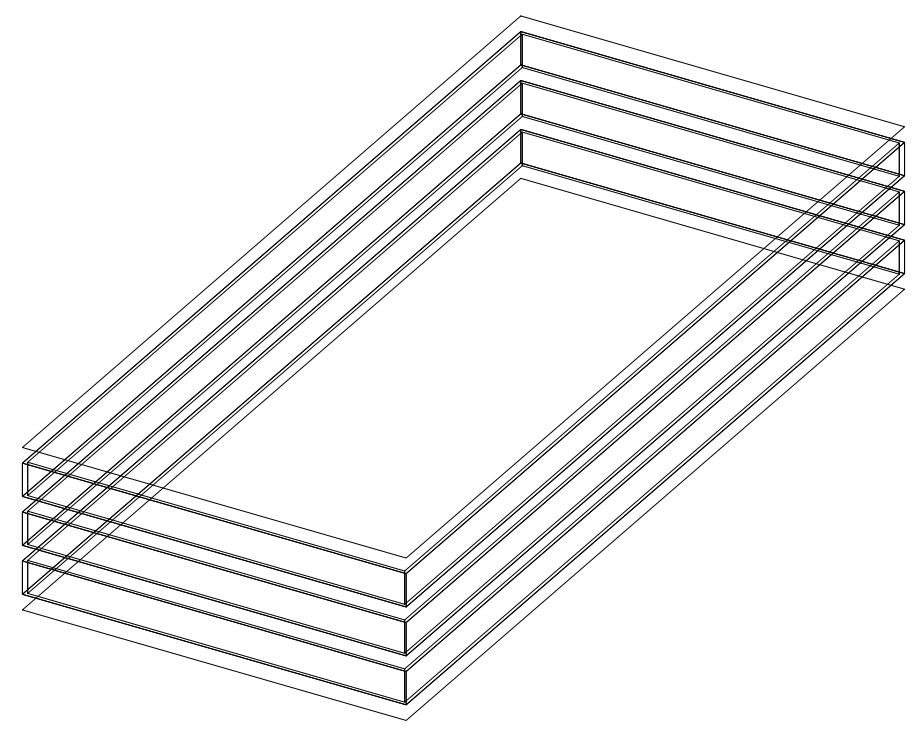

Figura 7.13: Edificio vacío de tres plantas

Los parámetros de la simulación se presentan en la tabla 7.7. Todos los materiales se han supuesto de hormigón. El dipolo elemental que actúa como antena se ha dispuesto en polarización horizontal respecto al suelo (eje OY).

\begin{tabular}{|l|c|}
\hline Frecuencia de trabajo $(\mathrm{MHz})$ & 900 \\
\hline Antena transmisora & Dipolo elemental vertical \\
\hline Resolución en el lanzado & $2^{o}$ \\
\hline Número de reflexiones/transmisiones & 10 \\
\hline Paredes exteriores, suelos y techos & $\underline{\varepsilon}_{r}=2-0.5 j$ \\
\hline
\end{tabular}

Tabla 7.7: Parámetros de la simulación en el edificio vacío de tres plantas

Se situó la antena transmisora en la planta superior, evaluándose la potencia recibida en una matriz de receptores situada en un plano perpendicular al suelo y paralelo a las paredes, que abarcaba las dos plantas inferiores. Los resultados de tal simulación se representan en la figura 7.14. Se ha eliminado parte del hueco entre plantas (en el que no se ha evaluado la potencia recibida) para no hacer excesivamente grande la figura. 

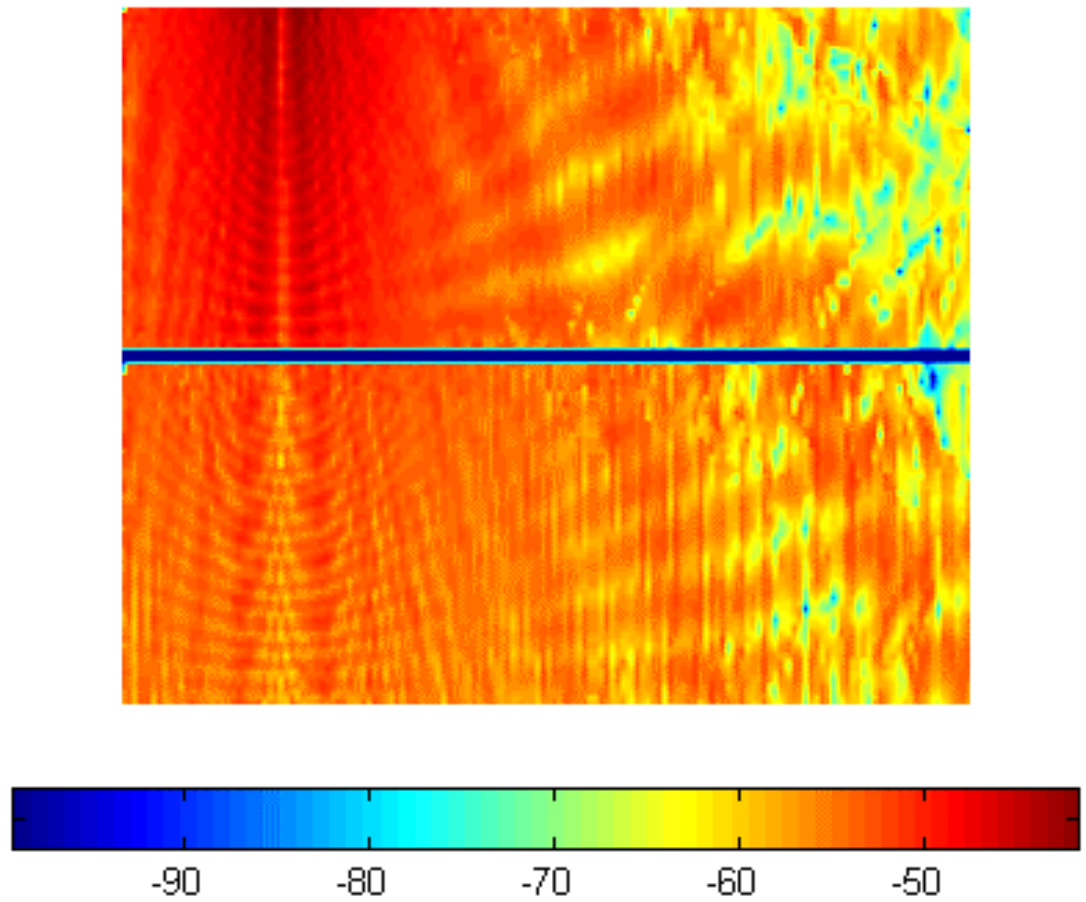

Figura 7.14: Potencia recibida en las plantas inferiores del edificio vacío 
Se aprecia que, a pesar de la sencillez del entorno de simulación, existen fuertes variaciones de la señal recibida. Nótese que esta simulación tiene un carácter marcadamente tridimensional, por lo que, una vez más, hay que recordar que nunca se puede obviar las fluctuaciones de la potencia en función de la altura de la antena receptora, pues los suelos y techos influyen de manera decisiva.

Mediante simulación se ha llegado, por tanto, a las mismas conclusiones que en el caso de la campaña de medidas que ya se describió. Esta ha de ser, sin duda, la principal ventaja de este tipo de simuladores.

\section{Simulación en banda ancha en un entorno complejo}

Para ver las posibilidades del simulador para trabajar en banda ancha en entornos complejos, se ha diseñado uno ficiticio, pero bastante realista.

Se trata de un edificio de tres plantas idénticas, una de las cuales se muestra en la figura 7.15. Consta de diversos tipos de ambientes: habitaciones grandes y pequeñas, zonas amplias, varios pasillos, etc.
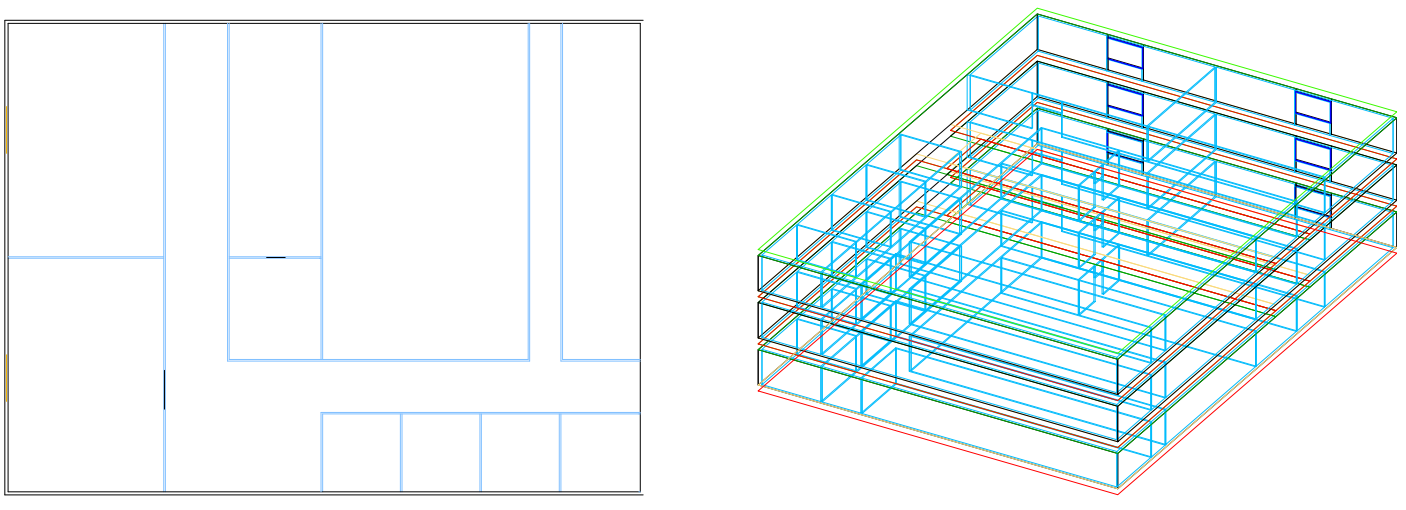

Figura 7.15: Planta y perspectiva 3D del edificio complejo

Para esta simulación, se ha escogido el pasillo principal que discurre horizontalmente según se representa en la figura 7.15. El transmisor se ha dispuesto al final del pasillo (a la derecha), de forma que todos los receptores de mantuvieran con visibilidad directa con él. Los parámetros de dicha simulación se presentan en la tabla 7.8

\begin{tabular}{|l|c|}
\hline Frecuencia de trabajo $(\mathrm{MHz})$ & 900 \\
\hline Antena transmisora & Dipolo en $\lambda / 2$ con pol. vertical \\
\hline Resolución en el lanzado & $1^{o}$ \\
\hline Número de reflexiones/transmisiones & 15 \\
\hline Paredes exteriores, suelo y techo & $\underline{\varepsilon}_{r}=9-0.9 j$ \\
Paredes interiores & $\underline{\varepsilon}_{r}=4-0.1 j$ \\
Vidrios de las ventanas & $\underline{\varepsilon}_{r}=6-0.05 j$ \\
\hline
\end{tabular}

Tabla 7.8: Parámetros de la simulación en banda ancha en edificio complejo

A pesar del alto número de reflexiones y transmisiones considerado, se puede apreciar 
en la figura 7.16 que el número de contribuciones recibidas no era excesivo. Ello se debe a la propia geometría del entorno, ya que en pasillos muy estrechos, los caminos con múltiples reflexiones en las paredes laterales pueden perderse con facilidad.

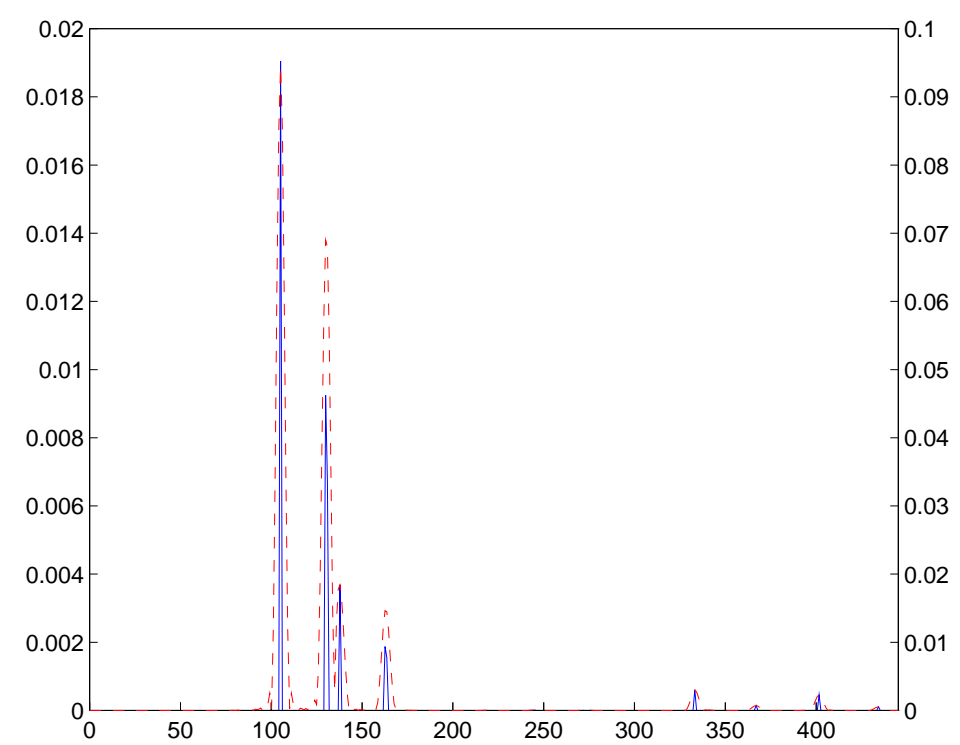

Figura 7.16: Módulo de la respuesta impulsional obtenida en un punto del pasillo. En trazo discontinuo se muestra la versión filtrada. Retardo en ns

Las muestras espaciales fueron dispuestas cada $10 \mathrm{~cm}(3 \lambda / 10)$ a lo largo de 30 metros. Esto permite estimar la función de scattering en varios tramos del recorrido. En la figura 7.17 se muestran las funciones de scattering en dos de esos tramos. El primero se corresponde con la zona más cercana al transmisor, y apenas se aprecian refexiones traseras (desplazamiento Doppler negativo), cosa que sí ocurre en la otra función, que se corresponde con el tramo más alejado del transmisor.

\subsection{Verificación de técnicas y fenómenos implementados}

Aparte de los mecanismos básicos de propagación de los frentes de onda, se han implementado una serie de fenómenos adicionales que permiten obtener resultados más acordes con la realidad. Tales efectos son la influencia de las antenas en cuanto a polarización y diagramas de radiación, la incidencia en estructuras multi-capa, la reflexión difusa (scattering) en superficies rugosas, y la difracción en esquinas.

Además, se evaluará el método empleado para eliminar los impactos redundantes que aparecen al utilizar el algoritmo de recepción en el Lanzado de Rayos genérico, y se comparará con el método utilizado por Durgin y Rappaport visto en la sección 5.4.2. 

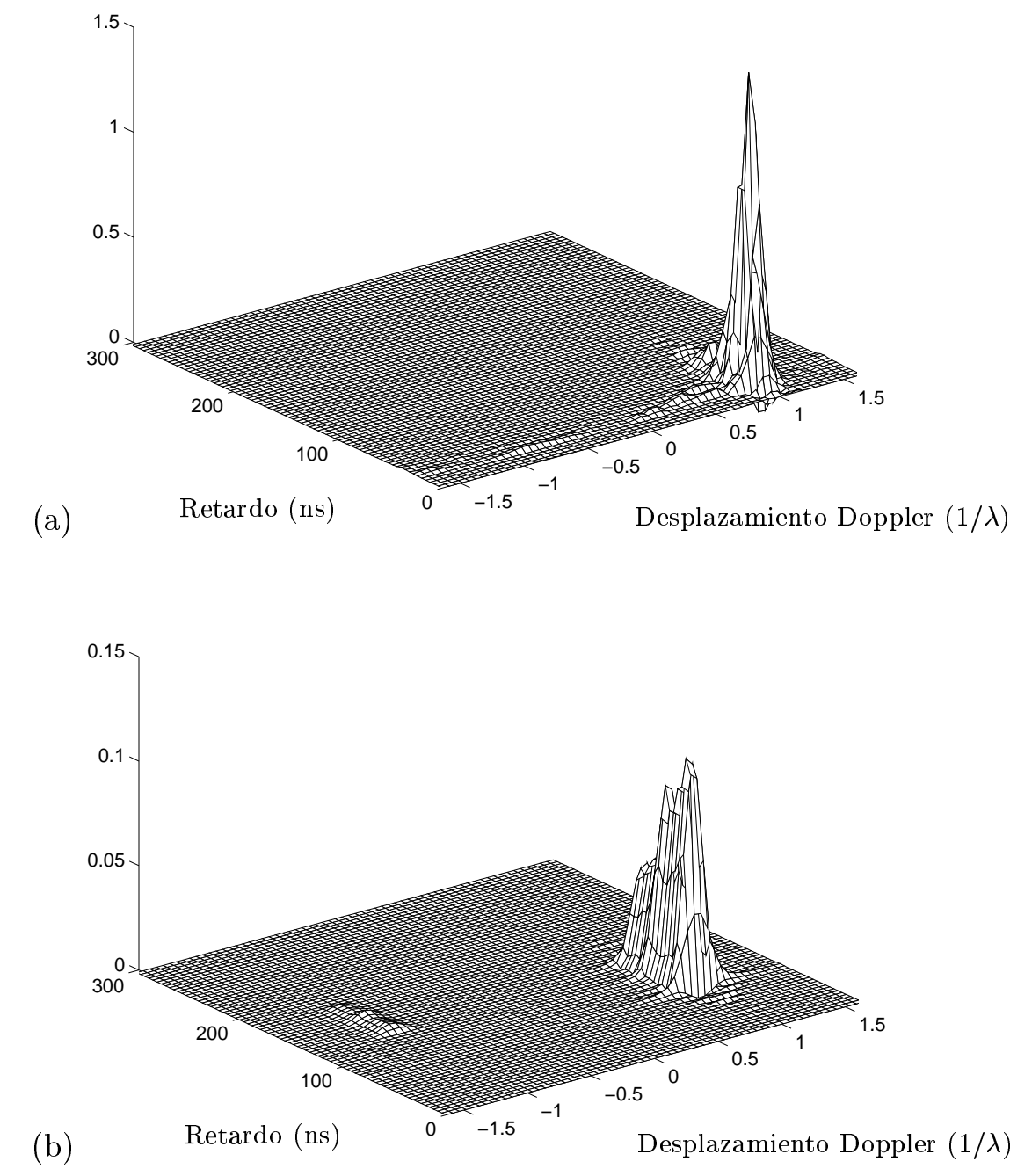

Figura 7.17: Funciones de scattering obtenidas de la trazas simuladas en el pasillo del edificio complejo. (a) Traza cercana al transmisor. (b) Traza alejada del transmisor (cercana a pared trasera) 


\subsubsection{Polarización y diagrama de radiación}

Según lo visto en el capítulo 6 , se ha implementado la posibilidad de utilizar antenas transmisoras con distintos diagramas de radiación, tanto académicos como reales.

Concretamente, se han diseñado diagramas de radiación para una antena isotrópica, un dipolo elemental, un dipolo resonante (de longitud $\lambda / 2$ ), y un dipolo de longitud arbitraria $L$. Todos ellos se corresponden con dipolos con polarización lineal, y pueden ser orientados en el simulador según alguno de los ejes coordenados, OX, OY u OZ.

También se ha implementado la posibilidad de diseñar un diagrama de radiación arbitrario, mediante un fichero de texto que lo defina con una resolución de un grado, tanto para el ángulo $\theta$ como para el $\phi$. La antena correspondiente a dicho diagrama se supondrá linealmente polarizada, por lo que también deberá darse una orientación, según algún eje coordenado, al vector de campo eléctrico que representa dicha polarización.

La mejor forma de verificar dichos diagramas de radiación y su comportamiento en función de la orientación dada la antena es mediante el estudio de la propagación en un plano paralelo al suelo de una habitación vacía, sin considerar ninguna reflexión en las paredes.

De esta forma, se pueden obtener representaciones de los distintos diagramas de radiación mediante curvas de nivel como las mostradas en las figuras 7.18 a 7.25. Los dipolos se han orientado para mostrar el corte en plano H (subfiguras (a)) y los cortes en plano $\mathrm{E}$ en sus dos posibles orientaciones respecto a la habitación (subfiguras (b) y (c)).

(a)

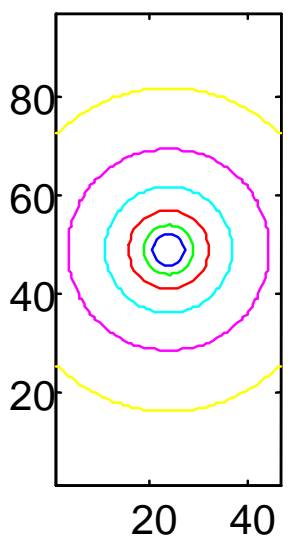

(b)

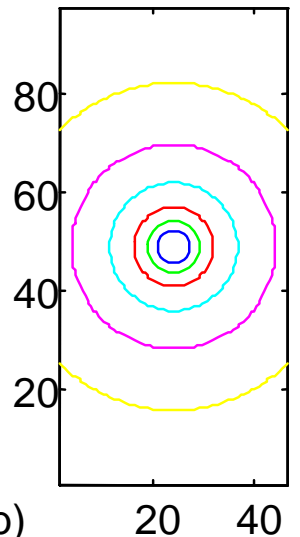

(c)

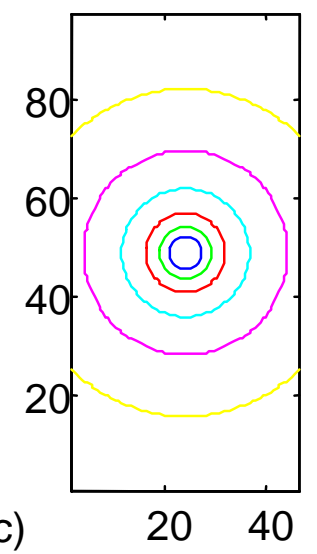

Figura 7.18: Diagrama de radiación de una antena isotrópica

Así mismo, en la figura 7.26 se muestran las curvas de nivel que representan la radiación de tres antenas definidas mediante ficheros de datos. Se tratan de ejemplos ilustrativos no reales representados en plano $\mathrm{H}$; concretamente una antena isotrópica (a), una antena que radía solamente en un semiespacio (b), y una antena que radía en dos cuadrantes opuestos del espacio total (c). 

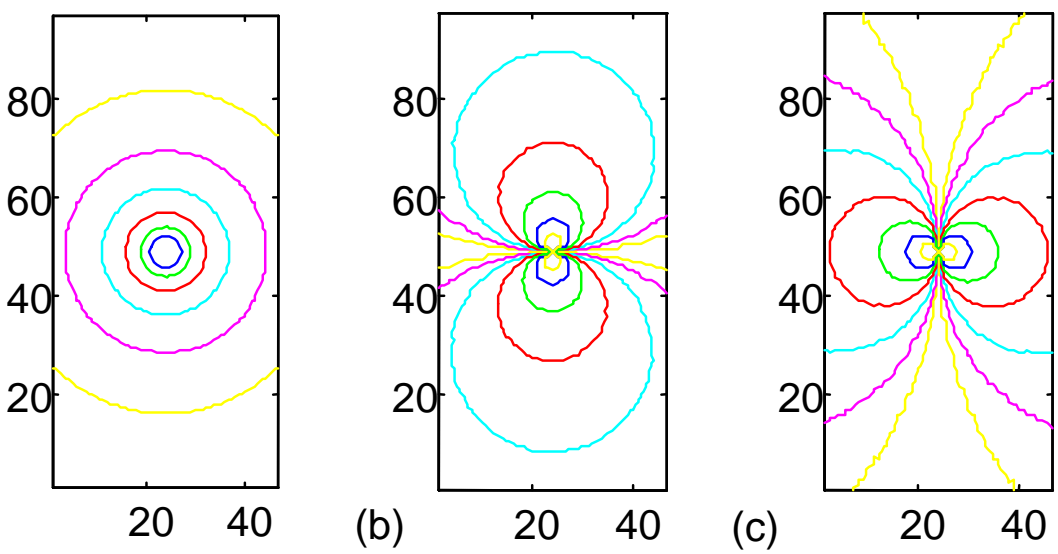

Figura 7.19: Diagrama de radiación de un dipolo elemental

(a)

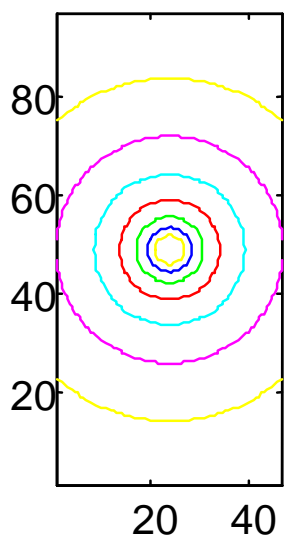

(b)

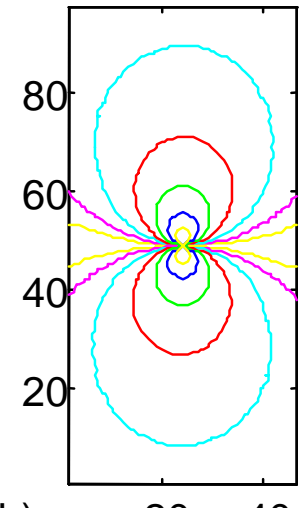

$20 \quad 40$ (c)

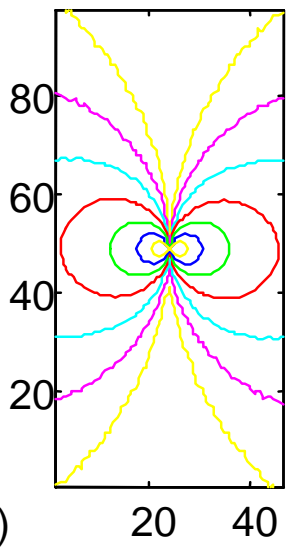

Figura 7.20: Diagrama de radiación de un dipolo en $\lambda / 2$

(a)

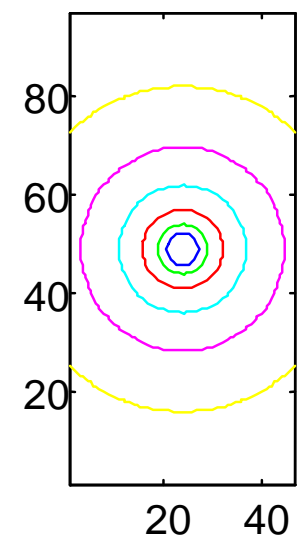

(b)

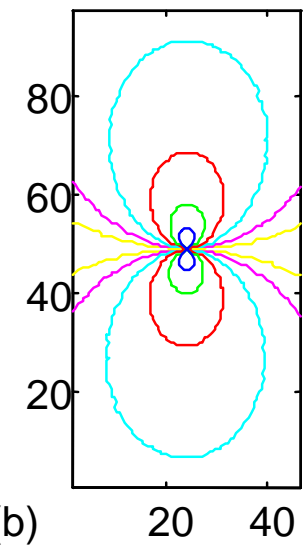

(c)

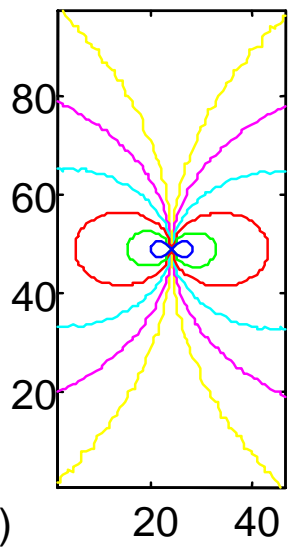

Figura 7.21: Diagrama de radiación de un dipolo de longitud $L=3 \lambda / 4$ 
(a)
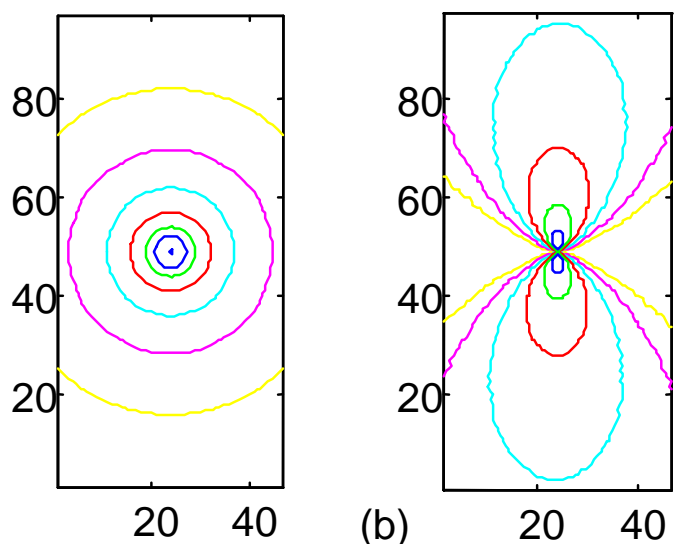

(c)

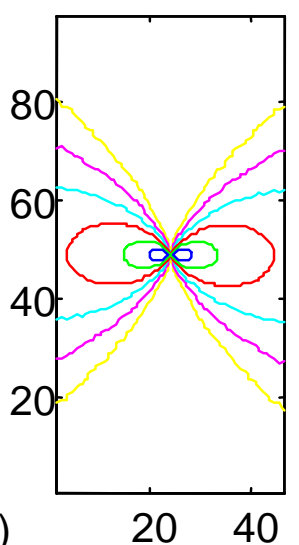

Figura 7.22: Diagrama de radiación de un dipolo de longitud $L=\lambda$

(a)
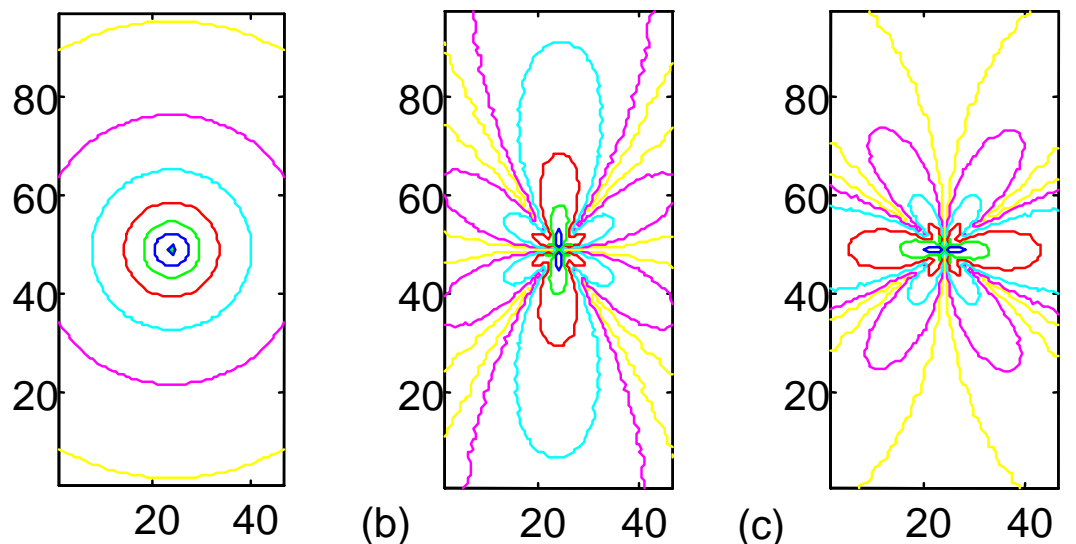

Figura 7.23: Diagrama de radiación de un dipolo de longitud $L=5 \lambda / 4$

(a)

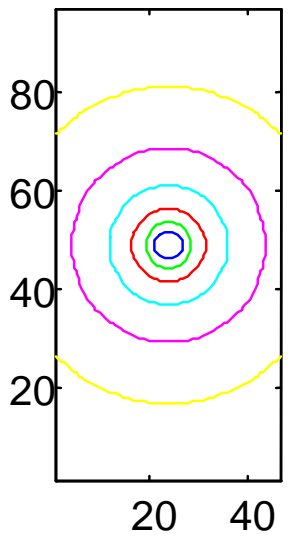

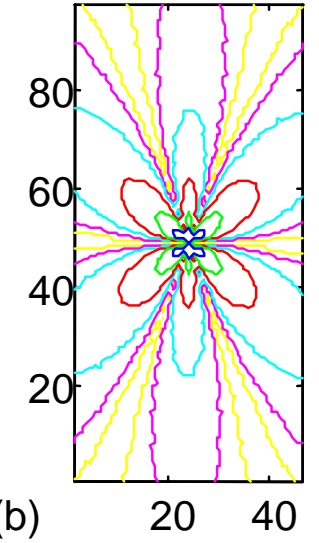

(c)

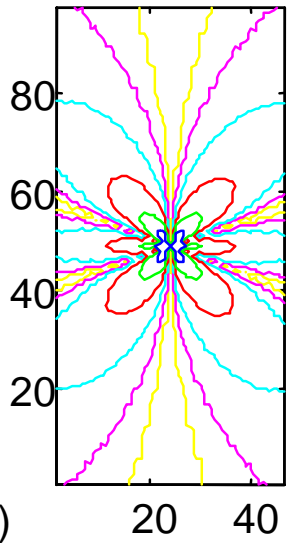

Figura 7.24: Diagrama de radiación de un dipolo de longitud $L=3 \lambda / 2$ 

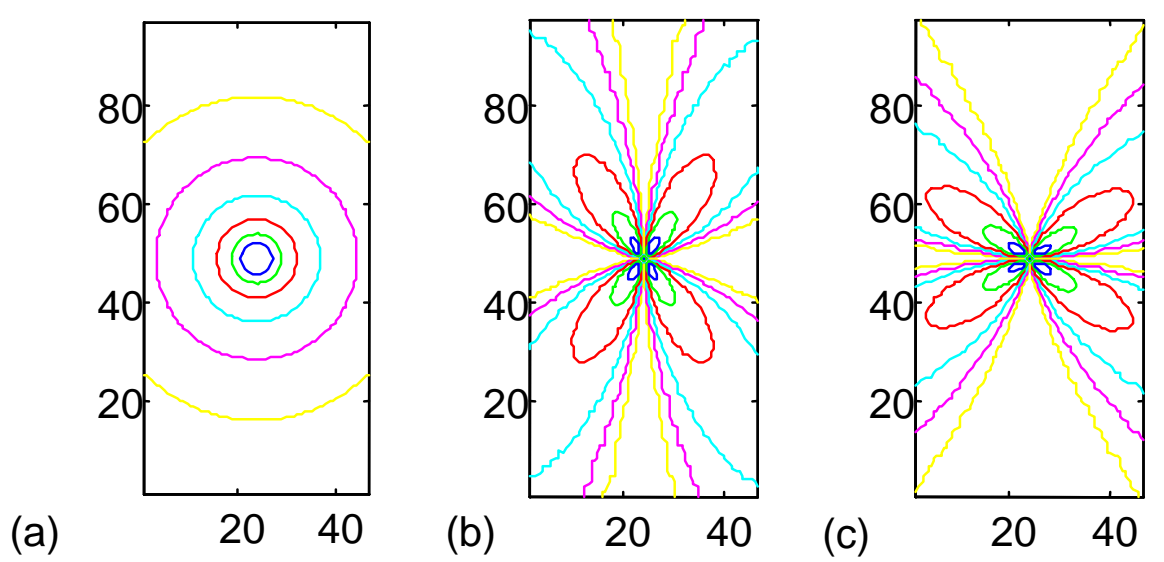

Figura 7.25: Diagrama de radiación de un dipolo de longitud $L=2 \lambda$

(a)

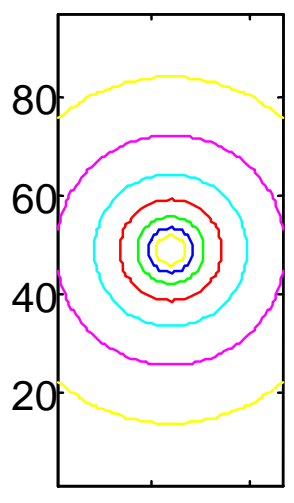

$20 \quad 40$

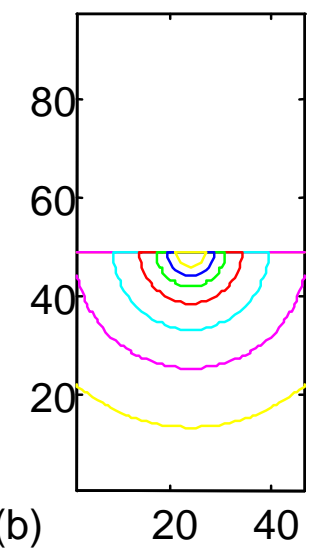

(c)

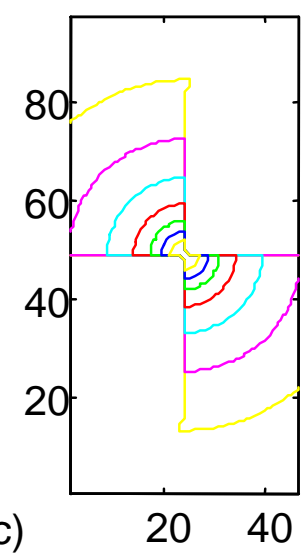

Figura 7.26: Ejemplos de diagramas de radiación de antenas definidas mediante ficheros. (a) Antena isotrópica, (b) antena radiante en un semiespacio, (c) antena radiante en dos cuadrantes opuestos 


\subsubsection{Eliminación de impactos redundantes}

Los modelos basados en el Lanzado de Rayos genérico presentan el gran inconveniente de tener que implementar complejos algoritmos de recepción, ya que, tanto las entidades lanzadas (rayos unidimensionales) como los receptores (considerados puntuales), no poseen grosor. Estos algoritmos suelen estar basados en la técnica de la esfera de recepción (capítulo 5) que, en propagación tridimensional, no resulta perfectamente válida.

Esta inexactitud, tal y como se comentó en la sección 5.4.2, consiste en que, muy a menudo, se considera alcanzado el receptor por dos o más rayos procedentes del mismo frente de ondas, con lo cual se incrementa la potencia recibida en el receptor.

Para resolver este problema de los impactos redundantes, se puede optar, bien por realizar un procesado de la potencia asociada a cada uno de los rayos, de forma que se minimice el error cometido, o bien por eliminar directamente aquellos rayos que puedan considerarse superfluos.

La técnica de los frentes de onda distribuidos, presentada en [Dur97a], consiste en ponderar el campo eléctrico asociado a cada rayo por una función dependiente de la distancia mínima del rayo al receptor, y se ha demostrado suficientemente aceptable en entornos amplios (exteriores) con abundancia de puntos en visibilidad directa con el receptor [Dur97b].

Sin embargo, como se va a poder comprobar con las simulaciones que en esta sección se presentan, este método no es adecuado al considerar propagación tridimensional en entornos indoor, especialmente en situaciones NLOS o con multitud de frentes de onda alcanzando a los receptores.

Se propone, por tanto, realizar una verificación exhaustiva de cada uno de los rayos recibidos, para ver si llegan con una dirección muy similar a la de otro rayo ya cuantificado, habiendo sufrido el mismo número de reflexiones o transmisiones. En caso de que esto se cumpla, dicho rayo no será tenido en cuenta en la potencia recibida.

Para comprobar la bondad de ambos métodos y poderlos comparar, se han realizado tres simulaciones en distintos entornos. El primero de ellos, y más sencillo, consiste en una habitación rectangular vacía en la que se ha dispuesto una pared metálica en uno de los extremos (figura 7.27). Se ha estudiado la recepción en una hilera de puntos cercano a dicha pared metálica, considerándose solamente una reflexión.

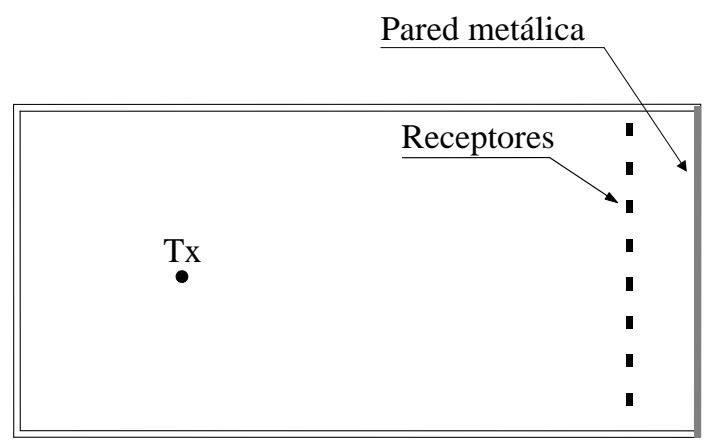

Figura 7.27: Primer entorno de prueba de los algorítmos de eliminación de impactos redundantes 
Si se observa la representación de la potencia recibida en la hilera de puntos considerada (figura 7.28), obtenida tanto sin eliminar impactos redundantes como eliminándolos según ambos algorítmos, se observa que el método de los frentes de onda distribuidos no es capaz de reducir el error cometido por los impactos redundantes en muchos de los receptores.

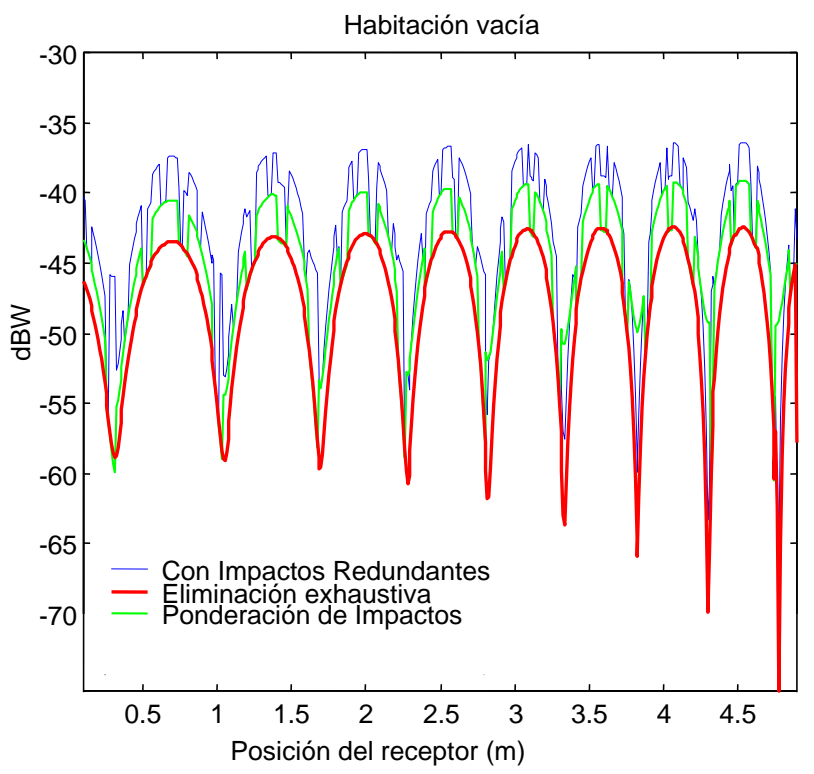

Figura 7.28: Comparación de la potencia recibida en el primer entorno

Concretamente, el método de los frentes de onda distribuidos reduce el error medio en tan solo $2.07 \mathrm{~dB}$ (diferencia entre la potencia media recibida obtenida sin descartar impactos y la obtenida con el método de ponderación), mientras que el método de verificación exhaustiva lo hace hasta en 5.1dB.

En la representación del PDP promediado de los puntos de dicho entorno (figura 7.29) se advierte que el método de los frentes de onda distribuidos, aunque se comporta bien con los rayos procedentes de la misma dirección en la que se encuentra el transmisor, no es capaz de reducir el error cometido por aquellos impactos redundantes alejados en el tiempo del rayo directo, es decir, las contribuciones redundantes procedentes de la reflexión en la pared metálica trasera, teniendo en cuenta el entorno (retardos superiores a 20ns).

Tras esta primera comparación, se realizaron simulaciones en entornos más complejos, como los representados en la figura 7.30. Se tratan de situaciones en las que, en la mayoría de los casos, no existe visibilidad directa con el transmisor. El primero consiste en un pasillo en el que se coloca el transmisor, ubicando los receptores tras una esquina, y considerando hasta 10 reflexiones. El otro se trata de una habitación con algunos muebles y pilares intermedios, permitiendo que los rayos pudieran sufrir hasta 200 transmisiones o reflexiones.

Los resultados de la potencia recibida se muestran en la figura 7.31. La reducción del error producido por los impactos redundantes es de apenas $0.37 \mathrm{~dB}$ y $0.72 \mathrm{~dB}$ en el caso del método de los frentes de onda distribuidos, mientras que con la verificación exhaustiva se 

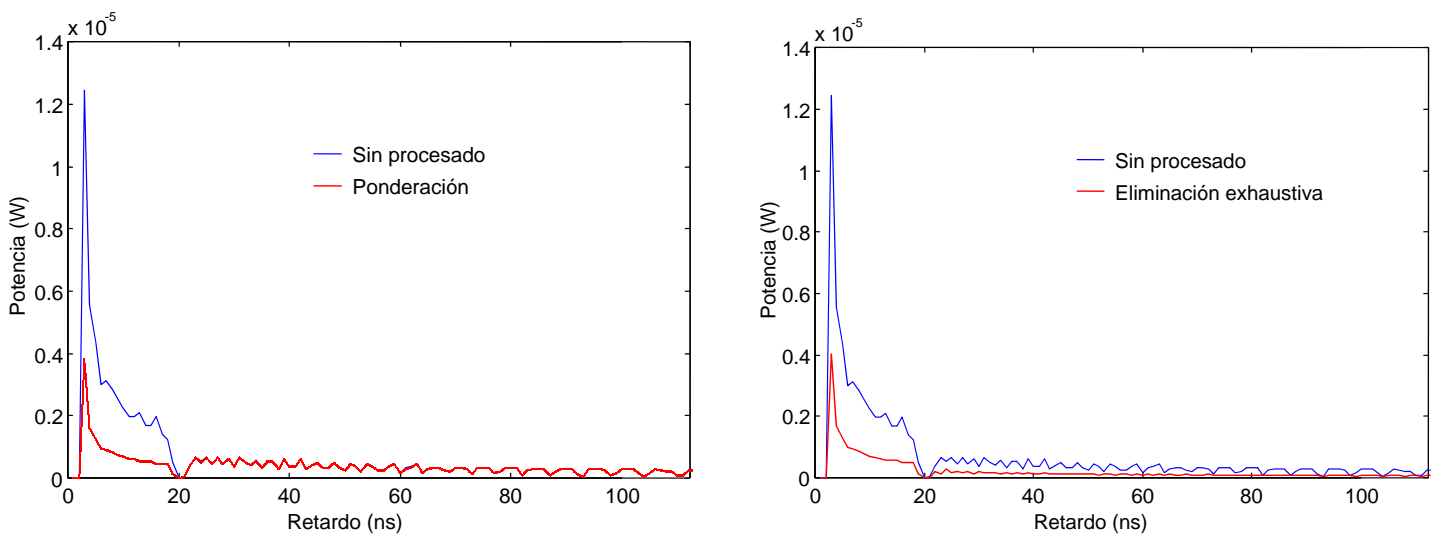

Figura 7.29: Comparación de los PDP promediados en el primer entorno
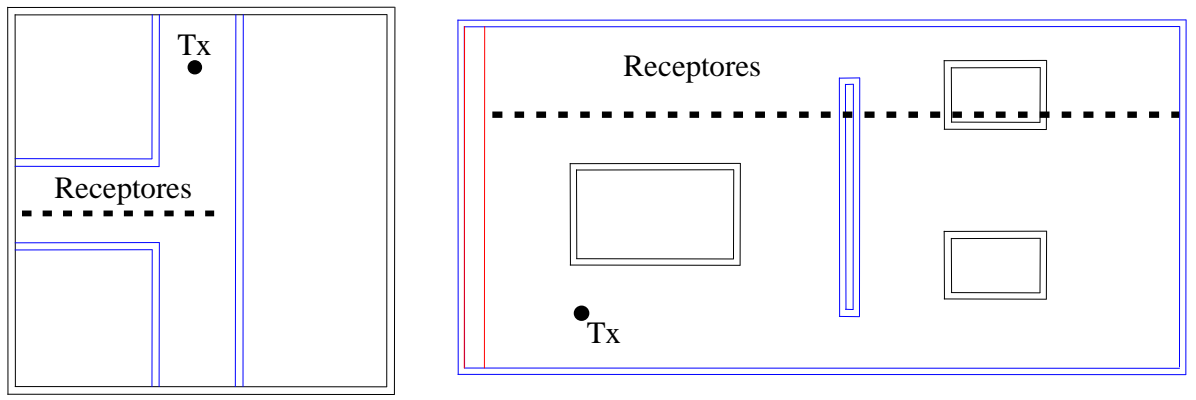

Figura 7.30: Segundo y tercer entorno de prueba de los algorítmos de eliminación de impactos redundantes 
llega a redudir la potencia media recibida en $9.36 \mathrm{~dB}$ y $6.29 \mathrm{~dB}$ de media, según el entorno considerado.

Así mismo, se han hecho diversas simulaciones para comparar la reducción del error de cada algoritmo, en función de la resolución empleada y el número de rayos procesados (dependiente del número de trasmisiones o reflexiones considerado).

El entorno escogido ha sido el de la habitación rectangular vacía, calculando la potencia recibida en puntos contenidos en un plano horizontal de la misma. En la figura 7.32 se representa el error reducido por cada algorítmo, es decir, la diferencia en la potencia media recibida respecto a no eliminar impactos redundantes.

Puede observarse que, conforme aumenta la resolución y el número de impactos, mejor comportamiento tiene la verificación exhaustiva, al contrario de lo que ocurre con el algoritmo de ponderación. Esto último se debe a que, de esta forma, aumenta el número de rayos procedentes de direcciones distintas a la que está situado el transmisor, con los cuales dicho algoritmo no funciona correctamente, tal y como se ha demostrado.

Cabe pensar que la verificación exhaustiva pudiera requerir un mayor tiempo de computación que el algorítmo de ponderación del frente de ondas. Efectivamente, el número total de operaciones a realizar por el programa de simulación es mucho mayor en el primer caso. Sin embargo, estas operaciones son más sencillas, ya que se tratan de simples comparaciones de ángulos, al contrario del segundo algorítmo, que requiere complejas operaciones matemáticas, mucho más lentas.

En la figura 7.33, se representa el tiempo medio de procesado por impacto para cada algoritmo. Este tiempo medio por impacto se ha obtenido dividiendo el tiempo total de la simulación entre el número total de impactos procesados. A medida que aumenta el número de impactos, el algoritmo de ponderación resulta ligeramente más eficiente, aunque, como se ha visto, con un peor comportamiento. Cuando el número de impactos recibidos es reducido, el algoritmo de eliminación es similar en tiempo de simulación al algoritmo de ponderación, y obtiene mejores resultados. En cualquier caso, las diferencias son mínimas.

\subsubsection{Modelo de pared multi-capa}

A continuación se mostrarán las simulaciones que se realizaron tanto para demostrar la necesidad de modelar las paredes suelos y techos mediante estructuras multi-capa, como para validar la técnica que se propuso en la sección 6.3.3 para modelar la incidencia en tal tipo de estructuras.

En primer lugar, se procederá a mostrar una simulación en la que se evidencia la necesidad de modelar las paredes mediante este tipo de estructuras. Para ello se considerará el entorno de la figura 7.34, que muestra una habitación vacía separada en dos compartimentos estancos mediante una pared central.

Se simulará la propagación en la habitación considerando las reflexiones sobre todas las paredes del entorno, así como las transmisiones a través de la pared central. Primeramente, se considerará que la pared central está formada tan sólo por una capa de hormigón 

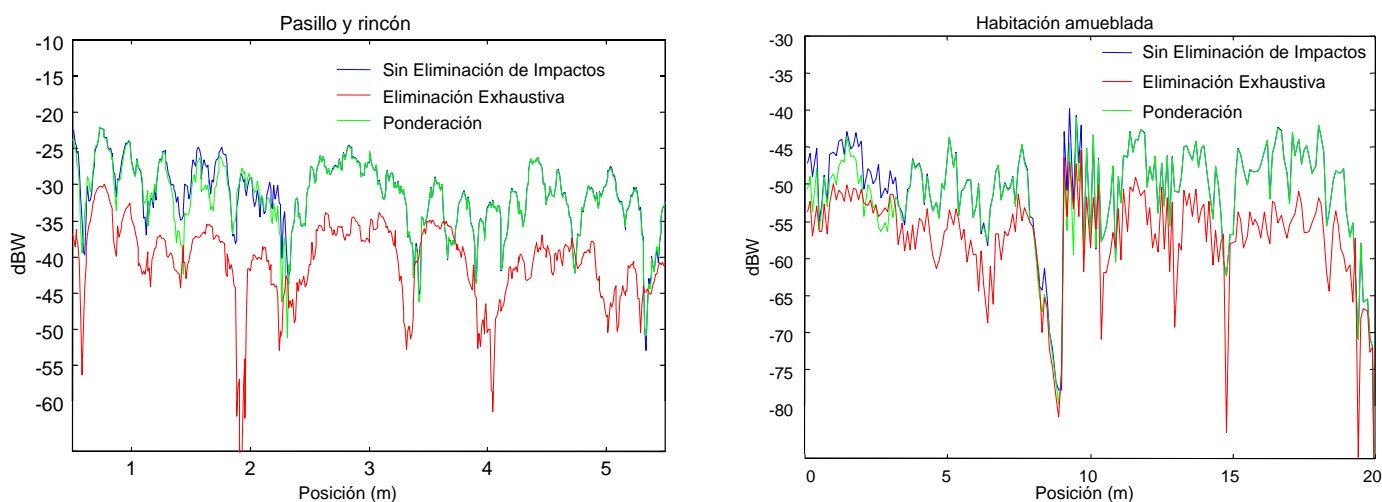

Figura 7.31: Comparación de la potencia recibida en el segundo y tercer entorno
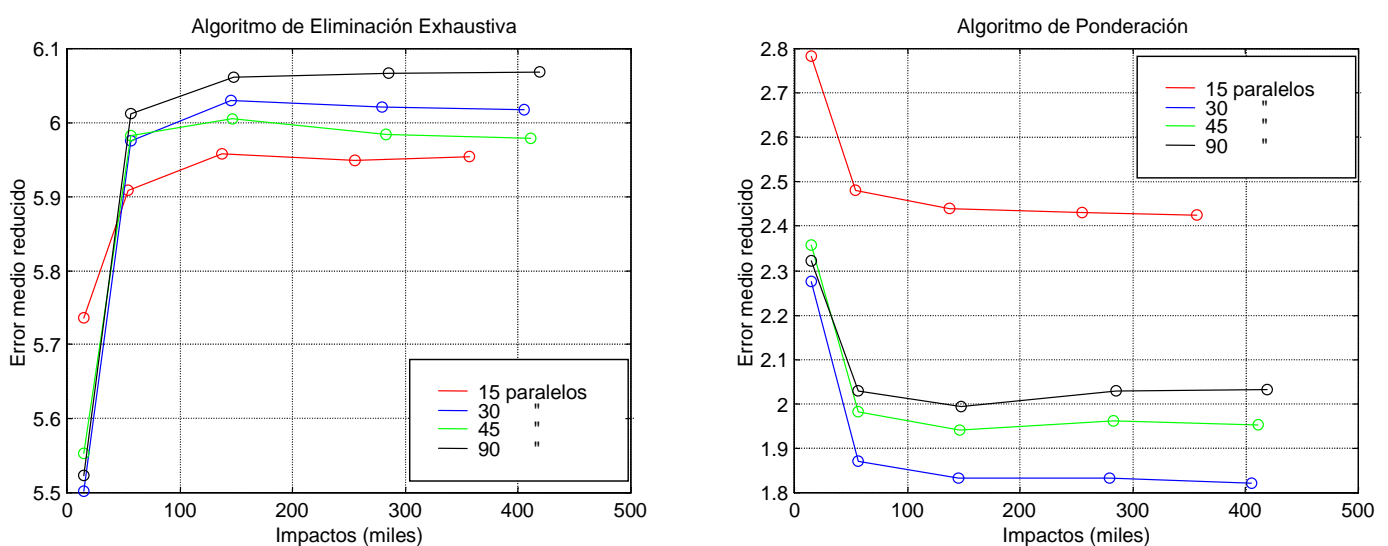

Figura 7.32: Reducción del error medio de cada algorítmo de eliminación de impactos redundantes
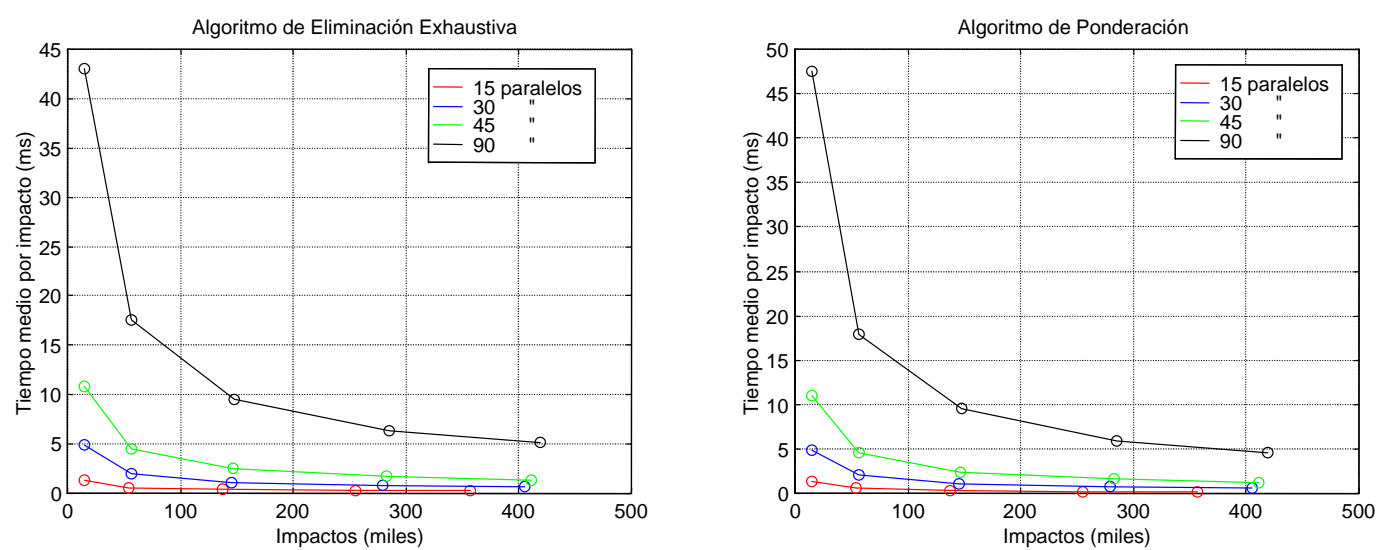

Figura 7.33: Comparación de tiempos de ejecución de cada algorítmo de eliminación de impactos redundantes 


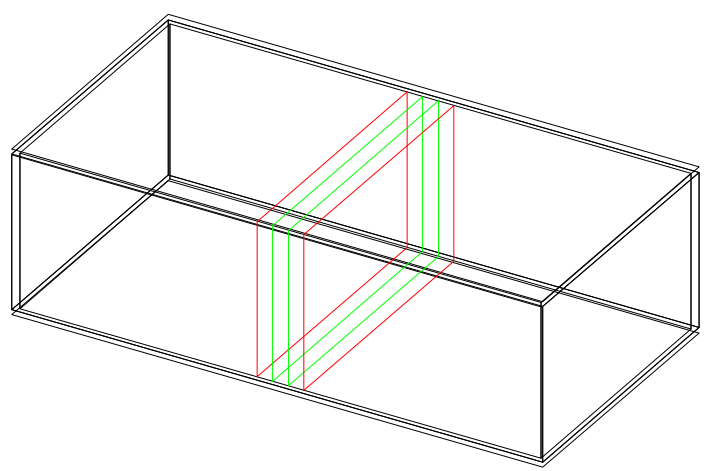

Figura 7.34: Habitación con pared multi-capa central

$\left(\underline{\varepsilon}_{r}=9+0.9 j\right)$, con un grosor de $30 \mathrm{~cm}$, y no se calcularán las reflexiones internas a ella. Posteriormente se considerará que la pared, además, posee un recubrimiento de madera $\left(\underline{\varepsilon}_{r}=2.5-0.3 j\right)$ a cada lado, formando así una estructura multi-capa manteniendo el grosor total en $30 \mathrm{~cm}$. Se tendrán en cuenta las múltiples reflexiones internas mediante el método de los coeficientes equivalentes. Los parámetros de la simulación se muestran en la tabla 7.9.

\begin{tabular}{|l|c|}
\hline Frecuencia de trabajo $(\mathrm{MHz})$ & 900 \\
\hline Antena transmisora & Dipolo elemental vertical \\
\hline Resolución en el lanzado & $1^{o}$ \\
\hline Número de reflexiones/transmisiones & 6 \\
\hline Paredes exteriores, suelo y techo & $\underline{\varepsilon}_{r}=5-0.4 j$ \\
Pared interior central & $\underline{\varepsilon}_{r}=9-0.9 j$ \\
Recubrimiento de pared central & $\underline{\varepsilon}_{r}=2.5-0.3 j$ \\
\hline
\end{tabular}

Tabla 7.9: Parámetros de las simulaciones para evaluar la transmisión a través de paredes multi-capa

Los resultados de la potencia recibida en cada caso se muestran en la figura 7.35. Se aprecia que, al considerar las múltiples reflexiones internas, se obtienen potencias recibidas al otro lado de la pared, debidas a la transmisión, claramente inferiores. Esto quiere decir que es muy importante considerar las pérdidas de propagación internas, que con este modelo sí son tenidas en cuenta. Estas pérdidas (de 15 a 20dB) son mucho más realistas que las obtenidas sin múltiples reflexiones internas (mucho menores), de acuerdo con lo visto en las campañas de medidas referenciadas en la literatura.

Por otro lado, las diferencias en la parte de la habitación en la que está situado el transmisor no son tan grandes. La potencia media es prácticamente igual y la distribución de potencia por esa zona de la habitación es muy simular. Eso significa que el modelo multi-capa no altera apenas las condiciones de reflexión de las paredes, aunque sí las de transmisión, como se ha visto.

En segundo lugar, se ha querido comparar el método de los coeficientes equivalentes con el el de seguimiento del rayo interno, mucho más exhaustivo y, consiguientemente, extremadamente lento. Para ello se ha considerado un nuevo entorno consistente en una habitación vacía en la que la pared multi-capa se ha dispuesto en un fondo (figura 7.36). 

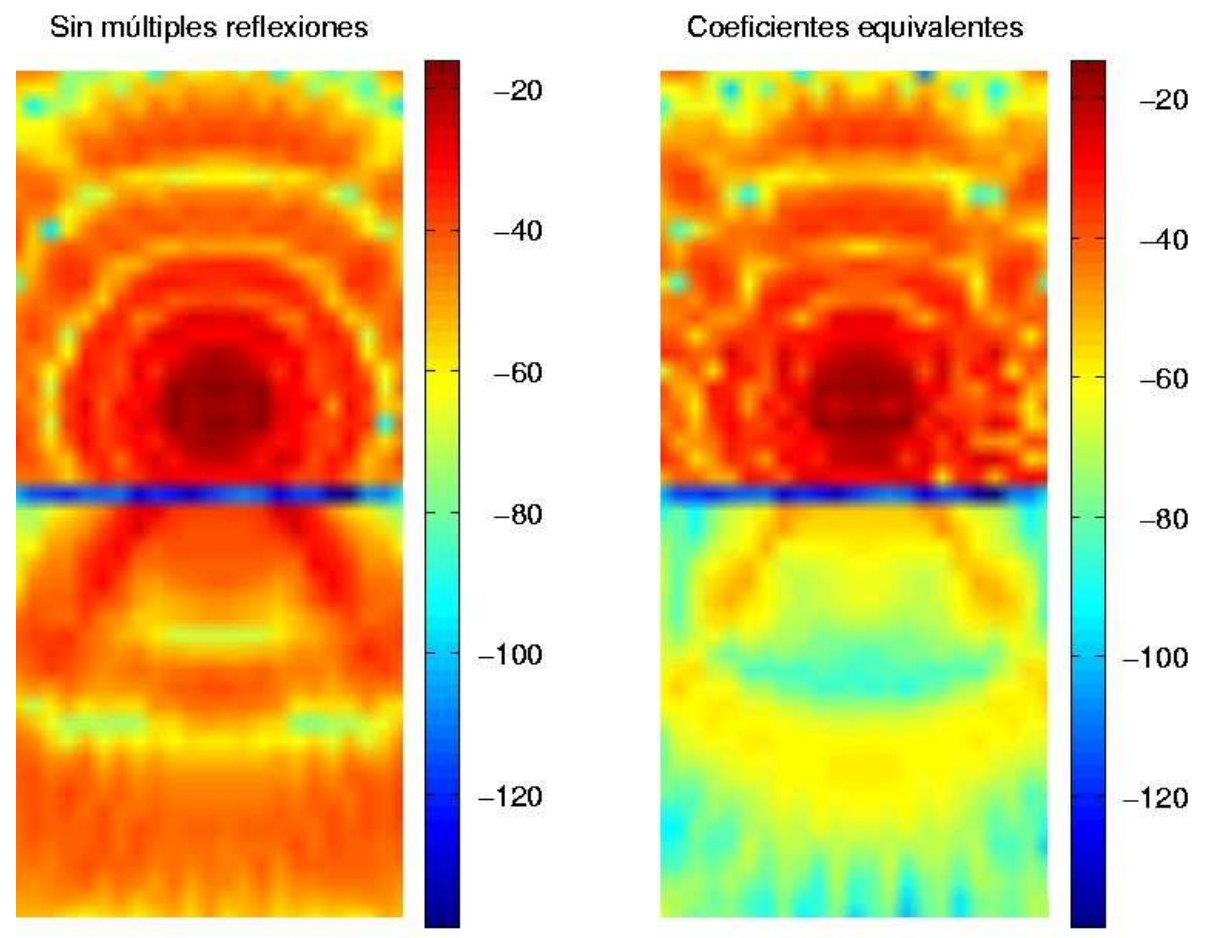

Figura 7.35: Potencia recibida en la habitación con pared multi-capa central. Resultados sin considerar múltiples reflexiones (izquierda) y considerándolas mediante coeficientes equivalentes (derecha)

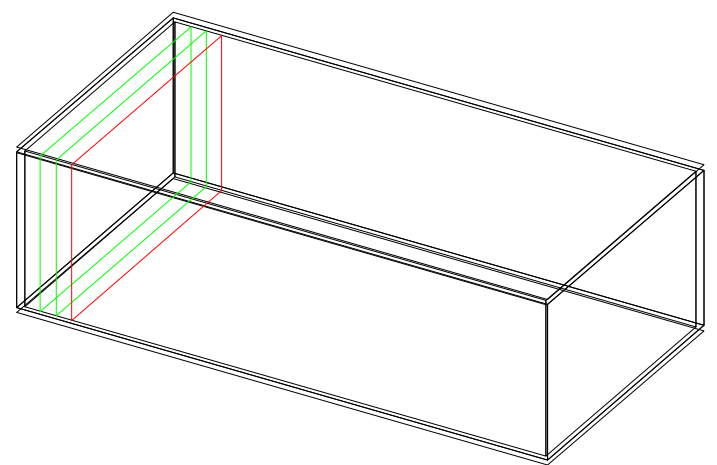

Figura 7.36: Habitación vacía con pared multi-capa en un fondo 
Para reforzar las reflexiones, la pared multi-capa se ha considerado formada por una capa central de metal, recubierta de madera a ambos lados.

Bajo las condiciones resumidas en la tabla 7.10, se simuló la propagación considerando las múltiples reflexiones internas en la estructura multi-capa, primeramente mediante el método exhaustivo de seguimiento del rayo, y posteriormente mediante el más recomendable de los coeficientes equivalentes.

\begin{tabular}{|l|c|}
\hline Frecuencia de trabajo $(\mathrm{MHz})$ & 900 \\
\hline Antena transmisora & Dipolo elemental vertical \\
\hline Resolución en el lanzado & $1^{o}$ \\
\hline Número de reflexiones & 6 \\
\hline Paredes exteriores, suelo y techo & $\underline{\varepsilon}_{r}=5-0.4 j$ \\
Pared interior lateral & $\underline{\varepsilon}_{r}=1-100000 j$ \\
Recubrimiento de pared lateral & $\underline{\varepsilon}_{r}=2.5-0.3 j$ \\
\hline
\end{tabular}

Tabla 7.10: Parámetros de las simulaciones para evaluar los métodos de múltiples reflexiones internas en estructuras multi-capa

Los resultados de ambas simulaciones se muestran en la figura 7.37. Claramente se aprecia que no existe diferencia en los resultados de cada método.
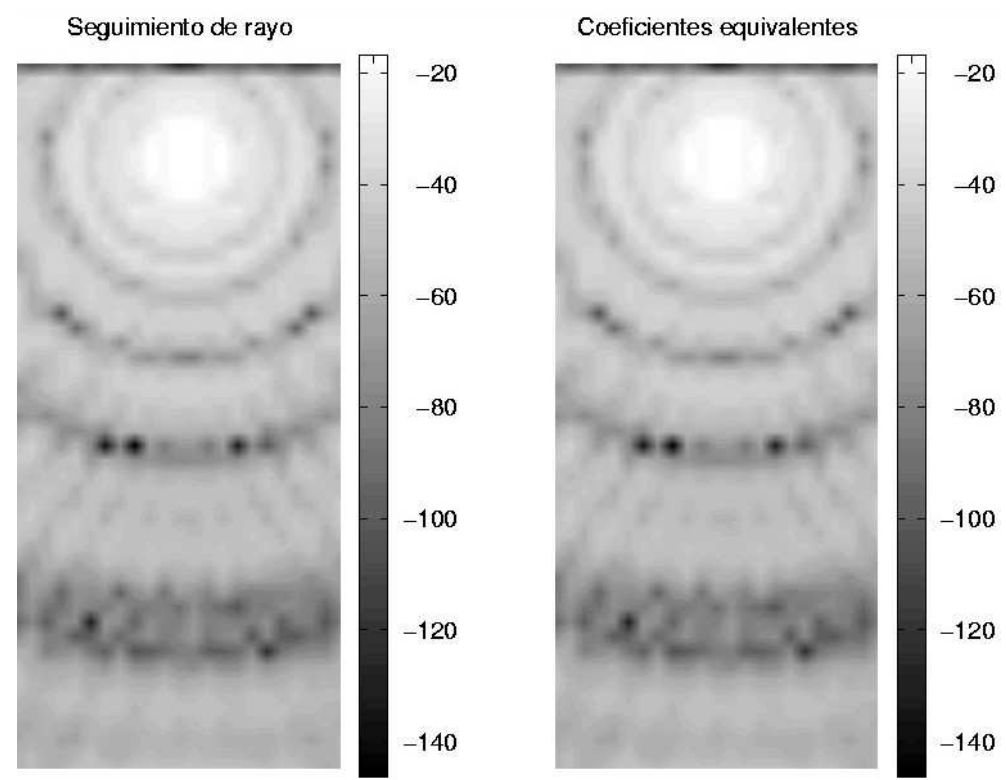

Figura 7.37: Potencia recibida en la habitación con pared multi-capa lateral. Resultados con el método del seguimiento del rayo interno (izquierda) y mediante coeficientes equivalentes (derecha)

Donde sí aparece la diferencia es en el tiempo de ejecución de las simulaciones. El método del seguimiento de rayo interno, tal y como era de esperar, se dispara en tiempo de ejecución, mientras que el de los coeficientes equivalente apenas incrementa la complejidad numérica del algoritmo. En la tabla 7.11 se muestran los tiempos de ejecución, para rayos y tubos, con ambos métodos, comparándolos con una simulación en la que no se ha 
implementado ninguno de ellos.

\begin{tabular}{|c|c|c|c|}
\hline & $\begin{array}{c}\text { Sin múltiples } \\
\text { Reflexiones }\end{array}$ & $\begin{array}{c}\text { Seguimiento del } \\
\text { rayo interno }\end{array}$ & $\begin{array}{c}\text { Coeficientes } \\
\text { equivalentes }\end{array}$ \\
\hline Tubos & $0 \mathrm{~h} 30 \mathrm{~m} 22 \mathrm{~s}$ & $3 \mathrm{~h} 8 \mathrm{~m} 04 \mathrm{~s}$ & 0h 30m 23s \\
\hline Rayos & $0 \mathrm{~h} 25 \mathrm{~m} 10 \mathrm{~s}$ & $1 \mathrm{~h} 28 \mathrm{~m} 9 \mathrm{~s}$ & $0 \mathrm{~h} 25 \mathrm{~m} 30 \mathrm{~s}$ \\
\hline
\end{tabular}

Tabla 7.11: Tiempo de ejecución de los métodos que consideran las múltiples reflexiones internas en las estructuras multi-capa

\subsubsection{Pérdidas por scattering}

A fin de comprobar la influencia de las pérdidas por reflexión difusa (scattering) en los entornos indoor, se eligió una situación sencilla: una habitación completamente vacía, de dimensiones $5 \times 10 \times 3$ metros, con el transmisor situado en el centro (figura 7.1). Tanto paredes como suelo y techo se han considerado con una constante dieléctrica relativa de $\underline{\varepsilon}_{r}=5-0.4 j$. Se ha estudiado la recepción en una matriz de receptores equiespaciados cada $10 \mathrm{~cm}$, que se extiende paralela al suelo por toda la habitación.

Como el scattering afecta solamente a las ondas reflejadas, se ha permitido un número alto de reflexiones (hasta 5) para así observar cómo afecta a la señal. Así, se han realizado simulaciones tanto sin considerar el efecto del scattering, como introduciéndolo con distintos parámetros de rugosidad de las superficies. Concretamente, se ha variado su valor desde $\sigma_{h}=0 \mathrm{~mm}$, para ver si existe error en la aproximación, hasta $10 \mathrm{~mm}$, pasando por $0.01 \mathrm{~mm}, 0.1 \mathrm{~mm}$ y $1 \mathrm{~mm}$, para comprobar la influencia de los distintos niveles de rugosidad. Se utilizó Lanzado de Rayos con dos resoluciones angulares, $1^{\circ}$ y $2^{\circ}$. Además, se comprobó la diferencia en tiempo de ejecución en cada caso.

En resumen, los parámetros elegidos para las simulaciones fueron los mostrados en la tabla 7.12.

\begin{tabular}{|l|c|}
\hline Frecuencia de trabajo (MHz) & 900 \\
\hline Antena transmisora & Dipolo elemental vertical \\
\hline Resolución en el lanzado & $1^{o}$ y $2^{o}$ \\
\hline Número de reflexiones & $1-5$ \\
\hline Paredes & $\underline{\varepsilon}_{r}=5-0.4 j$ \\
& $\sigma_{h}=0,0.01,0.1,1,10 \mathrm{~mm}$ \\
\hline
\end{tabular}

Tabla 7.12: Parámetros de las simulaciones para evaluar las pérdidas por scattering

En primer lugar, para una reflexión y una resolución de $2^{\circ}$, se representa la potencia obtenida sin considerar el efecto del scattering, y considerándolo, pero con $\sigma_{h}=0 \mathrm{~mm}$, para así comparar la exactitud de las aproximaciones (figura 7.38). Los resultados son idénticos, resultando nulo el error.

A continuación, se representa la diferencia de nivel de potencia entre la versión sin scattering y la versión con scattering con $\sigma_{h}=10 \mathrm{~mm}, 1 \mathrm{~mm}, 0.1 \mathrm{~mm}$, y $0.01 \mathrm{~mm}$ (figura 7.39$)$. 

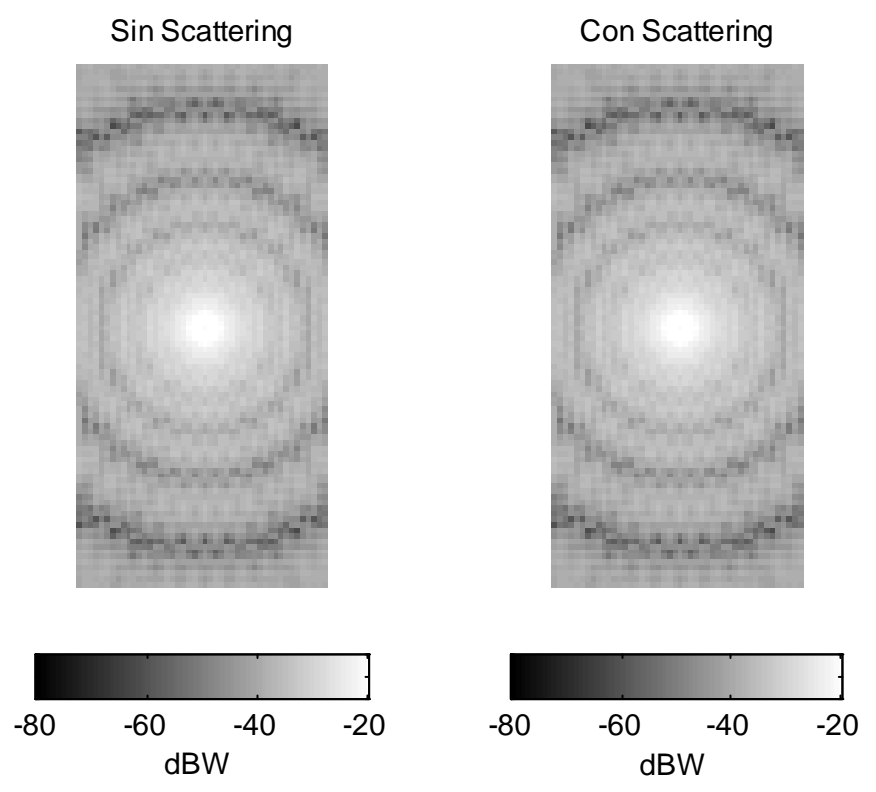

Figura 7.38: Resultados sin considerar el scattering y considerándolo con $\sigma_{h}=0 \mathrm{~mm}$

Como puede apreciarse, la diferencia es muy pequeña en aquellos casos en que $\lambda \gg \sigma_{h}$. Como máximo, difieren en décimas de dB. Sin embargo, en el caso de $\sigma_{h}=10 \mathrm{~mm}$ sí se aprecia una mayor influencia, sobre todo en puntos aislados lejanos al transmisor y cercanos a una de las paredes, donde la diferencia en potencia es apreciable, aunque el error medio sigue siendo insignificante. Por tanto, efectivamente, tal y como se adelantó en el capítulo 6, el efecto del scattering en las paredes es inapreciable en el resultado final cuando la longitud de onda es mayor que la rugosidad.

Se observa también que la diferencia aumenta ligeramente lejos del transmisor, apareciendo pequeñas islas situadas en coronas circulares alrededor del transmisor, en las que el error crece apreciablemente. Esto es debido a que se ha utilizado una resolución de lanzado baja $\left(2^{\circ}\right)$, con un umbral de atenuación de $-100 \mathrm{~dB}$, considerando el scattering en todas las superficies, incluidos suelo y techo.

Los resultados obtenidos aumentando el número de reflexiones y la resolución del lanzado están reflejados en la tabla 7.13. Solamente se muestran los casos extremos, es decir, para 1 y 5 reflexiones. Se aprecia que, al aumentar el número de reflexiones, el error máximo y medio aumentan, mientras que si se aumenta la resolución, disminuyen. En cualquier caso, la desviación típica se mantiene en los mismos órdenes de magnitud tanto si se varía la resolución como el número máximo de reflexiones.

Si se aumenta la frecuencia hasta $1.9 \mathrm{GHz}$, los valores de $\sigma_{h}$ considerados comienzan a ser comparables a $\lambda$, apreciando una mayor influencia del scattering, pero siendo despreciable todavía. Los resultados para 5 reflexiones y $1^{\circ}$ de resolución se muestran en la tabla 7.14.

Por último, como era de esperar, a una frecuencia de $4 \mathrm{GHz}$, se aprecia una mayor influencia del scattering, tal y como se aprecia en la tabla 7.15. 

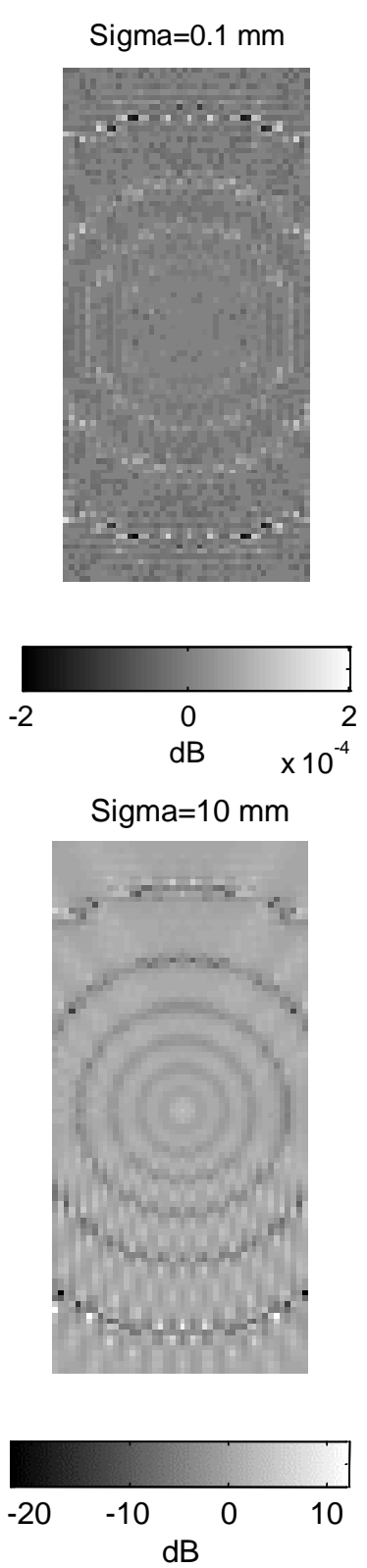

Sigma $=0.01 \mathrm{~mm}$
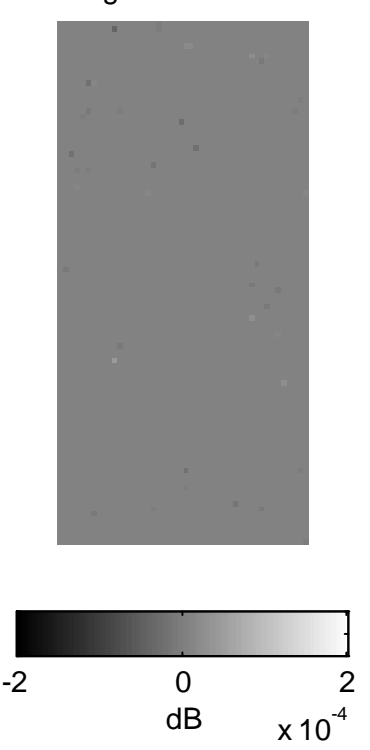

Sigma $=1 \mathrm{~mm}$
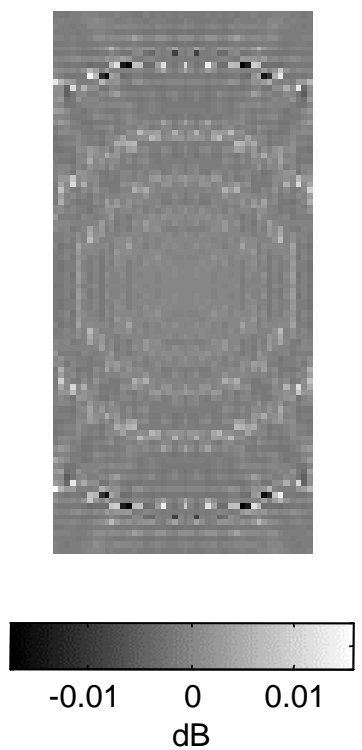

Figura 7.39: Diferencia en la potencia recibida al considerar el scattering con distintos niveles de rugosidad 


\begin{tabular}{|c|c|c|c|c|c|}
\hline $\begin{array}{l}\text { Número de } \\
\text { reflexiones }\end{array}$ & Resolución & $\sigma_{h}(\mathrm{~mm})$ & $\begin{array}{c}\text { Error } \\
\text { máximo }(\mathrm{dB})\end{array}$ & $\begin{array}{c}\text { Error } \\
\text { medio }(\mathrm{dB})\end{array}$ & $\begin{array}{l}\text { Desviación } \\
\text { típica }(\mathrm{dB})\end{array}$ \\
\hline 1 & $1^{o}$ & $\begin{array}{c}0 \\
0.01 \\
0.1 \\
1 \\
10\end{array}$ & $\begin{array}{c}0 \\
-41 \cdot 10^{-6} \\
-21 \cdot 10^{-5} \\
-19 \cdot 10^{-3} \\
-23.4\end{array}$ & $\begin{array}{c}0 \\
-13 \cdot 10^{-9} \\
-31 \cdot 10^{-7} \\
-30 \cdot 10^{-5} \\
-36 \cdot 10^{-4}\end{array}$ & $\begin{array}{c}0 \\
19 \cdot 10^{-7} \\
21 \cdot 10^{-6} \\
19 \cdot 10^{-4} \\
1.9\end{array}$ \\
\hline 1 & $2^{o}$ & $\begin{array}{c}0 \\
0.01 \\
0.1 \\
1 \\
10\end{array}$ & $\begin{array}{c}0 \\
-43 \cdot 10^{-6} \\
-19 \cdot 10^{-5} \\
-17 \cdot 10^{-3} \\
-21.9\end{array}$ & $\begin{array}{c}0 \\
-32 \cdot 10^{-9} \\
-28 \cdot 10^{-7} \\
-29 \cdot 10^{-5} \\
-26 \cdot 10^{-4}\end{array}$ & $\begin{array}{c}0 \\
15 \cdot 10^{-7} \\
21 \cdot 10^{-6} \\
19 \cdot 10^{-4} \\
1.9\end{array}$ \\
\hline 5 & $1^{o}$ & $\begin{array}{c}0 \\
0.01 \\
0.1 \\
1 \\
10\end{array}$ & $\begin{array}{c}0 \\
-42 \cdot 10^{-6} \\
-64 \cdot 10^{-6} \\
-62 \cdot 10^{-3} \\
-37.0\end{array}$ & $\begin{array}{c}0 \\
-46 \cdot 10^{-9} \\
-46 \cdot 10^{-7} \\
-47 \cdot 10^{-5} \\
16 \cdot 10^{-2}\end{array}$ & $\begin{array}{c}0 \\
20 \cdot 10^{-7} \\
35 \cdot 10^{-7} \\
34 \cdot 10^{-4} \\
2.19\end{array}$ \\
\hline 5 & $2^{o}$ & $\begin{array}{c}0 \\
0.01 \\
0.1 \\
1 \\
10\end{array}$ & $\begin{array}{c}0 \\
-43 \cdot 10^{-6} \\
-40 \cdot 10^{-5} \\
-39 \cdot 10^{-3} \\
-36.64\end{array}$ & $\begin{array}{c}0 \\
-61 \cdot 10^{-9} \\
-50 \cdot 10^{-7} \\
-51 \cdot 10^{-5} \\
14 \cdot 10^{-2}\end{array}$ & $\begin{array}{c}0 \\
18 \cdot 10^{-7} \\
29 \cdot 10^{-6} \\
29 \cdot 10^{-4} \\
2.18\end{array}$ \\
\hline
\end{tabular}

Tabla 7.13: Influencia del scattering en la potencia media recibida a $900 \mathrm{MHz}$

\begin{tabular}{|c|c|c|c|c|c|}
\hline $\begin{array}{c}\text { Número de } \\
\text { reflexiones }\end{array}$ & Resolución & $\sigma_{h}(\mathrm{~mm})$ & $\begin{array}{c}\text { Error } \\
\text { máximo }(\mathrm{dB})\end{array}$ & $\begin{array}{c}\text { Error } \\
\text { medio }(\mathrm{dB})\end{array}$ & $\begin{array}{c}\text { Desviación } \\
\text { típica }(\mathrm{dB})\end{array}$ \\
\hline & & 0 & 0 & 0 & 0 \\
5 & $1^{o}$ & 0.01 & $70 \cdot 10^{-6}$ & $-38 \cdot 10^{-8}$ & $42 \cdot 10^{-7}$ \\
& & 0.1 & $75 \cdot 10^{-4}$ & $-32 \cdot 10^{-6}$ & $26 \cdot 10^{-5}$ \\
& & 1 & 0.72 & $-37 \cdot 10^{-4}$ & 0.03 \\
& & 10 & -39.95 & -0.42 & 7.21 \\
\hline
\end{tabular}

Tabla 7.14: Influencia del scattering en la potencia media recibida a $1.9 \mathrm{GHz}$

\begin{tabular}{|c|c|c|c|c|c|}
\hline $\begin{array}{c}\text { Número de } \\
\text { reflexiones }\end{array}$ & Resolución & $\sigma_{h}(\mathrm{~mm})$ & $\begin{array}{c}\text { Error } \\
\text { máximo }(\mathrm{dB})\end{array}$ & $\begin{array}{c}\text { Error } \\
\text { medio }(\mathrm{dB})\end{array}$ & $\begin{array}{c}\text { Desviación } \\
\text { típica }(\mathrm{dB})\end{array}$ \\
\hline & & 0 & 0 & 0 & 0 \\
5 & \multirow{2}{*}{$1^{o}$} & 0.01 & 1.9 & $52 \cdot 10^{-4}$ & 0.03 \\
& & 0.1 & 1.9 & $32 \cdot 10^{-5}$ & 0.03 \\
& & 1 & 5.24 & $-18 \cdot 10^{-3}$ & 0.14 \\
& & 10 & 22.08 & -0.54 & 2.5 \\
\hline
\end{tabular}

Tabla 7.15: Influencia del scattering en la potencia media recibida a $4 \mathrm{GHz}$ 
En cuanto al tiempo de ejecución, a pesar de aumentar ligeramente la complejidad del código para calcular los coeficientes de reflexión, se obtienen tiempos similares, incluso se reduce en algún caso, debido a que, en general, los coeficientes de reflexión con scattering aumentan la pérdida de potencia de los rayos, por lo que el seguimiento de algunos rayos finaliza antes. En la tabla 7.16 se compara el tiempo que tarda la versión sin scattering, con la que lo lleva implementado, para el caso de $\sigma_{h}=1 \mathrm{~mm}$ y una resolución de $1^{\circ}$.

\begin{tabular}{|c|c|c|c|}
\hline $\begin{array}{c}\text { Número de } \\
\text { reflexiones }\end{array}$ & $\begin{array}{c}\text { Tiempo con } \\
\text { scattering }\left(T_{s}\right)\end{array}$ & $\begin{array}{c}\text { Tiempo sin } \\
\text { scattering }\left(T_{0}\right)\end{array}$ & $\begin{array}{c}\text { Cociente } \\
T_{s} / T_{0}\end{array}$ \\
\hline 1 & $0 \mathrm{~h} 45 \mathrm{~m} 53 \mathrm{~s}$ & $0 \mathrm{~h} 45 \mathrm{~m} 37 \mathrm{~s}$ & 1.00 \\
\hline 2 & $1 \mathrm{~h} 9 \mathrm{~m} 1 \mathrm{~s}$ & $1 \mathrm{~h} 10 \mathrm{~m} 58 \mathrm{~s}$ & 0.97 \\
\hline 3 & $1 \mathrm{~h} 36 \mathrm{~m} 21 \mathrm{~s}$ & $1 \mathrm{~h} 35 \mathrm{~m} 10 \mathrm{~s}$ & 1.01 \\
\hline 4 & $2 \mathrm{~h} 10 \mathrm{~m} 13 \mathrm{~s}$ & $2 \mathrm{~h} 10 \mathrm{~m} 11 \mathrm{~s}$ & 1.00 \\
\hline 5 & $2 \mathrm{~h} 16 \mathrm{~m} 35 \mathrm{~s}$ & $2 \mathrm{~h} 14 \mathrm{~m} 25 \mathrm{~s}$ & 1.01 \\
\hline
\end{tabular}

Tabla 7.16: Influencia del scatering en los tiempos de ejecución

Queda claro que la influencia del scattering en entornos indoor es prácticamente despreciable, excepto en el caso de utilizar una frecuencia elevada, según la cual la rugosidad de las paredes sea comparable con la longitud de onda. Ello se debe a que la definición del entorno indoor parece ser más que suficiente para tener en cuenta las irregularidades de las superficies que lo componen

\subsubsection{Difracción}

Para comprobar la influencia de la difracción tal y como se ha implementado en el modelo de Lanzado de Tubos, se han realizado varias simulaciones en entornos relativamente sencillos. En primer lugar, se ha utilizado una habitación cuadrada de $5 \times 5$ metros con un pilar metálico en el centro de $1.5 \times 1.5$ metros (figura 7.40). De esta forma, se podrá observar el efecto de la difracción en zonas próximas a las esquinas difractantes. Las condiciones de simulación fueron las que se muestran en la tabla 7.17.

\begin{tabular}{|l|c|}
\hline Frecuencia de trabajo $(\mathrm{MHz})$ & 900 \\
\hline Antena transmisora & Dipolo elemental vertical \\
\hline Resolución en el lanzado & $2^{o}$ \\
\hline Número de reflexiones/transmisiones & $0-5,10,15$ y 20 \\
\hline Paredes exteriores, suelo y techo & $\underline{\varepsilon}_{r}=5-0.4 j$ \\
Pared interiores & $\underline{\varepsilon}_{r}=5-0.4 j$ \\
Paredes del pilar interior & $\underline{\varepsilon}_{r}=1-100000 j$ \\
\hline
\end{tabular}

Tabla 7.17: Parámetros de las simulaciones para comprobar los efectos de la difracción

En primer lugar, no se permitió ninguna reflexión, de manera que sólo debían existir contribuciones por tubos directos o difractados. Los receptores se situaron en un plano paralelo situado un metro por encima del transmisor, para así obtener un ángulo $\beta$ no nulo. En la figura 7.41 se muestran los resultados obtenidos al considerar la difracción, comparados con la misma simulación sin difracción. 


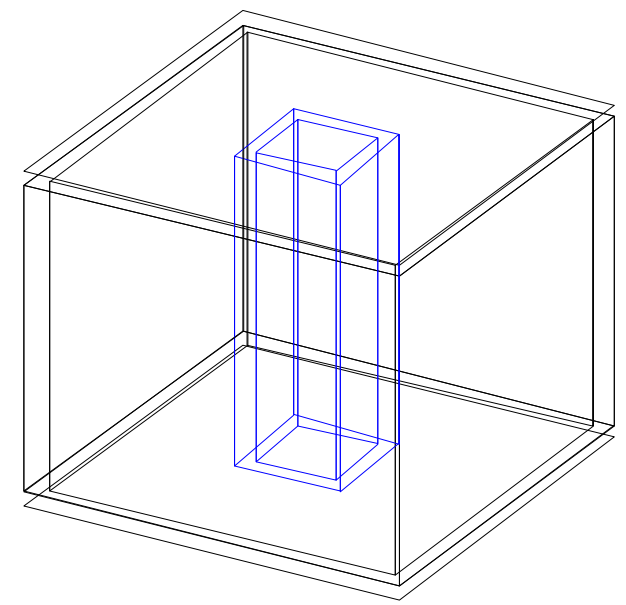

Figura 7.40: Entorno de simulación simple para difracción
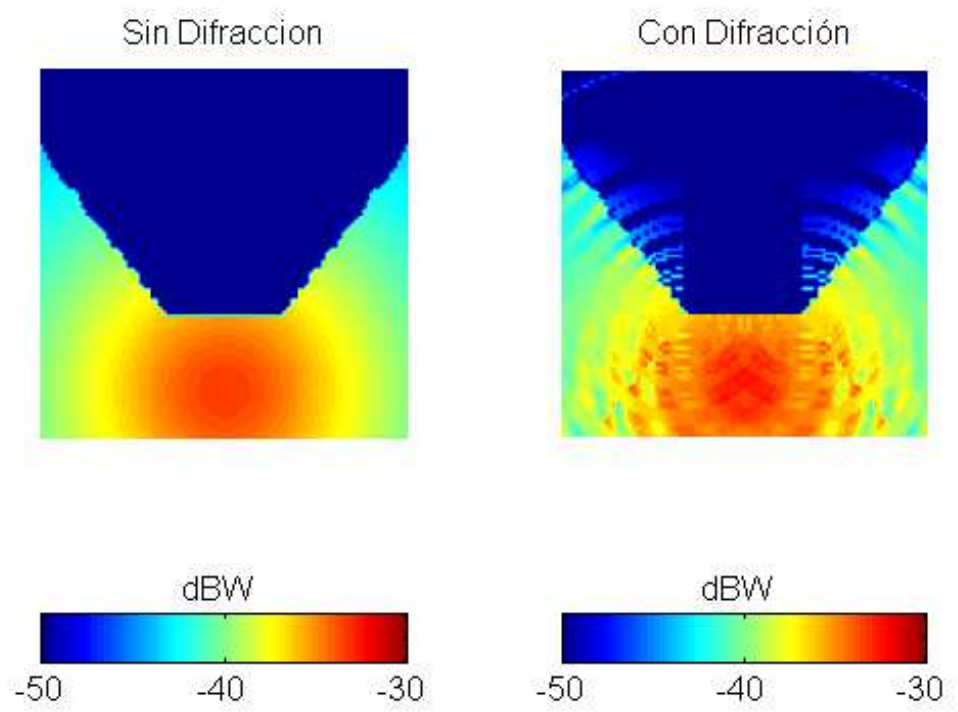

Figura 7.41: Nivel de potencia sin difracción y con difracción (sin reflexiones) 
A continuación, se repitió la simulación permitiendo una reflexión, de manera que pudieran existir contribuciones adicionales por rayos reflejados (figura 7.42).

En ambos casos se aprecia claramente, el efecto de la difracción sobre el nivel de potencia, elevándolo en algunos receptores y disminuyéndolo en otros. Cuando no se permiten reflexiones, algunos receptores situados en las regiones de sombra, que antes no podían recibir contribuciones por Óptica Geométrica, ahora sí lo hacen por difracción. Sin embargo, la mayor parte de los receptores no han visto alterado el nivel de señal recibida debido a que se encuentra fuera de las múltiples superficies cónicas de difracción, al formar un ángulo con el punto de difracción distinto de $\beta$.

Al permitir una reflexión, la contribución debida a los rayos directos y reflejados es mucho mayor que la contribución por difracción en las zonas donde existe visión directa (LOS) entre emisor y receptores. Sin embargo, esta contribución es algo mayor cuando sólo se tienen contribuciones por rayos reflejados y difracciones. Por último, se aprecia que la contribución debida a la difracción de un tubo que haya sufrido una reflexión previa es casi insignificante. Efectivamente, analizando con detalle la figura 7.43, se aprecia que detrás del pilar metálico la contribución predominante es debida a rayos reflejados.

$\mathrm{Al}$ aumentar el número de reflexiones permitidas, la contribución por difracción disminuye, convirtiéndose en un fenómeno local al punto difractante. Los tiempos de ejecución aumentan, aunque no desmesuradamente, y depende directamente del número de receptores a considerar, debido a la estructura del algoritmo implementado para calcular la contribución de la difracción.

Para poder apreciar mejor la contribución de la difracción según exista visión directa, contribución de rayos reflejados, o sólo difracción, se ha utilizado el entorno de la figura 7.44, donde se distingue la zona I, que contiene receptores con visión directa al emisor (LOS), y la zona II que contiene receptores sin visión directa (NLOS). Las paredes fueron consideradas metálicas, para así magnificar los efectos de la difracción.

En primer lugar, se realizó una simulación en la que no se permitió ninguna reflexión, de manera que las posibles contribuciones fueran dadas por los rayos directos y difractados en la zona II, y por difracción únicamente en la zona I. A continuación, se permitió la existencia de una sola reflexión, para así poder comparar la influencia de la difracción sobre el nivel de la señal en ambas zonas (figura 7.45).

En el primer caso (figura 7.45, izquierda), si no se considera la difracción, la zona I, en donde sólo pueden existir contribuciones por rayos directos, queda perfectamente definida entre los 3.8 y 5.5 metros. En esta zona, el nivel de potencia se sitúa en torno a $-45.6 \mathrm{dBW}$ de forma continua. Si se añade la contribución por difracción, aparecen picos discontinuos de potencia en la zona II, de nivel más reducido. En la zona I, el nivel de potencia se mantiene sobre el mismo nivel medio que en el caso anterior, con picos de potencia máximos de $\pm 3 \mathrm{~dB}$.

Al permitir una reflexión (figura 7.45, derecha), se observa claramente que en la zona donde existen todas las contribuciones (rayos directos, reflejados y difractados), el nivel de la señal al considerar la difracción sigue casi perfectamente al nivel de señal cuando no es considerada, con pequeñas oscilaciones máximas de apenas $\pm 1 \mathrm{~dB}$.

Por último, se realizó una simulación en la que se permitían hasta 10 reflexiones (fi- 

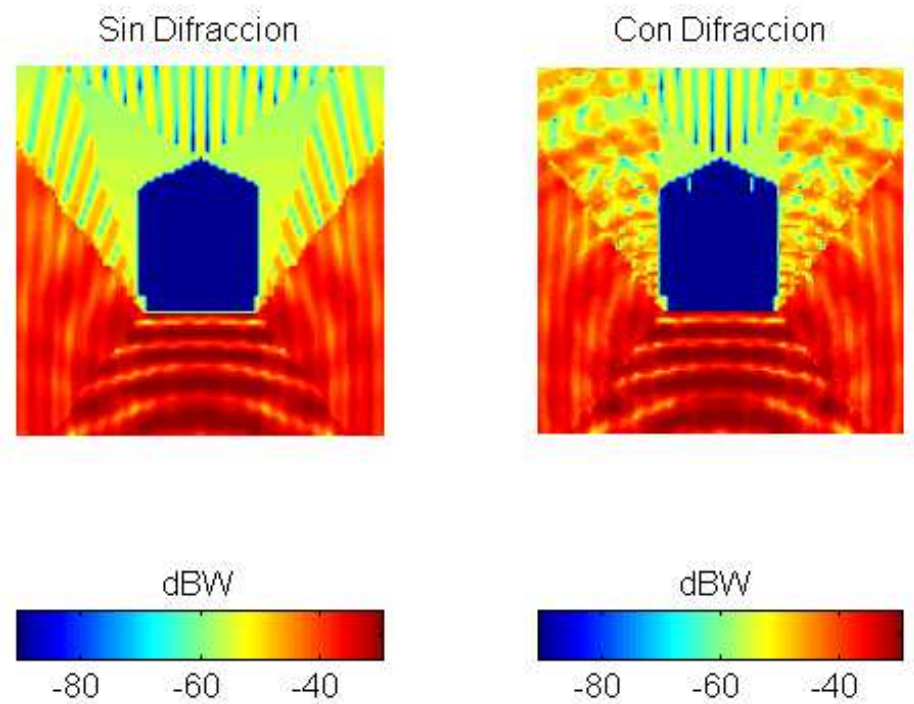

Figura 7.42: Nivel de potencia sin difracción y con difracción (1 reflexión)

Sin Reflexiones
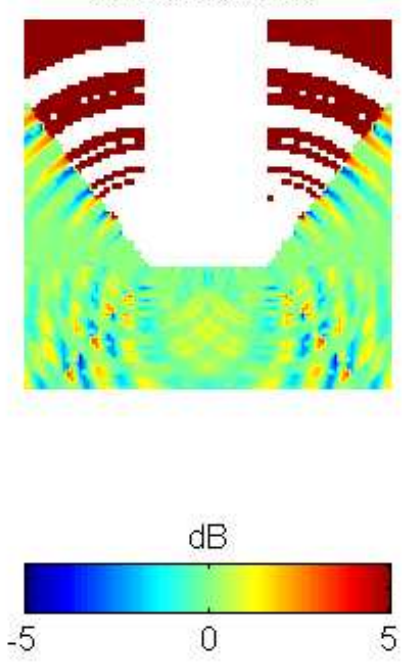

1 Reflexion
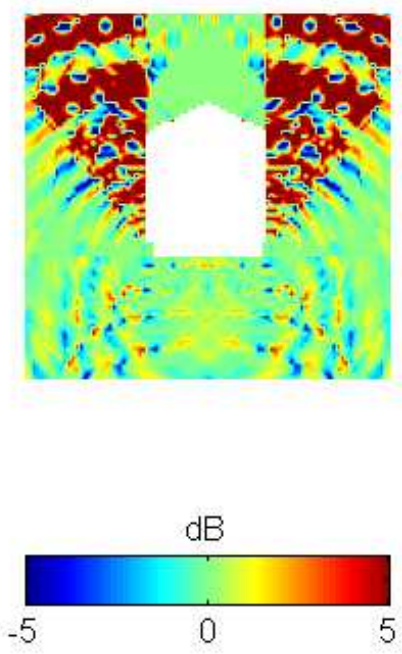

Figura 7.43: Diferencia en la potencia sin reflexiones (izquierda) o con una reflexión (derecha), al considerar la difracción 


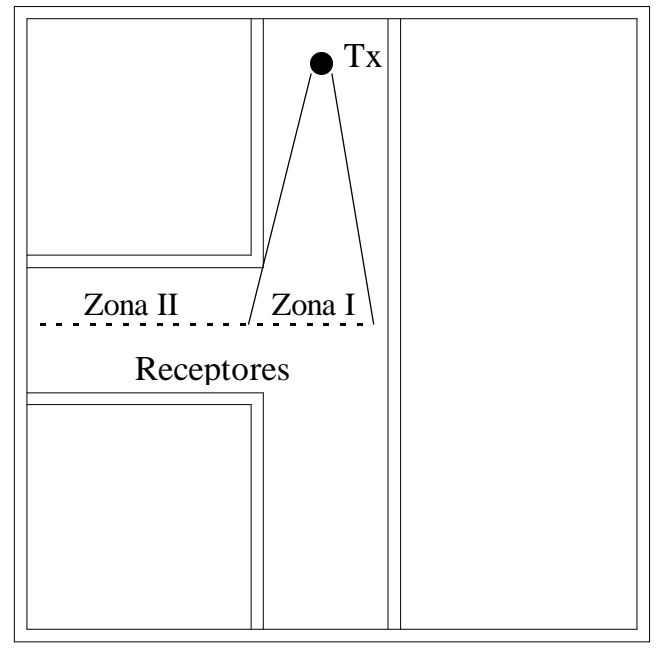

Figura 7.44: Entorno de simulación más complejo para difracción
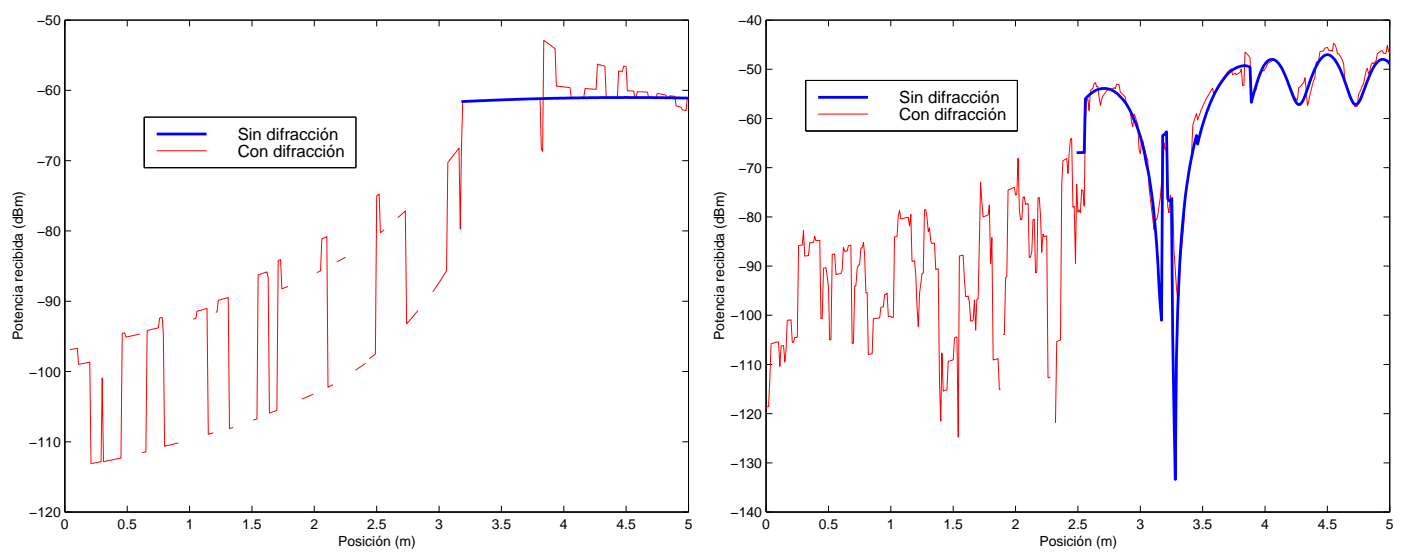

Figura 7.45: Nivel de señal en entorno más complejo. Sin reflexiones (izquierda), y con una reflexión (derecha) 
gura 7.46). Debido al algoritmo de difracción implementado, a medida que aumentan las reflexiones, crece la posibilidad de difractarse un tubo en una esquina, por lo que los resultados se aproximarán más a la realidad. Se puede observar la insignificante influencia de la difracción en el nivel de señal recibido, provocando tan sólo ligeras oscilaciones alrededor del nivel medio de la señal.

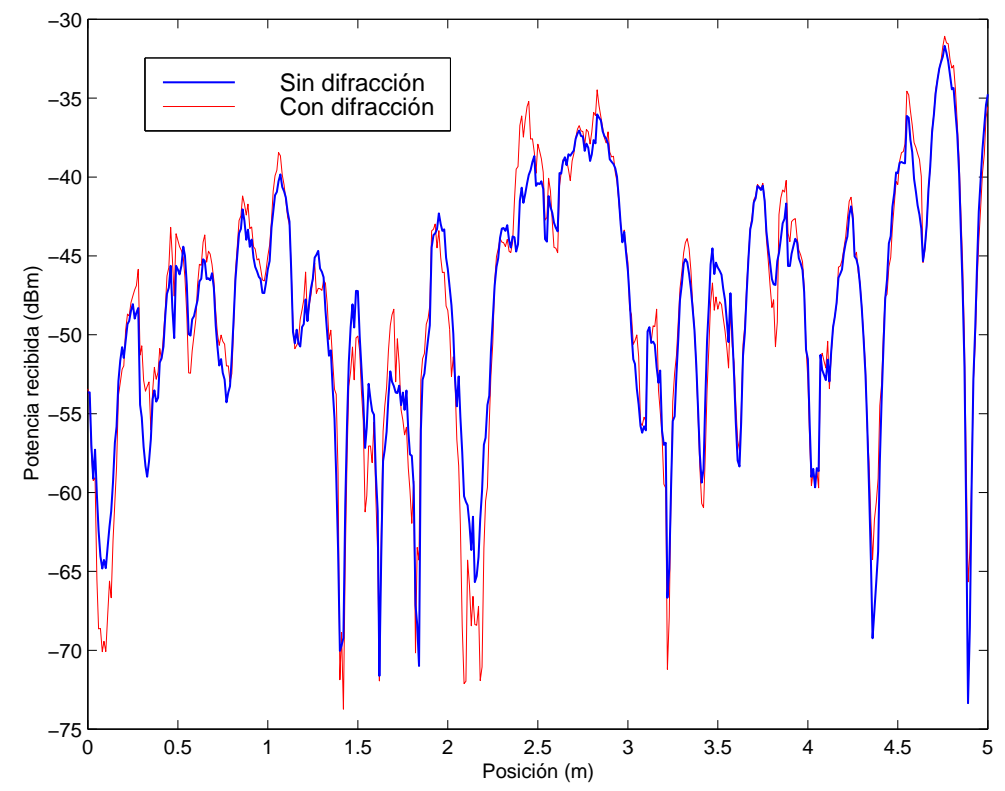

Figura 7.46: Nivel de señal en entorno más complejo al permitir hasta 10 reflexiones

A continuación, se sutituyó el material de las paredes difractantes por un material menos reflectante, más normal en las paredes de un edificio común. El efecto resultante se presenta en la figura 7.47.

En este caso, el nivel de señal considerando la difracción vuelve a seguir casi perfectamente al nivel de señal respecto a cuando no es considerada, presentando desviaciones significativas únicamente cuando los receptores se encuentran muy próximos a las aristas difractantes. En la realidad, en un entorno indoor complejo como pueda ser un edificio de oficinas, un centro comercial, etc., existen pocas superficies difractantes, y están compuestas mayoritariamente de dieléctricos poco reflectantes, por lo que el coeficiente de difracción será menor. Por tanto, se puede asegurar que la contribución de la difracción va a ser, en general, mínima.

Sin embargo, los muebles metálicos típicos en edificios son una fuente importante de difracción y reflexión. Para analizar su influencia, se ha considerado, en primer lugar, una habitación vacía a la que, a continuación, se le han ido introduciendo elementos metálicos simulando ser mesas, armarios, sillas ... (figura 7.48). Se distinguen dos zonas, la zona I o zona de visión directa entre el emisor y los receptores, y la zona II, sin visión directa. Las condiciones de simulación fueron las que se dan el la tabla 7.18.

En primer lugar, se obtuvo la distribución de potencia para la habitación vacía, introduciendo a continuación, un armario metálico de 2 metros de altura situado en el centro de la habitación (figura 7.49). En ninguno de los casos se consideró difracción. 


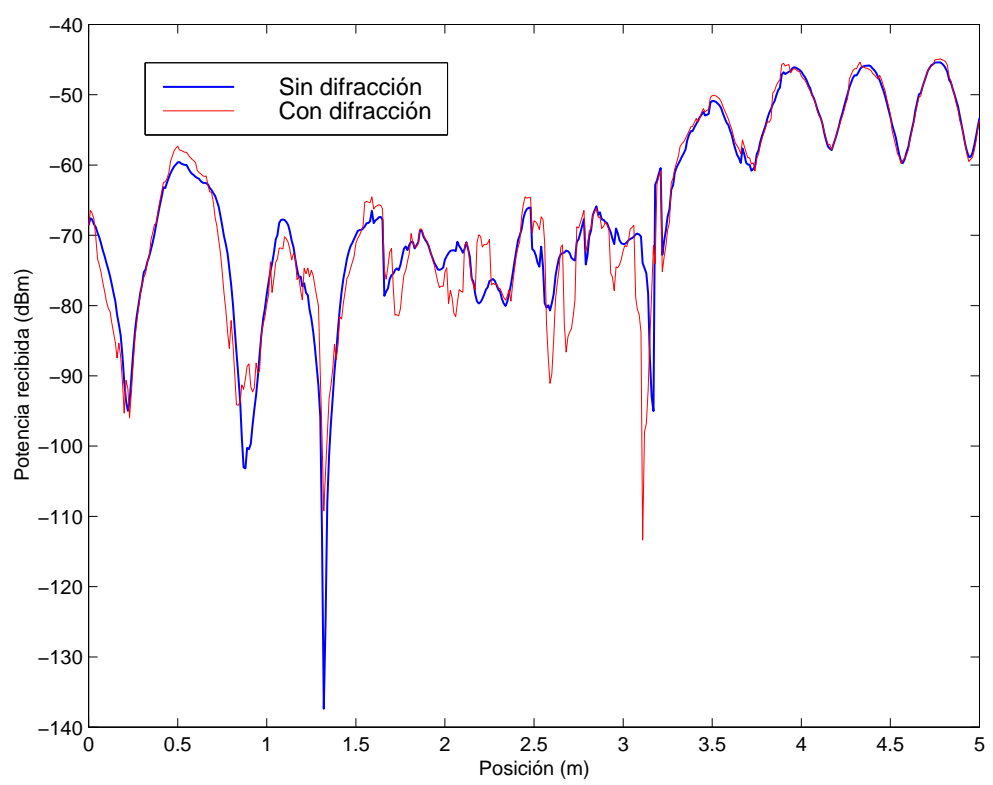

Figura 7.47: Nivel de señal en entorno más complejo con hasta 10 reflexiones. Paredes menos reflectantes
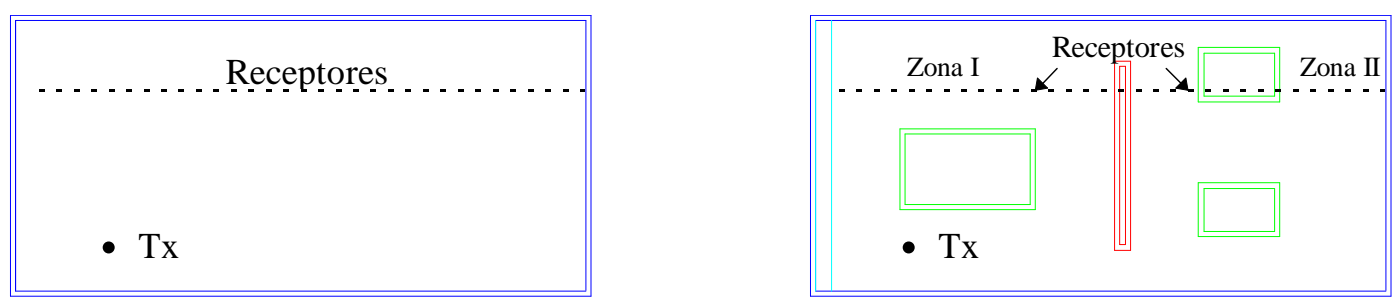

Figura 7.48: Habitación vacía y posteriormente amueblada

\begin{tabular}{|l|c|}
\hline Frecuencia de trabajo $(\mathrm{MHz})$ & 1000 \\
\hline Antena transmisora & Dipolo elemental vertical \\
\hline Resolución en el lanzado & $1^{o}$ \\
\hline Número de reflexiones/transmisiones & 200 \\
\hline Paredes exteriores & $\underline{\varepsilon}_{r}=4-0.36 j$ \\
Suelo y techo & $\underline{\varepsilon}_{r}=6-0.18 j$ \\
Muebles metálicos & $\underline{\varepsilon}_{r}=1-100000 j$ \\
\hline
\end{tabular}

Tabla 7.18: Parámetros de simulación en la habitación amueblada 


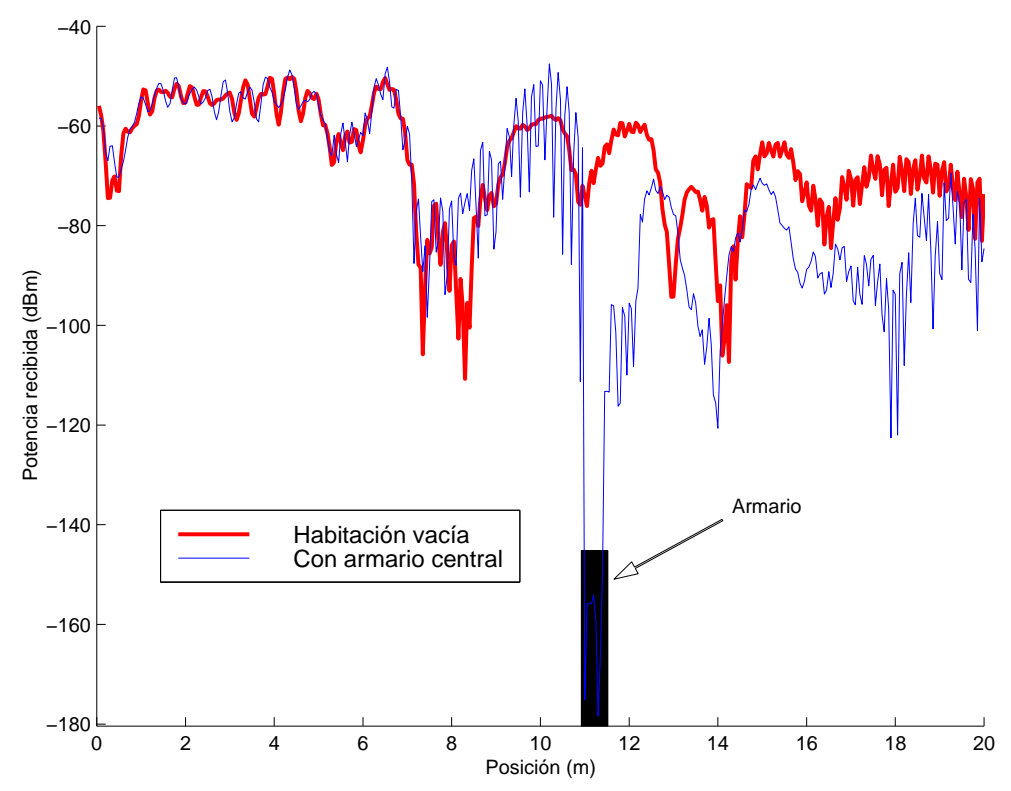

Figura 7.49: Nivel de potencia en la habitación vacía y con armario metálico central

Al introducir el armario metálico en la habitación vacía, se observa claramente que en la zona I (LOS) lejos del armario, el nivel de señal es prácticamente el mismo. Sin embargo, cuanto más cerca se está del armario, su influencia es más importante, haciendo variar la señal rápidamente alrededor de su media. Tras el armario, la única contribución posible vendrá dada por los rayos reflejados, especialmente en el techo. En este caso, la contribución del armario es muy significativa sobre el nivel de señal, hecho ya conocido de antemano al ser un elemento de grandes dimensiones respecto a la longitud de onda de la frecuencia de trabajo, además de altamente reflectante.

Posteriormente se hizo la misma simulación, pero considerando el efecto de la difracción en el armario central (figura 7.50).

La difracción no introduce una variación significativa de señal en la región sin visión directa (zona II), ya que en esta situación, predomina el efecto de la reflexión de los rayos que pasan por encima del armario y llegan a los receptores. La contribución de estos rayos es mucho mas significativa que la de los rayos difractados en los bordes del armario. Sin embargo, en la zona I, el nivel de señal con difracción fluctúa mucho más rápidamente que la señal obtenida anteriormente. En dicha zona, el armario metálico se comporta como un gran reflector de radiación, pero es un obstáculo para la zona II. Así pues, cuando se introduce el efecto de la difracción, aparecen contribuciones en la zona I comparables a las procedentes directamente del transmisor, provocando que la señal recibida presente mayores oscilaciones alrededor del nivel medio.

Por último, se realizó una nueva simulación añadiendo una mesa situada a la izquierda del armario metálico, dos elementos metálicos a la derecha de 1 metro de altura, y otro posible armario metálico pegado a la pared izquierda de la habitación, también de 1 metro de altura. El nivel de señal obtenido puede verse en la figura 7.51.

$\mathrm{Al}$ introducir los muebles en la habitación vacía el nivel de la señal fluctúa aún más 


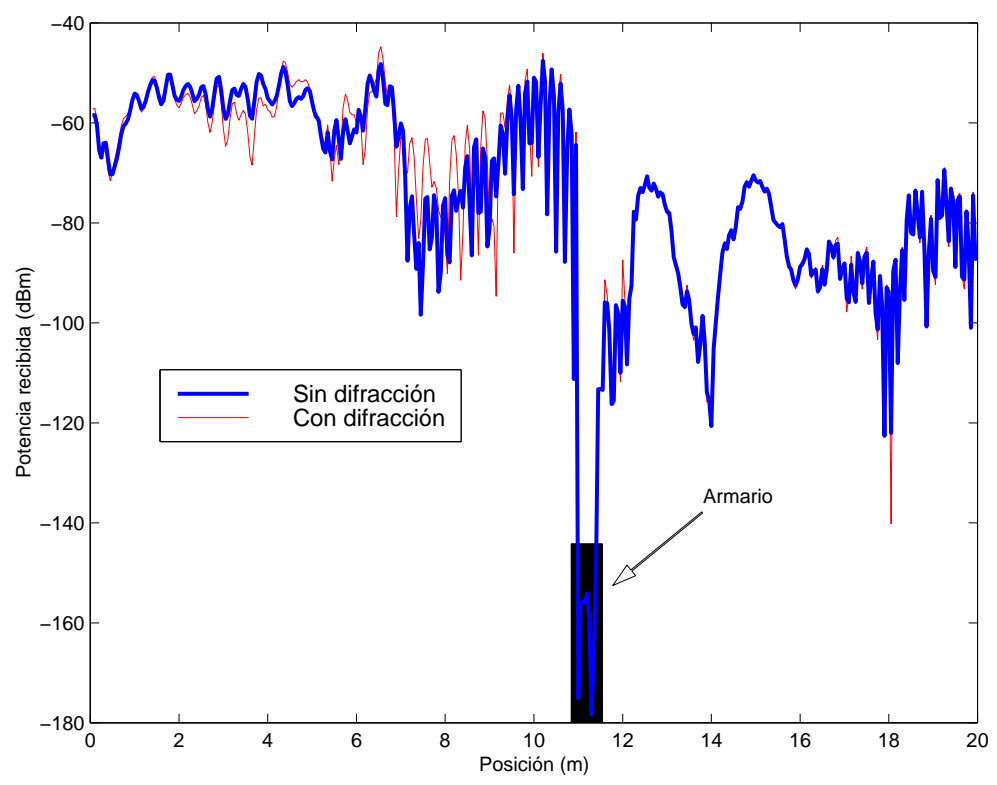

Figura 7.50: Influencia de la difracción en el armario metálico central

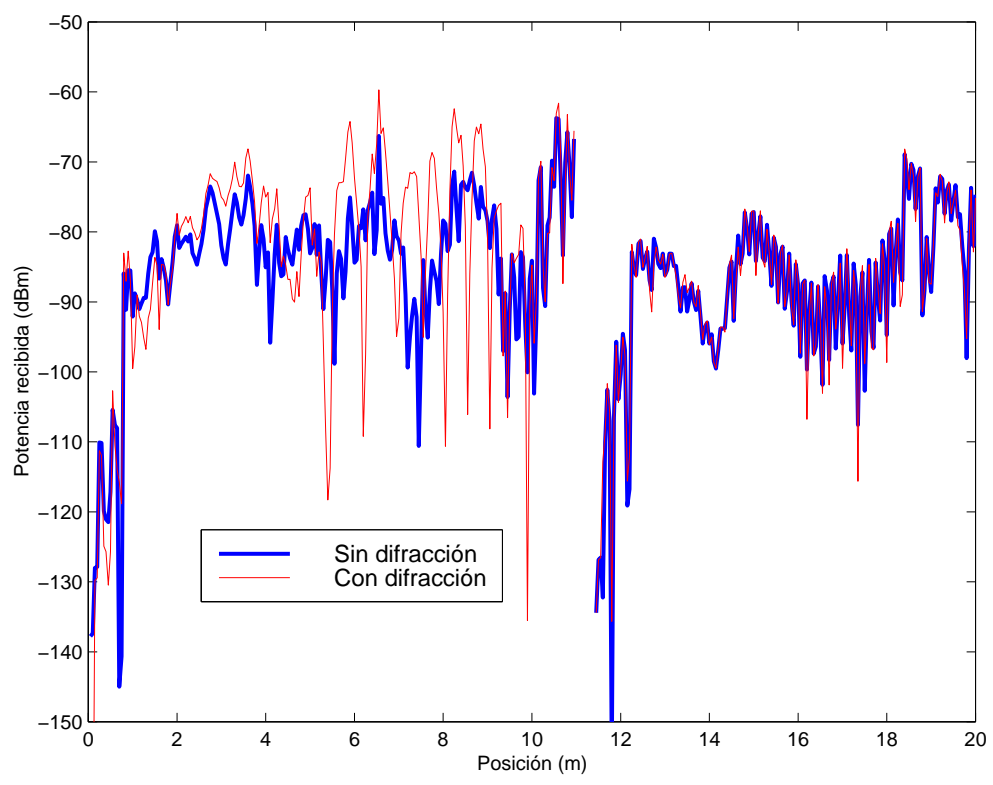

Figura 7.51: Nivel de potencia en la habitación totalmente amueblada 
rápidamente alrededor de su nivel medio, dando como resultado un fading rápido de la señal en la zona I. Esto es debido a la consideración de mayor número de rayos reflejados que llegan al receptor con más retraso temporal que el resto. Lo mismo ocurre cuando se introduce el efecto de la difracción en la misma zona. Aparecen componentes difractadas que provocan un fading rápido alrededor incluso del nivel de la señal obtenida cuando sólo se considera el efecto de las reflexiones, siendo despreciable en la zona sin visibilidad directa.

Los tiempos empleados por las simulaciones al considerar la difracción son ligeramente superiores a los obtenidos cuando no se considera, y dependen únicamente del número de receptores a considerar y del número total de tubos difractados (tabla 7.19). A medida que el entorno de simulación se vuelve más complejo y se incluye la difracción, se obtiene un incremento en torno al $25 \%$ en los tiempos de simulación respecto a no incluir el estudio de la difracción. La diferencia de resultados no justifica el importante aumento del tiempo de simulación.

\begin{tabular}{|l|c|c|}
\hline & Sin Difracción & Con Difracción \\
\hline Sólo armario central & 0h $7 \mathrm{~m} 09 \mathrm{~s}$ & 0h $7 \mathrm{~m} 49 \mathrm{~s}$ \\
\hline Totalmente amueblada & $0 \mathrm{~h} 11 \mathrm{~m} \mathrm{41s}$ & $0 \mathrm{~h} 14 \mathrm{~m} 05 \mathrm{~s}$ \\
\hline
\end{tabular}

Tabla 7.19: Tiempos de simulación en la habitación amueblada

Se ha demostrado, por tanto, que la difracción es un efecto local muy cercano a los posibles puntos de difracción, y su contribución al nivel de señal es muy reducida, apareciendo en forma de un fading rápido de la señal. El fenómeno predominante en estas situaciones es la reflexión y, por lo tanto, el estudio de la difracción queda como un efecto a considerar en las cercanías de los pocos bordes o zonas difractantes que se puedan encontrar en un edificio común.

\subsection{Prestaciones del programa de simulación}

Antes de pasar a comparar los resultados obtenidos mediante simulación, con las medidas realizadas en el edificio de la ETSIT, se procederá a describir una serie de simulaciones que fueron realizadas con el propósito de analizar las prestaciones de las técnicas de modelado implementadas.

Dicho análisis se centrará en tres puntos fundamentales. En primer lugar, se estudiará el grado de precisión obtenido por las simulaciones, en función del grado de resolución con que se realiza el lanzado y el número máximo de transmisiones o reflexiones permitidas para cada rayo o tubo.

Como estos dos parámetros también afectarán al tiempo total necesario para realizar dichas simulaciones, se estudiará esta dependencia, para así saber si vale la pena aumentar dicho tiempo de ejecución.

Por último, se verificará en qué medida es sensible el simulador a errores en los datos de entrada, especialmente las caracterísicas electromagnéticas de los materiales del entorno y la posición relativa de los receptores. 


\subsubsection{Precisión de los resultados y tiempo de ejecución}

Conforme se aumenta el número de rayos o tubos a transmitir (es decir, se disminuye el grado de resolución) y se considera mayor número de posibles transmisiones o recepciones para cada uno de ellos, se obtendrán resultados más fiables, a costa, eso sí, de necesitar mayor tiempo para la ejecución.

Con el fin de evaluar estas dependencias, se realizó en primer lugar una serie de simulaciones en el edificio ficticio complejo de la figura 7.15. Se consideraron los receptores uniformemente distribuidos por toda una planta del edificio, y se situó el tranmisor en el interior de la habitación más grande que hay aproximadamente en su centro. La simulación fue realizada mediante Lanzado de Tubos.

Fueron considerándose paulatinamente mayor número de paralelos con los que se dividía la esfera unidad. Se empezó con una baja resolución (5 paralelos por semiesfera, es decir, $18^{\circ}$ de resolución angular, aproximadamente), llegando a una resolución angular de $2^{\circ}$ (45 paralelos por semiesfera). Esta última simulación fue la que se tomó como referencia para analizar las precisiones obtenidas, al ser, evidentemente, la más fiable. El resto de parámetros de simulación se muestra en la tabla 7.20.

\begin{tabular}{|l|c|}
\hline Frecuencia de trabajo $(\mathrm{MHz})$ & 900 \\
\hline Antena transmisora & Dipolo en $\lambda / 2$ con pol. vertical \\
\hline Resolución en el lanzado & $2^{o}, 2.25^{\circ}, 2.57^{\circ}, 3^{\circ}, 4.5^{\circ}, 9^{\circ}$ y $18^{\circ}$ \\
\hline Número de reflexiones/transmisiones & 10 \\
\hline Paredes exteriores, suelo y techo & $\underline{\varepsilon}_{r}=9-0.9 j$ \\
Paredes interiores & $\underline{\varepsilon}_{r}=4-0.1 j$ \\
Vidrios de las ventanas & $\underline{\varepsilon}_{r}=6-0.05 j$ \\
\hline
\end{tabular}

Tabla 7.20: Parámetros de la simulación para evaluar la velocidad y precisión del simulador en función del grado de resolución del lanzado

En la tabla 7.21 se presentan los resultados obtenidos, mostrándose los errores medio, máximo y desviación estándar de cada una de las simulaciones al compararlas con la de mayor grado de resolución.

\begin{tabular}{|c|c|c|c|c|c|}
\hline $\begin{array}{c}\text { Número de } \\
\text { paralelos }\end{array}$ & $\begin{array}{c}\text { Resolución } \\
\text { angular }\end{array}$ & \multicolumn{3}{|c|}{$\begin{array}{c}\text { Errores } \\
\text { medio }(\mathrm{dB})\end{array}$} & $\begin{array}{c}\text { máximo }(\mathrm{dB}) \\
\text { ejecución }\end{array}$ \\
\hline \hline 45 & $2^{\circ}$ & \multicolumn{4}{|c|}{ referencia } \\
\hline 40 & $2.25^{\circ}$ & 0.0136 & -48.71 & 5.65 & $2 \mathrm{~h} 30 \mathrm{~m} 4 \mathrm{~s}$ \\
\hline 35 & $2.57^{\circ}$ & -0.8013 & -50.03 & 6.74 & $0 \mathrm{~h} 51 \mathrm{~m} 48 \mathrm{~s}$ \\
\hline 30 & $3^{\circ}$ & -0.0666 & 50.22 & 7.02 & $0 \mathrm{~h} 34 \mathrm{~m} 59 \mathrm{~s}$ \\
\hline 20 & $4.5^{\circ}$ & -0.0172 & 55.83 & 7.754 & $0 \mathrm{~h} 15 \mathrm{~m} 8 \mathrm{~s}$ \\
\hline 10 & $9^{\circ}$ & 1.2786 & 64.42 & 11.85 & $0 \mathrm{~h} 2 \mathrm{~m} 11 \mathrm{~s}$ \\
\hline 5 & $18^{\circ}$ & 0.2683 & -61.64 & 11.29 & $0 \mathrm{~h} 0 \mathrm{~m} 23 \mathrm{~s}$ \\
\hline
\end{tabular}

Tabla 7.21: Prestaciones del simulador en función del grado de resolución empleado

Para las estadisticas mostradas, solamente se han considerado los receptores del interior del mismo hall donde estaba situado el transmisor, pues con muy bajas resoluciones, 
aparecían receptores a los que no les llegaba ninguna contribución de campo eléctrico recibido, debido a los problemas que presentan los tubos bajo estas circunstancias.

En la figura 7.52 se representa tanto la desviación típica del error, como el tiempo de ejecución total, en función del número de paralelos considerados. También se representan ambos datos comparados entre sí.
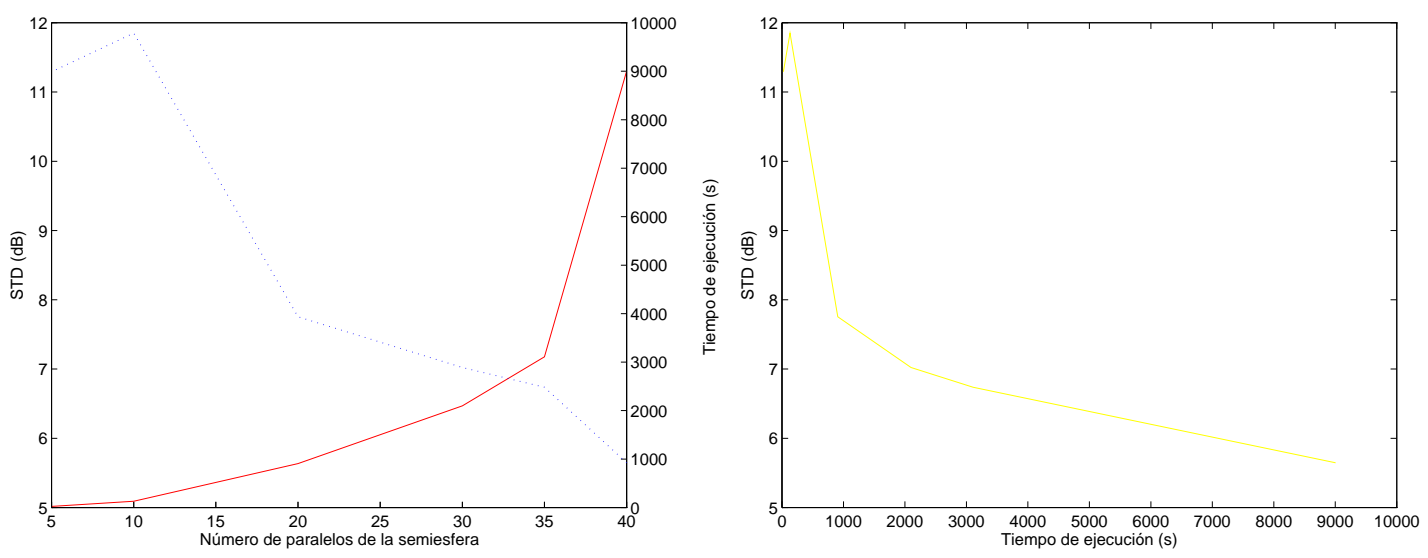

Figura 7.52: Reducción de error (desviación estándar, línea discontinua) y tiempo de ejecución (linea continua), en función del grado de resolución empleado

Se aprecia que, aunque el aumento del tiempo de ejecución crece exponencialmente con el número de tubos lanzados, la precisión deja de mejorar significativamente a partir de un cierto nivel.

En el mismo entorno, se procedió a realizar una serie de simulaciones para comprobar la infuencia del número máximo de transmisiones y reflexiones permitido para cada rayo o tubo. Para ello se fue variando este número desde 4 hasta 15 , tal y como se resume en la tabla 7.22 .

\begin{tabular}{|l|c|}
\hline Frecuencia de trabajo $(\mathrm{MHz})$ & 900 \\
\hline Antena transmisora & Dipolo en $\lambda / 2$ con polarización vertical \\
\hline Resolución en el lanzado & $2^{o}$ \\
\hline Número de reflexiones/transmisiones & $4,6,810$ y 15 \\
\hline Paredes exteriores, suelo y techo & $\underline{\varepsilon}_{r}=9-0.9 j$ \\
Paredes interiores & $\underline{\varepsilon}_{r}=4-0.1 j$ \\
Vidrios de las ventanas & $\underline{\varepsilon}_{r}=6-0.05 j$ \\
\hline
\end{tabular}

Tabla 7.22: Parámetros de la simulación para evaluar la velocidad y precisión del simulador en función del número máximo de transmisiones y reflexiones permitido para cada tubo

Las estadísticas de precisión, referidas a la simulación más fiable (es decir, la que admitía hasta 15 transmisiones y reflexiones por tubo), se presentan en la tabla 7.23.

$\mathrm{Al}$ igual que en el caso anterior, se han eliminado para las estadísticas aquellos puntos que no recibían impactos en alguna de las simulaciones, concretamente las de bajo número de transmisiones y reflexiones.

Representando dichas estadísticas (figura 7.53), se aprecia que, mientras el error de- 


\begin{tabular}{|c|c|c|c|c|}
\hline $\begin{array}{c}\text { Número máximo } \\
\text { de trans./refl. }\end{array}$ & \multicolumn{3}{|c|}{$\begin{array}{c}\text { Errores } \\
\text { medio }(\mathrm{dB})\end{array}$} & $\begin{array}{c}\text { Tiempo de } \\
\text { ejecucióno }(\mathrm{dB})\end{array}$ \\
\hline \hline 15 & \multicolumn{3}{|c|}{ referencia } \\
\hline 10 & -0.0215 & 4.04 & 0.616 & $3 \mathrm{~h} 10 \mathrm{~h} 28 \mathrm{~m} 28 \mathrm{~s}$ \\
\hline 8 & 0.0120 & 17.38 & 1.112 & $2 \mathrm{~h} 12 \mathrm{~m} 59 \mathrm{~s}$ \\
\hline 6 & 0.0365 & 42.33 & 2.425 & $1 \mathrm{~h} 37 \mathrm{~m} 56 \mathrm{~s}$ \\
\hline 4 & 0.4332 & -62.96 & 5.302 & $1 \mathrm{~h} 7 \mathrm{~m} 26 \mathrm{~s}$ \\
\hline
\end{tabular}

Tabla 7.23: Prestaciones del simulador en función del número máximo de transmisiones y refexiones permitido. Resultados en el edificio completo

crece exponencialmente con el número máximo de transmisiones y reflexiones, el tiempo aumenta más o menos de forma lineal. Resulta, por tanto, que el error disminuye aproximadamente de forma exponencial con el tiempo de ejecución empleado.
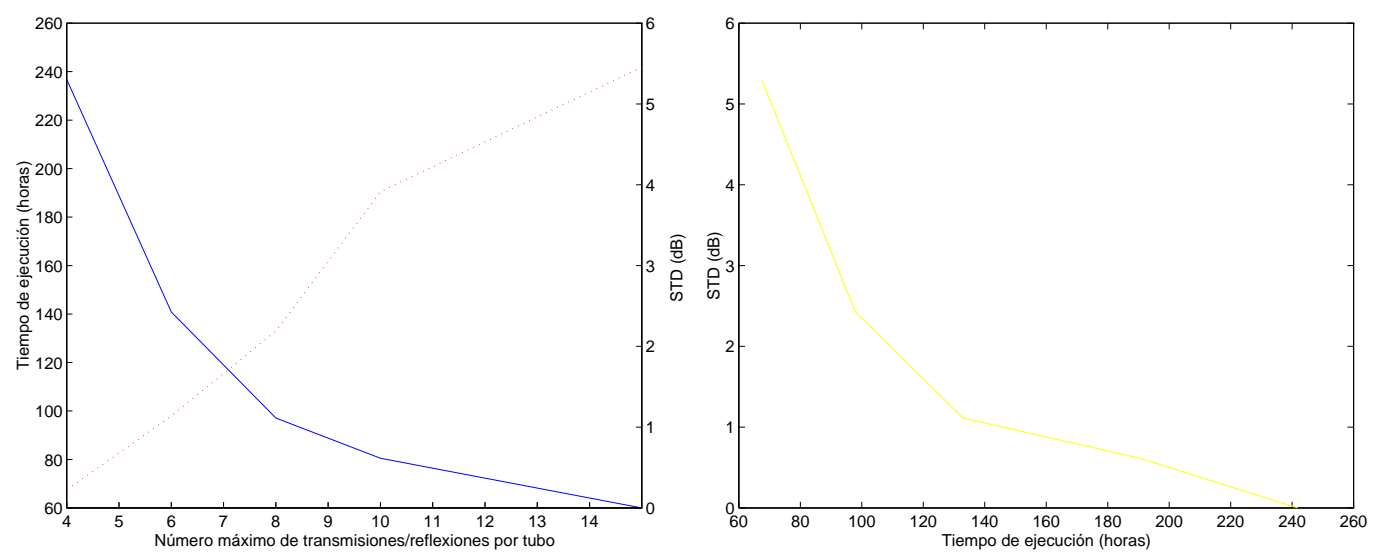

Figura 7.53: Reducción de error (desviación estándar, línea continua) y tiempo de ejecución (linea discontinua), en función del número máximo de transmisiones y reflexiones permitido. Resultados en el edificio completo

También se realizó una serie similar de simulaciones, pero en otro entorno. Esta vez se escogió el pasillo del mismo edificio, evaluando la recepción en una traza a lo largo de él, con el transmisor situado en visibilidad directa. Algo similar a lo que se vio en la simulación de la página 188, cuyos parámetros se mostraron en la tabla 7.8. Sin embargo, se fue variando el número máximo de transmisiones y reflexiones, tomando los valores de 0 (es decir, considerando sólo la componente directa), 1, 2, 4, 6, 8, 10 y 15 . El método utilizado fue Lanzado de Rayos.

Los resultados del grado de aproximación y tiempo de ejecución, en función de dicho parámetro, se presentan en la tabla 7.24.

Lo primero que se puede apreciar es que, en este entorno tipo pasillo con visibilidad directa, el grado de aproximación ya no es tan sensible al número de transmisiones y reflexiones considerado, sobre todo a partir de un cierto valor. Este hecho queda corroborado al representar las potencias recibidas obtenidas mediante simulación en cada caso (figura 7.54). 


\begin{tabular}{|c|c|c|c|c|}
\hline $\begin{array}{l}\text { Número máximo } \\
\text { de trans./refl. }\end{array}$ & medio $(\mathrm{dB})$ & $\begin{array}{c}\text { Errores } \\
\text { máximo }(\mathrm{dB})\end{array}$ & STD (dB) & $\begin{array}{l}\text { Tiempo de } \\
\text { ejecución }\end{array}$ \\
\hline 15 & \multicolumn{3}{|c|}{ "referencia } & "10m 54s \\
\hline 10 & 0.0006 & -0.0055 & 0.0021 & $9 \mathrm{~m} \mathrm{45s}$ \\
\hline 8 & 0.0024 & 0.0160 & 0.0050 & $8 \mathrm{~m} \mathrm{55s}$ \\
\hline 6 & 0.0050 & 0.0637 & 0.0132 & $7 \mathrm{~m} \mathrm{38s}$ \\
\hline 4 & 0.0207 & -0.3226 & 0.0705 & $6 \mathrm{~m} \mathrm{16s}$ \\
\hline 2 & -0.0301 & -1.2856 & 0.5126 & $4 \mathrm{~m} \mathrm{45s}$ \\
\hline 1 & 1.1733 & 3.1659 & 1.0453 & $3 \mathrm{~m} \mathrm{47s}$ \\
\hline 0 & 1.1524 & 5.2221 & 1.8482 & $2 \mathrm{~m} \mathrm{11s}$ \\
\hline
\end{tabular}

Tabla 7.24: Prestaciones del simulador en función del número máximo de transmisiones y refexiones permitido. Resultados en pasillo con visibilidad directa
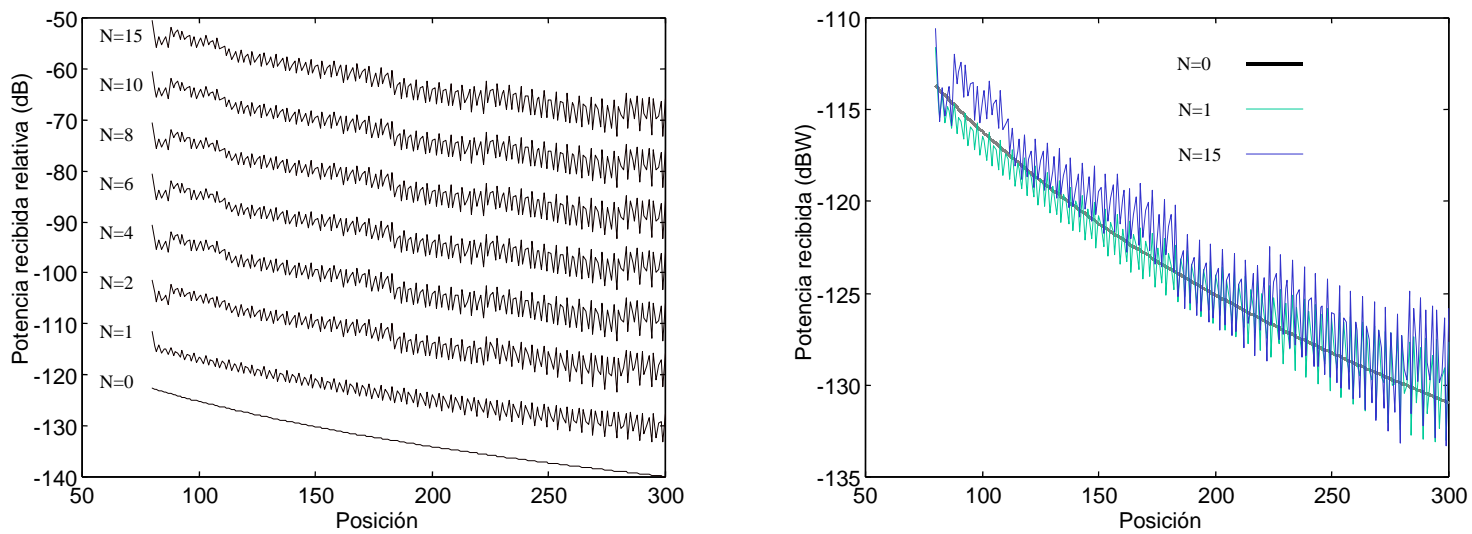

Figura 7.54: Potencias recibidas a lo largo del pasillo, en función del número máximo permitido de transmisiones y reflexiones. En el gráfico de la izquierda, se han separado las trazas cada 10dB, para discernir mejor el grado de aproximación 
Analizando este caso más en detalle, se aprecia que el error disminuye muy rápidamente con el tiempo empleado por la simulación, llegando un momento en el que apenas varía (figura 7.55).
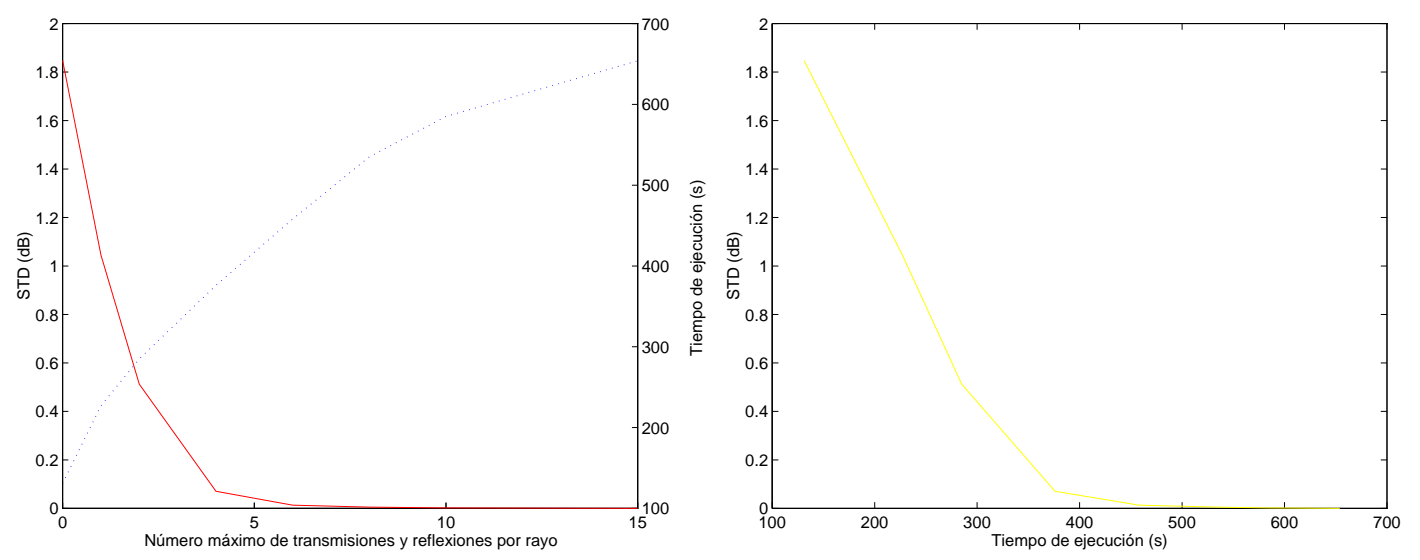

Figura 7.55: Reducción de error (desviación estándar, línea continua) y tiempo de ejecución (linea discontinua), en función del número máximo de transmisiones y reflexiones permitido. Resultados en pasillo con visibilidad directa

En conclusión, se puede decir que ambos parámetros (número máximo de transmisiones y reflexiones por tubo o rayo, y grado de resolución empleado), son muy influyentes en el tiempo de ejecución. Su elección no sólo dependerá del grado de precisión requerido, sino también del tipo de entorno sobre el cual se realizará la simulación. Todo parece indicar que, si existe visibilidad directa con los receptores, no será necesario permitir gran número de transmisiones y reflexiones. El grado de resolución empleado habrá de ser compatible con la distancia máxima recorrida y el tamaño de los obstáculos principales, pero no será necesario mejorarlo mucho más, a no ser que se quiera obtener resultados de gran precisión.

\subsubsection{Sensibilidad a las tolerancias en la definición del entorno}

La propia complejidad de los entornos reales de simulación provoca que el grado de determinismo de los modelos de Lanzado de Rayos sea mucho menor de lo esperado.

Teóricamente, para poder hacer una simulación, se han de conocer las propiedades electromagnéticas de todos los materiales del entorno. Estos datos tan sólo pueden obtenerse mediante complejos métodos de medida, que involucran la participación de costoso equipamiento (sistemas de transmisión y recepción precisos, antenas directivas de altas prestaciones, cámara anecoica, ... ).

La mayoría de las veces no se dispone de tales medios por lo que se ha de recurrir a datos aproximados basados en estimaciones y medidas realizadas por otros colegas del ramo. Esto ya supone de por sí una aproximación un tanto burda, pues sería muy casual que los materiales analizados fueran idénticos a los que se pretenden modelar.

Por tanto, existe un grado de incertidumbre a la hora de definir las características electromagnéticas de los materiales del entorno. Y esto no es todo. Conseguir modelar 
con exactitud, tanto en dimensiones como en ubicación, todas y cada una de las estructuras que vayan a influir en la propagación constituye una tarea ardua, a la vez que un tanto inútil. Y lo mismo con las características exactas de transmisor y receptores, especialmente en lo que se refiere a la posición de estos últimos cuando son móviles. Con los modelos de propagación (deterministas o no) se pretende simplificar dicho entorno y las circunstancias de propagación, no reproducirlo con exactitud.

Estas tolerancias en la definición del entorno, provocarán en el simulador unas variaciones en los resultados de las predicciones. Esto es lo que se pretende analizar en esta sección.

En primer lugar se analizarán una serie de simulaciones que pretenden calibrar la influencia en la potencia recibida al variar en un cierto porcentaje las constantes dieléctricas de los materiales que forman el entorno. Posteriormente se analizará la potencia recibida a lo largo de un trayecto de un supuesto móvil, pero considerando un cierto margen de variación en su trayectoria. En ambos casos se medirá el error medio así como la desviación estándar de los resultados, que servirán para dar una medida de la sensibilidad de los modelos de Lanzado de Rayos a estas tolerancias.

\section{Variación de los parámetros electromagnéticos}

El entorno escogido para analizar la influencia en la señal recibida de las posibles variaciones en las constantes dieléctricas de los materiales, ha sido la planta del edificio pequeño vista en la figura 7.10. Se trata de un entorno denso en el que abundarán las reflexiones y transmisiones, por lo que es óptimo para realizar este análisis.

El número de receptores a considerar fue relativamente bajo: una matriz $10 \times 10$ (cien receptores en total) que cubría de forma equiespaciada toda la planta. Todos los posibles casos (visibilidad directa, obstruida o ausencia total de visibilidad) quedaban representados.

En primer lugar se realizó la simulación cuyos parámetros se presentan en la tabla 7.25, y que fue tomada como referencia.

\begin{tabular}{|l|c|}
\hline Frecuencia de trabajo $(\mathrm{MHz})$ & 900 \\
\hline Antena transmisora & Antena isotrópica con pol. vertical \\
\hline Resolución en el lanzado & $2^{o}$ \\
\hline Número de reflexiones/transmisiones & 6 \\
\hline Paredes exteriores, suelo y techo & $\underline{\varepsilon}_{r}=9-0.9 j$ \\
Paredes interiores de ladrillo & $\underline{\varepsilon}_{r}=4-0.1 j$ \\
Paredes interiores de material plástico & $\underline{\varepsilon}_{r}=2.5-0.1 j$ \\
Vidrios de las ventanas & $\underline{\varepsilon}_{r}=6-0.05 j$ \\
\hline
\end{tabular}

Tabla 7.25: Parámetros de la simulación para evaluar la influencia de las variaciones en las constantes dieléctricas

Posteriormente, fueron realizándose más simulaciones, en las que se variaban todos los valores de las constantes dieléctricas complejas, bien en su parte real, bien en la imaginaria. El resumen de los resultados obtenidos al comparar las simulaciones se presenta en la 
tabla 7.26 .

\begin{tabular}{|l|c|c|}
\hline & Error medio $(\mathrm{dB})$ & Desviación típica $(\mathrm{dB})$ \\
\hline Parte real $+20 \%$ & -1.8095 & 8.9454 \\
\hline Parte real $-20 \%$ & 0.7245 & 7.9249 \\
\hline Parte imaginaria $+20 \%$ & -0.2391 & 2.0939 \\
\hline Parte imaginaria $-20 \%$ & 0.1741 & 1.4499 \\
\hline
\end{tabular}

Tabla 7.26: Resultados obtenidos al variar las características eléctricas de los materieles del entorno

De dicha tabla se aprecia que, aunque el error medio no es excesivo, existe una gran variabilidad puntual. Se puede comprobar que los errores son mayores en las zonas cercanas a los rincones, lo cual es lógico dada la abundancia de reflexiones en dichas zonas. Es curioso observar que existe una mayor sensibilidad a las variaciones de la parte real de la constante dieléctrica compleja (es decir, la permitividad relativa).

En conclusión, resulta imprescindible disponer de datos con la mayor exactitud que sea posible (y acordes a la frecuencia de trabajo) de los materiales de construcción, especialmente cuando se requiere gran precisión en los resultados de las simulaciones.

\section{Error en la posición del receptor}

Para evaluar la influencia de los errores al definir la posición de los móviles (de esta forma, implícitamente se evalúan también los errores en las posiciones de los objetos del entorno), se ha considerado el edificio mostrado en la figura 7.15.

Concretamente, se ha evaluado la potencia recibida en el pasillo que discurre horizontalmente, según está orientada la planta en la figura 7.15. Pero esta vez, el transmisor se ha dispuesto en el pasillo transversal (el primero por la izquierda), de forma que sólo apareciera una pequeña zona con visibilidad directa. Los parámetros de la simulación se presentan en la tabla 7.27 .

\begin{tabular}{|l|c|}
\hline Frecuencia de trabajo $(\mathrm{MHz})$ & 900 \\
\hline Antena transmisora & Dipolo en $\lambda / 2$ con polarización vertical \\
\hline Resolución en el lanzado & $2^{o}$ \\
\hline Número de reflexiones/transmisiones & 12 \\
\hline Paredes exteriores, suelo y techo & $\underline{\varepsilon}_{r}=9-0.9 j$ \\
Paredes interiores & $\underline{\varepsilon}_{r}=4-0.1 j$ \\
Vidrios de las ventanas & $\underline{\varepsilon}_{r}=6-0.05 j$ \\
\hline
\end{tabular}

Tabla 7.27: Parámetros de la simulación para evaluar la influencia de las variaciones en las posiciones de los receptores

Se ha considerado una matriz de receptores formada por 16 trazas que recorrían todo el pasillo, abarcando un metro y medio de anchura. Se tomado la traza central como la buena, es decir, se ha calculado el error en cada posición restando su potencia recibida en dBm a la obtenida en la hilera central de receptores de la matriz. 
La potencia recibida por cada una de esas trazas se presenta en la figura 7.56. Se aprecia que, aunque todas las trazas siguen una distribución de potencia recibida similar a lo largo del pasillo, existen grandes diferencias en la misma posición.

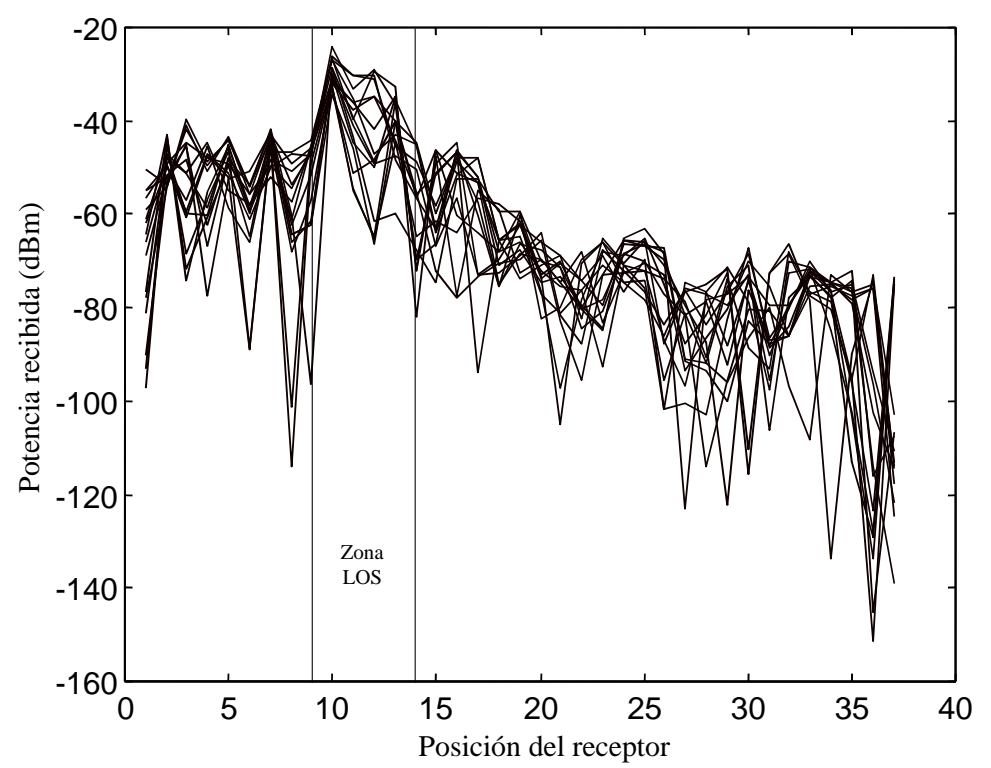

Figura 7.56: Potencia recibida a lo largo de las distintas trazas que recorren el pasillo

Estas diferencias entre las potencias se aprecia mejor en la figura 7.57. En ella se representa la diferencia en $\mathrm{dB}$ entre las potencias recibidas en cada traza y la que se obtiene en la central, que es tomada como referencia. Se observa más claramente que, efectivamente, existen grandes diferencias, especialmente hacia el final del recorrido.

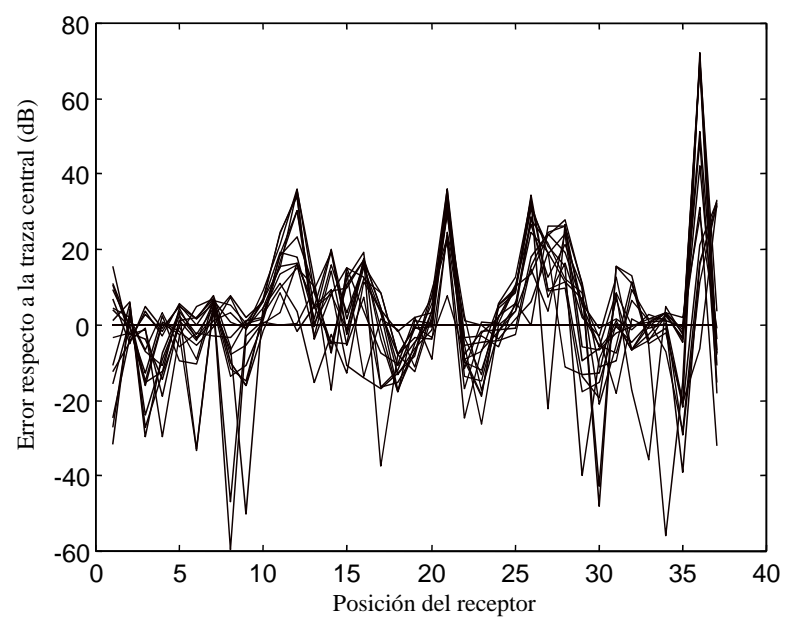

Figura 7.57: Error en la potencia recibida en cada traza del pasillo, respecto a la central

Este hecho es esperable pues el número medio de impactos recibidos es mucho menor al final del pasillo, tal y como se aprecia en la figura 7.58, debido a la mayor obstrucción existente respecto al transmisor. A menor número de impactos recibidos, mayor es la probabilidad de que cada uno altere más la potencia total recibida. 


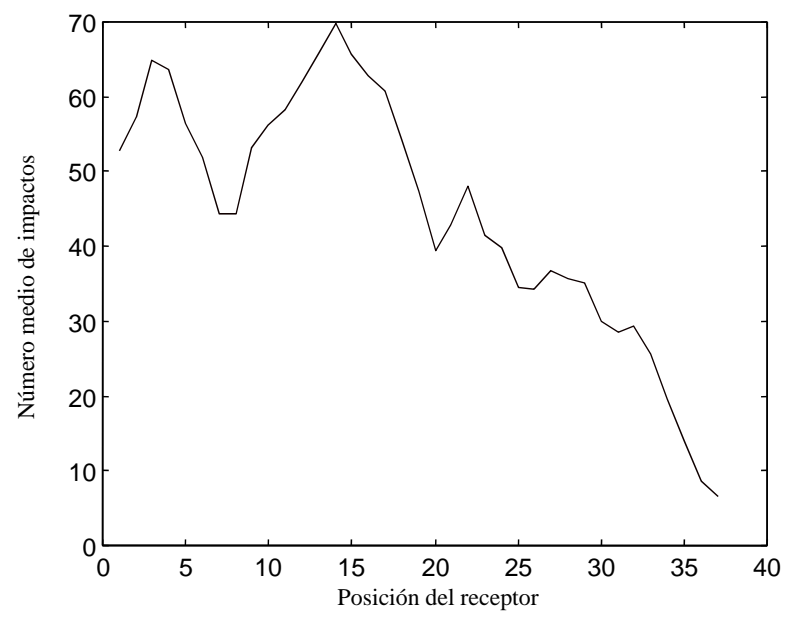

Figura 7.58: Número medio de impactos recibidos a lo largo del pasillo

Por tanto, es evidente una gran sensibilidad del simulador a la determinación correcta de la posición de los receptores y, con ello, de cualquier otro objeto involucrado en la propagación (transmisor u obstáculos), lo cual resulta lógico y predecible teniendo en cuenta las características multi-camino del canal, y las altas frecuencias de trabajo que se suelen utilizar.

Esta sensibilidad se pone aún más de manifiesto al representar el error absoluto en la potencia recibida en los distintos puntos de cada traza, respecto a la posición central, que es la tomada como referencia (figura 7.59(a)). También se representa la desviación típica de dicho error. Para evaluar con más detalle este último estadístico, se procedió a realizar una nueva simulación en las proximidades de la traza central (21 trazas abarcando un total de $10 \mathrm{~cm}$ ), cuyo resultado se muestran también en la misma figura. Efectivamente, a mayor distancia respecto a la posición nominal, mayor es la variación en la potencia recibida.
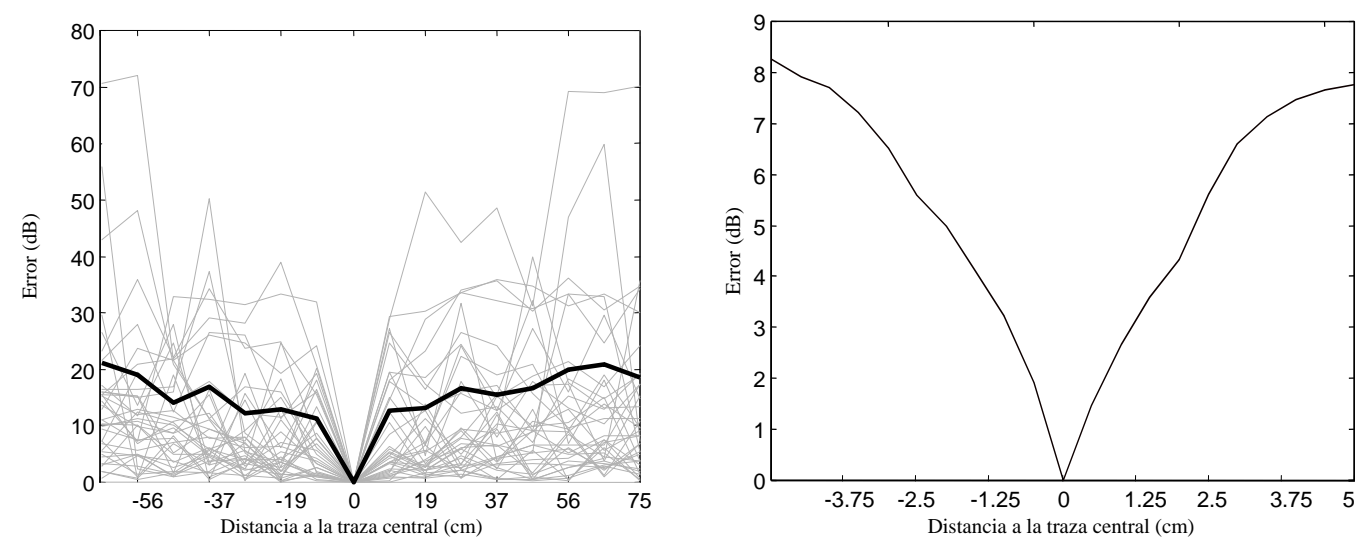

Figura 7.59: (a) Errores absolutos y desviación típica (en trazo grueso) en la potencia recibida en cada punto a lo largo del pasillo, respecto a la posición central. (b) Desviación típica del error en las cercanías de la traza central 
Se concluye, por tanto, que también es necesario poner un especial cuidado en la definición geométrica del entorno, pues pequeñas desviaciones provocan grandes oscilaciones en la potencia recibida, como era de prever, por otro lado, dadas las altas frecuencias de trabajo.

\subsection{Comparación con medidas en el edificio de la ETSIT}

Y llega el momento de la verdad. Se trata de poner a prueba el simulador implementado con las técnicas de Lanzado de Rayos, en un entorno real en el que se hayan realizado medidas. Estas medidas van a ser las presentadas en el capítulo 4, y que fueron hechas en el interior del edificio de la ETSIT de Valencia.

Las pegas que se pueden encontrar a dicho entorno están, fundamentalmente, relacionadas con su complejidad. A pesar de ello, precisamente esta complejidad ha supuesto un reto añadido para verificar el comportamiento del simulador en situaciones realistas.

Para definir el entorno del edificio de la ETSIT, se ha partido de una serie de ficheros DXF en dos dimensiones ya existentes, en los que se describe cada una de las plantas correspondientes a los pisos que integran el edificio (figura 7.60).

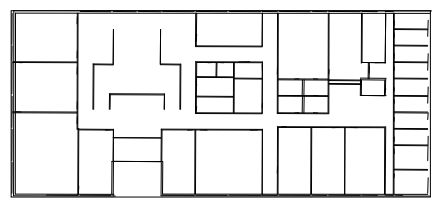

PISO $1^{\circ}$

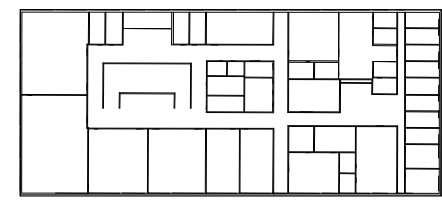

PISO 20

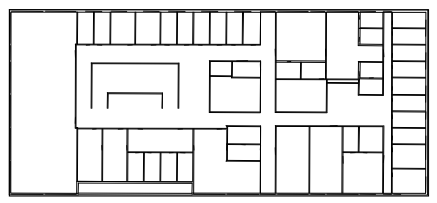

PISO 3o

Figura 7.60: Planos DXF bidimensionales de los pisos que forman parte del edificio de la ETSIT

A partir de estos ficheros, se ha generado un fichero DXF tridimensional, añadiendo a la estructura de cada piso las capas de suelo o de techo que separan los distintos pisos. El alzado de la estructura obtenida puede verse en la figura 7.61.

Como puede verse en la figura 7.62, el entorno es extremadamente complejo, lo cual provoca que las simulaciones requieran de una gran cantidad de tiempo de ejecución.

Debe advertirse que, con toda su complejidad, el modelo que se ha usado para describir el entorno presenta una serie de simplificaciones importantes con respecto de la realidad. En primer lugar, no se ha incluido la planta baja del edificio en el modelo. Esta simplificación es perfectamente válida, puesto que las simulaciones que se han de efectuar presentan transmisores localizados en el piso más alto, por lo que es lógico suponer que las reflexiones originadas en la planta baja, que corresponderán a rayos que hayan atravesado al menos cuatro capas de techo, estarán lo bastante atenuados como para poder despreciar sus contribuciones correspondientes.

Otra importante simplificación del modelo respecto de la realidad es el hecho de que no se ha considerado la presencia de importantes huecos entre suelos y techos, en concreto los que se corresponden con las escaleras. Al contrario, se ha supuesto que dichas capas 


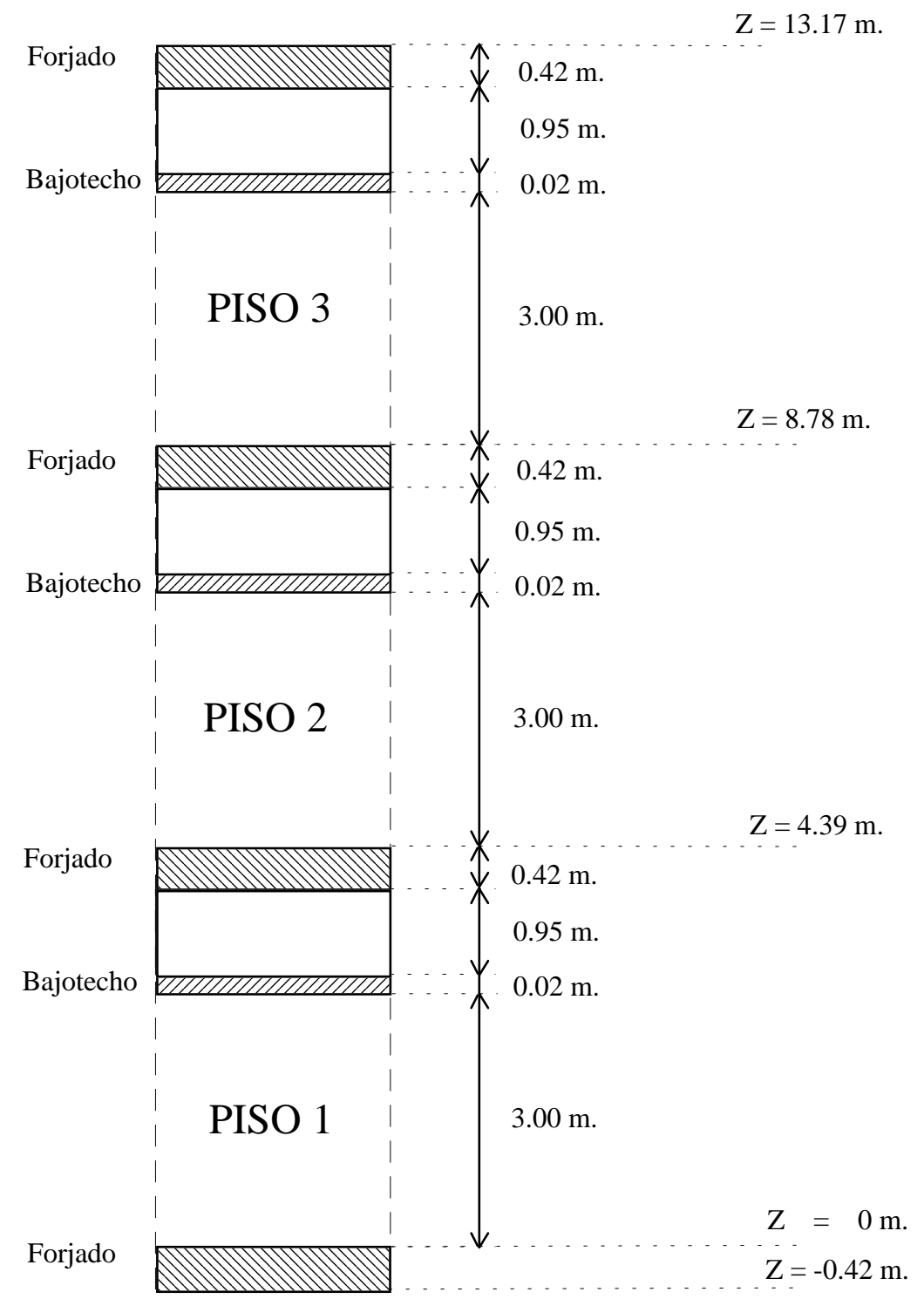

Figura 7.61: Alzado del edificio de la ETSIT, tal y como ha sido modelado para las simulaciones 


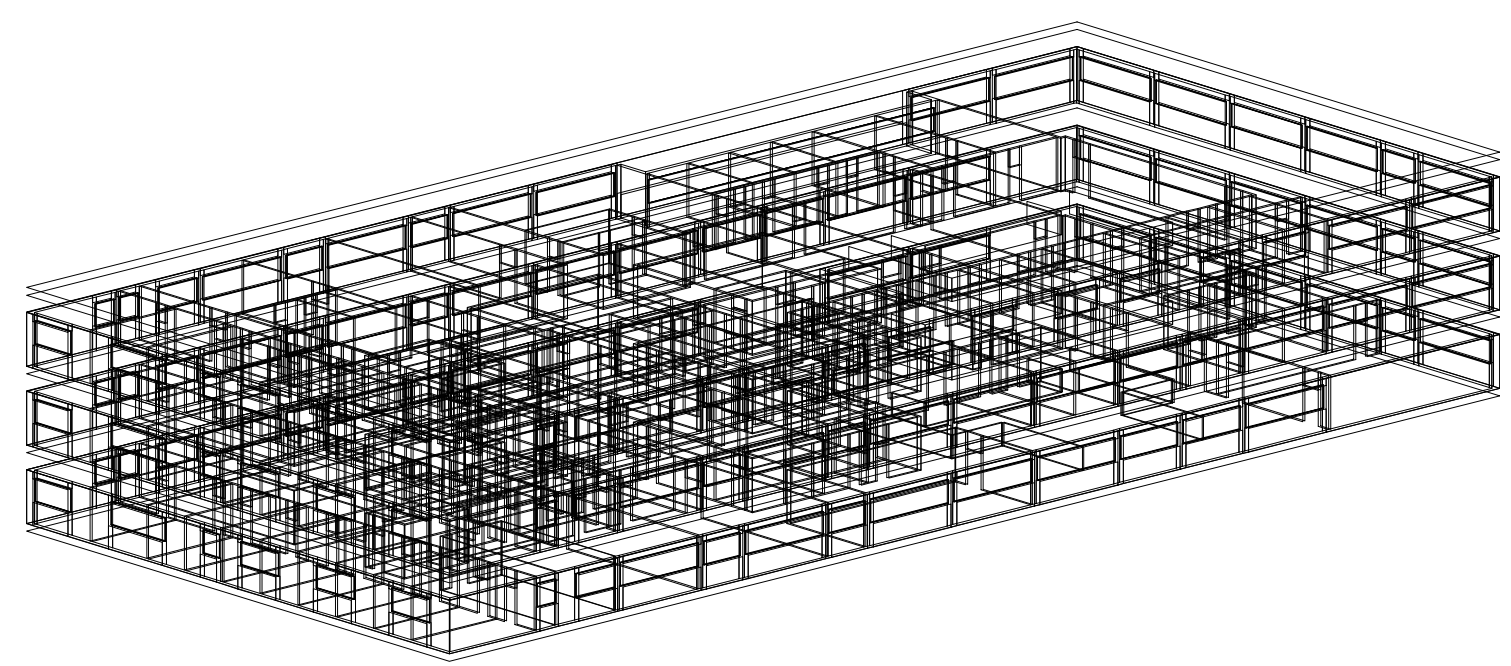

Figura 7.62: Representación gráfica del modelo de la ETSIT empleado en la simulación

son continuas, y separan por completo a los pisos vecinos entre sí.

Además, el modelo no incluye el mobiliario que pueda haber en el interior de las habitaciones (incluyendo objetos compuestos de piezas metálicas de tamaño considerable, como mesas o armarios). Todo ello hace que la descripción del entorno diste mucho de ser perfecta, lo cual, en principio, se dejará sentir en los resultados que se obtengan.

Por otra parte, determinar las características electromagnéticas de los materiales del entorno es una de las cuestiones más delicadas de cara a configurar los parámetros de la simulación. Según lo expuesto en la sección 7.4.2, los valores escogidos determinarán en buena medida la atenuación que sufran los rayos o tubos al ser reflejados o transmitidos. Se ha optado por tomar los valores que se muestran en la tabla 7.28 para los distintos materiales que forman el edificio de la ETSIT.

\begin{tabular}{|l|c|c|}
\hline Descripción de la estructura & Material & Constante dieléctrica \\
\hline \hline Pared exterior del edificio & Cemento & $9-0.9 j$ \\
\hline Vidrio de ventana & Vidrio & $6-0.05 j$ \\
\hline Pared interior del edificio & Ladrillo & $4-0.1 j$ \\
\hline Barandillas de escaleras & Ladrillo & $4-0.1 j$ \\
\hline Cristalera del hall & Vidrio & $6-0.05 j$ \\
\hline Puerta de cámara anecoica & Metal & $1-100000 j$ \\
\hline Forjado del suelo & Forjado & $9-9000 j$ \\
\hline Bajotecho & Escayola & $6-0.6 j$ \\
\hline Capas entre bajotecho y forjado & Aire & 1 \\
\hline Espacio entre paredes & Aire & 1 \\
\hline Balconadas & Ladrillo & $4-0.1 j$ \\
\hline
\end{tabular}

Tabla 7.28: Listado de los materiales que componen el edificio de la ETSIT, y valores de constantes dieléctricas asociadas

Otro parámetro fundamental para la simulación es la resolución angular escogida para 
el lanzado. Debido a las grandes dimensiones del entorno de trabajo, que hace que la separación de los rayos entre sí se haga muy elevada con la distancia, es conveniente trabajar con la máxima resolución posible. Se ha escogido una resolución angular de $1^{o}$, o lo que es lo mismo, una división de cada hemisferio de la esfera unidad del emisor en 90 paralelos. Trabajar con una resolución angular mayor haría prohibitivo el tiempo necesario para cada simulación.

Finalmente, se debe comentar que se ha escogido para las simulaciones el mecanismo de Lanzado de Rayos y no el de Tubos ya que, como se vio en el capitulo 5, el primer procedimiento resulta más apropiado para entornos complejos, tales como edificios complejos y de grandes dimensiones.

Se presentan en las figuras 7.63, 7.64 y 7.65 las simulaciones realizadas de algunas las trazas verticales descritas en el capítulo 4, comparándolas con las medidas obtenidas.

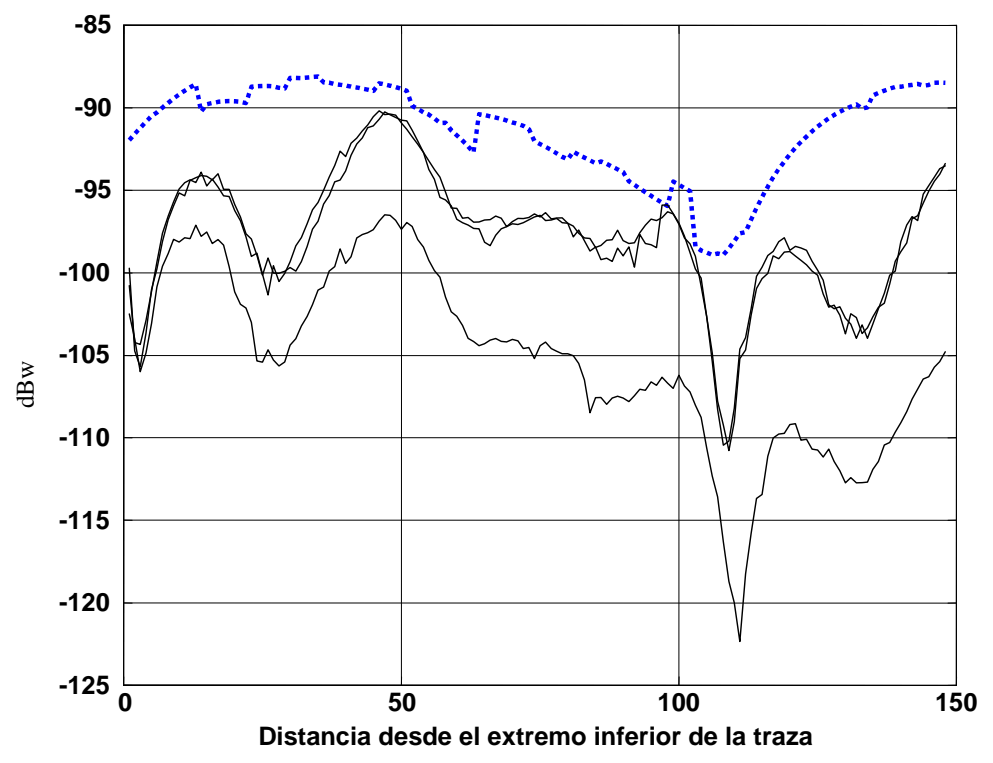

Figura 7.63: Simulación (línea a trazos) y medidas (lineas continuas) en el punto 3 del piso 2

Lo primero que se observa en los resultados es que las curvas de potencia obtenidas por simulación no se ajustan de forma precisa a las correspondientes a las medidas, apreciándose divergencias importantes. Esto es algo inevitable, debido a que el modelado del entorno incurre en numerosas aproximaciones e inexactitudes respecto de la realidad. La resolución angular del lanzado (insuficiente, aunque lo bastante importante como para requerir una gran cantidad de tiempo de ejecución) no es tan buena como sería lo apropiado en un entorno de dimensiones tan grandes; la descripción del edificio que constituye el entorno está muy simplificada respecto de la real; los valores de las constantes dieléctricas que se asignaron a los materiales eran estimaciones sin confirmar. Todo ello hace inevitable que los resultados obtenidos se diferencien de forma importante de los resultados reales.

Sin embargo, a pesar de todas estas limitaciones, existen importantes puntos en común entre los resultados simulados y los reales, que deben ser tenidos en cuenta. Para empezar, 


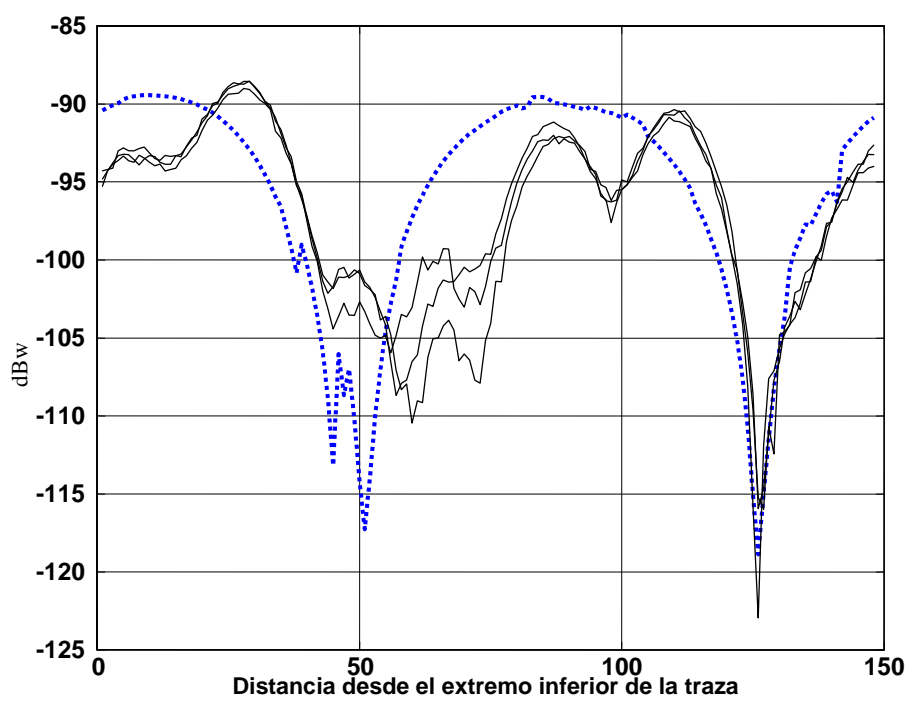

Figura 7.64: Simulación (línea a trazos) y medidas (líneas contínuas) en el punto 4 del piso 2

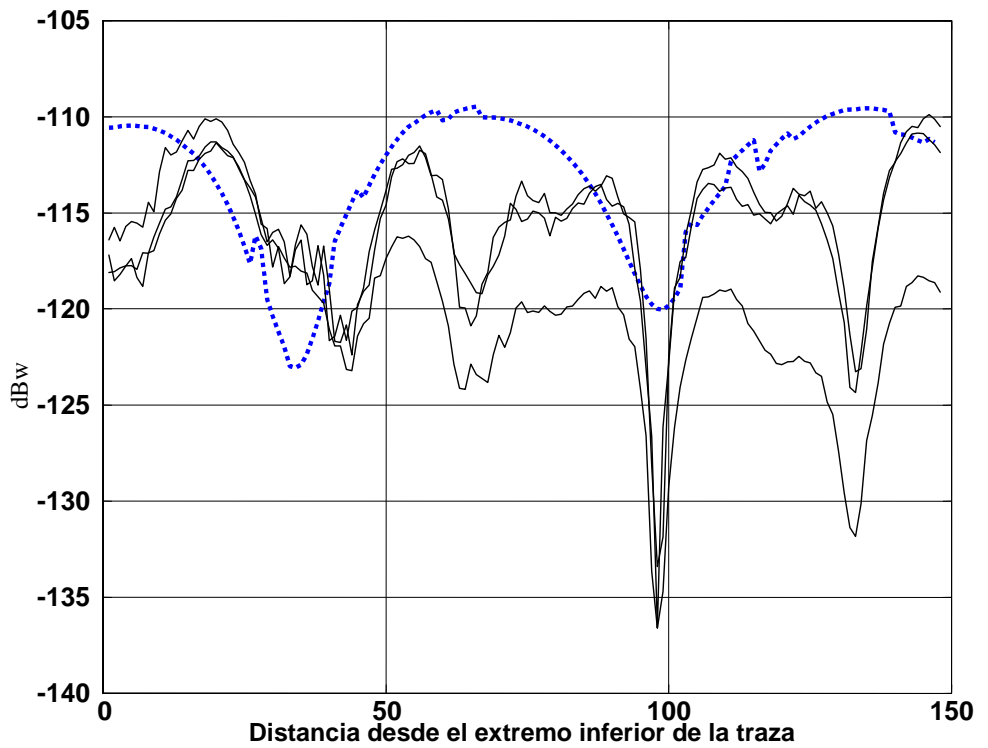

Figura 7.65: Simulación (línea a trazos) y medidas (líneas continuas) en el punto 2 del piso 1 
los niveles promedio de potencia de cada trama. Aunque no coinciden con exactitud, la diferencia entre los valores simulados y los reales se mantiene siempre por debajo de los $15 \mathrm{~dB}$.

Es de suponer que, de haber dispuesto de datos más precisos sobre las características electromagnéticas de los materiales del edificio, y más concretamente sobre los de los valores de los suelos y techos que separan a los pisos entre sí, se habría conseguido ajustar con mayor fidelidad los niveles de potencia media entre las simulaciones y las mediciones reales.

Otra cuestión es que, a pesar de que el aspecto de las curvas de potencia de las simulaciones y las medidas no coinciden con exactitud, sí que existe un parecido razonable. Esto se observa, sobre todo, en la coincidencia de la posición aproximada de los desvanecimientos más profundos. En muchos de los casos estudiados, algunos de los mínimos que aparecen en las curvas de las mediciones, generados por la atenuación provocada por el multi-camino, se mantienen también en la curva simulada.

A pesar de esto, algunos de los desvanecimientos que se observan en las mediciones no aparecen reflejados en los resultados de la simulación. Esto es lógico, debido a que todas las imperfecciones del modelo, hacen que se pierdan impactos y que algunos de los efectos de atenuación del multi-camino en los niveles de potencia no se dejen sentir.

Otro hecho que es conveniente señalar es que, en términos generales, las curvas simuladas se parecen más a las medidas en aquellas trazas que se hayan en el segundo piso, es decir en el más próximo al transmisor. Esto era esperable ya que, a medida que los receptores se alejan del emisor, los rayos se separan cada vez más, con lo que la posibilidad de que se pierdan caminos se incrementa.

Finalmente, debe decirse que las simulaciones modelan bastante bien las variaciones significativas del nivel de potencia con la altura para desplazamientos cortos respecto de la longitud de onda de la frecuencia de trabajo. A pesar de las divergencias con los datos reales, estas variaciones con la altura son perfectamente apreciables en las curvas simuladas.

\subsection{Conclusiones}

Como conclusión fundamental de este capítulo, se puede decir que todas y cada una de las técnicas empleadas en la simulación de la propagación mediante Lanzado de Rayos o Tubos, tienen su razón de ser y resultan razonables.

El propio lanzado, a pesar de su naturaleza discreta, modela bien los frentes de onda, incluso con resoluciones relativamente bajas, si el entorno lo permite. El único problema aparece al implementar los algorítmos de recepción en el caso de Lanzado de Rayos, pero se ha visto que la técnica de eliminación de impactos redundantes es perfectamente útil en entornos indoor, y no excesivamente lenta.

Por otro lado, se está en disposición de modelar con detalle la incidencia en estructuras de tipo multi-capa, mediante una técnica que no incrementa apenas el tiempo de ejecución y que da resultados equivalentes a considerar el seguimiento de los rayos o tubos por su 
interior.

Además, se ha comprobado la influencia de la difracción y la reflexión difusa, resultando que no afecta a la propagación en media, aunque sí en circunstancias puntuales (cercanías de una esquina difractante o longitudes de onda muy pequeñas en comparación con la rugosidad de los materiales del entorno). Resulta importante poder optar por añadir estas contribuciones en simulaciones específicas, aunque, en general, se podrá prescindir en ellas sin menoscabo en los resultados finales, aumentando con ello la velocidad de ejecución del programa de simulación.

También se han analizado las prestaciones del simulador, poniendo énfasis a su sensibilidad con los parámetros de definición del entorno (ubicaciones de elementos del sistema y características de los materiales). Se ha llegado a la conclusión de que resulta importante poner un especial cuidado en definir correctamente dichos datos, pues influyen de manera decisiva en los resultados obtenidos.

Por último, el simulador se ha demostardo lo suficientemente práctico como para modelar el comportamiento del canal en el interior de edificos tan complejos como el de la propia ETSIT de Valencia. Los resultados son todo lo buenos que cabría esperar, dado el nivel de definición del entorno que se disponía.

En definitiva, se dispone de una potente herramienta que puede modelar, y en cierta medida incluso predecir con bastante exactitud, el comportamiento del canal radio móvil en el interior de edificios con múltiples plantas. 


\section{Capítulo 8}

\section{Caracterización Estadística del Canal Indoor}

\section{$8.1 \quad$ Introducción}

Tal y como se adelantó en el capítulo 2, en Comunicaciones Móviles, la propagación radioeléctrica tiene lugar a través de un medio que experimenta variaciones aleatorias en sus características físicas. Estas variaciones, totalmente impredecibles, afectan a la intensidad de campo eléctrico recibido, provocando que la señal en recepción presente importantes variaciones*.

Estas fluctuaciones pueden experimentarse tanto al considerar distintas ubicaciones del receptor (diferencias de potencia recibida en puntos equidistantes al transmisor), como en un punto fijo pero a lo largo del tiempo (variaciones temporales). En realidad poco importa cómo sean tratadas estas variaciones, si desde el punto de vista espacial o desde el punto de vista temporal, pues lo verdaderamente importante es que son debidas al carácter variante del canal radio móvil. Y el canal es variante, fundamentalmente, porque la posición del receptor lo es y/o porque el entorno cambia.

Tradicionalmente se han estudiado estas fluctuaciones desde el punto de vista espacial (spatial scale), debido a la naturaleza intrínseca del receptor móvil. Así, la propagación de la señal suele describirse a través de tres mecanismos diferenciados según sea la longitud del recorrido considerado:

- A lo largo de grandes trayectos, el comportamiento del canal suele caracterizarse de forma sencilla con lo que se denomina ecuación de pérdidas, en la cual la potencia recibida por el móvil decrece exponencialmente conforme aumenta la distancia entre el transmisor y el receptor.

- En trayectos más reducidos, de varios centenares de longitudes de onda, se puede comprobar que la potencia media local recibida no es constante, más bien viene

\footnotetext{
* Recuérdese la figura 2.1, donde se mostraba las fluctuaciones de la señal recibida a lo largo de una trayectoria recorrida por el receptor móvil.
} 
a distribuirse según una ley log-normal, con variaciones lentas en la media de la envolvente de la señal recibida. A este tipo de desvanecimientos se les denomina a largo plazo (long-term fading) o shadowing. La desviación típica de dicha ley log-normal está relacionada con la diversidad del entorno, siendo el valor medio de la distribución el determinado, como se ha apuntado antes, por la ecuación de propagación.

- En pequeñas distancias recorridas, de no más de unas decenas de longitudes de onda, la envolvente de la señal recibida experimenta unos desvanecimientos rápidos y profundos en torno a la media local, conocidos como desvanecimientos a corto plazo (short-term fading) o fast fading. Estas variaciones rápidas, son debidas a las diferencias de caminos que recorren las contribuciones que llegan al receptor, traduciéndose en unas diferencias de fase apreciables, tanto como para que se produzcan desvanecimientos de 20 a $30 \mathrm{~dB}$.

El objetivo de este capítulo es describir las distribuciones estadísticas que habitualmente se han propuesto para modelar esas variaciones del campo eléctrico debido al movimiento del receptor, poniendo especial énfasis en el caso de entornos indoor. También se comentará el sentido físico de las principales distribuciones, mostrando sus expresiones matemáticas y la de sus estadísticos.

Con todo esto, se intentará validar la capacidad del simulador desarrollado para modelar los desvanecimientos según alguna de las estadísticas que habitualmente se proponene en la literatura.

\subsubsection{Estimación de parámetros. Método de la Función de Máxima Verosimilitud}

Resulta necesario obtener una estimación de los estadísticos de esas distribuciones, para lo cual se suele acudir a datos experimentales obtenidos habitualmente mediante campañas de medidas. El objetivo puede ser validar los modelos de propagación, o bien simplemente estudiar la distribución estadística de la señal recibida. Existen varios métodos para realizar esa estimación, siendo los principales los siguientes:

Método de los momentos. Consiste en la obtención de un sistema de ecuaciones igualando los momentos muestrales a los poblacionales, donde las incógnitas son los parámetros a estimar. Para proporcionar buenas estimaciones deben considerarse los momentos de menor orden posible (hasta el segundo, como máximo).

Método de los cuadrados. Trata de obtener el estimador que minimice el error cuadrático medio entre la función de densidad de probabilidad teórica y la experimental.

Método de la función de máxima verosimilitud. Consiste en la maximización mediante derivadas parciales de la Función de Máxima Verosimilitud (FMV), definida como la función de densidad conjunta de $N$ muestras de la variable aleatoria a describir. 
Este último método es el más aconsejable, por dar lugar a estimadores insesgados, eficientes y de mínima varizanza. En [Rub96] se explica detalladamente, obteniéndose la estimación de los estadísticos de las distribuciones más importantes.

\subsection{Desvanecimientos a largo plazo}

Se ha observado que, cuando aparecen grandes cambios en el trayecto de propagación o en el entorno que rodea al receptor, la intensidad de campo eléctrico medido en $\mathrm{dBu}, E_{\mathrm{dBu}}$, sigue una distribución normal (o gausiana) de media $\bar{E}$ y desviación típica $\sigma_{E}$, aunque las distintas contribuciones que lleguen al receptor por separado no sean de tipo gausiano [Suz77]. Así, su función de densidad de probabilidad viene dada por:

$$
f_{E_{\mathrm{dBu}}}\left(E_{\mathrm{dBu}}\right)=\frac{1}{\sqrt{2 \pi \sigma_{E}^{2}}} \exp \left(-\frac{1}{2 \sigma_{E}^{2}}\left(E_{\mathrm{dBu}}-\bar{E}\right)^{2}\right)
$$

Si los valores de campo en $\mathrm{dBu}$ siguen una ley normal, los valores de campo en escala lineal $(\mu \mathrm{V} / \mathrm{m})$ siguen una ley log-normal, cuya función de densidad de probabilidad viene dada por:

$$
f_{E}(E)=\frac{1}{E \sigma \sqrt{2 \pi}} \exp \left(-\frac{1}{2 \sigma^{2}}(\ln E-\mu)^{2}\right)
$$

donde $\sigma$ y $\mu$ son los estadísticos de la distribución, correspondiéndose con la desviación típica y la media, respectivamente.

Una explicación teórica a la aplicabilidad de esta distribución sería que, debido a las múltiples contribuciones recibidas en una ambiente con presencia del fenómeno de multicamino, la señal total recibida puede ser caracterizada como un proceso multiplicativo [Has93]. La multiplicación de las amplitudes de la señal daría lugar a una distribución lognormal, de la misma forma que un proceso aditivo da lugar a una distribución gausiana, según el Teorema Central del Límite.

Si se realiza una campaña de medidas y se obtienen $N$ muestras, los estadísticos se pueden estimar inmediatamente de la manera siguiente (el símbolo^ ${ }^{\wedge}$ indica valor estimado):

$$
\begin{gathered}
\hat{\mu}=\frac{1}{N} \sum_{i=1}^{N} \ln E_{i} \\
\hat{\sigma}^{2}=\frac{1}{N} \sum_{i=1}^{N}\left(\ln E_{i}-\mu\right)^{2}
\end{gathered}
$$

donde $E_{i}$ es el valor de campo, en $\mathrm{V} / \mathrm{m}$, medido en el punto $i$. El parámetro $\sigma$ se expresa en neperios* ${ }^{*}$ y $\mu$ viene dado en unidades logarítmicas absolutas de potencia, aunque el logaritmo usado es el neperiano.

${ }^{*}$ La relación entre $\sigma_{\mathrm{dB}}$ en $\mathrm{dB}$ y $\sigma$ en neperios es $\sigma_{\mathrm{dB}}=8,68 \sigma$ 
Se ha de recordar que la función de densidad de probabilidad es adimensional, con lo que no importa qué unidades se empleen para el campo eléctrico, siempre que sean unidades lineales. El emplear $\mathrm{V} / \mathrm{m}$ ó $\mu \mathrm{V} / \mathrm{m}$ es una cuestión de nomenclatura que debe tenerse en cuenta solamente al representar gráficamente la función de densidad de probabilidad, en la que el eje referido a los valores de campo debe tener las mismas unidades que se han empleado en la función de densidad.

Para dar una idea de cuál es la forma de esta distribución de probabilidad, en la figura 8.1 aparece representada la función de densidad de probabilidad para distintos valores de los estadísticos $\sigma$ y $\mu$.

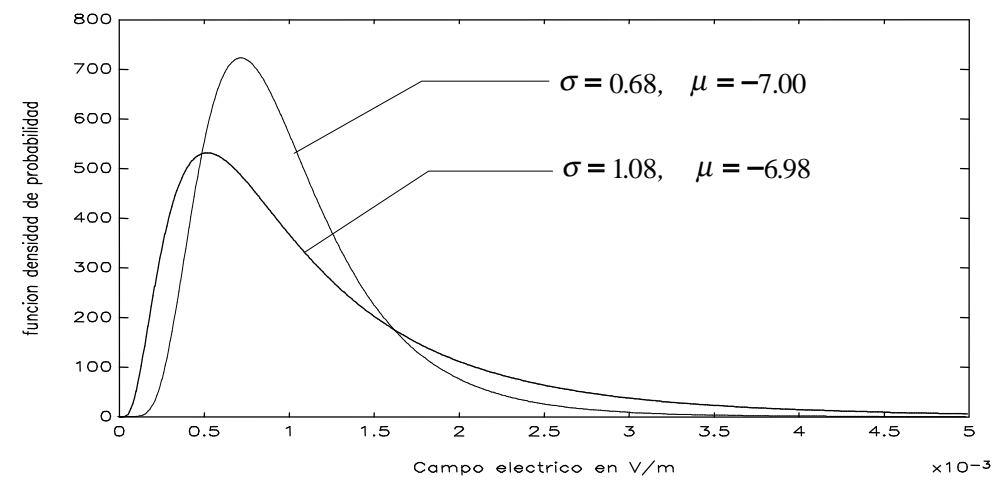

Figura 8.1: Función de densidad de probabilidad log-normal para distintos valores de $\sigma$ y $\mu$

No debe extrañar que $\mu<0$, ya que el campo medido en $\mathrm{V} / \mathrm{m}$ es siempre menor que la unidad, y su logaritmo neperiano es entonces negativo.

En la mayoría de las ocasiones se trabaja con potencia en vez de con campo eléctrico. En [Rub96] se recomienda, muy acertadamente, trabajar con las funciones de densidad de probabilidad de la potencia en $\mathrm{dBm}$, pues permite observar con más detalle las variaciones alrededor de la media de la envolvente de la señal, ya que el ensanchamiento de la función de densidad de probabilidad da una idea del margen dinámico de esas variaciones en dB. Para poder obtener las funciones de densidad de probabilidad de la potencia en $\mathrm{dBm}$ a partir de las distribuciones de campo eléctrico, no hay más que aplicar el siguiente cambio de variable:

$$
P[\mathrm{dBm}]=10 \log \left(K|E[\mathrm{~V} / \mathrm{m}]|^{2}\right)+30
$$

con lo que la función de densidad de probabilidad de la potencia en $\mathrm{dBm}$ vendrá dada por:

$$
f_{P}(P)=f_{E}(E) \cdot\left|\frac{d E}{d P}\right|=\frac{\ln 10}{20} E f_{E}(E)
$$

En particular, para la distribución log-normal, se obtiene la siguiente expresión de la función de densidad de probabilidad de la potencia recibida expresada en dBm:

$$
f_{P}(P)=\frac{\ln 10}{20 \sigma \sqrt{2 \pi}} \exp \left(-\frac{1}{2 \sigma^{2}}\left(\ln \frac{10^{\frac{P-30}{20}}}{\sqrt{K}}-\mu\right)^{2}\right)
$$


Recuérdese que la estimación de los estadísticos $\sigma$ y $\mu$ sigue siendo la dada por las ecuaciones (8.3) y (8.4), respectivamente. Llamando $\bar{P}$ a la potencia en $\mathrm{dBm}$ relativa al valor medio del campo eléctrico, es decir:

$$
\bar{P}=10 \log \left(K \bar{E}^{2}\right)+30
$$

donde $\bar{E}$ viene dado en $\mathrm{V} / \mathrm{m}$, la ecuación (8.7) puede ponerse de esta otra forma:

$$
f_{P}(P)=\frac{\ln 10}{20 \sigma \sqrt{2 \pi}} \exp \left(-\frac{1}{2 \sigma^{2}}\left(\frac{\ln 10}{20}(P-\bar{P})\right)^{2}\right)
$$

$\mathrm{Al}$ parámetro $\bar{P}$ se le puede llamar potencia media recibida, midiéndose en $\mathrm{dBm}$, pero debe aclararse que no se obtiene mediante media aritmética de las potencias instantáneas recibidas en $\mathrm{dBm}$, sino directamente a partir del estadístico $\mu$ o del campo medio recibido (este sí como media aritmética).

En la figura 8.2 puede verse la forma de la función de densidad de probabilidad de la potencia en $\mathrm{dBm}$. Se han utilizado los mismos estadísticos que para figura 8.1.

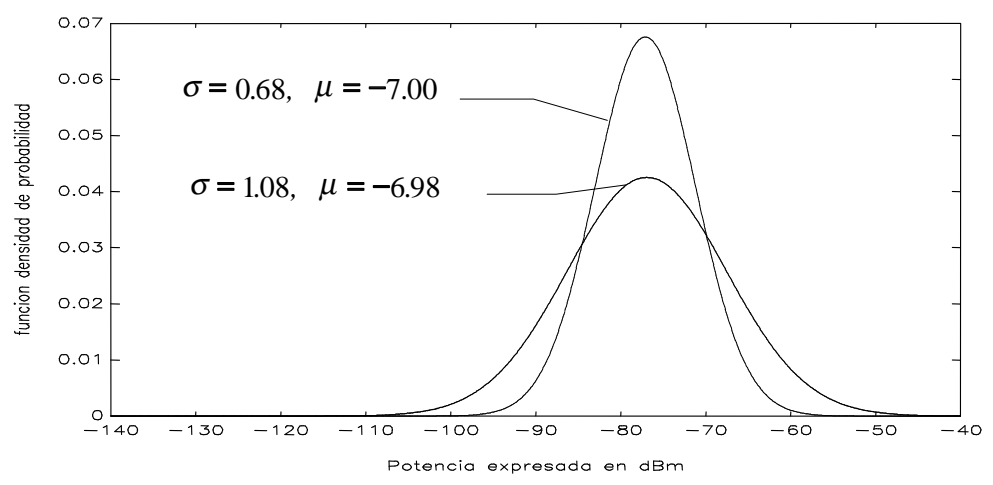

Figura 8.2: Función de densidad de probabilidad log-normal de la potencia en dBm, para distintos valores de $\sigma$ y $\mu$

En dicha figura 8.1, las funciones de densidad de probabilidad representadas, con los valores utilizados de los estadísticos, están centradas aproximadamente en $-77 \mathrm{dBm}$. Efectivamente, el ensanchamiento de estas funciones da una idea de cómo son los desvanecimientos alrededor de la media de la envolvente de la señal recibida.

Se ha comprobado suficientemente que la distribución log-normal describe con precisión la estadística de desvanecimientos a largo plazo en entornos exteriores [Rub96], estando relacionado el parámetro desviación típica con la diversidad del entorno, y dado el valor medio de la distribución por la ecuación de propagación.

En el caso de entornos indoor, también se ha demostrado la aplicabilidad de la distribución log-normal al considerar medidas realizadas en entornos globales, de forma que abarcaran entornos muy distintos o ambientes con una acusada inhomogeneidad espacial [Has92b, Has92a]. 


\subsection{Desvanecimientos a corto plazo}

Existen varias distribuciones propuestas en la literatura para caracterizar de forma estadística las variaciones rápidas sufridas por la señal recibida en torno a una media local.

En esta sección se van a describir las estadísticas tipo Rice y Rayleigh, las más empleadas en comunicaciones móviles, junto a la Nakagami, que aunque es menos conocida que las anteriores, se ha demostrado capaz de proporcionar mejores resultados en el estudio del comportamiento a corto plazo. Todas estas distribuciones son aplicables a entornos indoor y se hará referencia a los resultados experimentales presentados en la literatura para validar estas estadísticas en este tipo de entornos. También se mostrará, adicionalmente, la estadística tipo Weibull como específicamente aplicable a entornos indoor.

Un hecho clave que debe tenerse en cuenta al abordar el estudio del comportamiento a corto plazo es que la estadística del canal no debe cambiar en el área local a estudiar. Esto implica que es necesario limitar suficientemente el entorno bajo estudio para asegurar una cierta homogeneidad espacial. Precisamente, a la hora de validar los modelos propuestos para las estadísticas con datos obtenidos experimentalmente, se ha de procurar que éstos queden limitados en una zona que cumpla dicha premisa.

\subsubsection{Desvanecimientos con estadística tipo Rice}

En comunicaciones móviles, se suele usar la distribución Rice para describir de forma estadística las variaciones que experimenta la señal recibida en torno a una media local cuando, del total de contribuciones recibidas, aparece una o varias con amplitud significativamente mayor que la del resto.

Esta situación es frecuente en comunicaciones móviles en zonas rurales y, en bastantes casos, también en entornos urbanos cuando hay visibilidad directa con el transmisor. Además, en comunicaciones móviles indoor, hay muchas situaciones en las que el receptor es visible desde el transmisor, con lo que la componente directa es dominante frente a contribuciones que sufren procesos de reflexión, difracción y scattering. Incluso sin haber visibilidad total entre transmisor y receptor, puede darse el caso de contribuciones principales cuyas pérdidas por transmisión o difracción final sean muy bajas, comparadas con las pérdidas de las componentes secundarias.

Cuando tales componentes dominantes existen, puede considerarse que el vector que representa la señal recibida está formado por la suma de dos vectores: uno aleatorio tanto en módulo (con estadística tipo Rayleigh, que se comentará más adelante) como en fase (considerada uniformemente distribuida entre $-\pi$ y $\pi$ ), más otro determinista en módulo y fase, que representa dicha contribución dominante.

Puede demostrarse que, en tal caso, la función de densidad de probabilidad del módulo del campo eléctrico recibido, en unidades lineales, sigue una estadística tipo Rice, que viene dada por [Ric54]:

$$
f_{E}(E)=\frac{E}{\sigma^{2}} \exp \left(-\frac{E^{2}+C^{2}}{2 \sigma^{2}}\right) I_{0}\left(\frac{E C}{\sigma^{2}}\right)
$$


donde $I_{0}(x)$ es la función de Bessel modificada de orden cero:

$$
I_{0}(x)=\sum_{i=1}^{\infty} \frac{(x / 2)^{2 i}}{\Gamma(i+1)^{2}}
$$

siendo $\Gamma(x)$ la función Gamma.

Como puede apreciarse, la distribución Rice es biparamétrica con parámetros $C$ y $\sigma$. Si se realiza una campaña de medidas y se obtienen $N$ muestras, los parámetros se pueden estimar, usando la FMV, a partir de los momentos muestrales de primer y segundo orden, quedando de la siguiente manera [Rub96]:

$$
\begin{gathered}
\hat{C}=m_{1}=\frac{1}{N} \sum_{i=1}^{N} E_{i} \\
\hat{\sigma}^{2}=\frac{m_{2}}{2}-\frac{m_{1}^{2}}{2}=\frac{1}{2 N} \sum_{i=1}^{N} E_{i}{ }^{2}-\frac{1}{2 N^{2}}\left(\sum_{i=1}^{N} E_{i}\right)^{2}
\end{gathered}
$$

En estas ecuaciones, las muestras del campo eléctrico van expresadas en unidades lineales, con lo que los estadísticos se obtienen también en las mismas unidades lineales.

La forma de estimar $C$ mediante la expresión (8.12) indica que este estadístico da información de la media de la distribución. Esto es lógico, ya que, si existe una contribución dominante, la media de la distribución estará próxima a la amplitud de dicha contribución. Y si existen varias componentes dominantes, la media de la distribución se aproximará a la media de éstas.

Por otra parte, la forma de estimar $\sigma$ a través de (8.13) indica que representa, en cierta medida, la desviación típica de la distribución. Para ser más exactos, se debe decir que representa la desviación típica de las contribuciones no dominantes, debido a la presencia del momento muestral de primer orden.

En la figura 8.3 aparece representada la función de densidad Rice. Se observa que, efectivamente, permanece centrada en valores próximos al parámetro $C$.

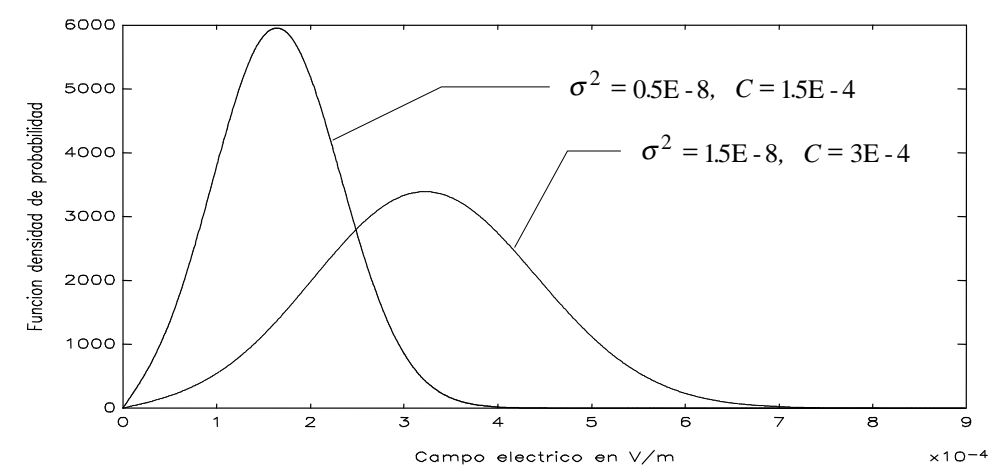

Figura 8.3: Función de densidad de probabilidad Rice para distintos valores de $C$ y $\sigma$ 
Para obtener la función de densidad de probabilidad de la potencia recibida en $\mathrm{dBm}$, se aplica la transformación (8.6) a la ecuación (8.10), obteniéndose finalmente:

$$
f_{P}(P)=\frac{10^{\frac{P-30}{10}} \ln 10}{20 K \sigma^{2}} \exp \left(-\frac{10^{\frac{P-30}{20}}+K C^{2}}{2 K \sigma^{2}}\right) I_{0}\left(\frac{10^{\frac{P-30}{20} C}}{\sigma^{2} \sqrt{K}}\right)
$$

No debe olvidarse que, en la ecuación anterior, a pesar de la transformación, los estadísticos siguen siendo los estimados por (8.12) y (8.13), en unidades lineales.

En la figura 8.4 aparecen las mismas funciones que se representan en la figura 8.3, pero ahora para la potencia en $\mathrm{dBm}$, viéndose que, para $C=1.5 \times 10^{-4} \mathrm{~V} / \mathrm{m}$, la función de densidad de probabilidad queda centrada en $-92.5 \mathrm{dBm}$, mientras que para $C=3 \times$ $10^{-4} \mathrm{~V} / \mathrm{m}$ está centrada en $-86 \mathrm{dBm}$.

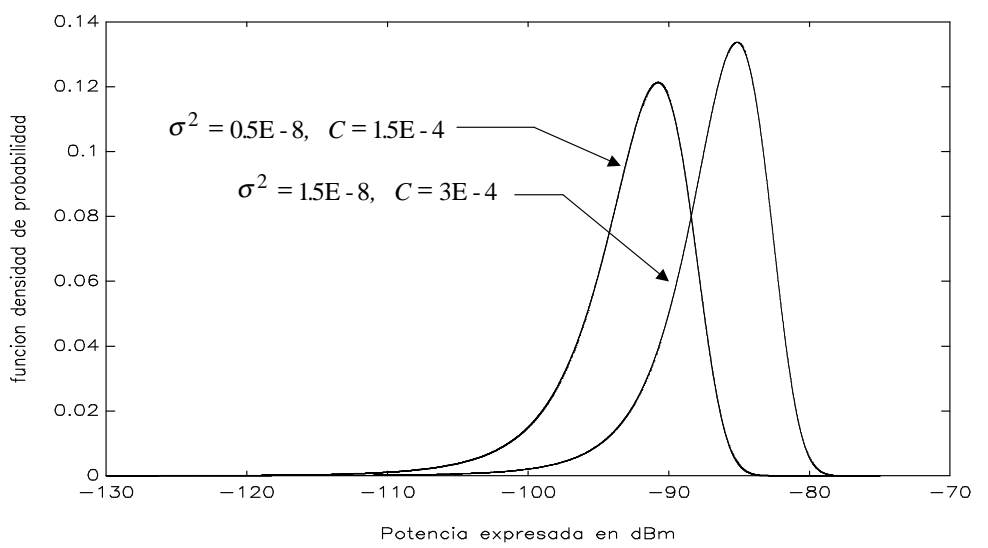

Figura 8.4: Función de densidad de probabilidad Rice de la potencia en dBm, para distintos valores de $C$ y $\sigma$

Si se comparan los resultados reflejados en ambas figuras, parece haber una contradicción, ya que en la figura 8.3 la función de densidad de probabilidad más ancha es aquella que tiene mayor desviación típica, no ocurriendo lo mismo en la figura 8.4. La escala logarítmica revela algo que no puede observarse con tanta claridad en la escala lineal, y es que, para el caso de la distribución Rice, los estadísticos dan de forma conjunta la posición y ensanchamiento de la función de densidad de probabilidad. Una vez más, es necesario recordar que $\sigma$ representa la desviación típica de las componentes no dominantes, que no debe coincidir con la de la distribución total, si bien es cierto que para valores de la media pequeños puede llegar a aproximarse.

En entornos indoor, la distribución Rice se ha demostrado especialmente aplicable en ambientes abiertos (almacenes y naves industriales, grandes halls, ... ), aunque también en edificios de oficinas y con moderada densidad de objetos, siempre y cuando exista visibilidad directa entre transmisor y receptor [Ale82], o al utilizar antenas directivas o fuentes distribuidas, tipo leaky feeder [Has93]. 


\subsubsection{Desvanecimientos con estadística tipo Rayleigh}

La distribución Rayleigh es la más utilizada para describir las variaciones estadísticas de la envolvente de la señal resultante de la propagación multi-camino. Una de las razones de su éxito es la elegante justificación teórica de la que se deriva.

Así, supóngase un modelo de propagación en el que se asuma que al receptor le llegan un total de $N$ contribuciones, entre principales y secundarias, cada una representada por un campo eléctrico complejo $E_{i} e^{j \phi_{i}}$. El campo complejo total podrá escribirse como la suma vectorial (es decir, en módulo y fase) de todas las contribuciones:

$$
E e^{j \phi}=\sum_{i=1}^{N} E_{i} e^{j \phi_{i}}
$$

Si el número de contribuciones $N$ es elevado, sus fases pueden considerarse uniformemente distribuidas entre $-\pi$ y $\pi$, y en un área lo suficientemente reducida con ausencia de visibilidad directa, puede suponerse que las amplitudes de todas las contribuciones son similares sin haber ninguna que destaque sobre las demás, es decir, $E_{i} \approx E^{\prime}$ para $i=1, \ldots, N$. Por tanto:

$$
E e^{j \phi}=E^{\prime} \sum_{i=1}^{N} e^{j \phi_{i}}
$$

El problema se reduce, de esta forma, a calcular la distribución de la envolvente de la resultante de sumar un gran número de sinusoides con amplitud constante y fases aleatorias uniformemente distribuidas.

Puede demostrarse que las componentes en fase y cuadratura de dicha señal recibida (llámense $I$ y $Q$, respectivamente) resultan ser, por el Teorema Central de Límite, dos variables aleatorias independientes con estadística gausiana. Por tanto, la distribución de la envolvente $E=\sqrt{I^{2}+Q^{2}}$ resulta ser tipo Rayleigh:

$$
f_{E}(E)=\frac{E}{\sigma^{2}} \exp \left(-\frac{E^{2}}{2 \sigma^{2}}\right)
$$

y la de la fase $\phi=\arctan (Q / I)$, resulta uniforme, siendo ambas independientes entre sí [Pap84].

En campañas de medidas realizadas, se ha comprobado que, efectivamente, esta distribución aparece en situaciones de no visibilidad, donde todas las contribuciones vienen a tener, más o menos, la misma amplitud y las fases son tan distintas que pueden considerarse uniformemente distribuidas entre $-\pi$ y $\pi$.

En la distribución Rice debía existir al menos una componente dominante. Si esto no ocurriera, tendría la misma justificación física que la distribución Rayleigh. Así, tomando $C=0$, la ecuación (8.10) se transforma en la ecuación (8.17), pasándose de una distribución Rice a una Rayleigh. De ahí que la distribución Rayleigh se considere un caso particular de la distribución Rice. 
Puede observarse que la distribución Rayleigh es uniparamétrica, con parámetro $\sigma$. La forma de estimarlo a partir de una campaña de medidas donde se hayan tomado $N$ muestras, y utilizando el método de la FMV, es la siguiente:

$$
\hat{\sigma}^{2}=\frac{1}{2 N} \sum_{i=1}^{N} E_{i}^{2}
$$

donde $E_{i}^{2}$ debe ir en unidades lineales, resultando así $\sigma$ en las mismas unidades.

La forma de estimar $\sigma$, a través de la ecuación anterior, induce a pensar que proporciona información de la desviación típica de la distribución.

En la figura 8.5 aparece representada la función de densidad de probabilidad para dos valores distintos de $\sigma$.

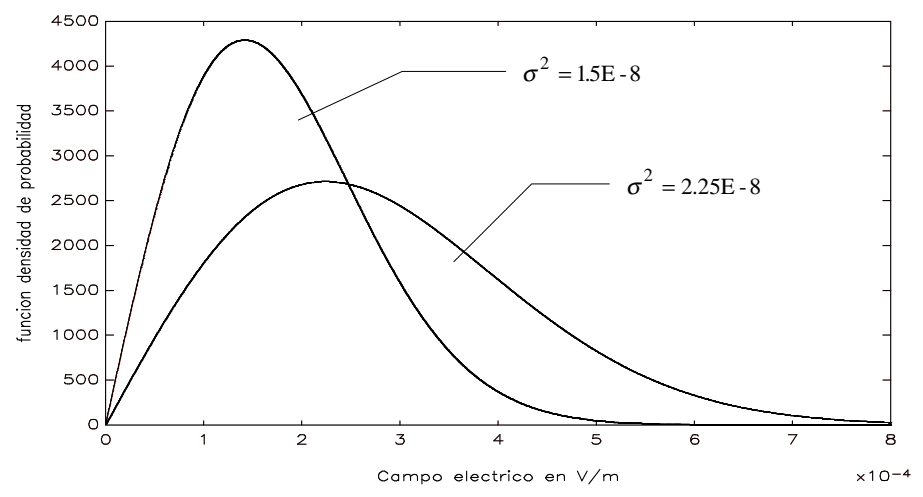

Figura 8.5: Función de densidad de probabilidad Rayleigh para dos valores distintos de $\sigma$

La distribución Rayleigh es nula para $E=0$, con lo que, si las amplitudes de las componentes aumentan en la misma proporción*, la función de densidad tiende a suavizarse para mantener constante el área bajo la curva, que debe ser igual a la unidad. El máximo de la función de densidad se tiene para $E=\sigma$ y su valor es $\frac{1}{\sigma \sqrt{e}}$.

Matemáticamente, es fácil de trabajar con la estadística Rayleigh, ya que admite una integración inmediata. El valor medio del módulo del campo eléctrico es:

$$
\bar{E}=\int_{0}^{\infty} E f_{E}(E) d E=\sigma \sqrt{\frac{\pi}{2}}=1,2533 \sigma
$$

y el valor cuadrático medio es:

$$
\overline{E^{2}}=\int_{0}^{\infty} E^{2} f_{E}(E) d E=2 \sigma^{2}
$$

con lo que la varianza de la distribución puede calcularse como:

$$
{\sigma_{E}}^{2}=\overline{E^{2}}-\bar{E}^{2}=2 \sigma^{2}-\frac{\sigma^{2} \pi}{2}=\sigma^{2}\left(\frac{4-\pi}{2}\right)=0,4292 \sigma^{2}
$$

\footnotetext{
*Es importante recalcar lo de en la misma proporción, porque de no ser así, habría componentes dominantes y tendría considerarse una distribución Rice.
} 
La ecuación anterior confirma que, efectivamente, $\sigma$ da información de la varianza. Pero, según la ecuación (8.19), también da, conjuntamente, información sobre la media de la distribución.

Aplicando la transformación (8.6), se puede calcular la función de densidad de probabilidad de la potencia expresada en $\mathrm{dBm}$, que vendrá dada por:

$$
f_{P}(P)=\frac{10^{\frac{P-30}{10}} \ln 10}{20 K \sigma^{2}} \exp \left(-\frac{10^{\frac{P-30}{10}}}{2 K \sigma^{2}}\right)
$$

La estimación de $\sigma$ sigue siendo la dada por la ecuación (8.18), es decir, en unidades lineales.

En la figura 8.6 aparecen representadas las funciones de densidad de probabilidad de la potencia en $\mathrm{dBm}$, para los mismos valores de $\sigma$ utilizados en las funciones de la figura 8.5.

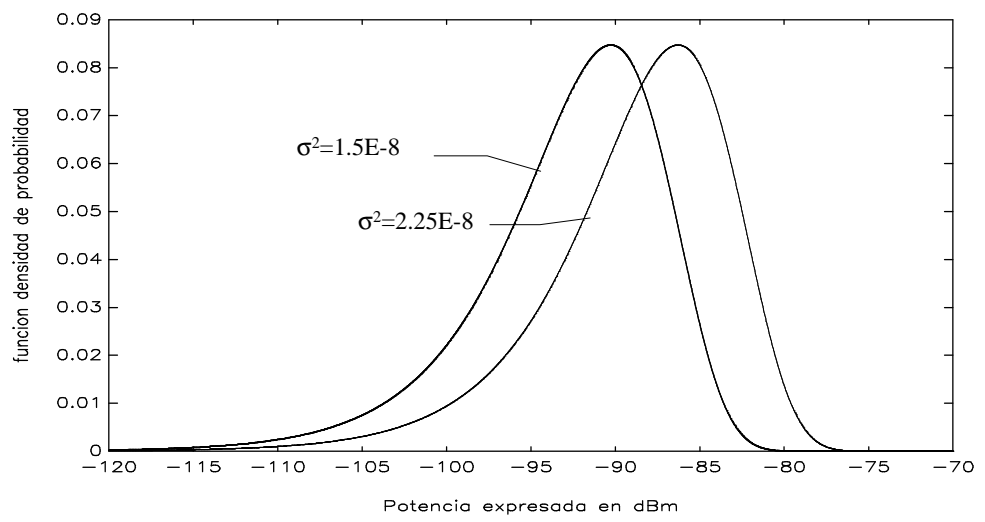

Figura 8.6: Función de densidad de probabilidad Rayleigh de la potencia en dBm, para dos valores distintos de $\sigma$

Al observar la figura 8.6, se aprecia que ambas funciones son la misma, pero desplazadas. Con la transformación logarítmica, $\sigma$ pasa a dar información de la posición de la función de densidad de probabilidad, pero nunca de desviación típica, que es constante y cuyo valor se calculará a continuación.

La potencia en $\mathrm{dBm}$, se puede expresar en función del campo eléctrico en $\mathrm{V} / \mathrm{m}$, mediante:

$$
P=10 \log \left(K E^{2}\right)+30=20 \log E+10 \log K+30
$$

El campo eléctrico en $\mathrm{dBV} / \mathrm{m}$ es:

$$
E_{\mathrm{dBV} / \mathrm{m}}=20 \log E=\alpha \ln E^{2}
$$

con $\alpha=10 \log e$, por lo que la ecuación (8.23) puede reescribirse como:

$$
P[\mathrm{dBm}]=E_{\mathrm{dBV} / \mathrm{m}}+\text { cte }
$$


Si se calcula la desviación típica del campo eléctrico en unidades logarítmicas, según la ecuación anterior, debe resultar igual a la desviación típica de la potencia en $\mathrm{dBm}$. Se trabajará con la anterior, ya que la ecuación (8.17) es matemáticamente más fácil de manipular que la ecuación (8.22). Así, se tiene que:

$$
\begin{gathered}
\overline{E_{\mathrm{dBV} / \mathrm{m}}}=\int_{0}^{\infty} \alpha \ln E^{2} f_{E}(E) d E=10 \log \left(2 \sigma^{2}\right)-2,51 \\
\overline{E_{\mathrm{dBV} / \mathrm{m}}{ }^{2}}=\int_{0}^{\infty} \sigma^{2}\left(\ln E^{2}\right)^{2} f_{E}(E) d E=\sigma^{2}\left(\frac{\pi^{2}}{6}+\left(\gamma-\sigma^{2} \ln 2\right)^{2}\right)
\end{gathered}
$$

donde $\gamma=0,5772$ es la constante de Euler. Por tanto, la varianza $\sigma_{\mathrm{dB}}{ }^{2}$ vendrá dada por:

$$
\sigma_{\mathrm{dB}}^{2}={\overline{E_{\mathrm{dBV} / \mathrm{m}}}}^{2}-{\overline{E_{\mathrm{dBV} / \mathrm{m}}}}^{2}=\frac{\alpha^{2} \pi^{2}}{6}
$$

con lo que, finalmente, la desviación típica valdrá:

$$
\sigma_{\mathrm{dB}}=\sqrt{\frac{\alpha^{2} \pi^{2}}{6}}=5,57 \mathrm{~dB}
$$

que, como puede observarse, no depende del estadístico de la distribución y es constante.

El máximo de la función de densidad de probabilidad se tiene para $10^{\frac{P-30}{10}}=2 \mathrm{~K}^{2}$, es decir, cuando $P=10 \log \left(2 K \sigma^{2}\right)+30$. Si se sustituye esta condición de máximo en (8.22), se obtiene:

$$
f_{P}(P)_{\max }=\frac{\ln 10}{10 e}=0,0847
$$

Por tanto, el máximo de la función de densidad, en escala logarítmica, es constante, con lo que la forma de la función de densidad también es constante y la única variación que puede experimentar es el desplazamiento, determinado por el valor de $\sigma$. Esto es lógico, ya que la distribución Rayleigh es uniparamétrica, y en el caso de usar la escala logarítmica, el estadístico sólo puede dar una información, que en este caso es la posición de la función de densidad.

En la práctica, el número de contribuciones que llegan al receptor no es lo suficientemente grande como para poder aplicar el Teorema Central del Límite, y no todas las contribuciones tienen la misma amplitud. Entonces, la estadística que describa realmente las variaciones rápidas de la señal recibida tendrá que ser una solución intermedia entre la distribución Rice y Rayleigh. Pero, aún así, muchos modelos de propagación siguen utilizando la estadística Rayleigh, fundamentalmente debido a su facilidad de integración.

En la literatura, puede encontrarse una gran cantidad de justificaciones empíricas del uso de la distribución Rayleigh para caracterizar el fading en entornos indoor, especialmente en ambientes densos con gran presencia de componentes multicamino [Has93]. 


\subsubsection{Desvanecimientos con estadística tipo Nakagami}

En un principio, la distribución Nakagami (también llamada distribución m) se empleó para describir de forma estadística las variaciones rápidas de la señal en propagación ionosférica y estratosférica, con buenos resultados. Estudios posteriores, y basados en campañas de medidas, han revelado que esta distribución modela, con bastante aproximación, las variaciones rápidas de la señal en comunicaciones móviles.

El fundamento físico de esta distribución es similar al de la Rayleigh, sólo que permitiendo que las amplitudes de las contribuciones sean también aleatorias [Nak60]. Así, se obtiene la expresión matemática de la función de densidad Nakagami para el módulo del campo eléctrico en unidades lineales, y que viene dada por:

$$
f_{E}(E)=\frac{2}{\Gamma(m)}\left(\frac{m}{\Omega}\right)^{m} E^{2 m-1} \exp \left(-\frac{m}{\Omega} E^{2}\right)
$$

donde $\Gamma(m)$ es la función Gamma.

Como puede apreciarse, la distribución Nakagami es biparamétrica, con parámetros $m$ y $\Omega$. El parámetro $m$ se denomina parámetro de forma por cuestiones que se detallarán más adelante, y $\Omega$ es el valor cuadrático medio de la distribución.

La función de densidad de probabilidad Nakagami está definida para $E \geq 0$ y $m \geq 1 / 2$. Si $m=1$, se convierte en la distribución Rayleigh, y si $m=1 / 2$, se reduce al tramo de una gausiana centrada en cero para valores de $E \geq 0$.

Abundando un poco más en la interpretación física de esta estadística, se puede afirmar que, para valores enteros de $m$, la distribución describe la suma de $m$ variables aleatorias con distribución Rayleigh, independientes entre sí. O, más exactamente, que la variable aleatoria dada por $Y=\sqrt{\sum_{i=1}^{m} X_{i}^{2}}$ tiene una distribución Nakagami de orden $m$ si cada variable aleatoria $X_{i}$ tiene una distribución Rayleigh y son independientes entre sí. Por ello, si $m=1$, la distribución Nakagami se convierte en Rayleigh, tal y como se ha dicho. Si $m$ no es entero, la interpretación física resulta más difícil.

En definitiva, la distribución Nakagami es una solución intermedia entre las distribuciones Rice y Rayleigh, ya que describe el módulo de la suma de un conjunto de vectores sobre los que no se impone ninguna restricción en módulo y fase, sin importar ni siquiera el número de contribuciones que llegan al receptor.

A partir del método de la FMV se puede estimar fácilmente el parámetro $\Omega$. Sin embargo, no se puede llegar a una expresión cerrada en la estimación del otro parámetro $m$. Se necesita utilizar entonces el método de los momentos, pero haciendo uso únicamente de los momentos necesarios de menor orden. Una buena aproximación de la estimación de $m$ es la proporcionada en [Par92]. Así pues, en una campaña de medidas, donde se tomen $N$ muestras, una buena estimación de los estadísticos será la siguiente:

$$
\begin{gathered}
\hat{\Omega}=\frac{1}{N} \sum_{i=1}^{N} E_{i}{ }^{2} \\
\hat{m}=\frac{4,4}{\sqrt{u_{2}}}+\frac{17,4}{1,29 u_{2}}
\end{gathered}
$$


donde:

$$
\begin{aligned}
u_{i} & =20 \log E_{i} \\
u_{1} & =\frac{1}{N} \sum_{i=1}^{N} u_{i} \\
u_{2} & =\frac{1}{N} \sum_{i=1}^{N}\left(u_{i}-u_{1}\right)^{2}
\end{aligned}
$$

En estas expresiones, las muestras de campo eléctrico $E_{i}$ van expresadas en unidades lineales, con lo que los estadísticos estimados estarán en las mismas unidades empleadas.

En la figura 8.7 aparece representada la función de densidad de probabilidad del módulo del campo eléctrico para dos valores distintos de $m$ y $\Omega$.

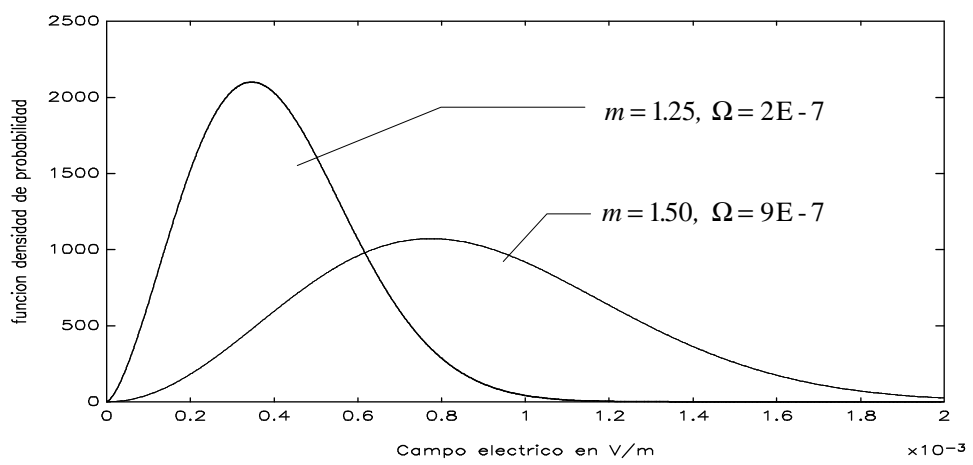

Figura 8.7: Función de densidad de probabilidad Nakagami para dos valores distintos de $m$ у $\Omega$

Las ventajas que aporta esta distribución en el estudio de las variaciones rápidas de la señal recibida, se observan al representarla en escala logarítmica. Así, la función de densidad para la potencia expresada en $\mathrm{dBm}$, se calcula a partir de la transformación (8.6), y viene dada por:

$$
f_{P}(P)=\frac{2}{\Gamma(m)}\left(\frac{m}{\Omega}\right)^{m}\left(\frac{10^{\frac{P-30}{20}} \ln 10}{20 \sqrt{K}}\right)\left(\frac{10^{\frac{P-30}{20}}}{\sqrt{K}}\right)^{2 m-1} \exp \left(-\frac{m}{\Omega} \frac{10^{\frac{P-30}{10}}}{K}\right)
$$

Al igual que se hizo con las distribuciones anteriormente explicadas, a la función de densidad de probabilidad de la potencia en $\mathrm{dBm}$, se le seguirá llamando función de densidad Nakagami, ya que de ella directamente se deriva. Hay autores que trabajan con tensión $(\mathrm{V})$ en vez de trabajar con campo eléctrico $(\mathrm{V} / \mathrm{m})$, con lo que al aplicar el cambio de variable que relaciona potencia instantánea con tensión, la función de densidad de probabilidad pasa a convertirse en la distribución Gamma [Lin93, Zha95].

En la figura 8.8 aparece representada la función de densidad de la potencia en $\mathrm{dBm}$, para los mismos valores de $m$ y $\Omega$ empleados en la representación de la figura 8.7. 


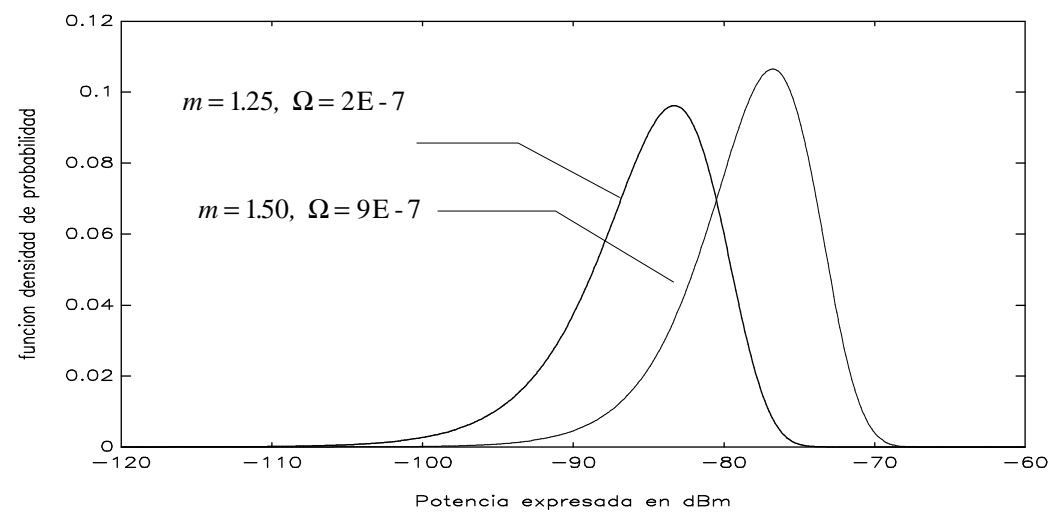

Figura 8.8: Función de densidad de probabilidad Nakagami de la potencia en dBm, para dos valores distintos de $m$ y $\Omega$

El parámetro $\Omega$ da información de la posición de la función de densidad en potencias, mientras que el parámetro $m$ da información de la forma. Si $m$ crece, la función de densidad se hace más estrecha y aumenta su altura; si $m$ disminuye, la función de densidad se ensancha, disminuyendo su altura para mantener constante el área bajo la curva.

De esta forma, según sea el valor de $m$, puede barrerse todo el abanico de posibilidades existente entre una distribución Rayleigh (cuya forma es constante) y una distribución Rice, tal y como se refleja en la figura 8.9.

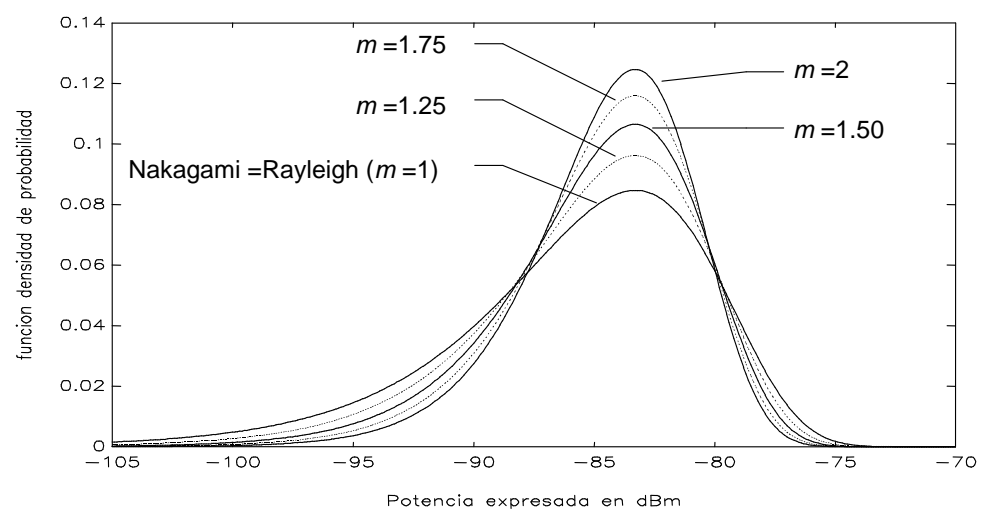

Figura 8.9: Funciones de densidad de probabilidad Nakagami para distintos valores de $m$, junto a la función de densidad de probabilidad Rayleigh

Debe aclararse que la distribución Nakagami no es una solución intermedia entre una distribución log-normal y una distribución Rice, como algunos de los autores defienden. Es cierto que la distribución Nakagami pierde su asimetría para valores de $m$ elevados $(m \gg 10)$, y puede ser aproximada por una distribución log-normal, que sí es simétrica para ciertos valores de $\mu$ y $\sigma$.

Incluso desde el punto de vista teórico expuesto, dado el significado físico de cada una de 
las estadísticas estudiadas para modelar el fading a corto plazo, se puede considerar como mejor solución la distribución Nakagami. Estos resultados teóricos han sido confirmados a través de diversas campañas de medidas, al menos en el caso de entornos urbanos, como por ejemplo en [Rub96]. En este mismo trabajo, también se demuestra que tratar de modelar la estadística a corto plazo de la señal recibida en entornos urbanos mediante Rayleigh resulta claramente pesimista respecto a los datos obtenidos experimentalmente, mientras que hacerlo mediante la distribución Nakagami permite acercase mucho más a la realidad.

Sin embargo, tal y como se ha comentado, la mayoría de los modelos de propagación empleados en comunicaciones móviles, tanto en la predicción de pérdidas como en la simulación de sistemas, consideran una estadística tipo Rayleigh para el desvanecimiento a corto plazo, con el resultado pesimista de asumir que la señal en el receptor la conforman un elevado número de contribuciones con amplitudes similares y distribución de fase uniforme. Esto puede ser debido a dos motivos; por un lado la distribución Rayleigh admite un tratamiento matemático más sencillo que la distribución Nakagami; y, por otro lado, la distribución Nakagami ha sido muy poco utilizada hasta hoy. Una de las razones que se apuntan para la escasa difusión de esta estadística, es que la mayor parte de los trabajos están escritos en japonés [Has93].

Particularmente, en el caso de comunicaciones indoor, esta distribución ha sido tradicionalmente descartada o simplemente no estudiada. En este sentido, solamente es destacable el trabajo presentado en [She93].

En la actualidad están apareciendo más publicaciones referentes a esquemas de modulación, modelado y análisis de interferencias, mecanismos de acceso celular, etcétera, basados en la estadística Nakagami. Es previsible, por tanto, que en un futuro muy próximo la distribución Nakagami sea más utilizada que en la actualidad.

\subsubsection{Desvanecimientos con estadística tipo Weibull}

La función de densidad de probabilidad de la envolvente de campo eléctrico con estadística de desvanecimientos tipo Weibull, es la siguiente:

$$
f_{E}(E)=\frac{\beta}{\alpha}\left(\frac{E}{\alpha}\right)^{\beta-1} \exp \left(-\left(\frac{E}{\alpha}\right)^{\beta}\right)
$$

Es, por tanto, una función biparámetrica, cuyos parámetros son $\alpha$, relacionado con el valor medio de la distribución, y $\beta$, denominado parámetro de forma, y que determina el ensanchamiento o dispersión (spread) de la función, así como su grado de asimetría.

$\mathrm{Al}$ contrario de lo que ocurre con las anteriores, no existe ninguna justificación teórica para utilizar esta distribución. Sin embargo, contiene a la distribución Rayleigh para el caso especial $\beta=1 / 2$. Cuando, $\beta=1$, se convierte en una función exponencial.

En la figura 8.10 se representa la función de densidad de probabilidad tipo Weibull para distintos valores de los parámetros $\alpha$ y $\beta$.

El método elegido para estimar estos parámetros a partir de una campaña de medidas 


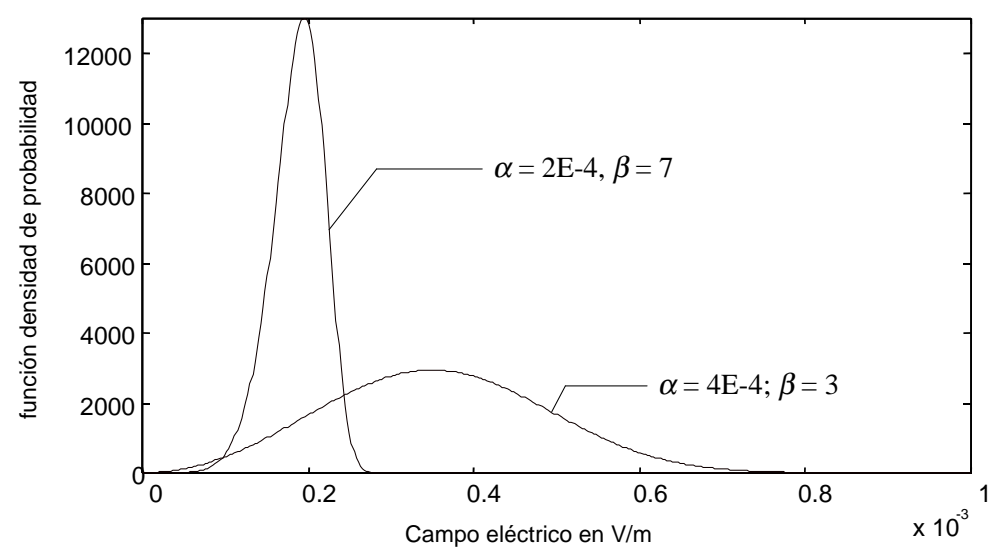

Figura 8.10: Función de densidad de probabilidad Weibull para dos valores distintos de $\alpha$ y $\beta$

ha sido el de los momentos, aunque no se llega a una solución cerrada. Así, si se calcula la media y el valor cuadrático medio de la distribución, se obtiene:

$$
\begin{aligned}
& \bar{E}=\alpha \Gamma\left(1+\frac{1}{\beta}\right) \\
& \overline{E^{2}}=\alpha^{2} \Gamma\left(1+\frac{2}{\beta}\right)
\end{aligned}
$$

A partir de estas dos expresiones, se puede llegar a la siguiente ecuación no lineal:

$$
\Gamma^{2}\left(1+\frac{1}{\beta}\right)=p \cdot \Gamma\left(1+\frac{2}{\beta}\right)
$$

siendo $p=\bar{E}^{2} / \overline{E^{2}}$. Este parámetro adicional puede ser inmediatamente estimado a partir de $N$ medidas de campo eléctrico $E_{i}$, mediante:

$$
\hat{p}=\frac{\left(\frac{1}{N} \sum_{i=1}^{N} E_{i}\right)^{2}}{\frac{1}{N} \sum_{i=1}^{N} E_{i}{ }^{2}}
$$

y, al sustituirlo en la ecuación (8.39), permitirá obtener una estima del parámetro $\beta$, a la que se llamará $\hat{\beta}$.

Posteriormente, se podrá fácilmente estimar el parámetro $\alpha$ mediante:

$$
\hat{\alpha}=\frac{\frac{1}{N} \sum_{i=1}^{N} E_{i}}{\Gamma\left(1+\frac{1}{\hat{\beta}}\right)}
$$


La función de densidad de probabilidad de la potencia en $\mathrm{dBm}$, puede ser calculada mediante la transformación (8.6), quedando como:

$$
f_{P}(P)=\frac{\beta \ln 10}{20}\left(\frac{10^{\frac{P-30}{10}}}{\alpha \sqrt{K}}\right)^{\beta} \exp \left(-\left(\frac{10^{\frac{P-30}{10}}}{\alpha \sqrt{K}}\right)^{\beta}\right)
$$

En la figura 8.11 se representa esta función de densidad de probabilidad de la potencia en $\mathrm{dBm}$ los mismos valores de los parámetros $\alpha$ y $\beta$ que en la figura 8.10.

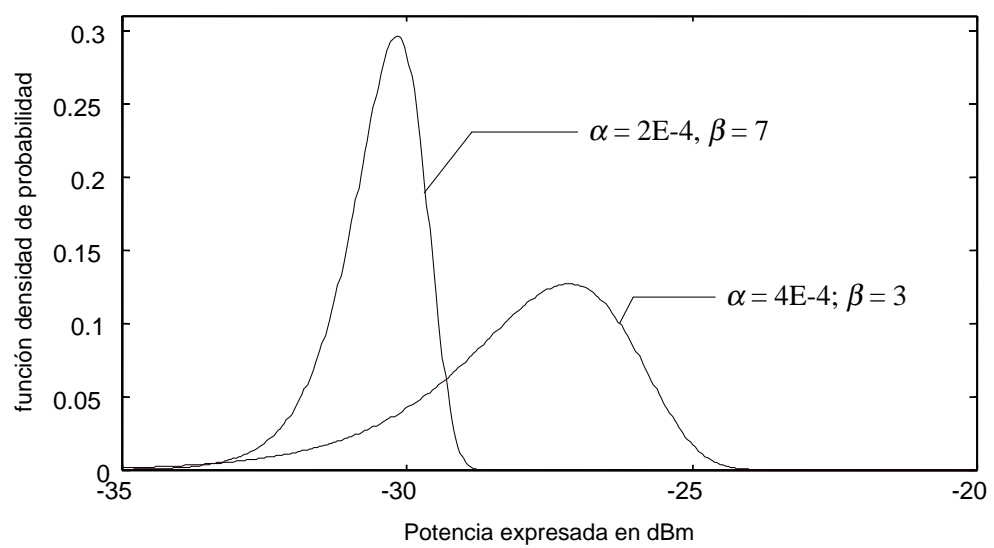

Figura 8.11: Función de densidad de probabilidad Weibull de la potencia en dBm, para dos valores distintos de $\alpha$ y $\beta$

La distribución tipo Weibull se ha ajustado bastante bien en algunas medidas generales [She77] y, más concretamente, en medidas indoor a $910 \mathrm{MHz}$, con las antenas estáticas y presencia de gente en movimiento [How91].

\subsection{Validación de los modelos de distribución estadística. Tests estadísticos}

A la hora de decidir si efectivamente una distribución estadística se ajusta realmente a las medidas obtenidas, pueden seguirse varios procedimientos.

El más inmediato es la comparación visual de las funciones de distribución de los datos con las de las estadísticas modelo. Este método resulta desaconsejable por varias razones. En primer lugar, se trata de un análisis subjetivo del que no se podrán obtener valores concretos. Además, ha de tenerse en cuenta que, aunque los modelos propuestos se refieren a variables aleatorias continuas, los datos obtenidos necesariamente serán muestras poblacionales de dichas variables aleatorias, por muchas medidas que se dispongan del entorno. Por tanto, habrá que comparar una función de distribución continua (la del modelo propuesto) con otra discreta (la de las muestras). Y, por último, resulta evidente que todas las funciones de distribución son muy parecidas (el valor inicial siempre es cero, el final es uno, y son funciones monótonas crecientes), por lo que la comparación visual es dificultosa. 
Otra posibilidad es comparar las funciones de densidad de probabilidad de los modelos estadísticos propuestos, con los histogramas normalizados de las muestras poblaciones obtenidas mediante medidas. Este análisis no es menos subjetivo que el anterior, pero resulta más evidente a simple vista. En cualquier caso, no permite ponderar el grado de aproximación de los modelos.

La opción más fiable es la de efectuar un test de consistencia estadística (o, simplemente, test estadístico). Los tests estadísticos, al igual que cualquier otro contraste de hipótesis, consiste en analizar de forma matemática dos hipótesis contrarias, para determinar cuál de las dos es más probable, y en qué medida. En el caso que nos ocupa, las dos hipótesis serán:

1. Las medidas obtenidas siguen la ley de distribución propuesta.

2. Las medidas obtenidas no siguen la ley de distribución propuesta.

Hay dos variantes para la hipótesis positiva, con sus correspondientes para la negativa. La primera consiste en especificar completamente la distribución, con unos parámetros ya predeterminados. En este caso se estaría ante un test no paramétrico. La segunda variante consiste en especificar la forma, pero no los parámetros, que se estimarían a partir de los propios datos. En este caso, se trata de un test paramétrico.

Existen dos tipos básicos de test estadistico para comprobar la consistencia de una distribución estadística con los datos obtenidos: el test $\chi^{2}$ (o chi-cuadrado) de Pearson, y el test de Kolmogorov-Smirnov. El primero puede ser paramétrico o no, mientras que el segundo sólo puede ser no paramétrico.

Esta es una de las razones por la que se ha optado por el primero. La otra es que el test de Kolmogorov-Smirnov se basa en el cálculo de la discrepancia máxima entre las funciones de distribución teórica y empírica, por lo que puede llegar a rechazar una distribución que, en media, se aproxime bastante bien. El test $\chi^{2}$, por el contrario, estudia las diferencias entre las funciones de densidad de probabilidad a lo largo de todo el espacio muestral, obviando situaciones puntuales.

\subsubsection{El test $\chi^{2}$ de Pearson}

La idea del test $\chi^{2}$ es comparar las frecuencias observadas en un histograma de los datos obtenidos, con las especificadas por el modelo teórico que se contrasta. Este contraste es válido para todo tipo de distribuciones, discretas o continuas.

Está basado en la suposición (que puede ser demostrada matemáticamente) de que, cuando el modelo es correcto, las discrepancias entre las frecuencias observadas y las previstas por el modelo, están distribuidas de acuerdo con una distribución $\chi^{2}$ (chi-cuadrado). Esta distribución estadística tiene la siguiente función de densidad de probabilidad:

$$
f_{x}(x)=\frac{1}{2^{\frac{n}{2}} \Gamma\left(\frac{n}{2}\right)} x^{\frac{n-2}{2}} e^{-\frac{x}{2}}
$$


Es una distribución uniparamétrica, a cuyo parámetro $n$ se le denomina grado de libertad. La aplicación del test consiste en disponer de un vector de datos observados $X=\left(x_{1}, \ldots, x_{n}\right)$, donde $n \geq 25$, y que será una muestra aleatoria de la variable discreta o continua que se desea estudiar.

A continuación se agrupan los $n$ datos en $k$ clases, donde interesa que $k \geq 5$. Las clases se eligen de forma que cubran todo el rango posible de valores de la variable aleatoria, y que cualquier dato quede clasificado sin ambigûedad. Conviene obtener, aproximadamente, el mismo número de datos en cada clase, de forma que sean casi equiprobables. Se llamará $O_{i}$ a las frecuencias observadas en cada clase $i$, es decir, el número total de datos muestrales en cada clase.

Para cada una de las clases, se procede a calcular la probabilidad $p_{i}$ que le asigna el modelo estadístico a estudiar. Como estas han de cubrir todo el rango de la variable aleatoria, se tiene que $\sum_{i=1}^{k} p_{i}=1$. Se llamará $E_{i}=n p_{i}$ a la frecuencia esperada de la clase $i$, obtenida de acuerdo con el modelo supuesto.

Se denomina discrepancia del modelo $Q$ al siguiente valor:

$$
Q=\sum_{i=1}^{k} \frac{\left(O_{i}-E_{i}\right)^{2}}{E_{i}}
$$

Esta discrepancia, ha de ser comparada con la distribución $\chi^{2}$ de $k-p-1$ grados de libertad, siendo $p$ el número de parámetros de la distribución a estimar. Si el test se aplica en su variante no paramétrica, se toma $p=0$.

Se denomina valor crítico $\chi_{\alpha}^{2}(n)$, con $0>\alpha>1$, al valor de $x$ que cumple $F_{n}(x)=\alpha$, siendo $F_{n}(x)$ la función de distribución $\chi^{2}$ de $n$ grados de libertad, es decir, la primitiva de (8.43). Representa el valor límite de discrepancia para asegurar que el modelo se ajusta con una confianza dada por $1-\alpha$. Este grado de confianza suele expresarse en tanto por cien.

Por tanto, una vez calculada la discrepancia, que interesará que sea lo más pequeña posible, se aceptará el modelo cuando la probabilidad de obtener una discrepancia mayor o igual que $Q$ sea suficientemente baja, es decir, cuando:

$$
Q \leq \chi_{\alpha}^{2}(k-p-1)
$$

Habitualmente se toma un valor crítico dado por $\alpha=0,95$, lo cual significa que es aceptable un grado de confianza del 5\%. Por otra parte, independientemente de que el modelo sea aceptado o no, su grado de confianza viene determinado por $1-F_{n}(Q)$, siendo $F_{n}(x)$ la función de distribución $\chi^{2}$ de $n$ grados de libertad.

\subsubsection{Validación de las distribuciones mediante las medidas realizadas en la ETSIT de Valencia}

Dado que se dispone de un método objetivo para validar las distintas distribuciones propuestas en la literatura, se procederá a utilizarlo con las medidas que se presentaron en el capítulo 4. 
Concretamente, se han estimado los parámetros de las distribuciones presentadas en este capítulo, utilizándose las medidas en banda estrecha realizadas en las distintas trazas verticales analizadas en la sección 4.2.3, y validándose los resultados obtenidos con el test $\chi^{2}$.

Si se recuerda cómo fueron realizadas dichas medidas, se estará de acuerdo en que el entorno de medida puede considerarse bastante homogéneo, en el sentido de que las variaciones en la señal recibida son a corto plazo. A pesar de ello, también se ha incluido en el estudio la distribución log-normal, aunque se sabe que es más aplicable a entornos más amplios en los que se manifiesten más las variaciones a largo plazo.

Algunos de los resultados que se han obtenido se presentan resumidos en la tabla 8.1, concretamente los correspondientes a los cuatro puntos situados en el pasillo principal del primer piso. También se presentan algunas figuras representando los histogramas normalizados de varias medidas (que pueden servir como estimación de la función de densidad de probabilidad empírica de la potencia), comparados con las funciones de densidad de probabilidad teóricas, cuyos parámetros se han estimado a partir de dichas medidas (figuras 8.12 a 8.15).

\begin{tabular}{|c|c|c|c|c|c|c|c|c|c|}
\hline \multirow{2}{*}{\multicolumn{2}{|c|}{ Distribución }} & \multicolumn{2}{|c|}{ Punto 1} & \multicolumn{2}{|c|}{ Punto 2} & \multicolumn{2}{|c|}{ Punto 3} & \multicolumn{2}{|c|}{ Punto 4} \\
\hline & & Pol. H & Pol. V & Pol. H & Pol. V & Pol. H & Pol. V & Pol. H & Pol. V \\
\hline \multirow{3}{*}{ Log-normal } & $Q$ & 174.98 & 166.96 & 173.69 & 190.46 & 214.34 & 220.60 & 154.09 & 164.17 \\
\hline & $\chi_{0.95}^{2}$ & \multicolumn{8}{|c|}{107.52} \\
\hline & $\bar{C}$ & - & - & - & - & - & - & - & - \\
\hline \multirow{3}{*}{ Nakagami } & $\bar{Q}$ & 230.04 & 296.17 & 94.43 & 210.58 & 186.04 & 160.02 & 250.66 & 161.32 \\
\hline & $\chi_{0.95}^{2}$ & \multicolumn{8}{|c|}{107.52} \\
\hline & $C$ & - & - & $22.7 \%$ & - & - & - & - & - \\
\hline \multirow{3}{*}{ Rayleigh } & $Q$ & 189.33 & 233.83 & 113.36 & 245.11 & 163.23 & 188.87 & 242.48 & 136.29 \\
\hline & $\chi_{0.95}^{2}$ & \multicolumn{8}{|c|}{108.65} \\
\hline & $C$ & - & - & $2.6 \%$ & - & - & - & - & - \\
\hline \multirow{3}{*}{ Rice } & $Q$ & 1303 & 911.23 & 489.58 & 561.55 & 936.89 & 465.95 & 2368 & 741.42 \\
\hline & $\chi_{0.95}^{2}$ & \multicolumn{8}{|c|}{107.52} \\
\hline & $C$ & - & - & - & - & - & - & - & - \\
\hline \multirow{3}{*}{ Weibull } & $Q$ & 146.52 & 226.07 & 83.26 & 188.75 & 152.41 & 143.04 & 146.19 & 132.64 \\
\hline & $\chi_{0.95}^{2}$ & \multicolumn{8}{|c|}{107.52} \\
\hline & $C$ & - & - & $53.3 \%$ & - & - & $0.01 \%$ & - & $0.07 \%$ \\
\hline
\end{tabular}

Tabla 8.1: Test estadístico $\chi^{2}$ sobre las medidas realizadas en el pasillo principal del primer piso

En la tabla se representa, para cada función de distribución, la discrepancia $Q$ obtenida en el test, el valor crítico $\chi_{0.95}^{2}$ con el que se ha de comparar para superar el test (es decir, admitiendo un grado de confianza del $5 \%$ ), y el grado de confianza resultante $C=1-F_{n}(Q)$ en $\%$, aunque solamente para aquellos casos en que se obtenga un valor significativo.

En resumen, los resultados que se obtienen no validan con la suficiente fiabilidad ninguna de las funciones de densidad de probabilidad teóricas. Salvo contados casos, el grado de confianza obtenido por el test $\chi^{2}$ es despreciable (incluso muy inferior al $1 \%$ ). 


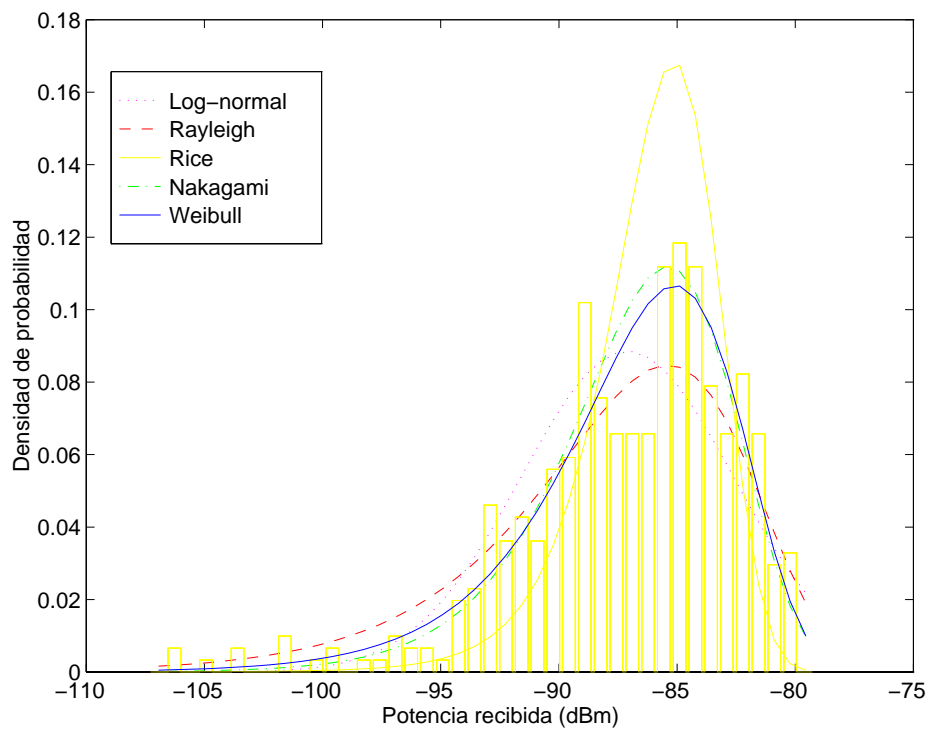

Figura 8.12: Histograma de medidas en el punto 2 del primer piso (polarización horizontal), comparado con las funciones de densidad de probabilidad teóricas

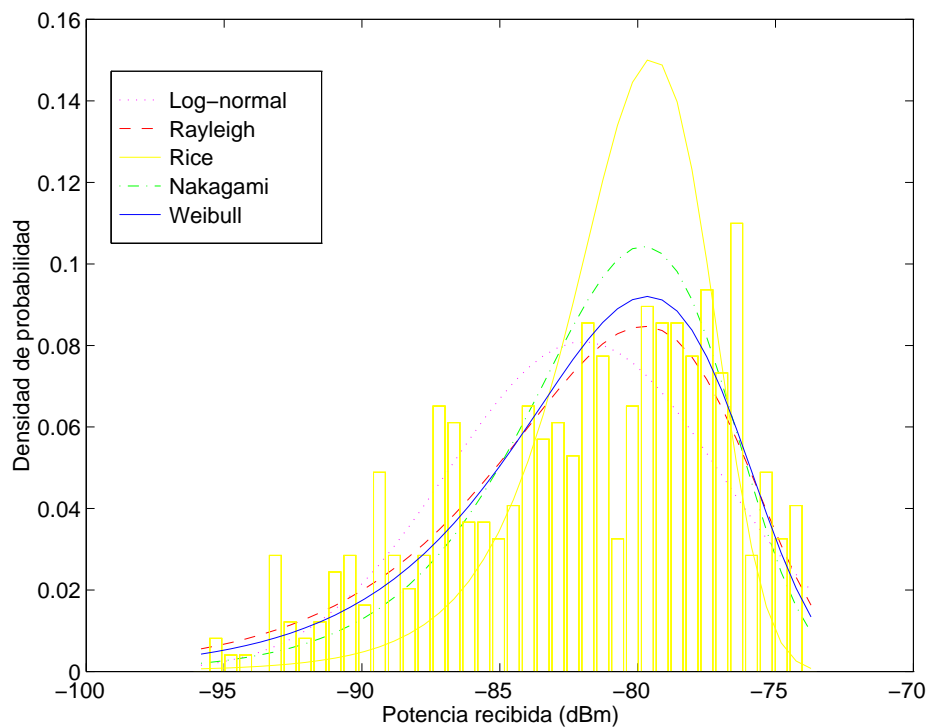

Figura 8.13: Histograma de medidas en el punto $\mathrm{C}$ (pasillo de despachos) del primer piso (polarización vertical), comparado con las funciones de densidad de probabilidad teóricas 


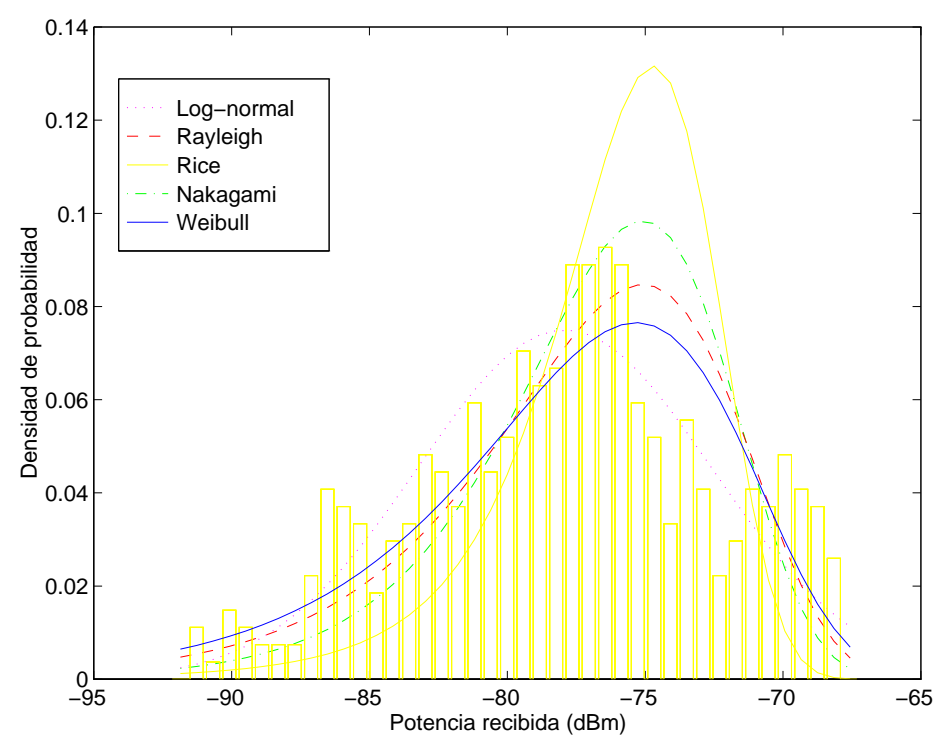

Figura 8.14: Histograma de medidas en el punto 2 del segundo piso (polarización vertical), comparado con las funciones de densidad de probabilidad teóricas

Ejemplos de medidas que se ajustan bien son la mostrada en la figura 8.12, cuyas medidas se aproximan a Weibull con un grado de confianza del $53.33 \%$ (altísimo, dados los resultados generalmente obtenidos) y a Nakagami con un $22.71 \%$; la figura 8.13 , que muestran medidas ajustadas a Rayleigh con una confianza del 1.29\% (por debajo del 5\% aconsejable), y la figura 8.14 donde el histograma se ajusta a una distribución log-normal con una confianza del $44.24 \%$ y a una Weibull con un $21.96 \%$ *

Por otro lado, en la figura 8.15 se muestran dos ejemplos de los muchos en los que las medidas no se ajustan con confianza a ninguna distribución de las expuestas. Esta circunstancia, como se ha comentado, es la más habitual y puede deberse a varias razones. En primer lugar, se parte de un conjunto muestral que puede resultar demasiado pequeño. Sería necesario obtener más datos de los mismos entornos para llegar a conclusiones más veraces. Otra posibilidad es que quizás no esté todavía todo dicho en cuanto a la caracterización estadística del canal radio móvil, especialmente en situaciones indoor. Se han de hacer estudios más profundos que escapan a los objetivos de esta Tesis, y quizás se deba proponer nuevas distribuciones que se ajusten mejor a las medidas obtenidas.

En cualquier caso, si bien el test $\chi^{2}$ no valida ninguna de las distribuciones a partir de los datos obtenidos, sí sirva para conocer qué función de densidad de probabilidad es la menos mala, es decir, cuál da un valor de $Q$ menor. Así, en los ejemplos de la figura 8.15, la distribución que mejor se ajusta según el test $\chi^{2}$ es la log-normal para el primer caso, y la Weibull para el segundo.

Hay que significar que es precisamente la distribución de Weibull la que mejor se ajusta en un $70 \%$ de los casos, mientras que el resto, salvo Rice, se reparte a partes iguales el

\footnotetext{
${ }^{*}$ Se ha detectado en muchas situaciones que, cuando las medidas se ajustan muy bien a una distribución, también lo hacen bastante bien a otra, aunque en menor grado. Esto quizás signifique que, al fin y al cabo, no son tan distintas las distribuciones teóricas que se proponen habitualmente en la literatura
} 

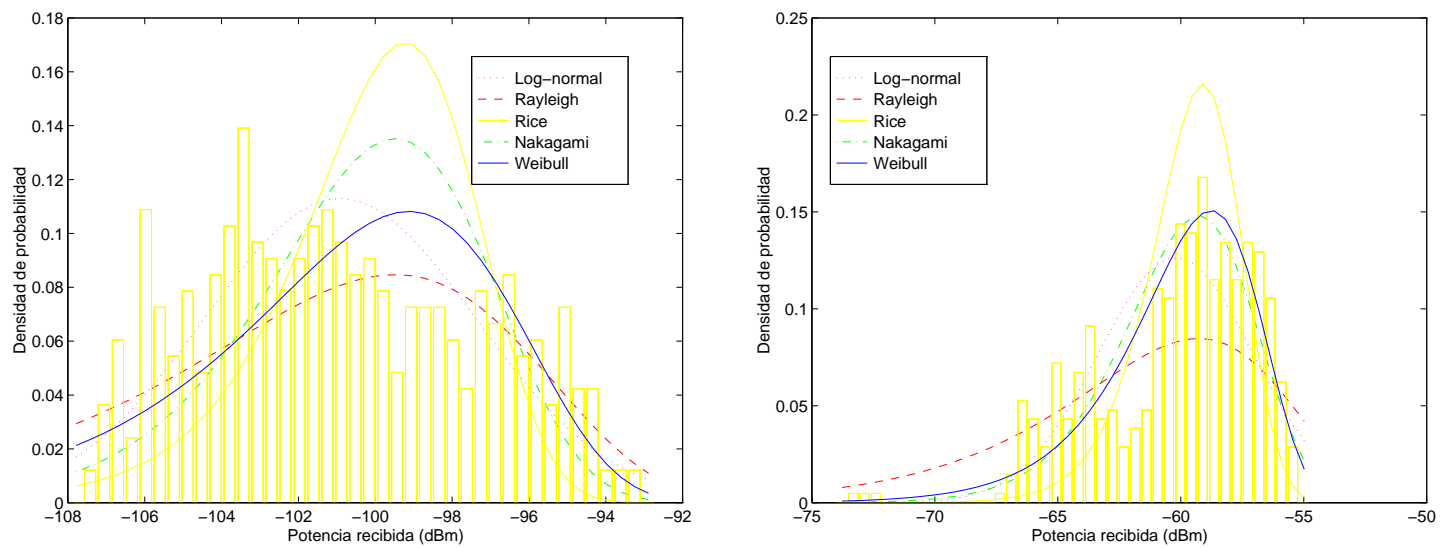

Figura 8.15: Ejemplos de histogramas de medidas que no se ajustan con confianza a ninguna función de densidad de probabilidad teórica

otro $30 \%$ de los casos. En ningún caso se aproxima más la distribución de Rice, cosa bastante lógica, ya que las medidas estaban hechas en ausencia de visibilidad directa con el transmisor.

Precisamente para estudiar este tipo de casos, a continuación serán analizadas estadísticamente dos medidas particularmente especiales. Son las dos trazas longitudinales obtenidas en banda ancha con visibilidad directa con el transmisor; una con polarización horizontal y la otra con polarización vertical. Previamente, eso sí, las funciones de transferencia obtenidas en cada punto de medida habrán sido convertidas a potencia total recibida, mediante el teorema de Parseval. Son de especial interés estas medidas debido precisamente a que era el único entorno LOS que se disponía, además de que las trazas son lo suficientemente largas como para apreciar grandes variaciones en las características del entorno. Los resultados de los tests estadísticos se presentan en la tabla 8.2.

Se aprecia que ahora la distribución de Rice se ajusta bastante mejor. De hecho es la que mejor se ajusta para el caso de polarización vertical, aunque sin superar el test de forma estricta. Por otra parte, tanto la distribución Nakagami como la log-normal superan el test $\chi^{2}$ para el caso de polarización horizontal, con un grado de confianza de casi el $9 \%$. Esto pudiera ser debido a que las múltiples reflexiones en suelo y techo de la planta donde se encontraban transmisor y receptor, favorecidas por tal tipo de polarización, provocasen que el entorno no pudiera ser considerado como perfectamente homogéneo.

Los histogramas de ambos grupos de medidas, comparados con las funciones de densidad de probabilidad teóricas, se presentan en la figura 8.16. Se observa inmediatamente lo poco apropiada que es la distribución de Rayleigh en este tipo de situaciones.

\subsection{Estudio estadístico de las simulaciones}

El objetivo principal de este capítulo no era sólo el de presentar el estado del arte en materia de caracterización estadística del canal radio móvil indoor, que es lo que se ha hecho hasta ahora. Ni tampoco el validar con absoluto rigor las distintas distribuciones 


\begin{tabular}{|c|c|c|c|}
\hline \multicolumn{2}{|l|}{ Distribución } & Pol. Horizontal & Pol. Vertical \\
\hline \multirow{3}{*}{ Log-normal } & $Q$ & 25.25 & 40.77 \\
\hline & $\chi_{0.95}^{2}$ & \multicolumn{2}{|c|}{27.59} \\
\hline & $C$ & $8.93 \%$ & $0.10 \%$ \\
\hline \multirow{3}{*}{ Nakagami } & $\bar{Q}$ & 25.27 & 41.26 \\
\hline & $\chi_{0.95}^{2}$ & \multicolumn{2}{|c|}{27.59} \\
\hline & $C$ & $8.88 \%$ & $0.09 \%$ \\
\hline \multirow{3}{*}{ Rayleigh } & $Q$ & 433.26 & 2576 \\
\hline & $\chi_{0.95}^{2}$ & \multicolumn{2}{|c|}{28.87} \\
\hline & $C$ & - & - \\
\hline \multirow{3}{*}{ Rice } & $Q$ & 38.33 & 29.92 \\
\hline & $\chi_{0.95}^{2}$ & \multicolumn{2}{|c|}{27.59} \\
\hline & $C$ & $0.22 \%$ & $2.69 \%$ \\
\hline \multirow{3}{*}{ Weibull } & $Q$ & 58.95 & 89.07 \\
\hline & $\chi_{0.95}^{2}$ & \multicolumn{2}{|c|}{27.59} \\
\hline & $C$ & - & - \\
\hline
\end{tabular}

Tabla 8.2: Test estadístico $\chi^{2}$ sobre las medidas realizadas con visibilidad directa
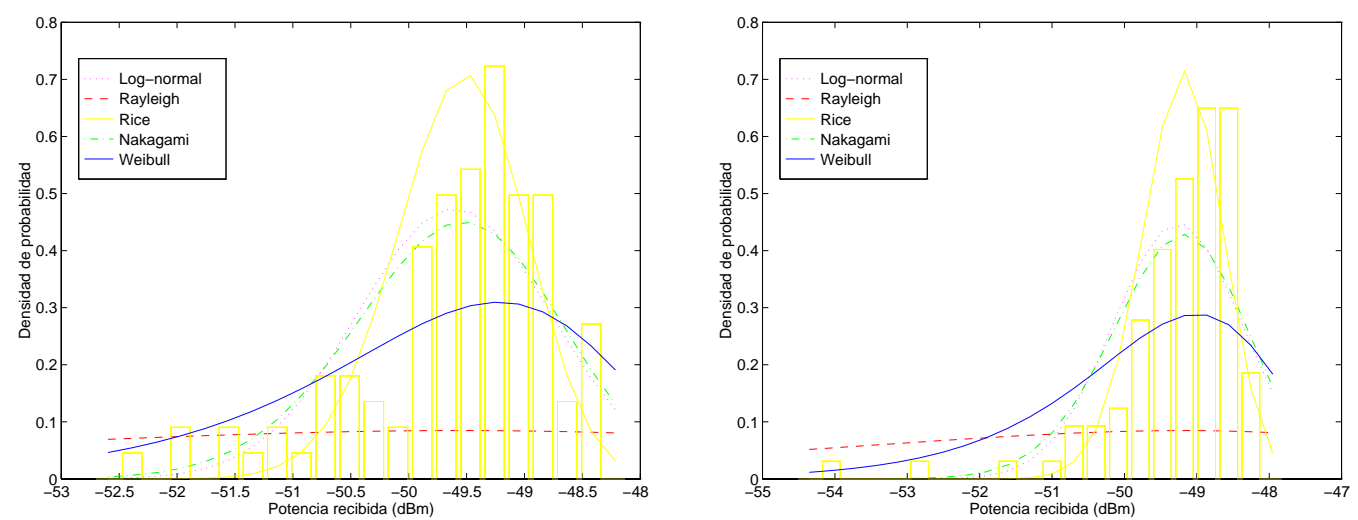

Figura 8.16: Histogramas de medidas realizados con visibilidad directa, comparados con las funciones de densidad de probabilidad teóricas. Polarización horizontal (izquierda) y vertical (derecha) 
que se proponen mediante las medidas que se presentaron en el capítulo 4 .

En realidad, la verdadera razón de ser de lo que se ha descrito en hasta aquí en este capítulo es el servir de introducción para lo que se va a desarrollar en esta sección.

Lo que aquí se pretende es intentar estudiar estadísticamente los resultados obtenidos con el simulador desarrollado, que implementa distintas técnicas de Lanzado de Rayos.

De esta forma, se analizará la capacidad del simulador para generar desvanecimientos con estadística modelable por alguna de la distribuciones propuestas en apartados anteriores.

La primera de las simulaciones que se va a analizar estadísticamente es la descrita en las páginas 184 y siguientes. Se trata de la realizada en la planta de un sencillo edificio. El entorno, a pesar de ser de reducidas dimensiones, no es estrictamente homogéneo, por lo que es de esperar que la distribución que mejor se ajuste sea la log-normal. En la tabla 8.3 se recogen los resultados del test estadístico $\chi^{2}$ obtenidos.

\begin{tabular}{|l|c|c|}
\hline Distribución & \multicolumn{2}{|c|}{ Resultados } \\
\hline Log-normal & $Q=54.74$ & $\chi_{0.95}^{2}=32.67$ \\
\hline Nakagami & $Q=3449$ & $\chi_{0.95}^{2}=32.67$ \\
\hline Rayleigh & $Q=40880$ & $\chi_{0.95}^{2}=33.92$ \\
\hline Rice & $Q=43372$ & $\chi_{0.95}^{2}=32.67$ \\
\hline Weibull & $Q=174$ & $\chi_{0.95}^{2}=32.67$ \\
\hline
\end{tabular}

Tabla 8.3: Test estadístico $\chi^{2}$ sobre las simulaciones realizadas en la planta del edificio sencillo

Efectivamente, se tiene que la mejor aproximación viene dada por la distribución lognormal, a pesar de que el nivel de confianza es muy bajo (muy por debajo del 1\%). También se observa lo poco adecuadas que resultan las distribuciones de Rice y Rayleigh. La otra distribución que se ajusta bastante bien es la Weibull. En la figura 8.17 se representa el histograma de los valores de potencia obtenidos mediante la simulación, junto con las funciones de distribución calculadas mediante ajuste de los parámetros a partir de dichos valores.

Igualmente, si se analiza la estadística de distribución de las potencias obtenidas en la simulación hecha en el edificio complejo, vista en las páginas 217 y siguientes (la de mayor resolución), también se obtiene que la función de distribución log-normal es la que mejor se aproxima al conjunto total de datos. Esta vez incluso con una grado de confianza de casi el $90 \%$. A este alto nivel de fiabilidad contribuye el hecho de que el número de muestras era muy alto. En la figura 8.18 se presenta el histograma de tal conjunto de medidas. Las distribuciones de Rayleigh y Rice se ajustaban muy pobremente, por lo que se han excluido de la comparativa. La distribución de Weibull también se aproxima bastante bien, aunque menos, claro está, que la log-normal.

Otras simulaciones que se han analizado son dos de las presentadas en las páginas 229 y siguientes, realizadas en el entorno de la ETSIT. Se presentarán directamente los histogramas, comparados con las funciones de densidad (figura 8.19). 


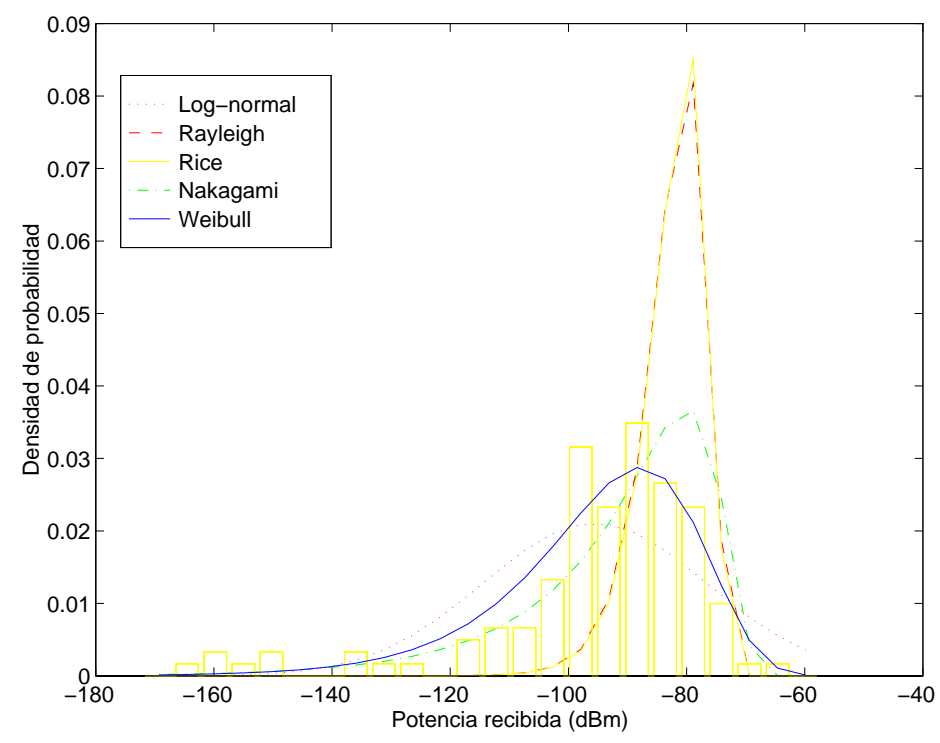

Figura 8.17: Histograma de potencias obtenidas mediante simulación en el edificio sencillo, comparado con las funciones de densidad de probabilidad teóricas

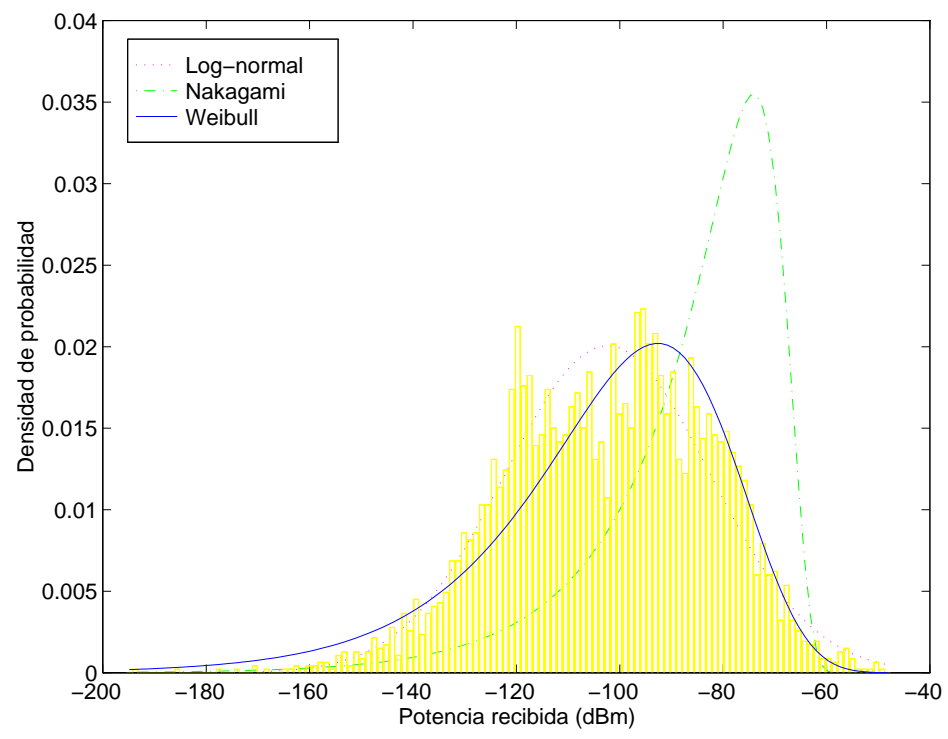

Figura 8.18: Histograma de potencias obtenidas mediante simulación en el edificio complejo, comparado con las funciones de densidad de probabilidad teóricas 

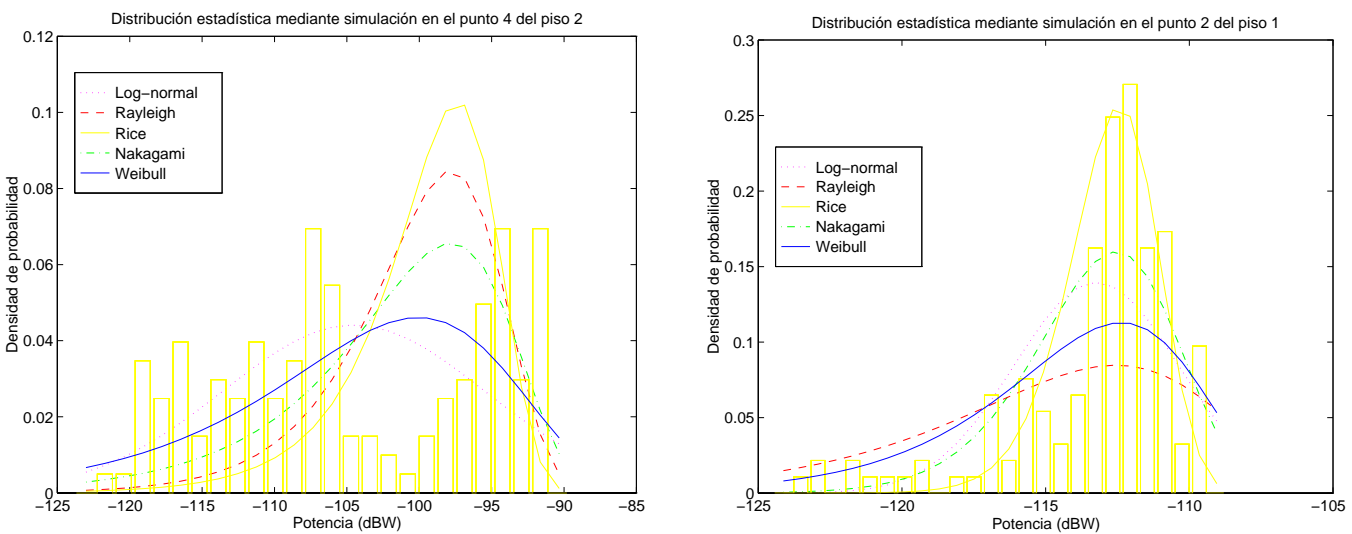

Figura 8.19: Histogramas de potencias obtenidas mediante simulación en dos puntos del edificio de la ETSIT, comparados con las funciones de densidad de probabilidad teóricas

Se aprecia subjetivamente que las distribuciones que mejor se aproximan son la Weibull para el primero y la Nakagami para el segundo. Los test $\chi^{2}$ realizados corroboran ambas observaciones, aunque no dan un grado de confianza suficiente como para superarlos.

En resumen, del conjunto de simulaciones analizadas, casi la mitad se ajustaban bien a la distribución de Weibull, aunque en ningún caso el grado de confianza era superior al 1\%. La distribución log-normal se aproximaba bastante bien en ciertas situaciones, especialmente cuando la variabilidad del entorno era manifiesta. Sólo esporádicamente se obtenía que la distribución Nakagami o la Rayleigh fuese apropiada, y nunca la de Rice, ni siquiera en situaciones LOS.

\subsection{Resumen y conclusiones}

En este capítulo, se han visto las distintas distribuciones que se han propuesto tradicionalmente en la literatura para caracterizar la estadística de las señales recibidas en comunicaciones móviles, poniendo especial énfasis en los implementados en entornos indoor.

Esta estadística ha de estudiarse en dos formas: a largo plazo, considerando que el entorno es muy cambiante y analizando las lentas variaciones de la señal en torno a su valor medio, y a corto plazo, estudiándose las rápidas variaciones que sufre la señal en pequeños desplazamientos en los que se puede considerar que el entorno es aproximadamente homogéneo.

En el primer caso, está ampliamente admitido que la distribución que mejor se puede ajustar a la realidad es la log-normal. Sin embargo, no ocurre lo mismo con el estudio del fading rápido. Se han propuesto varias distribuciones, siendo aplicable cada una en distintas circunstancias.

Además de repasar las distintas distribuciones, se ha explicado la forma de estimar sus parámetros de forma que se ajusten mejor a los datos obtenidos empíricamente. También se ha visto que la mejor forma de validar la bondad de este ajuste es mediante el test $\chi^{2}$ 
de Pearson. Con él se obtienen datos numéricos objetivos que dicen si el test es superado, y que incluso dan el grado de aproximación obtenido.

Una vez repasados todos estos puntos, se ha procedido a comprobar qué distribución se ajustaba mejor a las medidas realizadas en el edificio de la ETSIT. La conclusión a la que se llega es que, en un alto porcentaje de los casos, la distribución que mejor se ajustaba era la de Weibull que, paradójicamente, carece de interpretación física alguna. A pesar de ello, el grado de confianza que da el test $\chi^{2}$ es, en la mayoría de los casos, insignificante.

Por último, como objetivo principal de este capítulo, se han analizado estadísticamente algunas simulaciones realizadas mediante las técnicas de Lanzado de Rayos vistas en esta Tesis. Los resultados obtenidos al aplicar el test $\chi^{2}$ son similares al caso de medidas reales. Es decir, pocas veces el grado de confianza obtenido es significativo, pero en la mayoría de los casos la función que mejor se aproxima es la Weibull.

Solamente en casos particulares, las distribuciones mejor ajustadas son otras. Tal es el caso, por ejemplo, de entornos de gran variabilidad, donde se ajusta mejor la estadística $\log$-normal.

Se tiene, por tanto, un simulador que es capaz de generar señales con distribuciones estadísticas realistas, pudiendo ser utilizado para analizar métodos de modulación o de ecualización, técnicas de diversidad y otras tecnologías de recepción, sin necesidad de acudir a datos empíricos. 



\section{Capítulo 9}

\section{Conclusiones y trabajos futuros}

\subsection{Conclusiones}

La conclusión fundamental de esta Tesis es que, bajo ningún concepto, puede obviarse la naturaleza tridimensional del entorno a la hora de modelar la propagación en el interior de edificios. Máxime cuando dicho modelado tiene el propósito de ser utilizado para diseñar o analizar sistemas de comunicaciones indoor que van a involucrar más de una planta del edificio.

A esta conclusión se llega tanto después de analizar la campaña de medidas realizada en el interior de la ETSIT con tal propósito, como al obtener simulaciones mediante las distintas técnicas de Lanzado de Rayos que se han presentado en esta Tesis.

Son precisamente estas técnicas las más adecuadas para caracterizar con precisión en canal radio móvil en este tipo de entornos. Sin embargo, habrá de poner un cuidado especial al implementarlas, pues de ello depende el nivel de fiabilidad de los resultados.

En esta Tesis se han visto múltiples procedimientos que resuelven los principales problemas que aparecen al implementar estos modelos, y que permiten simular con detalle los distintos fenómenos de propagación que se producen en el interior de los edificios. Así se ha demostrado al proceder a validar con exhaustividad los resultados obtenidos, comparándolos, incluso, con medidas reales.

Mención especial merece la variante denominada Lanzado de Tubos que ha sido presentada en esta Tesis. Es particularmente útil para aquellos casos en los que el entorno de simulación no sea excesivamente grande o complejo. Concretamente, es recomendable en situaciones in-room, es decir, entornos cóncavos y cerrados, con abundancia de visibilidad directa con el transmisor, como podría ser una habitación de un edificio, siendo indiferente sus dimensiones. Hay que tener en cuenta que las futuras redes de comunicaciones indoor inalambricas, tienden a una superfragmentación celular, llegándose al caso de estaciones base que den cobertura a una zona muy pequeña como, por ejemplo, un laboratorio o un hall de un edificio.

Además, todas estas técnicas, a pesar de su naturaleza determinista, se han demostrado perfectamente válidas para simular propagación multi-camino, pudiéndose obtener 
desvanecimientos rápidos con estadística tan realista como la que pueda existir en la realidad.

En definitiva, el modelado proporciona una herramienta muy potente para la caracterización del canal radio móvil en el interior de edificios, tanto para el caso de banda estrecha (modelado de pérdidas de propagación y estadística de desvanecimientos), como en banda ancha (respuestas impulsionales, perfiles de potencia-retardo, funciones de scattering, etc.).

\subsection{Futuras líneas de investigación}

Las líneas de investigación que se proponen a partir de esta Tesis pueden agruparse en dos grupos.

Un primer grupo sería el constituído por aquellos trabajos tendentes a mejorar la capacidad de modelado óptimo de los métodos de Lanzado de Rayos. Aunque, tal y como se han propuesto en esta Tesis, son perfectamente utilizables en la mayoría de las situaciones habituales, hay todavía mucho que hacer para mejorar su velocidad de proceso sin merma de su capacidad de precisión. Sin embargo, son actuaciones que dejan a un lado el campo del modelado de la propagación para adentrarse más en el mundo de la algorítmica y la optimización de procesos informáticos.

El segundo grupo de líneas de trabajo (en opinión del autor de esta Tesis, el más importante) es el relacionado con la utilización práctica del simulador para el análisis, diseño y validación de técnicas de recepción, tales como modulaciones, métodos de ecualización, técnicas de diversidad, diseño de agrupaciones de antenas adaptativas, etc.

Para ello se pone a disposición toda la potencia del simulador para obtener señales recibidas con un acusado fading, con características bastante más realistas que las que pueda dar cualquier distribución estadística teórica; respuestas impulsionales y perfiles de potencia-retardo propios del entorno que se pretenda analizar, proporcionando incluso las distribuciones tridimensionales de los ángulos de llegada en cada receptor. 


\section{Bibliografía}

[Agu91] R. Agustí, F.J. Pérez, and S. Ruiz. Obtención del perfil de retardo de potencias en un entorno "indoor" mediante el uso de un analizador de redes. In VI Symposium Nacional de la URSI, Cáceres, Septiembre 1991. URSI.

[Ale82] S.E. Alexander. Radio propagation within buildings at 900MHz. Electronic Letters, 18(21):913-914, Octubre 1982.

[Ale83] S.E. Alexander. Characterising buildings for propagation at 900MHz. Electronic Letters, 19(20):860, Septiembre 1983.

[Al191] G. Allen and A. Hammoudeh. Frequency diversity propagation measurements for an indoor $60 \mathrm{GHz}$ mobile radio link. In Proceedings of the 7th Conference on Antennas and Propagation. IEE, Abril 1991.

[Ame53] W.S. Ament. Toward a theory of reflection by a rough surface. Proceedings of the IRE, 41(1):142-146, Enero 1953.

[Arr73] G.A. Arredondo, W.H. Chriss, and E.H. Walker. A multipath fading simulation for mobile radio. IEEE Transactions on Vehicular Technology, 22(4):241-244, Noviembre 1973.

[Baj82] A.S. Bajwa and J.D. Parsons. Small-area characterization of UHF urban and suburban mobile radio propagation. IEE Proceedings-F, 129(2):102-109, Abril 1982.

[Bal82] Constantine A. Balanis. Antenna theory analisis and design. John Wiley \& Sons, New York, 1982.

[Bal89] C. A. Balanis. Advanced Engineering Electromagnetics. John Wiley \& Sons, New York, 1989.

[Bar95a] Constantino Barber, Thomas Zwick, Narcís Cardona, and Santiago J. Flores. Wave propagation modeling in closed environments within the $\mathrm{mm}$ wave band. In X Symposium Nacional de la URSI, pages 845-848, Valladolid, Septiembre 1995. URSI.

[Bar95b] Constantino J. Barber. Wave propagation modeling in closed environments within the $\mathrm{mm}$ wave band. Proyecto fin de carrera, Institut für Höchstfrequenztechnik und Elektronik, Karlsruhe, Germany, Junio 1995. 
[Bel63] Philip A. Bello. Characterization of randomly time-variant linear channels. IEEE Transactions on Communication Systems, 4(11):360-393, Diciembre 1963.

[Bla91] K.L. Blackard, T.S. Rappaport, and C.W. Bostian. Radio frequency noise measurements and models for indoor wireless communications at $918 \mathrm{MHz}, 2.44 \mathrm{GHz}$ and 4.0GHz. In Conference Record of the International Conference on Communications, ICC'91, volume 1, pages 1.6.1-5, Denver, USA, Junio 1991. IEEE Communications Society.

[Bod82] W.F. Bodtmann and H.W. Arnold. Fade-duration statistics of Rayleighdistributed wave. IEEE Transactions on Communications, 30(3):549-553, Marzo 1982.

[Boi87] L. Boithias. Radio wave propagation. Mc-Graw-Hill Inc., New York, 1987.

[Bur83] W.D. Burnside and K.W. Burgener. High frequency scattering by a thin lossless dielectric slab. IEEE Transactions on antennas and Propagation, 31(1):104-111, Enero 1983.

[Cas90] E. Casas and C. Leung. A simple digital fading simulator for mobile radio. IEEE Transactions on Vehicular Technology, 39(3):205-212, Agosto 1990.

[Cel85] V. Celli, A.A. Maradudin, A.M. Marvin, and A.R. McGurn. Some aspects of light scattering from a randomly rough metal surface. Journal of the Optical Society of America, 2(12):2225-2239, Diciembre 1985.

[Che97] S. Chen and S. Jeng. An SBR/Image approach for radio wave propagation in indoor environments with metallic furniture. IEEE Transactions on Antennas and Propagation, 45(1):98-106, Enero 1997.

[Cic94a] D.J. Cichon, T. Becker, and W. Wiesbeck. A Ray Launching approach for indoor and outdoor applications. Temporary Document TD (94) 032, COST231, Lisboa, Portugal, Enero 1994.

[Cic94b] D.J. Cichon and W. Wiesbeck. Indoor and outdoor propagation modeling in pico cells. In Proceedings of PIMRC'94, pages 491-495, The Hague, Netherlands, Septiembre 1994.

[Cic95] D.J. Cichon, T. Zwick, and J. Lähteenmäki. Ray optical indoor modeling in multi-floored buildings: Simulations and measurements. In Proceedings of International Antennas and Propagation Symposium, pages 522-525, Newport Beach, USA, 1995.

[Col85] Robert E. Collin. Antennas and Radiowave Propagation. Electrical Engineering Series. McGraw-Hill International Editions, 1985.

[Cox72] D.C. Cox. Delay Doppler characteristics of multipath propagation at $910 \mathrm{MHz}$ in a suburban mobile radio environment. IEEE Transaction on antennas and Propagation, 20(5):625-635, Septiembre 1972. 
[Cox83] D.C. Cox, R.R. Murray, and A.W. Norris. Measurements of 800MHz radio transmission into buildings with metallic walls. The Bell System Technical Journal, 62(9):2695-2717, Noviembre 1983.

[Cox86] D.C. Cox, R.R. Murray, H.W. Arnold, A.W. Norris, and M.F. Wazowicz. Crosspolarization coupling measured for $800 \mathrm{MHz}$ radio transmision in and around houses and large buildings. IEEE Transactions on Antennas and Propagation, 34(5):83-87, Enero 1986.

[Dam96] Eraldo Damoso, editor. Final COST 231 Report. Digital Mobile Radio: COST 231 view on the evolution towards $3^{\text {rd }}$ generation systems. Springer Verlag, 1996.

[Der93] U. Dersch and E. Zollinger. Propagation mechanisms in microcell and indoor environments. In IEEE Proceedings, Joint COST 227 Workshop on Mobile Communications, Septiembre 1993.

[Dev90] D.M.J. Devarsirvatham, C. Banerjee, M.J. Krain, and D.A. Rappaport. Multifrequency radiowave propagation measurements in the portable radio environment. In Conference Record of the IEEE International Conference on Communications'90, volume 4. IEEE, Abril 1990.

[Dri93] P.F. Driessen, M. Gimersky, and T. Rhodes. Wireless Personal Communication, chapter Ray Model of Indoor Propagation. Kluwer Academic Publishers, 1993.

[Dur97a] Greg Durgin, Neal Patwari, and Theodore S. Rappaport. An advanced 3D Ray Launching method for wireless propagation prediction. In IEEE 47th Vehicular Technology Conference Proceedings, volume 2, pages 785-789, Phoenix, USA, Mayo 1997. IEEE.

[Dur97b] Greg Durgin, Neal Patwari, and Theodore S. Rappaport. Improved 3D ray launching method for wireless propagation prediction. Electronic Letters, 33(16):1412-1413, Julio 1997.

[Fai89] M. Failli, editor. Final COST 207 Report. Digital Land Mobile Communications. CEC, 1989.

[Flo93] Santiago J. Flores and Albert Prades. Diseño de un simulador de canal móvil en entornos microcelulares a $1.9 \mathrm{GHz}$. contrastación experimental. Proyecto fin de carrera, Universitat Politècnica de Catalunya, Barcelona, Mayo 1993.

[Flo95a] Santiago J. Flores, José C. Bautista, and Narcís Cardona. Influence of the antenna height on the analysis of the mobile radio channel inside multi-floored buildings. Temporary Document TD (95) 145 \& 145bis, COST 231, Poznan, Poland, Septiembre 1995.

[Flo95b] Santiago J. Flores, José C. Bautista, J. Félix Lanzuela, and Narcís Cardona. Medida y caracterización del canal radio móvil en el interior de edificios con múltiples plantas. In X Symposium Nacional de la URSI, pages 837-840, Valladolid, Septiembre 1995. URSI. 
[Gil94] George Gilder. Telecosm. Simon \& Schuster, 1994.

[Has92a] H. Hashemi, D. Lee, and D. Ehman. Statistical modeling of the indoor radio propagation channel - part II. In Proceedings of the IEEE Vehicular Technology Conference. VTC'92, pages 839-843, Denver, USA, Mayo 1992. IEEE VTS.

[Has92b] H. Hashemi, D. Tholl, and G. Morrison. Statistical modeling of the indoor radio propagation channel - part I. In Proceedings of the IEEE Vehicular Technology Conference. VTC'92, pages 338-342, Denver, USA, Mayo 1992. IEEE VTS.

[Has93] Homayoun Hashemi. The indoor radio propagation channel. Proceedings of the IEEE, 81(7):943-967, Julio 1993.

[Has94] H. Hashemi and D. Tholl. Statistical modeling and simulation of the RMS delay spread of indoor radio propagation channels. IEEE Transactions on Vehicular Technology, 43(1):110-120, Febrero 1994.

[Hon92] Walter Honcharenko, Henry L. Bertoni, James L. Dailing, J. Qian, and H.D. Lee. Mechanisms governing UHF propagation on single floors in modern office buildings. IEEE Transactions on Vehicular Technology, 41(4):496-504, Noviembre 1992.

[Hon93] W. Honcharenko, H.L. Bertoni, and J. Dailing. Mechanisms governing propagation between different floors in buildings. IEEE Trans. on Antennas and Propagation, 41(6):787-790, Junio 1993.

[How91] S.J. Howard and K. Pahlavan. Fading results from narrowband measurements of the indoor radio channel. In Proceedings of the 2nd IEEE International Symposium of Personal, Indoor and Mobile Radio Communications, pages 92-97, London, England, Septiembre 1991.

[How92] S.J. Howard and K. Pahlavan. Autorregresive modeling of wide-band indoor radio propagation. IEEE Transactions on Communication, 40(9):1540-1592, Septiembre 1992.

[Hus94] Thomas Huschka. Ray-tracing models for indoor environments and their computational complexity. In Proceedings of PIMRC'94, pages 486-490. PIMRC, 1994.

[Joe94] Wiart Joe. Indoor electromagnetic wave propagation measurements and modeling. Temporary Document TD (94) 024, COST 231, Lisbon, Portugal, Enero 1994.

[Kar95] P. Karlsson. Indoor radio propagation for personal communications services. PhD thesis, University of Lund, Lund, Sweden, 1995.

[Kee90] J.M. Keenan and A.J. Motley. Radio coverage in buildings. British Telecom Technology Journal, 8(1):19-24, Enero 1990.

[Kel62] J.B. Keller. Geometric Theory of Diffraction. Journal of the Optical Society of America, 52(2):116-130, Febrero 1962. 
[Kou74] R.G. Kouyoumjian and P.H. Pathak. A Uniform Geometrical Theory of Diffraction for an edge in a perfectly conducting surface. Proceedings of the IEEE, 61(11):1448-1461, Noviembre 1974.

[Koz84] S. Kozono, T. Tsuruhara, and M. Sakamoto. Base station polarization diversity reception for mobile radio. IEEE Transactions on Vehicular Technology, 33(4):301-306, Noviembre 1984.

[Kre93] P. Kreuzgruber, P. Unterberger, and R. Gahleitner. A ray splitting model for indoor radio propagation associated with complex geometries. In Proceedings of the VTC'93, pages 227-230, New Jersey, USA, Mayo 1993. IEEE VTS.

[Läh93] J. Lähteenmäki. Indoor path loss measurements at 1.7GHz. Temporary Document TD (93) 042, COST 231, Barcelona, Enero 1993.

[Läh94] J. Lähteenmäki. Indoor propagation between floors at $855 \mathrm{MHz}$ and $1.8 \mathrm{GHz}$. Temporary Document TD (94) 037, COST 231, Lisbon, Portugal, Enero 1994.

[Lan93] O. Landron, M.J. Feuerstein, and T.S. Rappaport. In situ microwave reflection coefficient measurements for smooth and rough exterior wall surfaces. In Proceedings of the Vehicular Technology Conference. VTC'93, pages 77-80, Secaucus, USA, Mayo 1993. IEEE.

[Lau94] David I. Laurenson. Indoor Radio Channel Propagation Modelling by Ray Tracing Techniques. PhD thesis, University of Edinburgh, Edinburgh, UK, 1994.

[Law92] M.C. Lawton and J.P. McGeehan. The application of GTD and Ray Launching techniques to channel modeling for cordless radio systems. In Proceedings of the $42^{\text {nd }}$ VTS Conference, volume 1, pages 125-130, Denver, USA, Mayo 1992. IEEE.

[Law94] M.C. Lawton and J.P. McGeehan. The aplication of a deterministic Ray Launching algorithm for the prediction of radio channel characteristics in small-cell environments. IEEE Transaction on Vehicular Technology, pages 955-976, 1994.

[Lay97] Frank Layer, Ralf Kattenbach, and Henning Früchting. Ray optical approach for a wideband indoor wave propagation model with moving receiver. In Proceedings of the PIMRC'97, pages 135-139, Helsinki, Finland, Septiembre 1997.

[Lee85] William C.Y. Lee. Estimate of local average power of a mobile radio signal. IEEE Transactions on Vehicular Technology, 34(2), 1985.

[Lee92] William C.Y. Lee. Mobile Communications Engineering. McGraw-Hill, 1992.

[Lin93] Jean-Paul Linnartz. Narrowband land-mobile radio networks. Artech-House, Boston, 1993.

[Lo92] T. Lo and J. Litva. Angles of arrival of indoor multipath. Electronic Letters, 28(18):1687-1689, Agosto 1992.

[Lue84] R.J. Luebbers. Finite conductivity Uniform GTD versus knife edge diffraction in prediction of propagation path loss. IEEE Transactions on Antennas and Propagation, 32(1):70-76, Enero 1984. 
[May97] Luis Mayorgas, Francisco Jiménez, and Santiago J. Flores. Estudio comparativo entre el Lanzado de Rayos y el Lanzado de Tubos para el modelado del canal radio móvil indoor. In XII Symposium Nacional de la URSI, Bilbao, Septiembre 1997. URSI.

[McK91] J.W. McKown and R.L. Hamilton, Jr. Ray tracing as a design tool for radio networks. IEEE Network Magazine, 5(6):27-30, Noviembre 1991.

[Mel92] P. Melancon and J. Lebel. Effects of fluorescent lights on signal fading characteristics for indoor radio channel. Electronic Letters, 28(18):1740-1741, Agosto 1992.

[Mol91] D. Molkdar. Review on radio propagation into and within buildings. IEE Proceedings- H, 138(1):61-73, Febrero 1991.

[Nak60] Minoru Nakagami. The m-distribution-A general formula of intensity distribution of rapid fading. In W.C. Hoffman, editor, Statistical Methods of Radio Wave Propagation: Proceedings of a Symposium Held at the University of California, pages 3-36. Pergammon Press, 1960.

[Nav94] Fernando Navarro. Modelo teórico del canal móvil en área urbana. Proyecto fin de carrera, Universidad Politécnica de Valencia, Valencia, 1994.

[Owe89] F.C. Owen and C.D. Pudney. In-building propagation at $900 \mathrm{MHz}$ and $1650 \mathrm{MHz}$ for Digital Cordless Telephones. In Sixth International Conference on Antennas and Propagation, ICAP'89, volume 2: Propagation, University of Warwick, Coventry, UK, Abril 1989. IEE.

[Pah89] K. Pahlavan and S.J. Howard. Frequency domain measurements of indoor radio channels. Electronic Letters, 27(24), Noviembre 1989.

[Pap84] A. Papoulis. Probability, Random Variables, and Stochastic Processes. McGrawHill Co., 1984.

[Par82] J.D. Parsons and A.S. Bajwa. Wideband characterization of fading mobile radio channels. IEE Proceedings-F, 129(2):95-101, Abril 1982.

[Par92] J.D. Parsons. The mobile radio propagation channel. Pentech House, London, UK, 1992.

[Pér93] V.M. Pérez and J. Jiménez. Medidas de propagación a $1.8 \mathrm{GHz}$ en ambientes interiores. In VII Symposium Nacional de la URSI, volume 2, pages 925-929, Valencia, Septiembre 1993. URSI.

[Pér95] V. Pérez, I. Ruiz, U. Dersch, and J. Jiménez. Microcell measurements analyisis. Temporary Document TD (95) 046, COST 231, Berna, Switzerland, Enero 1995.

[Pro89] J.G. Proakis. Digital communications. McGraw-Hill Series in Electrical Engineering. McGraw-Hill Book Company, second edition, 1989.

[Rap89] T.S. Rappaport. Characterization of UHF multipath radio channels in factory buildings. IEEE Transactions on Antennas and Propagation, 37(8):1058-1069, Agosto 1989. 
[Ree53] H.R. Reed and C.M. Russel. Ultra High Frequency Propagation. John Wiley \& Sons, 1953.

[Ric54] S.O. Rice. Mathematical analysis of random noise. Bell Systems Technology Journal, 24:46-156, 1954.

[Rub96] Lorenzo Rubio. Caracterización estadística del canal móvil en entorno urbano. Proyecto final de carrera, Universidad Politécnica de Valencia, Valencia, Marzo 1996.

[Rui90] Silvia Ruiz, Antonio Valdovinos, and Ramón Agustí. Fading and diversity measuremets inside buildings. Temporary Document TD (90) 094, COST 231, Enero 1990.

[Rui91] Silvia Ruiz, Ramón Agustí, and Javier Pérez. Indoor wideband channel characterization $(900$ and $1800 \mathrm{MHz})$ by means of a network analyzer. Temporary Document TD (91) 071, COST 231, Lund, Sweden, Febrero 1991.

[Rui93] Silvia Ruiz. Polarization diversity for indoor mobile communications. Temporary Document TD (93) 014, COST 231, Barcelona, Enero 1993.

[Rum81] W.D. Rummler. More on the multipath fading channel model. IEEE Transactions on Communication, 29(3):346-352, Marzo 1981.

[Sal87] A.A.M. Saleh and R.A. Valenzuela. A statistical model for indoor multipath propagation. IEEE Journal on Selected Areas in Communications, 5(2):128137, Febrero 1987.

[Sch33] J.C. Schelling, C.R. Burrows, and E.B. Ferrell. Ultra-Short wave propagation. Bell Systems Technology Journal, 12:125-161, Abril 1933.

[Sch92] K.R. Schubach, N.J. Davis, and T.S. Rappaport. A ray tracing method for predicting path loss and delay spread in microcellular environments. In Proceedings of VTC'92, pages 932-935, Denver, USA, Mayo 1992. IEEE VTS.

[Sei92] Scott Y. Seidel and T.S. Rappaport. 914MHz path loss prediction models for indoor wireless communications in multifloored buildings. IEEE Transactions on Antennas and Propagation, 40(2):207-217, Febrero 1992.

[Sei94] S.Y. Seidel and T.S. Rappaport. Site-specific propagation prediction for wireless in-building personal communication system design. IEEE Transactions on Vehicular Technology, 43(4):879-891, Noviembre 1994.

[She77] N.H. Shepherd. Radio wave loss deviation and shadow loss at 900MHz. IEEE Transactions on Vehicular Technology, 26(4):309-313, Noviembre 1977.

[She93] A.U. Sheikh, M. Handforth, and M. Abdi. Indoor mobile radio channel at 946MHz: Measurements and modeling. In Proceedings of the Vehicular Technology Conference. VTC'93, pages 73-76, Secaucus, USA, Mayo 1993. IEEE VTS. 
[Sie96] Miroslaw Siemczyk and Witold Holubowicz. Ray Tracing technique for radio prediction in microcells. Progress report. Temporary Document TD (96) 035, COST 231, Belfort, France, Enero 1996.

[Smi75] J.I. Smith. A computer generated multipath fading simulation for mobile radio. IEEE Trasactions on Vehicular Technology, 24(3):39-40, Agosto 1975.

[Suz77] H. Suzuki. A statistical model for urban radio propagation. IEEE Transactions on Communication, 25(7):673-680, Julio 1977.

[Tha88] A.R. Tharek and J.P. McGeehan. Propagation and bit error measurements within buildings in the mm-wave band around 60GHz. In IICC' 88 . IEEE, 1988.

[Tör93] C. Törnevik, J.E. Berg, and F. Lotse. 900MHz propagation measurements and path loss models for diferent indoor environments. In Proceedings of VTC'93, New Jersey, USA, Mayo 1993. IEEE.

[Val67] G.R. Valenzuela. Depolarization of EM waves by slightly rough surfaces. IEEE Transactions on Antennas and Propagation, 15(4):552-557, Julio 1967.

[Wöh90] H. Wöhler. Analytical and numerical methods for calculations of electro-optical properties of liquid cristal cells. PhD thesis, Universität Karlsruhe, Karlsruhe, Germany, 1990. (En alemán).

[Zha95] Q.T. Zhang. Outage probability of cellular mobile radio in the presence of multiple nakagami interferers with arbitrary parameters. IEEE Transactions on Vehicular Technology, 44(3):661-667, Agosto 1995. 


\section{Agradecimientos}

Esta es, sin duda, la parte de la Tesis que con mayor satisfacción redacta el autor. Entre otras cosas porque es la última que se escribe. Pero también porque, mientras se redacta, van acudiendo a la memoria los mejores momentos vividos durante el tiempo que ha durado el desarrollo de todo el trabajo que aquí se quiere exponer.

El lector curioso quizás se vea un tanto frustrado cuando vea que no encuentra ningún nombre propio en estos párrafos. Y no porque no me sienta agradecido a nadie en particular. Muy al contrario. Son tantas las personas que, directa o indirectamente, han contribuido a que este trabajo salga a la luz, que jamás me perdonaría el más mínimo olvido. Por eso, sólo voy a hablar de ellos de forma impersonal. Espero que, si lo leen, se sientan inmediatamente identificados.

En primer lugar, estoy profundamente agradecido y perpetuamente en deuda con todos los que han colaborado conmigo estrechamente durante todo este tiempo. Por lo que a mí respecta, esta colaboración continuará en el futuro y, sin duda, se ampliará.

También a todos los que me han ayudado, siempre desinteresadamente, resolviendo multitud de dudas (alguna de ellas de tipo existencial) que, inevitablemente, me han ido surgiendo. Dentro de este grupo, destaco a aquellos que han sabido darme, a veces de forma inconsciente, la justa medida que debe tener un trabajo de este tipo.

No me puedo olvidar de mis compañeros de fatigas. Juntos hemos recorrido (estamos recorriendo) un mismo camino que todos quisieramos que fuese menos tortuoso o, al menos, mejor definido. Sin el ambiente apropiado y los apoyos oportunos, sería imposible salvar ningún obstáculo, ni llegar a ninguna meta.

Y como todo no puede ser trabajo y sufrimiento, desde aquí quisiera agradecer a todos los que me han acompañado en los muchos momentos lúdicos que me han servido de solaz y evasión. Sin esos momentos, no podría haber hecho este trabajo, ni muchas cosas más.

A todos los que me he referido (sin nombrarlos, lo siento) los considero mis amigos. Y, viceversa, todo aquel que me honra con su amistad debería encajar en alguno de esos grupos (si no en todos). Amigos de toda la vida, viejos amigos, nuevos y también absolutamente recientes. A todos vosotros está dedicada esta Tesis. 
